\title{
Thermal and Flow Design of Helium-Cooled Reactors
}




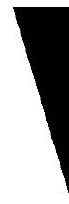




\section{Thermal and Flow Design of Helium-Cooled Reactors}

\section{Gilbert Melese \\ Robert Katz}

\section{DISCLAIMER}

This report was prepared as an account of work sponsored by an agency of the United States Government. Neither the United States Government nor any agency thereof, nor any of their employees, makes any warranty, express or implied, or assumes any legal liability or responsibility for the accuracy, completeness, or usefulness of any information, apparatus, product, or process disclosed, or represents that its use would not infringe privately owned rights. Reference herein to any specific commercial product, process, or service by trade name, trademark, manufacturer, or otherwise does not necessarily constitute or imply its endorsement, recommendation, or favoring by the United States Government or any agency thereof. The views and opinions of authors expressed herein do not necessarily state or reflect those of the United States Government or any agency thereof.

Prepared under the direction of the

American Nuclear Society

for the

U.S. Department of Energy
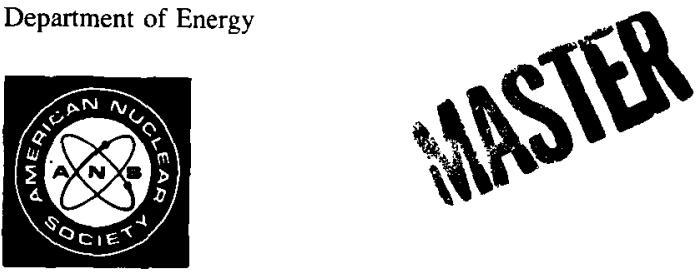

AMERICAN NUCLEAR SOCIETY

La Grange Park, Illinois USA 


\section{Library of Congress Cataloging in Publication Data}

\section{Melese, Gilbert}

Thermal and flow desıgn of helium-cooled reactors

"ANS order no 300019 "

Includes index

1 Gas cooled reactors--Desıgn and construction

2 Heluum I Katz, Robert, 1928- II American

Nuclear Society III United States Dept of Energy

IV Title

TK9203 G3M45 $1984 \quad 62148^{\prime} 33 \quad 84-14601$

ISBN $0-89448-027-8$

The Government reserves for itself and others acting on its behalf a royalty free, nonexclusive, irrevocable, world-wide 1 icense for governmental purposes to publish, distribute, translate, duplicate, exhibit, and perform any such data copyrighted by the contractor.

ISBN $0-894480278$

Library of Congress Catalog Card Number 84-14601

ANS Order No 300019

Copyright (C) 1984 by the Amencan Nuclear Society 555 North Kensington Avenue La Grange Park, Illıno1s 60525

All rights reserved No part of this book may be reproduced in any form without the written permission of the publisher

This copyright has been assigned and is held by the Secretary of the United States Department of Energy

All royaltues from the sale of this book accrue to the United States government

Printed in the United States of America 
Publısher's Foreword

\section{CONTENTS}

Foreword

$1 X$

Preface

\section{Chapter 1: History of First-Generation Gas-Cooled Reactors}

1-1 Development of Gas-Cooled Reactors

1-1A Early History of Gas-Cooled Reactors

1-1B Basic Characteristıcs of Gas-Cooled Reactors 3

1-2 Magnox $\mathrm{CO}_{2}$-Cooled Reactors

1-2A Characteristics of Magnox Reactors 7

1-2B Experience with Magnox Reactors 12

1-3 Advanced Gas-Cooled Reactors (AGRs) 15

$\begin{array}{lll}\text { 1-3A Windscale AGR } & 15\end{array}$

1-3B Commercial AGRs 19

1-4 Early U S Gas-Cooled Reactors $\quad 22$

1-4A Mobile Gas-Cooled Reactors $\quad 22$

1-4B Propulsion Gas-Cooled Reactors 23

1-4C The Experimental Gas-Cooled Reactor (EGCR) 25

1-4D Ultra-High-Temperature Reactor Experiment (UHTREX) 27

\section{Chapter 2: High-Temperature Gas-Cooled Reactor Developments}

2-1 The Dragon HTR 33

2-1A Reactor Description 33

2-1B Operational Experience $\quad 37$

2-2 Peach Bottom Atomic Power Station Unit 1

2-2A Reactor Description $\quad 39$

2-2B Operating Experience 41

2-3 The AVR Pebble Bed Reactor 43

2-3A Description of the AVR Plant 44

2-3B Operatıng Experience $\quad 47$

2-4 The THTR Pebble Bed Reactor 48

2-5 Fort St Vrain HTGR $\quad 52$

2-5A Plant Description $\quad 52$

2-5B Construction, Startup, Operation, and Research and Development $\begin{array}{ll}\text { Experience } & 57\end{array}$

2-6 HTGR Designs and Programs 59

2-6A Worldwide HTGR Programs $\quad 59$

2-6B U S HTGR Programs $\quad 62$

2-7 Summary of Gas-Cooled Reactor Experience $\quad 67$ 


\section{Chapter 3: Reactor Core Heat Transfer: Fundamentals}

3-1 Reactor Core Power Distribution $\quad 75$

3-2 Coolant Temperature Distribution 78

3-3 Fuel Element Surface Temperature $\quad 81$

3-3A Axıal Surface Temperature Variation $\quad 81$

3-3B Convective Heat Transfer Correlations $\quad 85$

3-4 Fuel Temperature $\quad 94$

3-4A Fuel Rod Temperature Distribution 95

3-4B Cladding Temperature $\quad 96$

3-4C Fuel/Cladding Gap Conductance $\quad 97$

3-4D Fuel Pellet Temperature Distribution $\quad 99$

3-4E Fuel Pellet Power T1t 100

3-4F Circumferential Variation in Convective Heat Transfer 102

3-4G Variable Fuel Conductivity 103

3-4H Fuel Restructuring 104

3-4I Packed-Bed Fuel Elements 105

3-5 Coolant Pressure Drop 106

3-5A Derivation of Pressure Drop Relations for Compressible Flow 106

3-5B Friction Factor Correlations 113

3-5C Parasitic Pressure Losses $\quad 116$

3-5D Parallel Channel Flow and Core Orificing 118

$\begin{array}{lr}3-5 E & 120\end{array}$

\section{Chapter 4: Reactor Core Heat Transfer: Special Topics}

4-1 Hot Spot Factors $\quad 126$

4-1A Definitions 126

4-1B Method to Determine the Hot Spot Factors 127

4-1C Calculational Procedures $\quad 129$

4-1D GCFR Hot Channel and Hot Spot Factors 130

4-2 Coolant Mixing in Rod Bundles 134

4-3 Core Temperature Shaping 137

4-4 Choice of Gas Coolants 142

4-5 Pebble Bed Reactor Thermal Hydraulics 145

\section{Chapter 5: Related Mechanical Problems}

5-1 Introduction 151

5-2 Flow-Induced Vibration $\quad 152$

5-2A Dimensional Analysis, Classification, and Testing 152

5-2B Flow-Induced Vibration in Cross Flow 155

5-2C Turbulence-Induced Vibration in Parallel Flow 158

5-3 Acoustic Vibration $\quad 159$

5-3A Acoustics of the Coolant Circuit 159 
5-3B Acoustic Sources of Sound 163

5-3C Acoustic Excitation of Cover Plates 165

5-4 Thermal Stress Analysis 167

5-4A General Aspects of Thermal Stress and Strain 167

$\begin{array}{ll}\text { 5-4B Thermal Stress } & 169\end{array}$

5-4C Strength of Materials Under Thermal Stress 171

\section{Chapter 6: HTGR Design Bases}

6-1 HTGR Design Features 177

$\begin{array}{ll}\text { 6-2 HTGR Nuclear Fuel Cycle } & 178\end{array}$

$\begin{array}{ll}\text { 6-3 HTGR Materials } & 181\end{array}$

6-3A Graphite 182

6-3B Coated Partıcles 186

$\begin{array}{lll}6-3 \mathrm{C} & \text { Fuel Rods } & 189\end{array}$

6-3D Control Rod Materials 193

6-3E Primary Circuit 193

6-4 Thermal Design Bases for HTGR Cores 196

\section{Chapter 7: HTGR Core Thermal Design}

$\begin{array}{lll}7-1 & \text { Introduction } & 202\end{array}$

7-2 Core Description $\quad 202$

$\begin{array}{lll}7-2 \mathrm{~A} & \text { Reactor Core } & 202\end{array}$

7-2B Refueling Region 205

$\begin{array}{lll}7-2 C & \text { Fuel Elements } & 205\end{array}$

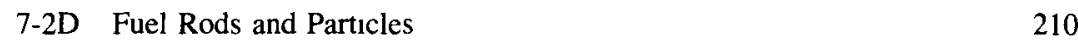

\begin{tabular}{ll}
$7-2 E$ & Control Rod System \\
\hline
\end{tabular}

$\begin{array}{lll}7-3 & \text { Nuclear Design } & 211\end{array}$

7-3A Definition of Power Peaking Factor 211

$\begin{array}{ll}7-3 B & \text { Fuel Rod Metal Loading } \\ 7-3 C & 215\end{array}$

\begin{tabular}{ll}
$7-3 C$ & Control Rod Program \\
\hline
\end{tabular}

7-3D Core Radial Power Distribution $\quad 216$

$\begin{array}{ll}7-3 E & \text { Core Axial Power Distribution } \\ 7-3 F & 217\end{array}$

7-3F Dependence of Fuel Temperature on the Power Peakıng Factor 219

$\begin{array}{ll}7-4 \text { Core Flow Distribution } & 220\end{array}$

7-4A Core Flow Paths 221

7-4B Flow Resistance of Coolant Paths 223

$\begin{array}{ll}7-4 \mathrm{C} \text { Crossflow } & 224\end{array}$

7-4D Core Flow Distribution $\quad 225$

\begin{tabular}{ll}
$7-4 E$ & Lamnar Instability \\
\hline
\end{tabular}

$\begin{array}{lll}7-5 & \text { Core Temperatures } & 230\end{array}$

7-5A Unit Cell Models of Heat Flow in Fuel Elements 230

7-5B Effect of Power Distribution on Core Temperatures 233

7-5C Fuel Element Temperature Distribution 236

$\begin{array}{lll}7-5 D & \text { Transient Thermal Analysis } & 238\end{array}$ 


\section{Chapter 8: The HTGR Gas Turbine}

8-1 Introduction $\quad 250$

8-1A HTGR Deployment 250

8-1B HTGR-GT Background 252

8-2 Thermodynamic Cycles and Performance 255

8-2A Thermodynamic Cycles 255

8-2B Gas Turbıne Plant Performance 257

8-3 Reference 2000-MW(t) HTGR-GT Plant Design Concept 262

8-4 Component Design Considerations 264

8-4A Helıum Turbomachine 265

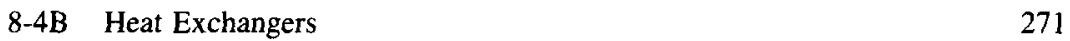

8-4C Systems Studies in Support of Component Design 278

$\begin{array}{lll}\text { 8-5 Waste Heat Utılization } & 278\end{array}$

8-5A Cogeneration Possibilities 278

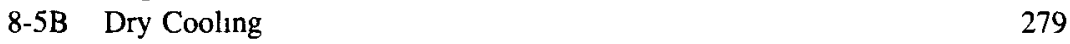

8-5C District Heatıng 280

8-5D Process Steam Production 282

8-5E Desalınation $\quad 282$

8-5F Hybrid Plant Operation 282

8-5G Bottoming Rankıne Cycles 283

8-6 Gas Turbıne Plant Development $\quad 286$

8-6A Technical Issues $\quad 286$

8-6B Safety Consıderations $\quad 286$

8-6C Development $\quad 287$

$\begin{array}{lll}8-7 & \text { Conclusions } & 292\end{array}$

\section{Chapter 9: Process Heat HTGRs}

$\begin{array}{llr}9-1 & \text { Introduction } & 299\end{array}$

9-2 HTGR Applications and Design Commonality 300

9-2A Process Steam/Cogeneration $\quad 302$

9-2B Process Heat $\quad 302$

9-3 Process Steam/Cogeneration Plant 303

9-3A Reactor Plant Description 303

9-3B HTGR Applications Survey 305

9-3C HTGR-SC/C Comparative Assessment 305

$\begin{array}{ll}\text { 9-3D Issues } & 306\end{array}$

9-4 Process Heat Plants $\quad 307$

9-4A $850^{\circ} \mathrm{C}$ Indrect-Cycle HTGR-PH Plant $\quad 307$

9-4B $950^{\circ} \mathrm{C}$ Direct-Cycle HTGR-PH Plant 308

$\begin{array}{lll}9-4 \mathrm{C} \text { Components } & 308\end{array}$ 
9-5 Process Heat Applications 311

$\begin{array}{ll}\text { 9-5A Synfuel Using Coal as a Feedstock } & 312\end{array}$

9-5B Nuclear-Chemical Energy Center $\quad 312$

9-5C O1l Shale Recovery $\quad 314$

9-5D Alternate Heat Transmission and Storage Systems 314

9-5E Hydrogen Production by a Closed-Loop Thermochemical Process 315

9-6 Companson of Prismatic and Pebble Bed HTGRs for Process Heat

Applications

\section{Chapter 10: Gas-Cooled Fast Breeder Reactor Thermal Hydraulics}

$\begin{array}{llr}10-1 & \text { Introduction } & 319\end{array}$

10-2 GCFR System Design Description $\quad 322$

$\begin{array}{lll}10-3 & \text { Surface Roughening } & 327\end{array}$

$\begin{array}{lll}10-3 A & \text { Performance Index } & 328\end{array}$

10-3B Types of Roughness $\quad 328$

10-4 Thermal-Hydraulic Codes 329

10-4A CALIOP Code $\quad 329$

10-4B COBRA*GCFR Code $\quad 330$

10-5 Thermal-Hydraulic Correlations 331

10-5A Laminar Flow $\quad 332$

10-5B Turbulent Flow 333

10-5C Transition Flow $\quad 334$

10-5D Other Considerations $\quad 336$

10-6 Thermal-Hydraulıc Desıgn Consıderatıons 336

$\begin{array}{lll}\text { 10-6A Hot Spot Analysis } & 337\end{array}$

10-6B Plant Size $\quad 337$

10-6C Component Technology 338

10-6D Fuel Life Goals $\quad 338$

10-6E Material Limitatıons $\quad 338$

10-6F Core Configuration and Core Assembly Desıgns 339

10-6G Thermal-Hydraulıc Core Assembly Desıgn and Performance 339

10-6H Fuel Rod Roughness Configuration $\quad 340$

10-6I Edge Channel Design 341

10-6J Effect of Fabrication Tolerances on Fuel Rod Life 343

10-6K Advanced Design Considerations 343

10-6L Fuel and Blanket Assembly Orificing 344

10-7 Safety Analyses $\quad 345$

10-7A Residual Heat Removal Followıng Depressurızation Accidents 345

10-7B Resıdual Heat Removal by Natural Circulation (Pressurized $\begin{array}{ll}\text { Coolant) } & 349\end{array}$

10-7C Compartson of Natural Circulation of Coolant Gases 353

\section{Chapter 11: Gas Cooling of Fusion Reactors}

11-1 Introduction

11-1A Fusion Energy Concepts 361

11-1B Fusion Energy Recovery 366 
11-1C Gas Cooling of Fusion Reactors $\quad 367$

11-2 Design of Gas-Cooled Fusion Reactor Systems $\quad 372$

$\begin{array}{lll}\text { 11-2A } & \text { First-Wall Designs } & 373\end{array}$

11-2B Blanket Designs $\quad 378$

11-2C Safety Issues $\quad 382$

11-3 Applications of Fusion Energy $\quad 387$

11-3A Electricity Production $\quad 389$

11-3B Process Heat/Synfuels $\quad 394$

11-3C Fusion-Fission Hybrid Reactors 395

$\begin{array}{lll}11-4 & \text { Conclusions } & 398\end{array}$

$\begin{array}{lr}\text { Appendix A } & 402\end{array}$

$\begin{array}{ll}\text { Appendix B } & 405\end{array}$

Index $\quad 407$ 


\section{Publisher's Foreword}

This book contınues the American Nuclear Society's serıes of monographs on nuclear science and technology ANS is pleased to prepare this publication for the U S Department of Energy

The objective of the ANS publications program is to bring into print information that advances the peaceful uses of nuclear energy and that satisfies the professional interests of ANS members This particular title not only fulfills those publishing aims-it is also especially timely because of the current renewed interest in gas-cooled reactors

In addition to those individuals and organizations cited in the authors' Preface, special thanks go to the U S Department of Energy for its financial support and to GA Technologies for its graphics assistance We are also very grateful for the help received from the Central and Reactor Analysis and Safety libraries at Argonne National Laboratory and the GA Technologies library

W Michael Diekman Manager, ANS Publications 


\section{AMERICAN NUCLEAR SOCIETY BOOK PUBLISHING COMMITTEE}

Henrı Fenech, Contınuing Technical Contact Unıversity of Calıfornia, Santa Barbara

Robert L Seale, Chairman

University of Arizona

Russell M Ball

Babcock \& Wilcox Company

James F Church

Combustion Engineering

John C Courtney

Louısıana State Unıversity

John E Cunnıngham

Oak Ridge Natıonal Laboratory

W Michael Diekman

Amencan Nuclear Society

Martın L Grossbeck

Oak Ridge National Laboratory

Raymond L Murray

North Carolına State Unıversıty
James H Rust

Consultant

Norman M Schaeffer

Radiation Research Associates

Roger W Tilbrook

Argonne Natıonal Laboratory

David K Trubey

Oak Rıdge National Laboratory

Belle R Upadhyaya

University of Tennessee

Alan E Waltar

Westınghouse Hanford Company

Monroe S Wechsler

Iowa State University

\section{NUCLEAR SCIENCE AND TECHNOLOGY MONOGRAPH SERIES}

prepared under the direction of the Book Publishing Committee of the American Nuclear Society

Reactivity Coefficients in Large Fast Power Reactors

Harry H Hummel and David Okrent

Direct Conversion of Nuclear Radiation Energy

George H Miley

Thermal Analysis of Pressurized Water Reactors

L S Tong and Joel Welsman

Small-Sample Reactlvity Measurements in Nuclear Reactors

Wesley K Foell

Promethium Technology

Earl J Wheelwright

Fusion Energy Conversion

George $\mathrm{H}$ Miley

Botling Liquid-Metal Heat Transfer

O E Dwyer

The Thermal Hydraulics of a Boling Water Nuclear Reactor

R T Lahey, Jr and F J Moody

Thermal Analysis of Liquid-Metal Fast Breeder Reactors

Y S Tang, R D Coffield, Jr, and R A Markley

Thermal and Flow Design of Hellum-Cooled Reactors

Gilbert Melese and Robert Katz 


\section{Foreword}

I welcome the opportunity to contribute a foreword to this book both because its subject has for so long been my principal concern and because its authors have for so long shared the resulting endeavors with me. Our interest in the subject in fact dates from the time, long ago, when there was talk of nuclear power being so cheap as to render the provision of light switches uneconomic. It may seem a monumental understatement to observe that general opinion seems to have changed somewhat since. Nevertheless, during this period it has become increasingly evident that without the kind of massive energy resource extension presently offered only by nuclear processes, those switches may eventually become really outdated-for want of anything to turn on.

Because of the immense outpouring of information accompanying the prodigious efforts so far expended in the field of nuclear engineering and physics, and particularly because of the problems of its assimilation and review, works like the present one-aimed at appropriate selection and orderly presentation relating to specific reactor types-are welcome, and indeed necessary for the effective continuity of effort.

In the field of safety measures, this separation of reactor types is particularly important since their strengths and weaknesses are markedly different-the ignoring of which leads not only to increased costs, but also obscures the value of inherent system merits.

The present subject-high-temperature gas-cooled reactors (HTGRs) - is one that categorizes only a minority of present nuclear power plants, but I firmly believe that their place will enjoy enhanced recognition in the future. This view stems primarily from properly growing recognition of the dominance of safetyrelated considerations in respect to which gas cooling offers features for which little or no credit was afforded at the time of its first inception. Compatibility with an integral prestressed concrete primary circuit containment and an absence of the problems of two-phase flow may indeed turn out to be even more important than the more widely proclaimed higher temperatures and efficiencies also offered by gas cooling. In the case of the HTGR, this is supplemented by "forgivingly" sluggish response to malfunction and the fission product retention ability conferred by nonmetallic coated particulate fuel. These features, in combination with a high conversion ratio capability and temperature possibilities extending well beyond that merely required to restore the norms of present steam plant efficiency, would seem to appeal particularly to a future that will require energy for an increasingly diverse number of uses and that will face dwindling resources, even of nuclear fuel.

For these reasons, the inclusion of both the HTGR and the prospects of the gas-cooled fast breeder reactor and of fusion in any comprehensive study of gas 
cooling is to be welcomed. Information provided in this book should be of interest to engineers wanting to familiarize themselves with gas-cooled reactor systems, and also to graduate students learning about various types of reactors. More detailed information could be found in the numerous references provided after each chapter. Both Dr. Gilbert Melese and Dr. Robert Katz have been personally involved in the development of gas-cooled reactors for over 25 years and bring considerable expertise to the field of thermal and flow analysis of helium-cooled systems.

September 1984

Peter Fortescue 


\section{Preface}

The use of gas as the working fluid in a nuclear reactor was proposed in the earliest days when atomic energy was first being considered for electricity production. A wide variety of gas-cooled reactors has been developed and placed into operation since those first days. However, it is the authors' belief that gascooled reactors have not attained their full potential as yet. This book can be viewed as a somewhat specialized benchmark in the history of gas-cooled reactor development and also suggests the direction in which future developments are likely to occur. The flexibility afforded by using gas as the cooling medium leaves considerable latitude for future reactor design engineers, and particularly the experts in heat transfer, to apply their imagination and ingenuity to improve the present state of the art.

A major aim of this book is to serve a broad audience-from the expert in reactor heat transfer to the person simply desiring to get an overview of the subject. To this end, the book treats gas-cooled reactors in a rather generic sense but with emphasis on the advanced, high-temperature, helium-cooled thermal reactor. It is expected that this book could be of some use to persons in industry and national laboratories as well as in universities.

In a book of this nature, choices had to be made as to the material that could be covered. Our choice was to limit the coverage to heat transfer and fluid flow design associated with the reactor core. This choice entailed omitting such interesting and important reactor power plant heat transfer subjects as thermal insulation for the prestressed concrete pressure vessel; primary and secondary heat transfer in compact, helically coiled, once-through steam generators; mixing of different temperature streams of gas ("hot streaks"); and a host of specialized heat transfer problems associated with cooling various reactor structural and operating components.

Even by limiting the main heat transfer subject to heat transfer in the reactor core, it was impossible to treat that area fully. Therefore, extensive references have been included in each chapter to allow the reader to go back to the original sources for more in-depth coverage. Consequently, it is hoped that the book can serve as a reference source for persons wishing to pursue gas-cooled reactor heat transfer and fluid flow.

Except for the historical perspective of the first chapter, this book is limited to helium-cooled nuclear reactors. This is because it is likely that all future developments in gas-cooled reactors worldwide will employ helium as the coolant.

Chapters 1 and 2 introduce and provide a perspective on the early history of the first- and second-generation gas-cooled reactors, namely, the $\mathrm{CO}_{2}$-cooled reactors and the high-temperature helium-cooled thermal reactors, respectively. 
The fundamentals of reactor heat transfer necessary to determine the temperature distribution in the core are developed in Chapter 3. Several special topics such as gas mixing within fuel elements and hot spot factors are dealt with in Chapter 4 and Chapter 5 is an introduction to flow-induced vibrations, acoustics, and thermal stress problems.

The high-temperature gas-cooled reactor (HTGR) system is covered in Chapters 6 and 7 , including a general discussion of the design basis, overall design features, and detailed coverage of heat transfer and flow issues in the reactor core. Safety problems are also considered.

Chapters 8 and 9 discuss the closed-cycle gas turbine power plant designs and also the use of the HTGR for producing process heat, respectively.

The gas-cooled fast reactor (GCFR) is presented in Chapter 10. It parallels the coverage of the HTGR, but concentrates on the heat transfer and flow issues characteristic of this system.

The book's concluding chapter, Chapter 11, deals with the potential uses of gas cooling for fusion reactor power plants.

SI units are used extensively throughout, but since many nuclear parameters have always been expressed in SI units, it should be no trouble for an engineer working in the nuclear field to convert between SI and English units. Appendix A should be helpful toward this end.

We are indebted to our many colleagues for providing guidance, acting as sounding boards for ideas, and sharing the frustrations that have come with the design and development of nuclear power plants. There are so many it would be unfair to name only a few, but we do wish to recognize the important contributions made to this book by Dr. R. D. Blevins, Dr. D. W. McEachern, Mr. C. F. McDonald, Mr. R. N. Quade, Dr. C. B. Baxi, and Drs. K. R. Schultz, G. R. Hopkins, and C. P. C. Wong from GA Technologies Inc., who are largely responsible for Chapters $5,7,8,9,10$, and 11 , respectively. The contribution of their expertise to this book has been invaluable.

There are a number of people whom we wish to thank. Dr. C. Rickard and Dr. A. J. Goodjohn of GA Technologies Inc. provided continual encouragement and support, for which we are grateful. Toni Ward, Carol A. Cale, and Berniece $R$. Cobb typed the many versions of the book, which was done before word processors with memory banks were common equipment in offices. Mr. Eugene Cramer started us out as the American Nuclear Society (ANS) monitor for the book but due to business commitments had to turn the job over to Professor $\mathrm{H}$. Fenech who continued to encourage and guide us to the completion of the work. We are grateful to the persons unknown to us who performed the peer review of the manuscript. Their corrections, comments, and suggestions were incorporated where possible. We would like to acknowledge help extended by the Nuclear 


\section{HISTORY OF FIRST-GENERATION GAS-COOLED REACTORS}

In this introductory chapter, the early developments of gas cooling for nuclear reactors are described briefly for both the European and U.S. programs. After some discussion of the different gas-cooled reactor concepts, experience with the $\mathrm{CO}_{2}$-cooled Magnox reactors in France and the United Kingdom is related. The evolution in the United Kingdom of these reactors into higher performance advanced gas-cooled reactors (AGRs), also $\mathrm{CO}_{2}$ cooled, is explained in Sec. 1-3. Finally, early experience with gas cooling in the United States is discussed, with emphasis on the first special-purpose helium-cooled reactors, EBOR, EGCR, and UHTREX. High-temperature gas-cooled reactors (HTGRs) for electricity production, helium cooled and graphite moderated, are introduced in Chapter 2.

\section{1-1 Development of Gas-Cooled Reactors}

\section{1-1A Early History of Gas-Cooled Reactors}

Gas cooling for nuclear reactors had been considered in the United States for production reactors and even for early power reactors. Both graphite-moderated experimental reactors at Brookhaven National Laboratory and at Oak Ridge National Laboratory were air cooled. In 1943, water cooling of the Hanford piles was chosen rather than helium cooling mainly because of the difficulties anticipated in procuring blowers and in preventing helium leakage from large pressure vessels. As early as 1945, Farrington Daniels proposed a helium-cooled, BeO- (or graphite)moderated, high-temperature power reactor ${ }^{1}$ (Fig. 1-1) that was not pursued since it required too much development and also because of the priority given to high power density, water-cooled submarine reactors, which led to the development of pressurized water reactors (PWRs). But interest in gas cooling was revived in the United States in the mid-1950s and a number of gas-cooled reactor projects were started both for power generation and for propulsion. Several of these reactors were built, as described later.

Although the development of nuclear power started later in other countries, interest in gas cooling led to early gas-cooled reactor construction and operation in the United Kingdom and France. Production reactors ("plutonium-producing piles") were built in the early 1950s in the United Kingdom with a graphite moderator and atmospheric air cooling; this design was chosen in the interest of 


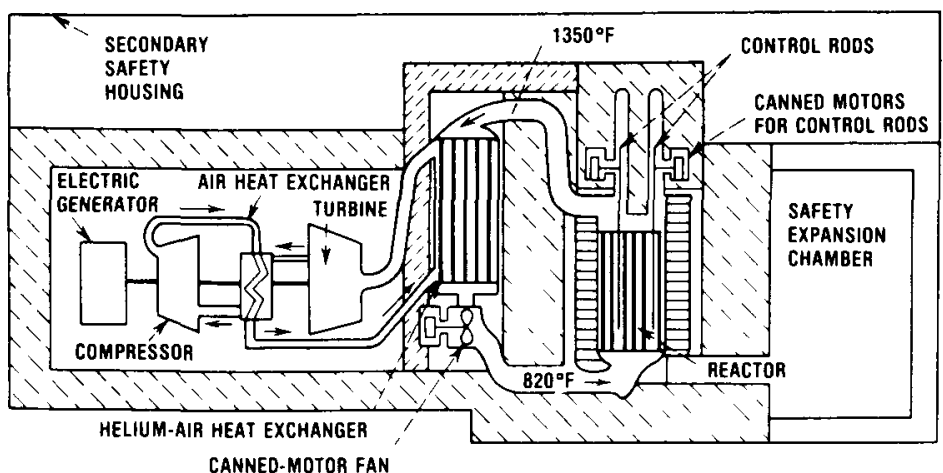

CANNED-MOTOR FAN

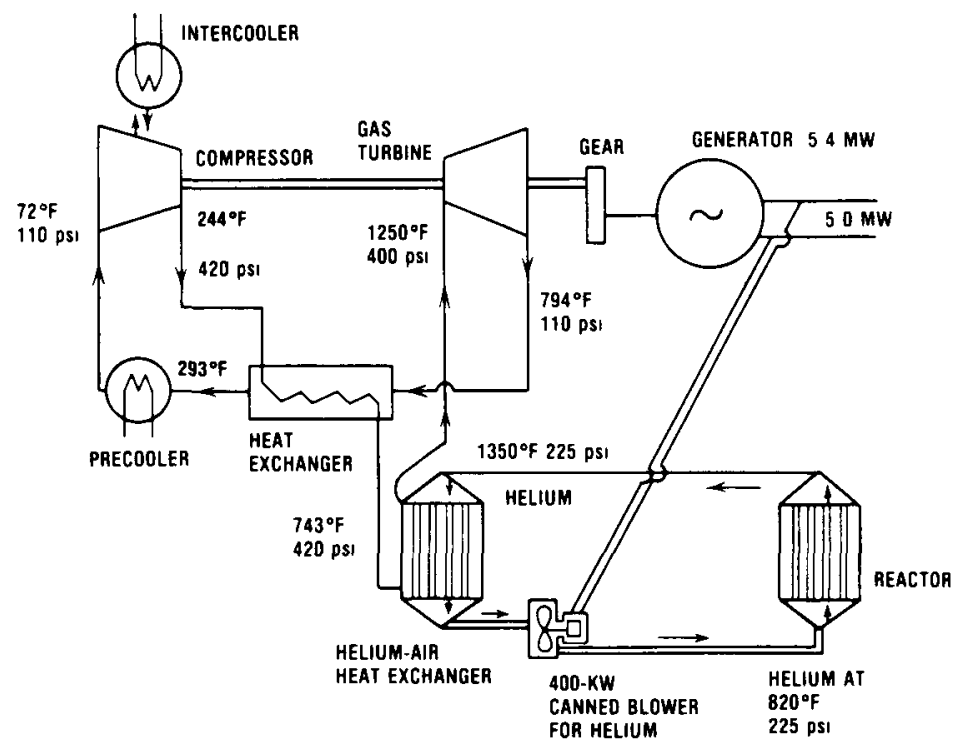

Fig. 1-1. (a) Profile of the 5-MW closed-cycle plant. The reactor, which produces $20 \mathrm{MW}$ of heat, has a graphite moderator and uses fuel rods of $10 \%$ enriched $U_{2}$. The entire 225-psi helium circuit for the reactor is gas tight. Heat in the helium is transferred to 400-psi air or nitrogen via a gas-tight heat exchanger that separates the two circuits. (b) A flow diagram for the $5-\mathrm{MW}$ gas-cooled plant shows a plant efficiency of $25 \%$. Coolant circulation by a cannedmotor blower uses $<10 \%$ of the plant output.

safety for the Windscale piles, rather than water cooling, because it was felt to be inherently stable and did not require isolation. ${ }^{2}$ For dual-purpose reactors (i.e., production of plutonium with power recovery), which were still graphite moderated since only natural uranium was available, pressurized $\mathrm{CO}_{2}$ was chosen as a coolant because of its better thermal properties and the potential for higher temperature operation than atmospheric air. Helium would have been preferred, but it was not indigenous to Europe and its cost at the time was too high. The first gas-cooled power reactor started operating at Calder Hall in England in 1956 and produced 
$40 \mathrm{MW}$ of electricity, one year before the PWR at Shippingport, Pennsylvania. It was followed in 1959 by a similar $\mathrm{CO}_{2}$-cooled graphite-moderated reactor at Marcoule, France, with a net power of $40 \mathrm{MW}(\mathrm{e})$. The French reasoning was similar to that of the English in selecting gas-cooled reactors. The Marcoule reactor brought about two innovations to be incorporated into the succeeding French and U.K. gas-cooled reactor programs: on-line refueling and the prestressed concrete reactor vessel (PCRV). Based on their experience with dual-purpose reactors, France and the United Kingdom have built or committed over $20 \mathrm{GW}(\mathrm{e})$ of gascooled power reactors.

\section{1-1B Basic Characteristics of Gas-Cooled Reactors}

It is well known from nuclear reactor theory that a number of low- $Z$ materials can be used as moderators to slow down fission neutrons to thermal energy: Graphite is the most common solid moderator and light water is the usual liquid moderator; heavy water $\left(\mathrm{D}_{2} \mathrm{O}\right)$ is also used and beryllium (or $\mathrm{BeO}$ ) has been used as the moderator in some experimental reactors. Pressurized $\mathrm{D}_{2} \mathrm{O}$ within pressure tubes is the coolant for most Canadian reactors, but pressurized gas could also be used as a coolant, as for instance in the French $\mathrm{D}_{2} \mathrm{O}$-moderated $\mathrm{CO}_{2}$-cooled 80 MW(e) EL4 reactor. ${ }^{3}$ In spite of the excellent neutronic properties ${ }^{4}$ of $\mathrm{BeO}$, graphite is the chosen moderator for all central station gas-cooled power reactors because of its low cost, excellent high-temperature properties, and acceptable radiation resistance.

As discussed in detail in Refs. 4 and 5, fuel element designs for gas-cooled reactors depend on the choice of type of fuel, moderator, coolant, etc. A description of fuel elements is given in the chapters covering the various types of power reactors, but a few general characteristics must be noted here. If natural uranium must be used, a low neutron absorption cladding is required with metallic uranium because of reactivity limitations: The low maximum allowable cladding temperature requires extended surfaces in order to obtain an acceptable gas outlet temperature with the modest heat transfer coefficients obtainable with gas cooling. With enriched uranium, oxide or carbide fuel can be used together with a higher temperature cladding material such as stainless steel. Acceptable rates of heat transfer from the fuel to the coolant may be obtained by subdividing the fuel into small rods or pins and/or by improving surface heat transfer with artificial roughening, i.e., small transverse fins. Limitations on the fuel element surface temperature can be practically eliminated by using all-ceramic materials. The ceramic material, such as graphite, serves both as a structural material and as containment for the fission products. The fuel, in carbide or oxide form, is dispersed through the ceramic material, which leads to high burnup by limiting radiation damage and parasitic neutron absorption. These features are common to all HTGRs with fuel in the form of coated particles (where coatings serve as pressure vessels for fission gases) within a graphite matrix.

Besides air, which was the obvious choice for the early low-power reactors 
and for the first production reactors in France and the United Kingdom, carbon dioxide is used for the British and French power reactors, primarily because it is readily available. Nitrogen has not been used much because of its relatively high neutron cross section, nitriding problems at high temperature, and poorer thermal performance compared to $\mathrm{CO}_{2}$. Hydrogen, which would give an excellent thermal performance, has only been used for special applications such as rocket propulsion because of its inferior chemical properties, i.e., reactions with oxygen and fuels, and diffusion through structural steel. In the end, helium was chosen as the best coolant for high-temperature gas-cooled thermal or fast reactors because of its good thermal performance, excellent radiation stability, and inertness. It is now readily available in the United States and abroad and its price is only a very small fraction of the total power cost. As is discussed in Chapter 10, dissociating gases and vapors have also been suggested as reactor coolants. Studies ${ }^{6}$ of $\mathrm{N}_{2} \mathrm{O}_{4}$ $\left(2 \mathrm{NO}_{2} \rightleftarrows \mathrm{N}_{2}+2 \mathrm{O}_{2}\right.$ ) are being pursued in the Soviet Union for possible applications to gas-cooled fast breeder reactors (GCFRs). A detailed discussion of the choice of coolant gas for power reactors is given in Chapter 4 of this monograph.

Power reactors have been developed for several principal purposes: production of fissile material (in thermal or fast reactors), electricity generation, propulsion, or process heat applications. Both the design of the reactor and the thermodynamic cycles are, of course, affected by the purpose of the reactor. The main cycles considered for gas-cooled power reactors are:

1. an indirect cycle with steam generation for electricity production

2. a direct gas turbine closed-cycle for electricity generation

3. an indirect cycle with heat generation for industrial applications

4. a direct gas turbine open cycle for propulsion.

Since this book is concerned mainly with electric power applications of nuclear reactors, the first two cycles are studied in following chapters, with some discussion of process heat applications in Chapter 9.

Before reporting on specific types of gas-cooled power reactors built around the world, the design and performance evolution of the existing three main types of gas-cooled reactors is briefly discussed: Magnox in France and the United Kingdom, the AGR in the United Kingdom, and the HTGR in Europe and the United States. The GCFR, which has been studied in Europe and in the United States, has been added to Table 1-I, which shows the common use of graphite as a moderator for thermal reactors, and PCRVs as the containment. It also shows the choice of helium for HTGRs and GCFRs and the very significant improvement in thermal efficiency with all advanced systems. Finally, both power density and burnup are shown to have increased considerably from the $\mathrm{CO}_{2}$-cooled reactors to helium-cooled thermal reactors and breeders, and the uranium ore requirements are very much reduced with HTGRs and, of course, practically eliminated with the breeders, which only need depleted uranium feed once the initial plutonium load is provided. 
TABLE 1-I

Design Evolution of Gas-Cooled Power Reactors

\begin{tabular}{|c|c|c|c|c|c|}
\hline \multirow{2}{*}{$\begin{array}{l}\text { Reactor Type } \\
\text { Date of operatıon }\end{array}$} & \multicolumn{2}{|c|}{ Magnox } & \multirow{2}{*}{$\frac{\text { AGR }}{1976}$} & \multirow{2}{*}{$\frac{\text { HTGR }}{1976}$} & \multirow{2}{*}{$\frac{\text { GCFR }}{\text { Desıgn }}$} \\
\hline & 1965 & 1972 & & & \\
\hline Moderator & \multicolumn{2}{|c|}{ Graphite } & Graphite & Graphite & None \\
\hline Coolant & \multicolumn{2}{|c|}{$\mathrm{CO}_{2}$} & $\mathrm{CO}_{2}$ & Helium & Helium \\
\hline Fuel & \multicolumn{2}{|c|}{ Natural uranium (metallic) } & Ennched $\mathrm{UO}_{2}(15$ to $25 \%)$ & $\begin{array}{l}\text { Highly enriched }{ }^{235} U+T h \\
\text { (coated particles) }\end{array}$ & Mixed $\mathrm{UO}_{2}-\mathrm{PuO}_{2}$ \\
\hline Fuel element & \multicolumn{2}{|c|}{ Slugs } & Rod bundles & Prismatic block or sphere & Rod bundles \\
\hline Fuel claddıng & \multicolumn{2}{|c|}{ Magnox } & Stainless steel & Graphite or ceramic & Stainless steel \\
\hline Refuelıng & Off-load & On-load & On-load & Off-load & Off-load \\
\hline Pressure vessel & Steel & PCRV & PCRV & PCRV & PCRV \\
\hline Coolant $\mathrm{T}_{\text {exit }}\left({ }^{\circ} \mathrm{C}\right)$ & \multicolumn{2}{|c|}{335 to 415} & 635 to 675 & 725 to 950 & 530 \\
\hline Coolant pressure (MPa) & \multicolumn{2}{|c|}{1 to 4} & 2 to 4 & 1 to 5 & $\sim 10$ \\
\hline Net steam cycle efficiency & \multicolumn{2}{|c|}{20 to $30 \%$} & $\sim 40 \%$ & $-39 \%$ & $\sim 37 \%$ \\
\hline Core power density $\left[\mathrm{MW}(\mathrm{e}) / \mathrm{m}^{3}\right]$ & \multicolumn{2}{|c|}{01 to 05} & $\sim 10$ & 27 to 34 & $\sim 100$ \\
\hline Fuel ratıng $[\mathrm{kW}(\mathrm{e}) / \mathrm{kg} \cdot$ fissıle] & \multicolumn{2}{|c|}{100 to 250} & 200 & $\sim 500$ & $\sim 350$ \\
\hline Average burnup (MWd/kg) & \multicolumn{2}{|c|}{3 to 4} & $\sim 20$ & 100 & 70 \\
\hline Conversion ratio & \multicolumn{2}{|c|}{$\sim 08$} & $\sim 06$ & 065 to 09 & 14 to 15 \\
\hline $\begin{array}{l}\text { 30-yr ore requirement } \\
\text { [tonnes } \mathrm{U}_{3} \mathrm{O}_{8} / \mathrm{MW}(\mathrm{e}) \text { ] }\end{array}$ & \multicolumn{2}{|c|}{10} & 5 & 27 & Depleted uranium \\
\hline
\end{tabular}




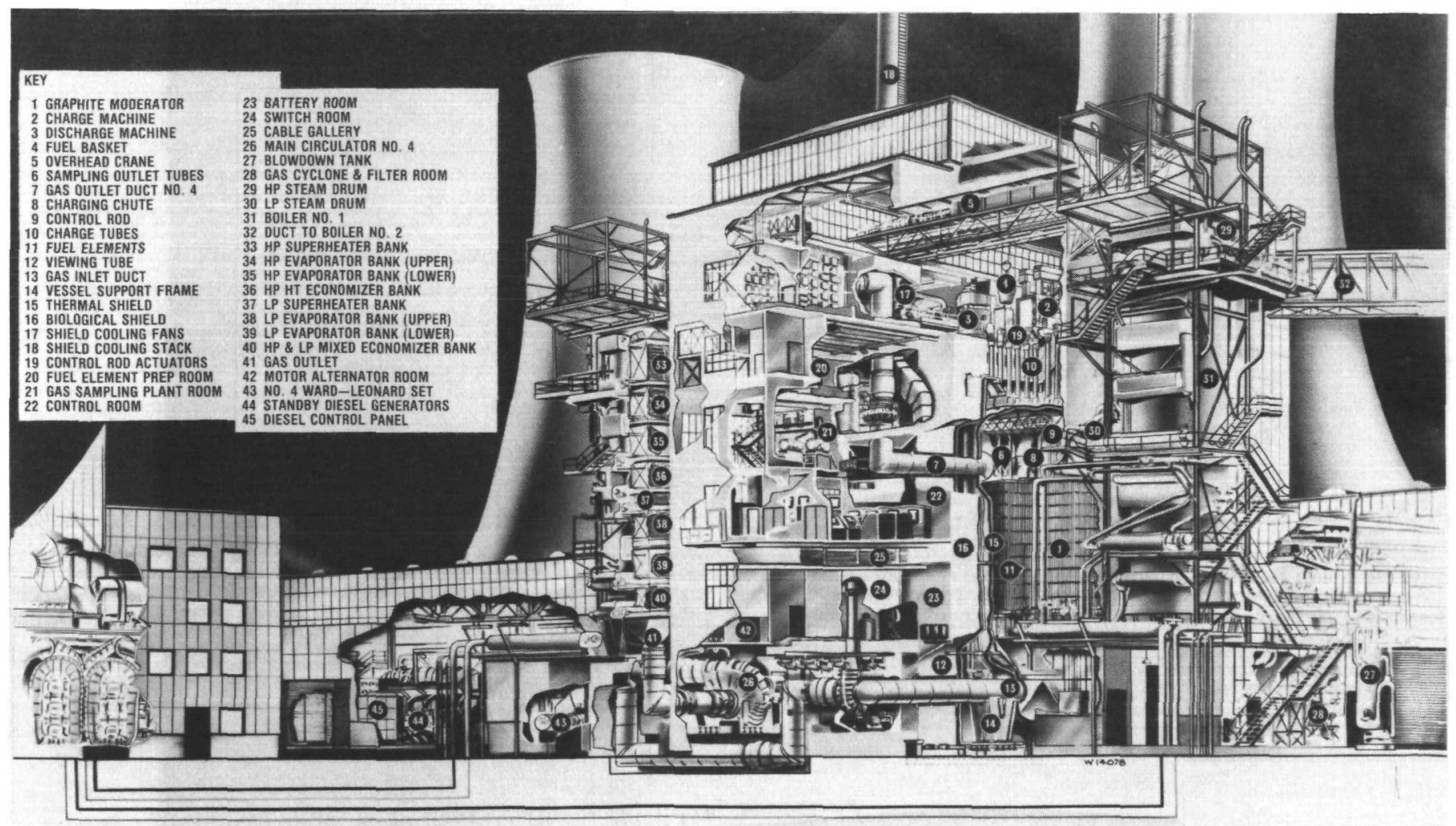

Fig. 1-2. Cutaway diagram of the Chapelcross and Calder Hall 268-MW(t), 50-MW(e) Magnox-type reactors. 


\section{1-2 Magnox $\mathrm{CO}_{2}$-Cooled Reactors}

The early Magnox reactors developed simultaneously in France and the United Kingdom are characterized by $\mathrm{CO}_{2}$ cooling, graphite moderation, metallic natural uranium fuel, and magnesium-aluminum (Magnox) fuel cladding. A total of 37 such reactors began operating between 1956 and 1972: 26 in the United Kingdom, 8 in France, and one each in Italy, Japan, and Spain. ${ }^{7-9}$ The cumulative output for this $9 \mathrm{GW}(\mathrm{e})\left(9 \times 10^{6} \mathrm{~kW}\right)$ of installed Magnox reactor capacity was $\sim 90 \mathrm{GW} \cdot \mathrm{yr}$ $\left(780 \times 10^{9} \mathrm{kWh}\right)$ by mid-1983. The cumulative electricity produced by these Magnox reactors was more than the production by all civilian light water reactors until sometime in 1973. Until 1980, most of the nuclear electricity in France was still produced by Magnox reactors. Out of 28.5 billion $\mathrm{kWh}$ generated by nuclear power in the United Kingdom during the first seven months of 1983, two-thirds came from Magnox reactors (and most of the remainder from AGRs).

\section{1-2A Characteristics of Magnox Reactors}

While the detailed designs of the various Magnox reactors built in France and the United Kingdom are somewhat different, they all have a number of characteristics in common that have evolved over the years from the early prototypes built for the dual purpose of plutonium production and electricity recovery (Figs. 1-2 and 1-3) to the later large commercial power stations (Figs. 1-4 and

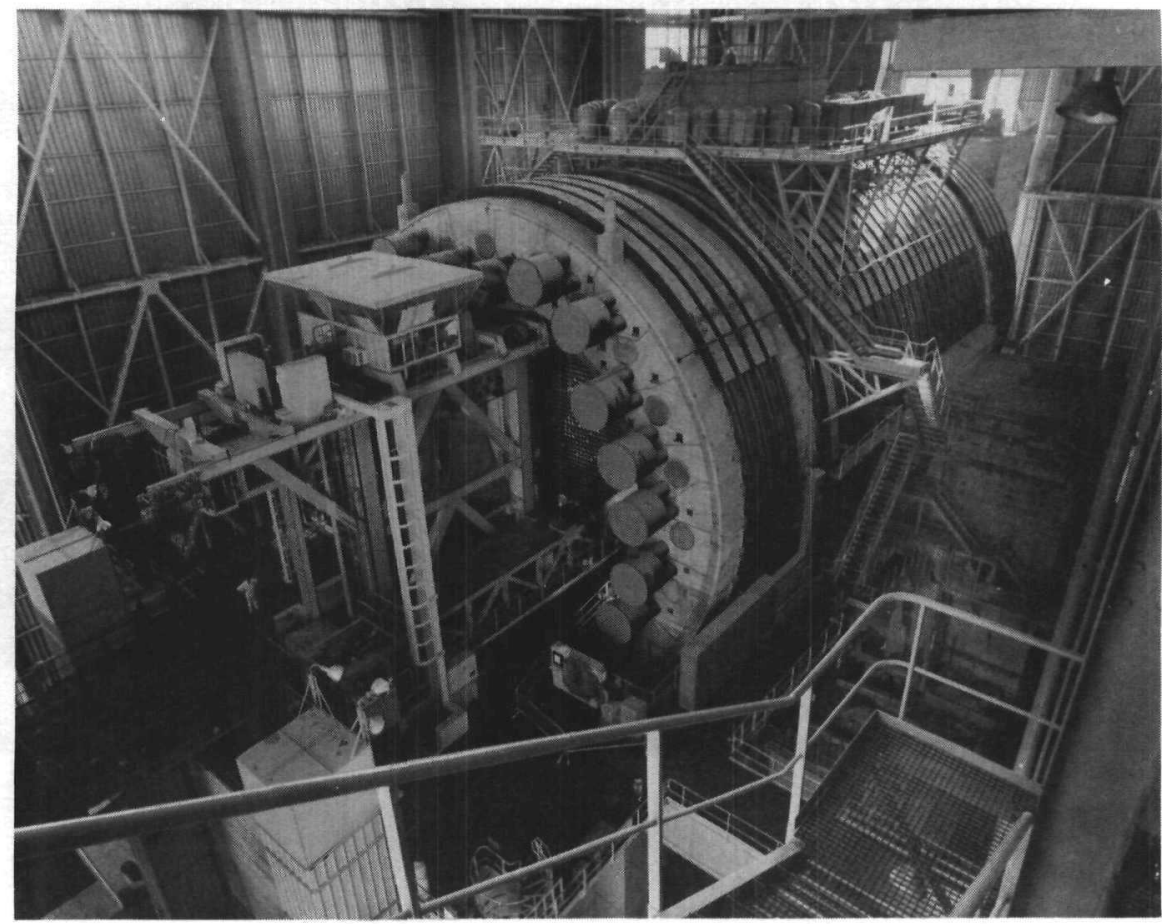

Fig. 1-3. The Marcoule G2 reactor. 
1-5). Table 1-II lists some typical parameters of the reactors showing an evolution from the small, low-efficiency, low power density plants to the larger, higher efficiency and higher power density stations.

Magnox reactors have a low power density- 0.1 to $0.5 \mathrm{MW}(\mathrm{e}) / \mathrm{m}^{3}-$ compared to $\sim 30 \mathrm{MW}(\mathrm{e}) / \mathrm{m}^{3}$ for PWRs. This results from using natural uranium as fuel and graphite as the moderator, which requires heterogeneous reactor designs with a very large carbon-to- ${ }^{235} \mathrm{U}$ ratio, typically 12000 to 18000 (compared to $\sim 3000$ in HTGRs). Furthermore, the maximum specific power is limited to 4 to $5 \mathrm{MW}(\mathrm{t}) /$ tonne of uranium (except for Bugey where the hollow fuel element is cooled on both sides) because of maximum permissible cladding and fuel temperatures and because of limitations on the transfer surface area. In order to increase the reactivity of the reactor, low cross-section cladding material must be used.

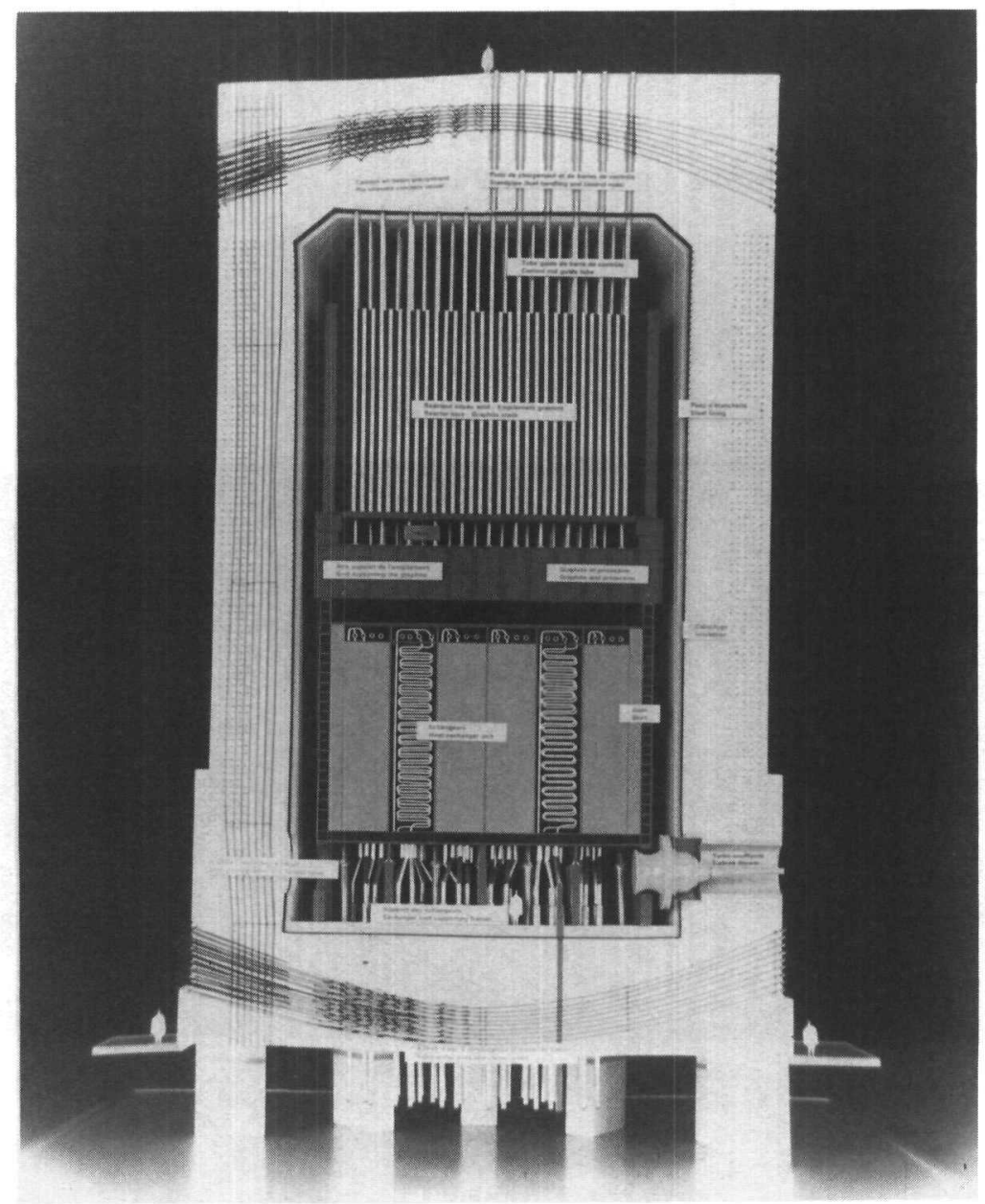

Fig. 1-4. EDF's St. Laurent 1 reactor. 


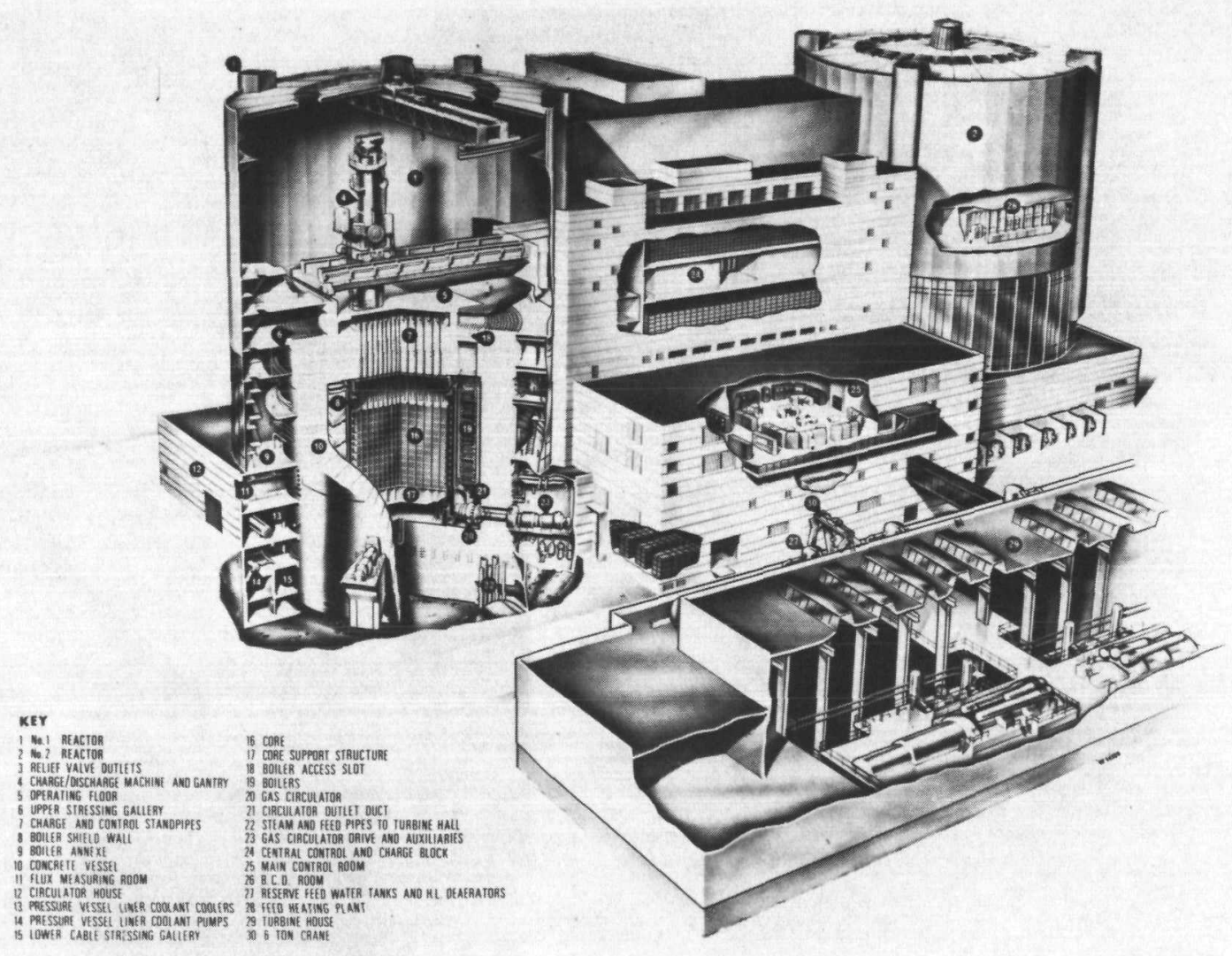

Fig. 1-5. The CEGB Magnox reactor at Oldbury. 
TABLE 1-II

Typical Parameters of Magnox Reactors

\begin{tabular}{|c|c|c|c|c|c|c|c|}
\hline & Calder Hall & Marcoule G2 & Hinkley Point A & Chinon 3 & Oldbury & Wylfa & Bugey 1 \\
\hline Country & $\begin{array}{c}\text { United } \\
\text { Kingdom }\end{array}$ & France & $\begin{array}{l}\text { United } \\
\text { Kingdom }\end{array}$ & France & $\begin{array}{l}\text { United } \\
\text { Kingdom }\end{array}$ & $\begin{array}{l}\text { Unıted } \\
\text { Kıngdom }\end{array}$ & France \\
\hline First power & 1956 & 1959 & 1965 & 1966 & 1968 & 1971 & 1972 \\
\hline Net power [MW(e)] & 35 & 40 & 250 & 480 & 300 & 590 & 540 \\
\hline Net design efficiency (\%) & 19 & 16 & 25 & 31 & 336 & 315 & 291 \\
\hline \multicolumn{8}{|l|}{ Active core } \\
\hline length $(m)$ & 64 & 785 & 76 & 9 & 96 & 915 & 9 \\
\hline duameter (m) & 945 & 845 & 149 & 14 & 13 & 1735 & 122 \\
\hline Power density $\left(\mathrm{MW} / \mathrm{m}^{3}\right)$ & 05 & 05 & 074 & 11 & 065 & 087 & 18 \\
\hline Specific power $\left(\mathrm{kW} / \mathrm{kg}{ }^{235} \mathrm{U}\right)$ & 190 & 250 & 360 & 470 & 400 & 450 & 870 \\
\hline Maxımum fuel bumup (MWd/kg) & 27 & 04 & $\geqslant 3$ & 5 & 45 & $\geqslant 36$ & 5 \\
\hline Number of fuel channels & 1696 & 1200 & 4500 & 2737 & 3308 & 6150 & 850 \\
\hline Fuel channel diameter (mm) & 54 & 71 & 96 & 140 & 97 & 965 & 224 \\
\hline Elements per channel & 6 & 28 & 8 & 15 & 8 & 8 & 15 \\
\hline \multicolumn{8}{|l|}{ Fuel element } \\
\hline diameter (mm) & 29 & 28 & 285 & $23 \times 43$ & 28 & 28 & $77 \times 95$ \\
\hline length $(\mathrm{mm})$ & 1015 & 282 & 900 & 560 & 960 & 1050 & 500 \\
\hline Maxımum claddıng temperature $\left({ }^{\circ} \mathrm{C}\right)$ & 418 & 400 & 430 & 445 & 472 & 451 & 510 \\
\hline \multicolumn{8}{|l|}{ Coolant } \\
\hline pressure $(\mathrm{MPa})$ & 08 & 15 & 136 & 3 & 255 & 27 & 42 \\
\hline temperatures $\left({ }^{\circ} \mathrm{C}\right)$ & 140 to 336 & $80 / 150$ to $305 / 354$ & 180 to 375 & 240 to 400 & 245 to 410 & 247 to 414 & 225 to 410 \\
\hline Power per circulator (MW) & 14 & 185 & 55 & 14 & 52 & 14 & 20 \\
\hline \multicolumn{8}{|l|}{ Steam } \\
\hline pressures (MPa) & $15 / 04$ & $1 / 02$ & $47 / 13$ & 53 & $10 / 5$ & 48 & 33 \\
\hline temperatures $\left({ }^{\circ} \mathrm{C}\right)$ & $314 / 182$ & $330 / 170$ & $363 / 350$ & 400 & $400 / 393$ & 396 & 380 \\
\hline Pressure vessel type & Steel & PCRV & Steel & PCRV & PCRV & PCRV & PCRV \\
\hline thıckness $(\mathrm{mm})$ & 508 & 3000 & 75 & 4200 to 5500 & 4600 to 6700 & 3350 & 5500 to 7500 \\
\hline length $(\mathrm{m})$ & 2165 & $277 \mathrm{IL}^{a}$ & 20 & $201 \mathrm{IL}$ & $183 \mathrm{IL}$ & $293 \mathrm{IL}$ & $401 \mathrm{IL}$ \\
\hline diameter (m) & 1125 & $14(1 \mathrm{~d})$ & 20 & $189(1 \mathrm{~d})$ & $236(1 d)$ & $293(1 \mathrm{~d})$ & $171(\mathrm{dd})$ \\
\hline
\end{tabular}

${ }^{a} \mathrm{IL}=$ inside length 
Magnesium alloy Magnox ( $0.8 \%$ aluminum, 0.002 to $0.50 \%$ beryllium, $0.008 \%$ calcium, and $0.006 \%$ iron additions) is used in the United Kingdom and a Mg$\mathrm{Zr}$ alloy in France. Because of $\mathrm{CO}_{2}$ oxidation and melting of the cladding at $\sim 645^{\circ} \mathrm{C}$, the maximum cladding temperature is limited to $500^{\circ} \mathrm{C}$ or less. Furthermore, a phase change in metallic uranium at $665^{\circ} \mathrm{C}$ (alpha to beta) limits the maximum fuel temperature to $600^{\circ} \mathrm{C}$ or below. A relatively high coolant pressure and high pumping power (as a ratio of thermal power), as well as extended surfaces on the fuel elements, are required in order to obtain an acceptable exit gas temperature of 375 to $415^{\circ} \mathrm{C}$. A further coolant temperature limitation of 360 to $365^{\circ} \mathrm{C}$ became necessary after operation of most U.K. Magnox reactors and the French Chinon 3 reactor because of oxidation of mild steel in high-temperature $\mathrm{CO}_{2}$. This phenomenon led to some derating of these reactors, but only $\sim 10 \%$ due to reoptimization of the systems. Graphite corrosion by $\mathrm{CO}_{2}$ could be reduced by hydrogen or methane injection in the coolant. ${ }^{10}$ Finally, the fuel burnup is limited to values on the order of 5 to $6 \mathrm{MWd} / \mathrm{kg}$ (compared to $30 \mathrm{MWd} / \mathrm{kg}$ in PWRs and 100 $\mathrm{MWd} / \mathrm{kg}$ in HTGRs) because of deformation of the metallic uranium under irradiation, and also because of reactivity limitations with natural uranium fuel.

One way of improving the neutron economy is frequent refueling, since less neutron poisons are required for control. If designed for on-load refueling, good plant availability is obtained, although problems did arise with the rather complex refueling machinery required for on-load and pressurized operation. Refueling machinery failures accounted for $45 \%$ of all reactor shutdowns in the United Kingdom. All commercial Magnox stations of French and U.K. design utilize this concept, which was started on the Marcoule G2 reactor in 1959 (see Fig. 1-3).

Another new concept introduced by the $\mathrm{G} 2$ reactor was the use of a prestressed concrete reactor pressure vessel (PCRV) rather than a thick steel vessel. The PCRV consists of a carbon steel vessel liner surrounded by concrete in compression, post-tensioned by sets of steel tendons. The liner, anchored to the concrete, is the gas barrier and acts as a membrane. This highly redundant structure, where the tendons are well protected from thermal and radiation fields, has an extremely low probability of catastrophic failure. ${ }^{11-13}$ The very thick concrete structure also acts as biological shielding for the reactor. With steel vessels, the coolant pressure and/or the reactor size are limited by the maximum thickness practical for welding and also by shipping problems; there is no such limitation with the PCRV, which can contain large cavities with high pressure, thus removing limitations on reactor power. Only the reactor core was contained in the Marcoule G2 and G3 and Chinon 3 nuclear plants, but the PCRV encloses the whole primary system in later reactors such as St.-Laurent-des-Eaux 1 and Oldbury (see Figs. 1-4 and 1-5). Including the two Marcoule reactors, 11 Magnox reactors use PCRVs, 8 of them with the entire primary system contained within the vessel.

Besides core-related components and reactor vessels, a number of major components, such as steam generators and coolant circulators, were developed for gas-cooled reactors. Operating conditions for these components have been uprated continuously from the early reactors operating at low pressure $(0.8 \mathrm{MPa}$ 
or 8 bars) and temperature $\left(336^{\circ} \mathrm{C}\right.$ maximum) to the latest Magnox reactors (4.3 $\mathrm{MPa}$ and $410^{\circ} \mathrm{C}$ ). The main gas circulators are driven either by electric motors, or by series or parallel steam turbines. The power required by one of the circulators for the Chinon 3 or Wylfa reactors is $\sim 15 \mathrm{MW}$, and even $20 \mathrm{MW}$ at Bugey (Table $1-$ II).

\section{1-2B Experience with Magnox Reactors}

In 1976, nearly $10 \%$ of the electricity generated in the United Kingdom was produced by Magnox reactors and the cost of nuclear electricity was $\sim 70 \%$ of the cost for coal-fired stations and only $60 \%$ of the cost for oil-fueled stations. The average lifetime load factor of the French Magnox reactors G2 and G3 at Marcoule was as high as $95 \%$ for the first 15 years of operation. ${ }^{14}$ The average load factor (based on the net output capability) for the seven fully commissioned stations of the Central Electricity Generating Board (CEGB) in the United Kingdom was $98 \%$ during the three winter months of 1974-1975. For the first half of 1983, the average capacity factor ${ }^{15}$ of U.K. Magnox reactors was close to $70 \%$.

Continuous improvements have occurred in plant and fuel performance, even after commissioning of the reactors; these improvements resulted in a lack of standardization of components and fuel elements for successive stations. For instance, introduction of a graphite core fuel element instead of a tubular element in the French Magnox reactors has allowed an increase in the maximum fuel burnup ${ }^{16}$ from 5 to $7 \mathrm{MWd} / \mathrm{kg}$. Fuel elements for French commercial Magnox reactors are contained in graphite sleeves. Similarly, in the United Kingdom, the average burnup ${ }^{17}$ has been raised from 3.5 to $4.5 \mathrm{MWd} / \mathrm{kg}$. Very satisfactory fuel performance has been obtained, with few element failures, in both French and U.K. reactors. ${ }^{18}$ For instance, of 1.5 million fuel elements used in the CEGB Magnox reactors between 1962 and 1975, only $0.1 \%$ have failed in service, and only 22 failures necessitated reactor shutdown. Similar results were obtained in France with very low fuel failure rates: only five cladding failures for 400000 elements.

The evolution of the finned fuel element in the United Kingdom is shown in Fig. 1-6 while Fig. 1-7 represents the advanced French fuel element finned both inside and outside. ${ }^{5}$ Longitudinal fins were used on the early French (G2, EDF1) and U.K. (Windscale) gas-cooled reactors' fuel elements to increase the heat flux from the cladding to the coolant, ${ }^{19,20}$ since minimizing the film drop is desirable because of temperature limitations. Transverse fins were used for the cladding of the Calder Hall reactor fuel elements ${ }^{21}$ while polyzonal fuel elements with helical fins and helical herringbone-type fins were employed in later Magnox reactors to improve gas mixing as well.

A consequence of the good fuel behavior, failed-fuel detection system, and on-load fuel handling is the low contamination level of the gas circuit, which makes it relatively accessible during shutdowns with low radiation exposure to personnel. The level of radioactive releases to the atmosphere is very low. For 


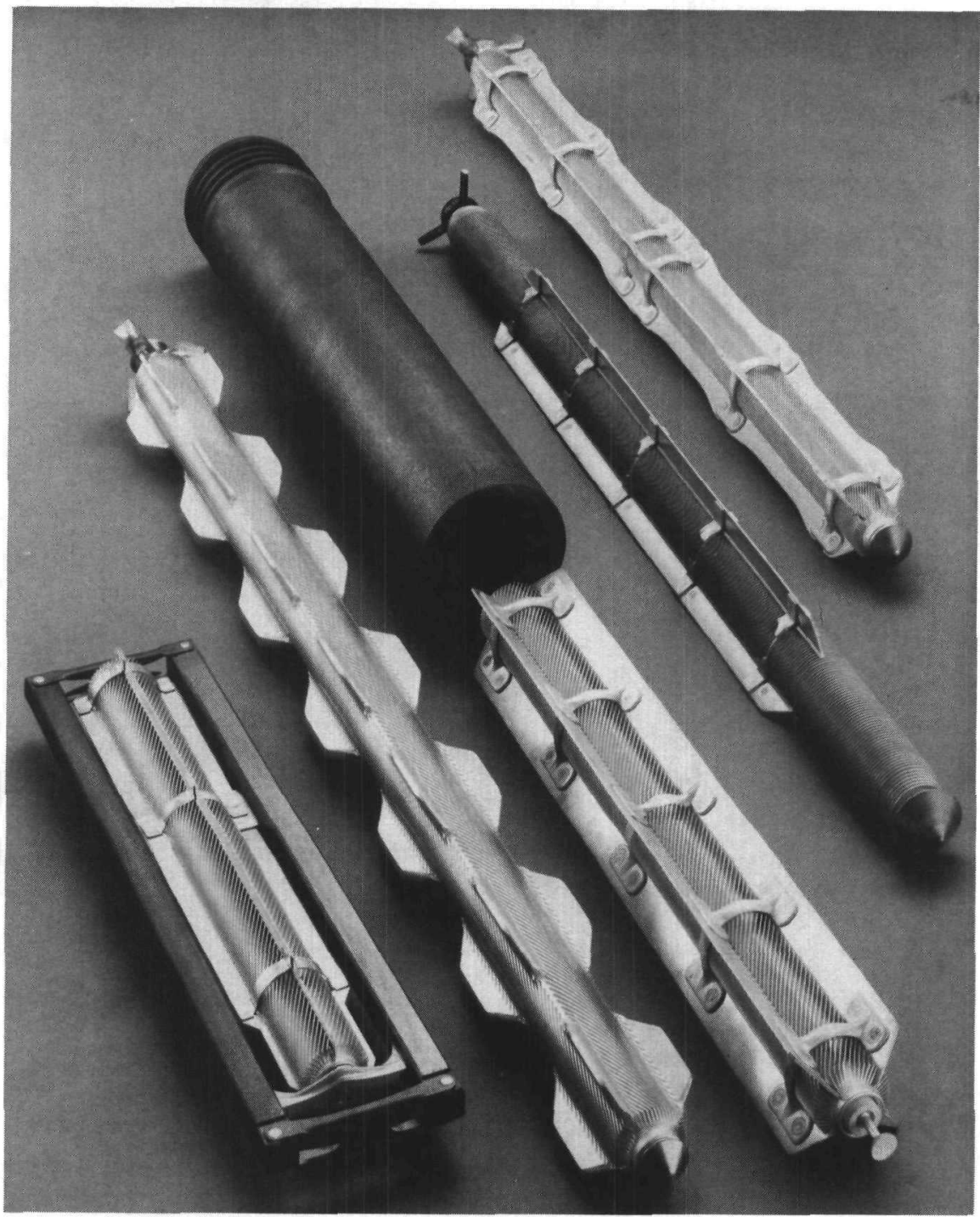

Fig. 1-6. UKAEA fuel elements. From left to right, Berkeley, Sizewell, Hunterston with sleeve, Pippa Mark-II, and Oldbury.

instance, in 1971 the gaseous releases ${ }^{22}$ in all French gas-cooled reactors were $\sim 1 \%$ of the allowed release, and liquid releases were $0.2 \%$.

Early problems occurred in heat exchangers because of manufacturing defects. Flow-induced vibrations with $\mathrm{CO}_{2}$ that caused failures through stress fatigue or fretting have occurred in a number of components such as cover plates, guide vanes, reactor internal casings, boiler tubes, circulator piping, etc. Even when 


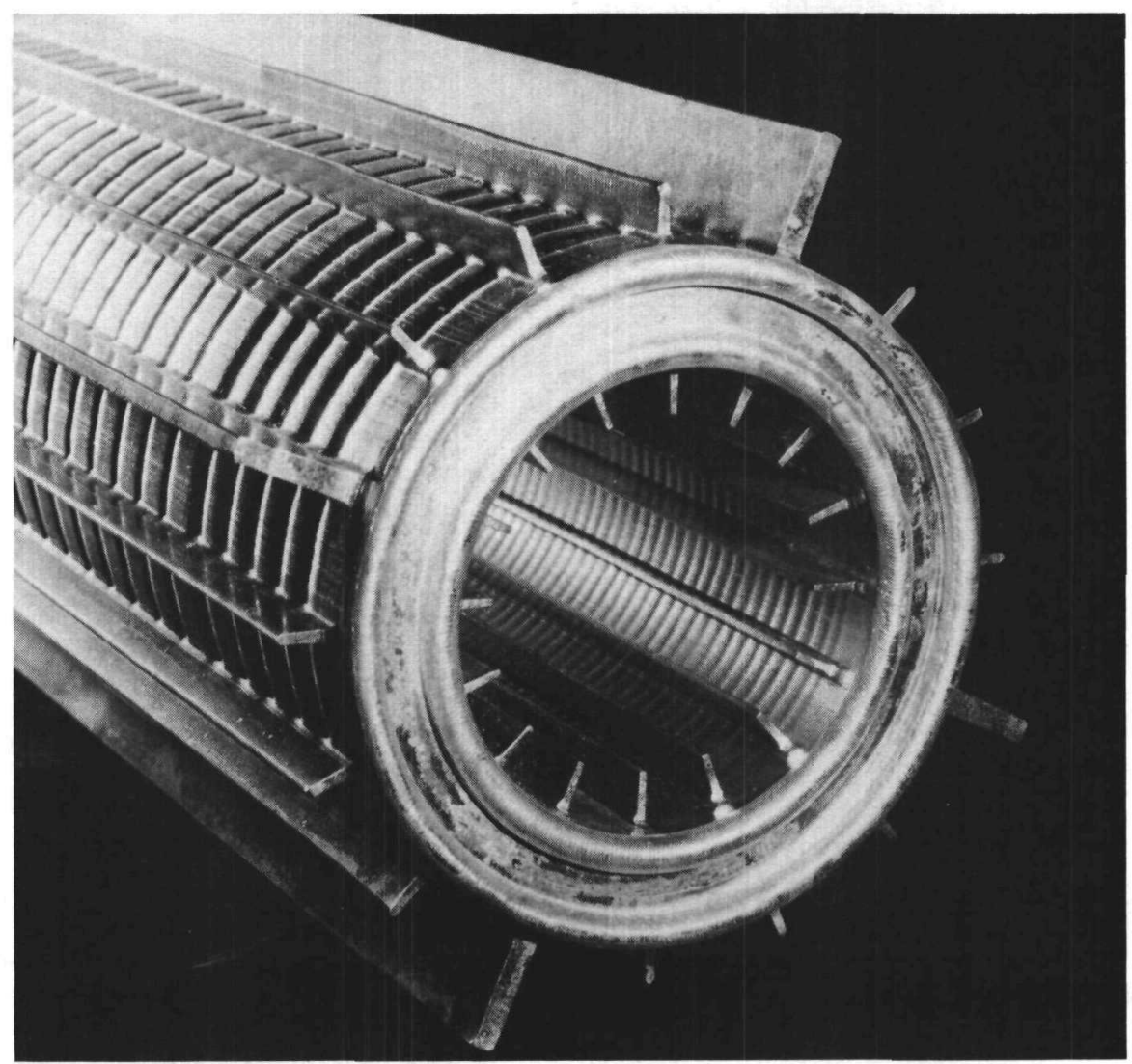

Fig. 1-7. Annular fuel element for French natural uranium graphite reactor.

such large components were tested out-of-pile, problems did occur within the reactor because of the complex phenomena occurring in the actual $\mathrm{CO}_{2}$ circuits. Defective bellows found in 1979 in the early British Magnox reactors had to be repaired or replaced. ${ }^{23}$

A great deal of experience has been accumulated through the construction and operation of Magnox reactor components such as PCRVs, steam generators, and circulators. This experience serves as a base for the development of similar components for more advanced reactors, AGRs, or HTGRs.

In general, once early problems were solved, long-term experience has been satisfactory $^{24-27}$ :

1. Eleven PCRVs have been built for Magnox reactors with a total experience of $\sim 180$ reactor-yr of operation by the end of 1983 .

2. Steam generator experience started in 1956 , with about 150 in operation as of 1983, all generating superheated steam. 
3. Since 1956,150 gas circulators have operated with both electric and steam drives up to a rating of $20 \mathrm{MW}$. Back-pressure steam-driven circulators, of $1.85 \mathrm{MW}$ each, have been used in the $\mathrm{G} 2$ and $\mathrm{G} 3$ reactors since 1959-1960.

Experience with other components such as a graphite moderator, control rods and drives, and thermal insulation has also been found to be very valuable for other types of gas-cooled reactors.

\section{1-3 Advanced Gas-Cooled Reactors (AGRs)}

To improve on the Magnox reactors significantly, both higher thermodynamic efficiency and better fuel utilization are required. Most limits for the Magnox designs derive from the use of metallic natural uranium as fuel. With enrichment, uranium oxide may be used (allowing a higher fuel temperature and longer fuel irradiation) and a better cladding material may be introduced (allowing a higher gas temperature and greater heat flux). Beryllium was first proposed as a low neutron absorption cladding but was never adopted because of material problems. ${ }^{28}$ Instead, stainless steel was chosen, and in 1958 the construction of the first AGR was begun to prove the concept of a $\mathrm{CO}_{2}$-cooled, graphite-moderated reactor with stainless steel clad oxide fuel. As shown in Table 1-III, the aim was to raise the coolant outlet temperature, to increase thermodynamic efficiency, and to greatly increase the fuel burnup, made possible because $\mathrm{UO}_{2}$ accommodates fission products better than metallic uranium, and also because the reactivity is not limited with enriched fuel. This type of fuel can be divided into smaller pins and more neutron absorption can be tolerated; the resultant higher fuel rating and power density lead to more compact reactors and a smaller total fuel requirement.

Another approach to such improvements over the earlier Magnox reactors was the replacement of $\mathrm{CO}_{2}$ by helium in an all-ceramic semi-homogeneous core; this is the HTGR concept that was begun about the same time as the first AGR was developed and led to prototype HTGRs in the mid-1960s (see Chapter 2). Helium was also chosen as coolant for the Experimental Gas-Cooled Reactor at Oak Ridge National Laboratory (see Sec. 1-4C).

\section{1-3A Windscale AGR (WAGR)}

The first AGR prototype, which started up in 1963 at Windscale, has been a test bed for fuel elements and for a number of core features for the later commercial AGRs (Fig. 1-8, Ref. 29). The main parameters of the WAGR (Table 1-III) show a considerable increase in $\mathrm{CO}_{2}$ outlet temperature over the $\mathrm{CO}_{2}$ temperature in Magnox reactors: $560^{\circ} \mathrm{C}$ versus 350 to $400^{\circ} \mathrm{C}$. The fuel assemblies are made up of a bundle of $\mathrm{UO}_{2}$ pellets contained in stainless steel tubes and assembled in graphite sleeves (Fig. 1-9). The fuel enrichment is $2.5 \%$; the 10 -mm-diam fuel is contained in a $0.375-\mathrm{mm}$-thick stainless steel cladding with small transverse 
TABLE 1-III

Main Parameters for AGRs

\begin{tabular}{|c|c|c|c|c|c|}
\hline & WAGR & Hinkley Point B & Dungeness $B$ & Hartlepool & Heysham 2/Torness \\
\hline First power & 1963 & 1976 & 1982 & 1983 & $1987-1988$ \\
\hline Net power [MW(e)] & 28 to 33 & 625 & 600 & 625 & 620 \\
\hline Net design efficiency $(\%)$ & 28 to 31 & 415 & 415 & 4165 & 40 \\
\hline \multicolumn{6}{|l|}{ Active core } \\
\hline length $(\mathrm{m})$ & 42 & 83 & 82 & 82 & 83 \\
\hline duameter (m) & 45 & 95 & 94 & 93 & 945 \\
\hline Power density $\left(\mathrm{MW} / \mathrm{m}^{3}\right)$ & 143 & 255 & 25 & 27 & 265 \\
\hline Specific power $\left(\mathrm{kW} / \mathrm{kg}{ }^{235} \mathrm{U}\right)$ & 350 & $\sim 600$ & $\sim 500$ & $\sim 600$ & $\sim 600$ \\
\hline Average fuel burnup ( $\mathrm{MWd} / \mathrm{kg}$ ) & 10 to 20 & $\sim 20$ & 18 to 20 & 18 to 20 & 18 \\
\hline Fuel enrichment $(\%)$ & 25 & 14 to 26 & 15 to 25 & 14 to 26 & 211 to 277 \\
\hline Number of fuel channels & 210 & 310 & 410 & 324 & 332 \\
\hline Graphte sleeve $1 \mathrm{~d}(\mathrm{~mm})$ & 130 & 190 & 178 & 190 & 190 \\
\hline Elements per channel & 8 & 8 & 8 & 8 & 8 \\
\hline \multicolumn{6}{|l|}{ Fuel element } \\
\hline number of rods & 21 & 36 & 36 & 36 & 36 \\
\hline rod diameter $(\mathrm{mm})$ & 102 & 145 & 145 & 145 & 145 \\
\hline rod length (mm) & 510 & 1040 & 1040 & 1040 & 1040 \\
\hline $\begin{array}{l}\text { Maximum cladding } \\
\text { temperature }\left({ }^{\circ} \mathrm{C}\right)\end{array}$ & 650 to 750 & 825 & 835 & 825 & - \\
\hline \multicolumn{6}{|l|}{ Coolant } \\
\hline pressure (MPa) & 19 & 42 & 345 & 42 & 435 \\
\hline temperatures $\left({ }^{\circ} \mathrm{C}\right)$ & 250 to 560 & 290 to 670 & 320 to 675 & 317 to 648 & 335 to 635 \\
\hline Power per circulator (MW) & 14 & 43 & 109 & 43 & 53 \\
\hline Circulator pressure nse (MPa) & 01 & 024 & 032 & - & 029 \\
\hline \multicolumn{6}{|l|}{ Steam } \\
\hline pressure (MPa) & 46 & 163 & 163 & 163 & 16 \\
\hline temperature $\left({ }^{\circ} \mathrm{C}\right)$ & 454 & 538 & 565 & 538 & 538 \\
\hline Reheat $\left(\mathrm{MPa} /{ }^{\circ} \mathrm{C}\right)$ & None & $44 / 538$ & $39 / 565$ & $38 / 538$ & $39 / 538$ \\
\hline Pressure vessel type & Steel & PCRV & PCRV & PCRV multicavity & PCRV \\
\hline thickness (mm) & 445 to 1111 & 4900 to 7300 & 3800 to 6400 & 5500 to 6400 & 5800 \\
\hline heıght (m) & 16 & 194 inside height & 177 inside height & 183 inside height & 219 inside height \\
\hline diameter (m) & 63 & $189(1 \mathrm{~d})$ & $20(1 \mathrm{~d})$ & $131(1 \mathrm{~d})$ & $202(1 \mathrm{~d})$ \\
\hline
\end{tabular}




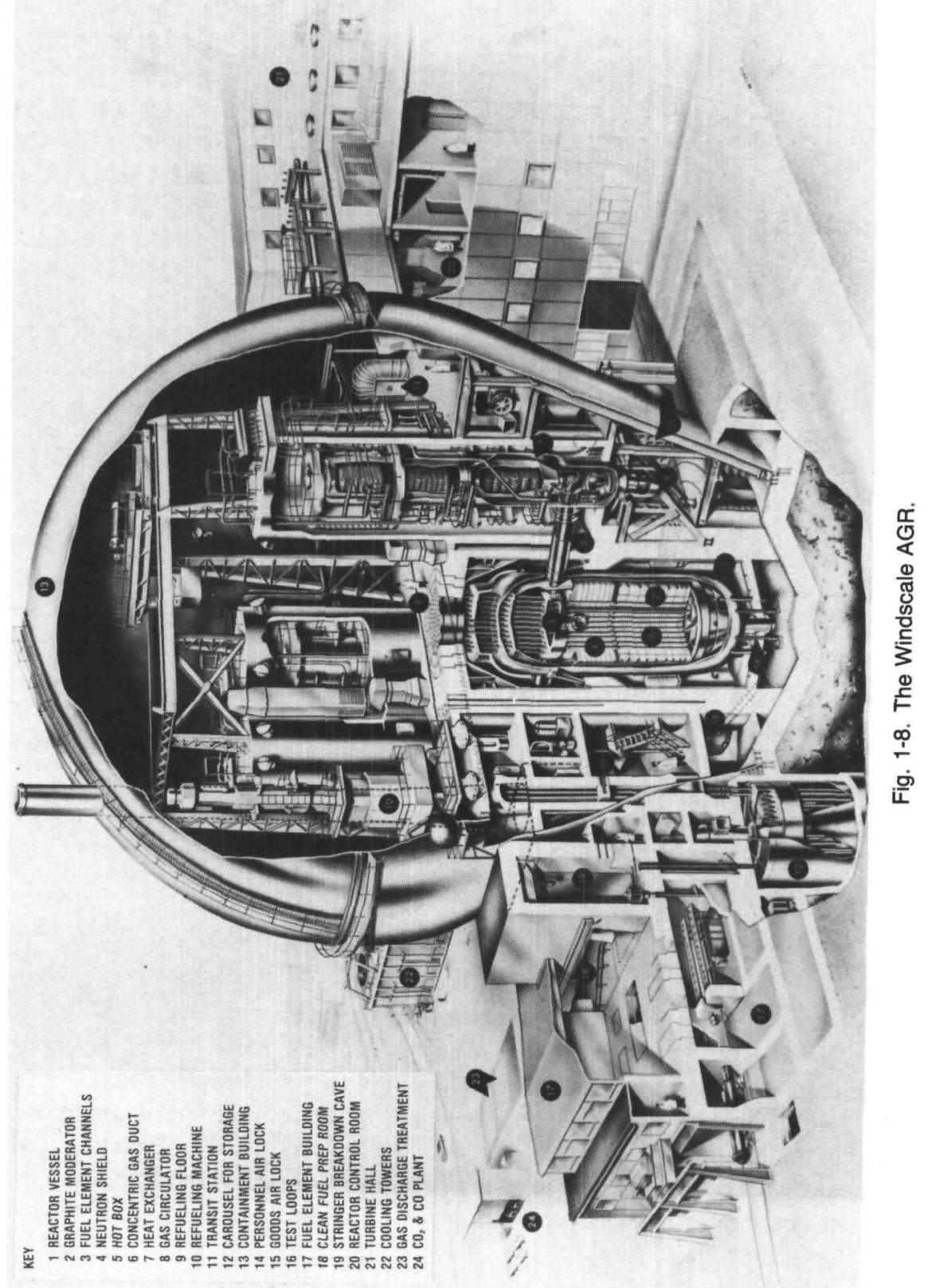




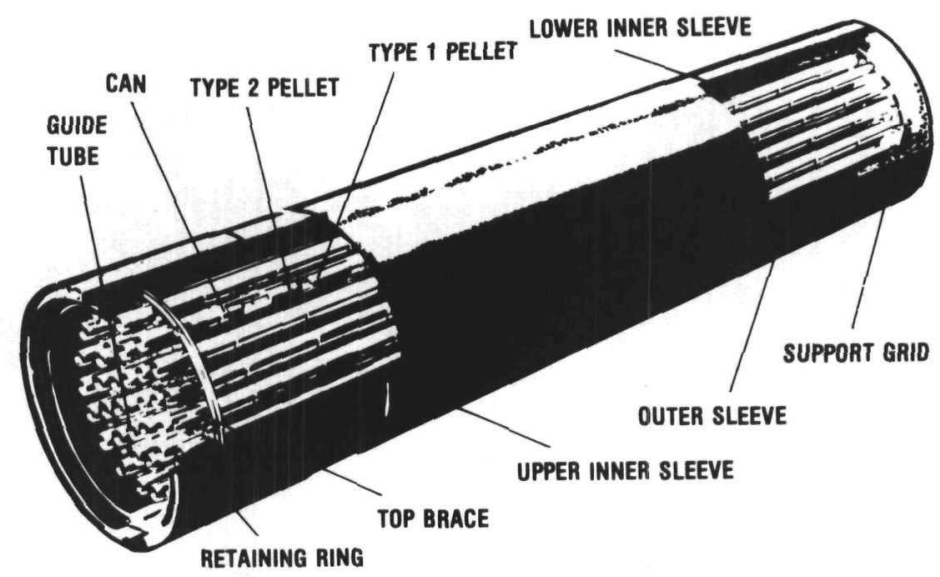

Fig. 1-9. Cutaway of a 36-pin AGR fuel assembly.

ribs, $0.15-\mathrm{mm}$ square on a $2.5-\mathrm{mm}$ pitch. This artificial surface roughness improves the surface heat transfer, with some penalty in pressure drop. Stainless steel fins would not be very useful since the neutron absorption would be too high and the fin efficiency would be low because of the relatively poor thermal conductivity of stainless steel. Surface roughening is also used in the larger AGRs and is the basis for designs of GCFR fuel rods (see Chapter 10).

Besides providing operating experience on fuel elements, the main functions of the WAGR were to provide information on the behavior of the graphite moderator at a higher rating, temperature, and coolant pressure than in Magnox reactors, and to permit investigation of the compatibility of reactor materials and other components (i.e., steam generator materials) in $\mathrm{CO}_{2}$ at the higher temperatures and pressures. ${ }^{30} \mathrm{~A}$ number of design features of the WAGR are directly applicable to commercial reactors:

1. single-channel access

2. fuel channel discharge on-load

3. the internal neutron shield above the core

4. the reentrant core.

In the reentrant core, before flowing over the fuel rods, about half of the coolant (at inlet temperature) first passes through the graphite moderator, which is maintained at a substantially constant temperature, lower than the maximum temperature in the Magnox reactors. In spite of the use of replaceable graphite sleeves in contact with the hot $\mathrm{CO}_{2}$ and in spite of the low moderator graphite temperature, a small quantity of methane must be added to the coolant to slow the reaction between graphite and $\mathrm{CO}_{2}$ at the relatively high fuel rating and gas pressure.

From startup in 1963 until the end of 1976, the WAGR generated close to $3 \times 10^{9} \mathrm{kWh}$. During its first ten years of operation, the load factor of the plant was $71 \%$, and would have been $85 \%$ if allowance had been made for deliberate 
reductions in power required by the experimental program. ${ }^{31}$ Many different designs of fuel pins have been tested including 4000 fuel pins made of annular $\mathrm{UO}_{2}$ pellets in 0.375 -mm-thick stainless steel cladding that exhibited very few failures under typical operating conditions for commercial AGRs. Special loops have been designed for testing fuel performance in the WAGR under power cycling conditions, such as changes from 100 to $75 \%$ power. Two special high-pressure loops were commissioned ${ }^{32}$ in the late 1970 s to test fuel up to a coolant pressure of $\sim 6 \mathrm{MPa}$.

Detailed studies have also been performed both in-pile and out-of-pile to determine the optimum coolant composition (i.e., small additions of $\mathrm{CH}_{4}, \mathrm{CO}$, and $\mathrm{H}_{2} \mathrm{O}$ to $\mathrm{CO}_{2}$ ) to inhibit corrosion effects of $\mathrm{CO}_{2}$ on graphite while minimizing carbon deposition, for instance, on heat transfer surfaces. There is confidence that the graphite moderator in the core could last for the 30-yr reactor design life.

Valuable experience has been gained from WAGR with on-load refueling, ${ }^{33}$ the reentrant flow sytem, on-load flow control of each fuel channel, and the use of encapsulated gas circulators. ${ }^{34}$ The laminated dimpled stainless steel insulation, necessitated by a maximum $\mathrm{CO}_{2}$ temperature up to $725^{\circ} \mathrm{C}$, has been found effective and inspection has shown no damage. ${ }^{35}$ The gas circulators have proved very reliable, but, in common with Magnox reactors, flow-induced vibration problems had to be overcome. After 18 years of operation, WAGR was decommissioned in 1981, following a series of severe experimental transients.

\section{1-3B Commercial AGRs}

Seven AGR stations, each with two reactors, for a total of $8.7 \mathrm{GW}(\mathrm{e})$, have been ordered in the United Kingdom. Commercial operation started in 1976 at Hinkley Point B and at Hunterston B. As shown in Table 1-III, the designs of the large AGRs are similar, with an $\sim 600-\mathrm{MW}$ (e) design output at a net efficiency of $41 \%$ with modern steam conditions. The fuel elements consist of a bundle of $36 \times 14-\mathrm{mm}$ enriched $\mathrm{UO}_{2}$ rods, clad in stainless steel, $\sim 1-\mathrm{m}$ long (Fig. 1-9). As in WAGR, artificial surface roughening is provided to improve heat transfer (single-start helix with square ribs). In all commercial AGRs, the whole primary system-core, steam generators, and circulators-is contained within a PCRV. For Dungeness B, Hinkley Point B, and Hunterston B, the boilers are located around the core within the PCRV, while for Hartlepool and Heysham 1, the boilers are located in cavities within the concrete vessel. ${ }^{36}$ The new Heysham 2 and Torness stations, due to be commissioned in 1987-1988, have a design similar to Hinkley Point B (see Table 1-III), with modifications for improved performance margins, easier personnel access, and updated safety standards. ${ }^{37}$

Figure 1-10 shows a section through the reactor of Hinkley Point B with the boilers located around the core and the gas circulators in horizontal cavities within the PCRV wall at the bottom. ${ }^{38}$ The design of the first AGR reactor ordered, Dungeness B, is similar. ${ }^{39}$ As shown in Fig. 1-11, later AGR designs incorporate pod boilers in eight smaller cavities around the central cavity containing the reactor 


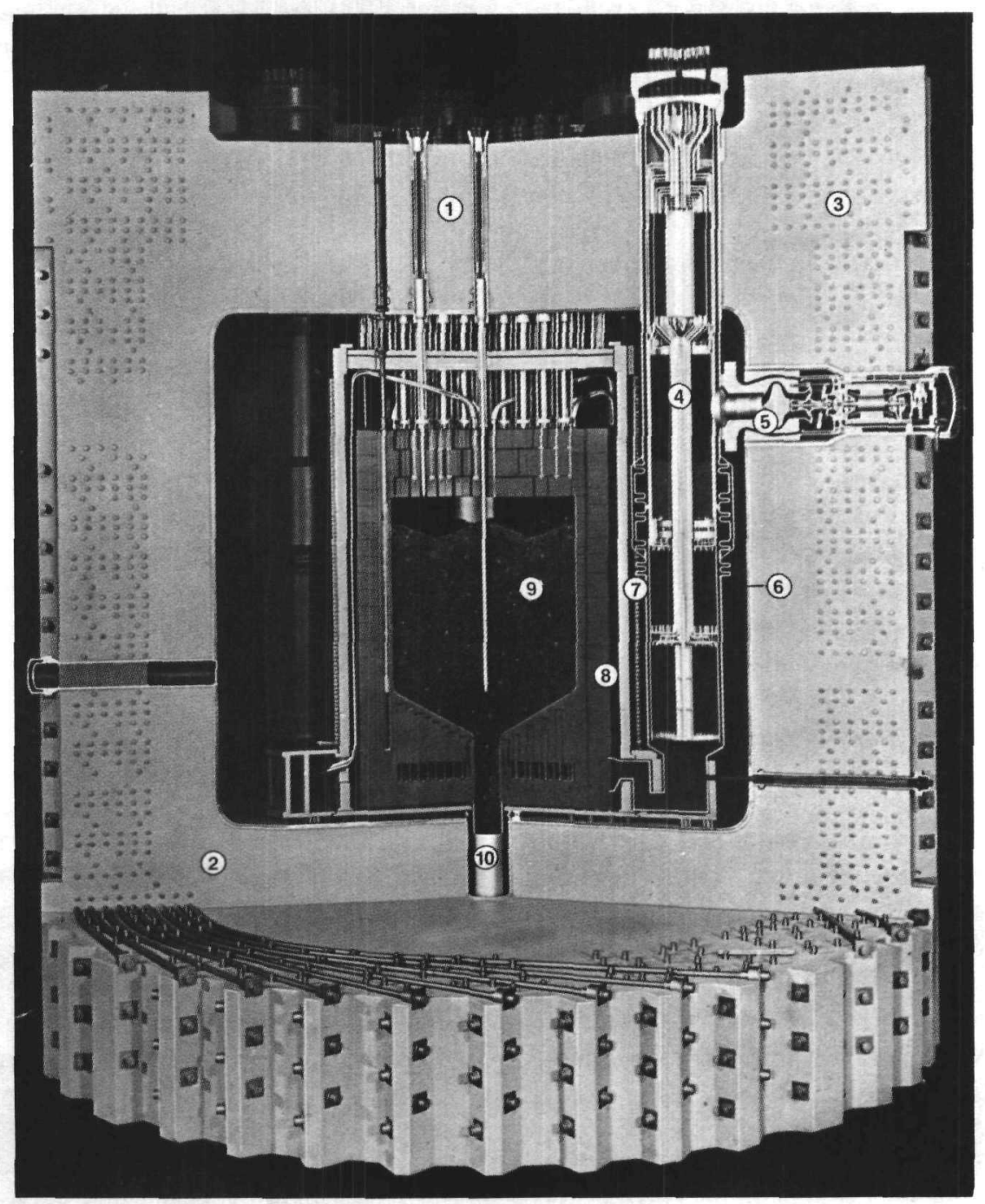

Fig. 1-10. Hinkley Point B AGR-section through reactor.

core ${ }^{40,41}$ For the Hartlepool and Heysham 1 reactors, circumferential prestressing of the PCRV is performed by wire winding. Both the reheater and high-pressure boiler surfaces are arranged in the form of concentric multi-start helices. ${ }^{42}$ These once-through boilers are completely removable and replaceable for inspection or repair. The centrifugal gas circulators are vertically mounted at the bottom of each 3-m-diam boiler cavity. ${ }^{43}$

Delays in the construction of the AGR reactors, ranging from 3 to 13 years, have been due both to managerial problems (several drastic changes in the U.K. 


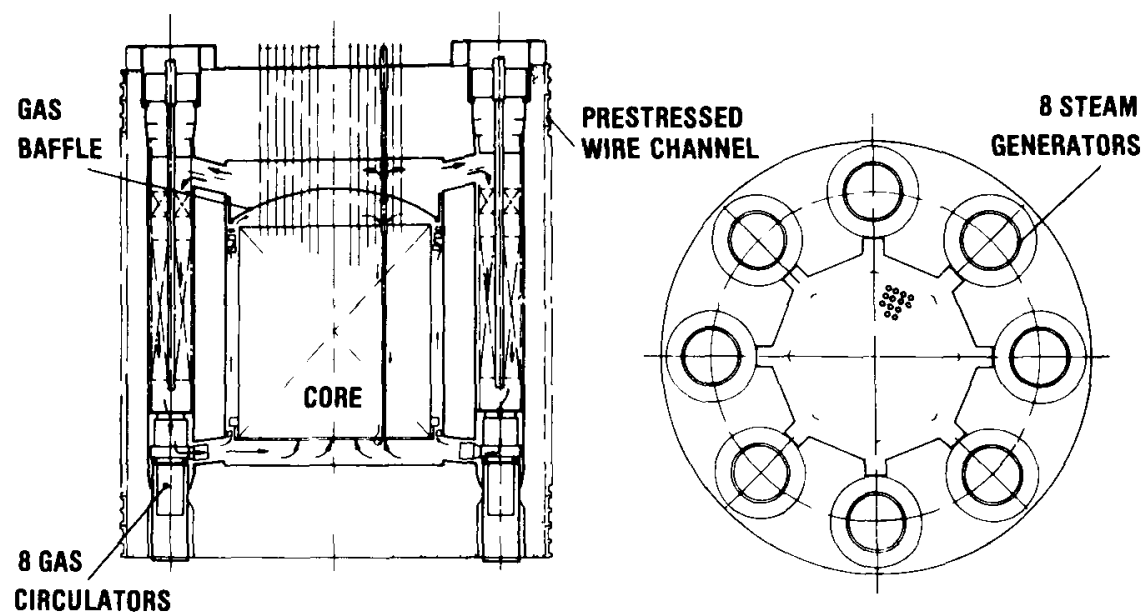

Fig. 1-11. Hartlepool AGR reactor sections.

nuclear industry occurred between 1965 and 1975) and to technical problems, such as construction and support of large metal sheets for PCRV liners, and of the hot box and dome on top of the reactor to separate the hot gas from the concrete vessel. Furthermore, circulator-induced vibration problems required redesign of thermal barrier cover plates, and modifications to the fuel stringer and orifices. ${ }^{44}$ Finally, $\mathrm{CO}_{2}$ oxidation of the $9 \%$ chromium steel used in the boilers has required the outlet gas temperature to be lowered to $\sim 600^{\circ} \mathrm{C}$ from the original conditions ( 650 to $675^{\circ} \mathrm{C}$ ), thus leading to an $\sim 20 \%$ power derating for the first year of operation. ${ }^{45}$ Problems were also encountered with on-load refueling and modifications were required to allow refueling at a high power level $(50 \%)$ without damage to the fuel stringer. But, with half a million fuel pins irradiated, only two stringers had to be discharged prematurely. ${ }^{46}$ Still, the availability in 1981 of the AGR at Hunterston B1 has been $85 \%$. Also, in spite of delays and cost overruns of $33 \%$, electricity produced by the two reactors at Hinkley Point B station [1200 MW(e)] could be 20 to $40 \%$ cheaper than coal. ${ }^{47}$

A lesson learned from the commissioning of AGR reactors is that vibrations (flow-induced or noise-induced) with $\mathrm{CO}_{2}$ cooling can create severe problems that are hard to detect with out-of-pile loops. This is especially true when the primary system is integrated within a PCRV. Similar problems could occur with other gascooled reactors, although flow-induced forces with helium are expected to be much smaller than with $\mathrm{CO}_{2}$, as is discussed in Chapter 5. While most startup problems seem to have been solved with the first AGR stations, there remain three areas of concern that are specific to this reactor type: $\mathrm{CO}_{2}$ corrosion of the steel components, especially in the boilers; a trade-off between carbon corrosion by $\mathrm{CO}_{2}$ and carbon deposition ${ }^{48}$; and the possibility of maintenance and repair work in the "hot box" area above the core, which is required in this upflow design. 
The burnup of the fuel could still be increased, from 18 to $21 \mathrm{MWd} / \mathrm{kg}$ and possibly to $24 \mathrm{MWd} / \mathrm{kg}$ (Ref. 46). The thermal performance of the fuel element could also be improved by further optimization ${ }^{49}$ to obtain lower power costs.

\section{1-4 Early U.S. Gas-Cooled Reactors}

A number of experimental gas-cooled reactors of different designs were built in the United States in the late 1950s and early 1960s for special purposes: mobile power (ML1), maritime or aerospace propulsion (EBOR, HTRE, Tory, and Kiwi), power generation (EGCR), and very high temperature gas operation (UHTREX). At the same time, construction was started on the first high-temperature gas-cooled power reactor, Peach Bottom Power Station Unit 1, with a helium-cooled, allceramic core. This first HTGR is described in Chapter 2 in some detail, together with other HTGR systems.

\section{1-4A Mobile Gas-Cooled Reactors}

The U.S. Army built two small nuclear plants using nitrogen-cooled reactors with a closed-cycle gas turbine, intending to develop a mobile power plant. Nitrogen was used because it is cheaper than helium and less corrosive than $\mathrm{CO}_{2}$ at elevated temperatures.

The Gas-Cooled Reactor Experiment (GCRE-1), designed for a thermal output of 2.2 MW, started operation ${ }^{50}$ in 1960 at the National Reactor Testing Station (NRTS). The heat removed by $1.2 \mathrm{MPa}(12 \mathrm{~atm})$ nitrogen (with $0.5 \% \mathrm{O}_{2}$ ) was transferred to a secondary circuit and dumped to the atmosphere. Core inlet and outlet temperatures were 425 and $650^{\circ} \mathrm{C}$, respectively. The reactor was water moderated with 73 pressure tubes, $47.5 \mathrm{~mm}$ in diameter, containing fuel elements and the coolant flow. The 56 fuel elements of the first core were in the form of curved plates of $\mathrm{UO}_{2}$-stainless steel with stainless steel cladding; the second core contained 56 fuel elements, each having 19 Hastelloy-X tubes filled with highly enriched $\mathrm{UO}_{2}$ pellets. The core was $560 \mathrm{~mm}$ in diameter and $710 \mathrm{~m}$ long.

The Mobile Low-Power Reactor (ML1), similar in design to GCRE-1, had a closed-cycle gas turbine and represented a real operational prototype. ${ }^{51}$ With $3.3 \mathrm{MW}$ of thermal power, the net electrical output was $330 \mathrm{~kW}$. The reactor went critical in 1961 at the NRTS in Idaho and achieved power in 1962-1963. The 61 fuel elements were made up of 19 rod clusters of $\mathrm{UO}_{2}$ pellets within Hastelloy-X tubes. The fuel rod diameter was $6.3 \mathrm{~mm}$, with $93 \%$ enriched fuel; the outer fuel elements contained $\mathrm{UO}_{2}-\mathrm{BeO}$ pellets. The nitrogen coolant entered the reactor at $425^{\circ} \mathrm{C}$ and $2 \mathrm{MPa}(20 \mathrm{~atm})$, and entered the gas turbine at $650^{\circ} \mathrm{C}$. The spacing of the stainless steel pressure tubes was varied to flatten the radial power distribution, while the fuel loadings of the rods within the bundle were varied to equalize the maximum cladding temperature. A 1-mm-diam Hastelloy-X wire separated the pins from each other and from the inner liner, itself insulated from the pressure tube. 


\section{1-4B Propulsion Gas-Cooled Reactors}

Nuclear reactors have been developed for both maritime propulsion (nuclear submarines and surface ships) and for aerospace propulsion (airplanes and rockets). Pressurized water reactors were developed for naval and maritime propulsion: the Nautilus PWR began operation in May 1953, while the merchant ship Savannah started operation in late 1961. A Maritime Gas-Cooled Reactor (MGCR) was designed in 1960 by General Atomic and Electric Boat, divisions of General Dynamics, with a 20000 -hp helium closed-cycle gas turbine propulsion plant. ${ }^{52-54}$ It was not taken beyond the design stage, although a prototype (EBOR) reactor was developed.

The Experimental Beryllium Oxide Reactor (EBOR) was designed and built as a prototype for the MGCR to test the high-temperature behavior of $\mathrm{BeO}$ as a reactor moderator, together with helium cooling. The selection of the EBOR fuel element was based, in part, on its inherent simplicity, readily predictable thermal performance, and satisfactory behavior in case of a loss-of-coolant accident. The main reactor characteristics are shown in Table 1-IV (Ref. 55). Helium at 7.6 MPa enters the reactor at $400^{\circ} \mathrm{C}$ and leaves at $690^{\circ} \mathrm{C}$ in 36 channels each containing 18 fuel rods. The fuel rods contain a mixture of $62.5 \%$ enriched $\mathrm{UO}_{2}$ with $\mathrm{BeO}$ within a 0.5 -mm-thick Hastelloy cladding (Fig. 1-12). These 8.5-mm-diam, 2550mm-long rods, spaced by helical wires, operate at a maximum surface (hot spot) temperature of $860^{\circ} \mathrm{C}$, equalized in each fuel element by proper orificing. Construction of this $10-\mathrm{MW}(\mathrm{t})$ reactor was begun at the NRTS in 1964, but because of budget restrictions, it was mothballed in 1967 just before completion. Several designs for BeO-moderated helium-cooled power reactors with the ${ }^{235} \mathrm{U}-\mathrm{Th}$ cycle have been proposed because of the excellent nuclear properties of $\mathrm{BeO}$, but were never developed in view of uncertainties in the irradiation behavior ${ }^{56}$ of $\mathrm{BeO}$ and a lack of specific mission requirements.

Under the U.S. aircraft nuclear propulsion program, a direct-cycle air-cooled reactor was designed that led to the operation of Heat Transfer Reactor Experiments (HTRE-1, -2, and -3) at the NRTS in Idaho between 1955 and 1958 (Refs. 57 and 58). The HTRE-1 and -2 were air-cooled water-moderated reactors coupled to a single $\mathrm{J}-47$ turbojet engine with a $17.5-\mathrm{MW}(\mathrm{t})$ output. Air at $0.3 \mathrm{MPa}$ (3 atm) was heated in the reactor from 180 to $725^{\circ} \mathrm{C}$ with a maximum fuel temperature of $\sim 1000^{\circ} \mathrm{C}$. The 37 fuel elements, which were $86 \mathrm{~mm}$ in diameter and $740 \mathrm{~mm}$ long, were contained inside $100-\mathrm{mm}$ pressure tubes. They were made of an $80 \mathrm{wt} \% \mathrm{Ni}-20 \mathrm{wt} \% \mathrm{Cr}$ alloy containing highly enriched $\mathrm{UO}_{2}$. Successful operation of the first two reactors was followed by operation of HTRE-3 between 1958 and 1961 at NRTS. The 32.4-MW(t) air-cooled zirconium-hydride-moderated reactor was coupled with two $\mathrm{J}-47$ turbojet engines and generated a total of $\sim 5000 \mathrm{MWh}$. By radial power flattening, the maximum fuel temperature was limited to $\sim 1040^{\circ} \mathrm{C}$ for a maximum air temperature of $900^{\circ} \mathrm{C}$.

Two air-cooled reactors with a $\mathrm{BeO}$ moderator were operated at the Nevada Test Site in 1960 and 1963 as part of the Pluto Program for ramjet propulsion. 
TABLE 1-IV

Thermal Characteristics of Some Early U.S. Helium-Cooled Reactors

\begin{tabular}{|c|c|c|c|}
\hline & EGCR & EBOR & UHTREX \\
\hline \multicolumn{4}{|l|}{ Power } \\
\hline thermal $[\mathrm{MW}(\mathrm{t})]$ & 85 & 10 & 3 \\
\hline electrical [MW(e)] & 25 & None & None \\
\hline \multicolumn{4}{|l|}{ Core } \\
\hline actıve diameter (m) & 36 & 059 side & $\begin{array}{l}0585 \mathrm{~d} \\
178 \circ \mathrm{od}\end{array}$ \\
\hline active length (m) & 44 & 193 & 10 \\
\hline power density $\left(\mathrm{MW} / \mathrm{m}^{3}\right)$ & 187 & 137 & 13 \\
\hline Power conversion & $\begin{array}{l}482^{\circ} \mathrm{C} \text { steam } \\
87 \mathrm{MPa}\end{array}$ & None & None \\
\hline \multicolumn{4}{|l|}{ Heat flux (maxımum) } \\
\hline $\mathrm{W} / \mathrm{cm}^{2}$ & 55 & 84 & 35 \\
\hline $\mathrm{W} / \mathrm{cm}$ & 330 & 250 & 140 \\
\hline \multicolumn{4}{|l|}{ Maxımum temperature } \\
\hline surface $\left({ }^{\circ} \mathrm{C}\right)$ & 816 & 860 & 1593 \\
\hline fuel $\left({ }^{\circ} \mathrm{C}\right)$ & 1650 & 1040 & 1610 \\
\hline Coolant gas & Helium & Helium & Helium \\
\hline total mass flow $(\mathrm{kg} / \mathrm{s})$ & 535 & 66 & 129 \\
\hline mlet temperature $\left({ }^{\circ} \mathrm{C}\right)$ & 266 & 400 & 870 \\
\hline outlet temperature $\left({ }^{\circ} \mathrm{C}\right)$ & 566 & 690 & 1320 \\
\hline pressure (MPa) & 22 & 76 & 34 \\
\hline coolant vord fraction $(\%)$ & 62 & 11 & - \\
\hline$\frac{\text { reactor pumping power }}{\text { thermal power }}(\%)$ & 2 & 14 & 007 \\
\hline Moderator & Graphıte & $\mathrm{BeO}$ & Graphite \\
\hline Number of channels & 234 & 36 & $312^{\mathrm{a}}$ \\
\hline Fuel & $\mathrm{UO}_{2}$ & $\mathrm{UO}_{2}-\mathrm{BeO}$ & $\begin{array}{c}\mathrm{UC}_{2} \text { coated } \\
\text { particles in graphite }\end{array}$ \\
\hline enrichment (\%) & 246 & 625 & 935 \\
\hline cladding material & $\begin{array}{c}\text { Type } 304 \\
\text { stainless steel }\end{array}$ & Hastelloy-X & None \\
\hline claddıng thıckness $(\mathrm{cm})$ & 005 & 005 & - \\
\hline fuel region id /o d (cm) & $082 \times 18^{b}$ & $00 \times 085^{\mathrm{c}}$ & $127 \times 254$ \\
\hline fuel element length $(\mathrm{cm})$ & $6 \times 736$ & 255 & $4 \times 14$ \\
\hline
\end{tabular}

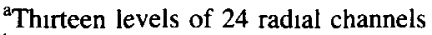

${ }^{\mathrm{b}}$ An element contains seven pins

${ }^{c}$ An element consists of an annular ring of 18 rods around a $\mathrm{BeO}$ spine

The Tory II-Al was operated at $40 \mathrm{MW}(\mathrm{t})$ at temperatures exceeding $1100^{\circ} \mathrm{C}$. Air supplied at $25 \mathrm{MPa}(250 \mathrm{~atm})$, preheated to $570^{\circ} \mathrm{C}$, entered the reactor at $\sim 2.5 \mathrm{MPa}$ (25 atm). The core contained $\sim 100000$ hexagonal $\mathrm{BeO}-\mathrm{UO}_{2}$ fuel elements, $100 \mathrm{~mm}$ long and $7.5 \mathrm{~mm}$ across flats with a 5 - $\mathrm{mm}$-diam central hole for air coolıng. The Tory II-C reactor, operated in 1963, was designed for short-term operation at $150 \mathrm{MW}(\mathrm{t})$.

Six rocket propulsion reactors with hydrogen cooling were tested ${ }^{59}$ in Nevada by the Los Alamos Scientific Laboratory between 1959 and 1962. All of the Kiwi reactors were graphite moderated and designed for an outlet temperature of $1650^{\circ} \mathrm{C}$. 


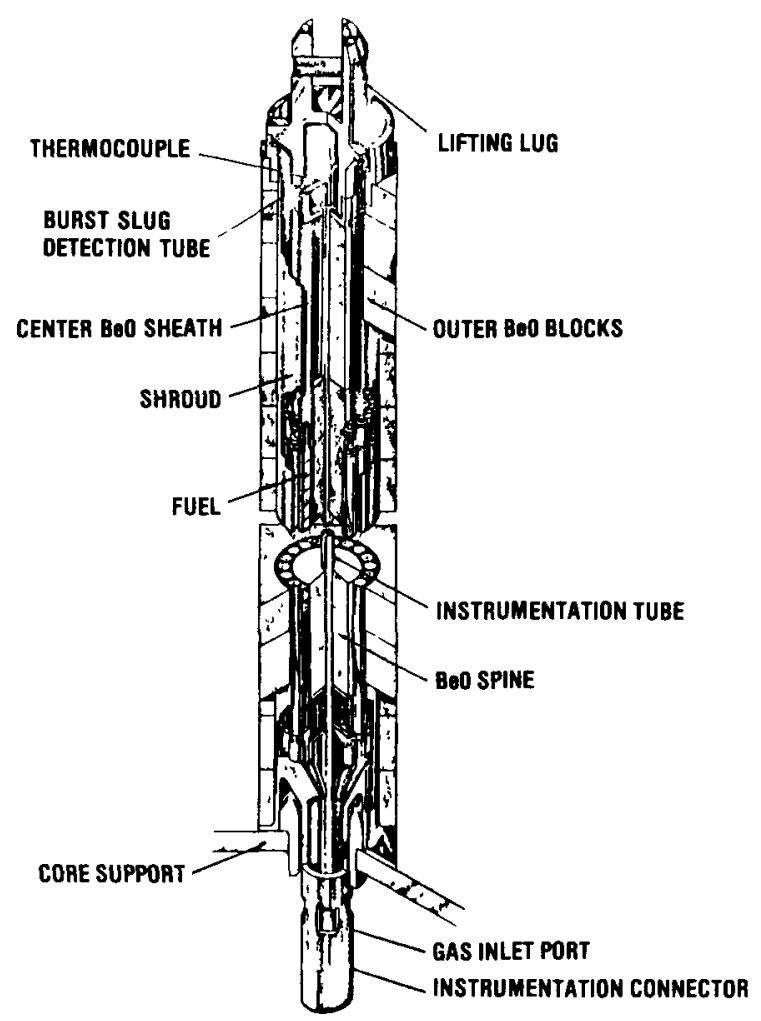

Fig. 1-12. EBOR 18-pin fuel element.

Typical conditions for a nuclear rocket would be 2 to $15 \mathrm{~min}$ of operation at $2500^{\circ} \mathrm{C}$ with a $10000-\mathrm{MW}(\mathrm{t})$ output. The fuel elements of the Kiwi-A series consisted of plates of graphite impregnated with uranium, with graphite as a structural material and reflector also. Hydrogen gas was used in the first tests, and liquid hydrogen in later tests with a modified core geometry. The aerospace reactor propulsion program was discontinued in the mid-1960s because of the treaty limiting the atmospheric testing of nuclear fission.

\section{1-4C The Experimental Gas-Cooled Reactor (EGCR)}

The main parameters of the helium-cooled graphite-moderated EGCR are given in Table 1-IV (Refs. 60, 61, and 62). It is basically an AGR-type reactor with a helium coolant. The gas entering the core at $266^{\circ} \mathrm{C}$ and $2.2 \mathrm{MPa}(22 \mathrm{~atm})$ is heated to $566^{\circ} \mathrm{C}$ before entering the steam generators. A thermal power of $85 \mathrm{MW}$ would lead to a net electricity production of $25 \mathrm{MW}$ with $482^{\circ} \mathrm{C}$ steam at $8.7 \mathrm{MPa}(87 \mathrm{~atm})$. The fuel assembly consisted of seven-rod clusters of stainless steel tubes filled with $18-\mathrm{mm}$ cored $\mathrm{UO}_{2}$ pellets, each cluster supported within a 
25-mm-thick graphite sleeve with a 75 -mm i.d. There were six stacked fuel assemblies in each coolant channel for a total height of $4420 \mathrm{~mm}$; they were located in 236 channels with an overall core diameter of $4877 \mathrm{~mm}$ (Fig. 1-13). The steel pressure vessel, $6 \mathrm{~m}$ in diameter and $14 \mathrm{~m}$ high, had a wall thickness of $70 \mathrm{~mm}$. The fuel enrichment was $2.5 \%$ and the average specific power $7.55 \mathrm{~kW} / \mathrm{kg} \mathrm{U}$. Extensive analyses as well as flow and heat transfer tests of the fuel assemblies have been performed. ${ }^{63}$ The reactor was constructed at Oak Ridge National Laboratory beginning in 1964, but was never completed because of budget restrictions.

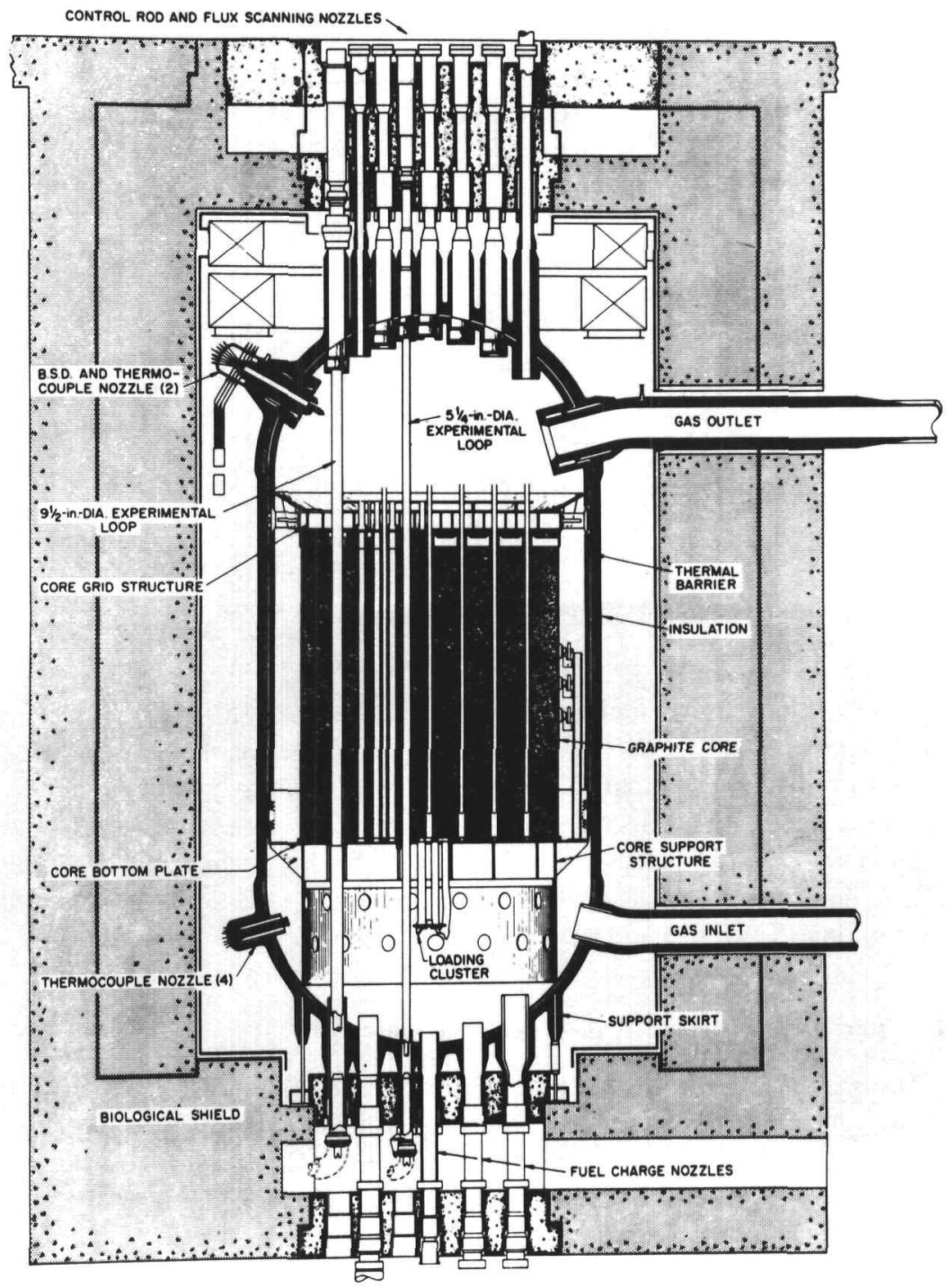

Fig. 1-13. EGCR cross section. 


\section{1-4D Ultra-High-Temperature Reactor Experiment (UHTREX)}

The 3-MW(t) UHTREX was built by the Los Alamos Scientific Laboratory and operated there between 1966 and 1970 (Refs. 64 and 65). The purpose of this experimental reactor was to provide very high temperature helium $\left(1300^{\circ} \mathrm{C}\right)$ at $3.4 \mathrm{MPa}(34 \mathrm{~atm})$ and to test various ceramic fuels in a graphite-moderated core. The main reactor characteristics are given in Table 1-IV, and a reactor cutaway is shown in Fig. 1-14. The fuel elements consisted of extruded hollow

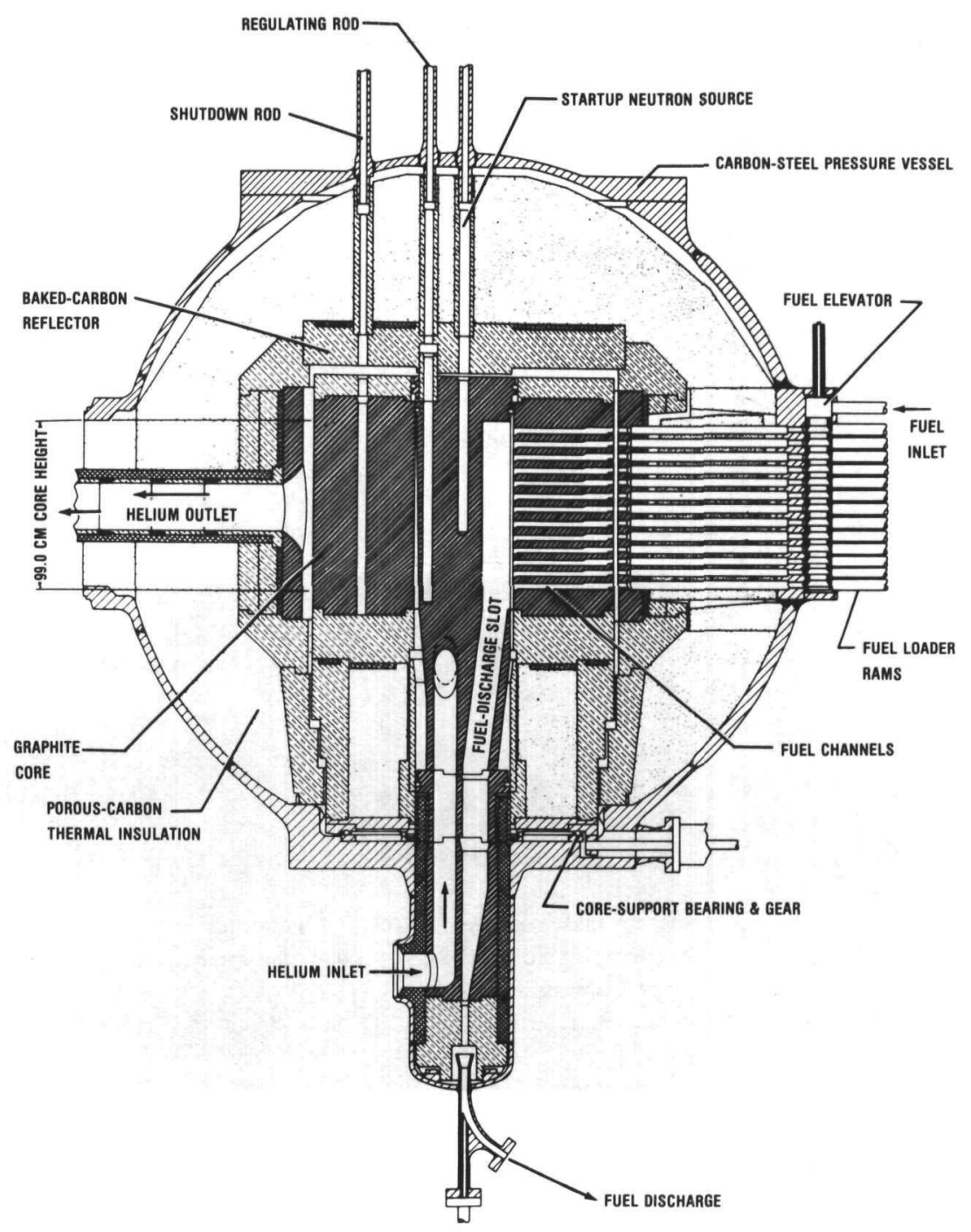

Fig. 1-14. UHTREX cutaway. 
cylınders made of a mixture of graphite and 93\% enrıched PyC-coated (Triplex) $\mathrm{UC}_{2}$ partıcles ${ }^{5}$

The reactor was designed with unique features

1 an annular core that is rotatable to facilitate on-line refueling

2 articulated control rods that can always be inserted directly into the core

3 the possibility of operation with a contaminated circuit and on-line coolant cleanup

Helium enters the core at its axis at a temperature of $870^{\circ} \mathrm{C}$, flows through the fuel channels, and leaves at $1320^{\circ} \mathrm{C}$ before entering a recuperator from which it emerges at $760^{\circ} \mathrm{C}$ to go through a helium heat exchanger where it is cooled to $315^{\circ} \mathrm{C}$ It is then pumped back to the recuperator by a gas-bearing 65 -hp centrifugal blower The secondary helium loop operatıng at a maxımum temperature of $540^{\circ} \mathrm{C}$ dumps the heat through an air-cooled heat exchanger

This reactor experiment has shown the feasibility of producing $1300^{\circ} \mathrm{C}$ helium, which is a much hotter temperature than the temperatures required for steam cycle HTGRs $\left(700\right.$ to $800^{\circ} \mathrm{C}$ ), gas turbine HTGRs $\left(800\right.$ to $900^{\circ} \mathrm{C}$ ), and even for high-temperature process heat reactors $\left(900\right.$ to $\left.1000^{\circ} \mathrm{C}\right)$

\section{REFERENCES}

1 R McCullough and C Rogers, "Summary Report on Design and Development of High-Temperature Gas-Cooled Power Pile," USAEC Mon N-383, Oak Ridge National Laboratory (1947)

2 Sir Christopher Hinton, "The Graphite-Moderated Gas-Cooled Plle and Its Place in Power Production," Proc 1st Int Conf Peaceful Uses of Atomic Energy, Geneva, Switzerland, August 8-20, 1955, Vol 3, p 322, United Nations, New York (1956)

3 B Bally du Bors, "Les Reacteurs de Purssance a eau Lourde," Ind At, (May/June 1966)

4 H B Stewart, C L Rickard, and G B Melese, "Gas-Cooled Reactor Technology," pp 15-23 in Advances in Nuclear Sctence and Technology, P Greebler and E Henley, Eds, Vol 4, Academic Press, Inc, New York (1968)

5 M Simnad, Fuel Element Experience in Nuclear Power Reactors, Gordon and Breach Science Publishers, Inc, New York (1971)

6 A K Krasın, "Dissociatıng Gases as Heat Transfer Medıa and Workıng Fluids in Power Installations," Academy of Sciences Bielorussian SSR, translated as AEC-Tr7295, U S Atomic Energy Commission (1975)

7 W Mitchell, "Gas-Cooled Clad Fuel Reactors," Power React Technol , 8, 1, 58 (Winter 1964-65)

8 Sir William Penney, "Nuclear Power in the United Kingdom," Proc 3rd Int Conf Peaceful Uses of Atomic Energy, Geneva, Switzerland, August 31-September 9, 1964, Vol 1, p 89, United Nations, New York (1965)

9 J Bourgeois and B Saltcevsky, "Developments in Natural Uranium Graphite Reactors," Proc 3rd Int Conf Peaceful Uses of Atomic Energy, Geneva, Switzerland, August 31-September 9, 1964, Vol 5, p 48, United Nations, New York (1965) 
10 J Best et al , “Inhibition of Moderator Graphite Corrosion in CEGB Magnox Reactors, Part 2 Hydrogen Injections into Wylfa Reactor 1 Coolant Gas," J $\mathrm{Br} \mathrm{NuCl}$ Energy Soc , 15, 4, 325 (Oct 1976)

11 R Marsh and G Melese, "Prestressed Concrete Pressure Vessels," Nucleonics, 23, 9, 63 (Sep 1965)

12 C Tan, "Recent Advances in Technology of PCRVs," React Technol, 13, 2, 109 (Spring 1970)

13 Zdenek P Bazant, "Safety Advantages of PCRVs," Nucl Technol, 30, 3, 256 (Sep 1976)

14 W Prior et al, "Gas-Cooled Reactor Operating Expenence," Nuclear Energy Maturtty, Proc Parls Conf, Progress in Nuclear Energy Series, Plenary Sessions, p 217, Pergamon Press (1976)

15 “Nuclear Electricity Generation," Nucleonics Week, 24, 34, 12 (Aug 25, 1983)

16 B Boudouresques et al , "20 Years Experience in Metallic Natural Uranium Fuel Cycle," Trans Am Nucl Soc, 20, 279 (1975)

17 G F Hines, "Magnox Fuel Element Endurance Studies A Review of CEGB Experience," Trans Am Nucl Soc, 20, 278 (1975)

18 A Hawkıns, "Britain's Nuclear Workhorses," J Br Nucl Energy Soc , 14, 4, 293 (Oct 1975)

19 J Waters and V Walker, "Fuel Elements," in The Design of Gas-Cooled GraphiteModerated Reactors, D Poulter, Ed, Oxford Unıversity Press (1963)

20 G Melese, "Efficiency of a Longitudinal Fin with Variable Surface Heat Transfer Coefficient," J Nucl Energy, 5, 285 (1957)

21 P Fortescue and W Hall, "Heat Transfer Experıments on the Fuel Element," Proc Symp Calder Works Nuclear Power Plant, Br Nucl Energy Conf J , 2, 83 (Apr 1957)

22 J Stolz, "Construction and Operatıng Experience with Thermal Power Reactors Outside the United States, Trans Am Nucl Soc, 15, 599 (1972)

23 H G Lyall, "Gas-Cooled Reactors Today," J Br Nucl Energy Soc , 22, 2, 101 (Apr 1983) and 22, 3, 183 (June 1983)

24 R Moore and P Tanguy, "A Review of Experience with Gas-Cooled Reactors," Trans Am Nucl Soc, 11, 425 (1968)

25 K Gibbs and D Tattersall, "The Influence of Operatıng Experience on Britısh GasCooled Reactor Design," Proc ANS Topl Mtg Gas-Cooled Reactors HTGRs and GCFBRs, Gatlinburg, Tennessee, May 7-10, 1974, CONF-740501, p 50, National Technical Information Service (1974)

26 J Stolz and B Boudouresques, "French Gas-Cooled Reactor Expenence," Proc ANS Topl Mtg Gas-Cooled Reactors HTGRs and GCFBRs, Gatlınburg, Tennessee, May 7-10, 1974, CONF-740501, p 60, National Technical Information Service (1974)

27 Proc BNES Conf Gas-Cooled Reactors Today, Bristol, United Kingdom, September 20-24, 1982, Vols 1-4, Britısh Nuclear Energy Society (1982)

28 G Brown et al , "AGR Fuel Elements," $J$ Br Nucl Energy Soc , 2, 186 (Apr 1963)

29 R Loftness, Nuclear Power Plants, pp 410-413, D Van Nostrand Co , New York (1964)

30 G Brown and J Thorn, "The Development of Gas-Cooled Nuclear Reactors in the United Kingdom, BNX Rev, No 1 (Nov 1966) 
31 W Prior et al , "Gas-Cooled Reactor Operatıng Expenience," J Br Nucl Energy Soc , 14, 4, 287 (Oct 1975)

32 D Chapman, "High-Pressure Fuel Test Loops in Windscale AGRs-Design, Installation, and Commissioning Experience," $J$ Br Nucl Energy Soc , 15, 4, 333 (Oct 1976)

33 E Slater, "Operatıng Experience with the WAGR Fuellıng Machine," Nucl Eng Int , 12, 600 (Aug 1967)

34 G Insch and D Trauger, "Advanced Gas-Cooled Reactor Systems," Trans Am Nucl Soc, 15, 600 (1972)

35 R R Gallie and P V Hewitt, "Eighteen Years' Operatıng and Development Experience with the Windscale AGR,' J Br Nucl Energy Soc , 21, 1, 21 (Feb 1982)

36 K Schaefer et al , "Experience of Design and Construction of PCPVs for AGRs and HTRs in Europe," Trans Am Nucl Soc, 20, 106 (Apr 1975)

37 "Heysham 2/Torness New Advanced Gas-Cooled Reactors Incorporate Design Improvements," Nucl Eng Int , 26, 310, 27 (Mar 1981)

38 "Hinkley Point B A Survey of Design and Construction," Nucl Eng Int , 13, 147, 652 (Aug 1968)

39 E P Duffy, “Dungeness B AGR Power Station,' Nucl Eng Int , 12, 134, 524 (July 1967)

40 "'Hartlepool," Nucl Eng Int , 14, 162, 973 (Nov 1969)

41 J D McKeen, J Tyrell, D S Lawson, and R E D Burrow, "Heysham Nuclear Power Station," Nucl Eng Int, 16, 186, 915 (Nov 1971)

42 A J Perrın, "Hartlepool and Heysham Pod Borlers,' Nucl Eng Int , 21, 239, 48 (Feb 1976)

43 W Fraser and James Howden, "Submerged Circulators for AGR Power Statıons," Nucl Eng Int , 16, 187, 997 (Dec 1971)

44 R Vaughan, "AGR Experience and Its Relevance to Future Gas-Cooled Reactors," Proc ANS/ASME Joint Int Conf Advanced Nuclear Energy Systems, Pittsburgh, Pennsylvania, March 14-17, 1976, CONF-760303, p 127, American Society of Mechanical Engineers (1976)

45 Simon Rippon, “The AGRs Make a Start," Nucl Eng Int , 21, 242/243, 54 (Apr/ May 1976)

46 P M Boocock et al , "A Review of CAGR Fuel Performance," J Br Nucl Energy Soc, 22, 2, 105 (Apr 1983)

47 “Generatıng Costs," J Br Nucl Energy Soc , 22, 3, 130 (June 1983)

48 Christopher J Wood, "Solving Moderator Corrosıon Problems in AGRs," Nucl Eng Int , 22, 252, 29 (Jan 1977)

49 D Wilkıe, "Alternative Heat Transfer Surfaces for AGR Fuel Pins," Proc BNES Conf Gas-Cooled Reactors Today, Bristol, United Kıngdom, September 20-24, 1982 , Vol 4, p 235, British Nuclear Energy Society (1982)

50 “GCRE-1 Hazards Summary Report," IDO-28506, U S Atomıc Energy Commıssion (1958)

51 “Army Reactor Systems Program," Power React Technol , 6, 3, 57 (June 1963)

52 Harry Browne, "Marıtıme Gas-Cooled Reactors," Proc Symp Gas-Cooled Reactors, J Franklin Inst, Monograph 7, p 52 (May 1960)

53 Paul Berman, "A Gas Turbıne for a Helıum-Cooled Reactor," Proc Symp GasCooled Reactors, J Franklin Inst, Monograph 7, p 293 (May 1960) 
54. S. McLain and John Martens, Eds., Reactor Handbook, 2nd ed., Vol. IV, pp. 705714, Wiley Interscience Publishers, New York (1964).

55. "Final Safety Analysis Report for the Experimental Beryllium Oxide Reactor,' GA5000, U.S. Atomic Energy Commission (Nov. 30, 1964).

56. A. D. McWhirter and A. J. Goodjohn, "Beryllium Oxide As a Moderator in HighTemperature Gas-Cooled Reactors,"' Trans. Am. Nucl. Soc., 6, 330 (1963).

57. G. Thornton and B. Blumberg, "ANP HTREs Fulfill Test Goals," Nucleonics, 19, 1, 45 (Jan. 1961).

58. S. McLain and John Martens, Eds., Reactor Handbook, 2nd ed., Vol. IV, pp. 697700, Wiley Interscience Publishers, New York (1964).

59. R. Loftness, “Aerospace Reactors,'” in Nuclear Power Plants, D. Van Nostrand Co., New York (1964).

60. M. Bender, "The Experimental Gas-Cooled Reactor Design," Proc. Symp. GasCooled Reactors, J. Franklin Inst., Monograph 7, p. 67 (May 1960).

61. G. Samuels, "Design and Analysis of the Experimental Gas-Cooled Reactor Fuel Assemblies," ORNL-3478, Oak Ridge National Laboratory (Sep. 27, 1963).

62. S. McLain and John Martens, Eds., Reactor Handbook, 2nd ed., Vol. IV, pp. 702710, Wiley Interscience Publishers, New York (1964).

63. M. Troost et al., "Thermal Design Aspects of Gas-Cooled Power Reactor Cores," Proc. 3rd Int. Conf. Peaceful Uses of Atomic Energy, Geneva, Switzerland, August 31-September 9, 1964, Vol. 8, p. 59, United Nations, New York (1965).

64. B. Hoglund, "UHTREX Operation Near,'" Power React. Technol., 9, 1, 51 (Winter 1965-1966).

65. "UHTREX: Alive and Running with Coolant at $2400^{\circ} \mathrm{F}, "$ Nucl. News, 12, 11,31 (Nov. 1969). 


\section{HIGH-TEMPERATURE GAS-COOLED REACTOR DEVELOPMENTS}

In parallel with the development of the advanced gas-cooled reactor (AGR), in the United Kingdom in the mid-1950s the idea for an all-ceramic helium-cooled graphite-moderated reactor using the thorium fuel cycle was proposed. A HighTemperature Gas-Cooled Reactor Project Group ${ }^{1}$ was set up at the Atomic Energy Research Establishment at Harwell, England, in 1956. The proposed reactor could operate at high temperature because of the absence of metal in the core and the inertness of the helium coolant; it was called the "HTR" in England and, later on, the "HTGR" in the United States. The fuel was to be a semi-homogeneous mixture of thorium and uranium carbides (or oxides) within a graphite moderator, leading to high burnup because of fuel dilution and the good irradiation properties of graphite, and a high conversion ratio because of the absence of neutron poisons and of the excellent neutronic properties of the new fissile material, ${ }^{233} \mathrm{U}$ bred in ${ }^{232} \mathrm{Th}$ (Ref. 2). These features define the HTGR. In addition, the primary system is integrated within a prestressed concrete reactor vessel (PCRV) for large plants, as with all large $\mathrm{CO}_{2}$-cooled reactors, Magnox, and AGRs. The common characteristics of HTGRs lead to the following advantages:

1. High-temperature operation improves thermodynamic efficiency, reduces steam generator surface area, and permits use of conventional turbogenerating equipment; it also reduces the amount of cooling water required to reject waste heat. The high helium outlet temperature also allows advanced applications, such as closed-cycle gas turbine or hightemperature process heat for industry (refer to Chapters 8 and 9).

2. The combination of graphite core structure and ceramic fuel, inert helium coolant, and a PCRV greatly increases the inherent safety of the system since sudden catastrophic vessel failure is not credible and the core has a very large thermal inertia. Furthermore, the level of radioactive releases-solid, liquid, and gaseous - is very low.

3. With ${ }^{233} \mathrm{U}$ as the best fissile material in a thermal neutron flux, and lacking parasitic neutron absorbers in a cladding, the HTGR has the potential of having a high conversion ratio (Chapter 6). The use of thorium in an HTGR with ${ }^{233} \mathrm{U}$ recycle could significantly reduce the consumption of uranium ores by adding the vast deposits of thorium to 
the reserves of nuclear fuels. As is seen later, it also produces the possibility of an effective symbiotic relationship with high-gain breeders, which can efficiently convert ${ }^{232} \mathrm{Th}$ into ${ }^{233} \mathrm{U}$, the preferred fissile material for HTGRs, which could themselves become quasi-breeders with the ${ }^{233} \mathrm{U}-\mathrm{Th}$ cycle.

In the following sections, the first HTGR prototypes started in the mid-1960s are described in some detail-Dragon in the United Kingdom, Peach Bottom Unit 1 in the United States, and AVR in West Germany. This is followed by the description of two demonstration plants, the Thorium High-Temperature Reactor (THTR) in West Germany, which went critical in 1983, and the Fort St. Vrain HTGR, which has operated in Colorado since 1976. Some designs for steam-cycle HTGRs for electricity and steam production in the United States and abroad are discussed. Finally, a summary of experience with gas-cooled reactors is presented.

\section{2-1 The Dragon HTR}

In 1958, two years after studies began at Harwell on a high-temperature gascooled reactor experiment, it was proposed that this HTGR project become the subject of a collaborative program with the Organization for European Economic Cooperation (OEEC), later to become the Organization for Economic Cooperation and Development (OECD). The agreement to set up a joint OEEC project, called "Dragon," at the United Kingdom Atomic Energy Authority (UKAEA) Establishment at Winfrith, Dorset, became effective on April 1, 1959. The Dragon project agreement was signed by the UKAEA, Euratom (Belgium, France, West Germany, Italy, Luxembourg, and the Netherlands), Austria, Denmark, Norway, Sweden, and Switzerland. These countries initially agreed to the construction of a 20-MW(t) reactor experiment and a five-year program of associated research and development. In effect, this European project was extended five times up to its completion on March 31, 1976. An exchange of information was started with the U.S. Atomic Energy Commission (AEC) in 1960, thus making it a truly international project. ${ }^{3}$

\section{2-1A Reactor Description}

Dragon is a $20-\mathrm{MW}(\mathrm{t})$ helium-cooled reactor operating at an inlet coolant temperature of $350^{\circ} \mathrm{C}$ and a mixed outlet temperature of $750^{\circ} \mathrm{C}$ with heat rejection to the atmosphere by air-blast coolers in a tertiary circuit. The helium temperature out of the hottest channel is $926^{\circ} \mathrm{C}$. The reactor is fueled with a mixture of $93 \%$ enriched uranium and thorium carbides in sintered compacts contained in graphite, which acts as both cladding and moderator. Double containment is provided, the region between the reactor vessel and the inner shell of the secondary containment being filled with nitrogen at atmospheric pressure. Figure 2-1 shows the general arrangement of the reactor whose main characteristics ${ }^{4,5}$ are given in Table 2-I.

The reactor vessel, which has a rather complex shape, is kept at coolant inlet 
1 REACTOR CORE

2 IMNER STEEL CONTAINUENT

2 IMNER STI

SHELL COMCOETE COHTAMMENT

sHet

1 PRIMARY HEAT EXCHaMGé

5 coolaut gas circulaton

G SECOMOARY MEAT EXCHAMEERS

7 CONTROL RODS

8 CONTHOL ROD DRIVES

9 FISSIOM PRODUCT PUBGE-

GAS MANIFOLD

TO FISSIOM PRODUCT REMOVAL \&

HELIUM PURIFICATION PLANT

\section{\begin{tabular}{c} 
때메 \\
$\square$ \\
\hline$\square$ \\
\hline$\square$
\end{tabular}}

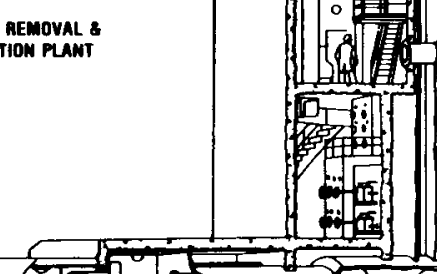

(3)

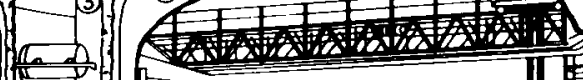

$=$

$=\pi$

$I=\Rightarrow$
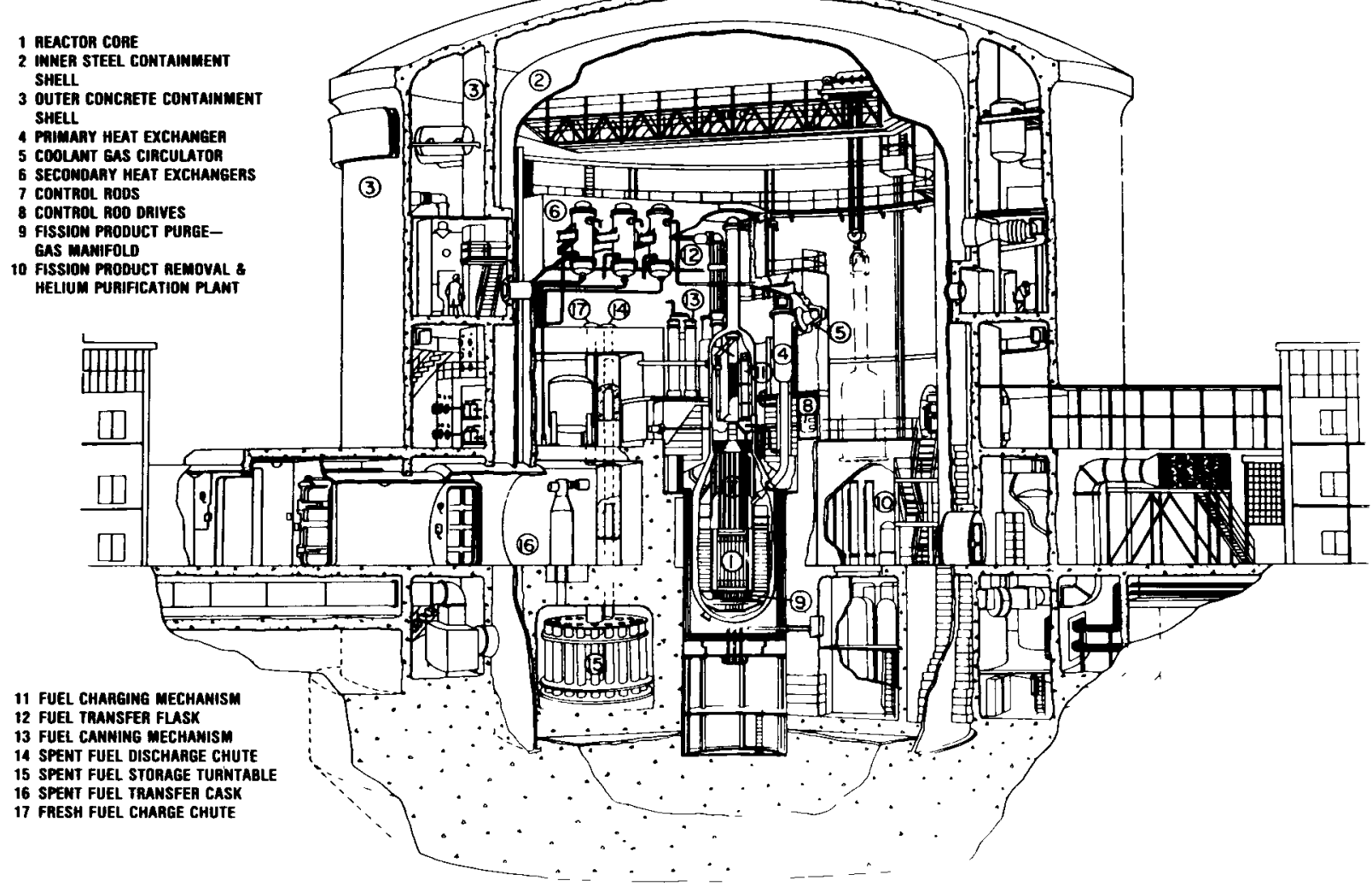

Fig. 2-1. General arrangement of the Dragon reactor plant. 
TABLE 2-I

Main Characteristics of HTGR Prototypes

\begin{tabular}{|c|c|c|c|}
\hline Reactor & Dragon & Peach Bottom & AVR \\
\hline Country & United Kıngdom & United States & West Germany \\
\hline Thermal power (MW) & 20 & 115 & 49 \\
\hline Net electrical power (MW) & - & 40 & 15 \\
\hline First power operation & 1965 & 1967 & 1968 \\
\hline Helium pressure (MPa) [atm] & $2[20]$ & $225\left[\begin{array}{ll}22 & 5\end{array}\right]$ & $225\left[\begin{array}{ll}22 & 5\end{array}\right]$ \\
\hline Helıum temperatures $\left({ }^{\circ} \mathrm{C}\right)$ & $350 / 750$ & $345 / 725$ & $200 / 850$ \\
\hline \multicolumn{4}{|l|}{ Active core } \\
\hline diameter (m) & 107 & 28 & 30 \\
\hline he1ght (m) & 16 & 23 & 35 \\
\hline Core power density $\left(\mathrm{MW} / \mathrm{m}^{3}\right)$ & 14 & 83 & 23 \\
\hline \multicolumn{4}{|l|}{ Fuel element } \\
\hline design & Hexagonal rods & Long cylınders & Sphencal pebbles \\
\hline number & $37 \times 7$ & 804 & 100000 \\
\hline diameter (mm) & 72 & 89 & 60 \\
\hline length (mm) & 2540 & 3660 & - \\
\hline Maxımum fuel burnup (MWd/kg) & $\geqslant 100$ & $\sim 75$ & 160 \\
\hline Steam conditions $\left(\mathrm{MPa} /{ }^{\circ} \mathrm{C}\right)\left[\mathrm{ps} /{ }^{\circ}{ }^{\circ} \mathrm{F}\right]$ & - & $10 / 538[1450 / 1000]$ & $72 / 504[1050 / 940]$ \\
\hline Net cycle efficiency $(\%)$ & - & 35 & 30 \\
\hline
\end{tabular}

temperature while the hot gas leaving the top of the core flows out of the vessel in the inner ducts of the six concentric coolant pipes Each of the six loops has its own gas-bearing circulator and heat exchanger Heat is transferred from the helium to a water/steam mixture in the heat exchangers at a pressure lower than the gas pressure, and then transferred from the secondary loops to water in tertiary loops Heat is finally rejected by arr-blast coolers Shutdown heat is normally removed by the helium circulators, but sufficient cooling can be provided by natural circulation All primary and secondary loops are located inside the containment shell as seen in Fig 2-1

The active portion of the core consists of 37 hexagonal fuel-moderator assemblies surrounded by movable and fixed reflector blocks The 10 central elements contain $\mathrm{ThC}_{2}-\mathrm{UC}_{2}$ fuels, while the other 27 contain diluted, highly enriched $\mathrm{UC}_{2}$ fuel As shown in Fig 2-2, each fuel assembly is made of seven rods, each consisting of a graphite box containing six carbide fuel rings inserted on a graphite spine The hexagonal external profiles of the fuel rods have ribs forming trefoll channels between fuel rods for the passage of helium Each fuel assembly is removed off-load with the help of an upper fitting, while it is positioned in the lower grid plate by a lower fitting, which contans the outlet purge tubes for the removal of fission gases A very small fraction of the coolant drawn through a small hole at the top of each fuel rod flows inside the impermeable graphite fuel boxes to the purge tubes at the bottom of the rod This fission product removal system sends the gases through charcoal delay beds and then to a purfication plant Although retentive coated particle fuels ${ }^{\mathrm{a}}$ have been used in the Dragon

${ }^{a}$ Small fuel particles are coated with pyrohtic carbon ( $\mathrm{PyC}$ ) and/or $\mathrm{SiC}$ to retain fission products (see Chapter 6) 


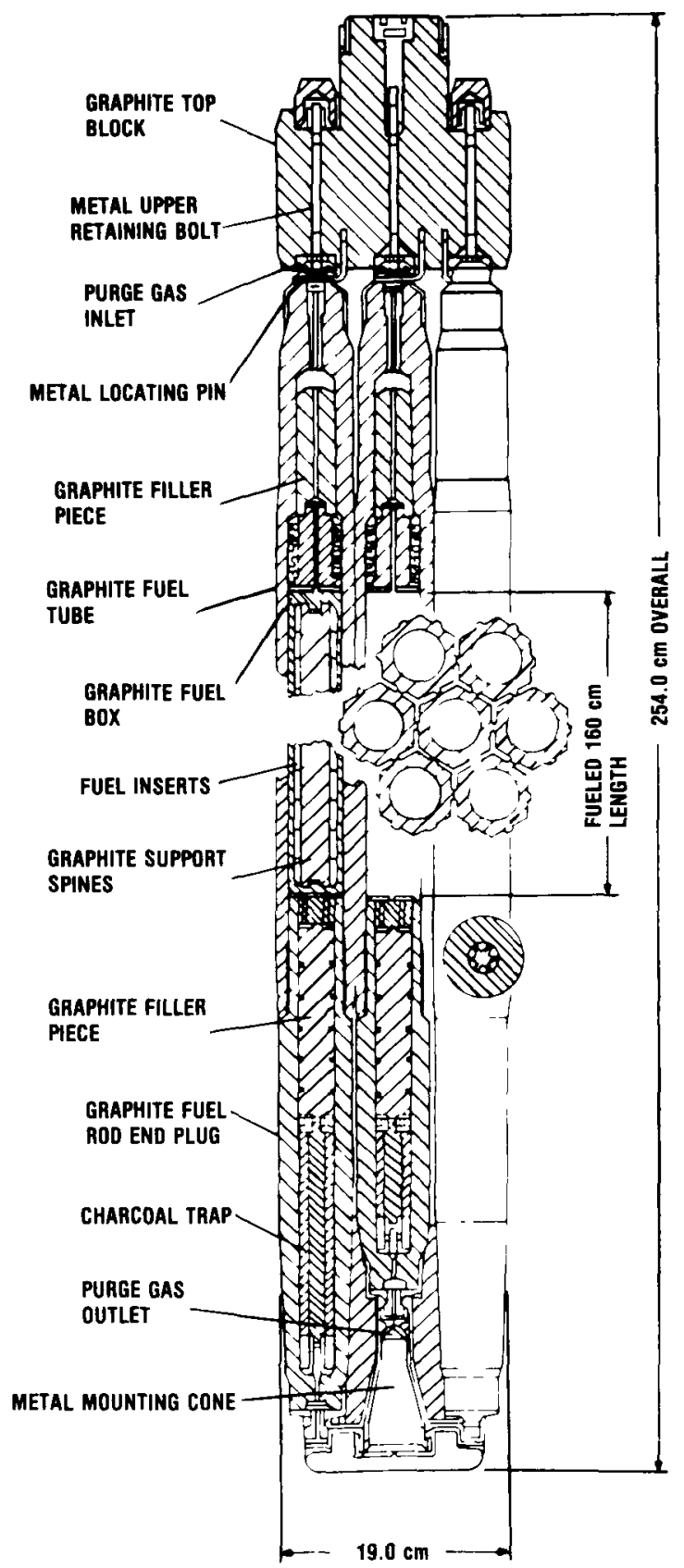

Fig. 2-2. Dragon fuel element. 
reactor, the purged fuel element design was kept for irradiating fuels at elevated temperatures, in case of fission product leakage.

The 24 control rods located at the circumference of the core are made up of concentric stainless steel tubes packed with $\mathrm{B}_{4} \mathrm{C}$. They are driven vertically by motors located above the reactor with the motor-drive mechanisms housed in gastight enclosures.

\section{2-1B Operational Experience}

The Dragon reactor achieved criticality in August 1964, operated at low power [2 MW(t)] with all systems functioning in June 1965 and started operation at $10 \mathrm{MW}(\mathrm{t})$ for 50 days commencing in November 1965. It reached its full design power of $20 \mathrm{MW}(\mathrm{t})$ in April 1966. There were many interruptions of the experimental program in 1967 and 1968 due to heat exchanger damage caused by waterside flow instability and corrosion/erosion. New heat exchangers were ordered and replacement of those units in 1969-1970 was done without personnel contamination; the estimated average dose per man was $\sim 0.3 \mathrm{rem}$. The levels of radioactivity on the heat exchanger and circulator surfaces were found to be very low $(\sim 1 / 3 \mathrm{Ci}$ of cesium activity on each heat exchanger after $30000 \mathrm{~h}$ of operation), in spite of the inferior quality of some of the early fuels. No special shielding was required for their removal. The inner reflector blocks distorted by fast neutron irradiation were replaced in 1973 , with a measured surface activity ${ }^{6-8}$ of only $200 \mathrm{mr} / \mathrm{h}$. The Dragon operating record shows very good reactor availabilityi.e., $89 \%$ for the fourth charge, comprising four different core loadings for experimental purposes. ${ }^{9}$ During its life, the Dragon reactor accumulated the equivalent of over 2000 days at nominal full power. Dragon operation has shown that the primary circuit could run with an extremely low concentration of impurities, $\sim 1$ part per million by volume, and a very low level of activity and fission gas concentration ( $<10 \mathrm{Ci}$ total, even with experimental fuel). Activated products of corrosion and erosion were virtually nonexistent in the circuit. The strength of the graphite structures has been demonstrated from both the mechanical standpoint and from the thermal and irradiation behavior standpoint. Low helium leak rates were observed, $<0.1 \%$ per day, and high reliability for the gas-bearing helium circulators was obtained. Because of its strong negative coefficient of reactivity, the reactor has proven to be very stable against nuclear transients, and also against loss-of-coolant accidents because of the high thermal capacity of the graphite in the core.

One of the primary tasks of the Dragon experiment was irradiation of test HTGR elements of various designs, fueled with oxides or carbides of uranium and/or thorium. The early Dragon core consisted of 27 driver fuel elements, $93 \%$ enriched, surrounding 10 fuel elements containing fertile material, initially thorium and later uranium for the low-enrichment uranium fuel cycle design. Multi-hole graphite fuel blocks were built for testing various fuel pins; both integral block fuel elements (multi-hole graphite block of U.S. design) and "block and 
pin"-type elements of $U \mathrm{~K}$ design have been tested ${ }^{10}$ The coated particle fuel used was predominantly of the "TRISO" type, ${ }_{1} \mathrm{e}$, a SIC layer between two PyC layers For the majority of expenmental fuels tested, the particle kernels were of the oxide type, rather than carbide, with either ${ }^{232} \mathrm{Th}$ or ${ }^{238} \mathrm{U}$ as the fertile material In 1975, the Dragon core contained fuel elements of eight different basic designs, with $<4 \%$ of the fuel being purged Fuel irradiation at an elevated temperature (up to $1800^{\circ} \mathrm{C}$ ) has shown an exponential increase in release as a function of irradiation time, thus showing that there would be a slow buildup of activity in the case of unexpected fuel fallure, which would indicate the need for locatıng and removing damaged fuel Fuel designed to operate at $1250^{\circ} \mathrm{C}$ (the normal peak operatıng fuel temperature in a power HTGR should be $\sim 1200^{\circ} \mathrm{C}$ ) was deliberately run at $1800^{\circ} \mathrm{C}$ in Dragon As expected, it only falled progressively over the experimental period of 80 days, with the release-to-birth ratio of ${ }^{133} \mathrm{Xe}$ increasing steadily from $10^{-4}$ to $10^{-2}$ Satisfactory experience has been obtained with a variety of coated fissile and/or fertile particles at burnups, fast neutron doses, and temperatures required for power reactors

The Dragon reactor has also been extremely helpful in demonstrating the behavior of graphites under fast neutron irradiation over a wide range of temperatures $\left(400\right.$ to $\left.1200^{\circ} \mathrm{C}\right)$ Graphite shrinkage is observed to increase with accumulated fast neutron dose, the rate of shrinkage being greater at higher temperatures, for many commercial graphite products, this behavior is anisotropic Fast neutron irradiation of graphite induces creep, which relieves mechanical-, thermal-, or irradiation-induced stresses In-pile experiments have been found useful to test new HTGR fuel element designs, including AVR pebbles Thus the Dragon reactor has proved to be an extremely valuable tool during its ten years of power operation at Winfrith ${ }^{1112}$

\section{2-2 Peach Bottom Atomic Power Station Unit 1}

Following initial studies performed by General Atomic in San Diego in 1957, Philadelphia Electric Company and 52 other U S utlities forming the HighTemperature Reactor Development Associates (HTRDA) group made a proposal to the U S Atomic Energy Commission (AEC) in 1958 to build an HTGR power reactor demonstration plant ${ }^{13} \mathrm{~A}$ contract was signed in 1959 between the AEC, General Atomic, and Philadelphia Electric, and a construction permit for the 40-MW(e) plant was issued in 1962 The goal of this prototype plant was to demonstrate production of $538^{\circ} \mathrm{C}\left(1000^{\circ} \mathrm{F}\right)$ steam from a reactor with good neutron economy and high fuel burnup, utılizing the U-Th fuel cycle ${ }^{14}$ The $35 \%$ net thermal efficiency of Peach Bottom 1 remained the highest efficiency of any operating nuclear power plant in the world untıl its scheduled shutdown in 1974 when the Phénix liquid-metal fast breeder reactor demonstration plant was operated in France at $40 \%$ efficiency

\footnotetext{
Befer to Chapter 6 for a detalled description
} 


\section{2-2A Reactor Description}

The active core is a cylinder, $2.8 \mathrm{~m}$ high, containing 804 fuel elements, 36 control rods, and 19 shutdown rods (see Table 2-I and Fig. 2-3). The fuel elements, $89 \mathrm{~mm}$ in diameter, are vertically oriented in a closely packed triangular array with helium flowing up between elements. The bottom and top graphite reflector sections are an integral part of the fuel element, which has a total height of $3.66 \mathrm{~m}$ including fuel element end fittings (Fig. 2-4). The side reflector, $\sim 60 \mathrm{~cm}$ thick, consists of an inner ring of hexagonal graphite elements surrounded by a segmented graphite ring, with a 4 -m o.d. Helium coolant at $345^{\circ} \mathrm{C}$ enters the reactor vessel from the outer annuli in the concentric ducts in each of the two loops. It cools the vessel walls and the reflector before flowing up through the core and leaving through the inner concentric ducts at $725^{\circ} \mathrm{C}$. The steel reactor pressure vessel, $4.2 \mathrm{~m}$ in diameter and $11 \mathrm{~m}$ high, is designed for $385^{\circ} \mathrm{C}$ and $3.1 \mathrm{MPa}(31 \mathrm{~atm})$, the actual helium pressure being $2.4 \mathrm{MPa}$.

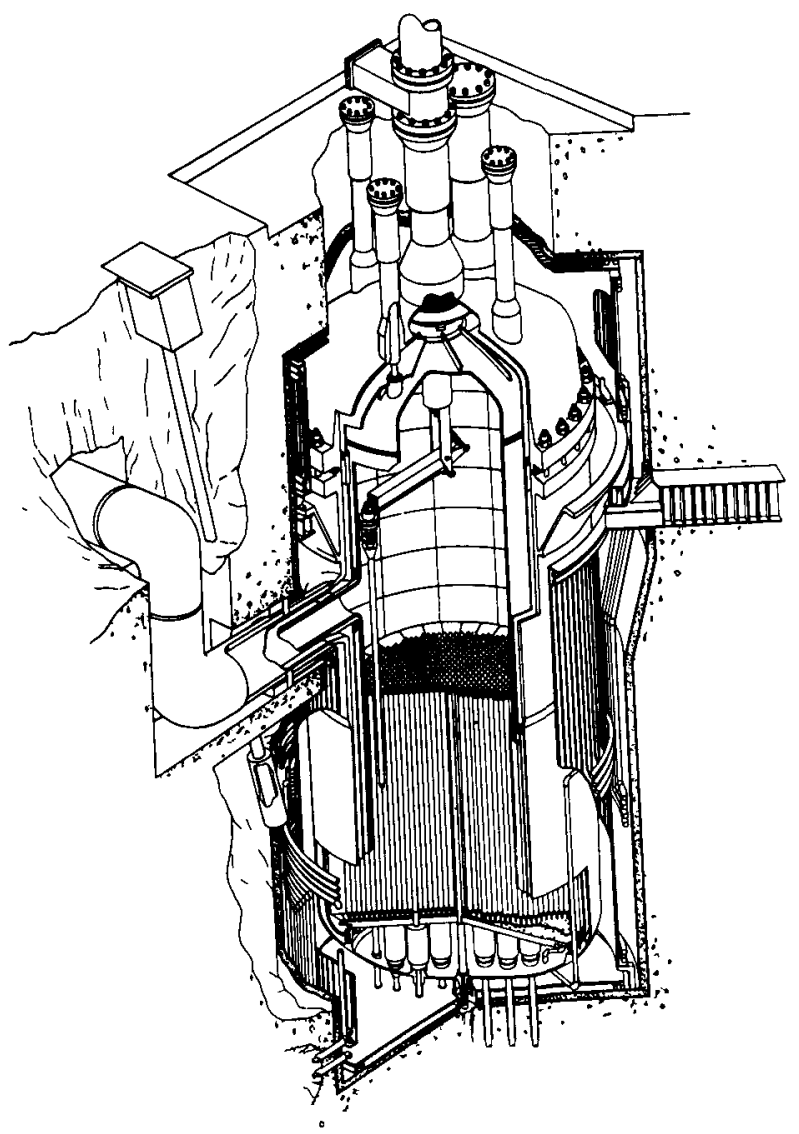

Fig. 2-3. Isometric view of the Peach Bottom reactor. 


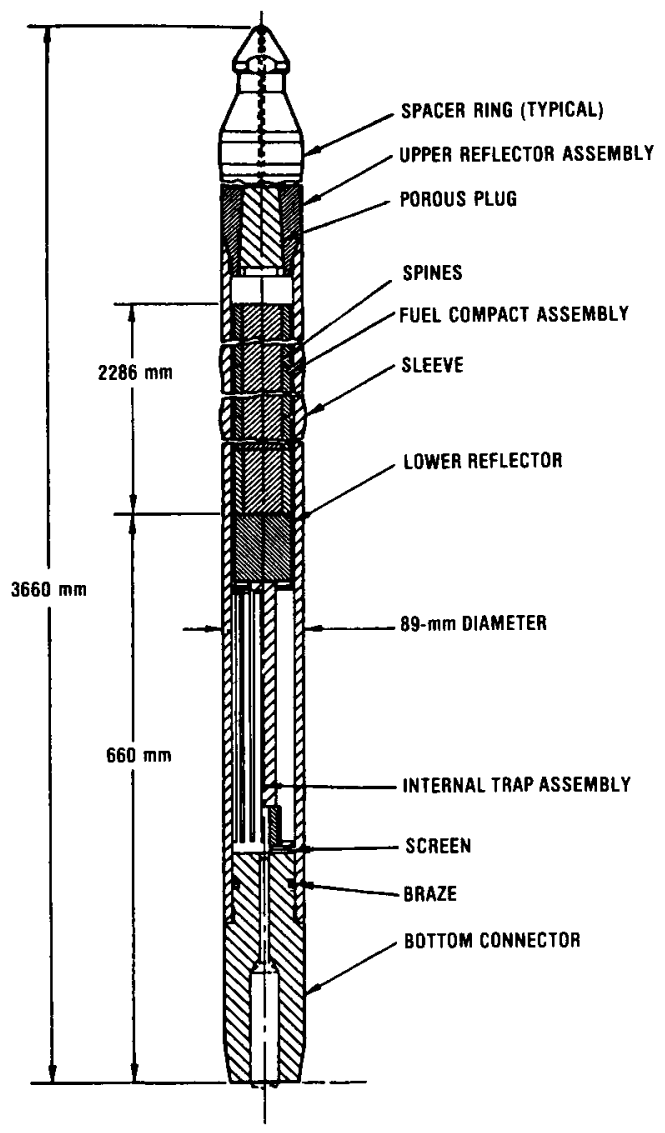

Fig. 2-4. Peach Bottom fuel element.

As shown in Fig. 2-4, the fuel elements are solid and semi-homogeneous with graphite serving as the moderator, cladding, fuel matrix, and structure. ${ }^{15}$ They consist of an upper reflector section, a fuel-bearing section, an internal fission product trap, and a bottom reflector. A low permeability graphite sleeve, $\sim 3 \mathrm{~m}$ long, is joined to the upper reflector at one end and to a bottom connector fitting at the other end. It contains the fuel bodies consisting of annular fuel compacts, $44 \times 69 \mathrm{~mm}$ and $76 \mathrm{~mm}$ long, stacked on a graphite spine. Uranium and thorium carbide particles, coated with PyC, are uniformly dispersed in the fuel compacts. The total fuel loading is $236 \mathrm{~kg}$ of $93.5 \%$ enriched uranium and $1450 \mathrm{~kg}$ of thorium. A small fraction of the helium coolant enters the fuel element through a porous plug in the upper reflector piece and flows downward between the fuel compacts and the graphite sleeve. After sweeping fission product gases from the active core zone, the purge gas flows through the internal traps and then through a purge line to external traps. The fuel elements are designed to stay in 


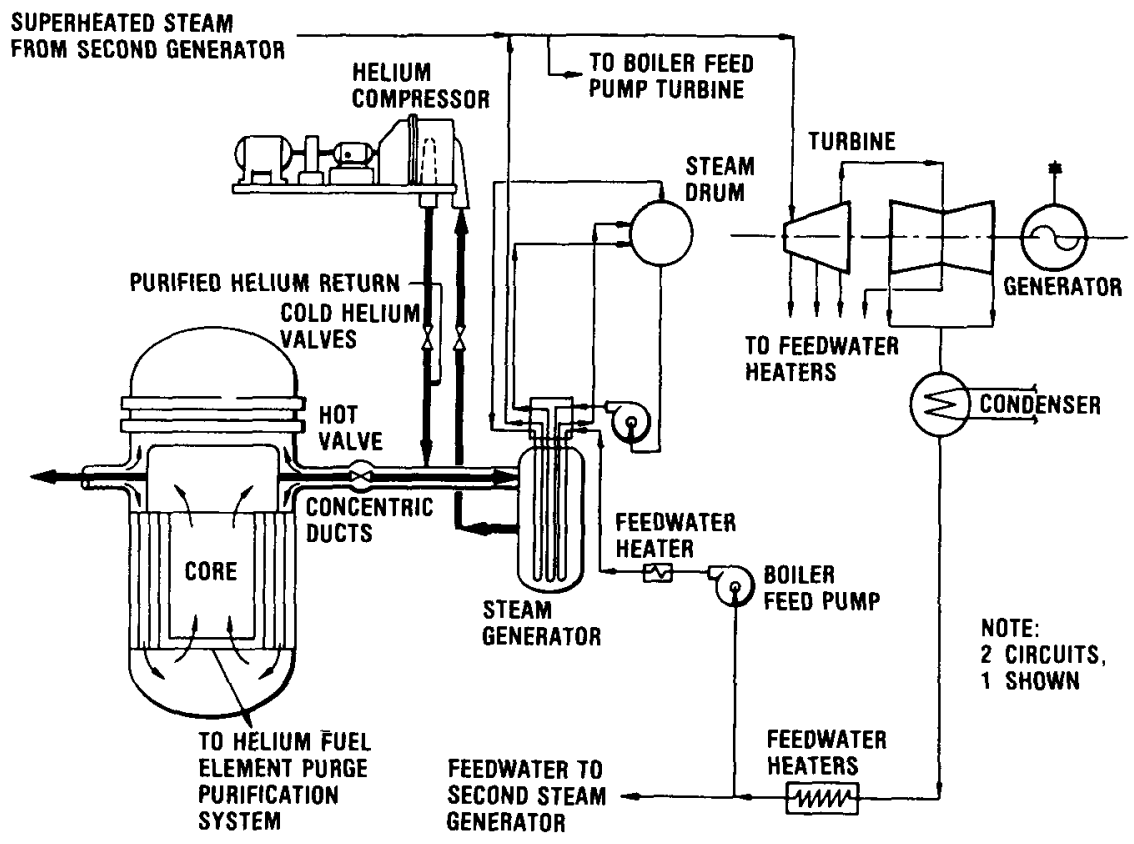

Fig. 2-5. Simplified process flow diagram for the main coolant system of Peach Bottom.

the reactor for three years and are batch-loaded with the reactor shut down, consistent with U.S. light water reactor conditions.

The schematic flow diagram of Fig. 2-5 shows that helium leaving the reactor flows through the two steam generators (one per loop) before being returned to the reactor by horizontal single-stage 3200-rpm electrically driven centrifugal compressors (1.85 MW each). Vertical shell-and-tube, forced recirculation steam generators are used, each section of which is constructed of a bank of U-tubes. Each steam generator shell, $\sim 2.4 \mathrm{~m}$ in diameter by $9 \mathrm{~m}$ high, is cooled by cold helium leaving the economizer. The secondary reactor containment is a vertical, cylindrical-shaped steel shell, $30.5 \mathrm{~m}$ in diameter and $49.5 \mathrm{~m}$ high, designed for an internal overpressure of $0.055 \mathrm{MPa}(0.55 \mathrm{~atm})$ at $65^{\circ} \mathrm{C}$.

\section{2-2B Operating Experience}

Criticality was achieved in March 1966, the first electricity was fed to the system in January 1967, and full power was reached in May 1967. The reactor had to be shut down between October 1969 and July 1970 to replace the first core, which had only operated for 450 equivalent full-power days. The second core operated for its full 900-day design life until the scheduled plant shutdown 
at the end of October 1974 (Ref. 16). Out of 804 elements of the first Peach Bottom core, 90 elements developed cracked sleeves caused by radial expansion of the fuel compacts because the single-layer PyC "primitive" coating of the fuel particles had cracked. The activity level in the primary system, designed for $4225 \mathrm{Ci}$, had reached a level of $270 \mathrm{Ci}$ when the first core was discharged and replaced by a core containing "BISO" fuel particles coated with a double layer of PyC; the inner one of low density, the outer one of high density. No cracked elements occurred with the second core; at the end of its life, the gaseous activity in the primary system remained $\angle 1 \mathrm{Ci}$ and the total activity of all fuel element purge streams during operation was $<1.5 \mathrm{Ci} / \mathrm{kg}$ of helium, compared to a design value of $4540 \mathrm{Ci} / \mathrm{kg}$.

After final plant shutdown, the radiation level in the general area around the steam generators was only $\sim 100 \mathrm{mr} / \mathrm{h}$ and 40 to $300 \mathrm{mr} / \mathrm{h}$ in contact with the coolant piping. These low radiation levels resulted in minimal radiation exposure to the plant personnel and very small release of activity to the environment. With the second core, the overall plant availability was $\sim 66 \%$ and the nuclear steam supply (NSS) availability was $69 \%$. The NSS availability would be $85 \%$ if outage time for the research and development programs (removal and insertion of experimental fuel elements) were taken into account. The lifetime gross plant capacity

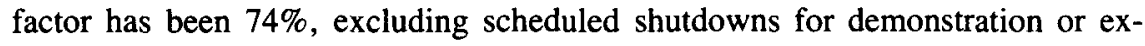
perimental purposes and a forced shutdown for replacement of the first core.

During plant construction, the stainless steel superheater tubes developed cracks from chloride stress corrosion; they were replaced with Incoloy-800 tubes, which were in excellent condition after eight years of operation. There were no water-to-helium leaks, and no external helium leaks. Both main helium circulators, including the seal system, motors, and hydraulic couplings, were trouble-free. The helium purification and chemical cleanup systems maintained low fission product and chemical impurity levels in the primary coolant system. No bindings or delays were experienced in the movement of the 36 hydraulically driven control rods.

The changes in coolant outlet temperature resulting from sudden changes in power, coolant inlet temperature, or coolant flow rate were quite slow in comparison with other reactor systems because of the large heat capacity of the fuel elements, which were designed for a maximum surface temperature of $1050^{\circ} \mathrm{C}$ and a maximum fuel temperature of $1330^{\circ} \mathrm{C}$. The limiting condition during transients was usually the helium outlet temperature that the ducts and steam generators could withstand. The structural graphite parts of the ceramic fuel elements could withstand high temperatures without damage to the structural integrity of the element. In Peach Bottom, emergency cooling would have been provided by cooling the pressure vessel, to which the afterheat of the fuel elements would be transported by conduction, natural convection, and radiation. During its lifetime, the plant had successfully experienced many temperature transients and had always returned to normal power without incident. The plant control and safety system 
both performed very well. ${ }^{17,18}$ The plant was operated in a load-following manner during most of its lifetime.

The Peach Bottom reactor was used extensively for irradiation of fuel elements for HTGRs. A total of 33 test elements were irradiated including Fort St. Vraintype fuel rods, candidate materials for large HTGRs, fuel rods for recycle process demonstration tests at Oak Ridge National Laboratory (ORNL), advanced coated particle fuels such as plutonium fuel, molded fuel bodies from West Germany (HOBEG/KFA) and fuel pins from the UKAEA. ${ }^{19}$ All of these test elements performed in a satisfactory manner. More than 1500 test fuel rods were successfully irradiated.

Following the permanent shutdown of the plant, an extensive end-of-life research program was started in early 1975 with equal financial support from the Electric Power Research Institute and the Energy Research and Development Administration. ${ }^{20}$ The four tasks of the program consisted of gamma scans of the fuel element and primary circuit, specimen removal and steam generator macroexamination, examination and testing of removed specimens, and design methods verification. Results have shown the reactor system to be in good condition with very low activity levels. No evidence has been found of deterioration of metal components, which would limit the lifetime of structural materials. ${ }^{21}$ Examination of the fuel elements has confirmed the acceptable performance of BISO-coated mixed carbide fuel particles. The nuclides, such as cesium, which had migrated from the hot fuel $\left(1200^{\circ} \mathrm{C}\right)$ to cooler parts of the fuel elements, have been strongly held by graphite.

\section{2-3 The AVR Pebble Bed Reactor}

While prototype HTGRs with prismatic (hexagonal) or cylindrical fuel elements were designed and built in the United Kingdom and the United States, pebble bed reactors were also considered in Europe and the United States. The idea of a reactor core composed of spherical fuel pebbles intermittently loaded on top and discharged at the bottom seems attractive. The manufacture of fuel would possibly be less expensive than regular fuel elements, and neutronic properties of the core could, in principle, be excellent with ceramic pebbles, since gross control of the reactivity could be achieved simply by addition of fueled, boronated, or graphite spheres. Since the coolant flows through the void space between the pebbles, the pressure drop must be kept low enough to avoid lifting the core with upflow. In view of the random location of the pebbles and of crossflow, the thermal hydraulics of a pebble bed reactor are quite different from those for cylindrical channels, as discussed in Chapter 4. Also, the flow of pebbles of different kinds-fueled, graphite, and control spheres-must be known and controlled. Detailed experiments are required for each new geometry. Fast insertion of control rods would be a difficult problem in large reactors where they cannot be located in the radial reflector, as they can be in the AVR. 


\section{2-3A Description of the AVR Plant}

The AVR is a small pebble bed HTGR built at Jülich, West Germany, by Hochtemperatur Reaktorbau gmbH (HRB) (previously Brown Boveri/Krupp) for a group of utilities named Arbeitsgemeinschaft Versuchsreaktor gmbH (AVR $\mathrm{gmbH}$ ). During the construction period, much research work for the spherical fuel elements, including irradiation testing, was performed at ORNL. The initial loading of 30000 fueled pebbles was fabricated in the United States by Union Carbide.

As seen in Fig. 2-6, the reactor core, the steam generator, and the two helium

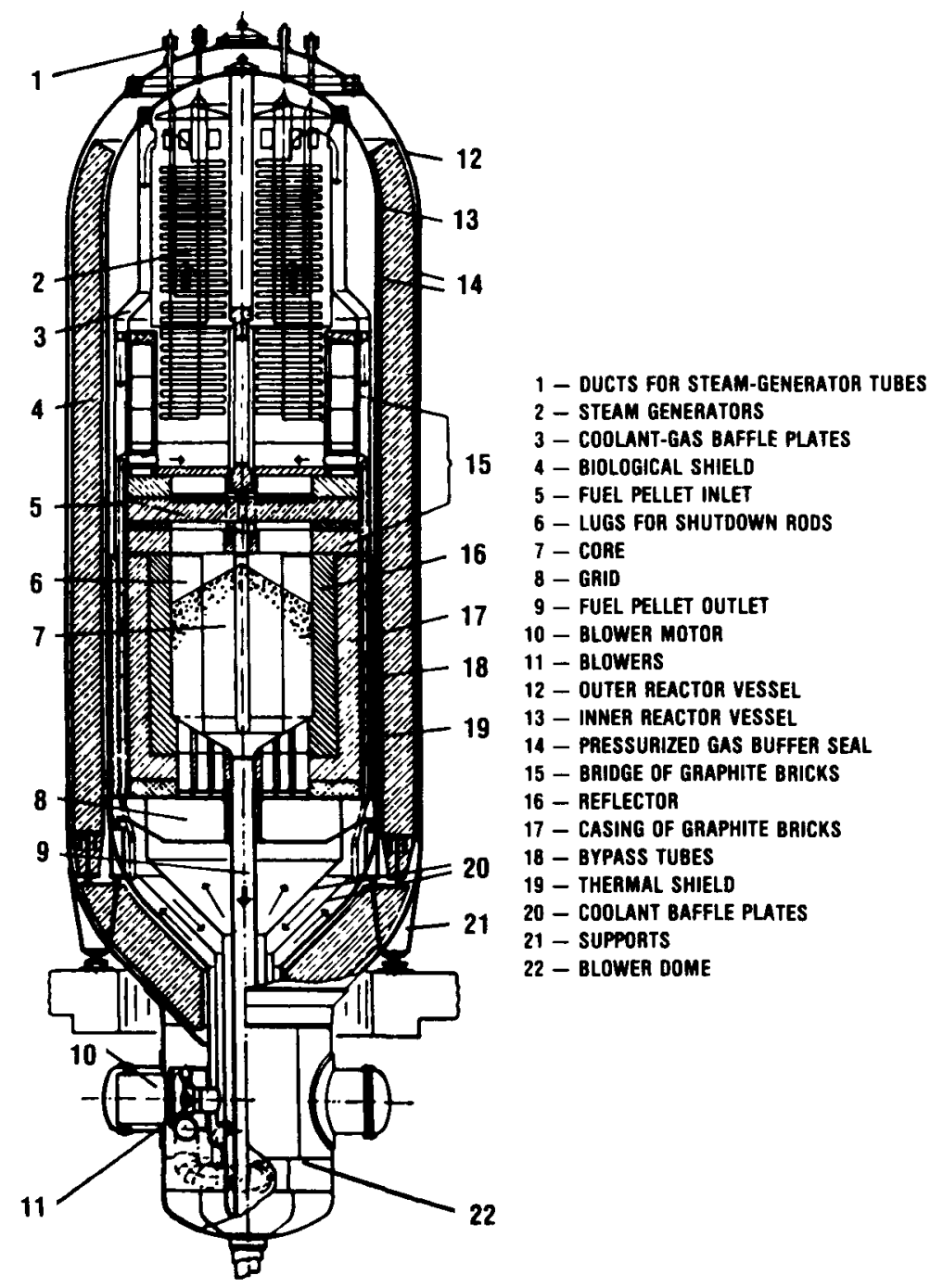

Fig. 2-6. Vertical cross section of the AVR reactor. 
circulators are contained in a double-walled pressure vessel. ${ }^{22}$ The intermediate space is intended as a barrier against leakage of radioactive gases. The first biological shield located in the space between the two reactor vessels is sufficient to allow personnel to stay inside the secondary containment during reactor shutdown. The steam generator located above the core uses ferritic materials and consists of four loops connected in parallel, each with its own regulating and shutoff devices. Helium at $\sim 1 \mathrm{MPa}(10 \mathrm{~atm})$ flows up through the core, enters the steam generator at $850^{\circ} \mathrm{C}$, and leaves it at $200^{\circ} \mathrm{C}$ to cool the thermal shield and reactor sleeve (at $300^{\circ} \mathrm{C}$ ) before reaching the two variable-speed electric motordriven circulators at the bottom of the vessel which pump helium back into the core.

The core of the pebble bed, $\sim 3 \mathrm{~m}$ in diameter and $3.5 \mathrm{~m}$ high (see Table 2-I), is enclosed by graphite reflector blocks, themselves surrounded by structural carbon blocks. Four reflector walls, arranged symmetrically, protrude radially into the core to serve as guide channels for the four shutdown rods. Two structural carbon layers on top of the graphite top reflector protect the steam generator from neutrons coming from the core. The ceramic hot gas duct between the core and the steam generator allows for a very high outlet helium temperature, up to $950^{\circ} \mathrm{C}$ (Ref. 23). The pebble bed is made up of 100000 six-cm-diam spheres, initially with only 30000 spheres that each contained $6.8 \mathrm{~g}$ of ${ }^{235} \mathrm{U}$ in the form of (ThU) $\mathrm{C}_{2}$ coated particles filling a 4-cm-i.d., 6-cm-o.d. graphite shell (Fig. 2-7). Initially there were also 70000 unfueled graphite spheres including a number of boronated graphite spheres for reactivity control. They are all introduced at the top of the core and removed from the bottom through the pebble discharge tube while the reactor is operating. The pebbles are inspected at the unloading point to determine

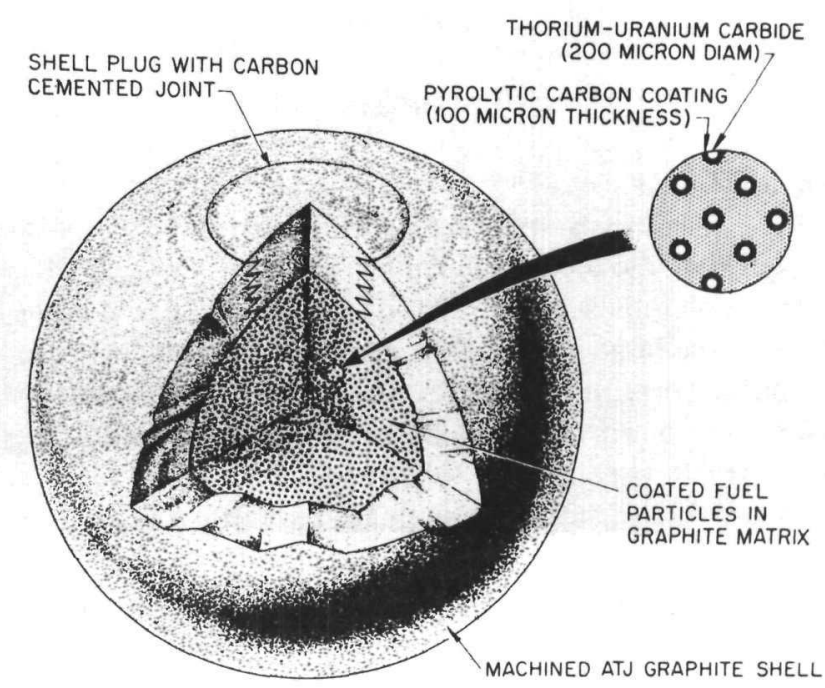

Fig. 2-7. Spherical AVR fuel element. 


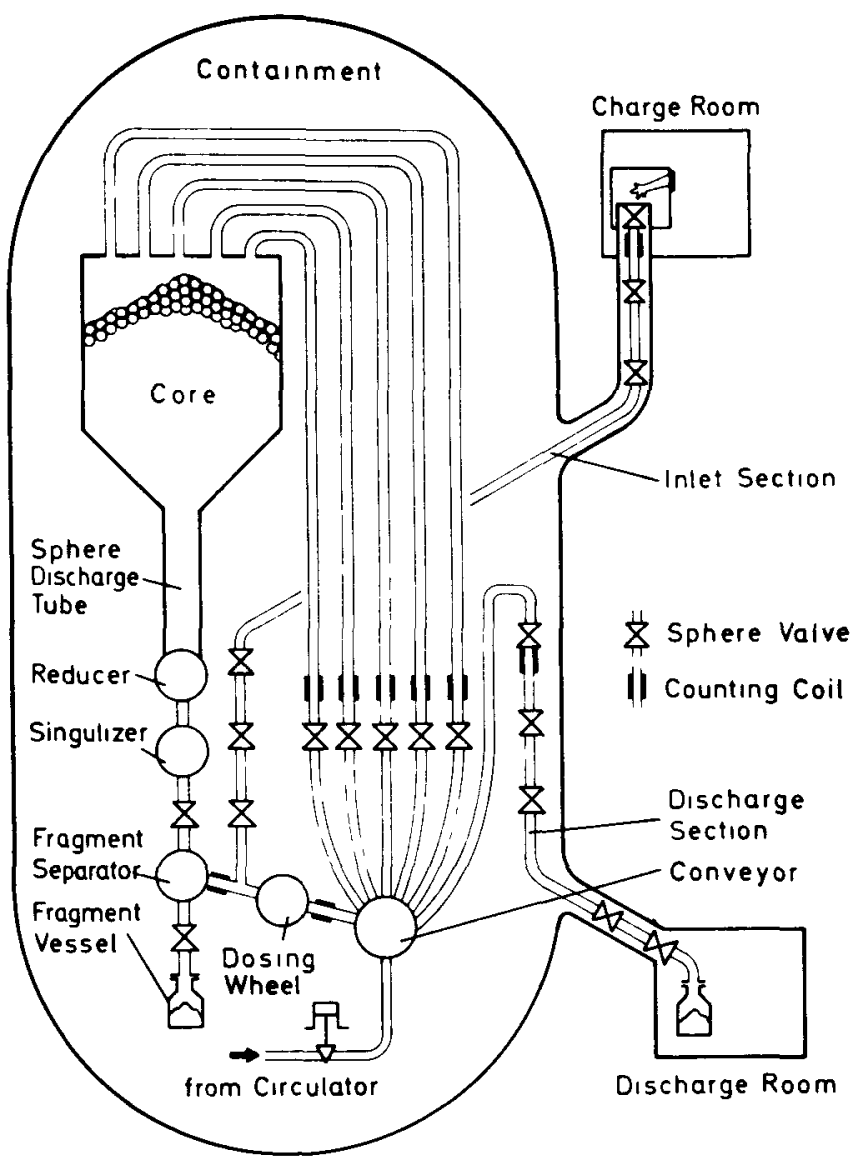

Fig. 2-8. Schematic diagram of the AVR charging equipment.

the burnup and decide whether to remove or reinsert them (Fig. 2-8). Experiments were performed to ensure an even flow of pebbles through the core without damage to the graphite spheres or to the reflector. Later on, nearly all pebbles were fueled.

Control of the plant is accomplished by variation of the coolant flow. Load following relies on the large negative temperature coefficient of reactivity of the nearly homogeneous core. In all HTGRs, since water in the steam generator is at a higher pressure than the coolant, boiler tube failure could result in water entering the reactor with the consequence of a water/graphite chemical reaction at the high operating temperature. If a sufficient amount of water entered the core, it could be vaporized and give rise to a large pressure increase. Usually, moisture monitors are used to shut down the plant when a preset level of humidity is reached. In the AVR, these problems are taken care of by dividing the steam generator into four separate units, by providing a reactor safety valve and special valves for each steam generator unit, and by adding a spray-cooled vessel to receive the steam/ 
gas mixture in case of excessive pressure. Radioactive helium is prevented from entering the steam circuit in case of boiler tube leaks by valves that would close if the boiler pressure were to fall below the gas pressure.

\section{2-3B Operating Experience}

The AVR went critical in August 1966, electricity production occurred in December 1967, and full power was reached in February 1968. The AVR was first operated at a gas outlet temperature of $750^{\circ} \mathrm{C}$, which was raised to the design value of $850^{\circ} \mathrm{C}$ in 1972 . In early 1974 , the helium outlet temperature was increased to $950^{\circ} \mathrm{C}$, with a core inlet temperature of $270^{\circ} \mathrm{C}$. To reach that high temperature without exceeding the permissible maximum fuel temperature, the pebble bed core was rearranged into two zones with different fuel loadings. ${ }^{24}$ The maximum temperature of the hot gas is $1033^{\circ} \mathrm{C}$ at a mean outlet temperature of $950^{\circ} \mathrm{C}$, with maximum fuel element surface and fuel temperatures of 1081 and $1154^{\circ} \mathrm{C}$, respectively. These temperatures are lower than the corresponding temperatures with the $850^{\circ} \mathrm{C}$ mean outlet gas temperature of the initial core $\left(1120\right.$ and $1225^{\circ} \mathrm{C}$, respectively).

A number of initial difficulties were encountered in starting the plant, such as insufficient shutdown worth of the rods, considerable degassing of the carbon bricks, and problems with large diaphragm compressors in the helium purification circuits. ${ }^{25}$ But plant availability improved considerably, to an overall value of $78 \%$ by the end of 1976 when AVR had produced $850 \times 10^{6} \mathrm{kWh}(\mathrm{e})$. Helium loss of $\sim 0.1 \%$ per day corresponds to the design value, and chemical impurities in the primary system are quite low. ${ }^{26}$ Safety tests have been performed with AVR; for instance, simulation of simultaneous failure of the cooling system and of the shutdown rods. The reactor became subcritical after $\sim 5 \mathrm{~s}$, and after $90 \mathrm{~s}$, the average moderator temperature reached a maximum only $25^{\circ} \mathrm{C}$ above its operating value. ${ }^{27}$ After $\sim 20 \mathrm{~h}$, the reactor became critical again. The decay heat was conducted to the reactor vessel by natural convection and from there to the containment.

By 1976, more than 2 million fuel pebbles had been circulated in the reactor during operation without mechanical difficulties, and six different types of fuel pebbles had been tested. The number of damaged spheres is $\sim 8$ per 100000 spheres circulated. One group of fuel pebbles attained a burnup of $160 \mathrm{MWd} / \mathrm{kg}$ at a maximum temperature of $1250^{\circ} \mathrm{C}$ without significant damage. [Some AVR pebbles have even reached a burnup of $200 \mathrm{MWd} / \mathrm{kg}$ (Ref. 28)]. No serious problems have occurred in the core due to corrosion or mechanical damage of the pebbles. The majority of the fuel elements now being tested are the molded elements in which the fuel particles are molded with graphite and binder material into a matrix and enclosed by an additional fuel-free graphite shell. Each pebble contains $1 \mathrm{~g}$ of $93 \%$ enriched uranium. The activity of the helium coolant in AVR has decreased to a low value of $50 \mathrm{Ci}$ for the overall circuit. The release of activity to the environment is also very low: $\sim 30 \mathrm{Ci} / \mathrm{yr}$, far below the permissible value. 
The activity comes from tritium in the primary circuit passing through the steam generator walls into the secondary circuit. Investigation of the deposition behavior of fission products on (cold) primary circuit surfaces is being done through operation of the VAMPYR loops. Tests of fuel elements for future pebble bed reactors are proceeding with top helium temperatures of $950^{\circ} \mathrm{C}$. With the low radioactive contamination, primary circuit components such as the fuel handling system could be maintained without special precautions.

Not a single leak had been observed in the AVR steam generator in the first seven years of operating experience (until the late 1970s; see below). The steam generator tubes have operated very satisfactorily with a gas outlet temperature of $950^{\circ} \mathrm{C}$ for several years. Because of a higher temperature rise in the core at the $950^{\circ} \mathrm{C}$ exit temperature, the helium mass flow is decreased and the circulator speed is reduced from 3800 to $3200 \mathrm{rpm}$; the two circulators have operated without service or breakdown. The only problems encountered with high-temperature operation were failure of thermocouples in the hot gas regions. In 1978, leakage in a steam generator led to a large ingress of water in the core. This incident did not create any safety problems, but the plant had to be shut down for 15 months before resuming full-power operation.

\section{2-4 The THTR Pebble Bed Reactor}

After studies by Euratom, KFA-Jülich, and Brown Boveri/Krupp, the German utility HKG issued a letter of intent in 1970 to a consortium consisting of BBC, Brown Boveri/Krupp (now HRB), and Nukem for construction of a 300-MW(e) pebble bed HTGR demonstration plant in Schmehausen, West Germany. ${ }^{29}$ For the first time in a nuclear plant, heat rejection is provided by a natural-draft dry cooling tower. ${ }^{30}$ Like all large gas-cooled reactors, the whole primary system is contained within a PCRV (Fig. 2-9). Construction was started in 1971 with commercial operation scheduled for 1984. The reactor went critical in September 1983.

The reactor core consists of a loose bed of $\sim 675000$ spherical fuel elements contained in a graphite cylinder $5.6 \mathrm{~m}$ in diameter and $\sim 6 \mathrm{~m} \mathrm{high}^{16}$ (see Table 2-II). The bottom reflector, conically shaped with an inclination of $30 \mathrm{deg}$, ends in an $800-\mathrm{mm}$-diam pebble withdrawal tube. The fuel element circulating facility (Fig. 2-10) permits continuous refueling with fresh fuel elements, continuous circulation of the pebbles, and removal of the used fuel elements. A 100-W solid moderator reactor developed by the Atomic Energy Establishment in Winfrith serves as the burnup measuring device, a sphere passing through it every $7 \mathrm{~s}$. The mean cycling time of a sphere is $\sim 6$ months and it will probably pass through the core six times during its lifetime. The pebbles have a $60-\mathrm{mm}$ o.d. like those in AVR. They contain (ThU)O $\mathrm{O}_{2}$ fuel particles with a $400-\mu \mathrm{m}$ kernel coated with two layers of PyC. Initially, every fuel element will contain $\sim 1 \mathrm{~g}$ of ${ }^{235} \mathrm{U}$ and $10 \mathrm{~g}$ of thorium dispersed in $\sim 33000$ coated particles embedded in a graphite matrix inside the fuel-free graphite shell of the sphere, which is at least $5 \mathrm{~mm}$ thick. ${ }^{26}$ The fuel pebbles are designed to withstand a minimum of 50 drops from 


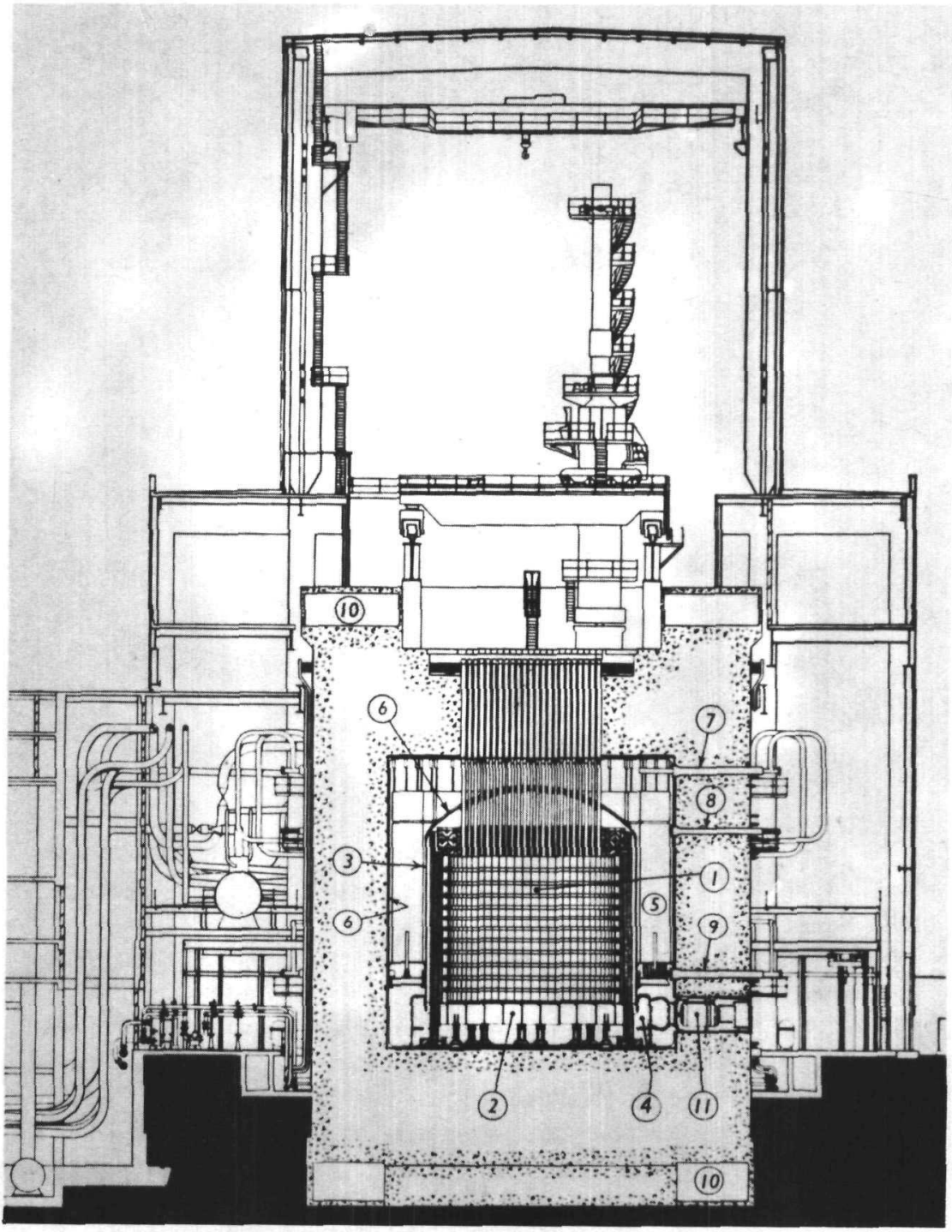

Fig. 2-9. Sectional view of the THTR pressure vessel.

a height of $4 \mathrm{~m}$ on a densely packed graphite pebble bed without damage. A considerable amount of fuel testing ${ }^{31}$ for THTR has been performed in AVR.

Reactivity control is achieved in the THTR by 36 absorber rods freely moving in bore holes of the graphite reflector near the core. They are used for normal shutdown, as well as for load-following control between 40 and $100 \%$ load. For long-term shutdown, 42 in-core rods are used: They are slowly inserted directly into the pebble bed with pneumatic drives. Extensive full-size experiments have been performed at KFA-Jülich to demonstrate satisfactory operation of these incore control rods. 


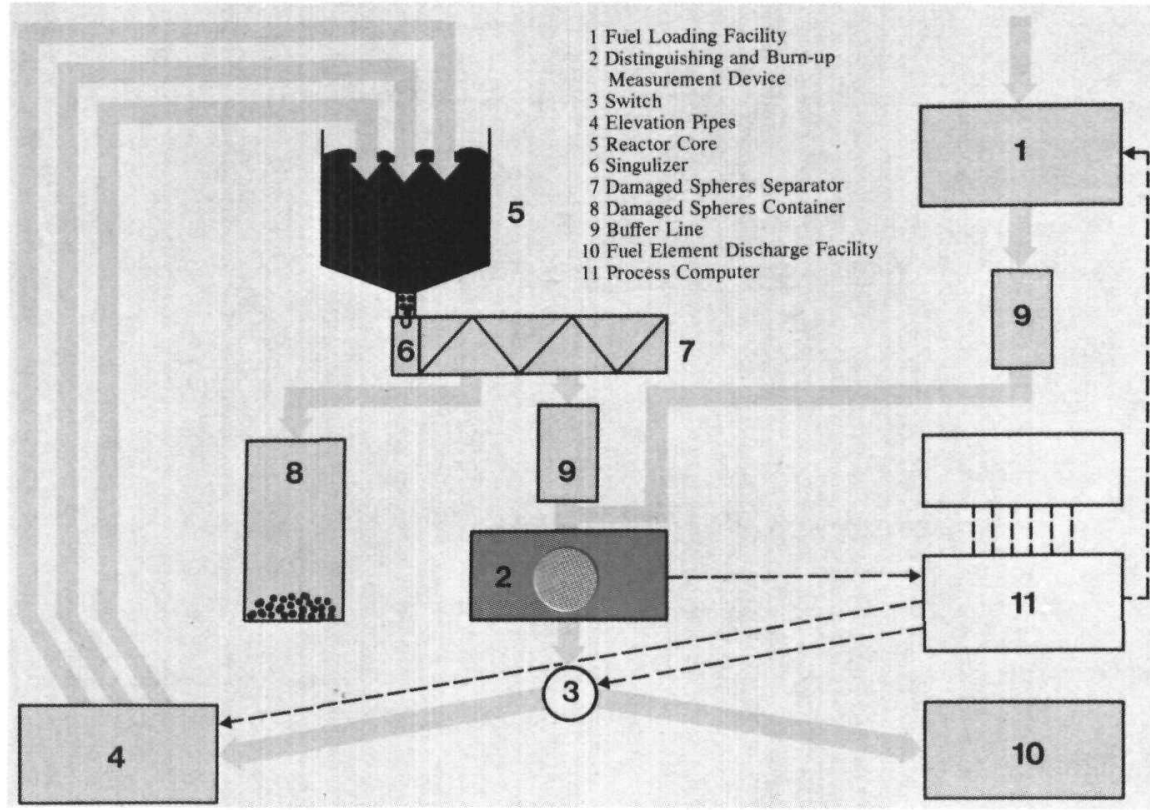

Fig. 2-10. Diagram of the THTR fuel element circulating facility.

The PCRV is prestressed by horizontal circumferential tendons and also by vertical tendons. ${ }^{32,33}$ The top and bottom slabs of the PCRV as well as the cylindrical wall contain numerous small and large penetrations (Fig. 2-9). They are equipped with steel liners and designed with double steel closures. A 20- to 30-mm-thick vessel liner ensures leak tightness, with 70-mm-thick multilayer steel foil insulation on its inner surface. A cooling system welded to the outer surface of the liner further protects the concrete against excessive temperatures and temperature gradients. A one-fifth-scale model of the vessel was tested by Krupp in 1972 at 2.1 times the normal working pressure of $4 \mathrm{MPa}$ (maximum load) and exhibited an elastic behavior after cyclic loadings. Tests performed with temperature gradients and pressure increases corresponding to accident conditions have demonstrated the large safety margins of such PCRVs. In view of the safety features of the PCRV, no secondary containment was deemed necessary; but evolving criteria by German licensing authorities have led to design modifications, cost overruns, and significant construction delays. ${ }^{34}$ There are six independent primary loops that can remove the reactor afterheat.

Helium flows downward through the core-contrary to helium upflow in AVR - to avoid lifting the pebble bed with the higher pressure drop. Helium then flows upward through the six steam generators located around the core within the PCRV and goes to the six helium circulators, which pump it back down the annular space between the PCRV and the thermal shields to cool the PCRV liner and internals. Finally, helium flows upward through the gaps between thermal 
TABLE 2-II

Main Parameters for HTGR Demonstration Plants

\begin{tabular}{|c|c|c|}
\hline & Fort St Vrain & THTR \\
\hline Country & United States & West Germany \\
\hline First electricity production & 1976 & 1984 \\
\hline Power thermal/electric (MW) & $842 / 330$ & $750 / 300$ \\
\hline Net electric efficiency $(\%)$ & 39 & 40 \\
\hline number of loops & 2 & 6 \\
\hline \multicolumn{3}{|l|}{ Steam conditions } \\
\hline superheat $\left(\mathrm{MPa} /{ }^{\circ} \mathrm{C}\right)\left[\mathrm{ps} 1 /{ }^{\circ} \mathrm{F}\right]$ & $165 / 538[2400 / 1000]$ & $18 / 550[2600 / 1020]$ \\
\hline reheat $\left(\mathrm{MPa} /{ }^{\circ} \mathrm{C}\right)\left[\mathrm{ps}{ }^{\circ}{ }^{\circ} \mathrm{F}\right]$ & $39 / 538[600 / 1000]$ & $5 / 535[700 / 995]$ \\
\hline turbıne condenser pressure $(\mathrm{mm} \cdot \mathrm{Hg})$ & 63 & 23 (alr cooling) \\
\hline feedwater temperature $\left({ }^{\circ} \mathrm{C}\right)$ & 206 & 180 \\
\hline Helium pressure/pressure drop (MPa) & $48 / 01$ & $4 / 011$ \\
\hline Helium temperatures $\left({ }^{\circ} \mathrm{C}\right)$ & $405 / 775$ & $250 / 750$ \\
\hline Number of blowers $\times$ unit power $(\mathrm{MW})$ & $4 \times 45$ & $6 \times 2$ \\
\hline \multicolumn{3}{|l|}{ Active core } \\
\hline diameter (m) & 59 & 56 \\
\hline height (m) & 475 & 6 \\
\hline \multicolumn{3}{|l|}{ Overall core } \\
\hline dıameter (m) & 875 & 76 \\
\hline height (m) & 71 & 6 \\
\hline Control rods/material & 37 pars $/ B_{4} C$ & $(36 / 42) / \mathrm{B}_{4} \mathrm{C}$ \\
\hline Average core power density $\left(\mathrm{MW} / \mathrm{m}^{3}\right)$ & 63 & 6 \\
\hline $\begin{array}{l}\text { Average specific power } \\
{[\mathrm{MW}(\mathrm{t}) / \mathrm{kg} \text { fissile] }}\end{array}$ & 11 (equil) & $\sim 12$ \\
\hline \multicolumn{3}{|l|}{ Fuel element } \\
\hline design & 1482 prisms & 675000 pebbles \\
\hline diameter (equivalent) $(\mathrm{mm})$ & 355 & 60 \\
\hline length (equivalent) $(\mathrm{mm})$ & 787 & - \\
\hline maximum fuel temperature $\left({ }^{\circ} \mathrm{C}\right)$ & 1260 & 1250 \\
\hline Fuel life ( $80 \%$ load factor) (yr) & 6 & 4 \\
\hline Average bumup (MWd/kg) & 100 & 109 \\
\hline Average/maxımum, heat flux $\left(\mathrm{MW} / \mathrm{m}^{2}\right)$ & $014 / 044$ & $\sim 01 / 03$ \\
\hline Fuel loadıng & Off-load & On-load \\
\hline Pressure vessel & Integrated PCRV & Integrated PCRV \\
\hline Internal diameter (m) & 95 & 159 \\
\hline internal height $(\mathrm{m})$ & 23 & 153 \\
\hline concrete wall thickness (m) & 275 to 46 & 445 to 510 \\
\hline
\end{tabular}

shields and side reflectors before returning to the top of the core. The electric motor-driven circulators are located and connected (but not anchored) radially to the steam generators in penetrations within the cylindrical wall of the PCRV. The single-stage radial circulator rotor, drive motor, and valves are integrated in a single removable unit. Mass flow is controlled by varying the electric motor speed from 3000 to $5600 \mathrm{rpm}$. The motor operates in a helium atmosphere at reactor pressure, and the rotor shaft bearings are oil lubricated. A helium buffer system separates the oll from the primary coolant gas. The steam generators are designed to permit replacement and are characterized by downward evaporation and helical coils. ${ }^{35}$ Comprehensive investigations have shown that this configuration ensures stable operation in the overall power range. The high helium temperature permits 
the use of conventional steam conditions, $18.5 \mathrm{MPa}, 550^{\circ} \mathrm{C}$ live steam, with $5 \mathrm{MPa} / 535^{\circ} \mathrm{C}$ gas reheat, leading to $40 \%$ net electrical efficiency.

\section{2-5 Fort St. Vrain HTGR}

Following extensive research and development programs after the Peach Bottom HTGR, General Atomic entered into a contract with Public Service Company of Colorado in 1965 for a 330-MW(e) HTGR nuclear generating station to be located at Fort St. Vrain. This plant, which is part of the U.S. AEC Power Reactor Demonstration Program, was issued a construction permit by the U.S. AEC in September 1968 and construction started immediately.

Novel features included in this HTGR plant compared with the Peach Bottom station are: a PCRV enclosing the whole primary system, once-through modular steam generators with integral superheaters and reheaters, steam-driven axial flow helium circulators, and hexagonal graphite fuel elements incorporating improved coated fuel particles. Also, no secondary reactor containment is provided, and the plant produces conventional steam conditions.

\section{2-5A Plant Description}

The reactor arrangement is shown in Fig. 2-11. The helium coolant at $\sim 4.8 \mathrm{MPa}$ and $405^{\circ} \mathrm{C}$ (see Table 2-II) flows downward through the reactor core where it is heated to an average temperature of $775^{\circ} \mathrm{C}$ (Refs. 36-41). It is then directed to the steam generators located below the core support floor to produce first reheated steam $\left(3.9 \mathrm{MPa} / 538^{\circ} \mathrm{C}\right)$ and then superheated steam $\left(16.5 \mathrm{MPa} / 538^{\circ} \mathrm{C}\right)$. Helium, now at $405^{\circ} \mathrm{C}$, then goes through the circulators, which discharge into a common plenum below the core support floor. All of the flow passes upward around the core support floor and the barrel to the core inlet plenum above the reactor before returning to the core. The coolant flow out of the reactor divides equally into two loops, each consisting of a six-module steam generator and of two helium circulators.

As seen in Fig. 2-11, the primary circuit is wholly contained within the PCRV: core and reflector in the top cavity, and steam generators and circulators in the lower cavity. The PCRV acts as both pressure vessel and biological shield. The internal dimensions are $9.5 \mathrm{~m}$ in diameter and $23 \mathrm{~m}$ high, while the exterior surface is approximately an hexagonal prism, $15 \mathrm{~m}$ across flats and $42 \mathrm{~m}$ high. The top head of the vessel has 37 refueling penetrations that also house the control rod drives. The bottom head has 12 penetrations for the steam generator modules plus a large central opening for access. All PCRV penetrations are provided with two independent closures: The PCRV inner cavity and the primary closures act as primary containment for the reactor; the PCRV itself and the secondary closures act as the secondary containment. A $19-\mathrm{mm}$-thick carbon steel liner anchored to the concrete provides a helium-tight membrane. Two independent systems of 


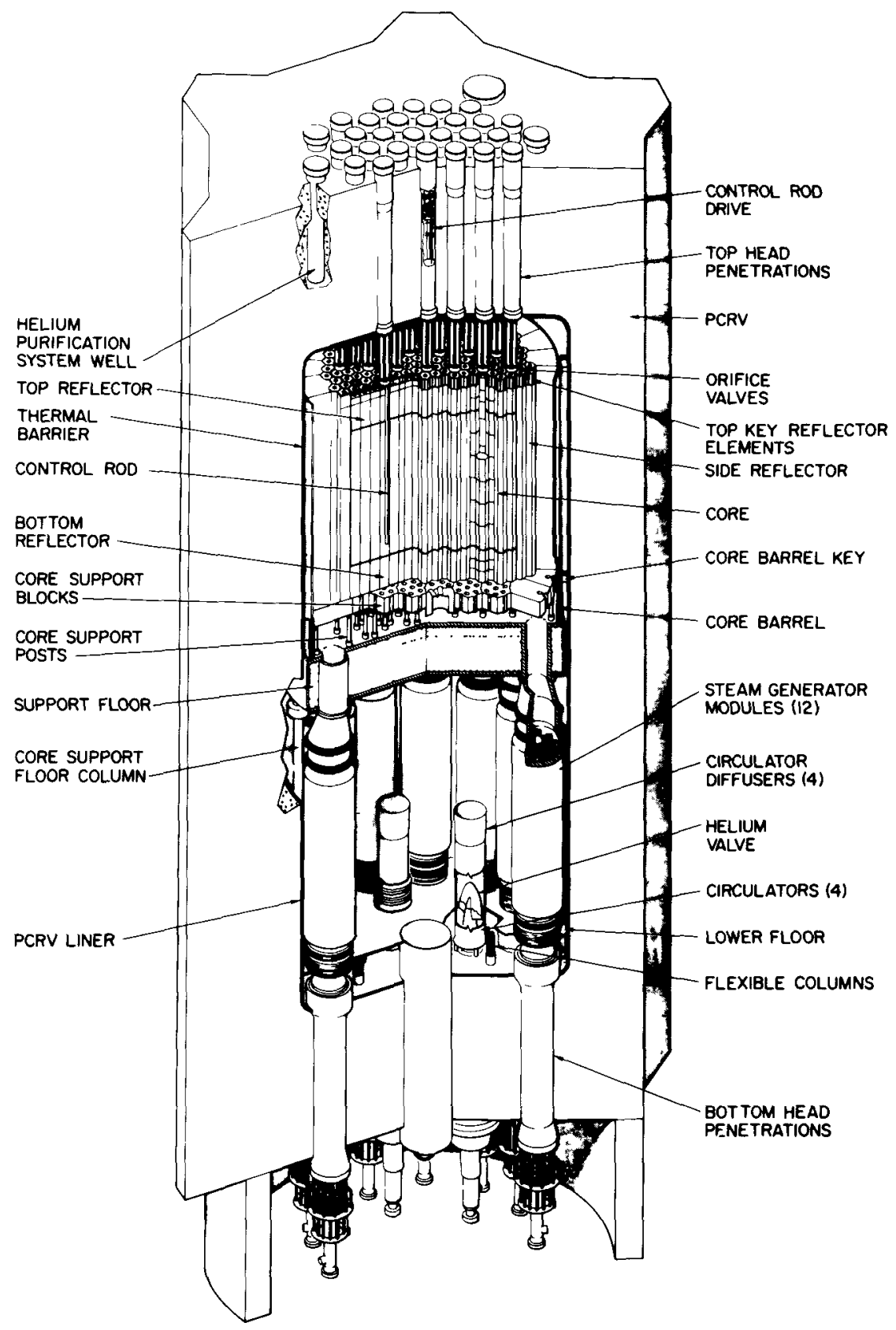

Fig. 2-11. The Fort St. Vrain nuclear steam supply system. 
water-cooled tubes welded to the concrete side of the liner and a thermal barrier on the reactor side of the liner act to control the temperatures in both liner and concrete and to limit heat losses. Sets of horizontal and vertical tendons located in steel tubes in the concrete are used to place the concrete structure in compression. These redundant tension members removed from both radiation and temperature fields can be monitored and even replaced if ever needed.

The Fort St. Vrain reactor core is composed of 247 columns made up of six hexagonal graphite fuel elements, each grouped in 37 refueling regions. The coolant flow in each region is controlled by an orifice valve at the top of the core. About one-sixth of the regions are refueled each year during shutdown through PCRV penetrations centrally located over each region. One pair of $\mathrm{B}_{4} \mathrm{C}$ control rods operated by electric drives and cable drums is provided for each refueling region; also, as reserve shutdown, $\mathrm{B}_{4} \mathrm{C}$ spheres can fall by gravity into the reactor core. The active core, $5.9 \mathrm{~m}$ in diameter and $4.75 \mathrm{~m}$ high, is surrounded by a graphite reflector, $1.2 \mathrm{~m}$ thick with one row of replaceable hexagonal graphite blocks. The top graphite reflector is $\sim 0.8 \mathrm{~m}$ thick, and the bottom reflector is $1.2 \mathrm{~m}$ thick. The core is divided into three radial and two axial zones with different loadings of fissile $\left({ }^{235} \mathrm{U}\right)$ and fertile $\left({ }^{232} \mathrm{Th}\right)$ material to minimize the peak fuel temperature. Each hexagonal fuel element is made up of a graphite prism, $360 \mathrm{~mm}$ across flats and $793 \mathrm{~mm}$ high with 108 coolant channels, $15.9 \mathrm{~mm}$ in diameter, and 210 fuel channels, $12.7 \mathrm{~mm}$ in diameter, and a central hole for handling (Fig. 2-12). Six fuel elements are stacked on top of each other and aligned with three graphite dowels each. The control fuel element of each refueling region has three larger holes, two are $102 \mathrm{~mm}$ in diameter for control rod insertion and one is $95 \mathrm{~mm}$ in diameter and is used for reserve shutdown (Fig. 2-13). The fuel holes are filled with rods made of coated fuel particles bonded together by a graphite matrix. Two types of coated particles are used: $400-\mu \mathrm{m}$-diam $\mathrm{ThC}_{2}$ kernels and $200-\mu \mathrm{m}$-diam (ThU) $\mathrm{C}_{2}$ kernels. Both have $\sim 120-\mu \mathrm{m}$ TRISO coatings, consisting of a first buffer layer of low-density $\mathrm{PyC}$, an inner high-density isotropic PyC layer, an intermediate $\mathrm{SiC}$ barrier, and an outer isotropic PyC layer. ${ }^{15}$ These coatings are designed to retain fission products and withstand the effects of irradiation and of fuel burnup up to $20 \%$ fissions per initial heavy metal atom in the fissile particles. The maximum fuel temperature is $1260^{\circ} \mathrm{C}$, maximum burnup is $200 \mathrm{MWd} / \mathrm{kg}$, and the maximum fast fluence $(E>0.18 \mathrm{MeV})$ is $8 \times 10^{21}$ $\mathrm{n} / \mathrm{cm}^{2}$. The initial fuel loading consists of $770 \mathrm{~kg}$ of ${ }^{235} \mathrm{U}$ (in the form of $93.15 \%$ enriched uranium), and $16000 \mathrm{~kg}$ of thorium. Approximately $75 \%$ of the fissions in the fuel at end of life will take place in ${ }^{233} \mathrm{U}$ bred from ${ }^{232} \mathrm{Th}$. Uranium-235 and thorium atoms constitute only $\sim 1 \%$ of the total atoms in the fuel, and this dilution ensures both structural integrity of the graphite elements and a high degree of safety because of the large heat capacity of the graphite.

Figure 2-14 shows the flow diagram for the Fort St. Vrain power plant. Feedwater at $206^{\circ} \mathrm{C}$ is transformed into superheated steam at $538^{\circ} \mathrm{C}$ in the oncethrough steam generator and flows to the high-pressure turbine. Cold reheat steam then flows to the helium circulator turbines before being reheated in the reheater 


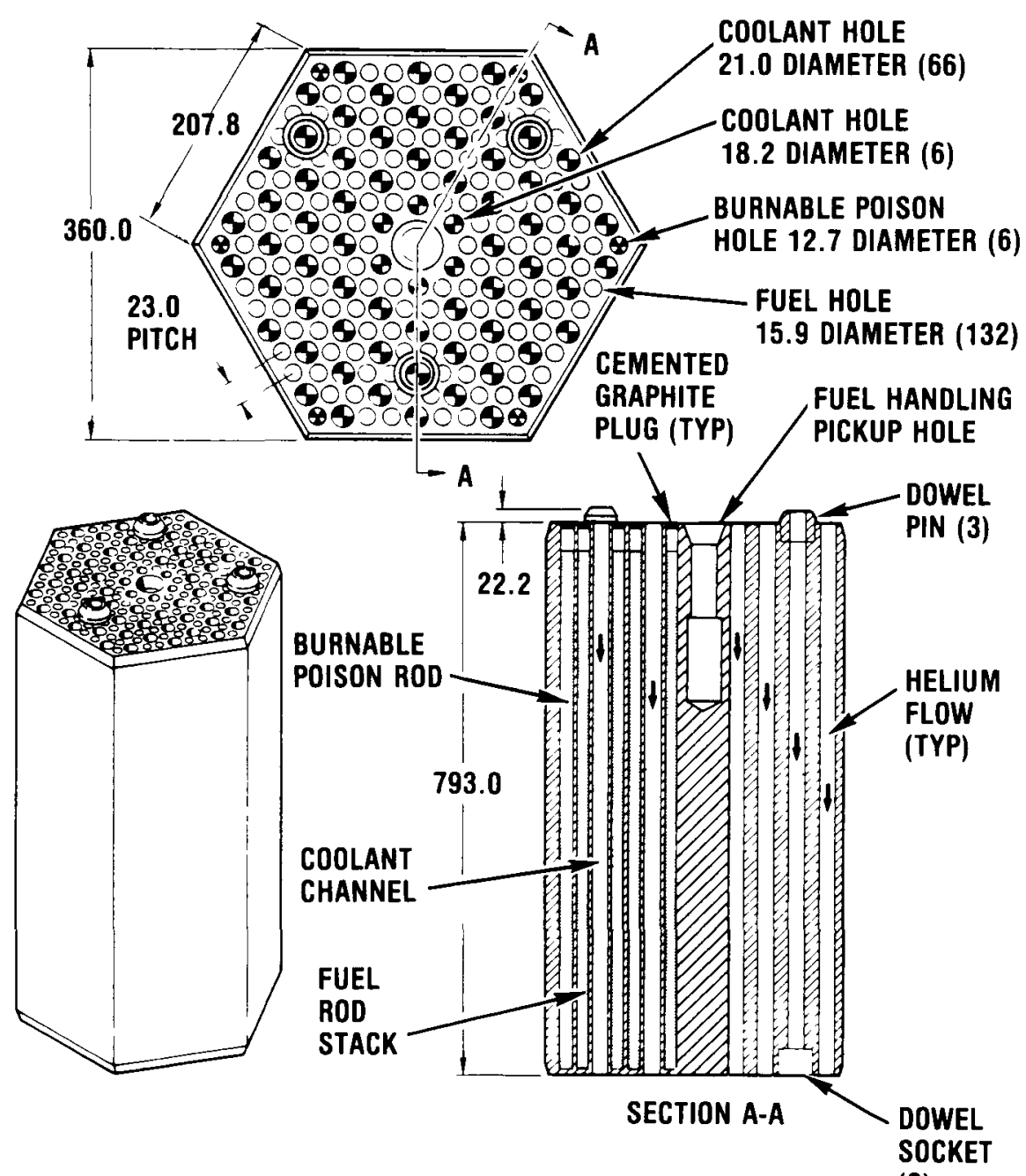

ALL DIMENSIONS IN MILLIMETERS

(3)

Fig. 2-12. HTGR standard fuel element.

section of the steam generator where it emerges at $538^{\circ} \mathrm{C}$ to return to the intermediate pressure turbine. The turbine generator is a conventional 3600 -rpm twocasing condensing turbine driving a synchronous generator. The rated exhaust pressure from the steam turbine is $63 \mathrm{~mm} \cdot \mathrm{Hg}$ and the condenser water is cooled in an induced-draft wet cooling tower. The steam generators are designed to operate continuously at full load or part load (down to 25\%) and also to remove decay heat during reactor shutdown. ${ }^{42}$ Hot helium from the reactor enters the top of the steam generator module and flows downward through the reheater, superheater, and evaporator-economizer helically coiled tube bundles in succession. The su- 


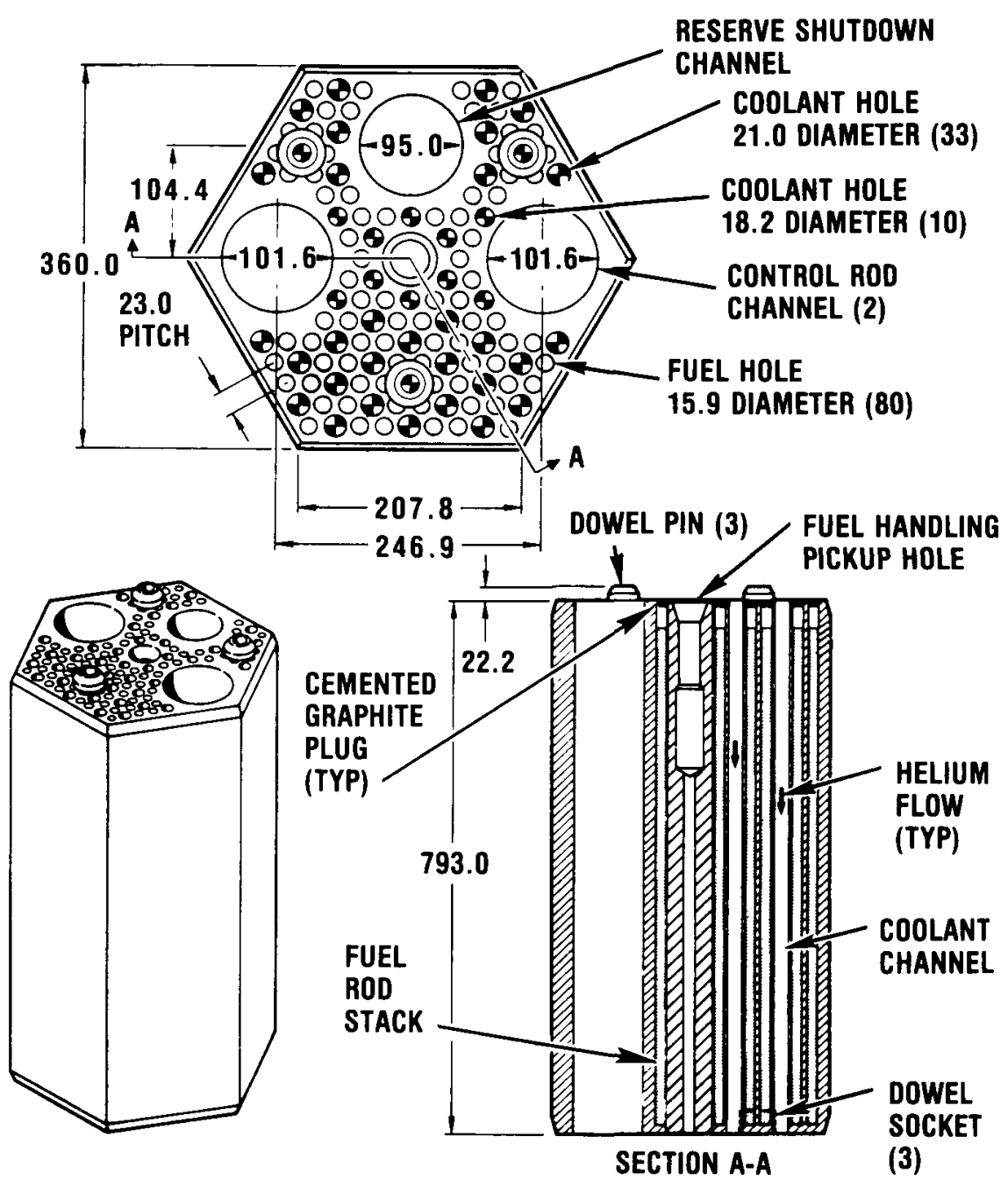

ALL DIMENSIONS IN MILLIMETERS

Fig. 2-13. Control fuel element.

perheater is designed for cocurrent flow of steam and helium, while the reheater is designed for countercurrent flow. All tubes are drainable and all water and steam piping go through bottom penetrations in the PCRV.

Each of the four helium circulators consists of a single-stage axial flow compressor, a single-stage steam turbine main drive, and a single-stage water turbine auxiliary drive - all mounted on a single vertical shaft, with water lubrication. ${ }^{43}$ The steam turbine drives are normally supplied with cold reheat steam 


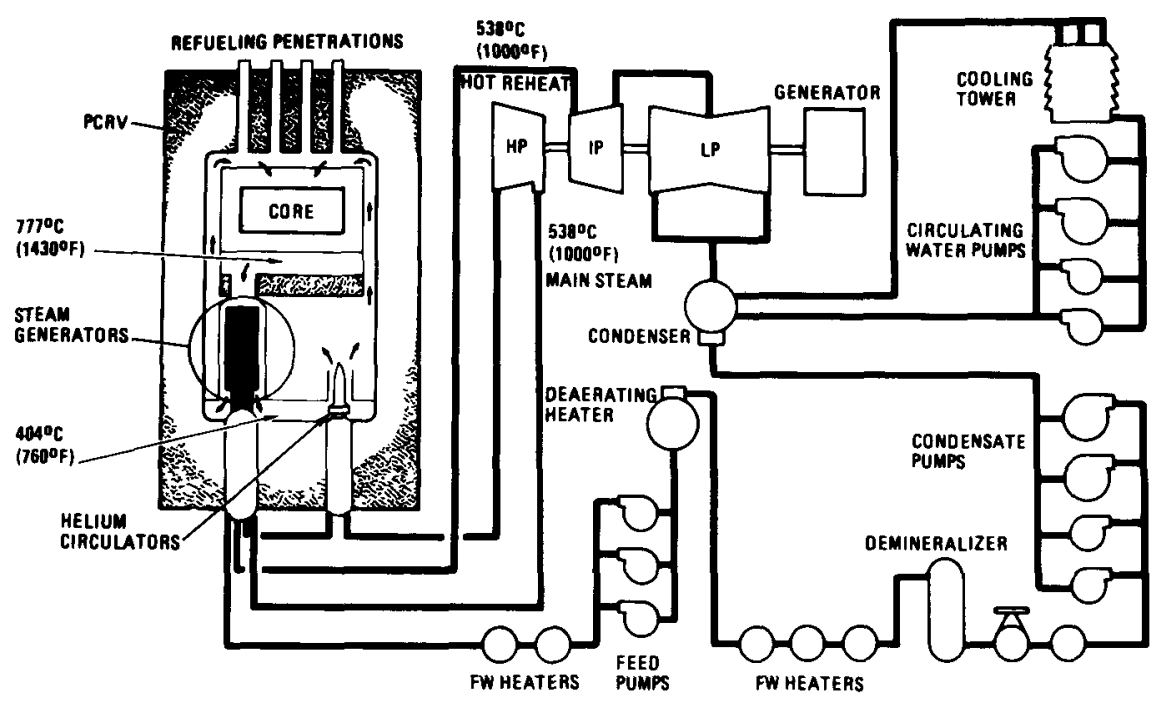

Fig. 2-14. Simplified Fort St. Vrain flow diagram.

from the main turbine at $5.8 \mathrm{MPa}$ and $389^{\circ} \mathrm{C}$ (see Fig. 2-14), although auxiliary steam could also be used. High-pressure water can be provided in emergencies to the auxiliary Pelton wheel drive. The normal speed of the circulator is $9550 \mathrm{rpm}$ at a helium flow rate of $110 \mathrm{~kg} / \mathrm{s}$ with a pressure rise of $0.1 \mathrm{MPa}$ corresponding to a power of $\sim 4.5 \mathrm{MW}$. A helium purification system maintains a low impurity level in the primary loop and provides purified helium to various subsystems, such as the helium circulator seals.

\section{2-5B Construction, Startup, Operation, and Research and Development Experience}

Site construction was started in September 1968 and prestressing of the PCRV by tendons was completed in May 1970. The PCRV pressure tests and leak tests were performed on schedule in mid-1971 when major plant construction was completed. Preliminary operating tests were started and hot functional tests ${ }^{44-47}$ began in mid-1972. They were interrupted because of cavitation damage to temporary circulator Pelton wheels and resumed in the first half of 1973. Fuel loading in late 1973 led to initial criticality in January 1974, followed by zero-power physics tests, and hot physics tests at $2 \%$ power later in 1974 . Accidental insertion of water in the reactor cavity led to several shutdowns, and overheating of the PCRV liner near some control rod drive penetrations had to be corrected by design modifications. Rerouting of essential electrical cables due to new U.S. Nuclear Regulatory Commission (NRC) safety requirements and modifications to the fire protection systems caused a one-year delay in plant startup. Rise to power was resumed in mid-1976 and the first electricity, at $28 \%$ power, was generated by 
the end of 1976 . The rise in power testing program through $40 \%$ power was completed in September 1977.

Hot functional tests included operation of the four helium circulators under various steam conditions, which also allowed determination of the effectiveness of the PCRV thermal barrier insulation, and provided a means of testing PCRV internal components at $\sim 400^{\circ} \mathrm{C}$ and of evaluating their acoustic responses. Test results showed that acoustically induced stresses in the PCRV components and internal structures were within design criteria and that no flow-induced vibration of any significance occurred. Measurements also showed that each of the two independent water cooling loops of the PCRV is capable of removing $100 \%$ of the design heat load with forced circulation. These tests are especially important to demonstrate the reactor safety features since these cooling systems must ultimately remove the core afterheat in the unlikely event of complete loss of forced helium circulation.

A great deal of experience was gained in the fabrication of the first core for Fort St. Vrain, and in performing fuel research and development. ${ }^{15,48-50}$ More than $800 \mathrm{~kg}$ of highly enriched ${ }^{235} \mathrm{U}$ and $15000 \mathrm{~kg}$ of thorium have been processed for the first core and an additional $2700 \mathrm{~kg}$ of heavy elements have been used in the fabrication of the initial fuel reload. The uncertainty in initial reactivity was found to be only $0.3 \%$, compared to an estimate of $1.8 \%$. The very low fission gas release from fuel rods $\left[{ }^{85 m} \mathrm{Kr}\right.$ release/birth ratio $(\mathrm{R} / \mathrm{B})$ at $1100^{\circ} \mathrm{C}$ of only $\left.10^{-5}\right]$ is more than a factor of 2 below predicted values. ${ }^{51}$ Actual reactor testing of the normal fuel handling equipment was performed successfully. Detailed measurements of installed core geometry showed acceptable tolerances.

Extensive physics tests performed both at low power (2\%) and at a higher power $(\sim 30 \%)$ and elevated temperature have shown good agreement between measured and calculated values. For instance, predictions of control rod worth, axial flux distributions, and temperature reactivity coefficient are very close to actual measurements. ${ }^{47}$ Measurements of fission gas release at low power give a sensitive evaluation of uranium contamination of fuel elements: Calculations indicate the fission product release during full-power operation will be well below design value, in spite of exposure of fuel elements to moisture during incidents of water ingress into the core. Helium impurities can be kept at a very low level during power operation: For instance, only $3 \mathrm{ppm}$ of oxidants were measured at $30 \%$ power in late 1976.

In late 1977, core outlet temperature fluctuations ${ }^{52}$ occurred during the plant's rise to power above $50 \%$. These temperature changes were apparently due to small movements of fuel and reflector columns induced by a combination of nonuniform fuel column temperatures and pressure differences in the gaps between blocks and columns. The reactor power was subsequently limited to $70 \%$ by the U.S. Nuclear Regulatory Commission. In October 1979, region constraint devices were installed on the top of the core; they were shown the following year to prevent temperature fluctuations. Testing above 70\% power was performed in the spring of 1981 and $100 \%$ power was reached in November 1981 without fluctuations and with per- 
formance close to design values (i.e., 38.5\% net thermal efficiency). Commercial operation (at $70 \%$ of full power) has occurred since the summer of 1979 , with acceptance of the plant by Public Service of Colorado. The majority of the problems at Fort St. Vrain has been associated with mechanical hardware; the PCRV, the steam generators, and the nuclear reactor core (except for the fluctuations) have performed quite well. ${ }^{53}$ The radiological consequences ${ }^{52}$ for Fort St. Vrain operation have been exceptionally low, on the order of 1 person-rem/yr. Detailed discussion of the performance of various components is given in Ref. 54 .

\section{2-6 HTGR Designs and Programs}

In the early 1970 s, following the successful operation of the prototype HTGRs, Dragon, Peach Bottom, and AVR, and the start of construction of HTGR demonstration plants, Fort St. Vrain and THTR, manufacturers in West Germany, the United Kingdom, and the United States prepared proposals for utilities for commercial HTGRs designed for electricity production. Two HTGR stations in the United States had reached the construction permit stage before they were cancelled in 1975 for financial reasons and reduced utility requirements: the two four-loop units, 770 MW(e) each, of Delmarva Power \& Light's Summit, Delaware, station and the two six-loop units, $1160 \mathrm{MW}(\mathrm{e})$ each, of Philadelphia Electric's Fulton, Pennsylvania, station.

Much research and development has been performed for both components and fuel, as well as the safety research and analysis required for preliminary safety analysis reports. A standard safety analysis report for HTGRs has also been prepared. ${ }^{55}$ Research and development programs for large HTGRs have also been going on in France, Germany, Japan, and the United Kingdom (see Sec. 2-6A for more details). Designs have been prepared in West Germany for 1000-MW(e) HTGR stations with spherical fuels, as an extrapolation of the 300-MW(e) THTR, and in the United Kingdom for a 1350-MW(e) HTGR with prismatic fuel elements using the low-enriched uranium cycle, as contrasted to the U/Th cycle of the German and U.S. designs. Table 2-III gives basic design data for three designsthe 3000-MW(t) U.S. HTGR (Ref. 57), the 2700-MW(t) German pebble bed reactor, and the 3430-MW(t) low-enriched HTR of the United Kingdom. A great deal of similarity can be seen in helium conditions (temperature and pressure), type of fuel particles and burnup (coated oxide kernels with 85 to $100 \mathrm{MWd} / \mathrm{kg}$ burnup), power density $\left(\sim 8 \mathrm{MW} / \mathrm{m}^{3}\right)$, cycle efficiency (37 to $39 \%$ ), and also PCRV design and multicavity vessels with wire-winding and ceramic-type thermal insulation.

\section{2-6A Worldwide HTGR Programs}

HTGR development programs in the early 1980s are under way in the Federal Republic of Germany (FRG), Switzerland, the Soviet Union, Japan, and the United 
TABLE 2-III

Basic Data of Pebble Bed and Prismatic Fuel HTGR Designs*

\begin{tabular}{|c|c|c|c|}
\hline & HTGR-1160 & THTR-1000 & Low-Enriched HTR \\
\hline \multicolumn{4}{|l|}{ Overall Plant Characteristics } \\
\hline $\begin{array}{l}\text { Country } \\
\text { Thermal power }(\mathrm{MW}) \\
\text { Net electrical power }(\mathrm{MW}) \\
\text { Fuel cycle } \\
\text { Steam reheating }\end{array}$ & $\begin{array}{c}\text { United States } \\
3000 \\
1150 \\
\text { U/Th } \\
\text { Gas to steam }\end{array}$ & $\begin{array}{c}\text { West Germany } \\
2700 \\
1000 \\
\text { U/Th } \\
\text { Gas to steam }\end{array}$ & $\begin{array}{c}\text { United Kingdom } \\
3430 \\
1350 \text { (sea cooling) } \\
\text { Low-enriched } \\
\text { Steam to steam }\end{array}$ \\
\hline \multicolumn{4}{|l|}{ Primary Circuit Data } \\
\hline $\begin{array}{l}\text { Core } \\
\text { diameter }(m) \\
\text { height }(m)\end{array}$ & $\begin{array}{l}847 \\
634\end{array}$ & $\begin{array}{l}89 \\
54\end{array}$ & $\begin{array}{c}98 \\
6\end{array}$ \\
\hline \multicolumn{4}{|l|}{ Fuel element } \\
\hline $\begin{array}{l}\text { number of spheres/blocks } \\
\text { diameter }(\mathrm{mm})\end{array}$ & $\begin{array}{c}3944 \\
360\end{array}$ & $\begin{array}{l}18 \times 10^{6} \\
60 \text { (sphere) }\end{array}$ & $\begin{array}{c}3768 \\
420\end{array}$ \\
\hline length $(\mathrm{mm})$ & 793 & - & 750 \\
\hline Mean power density $\left(\mathrm{MW} / \mathrm{m}^{3}\right)$ & 84 & 8 & $\sim 8$ \\
\hline Helium flow rate $(\mathrm{kg} / \mathrm{s})$ & 1473 & 1065 & 1460 \\
\hline $\begin{array}{l}\text { Helium temperature } \\
\text { outlet steam generator }\left({ }^{\circ} \mathrm{C}\right)\end{array}$ & 320 & 275 & 273 \\
\hline $\begin{array}{l}\text { Inlet steam generator }\left({ }^{\circ} \mathrm{C}\right) \\
\text { Mean operating pressure of helium }(\mathrm{MPa})\end{array}$ & $\begin{array}{c}723 \\
5\end{array}$ & $\begin{array}{c}750 \\
5\end{array}$ & $\begin{array}{c}724 \\
493\end{array}$ \\
\hline Number of shutdown and control rods & 146 & 120 & $141 / 47$ \\
\hline Number of main coolant loops & 6 & 6 & 4 \\
\hline Number of auxilary coolant loops & 3 & 3 & 4 \\
\hline Fuel loading and discharge tubes & 73 & $24+3$ & 54 \\
\hline Fuel loading & Off-load, mechanical & On-load gravity & Off-load, mechanical \\
\hline In-core instrumentation and control & Possible & None & Possible \\
\hline Shutdown and control system & Electrical/gravity & Electrical & Electrical/gravity \\
\hline
\end{tabular}


TABLE 2-III (continued)

Basic Data of Pebble Bed and Prismatic Fuel HTGR Designs*

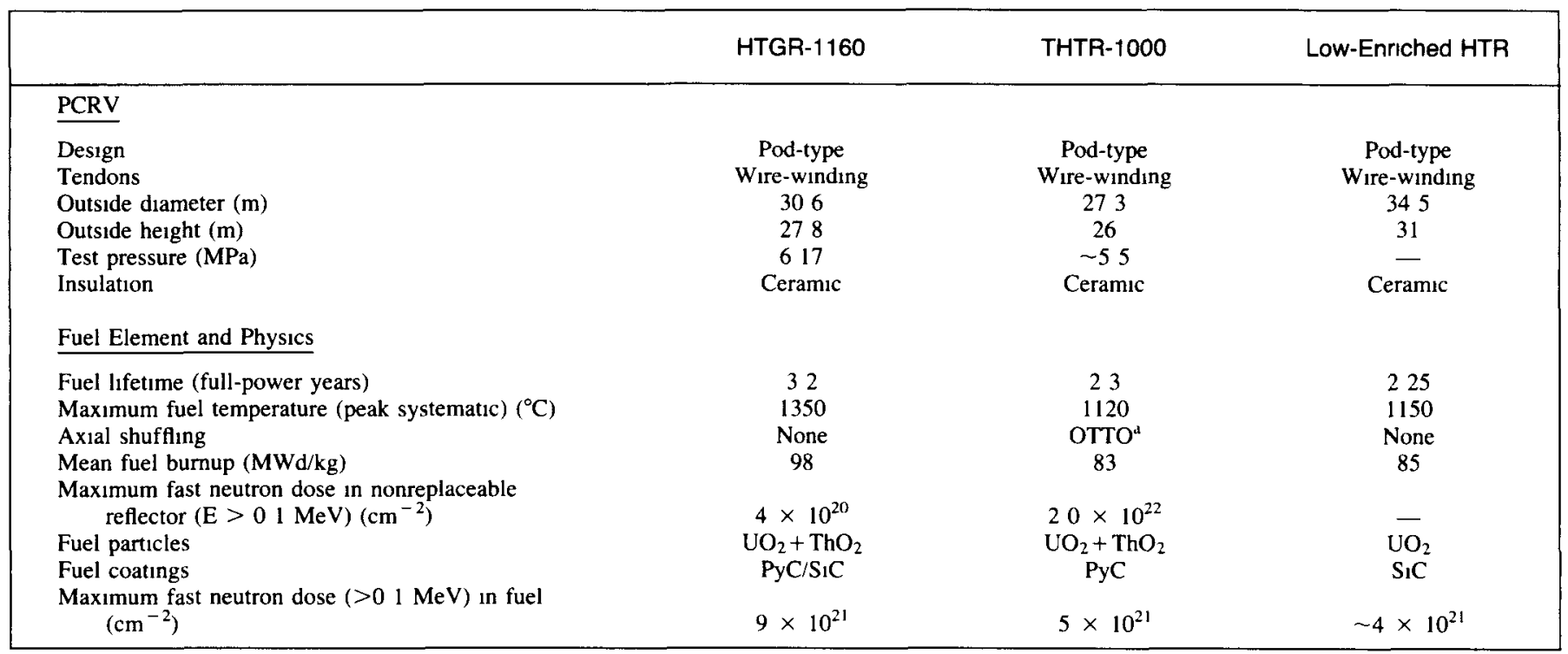

*From Ref 56

${ }^{a}$ Once Through Then Out 
States. Several international cooperative agreements have been arranged between the FRG, Switzerland, and the United States. ${ }^{53}$

Most of the present European activities are concentrated in the FRG where the prototype pebble bed reactor AVR has been in operation since 1966 and the demonstration plant THTR became critical in September 1983. The long-term goal of the West German HTGR development program is the introduction into the market of the THTR system for process heat and for electricity production. Design studies for an upgraded [500-MW(e)] THTR are being performed for the utilities; also, smaller modular reactors $[\sim 200 \mathrm{MW}(\mathrm{t})]$, with attractive safety characteristics, are being considered for use in multiple units. ${ }^{58}$ Advanced design projects in the FRG include both the direct-cycle helium gas turbine (HHT), and process heat generation for the production of synthetic natural gas (PNP) (see Chapters 8 and 9). Major test facilities include: a gas-fired helium turbine plant, EVO at Oberhausen, started in 1975, with an electric rating of $50 \mathrm{MW}(\mathrm{e})$ and 53 MW of district heating output; a helium circuit test facility, HHV, with 200 $\mathrm{kg} / \mathrm{s}$ mass flow of helium at $5 \mathrm{MPa}$ and $850^{\circ} \mathrm{C}$, tested in 1981; and EVA/ADAM, a demonstration facility of the "thermochemical pipeline" (see Chapter 9) with a helium-heated steam reformer installation (EVA) and a methanation plant (ADAM) in closed circuit. The EVA/ADAM 5.8-MW installation is designed for $950^{\circ} \mathrm{C}$ operation; a component test facility, $\mathrm{KVK}$, for operation with $4.6 \mathrm{MPa}, 950^{\circ} \mathrm{C}$ helium with rates of temperature changes up to $200^{\circ} \mathrm{C} / \mathrm{min}$.

The HTGR program in the Soviet Union is based on low-enrichment pebble bed fuel. ${ }^{59,60}$ Since 1978, a high-temperature loop has been in operation for tests of fuel and structural elements up to $900^{\circ} \mathrm{C}$ in 10-MPa helium. Two reactor designs have been presented: a 136-MW(t) [50-MW(e)] prototype, the VGR-50, for production of electricity and gamma irradiations and a 1060-MW(t) [300-MW(e)] demonstration plant, the VC- 400 , for production of electricity at $750^{\circ} \mathrm{C}$ and also eventually for $\mathrm{H}_{2}$ production at $950^{\circ} \mathrm{C}$, utilizing a multicavity PCRV.

The present Japanese HTGR program envisages operation of a very high temperature reactor, VHTR, $50-\mathrm{MW}(\mathrm{t})$ experiment with $1000^{\circ} \mathrm{C}$ helium for hightemperature process heat applications by the end of the 1980s. Possible applications are nuclear steelmaking, as well as coal gasification and liquefaction. Tests of fuels and materials in high-temperature helium are performed in an in-pile gas loop in the Japanese Materials Testing Reactor. The Helium Engineering Demonstration Loop (Hendel) is a large-scale (11-MW) model testing facility for hightemperature components, such as intermediate heat exchangers, up to $1000^{\circ} \mathrm{C}$.

\section{2-6B U.S. HTGR Programs}

Based on experience obtained from Peach Bottom, Fort St. Vrain, and international programs, the effort in the United States in 1983 was concentrated on the design of a 2240-MW(t) four-loop HTGR steam cycle/variable cogeneration (SC/C) system. It would have a maximum electrical output of $820 \mathrm{MW}$, in the all-electric mode, or a minimum of $231 \mathrm{MW}(\mathrm{e})$ while providing $631 \mathrm{~kg} / \mathrm{s}$ of high- 
quality steam $\left(59 \mathrm{MPa} / 538^{\circ} \mathrm{C}\right)$ These conditions, obtained with a maximum helium temperature of $690^{\circ} \mathrm{C}$, would lead to $385 \%$ net efficiency in the all-electric version ${ }^{61-63}$ A schematic flow diagram for the HTGR SC/C is shown in $\mathrm{Fig}$ 2-15, while the primary system is shown in Fig 2-16 Such use of a topping steam cycle for electricity production and of reduced pressure steam for process heat applications has the dual advantage of resource conservation and of savings in electricity and/or steam costs There is a large market potential for steam in the United States, the main problems appear to be institutional A number of modifications have been included in the design of the 2240-MW( $\mathrm{t}$ ) HTGR compared to the Fort St Vrain system. a multicavity PCRV rather than a single cavity, a non-reheat steam cycle instead of nuclear reheat, electric motor-driven circulators compared to steam drives, a core auxiliary heat removal system, a reactor secondary containment buılding, a reduced outlet helium temperature $\left(690\right.$ versus $\left.775^{\circ} \mathrm{C}\right)$, and a flexible fuel cycle, 1 e , 20 to $93 \%$ uranium enrichment Those changes are expected to improve plant performance and reliability, to simplify plant operation and maintenance, and to satisfy projected licensing and regulatory requirements Participants in the U S Department of Energy-funded program include utilities (Gas-Cooled Reactor Associates), a national laboratory (ORNL), and industry (GA Technologies and General Electric) with, as main subcontractors, Bechtel Power, Combustion Engineering, and United Engineers and Constructors

Research and development is also being performed on advanced HTGR systems, such as process heat or steam reforming applications (see Chapter 9), or direct-cycle design for cogeneration applications (see Chapter 8) Renewed interest has ansen in the United States as well as in other countries, like the FRG or Japan,

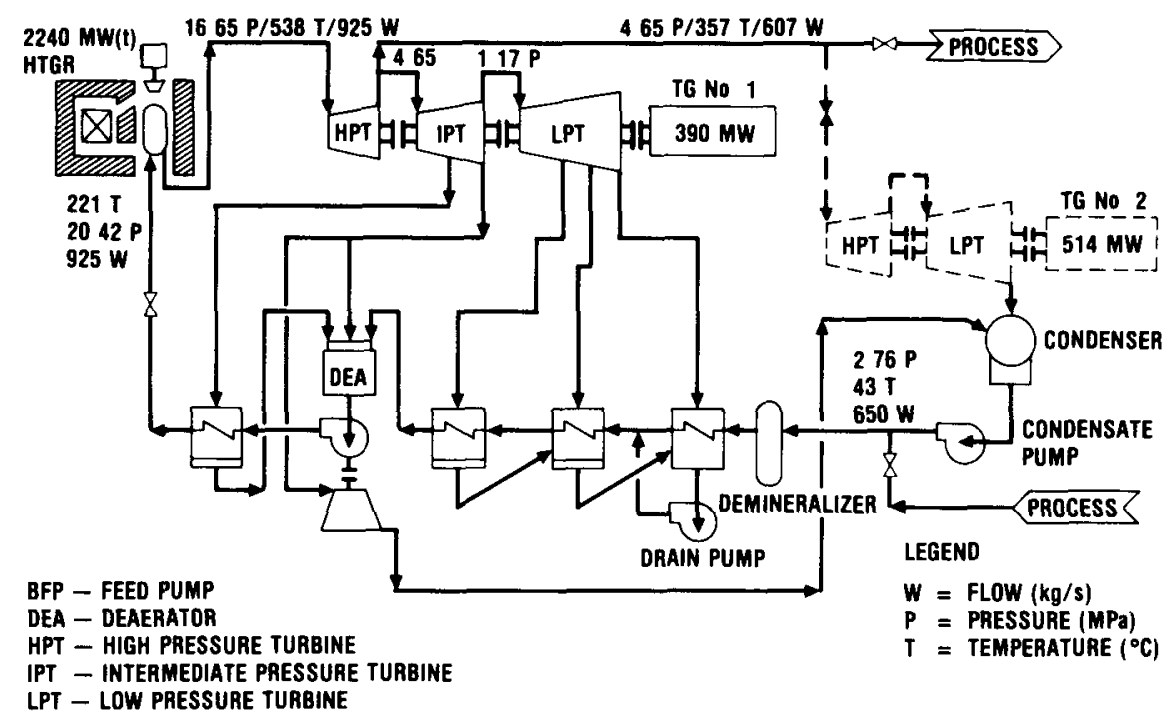

Fig 2-15 Flow diagram for HTGR-SC/C 


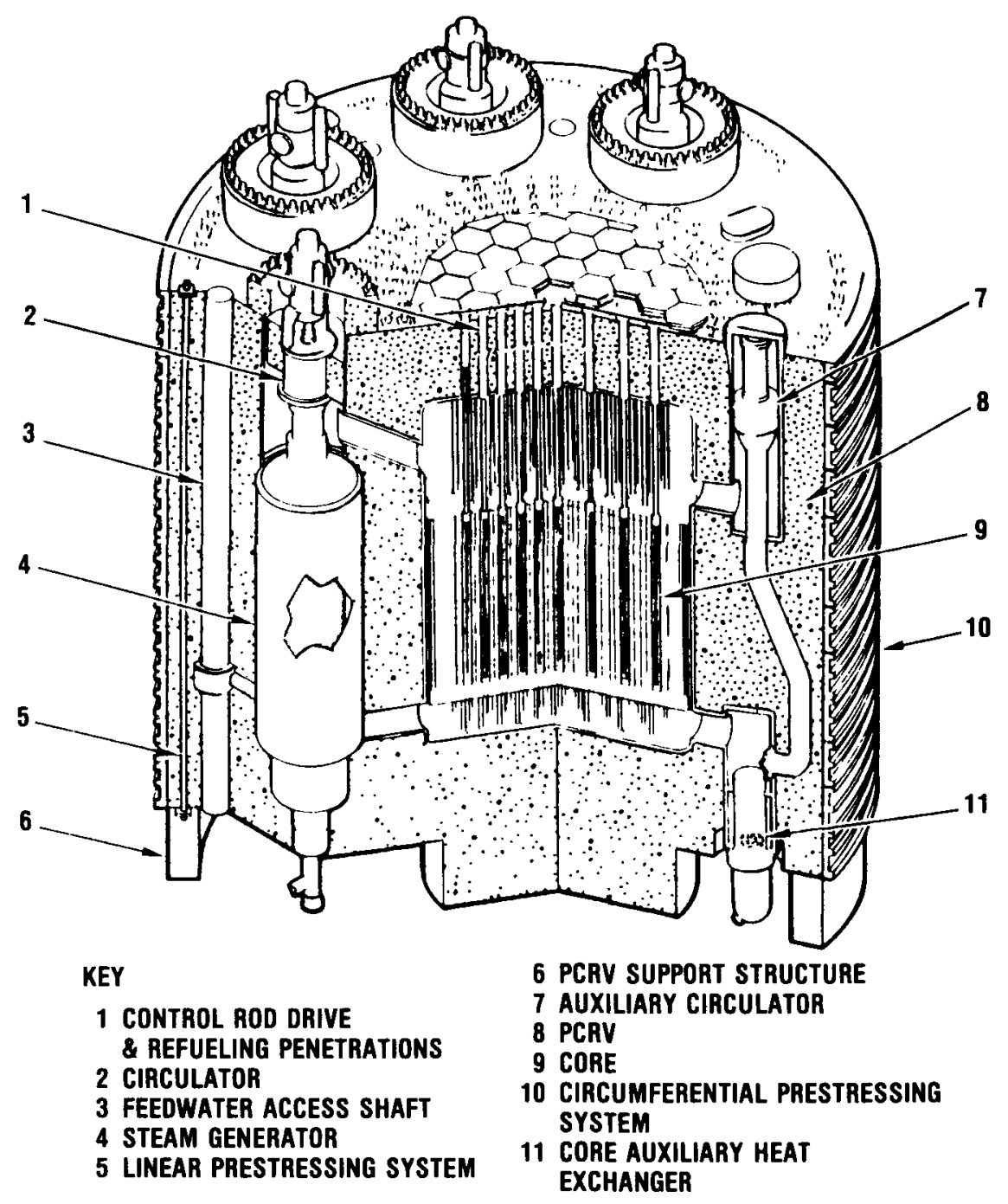

Fig. 2-16. HTGR-SC/C primary system.

in small or modular HTGR systems (see Table 2-IV). ${ }^{64-67}$ To obtain acceptable economics compared to fossil-fired plants, the goals of small HTGR power plant designs are: simplification of the overall system; reduction of construction time; standardized design; and maximum inherent safety with passive systems. Modular systems could be built on a phased basis, thus relieving the initial investment risk. Improved reliability with multiple units should facilitate applications to process heat. Modular designs with prismatic fuel elements are being considered in the United States with a thermal rating of $250 \mathrm{MW}(\mathrm{t})$ and a net plant efficiency of $\sim 37 \%$ with $4 \mathrm{MPa}$ helium at a top temperature of $690^{\circ} \mathrm{C}$. The small upflow, low- 
TABLE 2-IV

Salient Features of a Small HTGR Steam Cycle Plant*

\begin{tabular}{|c|c|}
\hline \multicolumn{2}{|l|}{ Ratıng and Performance } \\
\hline Thermal ratıng [MW(t)] & 250 \\
\hline Thermodynamic cycle & Rankıne steam cycle power conversıon system \\
\hline Outlet temperature $\left({ }^{\circ} \mathrm{C}\right)\left[{ }^{\circ} \mathrm{F}\right]$ & $688[1270]$ \\
\hline \multicolumn{2}{|l|}{ Maxımum system pressure (MPa) } \\
\hline [psia] & $414[600]$ \\
\hline Heat losses $[M W(t)]$ & 50 \\
\hline Net plant output [MW(e)] & 930 \\
\hline Overall plant efficiency (\%) & 372 \\
\hline \multicolumn{2}{|l|}{ Reactor Core } \\
\hline$\overline{\text { Type }}$ & HTGR \\
\hline Fuel element & Prismatic element \\
\hline Helıum flow configuration & Upflow \\
\hline Power density $\left(\mathrm{MW} / \mathrm{m}^{3}\right)$ & 41 \\
\hline Fuel cycle & Low-enriched U/Th \\
\hline Refueling interval and type & 4-yr biennial \\
\hline Control rods & In-core and reflector \\
\hline Decay heat removal & Passive, natural circulation system \\
\hline \multicolumn{2}{|l|}{ Plant Design Features } \\
\hline$\overline{\text { Reactor vessel type }}$ & PCRV or steel \\
\hline Nuclear heat source configuration & In-line single-vessel approach \\
\hline Steam generator type & Helical bundle with upflow boiling \\
\hline Circulator type & $\begin{array}{l}\text { Horizontal machine, electric motor-driven axıal } \\
\text { compressor }\end{array}$ \\
\hline Control rod drives & Bottom-mounted \\
\hline Refuelıng concept & Side arrangement \\
\hline Overall plant arrangement & $\begin{array}{l}\text { Single module unit, but adaptable to a plant with a } \\
\text { multiplicity of modules }\end{array}$ \\
\hline
\end{tabular}

*From Ref 64

power density (4 versus $6 \mathrm{MW} / \mathrm{m}^{3}$ in Fort St. Vrain) reactor core could be cooled by natural circulation of pressurized helium for decay heat removal. Designs have been proposed with both PCRV or steel pressure vessels. ${ }^{64,67}$ In both cases, the decay heat is transferred by passive means (even with the reactor depressurized) by conduction, radiation, and natural convection to the reactor cavity cooling system. Acceptable maximum temperatures are calculated under severe accident conditions, $\sim 1600^{\circ} \mathrm{C}$ in the core of a pebble bed reactor, for instance. ${ }^{66}$

Two typical preliminary designs are shown in Figs. 2-17 and 2-18 for a prismatic core within a PCRV or a steel vessel, respectively, ${ }^{64}$ and in Fig. 2-19 for a pebble bed with a steel vessel ${ }^{67}$ If economic calculations of competitiveness of a four-module [800-MW(t)] plant with a fossil fuel plant ${ }^{58}$ are confirmed, modular HTGR systems could have a useful role for electricity and for process heat generation. This role would be enhanced in U.S. locations that cannot accommodate a large-scale system because of modest demand, and also in many foreign countries. 


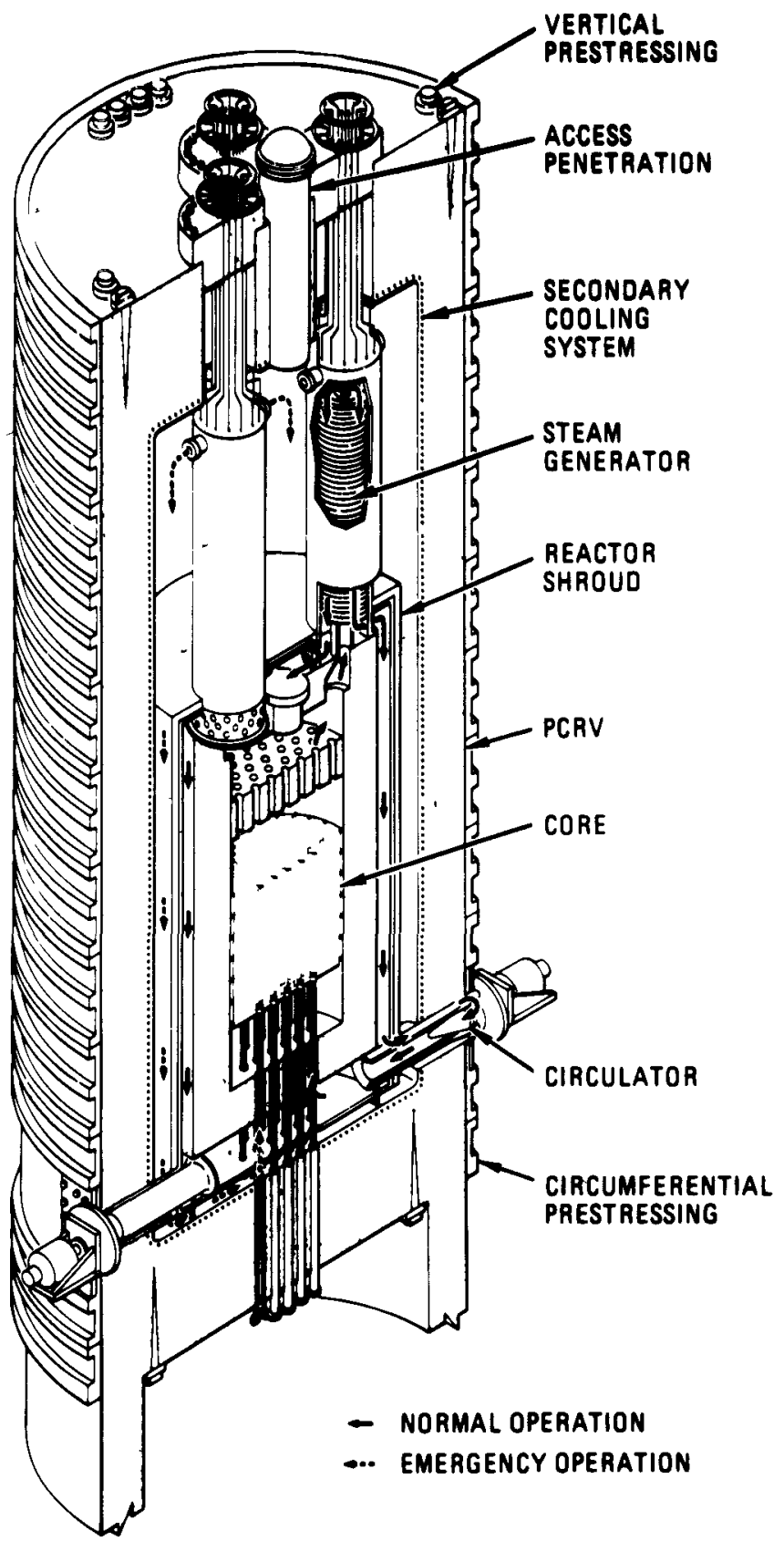

Fig. 2-17. PCRV design concept for a small HTGR steam cycle plant. 


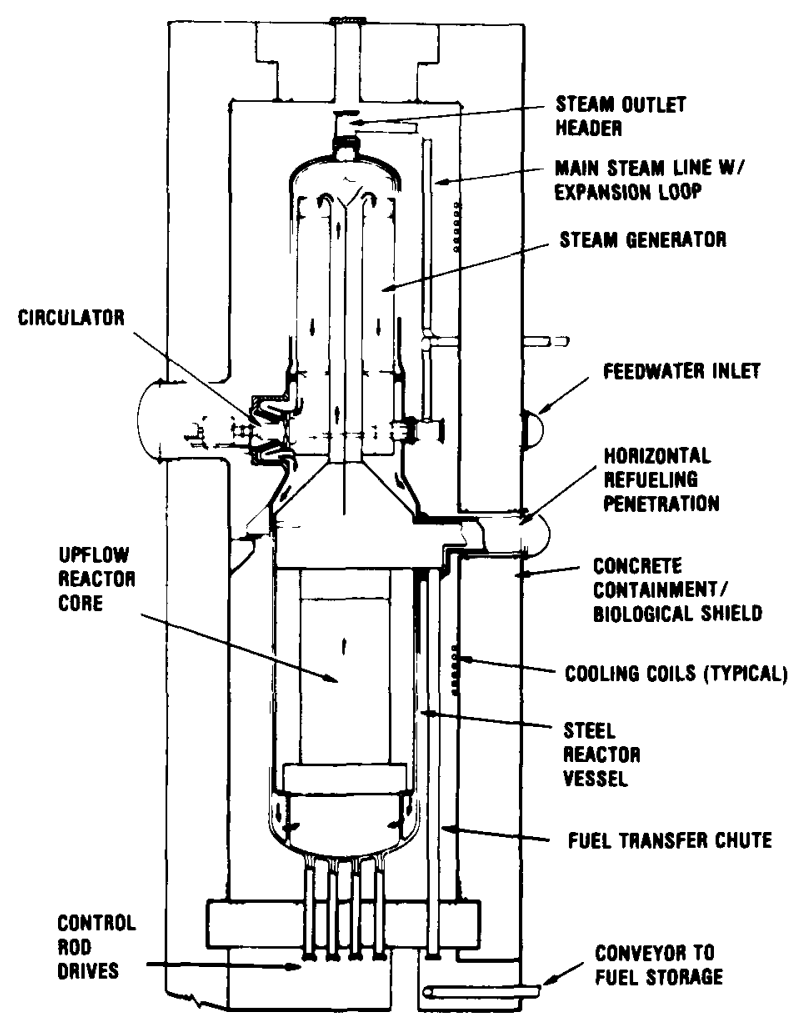

Fig. 2-18. Small HTGR steam cycle plant concept with a steel reactor vessel.

\section{2-7 Summary of Gas-Cooled Reactor Experience}

By the end of 1983, there were over 40 gas-cooled power reactors (Magnox and AGR) in operation, mostly in Europe, for a total installed capacity of 16 GW(e). The cumulative amount of electric power generated by these reactors up to mid1983 amounted to $\sim 100 \mathrm{GW}$-yr $\left(8.7 \times 10^{12} \mathrm{kWh}\right)$. Three more AGRs with a total capacity of $\sim 2 \mathrm{GW}(\mathrm{e})$ are scheduled to be in commercial operation by 1984 and two more AGR stations [2.6 GW(e)] are on order in the United Kingdom. Approximately two-thirds of the total amount of nuclear energy generated in Western Europe up to the end of 1976 was produced by gas-cooled reactors. More than 700 reactor-yr of experience with such reactors had been gained by the end of 1983. Furthermore, in the past 25 years, a number of experimental gas-cooled power reactors have been built and operated in France, the United Kingdom, and the United States, some of them helium cooled. Three HTGR prototypes have operated in West Germany, the United Kingdom, and the United States for a total of over 30 reactor-yr; a 330-MW(e) HTGR demonstration plant has been operating 


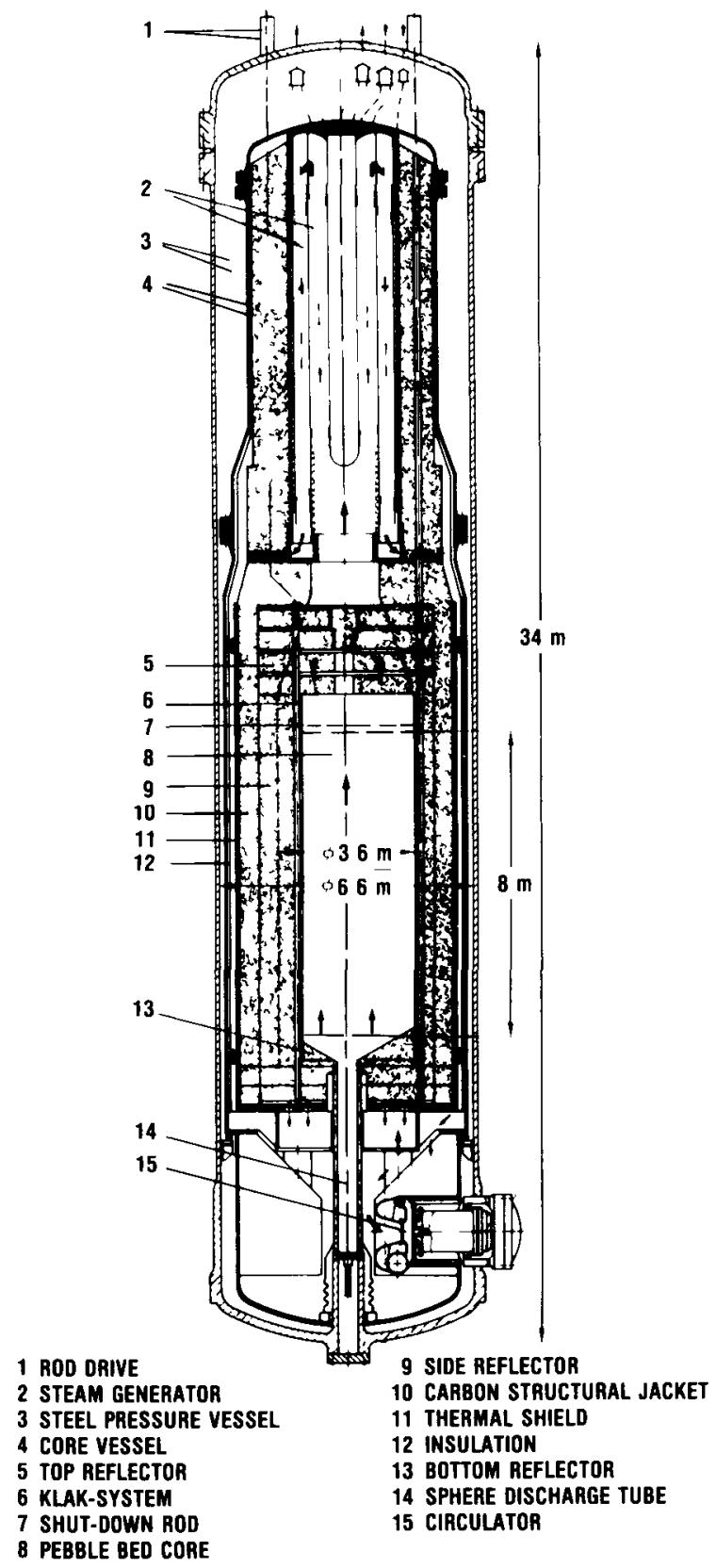

Fig. 2-19. The AVR 250 reactor concept 
in the United States since 1976 and another 300-MW(e) HTGR reached criticality in West Germany in late 1983.

Most present-day experience with gas cooling (to the end of 1983) has been with Magnox reactors, with only $\sim 50$ reactor-yr of AGR experience, but valuable experience has been gained with helium systems already ( $\sim 40$ reactor-yr). A great deal of construction and operating experience with $\mathrm{CO}_{2}$-cooled systems is transferable to helium-cooled reactors. Several of the problems experienced in Magnox and AGR reactors are caused by $\mathrm{CO}_{2}$ and are not expected to occur in HTGRs. Component failures caused by acoustic vibrations should not occur with helium, which has a lower density and higher sonic speed than $\mathrm{CO}_{2}$. Corrosion problems with $\mathrm{CO}_{2}$ have required derating of most Magnox stations, resulting in an $\sim 10 \%$ loss in capacity. Similarly, commercial AGR stations were first limited to $80 \%$ of their design capacity before enough experience became available on the behavior of steam generators. In spite of these problems, since the plants have been fully commissioned, their load factors have been satisfactory. The weighted-average load factor achieved by all nuclear power plants with gas-cooled reactors from their commercial startup until the end of 1981 was $66.7 \%$, compared to an average of $61.9 \%$ for all nuclear plants. ${ }^{68}$ Twenty PCRVs have been built, with a total of $\sim 200$ yr of satisfactory operating experience for the $\mathrm{CO}_{2}$ reactors; over 100 scale models have been tested for various PCRV configurations. ${ }^{69}$ Most of this experience is applicable to HTGRs, including all aspects of construction and operation of the PCRV and of its components such as the thermal barrier, liner, and cooling system. Although graphite operates at lower temperatures in $\mathrm{CO}_{2}$-cooled reactors than in helium systems, good experience is available on graphite fabrication, machining, and irradiation behavior. Similarly, $\sim 750$ reactor-yr of experience has been accumulated from $\sim 300$ steam generators for gas-cooled reactors, ${ }^{70}$ some of them having operated for over 25 yr. Steam generator availability for $\mathrm{CO}_{2}$ systems is found to be higher than for pressurized water reactors, with tube failure occurring mainly during the first two years because of manufacturing flaws. ${ }^{71}$ Experience with steam generator design and construction is available for HTGRs, which, furthermore, will nrt suffer from specific problems caused by $\mathrm{CO}_{2}$ such as shell-side corrosion and acoustic vibrations. Once-through steam generators with helical tubes have been chosen for HTGR power plants such as Fort St. Vrain, THTR, or other large systems. A similar design was chosen for the steam generators of the four AGR reactors with multicavity PCRVs (Hartlepool and Heysham stations), and has been successfully tested in the French $\mathrm{CO}_{2}$-cooled $\mathrm{D}_{2} \mathrm{O}$-moderated reactor EL4. Gas circulator experience is based on $\sim 200$ operating $\mathrm{CO}_{2}$ circulators of all types, centrifugal or axial, horizontal or vertical, with electric motor or steam drives, with unit power from 1 to $20 \mathrm{MW}$, pressure from 1 to $4 \mathrm{MPa}$, and pressure rise up to $0.3 \mathrm{MPa}$. After initial problems with $\mathrm{CO}_{2}$ circulators-such as vibrational oscillations of the circulator or flow and acoustic resonance-induced vibrations of guide vanes, diffusers, and casings-their availability has been quite good. ${ }^{72}$ 
Operatıng experience with the three prototype HTGRs-Dragon, Peach Bottom, and AVR - has shown high reactor avallability ( 85 to $90 \%$ between scheduled shutdowns), low primary system contamination (both coolant activity and plateout radiation level), low helium leakage ( $\sim 01 \%$ per day), and very good behavior of both graphite (up to $1200^{\circ} \mathrm{C}$ ) and coated particle fuels (up to $200 \mathrm{MWd} / \mathrm{kg}$ and $1400^{\circ} \mathrm{C}$ ) The steam generators in Peach Bottom and AVR have produced hightemperature high-pressure steam without any major tube fallure (except for AVR in 1978), helium circulators of vanous designs have been shown to be very reliable during 7 to $15 \mathrm{yr}$ of operation Other reactor components, such as control rods and drives and helium purification systems, have operated without problems The Fort St Vrain HTGR demonstration plant has been through an extensive testıng program and has been shown to be safe and able to operate at high thermal efficiencies $(\sim 39 \%)$ The radiological consequences of plant operation have been extremely low, with a total combined exposure of all personnel for 1980 and 1981 at 13 and 05 person-rems, respectively ${ }^{52}$ It has generated electricity at $70 \%$ full power since $1978\left(38 \times 10^{9} \mathrm{kWh}\right.$ by the end of 1983) and has been successfully tested at $100 \%$ power The main problems encountered were of a mechanical nature, and most of the basic components such as coated particle fuel, PCRVs, and steam generators have performed very well Coolant temperature fluctuations due to small motion in the fuel element columns were rectified in 1979

The large amount of information ${ }^{73}$ avalable on the design, construction, and operating experience with gas-cooled reactors since 1956 should benefit future developments of HTGR technology and applications

\section{REFERENCES}

1 P Fortescue et al , "Programme of Work Necessary for the Development of High Temperature Gas-Cooled Impregnated Reactors,' U K Atomic Energy Research Establıshment, Harwell (Jan 16, 1956)

2 C A Renne, "High-Temperature Gas-Cooled Reactors," Trans Am Nucl Soc 11, 425 (1968)

3 E N Shaw, Europe $s$ Nuclear Power Experiment History of the OECD Dragon Project, Pergamon Press, New York (1983)

4 L Sheperd et al , "The Possibilities of Achieving High Temperatures in a Gas-Cooled Reactor," Proc 2nd Int Conf Peaceful Uses of Atomic Energy, Geneva, Switzerland, September 1-13, 1958, Vol 9, p 289, United Nations, Geneva (1958)

5 "Dragon," Nucl Eng Int , 5, 299 (July 1960)

6 B G Chapman, "Dragon Reactor Operatıng Experience," paper $3 / 2$ presented at NUCLEX 1972 3rd Int Fair of Nuclear Industries and Technical Meetıngs, Basel, Switzerland, October 16-26, 1972, CONF-721062

7 B G Chapman, "Operation and Maintenance Experience with the Dragon Reactor Experıment," Proc ANS Topl Mtg Gas-Cooled Reactors HTGRs and GCFBRs, Gatlınburg, Tennessee, May 7-10, 1974, CONF-740501, p 13, Natıonal Technical Information Service (1974)

8 P D Capp and R A Simon, "Operational Expenence with the Dragon Reactor 
Experıment of Relevance to Commercial Reactors,' Proc IAEA Int Mtg Gas-Cooled Reactors, Julich, FRG, October 13-17, 1975, CONF-751007, SM-200/19, Vol I, p 95, International Atomic Energy Agency (1976)

9 G Insch and D Trauger, "Advanced Gas-Cooled Reactor Systems," Trans Am Nucl Soc, 15, 600 (1972)

10 L W Graham et al , "HTR Fuel Development and Testing in the Dragon Project," Proc ANS Topl Mtg Gas-Cooled Reactors HTGRs and GCFBRs, Gatlinburg, Tennessee, May 7-10, 1974, CONF-740501, p 218, National Technical Information Service (1974)

11 C A Rennie, "Achievements of the Dragon Project," Ann Nucl Energy, 5, 8-10, 305 (1978)

12 F P Ashworth et al , "A Summary and Evaluation of the Achevements of the Dragon Project and Its Contributions to the Development of the HTR," Dragon Project Report 1000, U K Atomic Energy Establıshment, Winfrith (Nov 1978)

13 P Fortescue, D Nicoll, C Rickard, and D Rose, "HTGR Underlyıng Principles and Design," Nucleonics, 18, I, 86 (Jan 1960)

14 J L Everett and E Kohler, "Peach Bottom Unit No 1 A High-Performance HeliumCooled Nuclear Power Plant," Ann Nucl Energy, 5, 321 (1978)

15 M Simnad, Fuel Element Experience in Nuclear Power Reactors, Gordon and Breach Science Publishers, Inc, New York (1971)

16 V S Boyer et al , "High-Temperature Reactors," Nuclear Energy Maturity, Proc Paris Conf, Progress in Nuclear Energy Sertes, Plenary Sessions, p 223, Pergamon Press (1976)

17 W Birely, "Operation Experience of the Peach Bottom Atomic Power Station," Proc ANS Topl Mtg Gas-Cooled Reactors HTGRs and GCFBRs, Gatlinburg, Tennessee, May 7-10, 1974, CONF-740501, p 1, National Technical Information Center (1974)

18 W J Scheffel et al , "Operating History Report for the Peach Bottom HTGR,' GAA13907, Vol I, UC-77, GA Technologies (Aug 1976)

19 W J Scheffel and C B Scott, "Irradiation Experience with HTGR Fuels in the Peach Bottom Reactor,' GA-A12897, GA Technologies (Nov 1974)

20 V S Boyer and G A Hunger, "High-Temperature Gas Reactor," Proc ANS/ASME Joint Int Conf Advanced Nuclear Energy Systems, Pittsburgh, Pennsylvanıa, March 14-17, 1976, CONF-760303, p 117, American Society of Mechanical Engineers (1976)

21 R Schulten and D Trauger, "Gas-Cooled Reactors," Trans Am Nucl Soc, 24, 15 (1976)

22 E L Ziermann, "Operating Experience with the AVR Experimental Power Station," Proc IAEA Int Mtg Gas-Cooled Reactors, Julich, FRG, October 13-17, 1975, CONF-751007, SM-200/39, Vol I, p 131, International Atomic Energy Agency (1976)

$23 \mathrm{H}$ Knuefer, "Prelımınary Operatıng Expenences with AVR at an Average Hot Gas Temperature of 950," Nucl Eng Des, 34, 73 (1975)

$24 \mathrm{G}$ Ivens and R Gillı, "The First Year of Operation at $950^{\circ} \mathrm{C}$ in the AVR Power Station," Proc IAEA Int Mtg Gas-Cooled Reactors, Julich, FRG, October 13-17, 1975, CONF-751007, SM-200/38, Vol I, p 117, International Atomic Energy Agency (1976)

25 G Ivens, "AVR-HTR Operation Experience," Proc ANS Topl Mtg Gas-Cooled 
Reactors HTGRs and GCFBRs Gatlinburg, Tennessee, May 7-10, 1974, CONF740501, p 34, National Technical Information Service (1974)

26 H W Mueller and J Schoening, "The Development and Characterıstics of the German High-Temperature Reactor,' J Br Nucl Energy Soc, 12, 95 (Jan 1973)

27 R Gillı et al , "The AVR Reactor-A Contribution to the Development of the HTR," Trans Am Nucl Soc, 20, 169 (1975)

28 R Schulten, "Pebble Bed HTRs," Ann Nucl Energy, 5, 357 (1978)

29 W Mattıck et al , "Technical Status and Potential of the High-Temperature Reactor Line in the Federal Republic of Germany," Proc 4th In Conf Peaceful Uses of Atomic Energy, Geneva, Switzerland, September 6-16, 1971, Vol 5, p 367, United Nations, New York (1972)

30 “Alumınum Wrap for Schmehausen's Coolıng Tower,' Nucl Eng Int , 21, 25I, 39 (Dec 1976)

31 L Wolf et al , "Fuel Elements of the High Temperature Pebble Bed Reactor," Nucl Eng Des, 34, 93 (1975)

32 H Lotz, H G Schwiers, and J Schoenıng, "PCPV of the THTR 300 MW(e) Prototype Nuclear Power Plant," Proc lst Int Conf Structural Mechanics in Reactor Technology, Berlın, FRG, September 20, 1971, Brown Boverı (Mar 1972) (nn German)

33 K Schaefer et al , "Experience of Design and Construction of PCPVs for AGRs and HTRs in Europe," Trans Am Nucl Soc, 20, 106 (1975)

34 J Schoenıng and G Wittchow, "Experience Gained from the Construction of the THTR 300 MW(e),"' Proc IAEA Int Mtg Gas-Cooled Reactors, Julich, FRG, October 13-17, 1975, CONF-751007, SM-200/70, Vol II, p 180, International Atomic Energy Agency (1976)

35 H Fricker, "Design and Manufacturing Experience for the German Thorium HighTemperature Reactor 300-MW(e) Steam Generator,' Nucl Technol , 28, 339 (Mar 1976)

36 R Walker and T Johnston, "Fort St Vrain Nuclear Power Statıon," Nucl Eng Int , 14, 163, 1069 (Dec 1969)

37 R Dahlberg et al , "Core Design Characterıstıcs for Fort St Vrain HTGR," Nucl Eng Int , 14, 163, 1073 (Dec 1969)

38 E Haake, "Fort St Vrain Instrumentation and Control," Nucl Eng Int 14, 163, 1078 (Dec 1969)

39 T Northup and C Peınado, "Prestressed Concrete Reactor Pressure Vessel for Fort St Vrain," Nucl Eng Int, 14, 163, 1082 (Dec 1969)

40 D Davis and J Krase, "Nuclear Components for Fort St Vrain," Nucl Eng Int , 14, 163, 1085 (Dec 1969)

41 A Habush and A Harris, "330-MW(e) Fort St Vrain High-Temperature Gas Cooled Reactor," Nucl Eng Des, 7, 312 (1968)

42 R N Quade et al , "The Design of the Fort St Vrain Steam Generators," Nucl Eng Des , 26, 118 (1974)

43 L Cavallaro and J Yampolsky, "Desıgn and Development of a Steam Turbıne Driven Circulator for High-Temperature Gas-Cooled Reactors,' Nucl Eng Des, 26, 135 (1974)

44 A Habush and R Walker, "Fort St Vrain Nuclear Generatıng Statıon Construction and Testıng Experience," Nucl Eng Des, 26, 16 (1974)

45 F E Swart et al, "Plant Completion, Fuel Loading, Testıng and Startup at the Fort 
St Vrain Nuclear Generatıng Station," Proc American Power Conf, Chıcago, Ill1nois, April 29-May 1, 1974, Vol 36, p 151, Illınors Institute of Technology (1975)

46 R Walker, "Fort St Vrain HTGR Operatıng Experıence," Proc ANS Topl Mtg Gas-Cooled Reactors HTGRs and GCFBRs, Gatlinburg, Tennessee, May 7-10, 1974, CONF-740501, p 472, Natıonal Technical Information Service (1974)

47 J Caldwell et al , "Operatıng Testıng Highlıghts of Fort St Vrain," Proc IAEA Int Mtg Gas-Cooled Reactors, Julıch, FRG, October 13-17, 1975, CONF-751007, SM200/58, Vol II, p 151, International Atomic Energy Agency (1976)

48 S Ross et al , "Initial Performance and Related Quality Assurance of the Fort St Vrain Fuel," Trans Am Nucl Soc, 20, 275 (1975)

49 T Gulden et al , "Present Thorium-Cycle Concepts and Performance Limitations," Proc ANS Topl Mtg Gas-Cooled Reactors HTGRs and GCFBRs, Gatlinburg, Tennessee, May 7-10, 1974, CONF-740501, p 176, National Technical Information Service (1974)

50 G Engle, M R Everett, and W P Eatherly, "Status of Graphite Technology and Requirements for HTGRs,' Proc ANS Topl Mtg Gas-Cooled Reactors HTGRs and GCFBRs, Gatlınburg, Tennessee, May 7-10, 1974, CONF-740501, p 288, National Technical Information Service (1974)

51 A J Goodjohn, J W Allen, and R F Turner, "HTGR Fuel and Fuel Cycle Experience in the United States," Trans Am Nucl Soc, 40, 256 (1982)

52 H L Brey and W A Graul, "Operation of the Fort St Vrain HTGR Plant," Proc American Power Conf , Chicago, Illınoıs, April 26-28, 1982, Vol 44, p 795, Illıno1s Institute of Technology (1983)

53 R A Moore et al, "HTGR Experience, Programs, and Future Applications,' Nucl Eng Des, 72, 153 (1982)

54 Nucl Eng Des, 53, (1979), 61 (1980), and 72 (1982)

55 "GASSAR General Atomic Company Standard Safety Analysıs Report," GA-A13200, GA Technologies (1975)

56 H Oehme, "Comparative HTGR Designs," Proc ANS Topl Mtg Gas-Cooled Reactors HTGRs and GCFBRs, Gatlunburg, Tennessee, May 7-10, 1974, CONF-740501, p 72, National Technical Information Service (1974)

57 “Fulton Station HTGR," Nucl Eng Int , 19, 219, 635 (Aug 1974)

58 H Reutler and G H Lohnert, "The Modular High-Temperature Reactor," Nucl Technol , 62, 22 (July 1983)

59 N N Panomaryev-Stepnoy et al , "The High-Temperature Gas-Cooled Reactor VGR50 for Power Technological Uses," Proc BNES Conf Gas-Cooled Reactors Today, Bristol, United Kingdom, September 20-24, 1982, Vol 4, p 111, Britısh Nuclear Energy Society (1982)

60 J N Koshkin et al , "The Automatıc Power Plant VG-400 Scheme and Construction Features,' Proc BNES Conf Gas-Cooled Reactors Today, Bristol, United Kingdom, September 20-24, 1982, Vol 4, p 115, Britısh Nuclear Energy Society (1982)

61 S R Penfield, "Prospects for the High-Temperature Gas-Cooled Reactor in the United States," Proc BNES Conf Gas-Cooled Reactors Today, Brıstol, United Kingdom, September 20-24, 1982, Vol 4, p 103, Britısh Nuclear Energy Society (1982)

62 A J Goodjohn and R N Quade, "'The Cogeneration Potential of the High-Temperature Gas-Cooled Reactor,' GA-A16706, GA Technologies (Mar 1982)

63 C R Boland et al , "The High-Temperature Gas-Cooled Reactor A Needed Option for Future Energy Requirements,' GA-A16804, GA Technologies (July 1982) 
64 C McDonald and D Sonn, "A New Small HTGR Power Plant Concept with Inherently Safe Features-An Engineerıng and Economic Challenge," Proc American Power Conf , Chicago, Illınots, April 18-20, 1983, Illınoıs Institute of Technology (to be published 1984)

65 G H Lohnert and H Reutler, "The Modular HTR-A New Design of High Temperature Pebble Bed Reactor,"' J Br Nucl Energy Soc , 22, 3, 197 (June 1983)

66 H Haque et al , "Thermal Response of a Modular HTR Under Accident Conditions," J Br Nucl Energy Soc , 22, 3, 201 (June 1983)

67 J Singh and H Barnert, "Modular Design Concept for the HTR on the Basis of AVR," J Br Nucl Energy Soc , 22, 3, 211 (June 1983)

68 Kurt P Kuffer, "Load Factors of Nuclear Plants," Nucl Europe, 4, 22 (1982)

69 A J Neylan, "Prestressed Concrete Reactor Vessels," Proc ANS/ASME Joint Int Conf Advanced Nuclear Energy Systems, Pittsburgh, Pennsylvania, March 14-17, 1976, CONF-760303, p 607, American Society of Mechanical Engineers (1976)

70 W G Schuetzenduebel et al , "HTGR Steam Generator Development," Proc ANS/ ASME Joint Int Conf Advanced Nuclear Energy Systems, Pittsburgh, Pennsylvania, March 14-17, 1976, CONF-760303, p 623, American Society of Mechanical Engineers (1976)

71 H J Bomelburg and W G Schuetzenduebel, "Operatıng Experience with Steam Generators in Gas-Cooled Reactors,"' Trans Am Nucl Soc, 19, 362 (1974)

72 E Oakes, "Gas-Cooled Reactor Circulators," Proc ANS/ASME Joint Int Conf Advanced Nuclear Energy Systems, Pittsburgh, Pennsylvania, March 14-17, 1976, CONF760303, p 619, American Society of Mechanical Engineers (1976)

73 Proc BNES Conf Gas-Cooled Reactors Today, Brıstol, United Kıngdom, September 20-24, 1982, British Nuclear Energy Society (1982) 


\section{REACTOR CORE HEAT TRANSFER: FUNDAMENTALS}

Heat transfer as an engineering discipline plays a major role in reactor design both in establishing performance capabilities and in determining the temperature distribution throughout the reactor. It is not the intention to present a complete exposition of gas-cooled reactor heat transfer in this book. Rather the approach is to survey the main topics of heat transfer with particular emphasis on the reactor core. This chapter develops the fundamentals of heat transfer analysis in gascooled reactors in a general way for a reactor operating at the steady-state design power point. Chapter 4 continues the general treatment but will deal with specialized topics relating to fuel element design and gas coolant properties. Discussion of heat transfer in specific gas-cooled reactors is taken up in Chapter 7 for the high-temperature gas-cooled reactor (HTGR), and in Chapter 10 for the gas-cooled fast breeder reactor (GCFR).

The aim of this chapter is to present the fundamentals of gas-cooled reactor heat transfer to the reader who is unfamiliar with the subject. The material is developed in a logical sequence that parallels the method used to determine the temperature distribution in a reactor core at its steady state. That is, after defining the core and fuel element geometry and describing the core power distribution, equations are derived to calculate, in sequence, the temperature distribution of the: coolant, fuel element surface, fuel cladding, fuel surface, and fuel maximum temperature point. Section 3-5 is concerned with core pressure drop and coolant flow distribution-subjects intimately associated with the determination of the reactor temperature distribution.

Since this chapter is not intended to be exhaustive, the reader may wish to consult standard textbooks ${ }^{1,2}$ to obtain further depth in heat transfer as well as other books on the subject of reactor heat transfer. ${ }^{3,4}$ The experienced heat transfer engineer may wish only to skim this chapter, then proceed to subsequent chapters.

\section{3-1 Reactor Core Power Distribution}

It is advantageous to make certain idealizations in defining the geometrical form of the core and in defining the power distribution in order to arrive expeditiously at the equations governing the temperature distribution. Assume the core is a homogeneous cylinder of radius $R$ and length $L$ and is penetrated with $N$ 


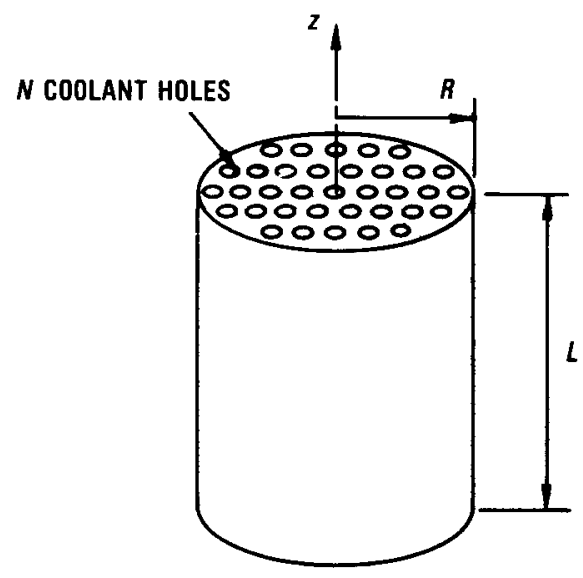

Fig. 3-1. Simplified core model.

identical and uniformly spaced coolant holes as depicted in Fig. 3-1. The detailed shape of the coolant hole need not be specified at this time.

The core will be assumed to produce total power $Q$ and will be cooled by helium entering the core with uniform temperature $T_{1}$ and with total mass flow rate $\dot{M}$ (see Nomenclature on p. 121).

A nuclear reactor may be thought of as a heat exchanger with prescribed heat generation. The distribution of heat production is determined by the nuclear design and is a function of the fuel, moderator and absorber loading, composition, and distribution. In the following sections, it is assumed that the heat generation distribution is specified by the nuclear performance at the steady-state design power point.

Since the reactor power is limited by the maximum structural or fuel temperature, attention is focused on the so-called "hot channel." The hot channel passes through that part of the core generating the maximum power. A unit cell is defined about the hot channel such that all the heat generated in the cell and no other cell is removed by the coolant flowing in the hot channel. That is, the unit cell has adiabatic boundaries. Let the power produced in the cell be expressed by

$$
q^{\prime}(z)=\frac{q}{L} \phi(z),
$$

where $q^{\prime}(z)$ is the power generation per unit length and $q$ is the total power produced in the unit cell. The term $\phi(z)$ represents the axial variation of power generation along the hot channel. The distribution $\phi(z)$ is normalized such that

$$
\frac{1}{L} \int_{0}^{L} \phi d z=1 \text {. }
$$


The power generation in the core may be expressed in several alternate forms:

$$
q^{\prime}(z)=\int_{P} q^{\prime \prime}(z, p) d p=\iint_{A_{F}} q^{\prime \prime \prime}(z, a) d a,
$$

where $q^{\prime \prime}$ is the heat flux and $q^{\prime \prime \prime}$ is the volumetric heat generation rate. In Eq. (3.3), $P$ and $A_{F}$ are the heated perimeter and fuel cross-sectional area, respectively.

It is convenient at this time to introduce a simple analytical form of the axial power variation called the "chopped-cosine distribution." The chopped-cosine axial flux shape is derived ${ }^{4}$ for a uniformly loaded cylindrical core without reflectors. The expression is

$$
\phi(z)=\varepsilon_{A} \cos \frac{\pi L}{L^{\prime}}\left(\frac{z}{L}-\frac{1}{2}\right) .
$$

The parameter $\varepsilon_{A}$ is the maximum-to-average value of the flux, sometimes referred to as the nuclear hot channel factor, ${ }^{5}$ and $L^{\prime}$ is the core extrapolated length. Introducing the dimensionless quantities gives

$$
\phi(\zeta)=\varepsilon_{A} \cos \lambda(2 \zeta-1),
$$

with

$$
\zeta=\frac{z}{L}
$$

and

$$
\lambda=\frac{\pi L}{2 L^{\prime}} .
$$

It can also easily be shown that $\varepsilon_{A}$ and $\lambda$ are related by

$$
\varepsilon_{A}=\frac{\lambda}{\sin \lambda} .
$$

By limiting attention in this chapter to the core hot channel, the radial distribution of power need not be specified. In actual practice, core physics analysis precedes a detailed thermal analysis and the complete power distribution is, therefore, known before core temperatures are calculated. For preliminary design analysis, it is usually sufficient to assume that the axial power distribution can be represented by the chopped-cosine distribution using a preliminary estimate of the maximum-to-average power generation parameter, $\varepsilon_{A}$. Likewise, an estimate of the core radial maximum-to-average power generation, $\varepsilon_{R}$, is also used in preliminary analysis to determine the total amount of power produced in the hot channel compared to the average power in the core.

The temperature of the fuel and fuel cladding can be influenced by localized perturbations in core heat generation. These affects are discussed in Sec. 3-4. 


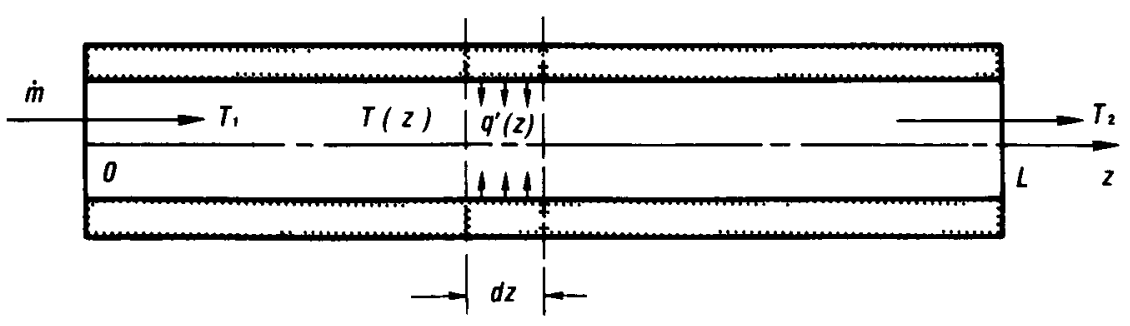

Fig 3-2 Hot channel model

\section{3-2 Coolant Temperature Distribution}

The coolant temperature through the core under steady-state conditions can be found by considering a heat balance on an element of length, $d z$, of the fuel element depicted in Fig 3-2 Let $\dot{m}$ be the coolant mass flow rate The heat balance on the element yields the differential equation

$$
m C_{p} \frac{d T}{d z}=q^{\prime}(z)
$$

Because the discussion is limited to helium-cooled reactors and helium can be considered a calonically perfect gas, the specific heat capacity at constant pressure, $C_{p}$, is independent of temperature and pressure Therefore, Eq (3 9) can be integrated to find the coolant temperature distribution

$$
T(z)=T_{1}+\frac{q}{m C_{p} L} \int_{0}^{z} \phi(z) d z
$$

As indicated in Fig 3-2, $T_{1}$ is the coolant inlet temperature Carrying out the integration over the length of the core results in

$$
T(1)-T_{1}=\frac{q}{m C_{p}}
$$

for the hot channel

A similar equation may be found by taking a heat balance over the whole core

$$
T_{2}-T_{1}=\frac{Q}{M C_{p}}
$$

with $T_{2}$ being the mixed mean outlet temperature, $M$ the total core flow, and $Q$ the total core power Note that the mixed mean outlet temperature for the core, $T_{2}$, is not necessarily equal to the coolant outlet temperature from the hot channel, $T(1)$, as given by Eq ( 311 )

Using the chopped-cosine axial power distribution defined in the previous 
section and described by Eq. (3.5), the axial distribution of the coolant temperature can be found. Substituting Eq. (3.5) into Eq. (3.10) and using the nondimensional length $\zeta=z / L$ gives

$$
T(\zeta)=T_{1}+\frac{q \varepsilon_{A}}{\dot{m} C_{p}} \int_{0}^{\zeta} \cos \lambda(2 \zeta-1) d \zeta,
$$

and carrying out the integration,

$$
T(\zeta)=T_{1}+\frac{q}{\dot{m} C_{p}}\left[\frac{\varepsilon_{A}}{2 \lambda} \sin \lambda(2 \zeta-1)+\frac{1}{2}\right] .
$$

The quantity in brackets is zero at $\zeta=0$ and unity at $\zeta=1$ corresponding to the core inlet and exit, respectively. The shape of the coolant distribution is the sine function as shown in Fig. 3-3. An important point to be noted is that the coolant temperature is always a monotonically increasing function regardless of the form of the power distribution.

It is desirable in some situations to design the core to achieve a uniform coolant outlet temperature. An alternate choice is to design to achieve the same maximum fuel surface or fuel centerline temperature in each unit cell of the core. There are competing factors that influence the designers choice. If the objective

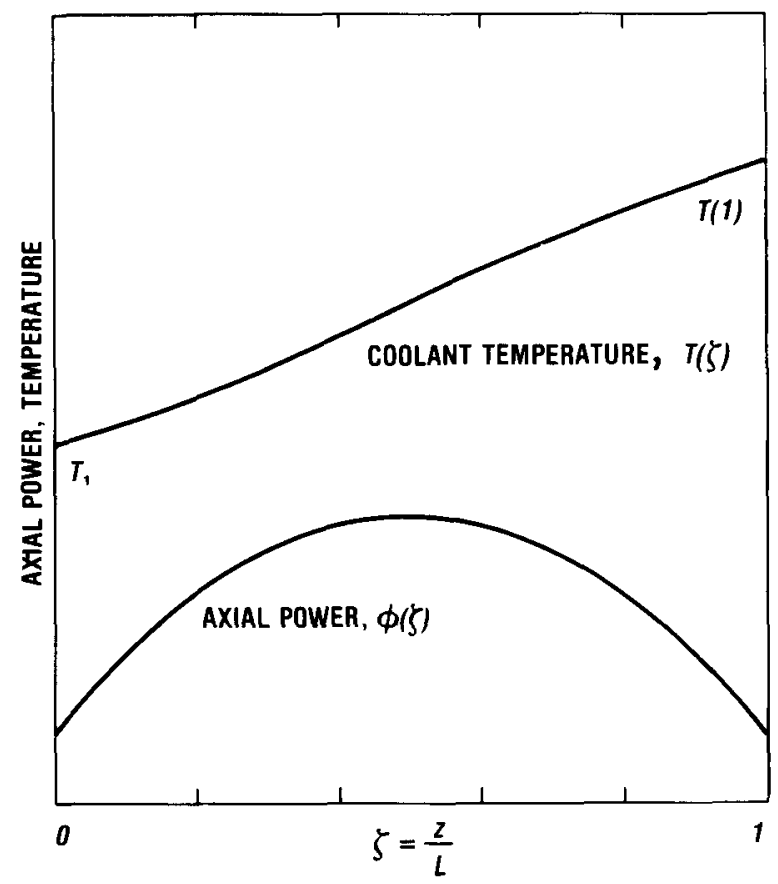

Fig. 3-3. Coolant temperature distribution. 
is to achieve the same maximum fuel surface or centerline temperature in all unit cells, then the core fuel will be worked as hard as possible within material limits. On the other hand, designing for a uniform coolant outlet temperature may be necessary to protect the structural integrity of other reactor components downstream of the core. Steam generators, thermal insulation, and core support structures fall into the category of components whose performance or structural integrity are adversely affected by large variations in the coolant temperature. Variations in the core coolant outlet temperature are sometimes called "hot streaks."

The practical approach to reactor design usually is to provide a uniform coolant outlet temperature from the core. When the axial power distribution is relatively flat, the fuel will all be operating at nearly the same temperature when the core is orificed for a uniform coolant outlet temperature. In addition, it is possible to measure the coolant outlet temperature from every fuel assembly and use these measurements to adjust and control reactor operation. It is extremely difficult to measure fuel or fuel surface temperatures in a nuclear reactor.

For uniform coolant outlet temperatures, $T(1)$ in Eq. (3.11) equals $T_{2}$ and Eqs. (3.11) and (3.12) may be combined to give

$$
\frac{q}{Q}=\frac{\dot{m}}{\dot{M}}
$$

This equation states that the mass flow to individual coolant channels must be in direct proportion to the power generated if the coolant outlet temperature is to be uniform. A uniform coolant outlet temperature can be obtained by a combination of radial power shaping and controlling coolant flow distribution.

If the reactor core is to be designed for equal coolant temperatures exiting each channel, Eq. (3.10) may be written

$$
T(z)=T_{1}+\frac{T_{2}-T_{1}}{L} \int_{0}^{z} \phi d z
$$

Thus far, only steady-state conditions have been considered and the law of conservation of energy simplified to a heat balance. The temperature effects arising from fluid shear stresses are completely negligible compared to the effects of nuclear heat addition and no work is being done by the fluid so the heat balance approach is perfectly justified. In gas-cooled reactors it is also usual in transient analyses to neglect the storage term in the energy equation for the fluid compared to the convection term. This is justifiable if the time scale of the transient problem under consideration is large compared to the characteristic or residence time of the fluid in the core. For a typical core length of $6 \mathrm{~m}$ and a fluid velocity of 60 $\mathrm{m} / \mathrm{s}$, the residence time is $0.1 \mathrm{~s}$, which is very small compared to the time scale of most HTGR reactor power transients. 


\section{3-3 Fuel Element Surface Temperature}

Having determined the coolant temperature distribution in the core, the next step in core thermal analysis is to determine the surface temperature distribution The first part of this section is devoted to calculating the surface temperature, assuming the coefficient of heat transfer is known The second part of the section deals with the task of evaluating the heat transfer coefficient

\section{3-3A Axial Surface Temperature Variation}

Newton's equation for convective heat transfer at a surface may be written

$$
q^{\prime \prime}=h\left(T_{s}-T\right),
$$

where $q^{\prime \prime}$ is the surface heat flux, $T_{s}$ is the surface temperature, $T$ is the flund temperature, and $h$ is the heat transfer coefficient The temperature difference $T_{s}-T$ is referred to as the film temperature rise This equation is actually the definition of $h$, the surface coefficient of heat transfer The surface coefficient of heat transfer is an empirical factor and one of the major research activities in the development of reactors has been the determination of this parameter for specific fuel elements

Equation ( 3 17) is written with the heat flux, $q^{\prime \prime}$, being positive when there is heat flow out of the fuel element and into the coolant since the surface temperature, $T_{s}$, is greater than the coolant temperature, $T$ The heat transfer coefficient is always a positive quantity

The heat flux can be elıminated from Newton's equation by using the differential equation obtained from a heat balance on the coolant [Eq (3 9)] Equation (3 3) relating the heat flux, $q^{\prime \prime}$, and the linear heat rating, $q^{\prime}$, is also used to give

$$
T_{s}=T+\frac{m C_{p}}{h P} \frac{d T}{d z}
$$

As before, it is convenient to introduce nondımensional terms The Stanton number, defined by

$$
\mathrm{St}=\frac{h}{\left(\frac{m}{A}\right) C_{p}},
$$

arises naturally in convective heat transfer The term $A$ is the coolant channel cross-sectional flow area Also, the length is made dimensionless by

$$
\zeta=\frac{z}{L}
$$

The dimensionless parameter, $\sigma$, is defined by 


$$
\sigma=\operatorname{St}\left(\frac{P L}{A}\right)
$$

It is to be noted that $\sigma$ is directly proportional to the heat transfer coefficient, $h$, the heated surface, $P L$, and inversely proportional to the coolant mass flow rate $\dot{m}$.

Substituting Eqs. (3.19) through (3.21) into (3.18) gives the simplified expression

$$
T_{s}=T+\frac{1}{\sigma} \frac{d T}{d \zeta}
$$

Now the coolant temperature can be eliminated from this equation by using the previously derived expressions for the coolant temperature, Eqs. (3.9) and (3.10). This results in:

$$
\frac{T_{s}(\zeta)-T_{1}}{T_{2}-T_{1}}=\frac{\phi(\zeta)}{\sigma}+\int_{0}^{\zeta} \phi(\zeta) d \zeta .
$$

By making the observation that $\phi(\zeta)$ is a function that may increase, then decrease, along the channel length while the integral of $\phi(\zeta)$ increases monotonically, it may be reasoned that the surface temperature, $T_{s}(\zeta)$, may have a maximum within the core rather than at the exit plane of the core where the coolant temperature is a maximum. The maximum value of $T_{s}$ may be found in the usual way by differentiating Eq. (3.23) with respect to $\zeta$ and setting $\frac{d T_{s}}{d \zeta}=0$. Doing this gives

$$
\frac{d \phi}{d \zeta}+\sigma \phi=0
$$

This expression may be solved for the coordinate point at which the maximum occurs. Let $\hat{\zeta}$ be the point where $T_{s}$ is a maximum. Substituting $\hat{\zeta}$ into Eq. (3.23) gives

$$
\frac{\hat{T}_{s}-T_{1}}{T_{2}-T_{1}}=\frac{\phi(\hat{\zeta})}{\sigma}+\int_{0}^{\hat{\zeta}} \phi(\zeta) d \zeta
$$

Equations (3.24) and (3.25) are general expressions for determining the maximum surface temperature once the axial power distribution is known. If the chopped-cosine power distribution defined by Eq. (3.5) is assumed, the following results can be derived:

$$
\hat{\zeta}=\frac{1}{2}\left[1+\frac{1}{\lambda} \tan ^{-1}\left(\frac{\sigma}{2 \lambda}\right)\right]
$$

and 


$$
\frac{\hat{T}_{s}-T_{1}}{T_{2}-T_{1}}=\frac{\varepsilon_{A}}{\sigma} \cos \lambda(2 \hat{\zeta}-1)+\frac{\varepsilon_{A}}{2 \lambda} \sin \lambda(2 \hat{\zeta}-1)+\frac{1}{2}
$$

The variation in the dimensionless maximum surface temperature, $\frac{\hat{T}_{s}-T_{1}}{T_{2}-T_{1}}$, and the point at which the maximum occurs, $\hat{\zeta}$, as a function of the heat transfer parameter, $\sigma$, is shown in Figs 3-4 and 3-5 The axial maximum-toaverage power factor, $\varepsilon_{A}$, is a parameter in these figures The value of $\varepsilon_{A}=1$ indicates a flat power distribution and is a limiting value that would be approached as the core becomes infinitely large $A$ value of $\varepsilon_{A}=12$ is a relatively low axial peaking factor and $\varepsilon=14$ is a moderate axial peaking factor

It is seen from Fig 3-4 that the maximum surface temperature always occurs at the core exit, $\hat{\zeta}=1$, for a flat power distribution The point at which the maximum surface temperature occurs moves increasingly toward the exit as the heat transfer parameter, $\sigma$, increases and as the axıal maxımum-to-average power factor, $\varepsilon_{A}$, decreases-implyıng a flatter axial power distribution For the case where $\varepsilon_{A}=12$, the maximum surface temperature occurs at the exit for $\sigma \geqslant 35$

The maximum surface temperature, $\hat{T}_{s}$, is seen from Fig 3-5 to decrease rapidly as the heat transfer parameter, $\sigma$, increases, regardless of the value of the axial power peakıng factor Recalling from Eq (3 21) that the heat transfer pa-

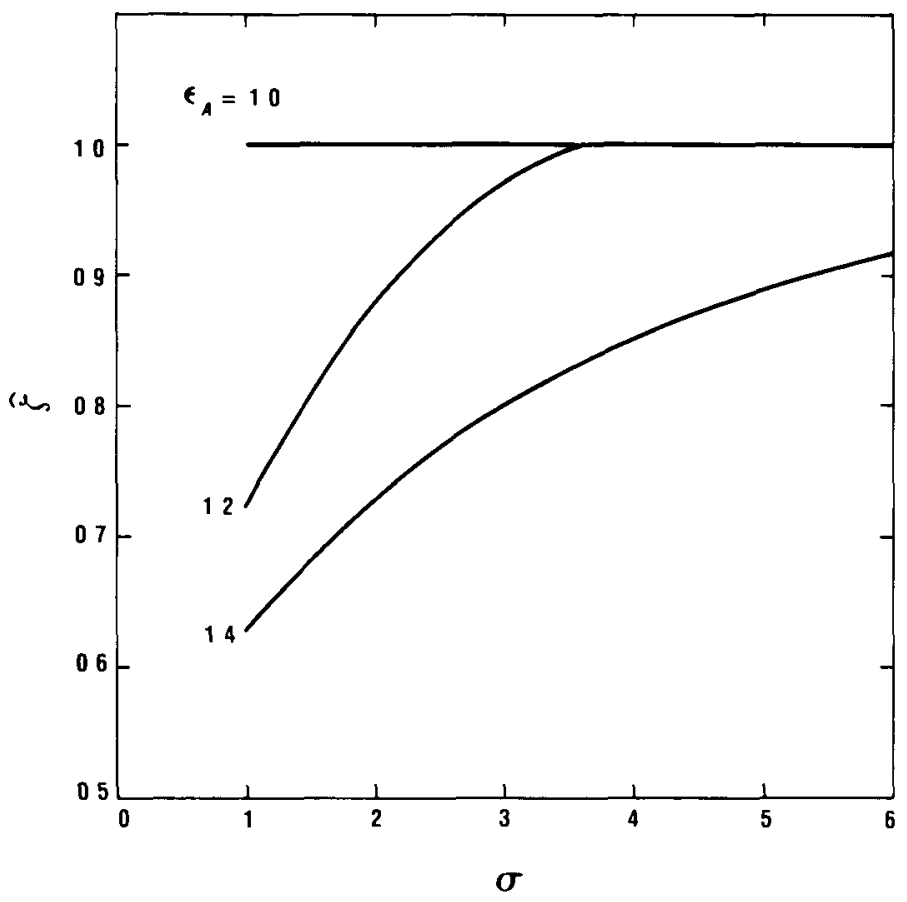

Fig 3-4 Point of maximum surface temperature 


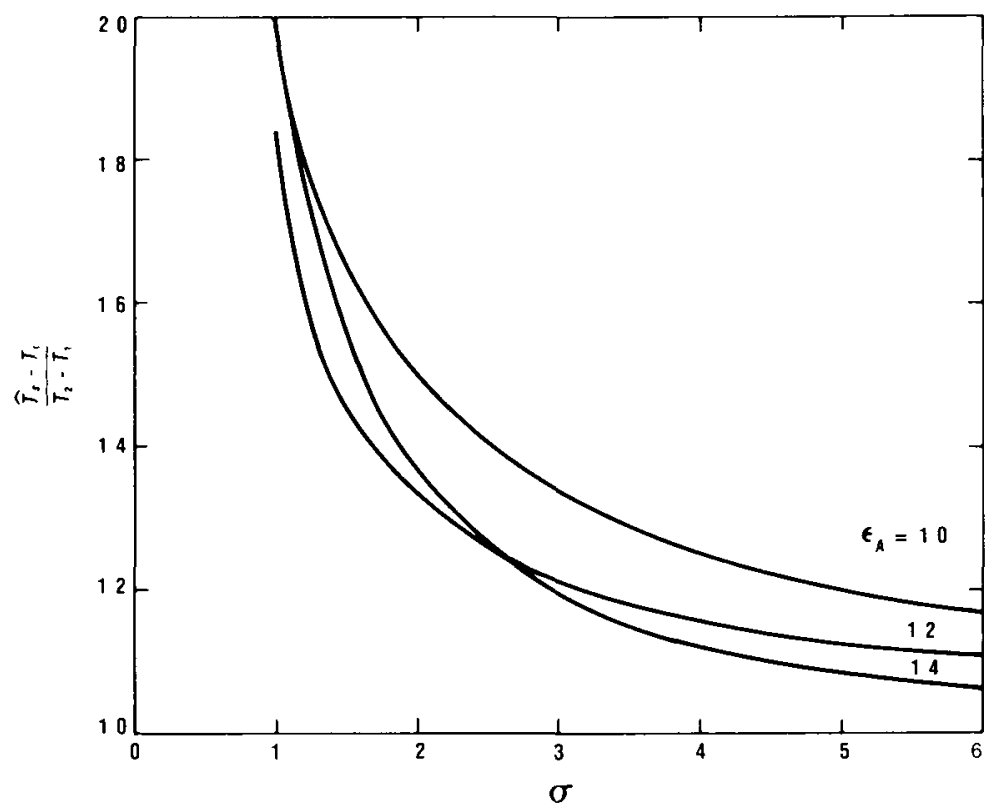

Fig. 3-5. Maximum surface temperature.

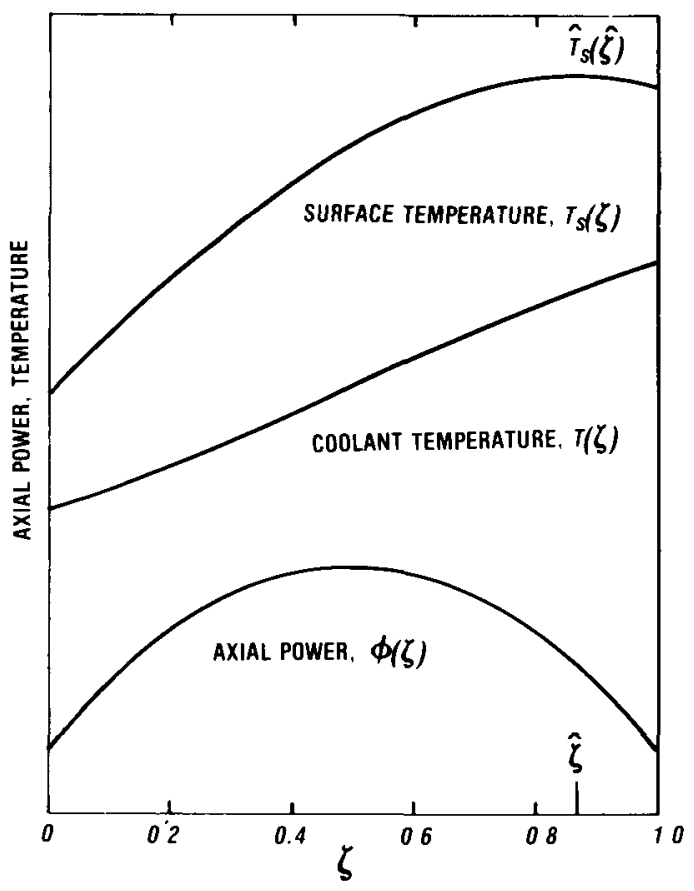

Fig. 3-6. Coolant and surface temperature distributions for a chopped-cosine power distribution. 
rameter is directly proportional to the heat transfer surface, the maximum surface temperature can be reduced by increasing the available heat transfer surface. Increasing the heat transfer surface may be accomplished by subdividing the fueled part of the core, which is the rationale for the many fuel element designs composed of bundles of fuel rods. Another means of increasing heat transfer surface is by the use of fins, and many intricate fuel element designs have been developed based on either transverse or longitudinal fin designs or both. Finally, another means of reducing the maximum surface temperature is by increasing the heat transfer coefficient. These topics are taken up in Sec. 4-3.

The surface temperature distribution for a chopped-cosine power distribution is depicted in Fig. 3-6. Also shown in this figure are the coolant temperature and power input distributions. It is typical that the difference between the maximum surface temperature and the surface temperature at the core exit, $\hat{T}_{s}-T_{s}(1)$, is small as shown in this figure. Therefore, the statement made in Sec. 3-2 that orificing the core for constant coolant outlet temperature results in nearly the same maximum fuel element surface temperature is seen to be justified.

The heat transfer characteristics-heat transfer surface and heat transfer coefficient-necessary to achieve a prescribed maximum surface temperature in the core can be found by eliminating $\hat{\zeta}$ between Eqs. (3.26) and (3.27). After some algebraic manipulation (e.g., see Ref. 3), it is found that

$$
\sigma=\left\{\left[\frac{1}{\varepsilon_{A}}\left(\frac{\hat{T}_{s}-T_{1}}{T_{2}-T_{1}}-\frac{1}{2}\right)\right]^{2}-\left(\frac{1}{2 \lambda}\right)^{2}\right\}^{-1 / 2} .
$$

Given the core thermodynamic requirements in terms of the core inlet and outlet temperatures, $T_{1}$ and $T_{2}$, respectively, and the core axial maximum-to-average power factor for a chopped-cosine flux distribution, it is possible to evaluate the heat transfer parameter, $\sigma$. The heat transfer parameter combines the heat transfer surface and heat transfer coefficient into a single parameter. To give some idea of the magnitude of the heat transfer parameter, it is found that $1<\sigma<2$ is representative of the GCFR and $5<\sigma<6$ is representative of the HTGR. In broad generalities, a low value of $\sigma$ applies to a small, high power density reactor and a large value of $\sigma$ is representative of a large, low power density reactor.

\section{3-3B Convective Heat Transfer Correlations}

In the preceding section, the discussion was concerned with the calculation of the surface temperature distribution and the determination of the heat transfer parameter, $\sigma$. This section discusses the estimation of the convective heat transfer coefficient, which is included in $\sigma$.

The heat transfer coefficient, $h$, for turbulent flow is correlated by the Stanton number, St, or equivalently, by the Nusselt number, Nu. The Stanton and Nusselt parameters are related by

$$
\mathrm{St}=\mathrm{Nu} \cdot \mathrm{Re} \cdot \mathrm{Pr},
$$


where Re is the Reynolds number and $\operatorname{Pr}$ is the Prandtl number Many correlations for the Stanton number or Nusselt number may be found in standard heat transfer sources $^{1-7}$ for various arrangements of the heat transfer surface For the present purposes, only flow through round holes and flow longitudinal to rod bundles is considered

It can be shown from dimensional analysis that the Stanton number for gascooled reactors has the functional form

$$
\mathrm{St}=\mathrm{St}\left(\mathrm{Re}, \operatorname{Pr}, \mathrm{M}, T_{s} / T, z / D, \theta, \text { geometry }\right)
$$

The Stanton number dependence on the Reynolds and Prandtl numbers is always present since the heat transfer coefficient is a strong function of the flow conditions and fluid properties The Stanton number dependence on Mach number, $\mathbf{M}$, is included for completeness in Eq (3 30) but is entirely negligible for gas-cooled power reactors, particularly helium-cooled reactors, and will be dropped from further discussion When there is a large difference between the fuel element surface temperature and the mean coolant temperature, the coolant properties vary through the boundary layer and this effect on the Stanton number is represented functionally by the term $T_{s} / T$ The term $z / d$ refers to the coolant channel lengthto-diameter at which the Stanton number is to be evaluated and accounts for the effect of the boundary layer development along the channel The term $\theta$ refers to the circumferential position of the heated surface and is intended to illustrate that the local Stanton number is a function of the flow field about the heated surface The last term in Eq (3 30) states the obvious fact that the Stanton number is a function of the geometry of the heated surface A discussion follows on the dependence of the Stanton number on all of these terms

In principle, the Stanton number can be calculated for laminar flow, although the mathematical problems may be formidable Also, when suttable approximations are made, the Stanton number in turbulent flow may be derived analytically However, the state-of-the-art of heat transfer for nuclear reactors is such that it is necessary to determine the Stanton number experimentally for the particular fuel element design under consideration Data must be obtained over the complete flow range of reactor operation, which means the laminar, transition, and turbulent flow regimes The Stanton number in the laminar and transition regimes is needed mainly for reactor thermal analysis during decay heat removal and for the analysis of various postulated accident cases It is normal and prudent practice for the design point of the reactor to correspond to completely turbulent flow tion, ${ }^{67}$

For fully developed flow in round holes, the well-known Dittus-Boelter equa-

$$
\mathrm{Nu}=0023 \operatorname{Re}^{08} \operatorname{Pr}^{04},
$$

correlates extensive experimental data in the range of the Reynolds number from $\sim 10000$ to 100000 and has been widely used for gases and liquids The Prandtl number for helium is about two-thirds, and for all gases ranges from $\sim 066$ to 
0.73. If an average value of the Prandtl number were chosen to represent gases, the Prandtl number could be eliminated from the Dittus-Boelter equation and the coefficient changed to 0.020 and the equation would correlate experimental data for all gases well within experimental error. In this monograph, the Prandtl number is retained in the correlations for completeness.

The Dittus-Boelter equation also correlates the heat transfer characteristics of a variety of flow channel shapes such as annuli, triangular, rectangular, and longitudinal flow over rod bundles as long as the characteristic length in the Reynolds number and Nusselt number is the equivalent hydraulic diameter defined by

$$
D_{e}=\frac{4 A}{P_{f}},
$$

where $P_{f}$ is the friction, or wetted, perimeter. How accurately Eq. (3.31) correlates heat transfer measurements in noncircular ducts depends on how far the duct shape deviates from a round hole. For example, the Dittus-Boelter equation based on the equivalent hydraulic diameter is good for an isosceles triangle but is no longer usable for a triangular duct with an acute angle of $\sim 15$ deg or smaller. Laminar and secondary flow in the corner of the acute angle invalidates the use of the hydraulic diameter. Similarly, if the channel shape had a high degree of asymmetry, it would be anticipated that the hydraulic diameter would not be applicable.

Another point to be considered when using the equivalent hydraulic diameter occurs when the friction perimeter, $P_{f}$, is not equal to the heated perimeter, $P$, as in reactor fuel elements using the common shrouded fuel bundle design concept. The shroud surrounds the bundle of fuel rods to define the coolant passage and provides structural support but is not heated. Therefore, from the flow and thermal point of view, the shroud is a parasitic surface. When the parasitic surface is small compared to the total surface, the equivalent hydraulic diameter is still usable for estimating the mean heat transfer coefficient.

It has been found experimentally that the Dittus-Boelter equation based on the equivalent hydraulic diameter predicts heat transfer for longitudinal flow along arrays of rods, except the numerical coefficient varies with the spacing between rods and the rod diameter. Since many nuclear reactors employ fuel elements composed of an array of rods, there has been a great deal of work done on determining the flow and heat transfer characteristics of these geometries. Regular arrays of rods in triangular and square patterns have been investigated and experimental data have been correlated by the pitch-to-diameter ratio, $p / d$. Figure 3-7 is a sketch of a triangular (sometimes called a "delta") array and a square array of fuel rods showing the pitch and diameter dimensions.

It has been found to be convenient when dealing with rod bundle arrays to express the Nusselt number as

$$
\mathrm{Nu}=G \cdot \mathrm{Nu}_{0},
$$

where $\mathrm{Nu}_{0}$ is the Nusselt number for a circular pipe, Eq. (3.31), and $G$ is a 

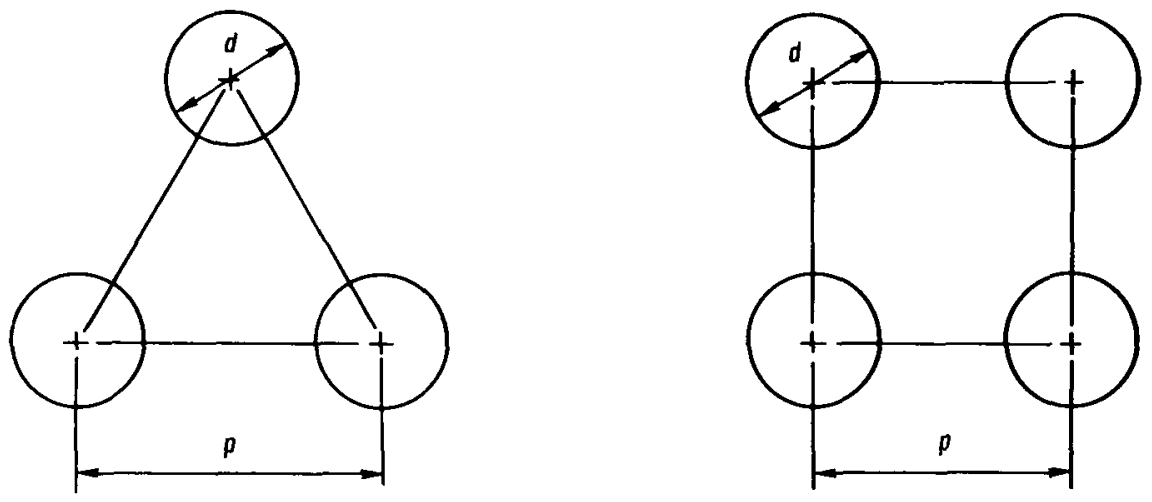

Fig. 3-7. Triangular and square fuel rod arrays.

correction factor to account for the spacing between rods; $G$ is sometimes called the "packing factor." The value of the packing factor for rod bundles can be found from the review of experimental data by Sutherland ${ }^{8}$ and by Kays in Ref. 7 . Markoczy ${ }^{9}$ has correlated the available data and gives for the packing factor:

$$
G=1+0.912 \operatorname{Re}^{-0.1} \operatorname{Pr}^{0.4}[1-2.0043 \exp (-B)],
$$

where

$$
B=\frac{D_{e}}{d}
$$

and for an infinite array of rods,

$$
\frac{D_{e}}{d}=\frac{2 \sqrt{3}}{\pi}\left(\frac{p}{d}\right)^{2}-1 \text { (triangular array) }
$$

and

$$
\frac{D_{e}}{d}=\frac{4}{\pi}\left(\frac{p}{d}\right)^{2}-1 \text { (square array) } .
$$

Figure 3-8 shows how the packing factor varies with the rod pitch-to-diameter ratio for the case of a triangular array with $\operatorname{Re}=10^{5}$ and $\operatorname{Pr}=0.67$. It can be observed that the correction to the Dittus-Boelter equation is $<1$ for tightly packed rods and $>1$ for an open array of rods. In this particular case, $G=1$ when $p / d$ $=1.24$. That is, the mean heat transfer coefficient in a triangular array of rods with $p / d=1.24$ is the same as in a circular pipe having the same equivalent hydraulic diameter.

The effect of local variations in the heat transfer coefficient represented by $\theta$ in Eq. (3.30) is now considered. Rods arranged in a triangular or square array would be expected to experience a variation in the heat transfer coefficient about 


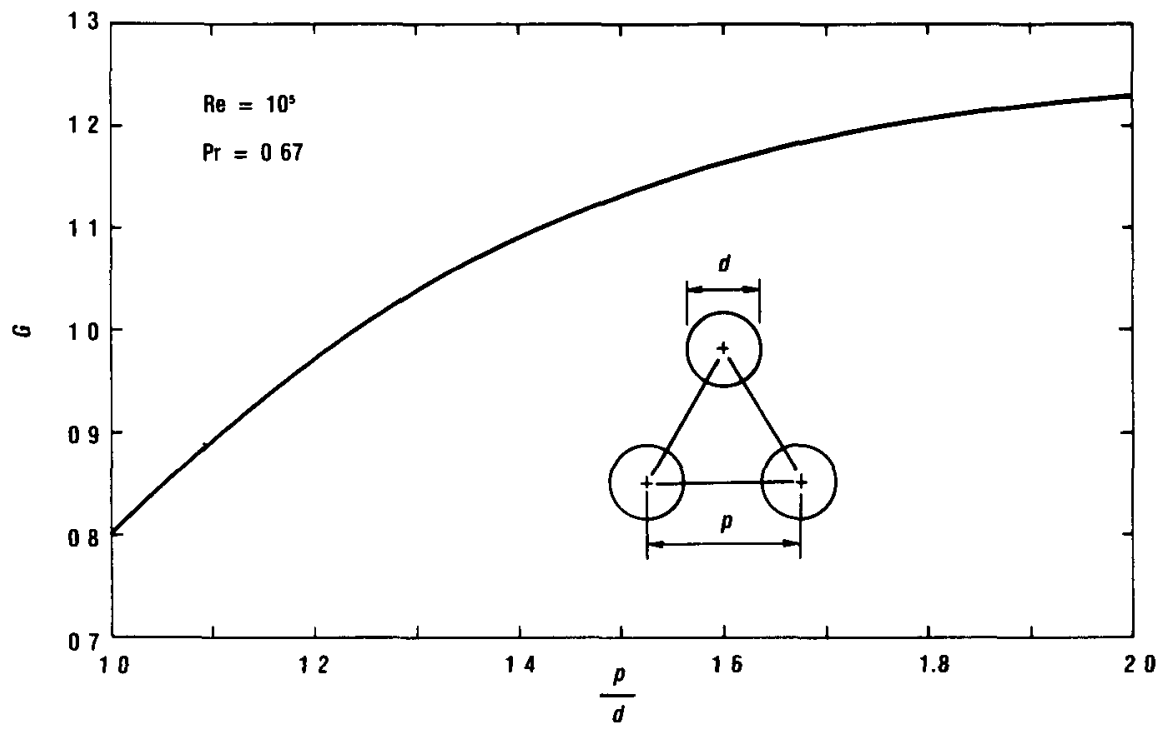

Fig 3-8. Packing factor variation with pitch-to-diameter ratıo.

the periphery of each rod due to the nonuniform flow field about each rod. It has been found experimentally ${ }^{8}$ for large arrays that there is no significant circumferential variation for $p / d \geqslant 1.1$. For this reason, if for no other, there is a great incentive to design fuel elements with a pitch-to-diameter ratio $>1$. 1 . With closely packed rods, the circumferential variation in heat transfer can be large, ${ }^{10}$ as illustrated in Fig. 3-9 for an infinite triangular array with $p / d=1.015$. If the minimum spacing is less than normal, large circumferential variations in the heat transfer coefficient may also occur about those rods located at the outer boundary of the cluster next to the shroud or wall of the element. This effect can be seen from experimental results from the seven-rod EGCR fuel element ${ }^{11}$ of Fig. 3-10, and the twelve-rod telephone-dial-type EBOR fuel element ${ }^{12}$ of Fig. 3-11, where the rod-to-wall spacing differs from the rod-to-rod spacing. The effect of a rod offset on the circumferential variation is also illustrated in Fig. 3-11.

The Dittus-Boelter heat transfer correlation of Eq. (3.31) is valid for fully developed flow. That is, the correlation is valid when the hydrodynamic and thermal boundary layers have reached a state where further changes in the heat transfer coefficient are no longer measurable. In round holes, fully developed conditions may be attained within 10 to 20 length-to-diameter's (L/D's) for certain inlet geometries (see Fig. 3-12). As an example, the HTGR coolant hole diameter is $\sim 16 \mathrm{~mm}$, so fully developed conditions would be reached in $\sim 300 \mathrm{~mm}$, which is $<5 \%$ of the total core length.

The effect of inlet length has been taken into account by various experimental investigations, the most usual being

$$
\frac{\mathrm{St}}{\mathrm{St} \infty}=1+\left(\frac{z}{D}\right)^{-07},
$$




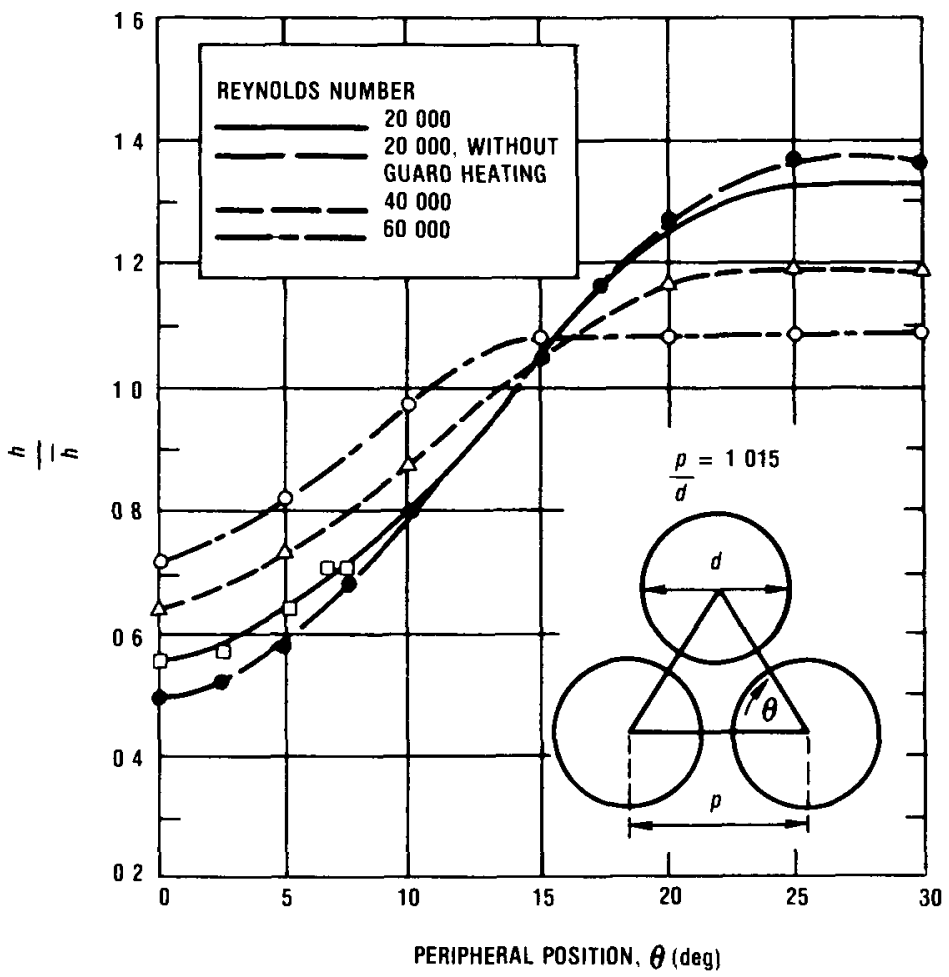

Fig. 3-9. Heat transfer coefficient peripheral variation for a triangular rod array (adapted from Ref. 10).
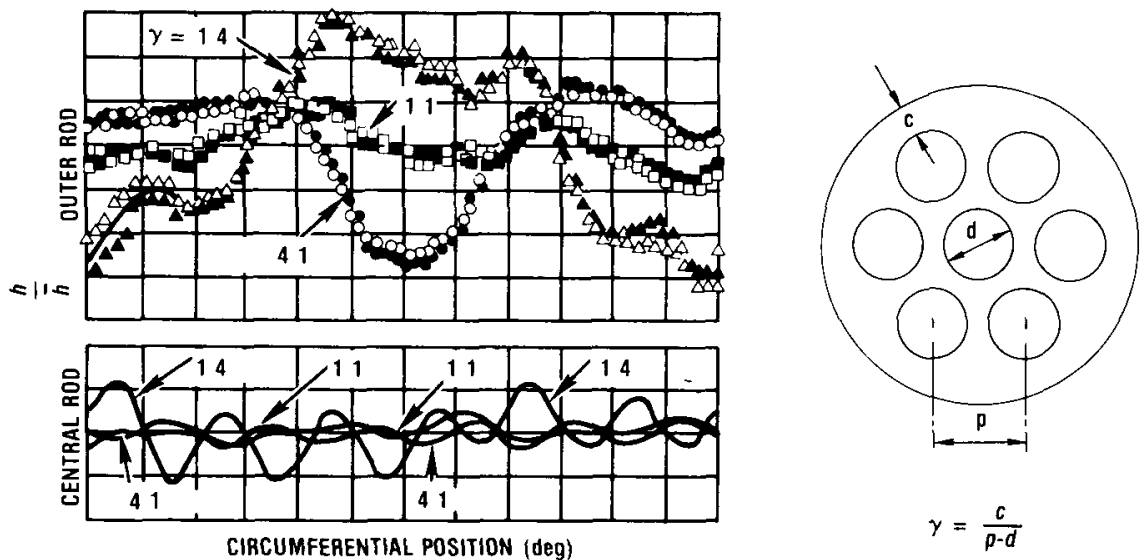

$$
\operatorname{Re}=60000 \quad \frac{p}{d}=171
$$

Fig. 3-10. Effect of shroud clearance on the local heat transfer coefficient (adapted from Ref. 11). 
which is valid for $z / D \leq 5$. With this relation, the Stanton number decreases more slowly to an equilibrium value than indicated in Fig. 3-12 for the straight inlets. For example, Eq. (3.37) predicts the Stanton number will be within $10 \%$ of the fully developed flow Stanton number when $z / D=27$ while Fig. 3-12 indicates this condition to occur in about half that length.

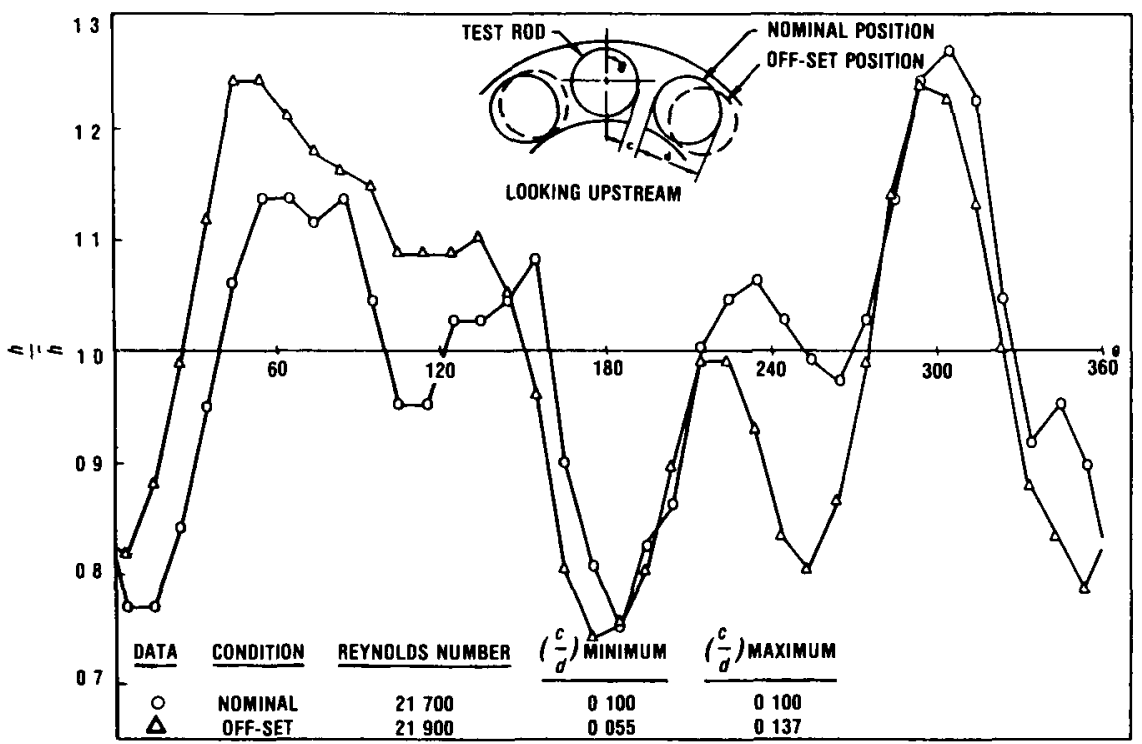

Fig. 3-11. Effect of fuel rod offset on the local heat transfer coefficient (Ref. 12).

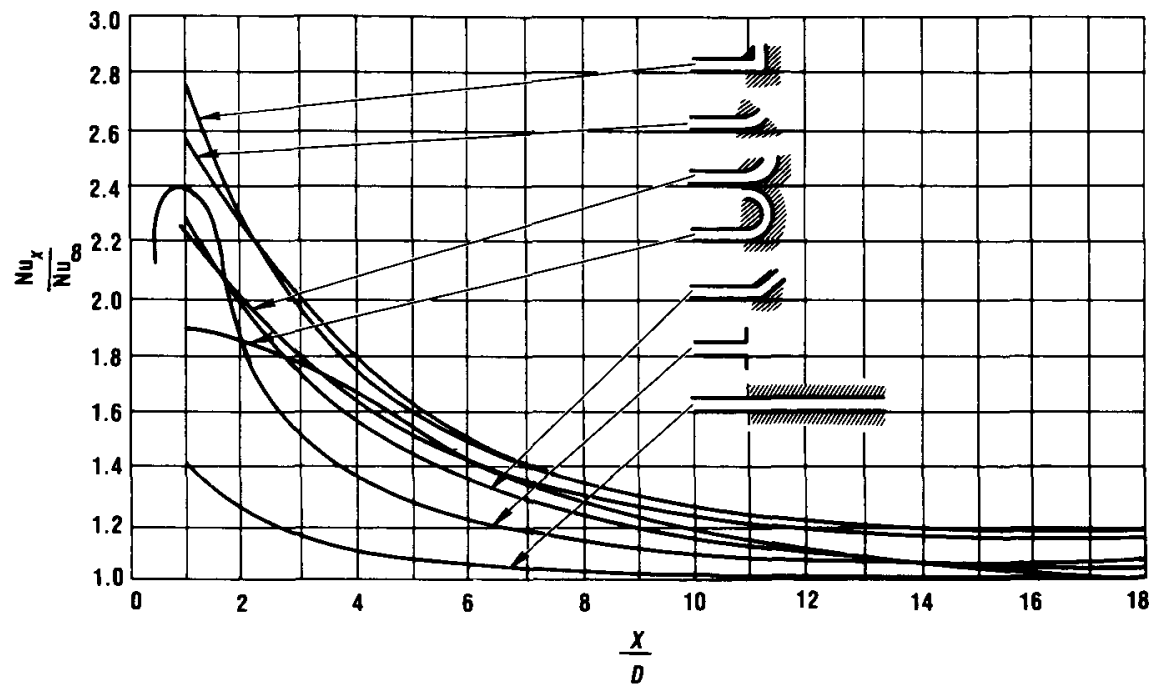

Fig. 3-12. Entrance length effects (adapted from Ref. 2). 
The thermal entry problem has been treated analytically mainly for two idealızed boundary conditions constant surface temperature and constant heat flux It has been shown, Fig 3-13, that the difference between the two heat transfer coefficients for fully developed conditions is of the order of $1 \%$ for gases, $\mathrm{Pr}=$ 07 , at $\operatorname{Re}=10^{5}$ In reality, thermal equilibrium is never attained in a nuclear reactor core since the heat flux varies continuously along the length, as, for example, with the chopped-cosine power distribution introduced in Sec 3-1 The effect of a varying heat flux on the local heat transfer coefficient has been considered by several authors, ${ }^{13}{ }^{14}$ but for gas-cooled reactors with $\operatorname{Pr}=07$, the effect of varying heat flux is not significant ${ }^{2}$

The thermal entry length is not always limited to the physical entrance of a coolant channel Spacers inserted to support fuel rods disrupt the coolant flow to such a degree that in effect a new thermal entry length is created The creation of a new thermal entry length is beneficial since the heat transfer coefficient is increased over the fully developed value-but, of course, the increase in heat transfer occurs at the expense of an increase in pressure loss or, equivalently, pumping power Spacers may also be designed with turbulence promoters that locally increase heat transfer In the EGCR reactor, the core was loaded with seven short fuel bundles to make up the full length and fully developed thermal conditions were never attained in these short segments because of end grids and a spacer in the middle of each segment

Before leaving the subject of entry conditions, it is important to note that the influence of a nonuniform velocity distribution because of a poorly designed inlet can persist for a considerable length ${ }^{15}$ Careful attention to the inlet design is absolutely necessary

A correction to the Dittus-Boelter correlation is required when the fluid properties change through the thermal boundary layer This condition may arise

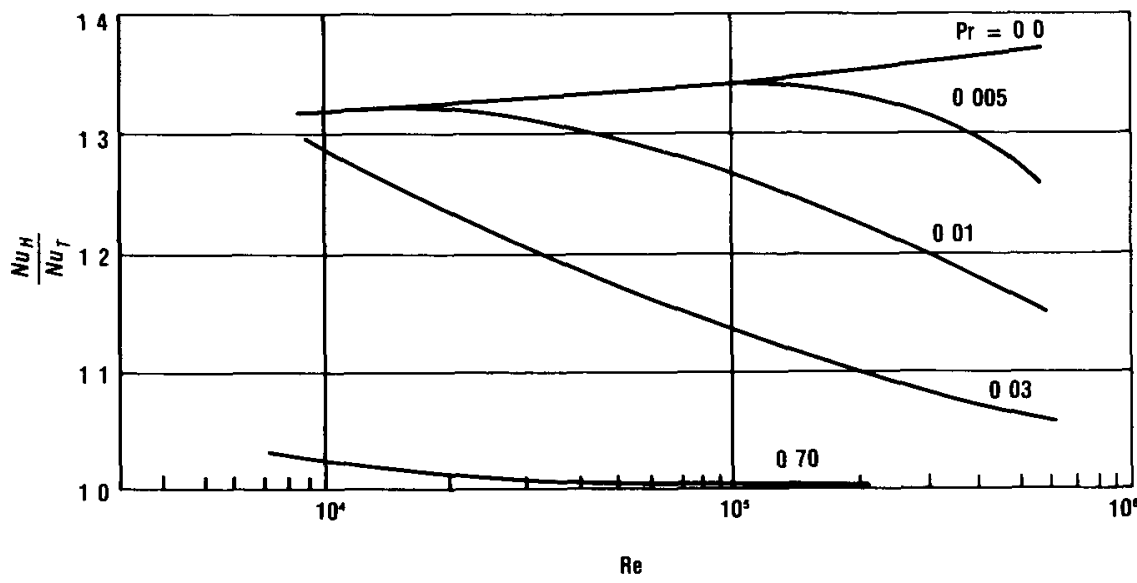

Fig 3-13 Constant heat flux versus constant surface temperature heat transfer coefficient (adapted from Ref 2) 
in high power density gas-cooled reactors since a large temperature gradient will occur across the thermal boundary layer. Many correction factors have been proposed through the years such as evaluating the fluid properties at the film temperature, ${ }^{6} T_{f}$, with

$$
T_{f}=\frac{1}{2}\left(T+T_{s}\right),
$$

or the reference temperature ${ }^{16}$

$$
T_{04}=T+0.4\left(T_{s}-T\right),
$$

or the surface temperature. ${ }^{17}$

Other corrections to the Dittus-Boelter correlation take the form of evaluating fluid properties at the bulk coolant temperature and multiplying by a temperature ratio, $\left(T_{s} / T\right)^{-n}$, where the exponent $n$ ranges from 0.1 to 0.8 . Whenever the temperature ratio occurs in a heat transfer correlation, the temperatures must be interpreted as being on the absolute scale, e.g., degrees Kelvin. An extensive review $^{18}$ of convective heat transfer correlations showed fair agreement among the correlations tested. The correlation of McEligot et al. ${ }^{19}$ for large temperature gradients is representative of the corrections useful for helium-cooled reactors:

$$
\mathrm{Nu}=0.021 \operatorname{Re}^{08} \operatorname{Pr}^{04}\left(\frac{T_{s}}{T}\right)^{-05}\left[1+\left(\frac{z}{D}\right)^{-07}\right],
$$

which is valid for helium and $z / D>5$; for $15000<\mathrm{Re}<600000$; and for $1<\left(T_{s} / T\right)<2.4$.

It is seen from Eq. (3.40) that the effect of a large temperature gradient across the thermal boundary layer is to decrease the heat transfer coefficient. For example, at a point in the reactor where the coolant temperature is, say $720^{\circ} \mathrm{C}$ and the surface temperature $820^{\circ} \mathrm{C}$, the local heat transfer coefficient is reduced $\sim 5 \%$ by the temperature ratio term.

Normally, when applying a convective heat transfer correlation of the form of Eq. (3.40) it is necessary to perform an iterative calculation since the unknown surface temperature $T_{s}$ appears in the correlation itself. However, Eq. (3.40) with the exponent of the temperature correction of -0.5 allows a direct solution. Combining Eqs. (3.17) and (3.19) gives

$$
\frac{T_{s}-T}{q^{\prime \prime}}=\frac{1}{\left(\frac{\dot{m}}{A}\right) C_{p} \mathrm{St}} .
$$

Writing Eq. (3.40) in the form of a Stanton number gives

$$
\mathrm{St}=0.021 \mathrm{Re}^{-02} \operatorname{Pr}^{-06}\left(\frac{T_{s}}{T}\right)^{-1 / 2}\left[1+\left(\frac{z}{D}\right)^{-07}\right] .
$$


Combining these two equations yields a quadratic equation in $\left(T_{s} / T\right)^{1 / 2}$ :

$$
\frac{T_{s}}{T}-2 \psi\left(\frac{T_{s}}{T}\right)^{1 / 2}-1=0
$$

where the parameter $\psi$ is

$$
\psi=\frac{q^{\prime \prime}}{2\left(\frac{\dot{m}}{A}\right) C_{p} T\left(0.021 \mathrm{Re}^{-02} \operatorname{Pr}^{-06}\right)\left[1+\left(\frac{z}{D}\right)^{-07}\right]} .
$$

The solution to the quadratic equation is

$$
\frac{T_{s}}{T}=\left[\psi+\left(\psi^{2}+1\right)^{1 / 2}\right]^{2},
$$

where the only physically real solution requires that the positive root of the quadratic equation solution be used. No iteration is needed to solve for $T_{s}$ since all factors on the right side of Eq. (3.45) can be computed for the known coolant temperature.

For completeness, the effect of surface roughness on the heat transfer coefficient should be considered. However, a discussion of the influence of roughness is postponed until Sec. 4-3.

Thus far, only the convective mode of heat transfer has been considered. Radiation and conduction also occur but these modes of heat transfer are usually negligible during power operation but may become predominant during postulated accident situations. Accounting for radiation and conduction along with convection necessitates numerical calculations since the heat transfer problem becomes twoor possibly three-dimensional and strongly nonlinear due to radiation being proportional to $T_{S}^{4}$. Neglecting these two modes of heat transfer results in a conservative design since including radiation and conduction will cause surface temperatures to be reduced from the one-dimensional approach that considers only convection heat transfer.

The discussion in this section is intended to summarize the factors influencing the determination of the heat transfer coefficient. The correlations given by Eq. (3.31) or Eq. (3.40) along with the correction factors given by Eqs. (3.32) and (3.34) may be used with confidence for rod bundle fuel element designs or fuel element designs employing simple channel shapes. The correlations may also be used for preliminary design estimates on new fuel element designs but experimental verification would be necessary before final design analysis.

\section{3-4 Fuel Temperature}

The most efficient thermal design of a reactor core calls for the fuel and structural materials to operate at their respective maximum temperatures. The maximum fuel temperature may be limited by the melting temperature, by a phase 
change that is accompanied by sizable volumetric change, or by fuel redistribution caused by diffusion or migration. Detailed calculations are needed to verify that the fuel temperature is safely below the maximum limit. In addition, a knowledge of the fuel temperature distribution is necessary for neutronic calculations and as a starting point for safety analyses when forced coolant flow is assumed lost.

Whereas the coolant temperature distribution throughout the core is independent of the specific fuel element design, and the surface temperature of the fuel element is not strongly dependent on the specific design, the fuel temperature distribution is completely dependent on the fuel geometry. The evolution of gascooled reactors has resulted in two main types of designs: the rod bundle where the fuel is in the form of cylindrical pellets contained in a metallic cladding and the all-ceramic packed-bed fuel element. These two general fuel element designs are discussed separately.

\section{3-4A Fuel Rod Temperature Distribution}

Figure 3-14 depicts the temperature distribution in a metal-clad fuel rod. The maximum fuel temperature occurs at the center of the fueled region and the greatest temperature difference occurs across the fuel. At the fuel/cladding interface, there is a temperature difference shown with a dotted line to indicate that the heat

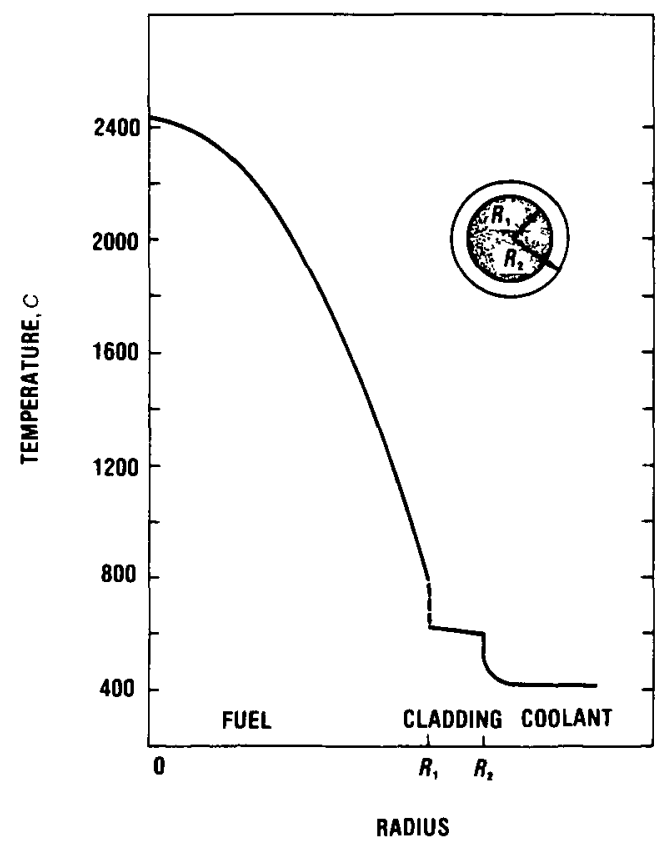

Fig. 3-14. Typical fuel/cladding temperature distribution $\left(R_{1}=3 \mathrm{~mm} ; R_{2}=3.5 \mathrm{~mm}\right.$; and $q^{\prime}=400$ W $/ \mathrm{cm}$ ). 
TABLE 3-I

Average Heat Transfer Conductances and Temperature Differences

\begin{tabular}{|lcc|}
\hline & $\begin{array}{c}\text { Thermal } \\
\text { Conductance } \\
\left(\mathrm{W} / \mathrm{cm}^{2} \cdot{ }^{\circ} \mathrm{C}\right)\end{array}$ & $\begin{array}{c}\text { Temperature } \\
\text { Difference } \\
\left({ }^{\circ} \mathrm{C}\right)\end{array}$ \\
\hline Coolant boundary layer & 1. & 180 \\
Cladding & 18. & 10 \\
Fuel/cladding interface & 1. & 180 \\
Fuel (oxide type) & 0.11 & 1640 \\
\hline
\end{tabular}

transfer process is a complex one occurring over an extremely short distance. The temperature difference across the fuel cladding is quite small compared to the other temperature differences.

Finally, the temperature difference through the coolant boundary layer is roughly indicated by the curve in Fig. 3-14. As an example, the average heat transfer conductances and temperature differences for a gas-cooled reactor with $q^{\prime \prime}=180 \mathrm{~W} / \mathrm{cm}^{2}$ are shown in Table 3-I as approximate values. The effective thermal conductance figures are based on the heat flux at the outside surface of the fuel rod and illustrate the relative magnitude of the conductances. Clearly, the cladding offers little resistance to heat flow while the fuel offers the greatest. The coolant conductance and the conductance at the fuel/cladding interface have nearly the same value for gas-cooled reactors at the point of maximum fuel temperature.

The fuel surface temperature has, in principle, been found by applying the analysis of the previous section. The temperature distribution through the cladding and fuel region can be found by solving the heat conduction equation with the appropriate boundary conditions, material properties, and power generation distribution. The governing differential equation in vector notation is

$$
\rho c \frac{\partial T}{\partial t}-\nabla \cdot k \nabla T=q^{\prime \prime \prime},
$$

where $\rho, c$, and $k$ are the density, specific heat capacity, and thermal conductivity of the material, respectively. All of these properties may be functions of the material temperature and $q^{\prime \prime \prime}$ may also be a function of temperature and position.

For steady-state conditions, the first term of Eq. (3.46) is dropped. The assumption is made that heat conduction in the axial direction may be neglected. It can be verified that axial conduction is usually negligible compared to radial and azimuthal conduction components and in any case the assumption is conservative in regard to evaluating the maximum fuel temperature.

\section{3-4B Cladding Temperature}

For the present, assume that the heat generation in the fueled region and that the heat transfer on the coolant side of the cladding are both axisymmetric. Since the power generation in the cladding is entirely negligible compared with the heat 
flux from the fueled region, and the cladding thermal conductivity is nearly constant, the conduction equation in cylindrical coordinates for the cladding becomes

$$
\frac{1}{r} \frac{d}{d r} r \frac{d T}{d r}=0
$$

The boundary conditions are a known surface temperature, $T_{s}$, on the coolant side and a given heat flux on the fuel side:

$$
T=T_{s} \quad \text { at } \quad r=R_{2}
$$

and

$$
-k \frac{d T}{d r}=\frac{q^{\prime}}{2 \pi r} \quad \text { at } \quad r=R_{1},
$$

where $q^{\prime}$ is the linear heat rating and $R_{1}$ and $R_{2}$ are the inner and outer cladding radii, respectively.

The solution to the differential equation and boundary conditions is found in a straightforward way to be

$$
T=T_{s}+\frac{q^{\prime}}{2 \pi k} \ln \left(\frac{R_{2}}{r}\right),
$$

with the temperature difference across the cladding given by

$$
\Delta T_{\text {cladding }}=\frac{q^{\prime}}{2 \pi k} \ln \left(\frac{R_{2}}{R_{1}}\right) .
$$

The cladding thermal conductance may be determined from Eq. (3.50):

$$
h_{\text {cladding }}=\frac{k}{R_{2} \ln \left(\frac{R_{2}}{R_{1}}\right)}
$$

When $R_{2}-R_{1}=\Delta R$ is small, the cladding conductance may be approximated by

$$
h_{\text {cladding }}=\frac{k}{\Delta R} \text {. }
$$

\section{3-4C Fuel/Cladding Gap Conductance}

When fuel rods are fabricated, a radial gap is allowed between the fuel pellets and metal cladding in order to allow assembly. This gap amounts to $\sim 0.05 \mathrm{~mm}$ for cladding with an inside diameter of $6 \mathrm{~mm}$. Assuming the fuel rod is backfilled with helium, a common practice, the thermal conductance amounts to $\sim 0.6 \mathrm{~W} / \mathrm{cm}^{2} \cdot{ }^{\circ} \mathrm{C}$. Thermal radiation only accounts for $\sim 1 \%$ of the thermal con- 
ductance. Referring to Table 3-I, it is seen that this is not an insignificant thermal resistance.

The initial gap between the fuel and the cladding is decreased once the fuel is in the reactor environment. Thermal expansion of the fuel, which is at a much higher average temperature than the cladding, tends to close the gap. However, with irradiation, gaseous fission products, krypton and xenon, mix with the initial helium inventory unless the fuel rod is vented or purged. These two factors oppose one another, the former causing an increase in the thermal conductance, the latter a decrease since the thermal conductivities of krypton and xenon are considerably less than helium in the helium-to-krypton-to-xenon ratio of 22:1.6:1.

As the fuel/cladding gap decreases such that the gap approaches the mean free path of the gas, continuum theory must be modified. There is no firm rule for the breakdown of continuum theory, but an accepted condition is $\mathrm{Kn} \geqslant 0.01$ where $\mathrm{Kn}$ is the Knudsen number defined by $\mathrm{Kn}=\lambda / l$ and $\lambda$ and $l$ are the gas mean free path and a characteristic length, respectively. Clearly, the characteristic length in this case is the fuel/cladding gap. Applying this condition shows that when the helium-filled gap closes to $<0.02 \mathrm{~mm}$, "slip" conditions must be taken into account. In effect, the helium atoms at the surface are no longer in thermal equilibrium with the surface and a "temperature jump" condition occurs. The magnitude of the temperature jump is evaluated by means of accommodation coefficients. ${ }^{7}$ The data on accommodation factors are meager. The accommodation coefficients are found to be functions of the surface materials and the gas under consideration and are greatly affected by surface roughness, surface contaminations, and average temperatures. The net result of the slip regime on heat flow is to reduce the effective thermal conductivity of the gas.

After the fuel/cladding gap closes sufficiently, contact between the two surfaces occurs at points corresponding to roughness peaks. Further closing causes more surface to come into contact. Conduction through these contact points increases the thermal conductance, finally overshadowing conduction through the interspace gas. Experiments have shown ${ }^{20}$ that the contact conductance can be expressed by

$$
h_{\text {gap }}=\alpha P+\beta k \text {, }
$$

illustrating the dependence of the contact conductance on both the contact pressure, $P$, and the conductivity, $k$, of the gas in the gap. The terms $\alpha$ and $\beta$ are experimentally determined coefficients. Other investigations ${ }^{21-23}$ have shown a more complex relationship between the parameters. Reference 21 is recommended for reactor applications.

For preliminary design, a fuel/cladding gap conductance of

$$
h_{\text {gap }}=1 \mathrm{~W} / \mathrm{cm}^{2} \cdot{ }^{\circ} \mathrm{C}
$$

is a good average value. Some of the newer computer programs developed to analyze the fuel and cladding as an integrated system incorporate one or the other of the complex formulations of contact conductance while the less sophisticated 
programs use Eq. (3.53) with the empirical constants adjusted for the particular fuel rod materials.

\section{3-4D Fuel Pellet Temperature Distribution}

The steady-state temperature distribution in the fuel is determined from the differential equation,

$$
\nabla \cdot K \nabla T=-q^{\prime \prime \prime}
$$

First consider the case where the fuel conductivity is constant and the power generation in the cylindrical fuel pellet is axisymmetric. The differential equation becomes

$$
\frac{1}{r} \frac{d}{d r} r \frac{d T}{d r}=\frac{-q^{\prime \prime \prime}}{K}
$$

and the boundary conditions are

$$
\frac{d T}{d r}=0 \quad \text { at } \quad r=0
$$

and

$$
T=T_{F S} \quad \text { at } \quad r=R_{1},
$$

where $T_{F S}$ is the fuel surface temperature known from a solution of Eq. (3.50) when the total pellet power is given.

For the case of constant power generation, the solution to Eq. (3.56) with the boundary conditions of Eq. (3.57) takes the simple form:

$$
T=T_{F S}+\frac{q^{\prime \prime \prime} R_{1}^{2}}{4 K}\left[1-\left(\frac{r}{R_{1}}\right)^{2}\right] .
$$

Another equivalent form of this result using the fuel linear heat rating, $q^{\prime}$, instead of the volumetric power generation rate is

$$
T=T_{F S}+\frac{q^{\prime}}{4 \pi K}\left[1-\left(\frac{r}{R_{1}}\right)^{2}\right] .
$$

The effective thermal conductance for the maximum fuel temperature, which is at the fuel pellet centerline, is

$$
h_{\text {fuel }}=\frac{2 K}{R_{1}} .
$$

Equations (3.58) and (3.59) are applicable to a fast reactor type fuel rod when the power rating is low enough that the fuel conductivity may be assumed constant. In a thermal reactor, it may be adequate to assume a constant mean 
value of the thermal conductivity, but the power generation will not be uniform due to the self-shielding effect. In a thermal reactor, the power generation in the fuel pellet is $q^{\prime \prime \prime} \propto I_{0}(\mathrm{kr})$ where $I_{0}$ is the zeroth-order modified Bessel function of the first kind and $\kappa$ is related to the neutron thermal diffusion length and is, therefore, a neutronic property of the fuel materials. Let

$$
q^{\prime \prime \prime}=\bar{q}^{\prime \prime \prime} \varepsilon_{f} I_{0}(\kappa r),
$$

with $\bar{q}^{\prime \prime \prime}$ being the average power density and $\varepsilon_{f}$ the minimum-to-average power factor, also called the "flux depression" factor. It can be shown that

$$
\varepsilon_{f}=\frac{\kappa R_{1}}{2 I_{1}\left(\kappa R_{1}\right)},
$$

where $I_{1}$ is the first-order modified Bessel function. The set of Eqs. (3.56) and (3.57) still determines the fuel pellet temperature distribution but the power generation is given by Eq. (3.61). The temperature distribution in the fuel pellet with a flux depression is

$$
T=T_{F S}+\frac{\varepsilon_{f} q^{\prime}}{\pi K}\left[\frac{I_{0}\left(\kappa R_{1}\right)-I_{0}(\kappa r)}{\left(\kappa R_{1}\right)^{2}}\right] .
$$

Letting $\Delta T_{\varepsilon_{f}}$ be the temperature difference across the fuel pellet with a flux depression and $\Delta T_{0}$ the temperature difference when the power density is constant, the ratio is

$$
\frac{\Delta T_{\varepsilon_{f}}}{\Delta T_{0}}=2\left[\frac{I_{0}\left(\mathrm{\kappa} R_{1}\right)-1}{\left(\mathrm{\kappa} R_{1}\right) I_{1}\left(\mathrm{\kappa} R_{1}\right)}\right] .
$$

As an example, for a relatively large flux depression of $20 \%, \varepsilon_{f}=0.8$, the temperature ratio $\Delta T_{\varepsilon f} / \Delta T_{0} \simeq 0.9$. That is, a flux depression of $20 \%$ causes a $10 \%$ decrease in the temperature difference based on a uniform power distribution. This temperature difference amounts to a decrease in the maximum fuel temperature of $\sim 30^{\circ} \mathrm{C}$ for a linear heat rating of $90 \mathrm{~W} / \mathrm{cm}$ and a fuel conductivity of $0.025 \mathrm{~W} / \mathrm{cm} \cdot{ }^{\circ} \mathrm{C}$. The temperature decrease is $\sim 15^{\circ} \mathrm{C}$ for a flux depression of $10 \%$ with these same fuel parameters. The rather small decrease in maximum fuel temperature that occurs with thermal reactor power ratings suggests that the flux depression effect may be neglected in thermal analyses. Neglecting a flux depression results in an overestimate and, therefore, conservatively calculated maximum fuel temperature.

\section{3-4E Fuel Pellet Power Tilt}

The overall reactor radial flux distribution is perturbed in the vicinity of neutron absorbers or reflectors causing a power tilt in fuel rods. The temperature distribution in a fuel rod having a power tilt may be determined readily for the case of constant fuel conductivity. In addition to the radial temperature gradient, 
there will be a circumferential gradient and the fuel and cladding should be treated as a single system. As a first approximation, the power tilt may be assumed to be linear, with the power density given by

$$
q^{\prime \prime \prime}=q_{0}^{\prime \prime \prime}\left[1+\varepsilon_{T}\left(\frac{r}{R_{1}}\right) \cos \theta\right] .
$$

The power tilt is depicted in Fig. 3-15 where the factor $\varepsilon_{T}$ is the magnitude of the power tilt.

The temperature distribution in the fuel and cladding can be found by assuming that the temperature distribution in each component is composed of two parts:

$$
T(r)=T_{0}(r)+T^{\prime}(r) \varepsilon_{T} \cos \theta
$$

The first term, $T_{0}$, is the temperature distribution for uniform power distribution while the second term, $T^{\prime}$, gives the effect of the power tilt. Both terms satisfy the differential Eq. (3.55). The boundary conditions are:

1. The temperature at the center of the fuel region is finite.

2. The temperature across the interface between the fuel and cladding is equal to the gap temperature difference.

3. The heat flux across the fuel/cladding interface is continuous.

The temperature distribution term $T^{\prime}$ is found in a straightforward manner to be a function of the fuel and cladding radii, the thermal conductivities of the two regions, the gap conductance, and the heat transfer coefficient at the cladding/ coolant surface. The actual solution is not given since it is found that the effect of a fuel pellet power tilt only causes a small increase in the fuel and cladding temperatures. For example, for conditions typical of a GCFR and for a rather
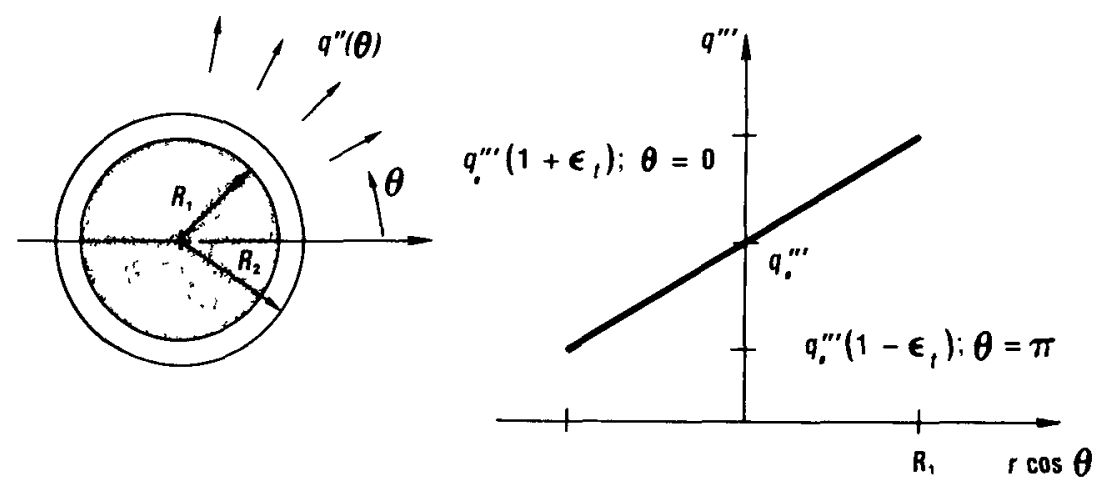

Fig. 3-15. Fuel rod power tilt. 
large power tilt of $20 \%$, the maximum fuel temperature is only $\sim 1^{\circ} \mathrm{C}$ greater and the fuel cladding only $\sim 3^{\circ} \mathrm{C}$ greater than for the uniform power generation case.

\section{3-4F Circumferential Variation in Convective Heat Transfer}

In Sec. 3-3B, the variation in convective heat transfer caused by close packing of fuel rods was discussed. It was indicated that the heat transfer coefficient is constant for loosely packed fuel element arrays but can have a large variation when the fuel rods are close together. The most usual situation for metal-clad fuel rod arrays is to have no variation in the heat transfer coefficient circumferentially or, at most, a small variation.

An estimate of the effect of a circumferential variation in the heat transfer coefficient can be made by assuming the heat transfer coefficient to be given by

$$
h(\theta)=h_{0}\left(1+\varepsilon_{c} \cos n \theta\right),
$$

where $h_{0}$ is the mean heat transfer coefficient, $\varepsilon_{c}$ is the circumferential variation magnitude, and $n$ is the number of variations around the circumference. For example, using the data of the central fuel rod from Fig. 3-10, it is seen that $n=6$ and $\varepsilon_{c}=0.10$ for the data labeled $1: 4$.

The temperature distribution in the fuel and cladding due to the circumferential variation in the heat transfer coefficient can be found by means of a perturbation analysis. Let the temperature in each component be expanded in the perturbation series:

$$
T=T_{0}+\varepsilon_{c} T^{\prime}+\varepsilon_{c}^{2} T^{\prime \prime}+\ldots,
$$

where $\varepsilon_{c}$ is the perturbation parameter and is taken to be a small quantity; the method of analysis is similar to that described in the previous section for the power tilt. As in the case of the solution for the power tilt, the result for $T^{\prime}$ is a complicated expression which is a function of the material conductivities, the fuel/ cladding interface conductance, and the mean heat transfer coefficient at the cladding/coolant surface. The expression is not given since it is found that the effect of a circumferential variation in heat transfer coefficient on the fuel and cladding temperatures is very small. For the example cited above where $n=6$ and $\varepsilon_{c}=0.10$ and for typical GCFR conditions, the fuel and cladding perturbations are calculated to be $\sim 0.1^{\circ} \mathrm{C}$; that is, the effect is negligible and can be considered to be part of the overall uncertainty in evaluating the fuel and cladding temperatures.

Analyses have also been performed ${ }^{24}$ to determine the effects of fuel pellet eccentricity and a cracked fuel pellet. As in the case of the variation in the circumferential heat transfer, the effects on fuel and cladding temperature were found to be small. 


\section{3-4G Variable Fuel Conductivity}

The assumption of constant fuel thermal conductivity thus far is acceptable for the relatively low power density thermal reactors as long as a conservatively low value is used in analyses. However, for the higher power density fast reactor that uses oxide fuels, the thermal conductivity varies considerably with temperature, as much as a factor of $\sim 2$; the analysis of fuel temperatures must take this into account.

The governing differential equation for the fuel temperature when considering a thermal conductivity that is a function of temperature is

$$
\frac{1}{r} \frac{d}{d r} r k \frac{d T}{d r}=-q^{\prime \prime \prime} \text {. }
$$

This equation may be integrated twice to give

$$
\int_{T_{F S}}^{T} k d T=\frac{q^{\prime \prime \prime} R^{2}}{4}\left[1-\left(\frac{r}{R}\right)^{2}\right],
$$

where $T_{F S}$ is the fuel surface temperature when $r=R$.

By introducing the fuel linear heat rating, $q^{\prime}$, and letting the upper limit of the integral be $T_{0}$ (the fuel center temperature when $r=0$ ), Eq. (3.70) becomes

$$
\int_{T F S}^{T_{0}} k d T=\frac{q^{\prime}}{4 \pi} .
$$

The left side is the conductivity integral and this equation expresses the important result that the linear fuel heat rating is only a function of temperature and is independent of the diameter for a solid cylindrical fuel rod.

The main utility of the conductivity integral expression is to set the thermal power limit of a particular fuel material. If fuel melting is accepted as the limiting condition for the fuel, then a series of in-pile experiments can be performed to evaluate the heat rating at which the fuel experiences melting at the center. The heat rating may be determined readily by calorimetry while the fuel temperature may be determined from post-test inspection and analysis.

Since the fuel surface temperature, $T_{F S}$, can vary considerably while the fuel melting temperature at the center of the rod, $T_{0}$, is a property of the material, the conductivity integral is usually written in terms of a reference temperature. Let the reference temperature be $T_{R}$; the conductivity integral is

$$
\int_{T_{F S}}^{T_{0}} k d T=\int_{T_{R}}^{T_{0}} k d T-\int_{T_{R}}^{T_{F S}} k d T .
$$

Typical maximum values of the linear heat ratings, in watts per centimeter, are: for the HTGR, $q^{\prime}=200$; for the GCFR, $q^{\prime}=500$; and for the LWR, $q^{\prime}=600$.

The conductivity integrals based on a reference temperature of $500^{\circ} \mathrm{C}$ for 
$\mathrm{UO}_{2}$ or mixed oxide fuel $(\mathrm{U}, \mathrm{Pu}) \mathrm{O}_{2}$ are estimated ${ }^{25}$ at 60 and $90 \mathrm{~W} / \mathrm{cm}$ for 90 and $100 \%$ theoretical density fuel, respectively. The conductivity integral for ( $\mathrm{U}, \mathrm{Pu}) \mathrm{C}$ fuel is estimated to be $>210 \mathrm{~W} / \mathrm{cm}$.

\section{3-4H Fuel Restructuring}

In the mixed oxide fuels of fast reactors, temperatures are higher than in thermal reactors and gross changes occur in the fuel structure with burnup. Initially, fuel pellets are formed by sintering to $\sim 85 \%$ theoretical density, since relatively porous fuel tends to contain gaseous fission products within the crystalline structure. After the fuel is irradiated at high linear heat ratings, the fuel pellet cross section will appear as depicted in Fig. 3-16. The original pellet, which was solid and composed of uniform grains, has been changed into a structure having bands of equiaxed grains and large columnar grains, and a central void region has developed. The reasons for the changes are complex but basically involve a redistribution of pores to the hotter center and grain growth. The interested reader will find the survey chapter of Ref. 25 useful in gaining an appreciation of the complex phenomena and there is extensive information in Ref. 26.

Various simplified methods for determining fuel structuring have been proposed ${ }^{27}$-all dependent on the fact that the equiaxed and columnar grain structures have well-defined densities and occur at well-defined temperatures. The simplified methods have given way to sophisticated numerical methods in which the fuel and cladding are treated as a single system taking into account the neutronic, physical, thermal, and structural behavior. In the early 1970s in the United States, a national effort was sponsored by the U.S. Department of Energy, with the major nuclear laboratories and companies cooperating, to develop a computing tool for fast reactor fuel performance. The LIFE $\operatorname{code}^{28-30}$ is the result of that effort.

The LIFE code accounts for fuel restructuring, fuel cracking and healing, hot pressing, fuel migration, fission gas release, fuel swelling due to fission gas release, and cladding swelling due to void nucleation and growth. The program predicts fuel/cladding interaction based on thermoelastic effects, creep, and swelling deformation. These effects are calculated as a function of the fuel operating history including steady-state and transient operation.

To illustrate the degree of fuel restructuring that can occur, calculations were performed using a simplified model. For a linear rating of $400 \mathrm{~W} / \mathrm{cm}$ and a surface temperature of $800^{\circ} \mathrm{C}$, a fuel with an $85 \%$ theoretical density would have a centerline temperature of $\sim 2800^{\circ} \mathrm{C}$, or nearly the melting temperature of oxide fuel, assuming no restructuring. After restructuring, the maximum temperature would be $2260^{\circ} \mathrm{C}$ and a central void region of $25 \%$ of the outside radius would be formed. To avoid fuel melting in this particular case, it would be necessary to operate below $400 \mathrm{~W} / \mathrm{cm}$ initially until restructuring occurs, then the linear heat rating could be increased to the design point.

Instead of starting with porous fuel (that is, had the initial fuel density been 


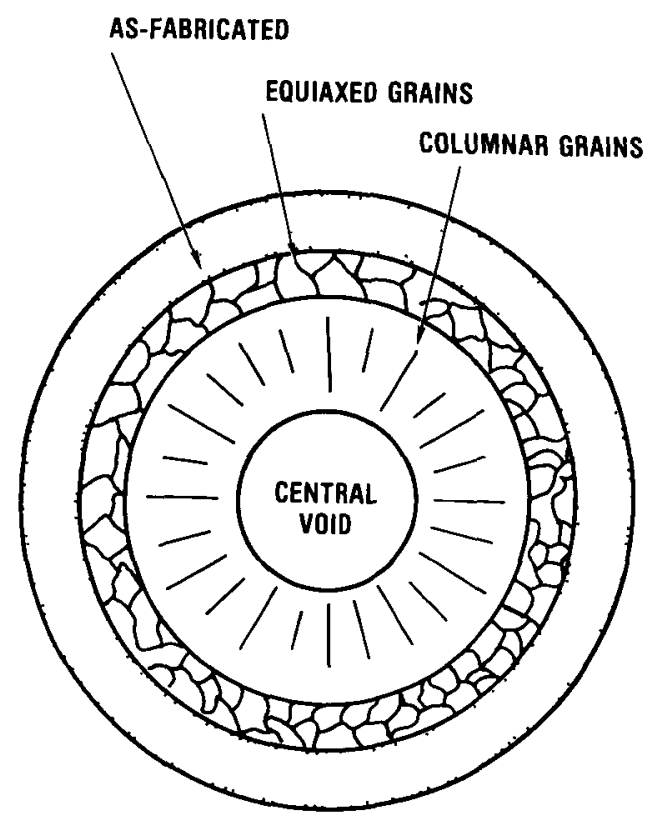

Fig. 3-16 Representation of restructured fast reactor fuel (adapted from Ref. 26).

very close to the theoretical density), restructuring would not occur but there would be a significant swelling caused by grain growth and bubble migration. To counter the swelling and to avold fracturing the cladding by overstraining, the cladding would have to be quite thick, which is undesirable.

\section{3-4I Packed-Bed Fuel Elements}

The fuel element for the HTGR shown in Fig. 7-5 of Chapter 7 belongs to a special class of fuel elements referred to as the "packed-bed" type. The fuel, in the form of small coated spheres, is sintered together into cylinders called "sticks," which are loaded into holes (or "beds") in the hexagonal moderator block and then plugged. The hexagonal moderator block also contains throughholes for coolant flow. Evaluation of the temperature distribution in the moderator and fuel regions gives rise to a degree of geometrical complexity not encountered in the previous sections where the fuel had a simple cylindrical form. In the analysis of the temperature distribution in the HTGR fuel element, it is appropriate to assume constant values for the conductivity of the fuel and cladding and a constant value for a contact conductance between the fuel and cladding-these are significant simplifying assumptions. The difficulty in the thermal analysis comes about because the shape of the fuel element does not conform to any orthogonal coordinate system such as rectangular, cylindrical, spherical, etc. How ever, one major simplification is possible in that a typical section (unit cell) out 
of the fuel block may be isolated for analysis. Such a section is shown in Fig. 7-18 of Chapter 7.

The circumferentially averaged coolant hole surface temperature, $\bar{T}_{S}$, can be found at any axial position along the coolant hole as discussed in Sec. 3-3. Then the maximum fuel temperature can be expressed by the equation:

$$
\hat{T}_{F}=\bar{T}_{S}+\frac{q^{\prime \prime}}{\hat{h}_{F}} .
$$

The maximum fuel temperature, $\hat{T}_{F}$, coolant hole mean surface temperature, $\bar{T}_{S}$, and the heat flux at the coolant hole, $q^{\prime \prime}$, are all functions of axial position, $z$. The term $\hat{h}_{F}$ is an equivalent heat conductance from the coolant surface to the point where the maximum fuel temperature occurs.

The equivalent heat conductance, $h_{F}$, must be found by solving the coupled equations of heat conduction in the moderator and fuel regions of the unit cell. Various methods can be used to determine the equivalent heat conductance, including analytical and numerical techniques.

The equivalent heat conductance for the HTGR was determined by an analytical method, ${ }^{31}$ which may be called the "method of singularities." This method of singularities has been used for determining the temperature distribution in other complicated geometrical shapes ${ }^{32,33}$ and is analogous to the method of singularities used for solving problems in fluid mechanics. The solution for the HTGR fuel element is expressed in the form of a series solution but it is found that the series is very rapidly convergent and only a few terms need be retained.

\section{3-5 Coolant Pressure Drop}

An evaluation of the core pressure drop, and also the pressure drop throughout the entire primary circuit, is an important step in establishing reactor performance. Further, orificing the core for a prescribed coolant outlet temperature distribution requires an accurate knowledge of the pressure drop through the core. In this section, the equations for determining the pressure drop through the primary coolant system are developed for the case of helium-cooled reactors. After the equations are derived, the subsections will deal with friction factor correlations, pressure losses through fuel element spacers, core orificing, and reactor pumping power.

\section{3-5A Derivation of Pressure Drop Relations for Compressible Flow}

The coolant pressure drop equation is derived assuming steady, one-dimensional, and constant mass flow. Body forces, e.g., the gravitational or head effect, are neglected in the derivation.

Consider the forces on the fluid element depicted in Fig. 3-17. Applying the 


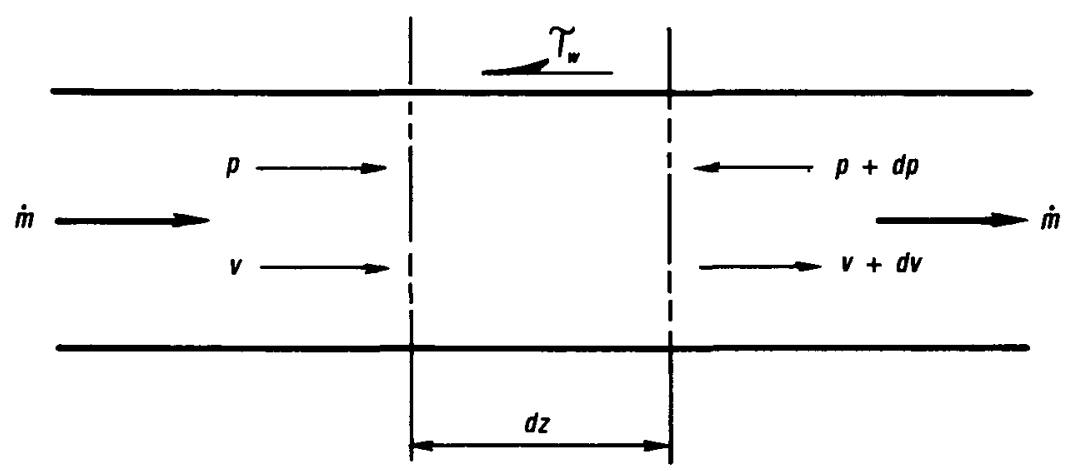

Fig. 3-17. Forces on fluid element.

conservation of momentum to the fluid element of length $d z$ gives

$$
\dot{m}[(v+d v)-v]=A[p-(p+d p)]-\tau_{w} P_{f} d z .
$$

The term $P_{f}$ is the frictional (sometimes called the "wetted") perimeter and may differ from the heat transfer perimeter $P$ introduced in Sec. 3-3.

The term $\tau_{w}$ is the wall shear stress and acts in a direction opposite to the flow direction. The shear stress is obtained from

$$
\tau_{w}=\frac{1}{2} \rho v^{2} f
$$

where $f$ is the Fanning friction factor, which is not to be confused with the Darcy friction factor $f_{\mathrm{D}}\left(4 f=f_{\mathrm{D}}\right)$. Equation (3.75) is really a definition of the Fanning friction factor. Introducing Eq. (3.75) into Eq. (3.74) gives

$$
\dot{m} \frac{d v}{d z}+A \frac{d p}{d z}+\frac{1}{2} \rho v^{2} f P_{f}=0 .
$$

In the analysis of pressure drop in gas-cooled reactors, the mass flow rate rather than the velocity is the appropriate parameter. These two variables are related through the continuity equation,

$$
\dot{m}=\rho v A \text {. }
$$

The final relation needed to derive the pressure drop equation is the equation of state of the fluid. In certain situations, it is valid to assume that the fluid, even though gaseous, is an incompressible fluid so the equation of state is:

incompressible fluid

$$
\rho=\text { constant }
$$


As indicated before, helium may be treated as a thermally perfect gas so in this case the equation of state is:

perfect gas

$$
p=\rho R T .
$$

At this point, it is possible to derive several equations that describe various flow processes in gas-cooled reactors.

\section{Frictionless Flow}

If the flow is assumed to be frictionless (perfect fluid), Eqs. (3.76) and (3.77) yield the familiar Bernoulli equation:

$$
p+\frac{1}{2} \rho v^{2}=\text { constant } .
$$

This expression is used, for example, to calculate the fluid pressure change from a plenum region into a duct since well-designed duct inlets can be assumed to accelerate the flow with zero loss. This equation is, therefore, applicable in the primary circuit when the flow may be considered to undergo an isentropic change.

\section{Incompressible Flow}

In the primary circuit where heat is neither added nor removed, helium can be treated as an incompressible fluid. Combining the equation of state for an incompressible fluid with the continuity equation gives $d v / d z=0$ so the momentum equation becomes

$$
\frac{d p}{d z}+\frac{1}{2} \rho v^{2} f \frac{P_{f}}{A}=0 .
$$

This can be integrated over the interval $z=0$ to $z=L$ to give the usual equation for an incompressible fluid:

$$
\Delta p=\frac{1}{2} \rho v^{2} f \frac{P_{f} L}{A} .
$$

\section{Compressible, Isothermal Creeping Flow}

This rather specialized case of isothermal creeping flow of helium arises in those situations where it is necessary to determine the flow in long instrumentation lines. The pressure difference across the instrumentation tube can be from reactor internal pressure to atmospheric pressure and, because the flow is very slow, the fluid tends to be in thermal equilibrium with the surroundings. In this case, the assumption is made that the first term of the momentum equation, Eq. (3.76), 
may be neglected since it is very small compared to the other two terms. Therefore, with this assumption and by means of Eqs. (3.75), (3.77), and (3.79), we arrive at the expression:

$$
\frac{d p}{d z}+\frac{R T}{2 p}\left(\frac{\dot{m}}{A}\right)^{2} f \frac{P_{f}}{A}=0
$$

Assuming $f$ is independent of $p$, which is valid for gases, the equation can be integrated between stations 1 and 2 , which are separated by the distance $L$, to give:

$$
p_{1}^{2}-p_{2}^{2}=R T\left(\frac{\dot{m}}{A}\right)^{2} f \frac{P_{f} L}{A} .
$$

It is only conceivable that this formula will be applied to round tubes when the flow is laminar. The friction factor for laminar flow in a round pipe is

$$
f=\frac{16}{\operatorname{Re}},
$$

and when introduced into Eq. (3.84) gives the final expression for isothermal creeping flow:

$$
p_{1}^{2}-p_{2}^{2}=\frac{256}{\pi} R T \mu \dot{m} \frac{L}{D^{4}}
$$

This equation is sometimes referred to as the Darcy equation. ${ }^{34}$

\section{Low Mach Number Flow}

The most important situation to be considered for gas-cooled reactors is the low Mach number flow case. This case is applicable to the reactor core where heat is added to the fluid and to the steam generator where heat is removed.

Combining Eqs. (3.76) to (3.79) gives

$$
\frac{d p}{d z}\left[1-\frac{R T}{p^{2}}\left(\frac{\dot{m}}{A}\right)^{2}\right]+\frac{R T}{p}\left(\frac{\dot{m}}{A}\right)^{2}\left[\frac{f}{2} \frac{P_{f}}{A}+\frac{1}{T} \frac{d T}{d z}\right]=0
$$

This differential equation may be integrated numerically in a stepwise fashion to give the pressure distribution along the flow channel. However, by making the justifiable assumption that the Mach number at the inlet station of the heated section is small compared to unity, a simplified algebraic equation can be derived.

As in previous developments, it will be convenient to introduce dimensionless parameters. Define a dimensionless length by

$$
\zeta=\frac{z}{L}
$$


where $L$ is the channel length. Let

$$
\Phi=\frac{f}{2} \frac{P_{f} L}{A},
$$

where $\Phi$ is analogous to the dimensionless heat transfer parameter $\sigma$ previously defined when discussing the surface temperature distribution [see Eq. (3.21)].

It can be shown in a straightforward way that

$$
\frac{\mathrm{RT}}{p^{2}}\left(\frac{\dot{m}}{A}\right)^{2}=\gamma \mathrm{M}^{2}
$$

where $\gamma$ is the ratio of specific heats and $M$ the Mach number. Letting $M_{1}$ be the inlet Mach number where the temperature and pressure are $T_{1}$ and $p_{1}$ gives

$$
\frac{\mathrm{M}^{2}}{\mathrm{M}_{1}^{2}}=\frac{\left(\frac{T}{T_{1}}\right)}{\left(\frac{p}{p_{1}}\right)^{2}}
$$

Substituting Eqs. (3.88) to (3.91) into the momentum equation, Eq. (3.87), yields

$$
\begin{gathered}
\frac{d\left(\frac{p}{p_{1}}\right)}{d \zeta}\left[\left(\frac{p}{p_{1}}\right)^{2}-\gamma \mathrm{M}_{1}^{2}\left(\frac{T}{T_{1}}\right)\right]+\gamma \mathrm{M}_{1}^{2}\left(\frac{p}{p_{1}}\right) \\
\quad \times\left[\Phi\left(\frac{T}{T_{1}}\right)+\frac{d\left(\frac{T}{T_{1}}\right)}{d \zeta}\right]=0 .
\end{gathered}
$$

The perturbation method is used to solve this equation by expressing the pressure ratio, $p / p_{1}$, in a power series in the parameter $\gamma \mathrm{M}_{1}^{2}$ where $\gamma \mathrm{M}_{1}^{2} \ll 1$ :

$$
\left(\frac{p}{p_{1}}\right)=1+\left(\gamma \mathrm{M}_{1}^{2}\right)\left(\frac{p}{p_{1}}\right)_{1}+\left(\gamma \mathrm{M}_{1}^{2}\right)^{2}\left(\frac{p}{p_{1}}\right)_{2}+\ldots .
$$

Note that the leading term is 1 because $p / p_{1}=1$ when $M_{1}$ is identically zero. Also note that the temperature may be approximated by

$$
d T=\frac{q^{\prime} d \zeta}{\dot{m} C_{p}}+\mathcal{O}\left(\mathbf{M}_{1}^{2}\right)
$$

The symbol $O\left(\mathrm{M}_{1}^{2}\right)$ stands for the "order of" and indicates that the remaining terms are no greater than $M_{1}^{2}$. This approximation was used in deriving the coolant temperature distribution in Sec. 3-1. 
For engineering calculations, only the first two terms of the series are retained. That is, terms of $O\left(\mathrm{M}_{1}^{4}\right)$ and so on will be dropped. The justification for this is the fact that the Mach number is found to be very small in gas-cooled power reactors. The maximum velocity in a gas-cooled reactor is $\sim 60 \mathrm{~m} / \mathrm{s}$ and the acoustic velocity for helium at $375^{\circ} \mathrm{C}$ is $\sim 1500 \mathrm{~m} / \mathrm{s}$ giving a Mach number of $\mathrm{M}_{1}=0.04$. The ratio of the second- to first-order terms is

$$
\frac{\left(\gamma \mathrm{M}_{1}^{2}\right)^{2}\left(\frac{p}{p_{1}}\right)_{2}}{\left(\gamma \mathrm{M}_{1}^{2}\right)\left(\frac{p}{p_{1}}\right)_{1}} \simeq \mathcal{O}\left(\mathrm{M}_{1}^{2}\right)
$$

Consequently, the second-order term is $\sim 1.6 \times 10^{-3}$ the magnitude of the firstorder term and neglecting it is obviously justified.

Substituting the perturbation series, Eqs. (3.93) and (3.94), into the momentum equation and collecting terms of order $\gamma \mathrm{M}_{1}^{2}$ gives

$$
\frac{d}{d \zeta}\left(\frac{p}{p_{1}}\right)_{1}+\Phi\left(\frac{T}{T_{1}}\right)+\frac{d}{d \zeta}\left(\frac{T}{T_{1}}\right)=0
$$

which may be integrated from station $\zeta_{1}$ to any point $\zeta$. There results:

$$
\left(\frac{p}{p_{1}}\right)_{1}+\int_{\zeta_{1}}^{\zeta} \Phi\left(\frac{T}{T_{1}}\right) d \zeta+\left(\frac{T}{T_{1}}-1\right)=0 .
$$

Finally, combining the terms of order unity and $\gamma \mathrm{M}_{1}^{2}$ produces the final formula:

$$
\Delta p=\frac{R T_{1}}{2 p_{1}}\left(\frac{\dot{m}}{A}\right)^{2}\left[2 \int_{\zeta_{1}}^{\zeta} \Phi\left(\frac{T}{T_{1}}\right) d \zeta+2\left(\frac{T}{T_{1}}-1\right)\right],
$$

where $\Delta p=p_{1}-p(\zeta)$ is the customary way of expressing pressure drop as a positive quantity.

If the further assumption is made that $\Phi$ is independent of temperature, then for the total channel length,

$$
\Delta p=\frac{R T_{1}}{2 p_{1}}\left(\frac{\dot{m}}{A}\right)^{2}\left[f \frac{P_{f} L}{A}\left(\frac{\bar{T}}{T_{1}}\right)+2\left(\frac{T_{2}}{T_{1}}-1\right)\right],
$$

where $\bar{T}$ is the mean temperature along the channel length. This equation is most often used in pressure drop analyses since $f$ is only a weak function of temperature through the fluid viscosity dependence on temperature. For helium and for turbulent flow, $f \propto T^{0.13}$.

The above pressure drop relation only includes the frictional and momentum change effects on the fluid pressure distribution and reduces to the incompressible formula of Eq. (3.82) when the temperature is constant.

To complete the analysis of channel pressure drop, it is necessary to add 
entrance and exit pressure losses plus any other parasitic losses along the channel. The complete equation to the same order of approximation as Eq. (3.98) is

$$
\begin{gathered}
\Delta p=\frac{R T_{1}}{2 p_{1}}\left(\frac{\dot{m}}{A}\right)^{2}\left[K_{S 1}+f\left(\frac{P_{f} L}{A}\right) \frac{\bar{T}}{T_{1}}+2\left(\frac{T_{2}}{T_{1}}-1\right)\right. \\
\left.+\sum_{n=1}^{N} C_{S N} \frac{T\left(\zeta_{n}\right)}{T_{1}}+K_{S 2} \frac{T_{2}}{T_{1}}\right] .
\end{gathered}
$$

The terms $K_{S 1}$ and $K_{S 2}$ are static pressure loss coefficients for the entrance and exit of the channel and are based on the area, $A$, of the channel. The temperature ratio multiplying the exit loss corrects for the local density. The $C_{S N}$ term represents static pressure loss coefficients at the points $\zeta_{n}$ along the channel.

Equation (3.99) expresses the static pressure drop for a channel. The total pressure drop, which is the unrecoverable pressure drop, is given by

$$
\begin{gathered}
\Delta p_{T}=\frac{R T_{1}}{2 p_{1}}\left(\frac{\dot{m}}{A}\right)^{2}\left[K_{T 1}+f\left(\frac{P_{f} L}{A}\right) \frac{\bar{T}}{T_{1}}+\left(\frac{T_{2}}{T_{1}}-1\right)\right. \\
\left.+\sum_{n=1}^{N} C_{T N} \frac{T\left(\zeta_{n}\right)}{T_{1}}+K_{T 2} \frac{T_{2}}{T_{1}}\right] .
\end{gathered}
$$

The $T$ subscripts in this equation denote total pressure loss coefficients.

Comparing the static pressure drop and total pressure drop equations shows that they are identical except for the pressure loss coefficients and the factor 2 , which occurs before the term $\left(\frac{T_{2}}{T_{1}}-1\right)$ in the static pressure drop formulation. When computing the core pressure drop, care must be exercised in selecting the proper loss factor, static or total, to go with each equation. For example, in an isentropic contraction from a plenum to a fuel channel, $K_{S 1}=1$ while $K_{T 1}=0$. The static pressure loss due to setting $K_{S 1}=1$ is not a true unrecoverable loss but only accounts for the fact that the static pressure drops because the fluid has been accelerated.

In the development of the pressure drop equations, the gravitational force was neglected, as is usually the case when dealing with a flowing gas. This is entirely appropriate for normal operation in gas-cooled reactors since the effect of elevation is insignificant-amounting to $<0.00007 \mathrm{MPa}$ out of a pressure drop of $\sim 0.07 \mathrm{MPa}$ for the HTGR. A similar conclusion is reached for the GCFR. In any event, the effect of elevation cancels in a closed system so it has no bearing on the design requirements for the circulator pressure rise.

Whereas the gravitational force is negligible during normal operation, it may be the only driving force during certain postulated accident cases. For these special situations, the most accurate analysis of pressure drop should utilize Eq. (3.87) with the gravitational term $g \rho$ added to the left side and a numerical solution 
employed. Where accuracy is not called for, the term $\int_{0}^{L} \rho d \zeta$ can be included in Eq. (3.99).

Situations arise in reactor flow analysis where the assumption of low Mach number is not valid. These situations are usually the analysis of postulated accidents. In that case, one must resort to numerical computations to evaluate flow and/or pressure drop. A complete discussion of compressible flow analysis is beyond the scope of this book. The textbook by Shapiro, ${ }^{34}$ as well as others, may be consulted when problems involving subsonic flow with large Mach numbers or choked flow are encountered.

\section{3-5B Friction Factor Correlations}

The predominant term in the pressure drop equation is the frictional term with $\sim 80$ to $90 \%$ of the pressure drop across the core of a gas-cooled reactor attributable to frictional losses. In view of this, it is important to have accurate data on the friction factor, which usually means obtaining experimental data on the actual configuration.

Fortunately, experimental data may be obtained on models scaled in size, using alternate materials and employing an alternate fluid. The theory of models ${ }^{35}$ applied to gas-cooled reactors requires that a test model be geometrically scaled, including surface roughness, and the similarity parameters-Reynolds number and Mach number - be equal for the model and prototype. In the previous section, the Mach number has been shown to be very small for helium-cooled reactors. In fact, compressibility effects being negligible, a liquid can be used in the test for determining the friction factor if this turns out to be convenient. Air, however, is a more usual choice for experiments, but the experimenter must design and analyze an air test properly so as not to introduce errors due to Mach number effects, which will be greater in air than helium for the same Reynolds number. Tests, therefore, reduce to measuring the pressure drop as a function of flow rate and representing the data in terms of a friction factor as a function of Reynolds number.

A further simplification can be made in performing friction factor tests; namely, they can be isothermal tests rather than heated ones. When large differences occur between the surface temperature and bulk temperature of the fluid, the normal velocity profile through the boundary layer is distorted due to the effect the temperature variation has on the fluid viscosity. With $f_{\text {so }}$ being the isothermal friction factor, the friction factor with heat transfer through the boundary layer can be approximated by ${ }^{19}$

$$
\frac{f}{f_{1 \mathrm{so}}}=\left(\frac{T_{S}}{T}\right)^{-01}
$$

This is similar to the correction applied to the Stanton number in Sec. 3-2B. In both cases-friction factor and Stanton number correlations-the temperature gradient through the boundary layer causes a decrease in the parameter compared 
to the isothermal situation. For the Stanton number, the decrease is detrimental to core performance since it reduces the heat transfer coefficient and increases the fuel element surface temperature, often a limiting condition; while for the friction factor, the temperature effect reduces the core pressure drop, a desirable result. The temperature effect is small for the friction factor because of the small exponent in Eq. (3.101), although there is some variation in the value of the exponent as proposed by various experimenters. In any case, there is conservatism in neglecting the temperature gradient effect since the actual pressure loss will be less than that based on an isothermally derived value.

For preliminary design purposes, the various empirical friction factor correlations found in the literature may be used. In the laminar flow regime, $\operatorname{Re} ₹$ 2000 , the expression for circular tubes is

$$
f=\frac{16}{\operatorname{Re}}
$$

and for the turbulent flow regime, $\operatorname{Re} S 5000$, there are various correlations to choose from including the well-known empirical equation, ${ }^{6}$

$$
f=0.046 \operatorname{Re}^{-0.2} ; 5000<\operatorname{Re}<200000 ;
$$

The Blasius formula, ${ }^{35}$

$$
f=0.079 \operatorname{Re}^{-1 / 4} ; 5000<\operatorname{Re}<100000 ;
$$

the Koo correlation, ${ }^{6}$

$$
f=0.00140+0.125 \operatorname{Re}^{-0.32} ; 3000<\operatorname{Re}<3000000,
$$

and, of course, the von Karman-Nikuradse equation ${ }^{35}$ derived from theoretical considerations and using the Nikuradse experimental data,

$$
\frac{1}{\sqrt{f}}=4.0 \log _{10}(\operatorname{Re} \sqrt{f})-0.40 \text {. }
$$

The choice of expression to use depends on the degree of accuracy required and the convenience in performing the calculations. The von Karman-Nikuradse equation is perhaps the most accurate for smooth pipes but requires an iterative type solution to evaluate the friction factor. The first two expressions are probably more widely used but are less accurate than the von Karman-Nikuradse equation.

Rarely does a fuel element surface have the smoothness that can be classified as hydraulically smooth. At large Reynolds numbers, even the relatively smooth surfaces of fuel elements can have a degree of roughness that can be characterized as being hydraulically rough and leading to a friction factor greater than obtained from one of the smooth pipe correlations. In this case, it is necessary to measure or estimate the relative roughness and evaluate the friction factor from the Moody diagrams, which are reproduced in texts and handbooks on fluid mechanics (noting that the Moody diagrams employ the Darcy friction factor, $f_{\mathrm{D}}=4 f$ ). For nu- 
merical calculations, the Moody diagram is inconvenient and the Colebrook-White correlation $^{35}$ is more useful:

$$
\frac{1}{\sqrt{f}}=3.48-4 \log _{10}\left[2\left(\frac{\varepsilon}{d}\right)+\frac{9.35}{\operatorname{Re} \sqrt{f}}\right] .
$$

This expression correlates the data from hydraulically smooth to rough with $\varepsilon$ being the root-mean-square roughness height and $d$ the pipe diameter. This expression reduces to the von Karman-Nikuradse formula for smooth pipes; that is, when $\varepsilon / d=0$. An even simpler relation is the Moody approximation ${ }^{36}$ to the ColebrookWhite equation:

$$
f=0.001375\left[1+\left(20000 \frac{\varepsilon}{d}+\frac{10^{6}}{\mathrm{Re}}\right)^{1 / 3}\right]
$$

Note that this last equation is practically the same as the Koo correlation, Eq. (3.105), when $\varepsilon / d=0$.

Any of the turbulent friction factor correlations can be used when the cross section of the flow channel is not circular as long as the diameter in the Reynolds number is the equivalent hydraulic diameter given by Eq. (3.32). In the case of fuel elements composed of a bundle of rods, the equivalent hydraulic diameter includes the frictional surface of the shroud. ${ }^{37}$ The packing factor used in the treatment of heat transfer in rod bundles, Eq. (3.34) of Sec. 3-3B, cannot be used for the friction factor since it does not take into account the wetted surface of a shroud around the fuel rods.

The turbulent friction factor correlation given by Eqs. (3.103) to (3.108) are for fully developed flow conditions. In the entrance section of the flow channel as the boundary layer is developing, the friction factor is greater than the fully developed value. To account for the starting length when experimental data are not available, the friction factor can be assumed to behave like the Stanton number over the same length [see Eq. (3.37) of Sec. 3-3B].

One way to maintain the relative position of fuel rods in a bundle is by means of helical spacers as shown in Fig. 3-18. The pressure drop in this type of fuel element is primarily frictional but increased over what would occur due to purely axial flow. The action of the helical spacers is to impart a whirl component both locally and overall causing both an increase in pressure drop and improved heat transfer. In addition to the equivalent hydraulic diameter, the helical wire-wrap element has other parameters influencing the pressure drop; namely, the wire width, height, and cross section and the wire pitch.

Complete and systematic friction tests of wire-wrap fuel elements are not available since all the various designs have been rather specialized. An approximate evaluation of the pressure drop can be made using the three-factor $X Y Z$ method of Sangster. ${ }^{38}$ In this method, the mass flow rate is multiplied by the factor $X$ to account for the relative number of center, edge, and corner flow passages (unit 

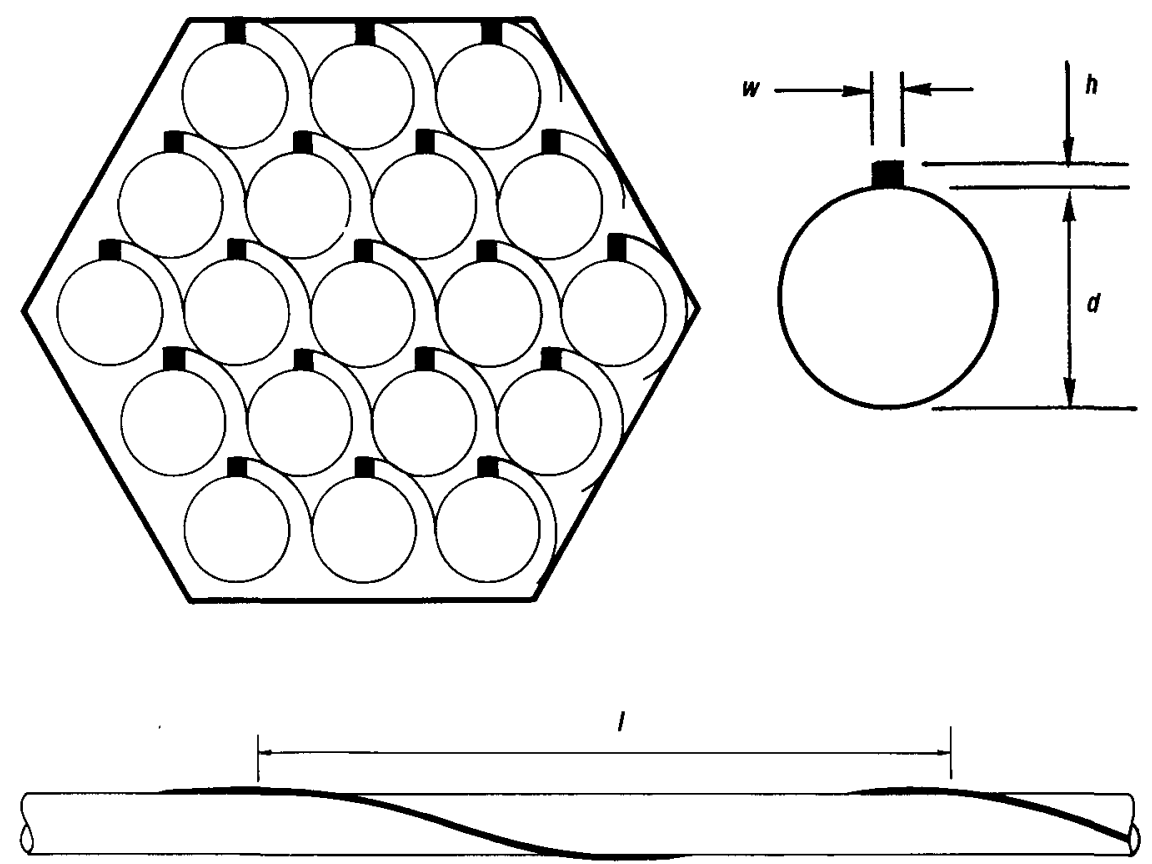

Fig. 3-18. Helical spacer fuel element.

cells), and the factors $Y$ and $Z$ multiply the friction factor to account for the packing factor (fuel rod pitch-to-diameter ratio) and the wire-wrap lead-to-rod diameter ratio, respectively. The main effect is in the wire-wrap lead and is given by

$$
Z=\frac{4.76}{(l / d)^{0.47}}
$$

The helical pitch-to-diameter ratio, $/ / d$, varies considerably but ranges between 6 to 40 so the $Z$ factor ranges between 2.1 to 1.2 .

\section{3-5C Parasitic Pressure Losses}

In a rod bundle fuel element assembly, there are end fixtures and intermediate spacers to position the fuel rods so as to prevent bowing and touching. There have been many intermediate spacer designs proposed over the years, but the most favored designs tend to be the egg-crate type composed of thin metal straps with small button extensions that actually touch the fuel rod. The end spacers or grids tend to be more massive and cause a greater pressure drop than the intermediate spacer.

Good aerodynamic design of spacers is required to achieve low parasitic pressure losses. If the design is good from the standpoint of aerodynamics, it should also be satisfactory with respect to vibrations and heat transfer. Obviously, 
the spacer should not cause a fuel rod hot spot and, in fact, the egg-crate-type design may actually act like a fin and locally reduce the fuel rod surface temperature. The low pressure drop spacer designs can have structural and manufacturing problems so there is a necessity for engineering compromises in the development of a satisfactory design.

It is quite difficult to calculate accurately the pressure drop due to a spacer, and experiments are required to obtain design data. However, an estimation of the pressure drop can be made for preliminary design purposes and for comparison of various conceptual designs. The pressure drop consists of two parts: form drag and skin friction. In some designs, only form drag is significant while in other designs both effects must be considered. For calculational purposes, it is appropriate to add the form drag and skin friction components.

The spacer pressure drop can be expressed as

$$
\Delta p=\frac{1}{2} \rho v^{2} \frac{\sigma}{(1-\sigma)^{2}}\left(C_{D}+C_{F}\right),
$$

where $\sigma$ is the solidity given by

$$
\sigma=\frac{A_{B}}{A}
$$

and where $A_{B}$ is the spacer frontal area (blockage area) and $A$ is the fuel element cross-sectional flow area. The drag coefficient, $C_{D}$, and friction coefficient, $C_{F}$, are based on the frontal area of the spacer. This equation is derived by applying the momentum equation across the spacer and evaluating the drag coefficient in terms of the maximum velocity in the area $A_{B}$ then expressing the pressure drop in terms of the mean velocity, $v$, upstream of the spacer. The factor $(1-\sigma)^{2}$ in the denominator converts the maximum velocity to the mean upstream velocity.

The form drag part of the overall drag coefficient can be estimated by assuming a sudden contraction followed by a sudden expansion. Normally, contraction losses are very small if the spacer has slight rounding of the leading edge, but for conservatism in estimating the pressure drop it is advisable to include the contraction loss as due to a sharp-edged inlet. The contraction loss can be estimated by

$$
k_{c}=\frac{1}{2}\left(1-\frac{A-A_{B}}{A}\right)=\frac{\sigma}{2},
$$

and the expansion loss is given by

$$
k_{e}=\left(1-\frac{A-A_{B}}{A}\right)^{2}=\sigma^{2} .
$$

Therefore, the drag coefficient is

$$
C_{D}=\left(\frac{\sigma}{2}+\sigma^{2}\right) \text {. }
$$


The frictional component of the overall drag can be estimated from

$$
C_{F}=2 f \frac{c L_{T}}{A},
$$

where $c$ is the chord, $L_{T}$ is the total length of the spacer elements, and $f$ is the friction factor for a flat plate. The factor 2 accounts for the skin friction on both surfaces of the spacer elements. The friction factor is

$$
f=\frac{1.328}{\sqrt{\operatorname{Re}_{c}}},
$$

which is the Blasius relation for flat plates at zero incidence angle under laminar flow conditions, $\operatorname{Re}_{c}<10^{5}$, and where the Reynolds number is referenced to the chord of the spacer element. The laminar skin friction equation is used rather than the turbulent one because it is to be expected that the boundary layer will not reach turbulent transition over the rather short length of the spacer chord.

The complete spacer loss coefficient to be inserted into Eq. (3.100), that is, the factor $C_{T}$, is the sum of the above terms and is given by

$$
C_{T}=\frac{\sigma}{(1-\sigma)^{2}}\left[\sigma\left(\sigma+\frac{1}{2}\right)+2 f \frac{c L_{T}}{A}\right] .
$$

Spacer pressure losses have been considered parasitic losses but, in fact, spacers can be designed to cause coolant mixing between unit cells of a fuel element bundle, so the pressure loss is not without benefit.

The pressure losses at the inlet and exit of the fuel element can be determined in a fashion similar to spacer pressure losses. The actual losses may have to be estimated when test data are not available and various reports ${ }^{39,40}$ and handbooks contain information helpful to this end.

\section{3-5D Parallel Channel Flow and Core Orificing}

The flow distribution among the fuel assemblies in a reactor will be different at normal operating conditions than when the reactor is first started up and no heat is being produced. If all of the fuel elements are identical, under cold conditions the flow will be the same in all of the fuel elements. The change in flow distribution as the reactor heat input is increased is mainly due to the momentum change term, $\left(\frac{T_{2}}{T_{1}}-1\right)$ in Eq. (3.100), and the density effect on the localized pressure loss terms. There are also secondary changes in flow distribution due to the change in the friction factor with temperature. To determine the flow distribution under all operating conditions, it is necessary to solve the equations governing the flow among parallel coolant channels.

Assume there are $N$ fuel elements in the core and the core is located between two plenums. The latter assumption implies that the pressure and temperature 
upstream and the pressure downstream of the core are the same for all of the fuel elements. Therefore, the pressure drop for the $i$ 'th fuel channel is

$$
\Delta p=\frac{R T_{1}}{2 p_{1}}\left(\frac{\dot{m}_{l}}{A}\right)^{2} \kappa_{l} \quad ; i=1,2, \ldots, N,
$$

where $\dot{m}_{l}$ is the mass flow rate for the $i$ 'th element and $\kappa_{l}$ the overall loss factor representing the frictional pressure drop, momentum change, and the inlet, exit, and other parasitic pressure losses. The parameter $\kappa_{l}$ represents the bracketed part of Eq. (3.99). Since the pressure drop is the same for each of the $N$ channels, Eq. (3.117) gives $N-1$ equations of the form

$$
\dot{m}_{1}^{2} \kappa_{1}=\dot{m}_{J}^{2} \kappa_{j} ; j=2,3, \ldots, N .
$$

Also there is the continuity equation, which can be written

$$
\dot{M}=\sum_{i=1}^{N} \dot{m}_{l}
$$

and $\dot{M}$ is the total flow through the core. The $N-1$ equations from Eq. (3.118) and the continuity equation comprise a set of $N$ equations for the $N$ unknown mass flow rates. Solving the set gives

$$
\frac{\dot{m}_{l}}{\dot{M}}=\frac{\sqrt{\frac{1}{\kappa_{t}}}}{\sum_{j=1}^{N} \sqrt{\frac{1}{\kappa_{j}}}} ; j=1,2,3, \ldots, N \text {. }
$$

The $\kappa_{l}$ terms on the right side of Eq. (3.120) are also functions of $\dot{m}$, albeit weak functions, so Eq. (3.120) is a set of transcendental algebraic equations for the unknown mass flow rates. An algorithm is easily devised to determine numerical results by a straightforward iteration scheme. It is first assumed that all the mass flow rates are equal and the $\kappa_{t}$ calculated. Next an improved value of $\dot{m}_{l}$ is determined from Eq. (3.120), which is then used to find an improved value of $\kappa_{t}$ and this procedure is continued until a convergence criterion is satisfied. Because of the weak dependence of $\kappa_{l}$ on mass flow rate, convergence is very rapid for turbulent flow conditions. For given inlet conditions and given total flow rate, the pressure drop can be shown to be

$$
\Delta p=\frac{R T_{1}}{2 p_{1}}\left(\frac{\dot{M}}{A}\right)^{2}\left(\sum_{J=1}^{N} \sqrt{\frac{1}{\kappa_{\jmath}}}\right)^{-2} .
$$

It was pointed out in Sec. 3-2 that it is desirable to orifice a reactor core to achieve a uniform coolant outlet temperature, which requires that the flow rate to a fuel element be proportional to the power generation in that fuel element. If the 
core were not orificed, the coolant flow in the hot channel would be less than the mean flow rate and the outlet temperature would be greater than the mean. ${ }^{41}$ Orificing the core for constant outlet temperature is determined in a straightforward manner. The mass flow rates to each channel are first found from Eq. (3.15) to give the desired constant coolant outlet temperature. Next the pressure drop for each fuel element is found from Eq. (3.99) or (3.100) and the mass flow rates just found from Eq. (3.15). The pressure drop across the hot channel will have the maximum value. All other channels will have to have orificing to increase their pressure drops to equal the one for the hot channel. The incremental pressure drop is

$$
\delta\left(\Delta p_{l}\right)=\frac{R T_{1}}{2 p_{1}}\left(\frac{\dot{m}_{l}}{A}\right)^{2} \kappa_{o l},
$$

where $\kappa_{o l}$ represents the total pressure loss of an orifice for the $i$ 'th fuel element. The physical dimensions of an orifice can be determined once the value of $\kappa_{o t}$ is evaluated.

Another strategy for orificing a reactor core is to orifice for a constant maximum surface temperature. This is an appropriate strategy for a metal-clad fuel element since the maximum surface temperature is the limiting design criterion. If the normalized axial power distribution is nearly the same for every fuel element, it is found that orificing for constant outlet temperature and orificing for constant maximum fuel element surface temperature have quite similar orificing requirements. Calculating the orificing requirements for constant maximum surface temperature is more involved than the former case since it is necessary to satisfy continuity, Eq. (3.119), equal pressure drops, Eq. (3.117), and equal maximum surface temperatures, Eq. (3.25).

Different orificing schemes, such as variable orifices, fixed orifices, inlet orificing, exit orificing, etc., are possible. The choice between fixed and variable orifices must take into account the costs of controls, sensors, and mechanisms to make orificing adjustments versus pressure drop penalties of setting fixed orifices to obtain safe operating conditions during burnup, the costs associated with more frequent refueling and changing of the fixed orifices.

The choice between fixed inlet and outlet orificing is primarily made on the basis of mechanical design features. The use of exit orificing does allow a special added feature in that the orificing device can be designed as a self-contained variable orifice using thermal expansion properties to change the flow rate. Such a device is limited in the amount of flow change that it can control but it can be designed to accommodate power perturbations.

\section{3-5E Pumping Power}

The ideal reactor pumping power is defined as the energy required to circulate the coolant through the flow circuit against the fluid resistance. The ideal pumping 
power does not account for the efficiency of the pump itself Let $P_{p}$ stand for the pumping power, which is given by

$$
P_{p}=\dot{M} \frac{R T_{1}}{p_{1}} \Delta p
$$

This equation is valid for compressible flow to the same degree as the equation for computing core pressure drop, $\mathrm{Eq}$ (3 99)

The pumping power found from this equation enters into reactor economic analyses since the power required to circulate the coolant is subtracted from the total plant power output. An advantage for gas-cooled reactors is the fact that the pumping power can be independently adjusted by varying the system pressure Since the pressure drop is inversely proportional to system pressure, the pumping power is found to vary like $P \propto 1 / p_{1}^{2}$ Consequently, an incremental increase in the system pressure means a much more significant incremental decrease in the pumping power. Obviously, the system pressure becomes an independent variable in the overall economic optimization of the reactor, balancing a decrease in pumping power against an increase in the cost of the containment structure

\section{NOMENCLATURE}

\begin{tabular}{|c|c|}
\hline Symbol & \\
\hline A & $=$ channel cross-sectional flow area \\
\hline$A_{B}$ & $=$ spacer frontal (blockage) area \\
\hline$A_{F}$ & $=$ fuel cross-sectional area \\
\hline$B$ & $=$ drameter ratıo $\left(D_{e} / d\right)[\mathrm{Eq}(335)]$ \\
\hline$C_{D}$ & $=$ spacer drag coefficient \\
\hline$C_{F}$ & $=$ spacer friction coefficient \\
\hline$C_{p}$ & $=$ specific heat capacity of gas at constant pressure \\
\hline$C_{S N}$ & $=$ local static pressure loss coefficient \\
\hline$C_{T}$ & $=$ total spacer loss coefficient \\
\hline$C_{T N}$ & $=$ local total pressure loss coefficient \\
\hline$c$ & $=$ minımum clearance between fuel rods \\
\hline c & $=$ specific heat capacity of solid \\
\hline$D$ & $=$ channel flow diameter \\
\hline$D_{e}$ & $=$ channel equivalent hydraulic diameter \\
\hline$d$ & $=$ fuel rod drameter \\
\hline$f$ & $=$ Fanning friction factor \\
\hline$f_{\mathrm{D}}$ & $=$ Darcy friction factor $\left(4 f=f_{\mathrm{D}}\right)$ \\
\hline$f_{\text {iso }}$ & $=$ isothermal Fanning friction factor \\
\hline$G$ & $=$ fuel rod bundle packıng factor $\left[\mathrm{Eq}\left(\begin{array}{l}34 \\
3\end{array}\right)\right]$ \\
\hline$g$ & $=$ gravitational acceleration \\
\hline & $=$ heat transfer coefficient \\
\hline$h_{F}$ & $=$ fuel conductance $[\mathrm{Eq}(3 \mathrm{73})]$ \\
\hline$h_{\text {gap }}$ & $=$ gap conductance \\
\hline
\end{tabular}




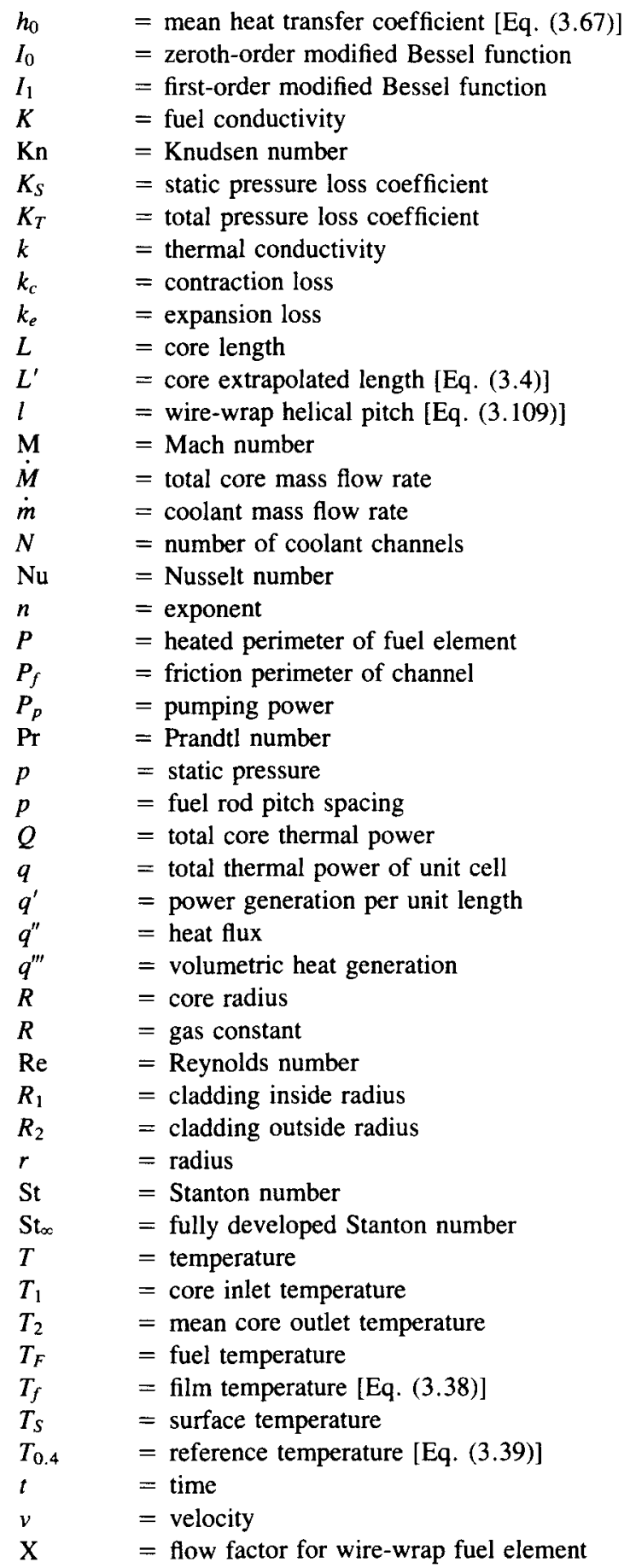


$=$ packing factor for wire-wrap fuel element

$=$ helical pitch factor for wire-wrap fuel element [Eq. (3.109)]

$=$ axial coordinate

Greek

$\alpha \quad=$ coefficient

$\beta \quad=$ coefficient

$\gamma \quad=$ ratio of specific heats

$\gamma \quad=$ fuel element geometry factor (Fig. 3-10)

$\Delta p \quad=$ static pressure drop

$\Delta p_{T} \quad=$ total pressure drop

$\Delta T_{\text {cladding }}=$ cladding temperature difference

$\delta=$ difference

$\varepsilon \quad=$ surface roughness

$\varepsilon_{A} \quad=$ axial power factor [Eq. (3.4)]

$\varepsilon_{c} \quad=$ circumferential heat transfer factor [Eq. (3.67)]

$\varepsilon_{f} \quad=$ flux depression factor [Eq. (3.61)]

$\varepsilon_{R} \quad=$ radial power factor

$\varepsilon_{T} \quad=$ power tilt factor [Eq. (3.65)]

$\zeta=$ dimensionless axial length

$\theta \quad=$ angle

$\kappa=$ neutron thermal diffusion length [Eq. (3.61)]

$\kappa_{\imath}=$ pressure loss factor [Eq. (3.117)]

$\boldsymbol{K}_{0}=$ orifice pressure loss coefficient

$\lambda=$ dimensionless length [Eq. (3.7)]

$\rho \quad=$ density

$\sigma \quad=$ heat transfer surface parameter [Eq. (3.21)]

$\sigma \quad=$ solidity parameter [Eq. (3.111)]

$\tau_{w} \quad=$ shear stress at wall

$\Phi=$ friction surface parameter [Eq. (3.89)]

$\phi \quad=$ normalized axial power distribution

$\psi \quad=$ parameter [Eq. (3.44)]

\section{Subscripts}

$0=$ reference condition

$1=$ core inlet, inside surface

$2=$ core outlet, outside surface

$\infty \quad=$ fully developed value

\section{Superscripts}

$=$ average value

$=$ maximum value

$=$ first perturbation term

$=$ second perturbation term

\section{REFERENCES}

1. W. M. Rohsenow and H. Y. Choi, Heat, Mass, and Momentum Transfer, PrenticeHall, Inc., Englewood Cliffs, New Jersey (1961). 
2 W M Kays, Convective Heat and Mass Transfer, McGraw Hill Book Co, New York (1966)

3 W B Hall, Reactor Heat Transfer, Temple Press Ltd, London (1958)

4 M M El-Wakıl, Nuclear Power Engineering, McGraw Hill Book Co, New York (1962)

5 L S Tong and J Weisman, Thermal Analysis of Pressurized Water Reactors, American Nuclear Society, La Grange Park, Illınoıs (1970)

6 W H McAdams, Heat Transmission, 3rd ed, McGraw-Hill Book Co, New York (1954)

7 W M Rohsenow and J P Hartnett, Eds, Handbook of Heat Transfer, McGrawHill Book Co , New York (1973)

8 W A Sutherland, "Experımental Heat Transfer in Rod Bundles," p 104 in Heat Transfer in Rod Bundles, American Society of Mechanical Engineers (1968)

9 G Markoczy, private communication

10 L D Palmer and L L Swanson, "Measurements of Heat Transfer Coefficients, Friction Factors, and Velocity Profiles for Air Flowing Parallel to Closely Spaced Rods," Proc Conf International Developments in Heat Transfer, Boulder, Colorado, August 28-September 1, 1961, American Society of Mechanical Engineers (1961)

11 H W Hoffman, J L Wantland, and W J Stelzman, "Heat Transfer with Axıal Flow in Rod Clusters,' Proc Conf International Developments in Heat Transfer, Boulder, Colorado, August 28-September 1, 1961, p 553, Part III, American Society of Mechanical Engineers (1961)

12 R Katz, "Thermal Design Aspects of Gas-Cooled Reactor Cores," GA 7941, GA Technologies (1967)

13 W A Sutherland and W M Kays, "Heat Transfer in Parallel Rod Arrays," J Heat Transfer, 88, 117 (Feb 1966)

14 C A Bankstron and D M McEligot, "Prediction of Tube Wall Temperatures with Axıal Varıation of Heatıng Rate and Gas Property Varıatıon," $\mathrm{Nucl}$ Scl Eng, 37, 157 (1969)

15 R C Marshall and R P Letendre, "Influence of Inlet Geometry on Flow in the Entrance Region of a Nuclear Reactor Rod Bundle," Paper 68-WA/HT-34, American Society of Mechanical Engineers (1968)

16 R G Deissler and A F Presler, "Computed Reference Temperature for Turbulent Variable-Property Heat Transfer in a Tube for Several Common Gases," Proc Conf International Developments in Heat Transfer, Boulder, Colorado, August 28-September 1, 1961, p 579, Part III, American Society of Mechanıcal Engineers (1961)

17 H C Perkıns and P Worsoe-Schmıdt, "Turbulent Heat and Momentum Transfer for Gases in a Circular Tube at Wall to Bulk Temperature Ratıos to Seven,' Int J Heat Mass Transfer, 8, 1011 (1965)

18 P F Marien and A D Richards, "Convective Heat Transfer Correlations for Use with Helium at High Heat Fluxes," Proc Symp High Pressure Gas As a Heat Transport Medium, March 9-10, 1967, Vol 181, Part 3I, p 198, Institution of Mechanical Engineers (1967)

19 D M McEligot, P M Magee, and G Leppert, "Effect of Large Temperature Gradients on Convectıve Heat Transfer The Downstream Regıon," $J$ Heat Transfer, 87, 1, 67 (Feb 1965)

20 R A Dean, Thermal Contact Conductance, Masters Thesıs, Unıversity of Pittsburgh (1963)

21 A M Ross and L L Stoute, "Heat Transfer Coefficient Between $\mathrm{UO}_{2}$ and Zircaloy- 
2," AECL-1552, Atomic Energy of Canada Limited (1962)

$22 \mathrm{H}$ Fenech and W H Rohsenow, "Prediction of Thermal Conductance of Metallıc Surfaces in Contact," J Heat Transfer, 82, 15 (1963)

23 C N Craig, G R Hull, and W E Baily, "Heat Transfer Coefficients Between Fuel and Claddıng in Oxıde Fuel Rods," GEAP-5748, General Electrıc Company (1969)

24 C A Olson and L H Boman, "Three Dimensional Thermal Effects in PWR Fuel Rods," Paper 75 WA/HT-78, American Society of Mechanical Engineers (1975)

25 M T Simnad and J P Howe, "Materials for Nuclear Fission Power Reactor Tech nology," p 32 in Material Science in Energy Technology, G G Libowitz and M S Whitıngham, Eds, Academic Press, Inc , New York (1979)

26 D R Olander, "Fundamental Aspects of Nuclear Reactor Fuel Elements," TID26711-P1, Energy Research and Development Admınıstration (1976)

27 R O Meyer and B J Buescher, "A Simple Method of Calculatıng the Radial Temperature Distribution in a Mixed-Oxide Fuel Element," Nucl Technol, 14, 153 (1972)

$28 \mathrm{~V} \quad \mathrm{Z}$ Jankus and $\mathrm{R}$ W Weeks, "LIFE-I A Fortran IV Computer Code for the Prediction of Fast-Reactor Fuel-Element Behavior," ANL-7736, Argonne National Laboratory (1970)

29 V Z Jankus and R W Weeks, "LIFE-II A Computer Analysis of Fast-Reactor Fuel-Element Behavior as a Function of Reactor Operatıng Hıstory,' Nucl Eng Des, 18, 83 (1972)

30 J D Stephen and R G Sım, "LMFBR Oxıde Fuel Analysıs System, Trans Am Nucl Soc , 24, 169 (1976)

31 R Katz, unpublished report (1965)

32 R Katz, "Temperature Distribution and Thermal Stresses in the Marıne Gas-Cooled Reactor Semı-Homogeneous Fuel Element," Trans Am Nucl Soc , 2, 2, 213 (Nov 1959)

33 J C Rowley and J B Payne, "Steady State Temperature Solution for a HeatGeneratıng Circular Cylınder Cooled by a Ring of Holes,' $J$ Heat Transfer, 86, 4, 531 (Nov 1964)

34 A H Shapiro, The Dynamics and Thermodynamics of Compressible Fluld Flow, Ronald Press Co, New York (1953)

35 H Schlıchtıng, Boundary Layer Theory, 4th ed, McGraw-Hill Book Co, New York (1960)

36 L F Moody, "An Approximate Formula for Pipe Friction Factors," Mech Eng , 69, 1005 (Dec 1947)

37 L R Galloway and N Epsteın, "Longitudinal Flow Between Cylınders in Square and Triangular Arrays and in a Tube with Square-Edged Entrance," AIChE-IChE Symp Series No 6, Vol 6, No 3, p 15, London Institute of Chemical Engineers (1965)

38 W A Sangster, "Calculation of Rod Bundle Pressure Loss," Paper 68-WA/HT-35, American Society of Mechanical Engineers (1968)

39 K Rehme, "Pressure Drop of Spacer Grids in Smooth and Roughened Rod Bundles," Nucl Technol, 33, 314 (1977)

40 P Barroyer, "Analytical Model for the Prediction of Space Pressure Loss," Trans Am Nucl Soc , 30, 525 (1978)

41 G Melese-d'Hospital, "Sımplıfied Analysıs of Coolant Flow and Outlet Temperature in Gas-Cooled Nuclear Reactor Cores," Nucl Scl Eng , 35, 165 (1969) 


\section{REACTOR CORE HEAT TRANSFER: SPECIAL TOPICS*}

In the previous chapter, the fundamentals of reactor core heat transfer were developed In this chapter, the subject of reactor core heat transfer is continued but with emphasis on several special topics The first section takes up the subject of hot spot factors Hot spot factors, or hot channel factors as they are sometımes called, are engineering uncertainty factors employed in the design of reactor cores to ensure that the limiting core temperature, structural component temperature, or fuel temperature will not be exceeded durng normal reactor operation The gas-cooled fast breeder reactor (GCFR) is used to illustrate the procedure for first estımatıng the hot spot factors and then estımatıng the method for applying these factors in design analysis

In Sec 4-2, the subject of coolant mixing within the rod bundle type of fuel element, such as the GCFR fuel element design, is introduced This coolant mixing is an example of a field where further research is required

Section 4-3 discusses core temperature shaping as a means for optımızing reactor design Of the various possibilities open to the reactor designer to employ temperature shaping, one method is used in the high-temperature gas-cooled reactor (HTGR) and another method in the GCFR

Section 4-4 develops thermodynamic criteria for evaluatıng gases for coolıng reactors Several common gases in use or considered for use for reactor cooling are compared on the basis of their thermodynamic performance

The last section discusses heat transfer and pressure drop correlations for pebble bed reactors

\section{4-1 Hot Spot Factors}

\section{4-1A Definition}

Hot spot factors used in reactor core thermal-hydraulic analyses are analogous to safety factors used in the design of structures for buldings, bridges, machine elements, etc That is, hot spot factors are used to account for various uncertainties that are a part of the engineering design process and assure that a specified

*Sections 4-1 and 4-2 were contributed by C B Baxı 
maximum temperature in the reactor core is not exceeded at any time and at any location for normal power operation. To illustrate how hot spot factors are determined and to further illustrate how hot spot factors are used in the thermalhydraulic analysis of the reactor core, the GCFR design is used as an example.

The limiting thermodynamic performance criterion for the GCFR design is that the midwall temperature of the cladding not exceed $750^{\circ} \mathrm{C}$ with a $95 \%$ confidence level. The $95 \%$ confidence level is equivalent to two standard deviations $(2 \sigma)$ of a Gaussian distribution. Based on this criterion, the midwall cladding temperature, $T_{c l}$, including hot spot factors is given by (see Nomenclature, p. 147):

$$
T_{c l}=T_{1}+F_{c} \cdot \Delta T_{c}+F_{f} \cdot \Delta T_{f}+F_{c l} \cdot \Delta T_{c l},
$$

where

$T_{1}=$ coolant inlet temperature to the core

$\Delta T_{c}=$ coolant temperature rise found from Eq. (3.10)

$\Delta T_{f}=$ film temperature rise found from Eq. (3.17) or (3.41)

$\Delta T_{c l}=$ temperature rise to the cladding midwall point found from Eq. (3.50) but for the midwall point

$F_{c}=$ hot spot factor for coolant temperature rise

$F_{f}=$ hot spot factor for film temperature rise

$F_{c l}=$ hot spot factor for cladding midwall temperature rise.

The coolant inlet temperature is a constant for any given reactor operating condition, but the midwall cladding temperature and the temperature rise terms are all functions of position. The maximum midwall cladding temperature, $\hat{T}_{c l}$, with hot spot factors does not occur at the same point in the core that the maximum midwall cladding temperature without hot spot factors is calculated to occur. In principle, it is necessary to solve Eq. (4.1) for every point in the reactor in order to find the maximum value.

\section{4-1B Methods to Determine the Hot Spot Factors}

To transform individual design and performance uncertainties into hot spot factors, a thermal-hydraulic analysis code is used, such as the COBRA-GCFR code. ${ }^{1}$ Subsequently, overall hot spot factors for coolant, cladding, and fuel temperatures are calculated from individual hot spot factors. Two methods can be used: totally deterministic or semi-statistical. For the totally deterministic method, the assumption is made that all uncertainties occur at their worst values all the time and everywhere in the core. This is a very conservative method of uncertainty analysis since a majority of the uncertainties are statistical in space or time or both.

For the semi-statistical method, each uncertainty is examined for its nature 
of occurrence. The uncertainties are divided into two groups: those occurring randomly over space and/or time and those that are deterministic. The deterministic uncertainties may have values that are statistical, but they occur constantly over the entire core or a large portion of it.

To combine the statistical and deterministic subfactors, two methods have been developed:

1. the Monte Carlo method, a numerical method that is closest to the way the uncertainties do occur

2. the semi-statistical "worst-value" method, a quick and nontedious analytical method.

\section{Monte Carlo Method}

The values of statistical uncertainties are picked randomly according to the nature of their distribution, and are applied to geometry, material properties, and operating conditions. Their effect is noted on the peak temperature of interest in the rod bundle (the "hot spot" temperature). A large number of computer runs have to be made before any conclusion can be drawn about the hot spot temperature. This method may be quite expensive. Also, there is no quick way to update the results should only a few of the uncertainties be revised.

\section{Worst-Value Method Analysis}

This is a standard method used for error analysis. The assumptions made for this analysis are:

1. The values of uncertainties are small deviations from their nominal values and, therefore, their effects on the core component temperatures can be considered to be linear.

2. For small deviations, the uncertainties can be considered to occurr independently.

This method is not mathematically as accurate as the Monte Carlo method; however, the results are close if the deviations are small and the number of uncertainties large. The biggest advantage is that uncertainties can be added, deleted, or revised without a lot of recalculation, because each is treated independently.

Both of the above semi-statistical methods calculate subfactors and total hot spot factors for any rod at a desired confidence level by simply using uncertainty values at that confidence level. Generally, it is sufficient to determine these values for the peak rods in the core to keep their temperatures within the specified limits. But, if information is desired on the probability of any assembly exceeding the limits or the number of rods in an assembly or in the core exceeding the limits, further statistical analysis has to be carried out as explained in the next section. 
In the design of the GCFR, the worst-value method is used together with determination of the probability of a hot spot in the core.

\section{4-1C Calculational Procedures}

The Monte Carlo method has been adopted by General Electric to calculate hot spot factors in the design of their breeder reactor. The worst-value analysis was used by Westinghouse in the design of the Clinch River Breeder Reactor and the same has been proposed for the GCFR. A description of the particular methods or codes used is given below.

\section{PACT-2}

The PACT code $^{2}$ computes the probability distributions of the coolant and cladding temperatures throughout a single assembly during steady-state operation. It uses a model that considers both thermal hydraulics in coolant subchannels and Monte Carlo sampling of the uncertainties. It uses a skewed random distribution for uncertainties so that most of the values picked are near the extreme value of interest. PACT-2 generates the hot spot factor and standard deviation for coolant and cladding temperatures in addition to generating nominal and hot spot temperature maps.

\section{GCFR and CRBRP Hot Spot Analysis ${ }^{3}$}

To determine the overall hot spot factor, $F_{b}$, each component, $f b_{l}$, of that factor is determined individually according to the functional relationship between the uncertainty and the temperature under consideration. The subchannel analysis code COBRA is used for determining channel and film factors; in this way, the effect of inter-subchannel coolant mixing is taken into account. These subfactors are divided into two groups; those that occur randomly, e.g., manufacturing and assembling tolerances and the properties of materials and the coolant, and those that are determined by experiments and listed as statistical subfactors. The cumulative components (uncertainties in calculations and measurements) are those that affect the entire core or large portions of it.

The statistical subfactors, $f s b_{l}$, are combined to give the total statistical factor, $F s_{b}$

$$
F s_{b}=1+\left[\sum_{l}\left(f s b_{l}-1\right)^{2}\right]^{1 / 2},
$$

and the total cumulative subfactor, $F c_{b}$, is given by combining the deterministic subfactors, $f c b_{i}$ :

$$
F c_{b}=\prod_{1} f c b_{l}
$$


The overall hot spot factor affecting component $b$ is then defined by

$$
F_{b}=F s_{b} \cdot F c_{b} .
$$

For both the above methods, the defined confidence level of the hot spot factors is obtained simply by using the uncertainties at that confidence level for all the calculations.

\section{SHOSPA}

The methods discussed above give nominal temperatures and the standard deviations of each rod in a fuel assembly, but neither of them directly gives the probability of the assembly (or core) or the number or rods in an assembly (or core) exceeding the limiting temperature.

The SHOSPA computer code ${ }^{4}$ provides this information. It determines the probability of each rod (or subchannel) exceeding the limiting temperature. For $n$ rods in an assembly, the probability $P(A)$ of exceeding the limiting temperature is given by

$$
P(A)=\prod_{l=n}\left[P_{\imath}\left(T_{\mathrm{llm}}\right)\right] \quad ;
$$

and for $N$ rods in a core, the probability $P(C)$ of exceeding the limiting temperature is given by

$$
P(C)=\prod_{i=N}\left[P_{t}\left(T_{1 \mathrm{~lm}}\right)\right] .
$$

The SHOSPA code calculates Eqs. (4.5) and (4.6) in addition to:

1. hot channel and hot spot factors using single subchannel analysis

2. the margin from nominal to limiting temperature and the probability of exceeding this temperature

3. the probability of at least one hot spot in the core

4. the probability of exactly $n$ hot spots in the core $(n=1$ to 10$)$.

\section{4-1D GCFR Hot Channel and Hot Spot Factors}

The subfactors for each of the components of the GCFR fuel hot spot analysis are listed in Table 4-I for turbulent flow conditions. Major subfactors are discussed below.

Rod Pitch, Wire Outside Diameter, and Cladding Outside Diameter: These describe the nominal flow area for each subchannel. The real area can vary due to fabrication tolerances along the length of a subchannel. For the analysis, a uniform deviation was assumed along the length, which gives a conservative result.

Grid Spacer Tolerances: These tolerances can result locally in an additional deviation of the rod pitch. Local area changes were modeled in COBRA and the effects were found to be very small for the fuel assembly and somewhat larger for the low pitch-to-diameter blanket design. 
Cladding Inside and Outside Diameter Tolerances: The effect of the cladding thickness on the cladding temperature drop is determined by taking the statistical sum of the individual effects of a larger than nominal outside diameter and a smaller than nominal inside diameter.

Cladding Outside to Inside Diameter Eccentricity: This eccentricity causes a nonuniform distribution of the heat flux contributing to hot channel and film on the thin wall side and hot cladding on the thick wall side. The largest of these two effects is considered.

Pellet Size and Fissile Content Tolerances: A batch of pellets may be oversized or contain more than a nominal amount of fissile material, resulting in hot channels and local hot spots.

Orifice Tolerance: This type of tolerance accounts for any misassignment of closely sized orifices.

Rib Height Tolerance: For the fuel rod, a higher than nominal rib height reduces the flow through its associated subchannel, making it hotter but at the same time improving the heat transfer coefficient. On the other hand, a lower rib height overcools the channel, but the heat transfer is not as effective. The condition leading to higher cladding temperature has been considered here.

Swelling, Creep, Duct Dilation, and Rod Bowing: These effects change flow areas locally. The effects of uncertainties in these parameters on the channel and film temperatures are small, but the parameters themselves have a significant effect. They are considered as the geometry changes in the assembly during the safety analysis of transients.

Properties of Materials, the Coolant, and Correlations: Considered as local effects, these subfactors are caused mainly by impurities in the coolant, fuel cladding, gap and cladding, and fuel materials. Coolant uncertainties can be eliminated when heat transfer, mixing, and friction data are available from tests of helium-cooled bundles. The uncertainties of helium properties will then be part of heat transfer, mixing, and friction factor correlations.

Thermal-Hydraulic and Physics Methods: Values have been estimated for the accuracy of the codes and other tools used for thermal-hydraulic and physics calculations that account for errors in core temperatures, peaking factors, and gamma heating.

Inlet Temperature Variation Due to Loop Imbalances: This uncertainty raises the temperature of all the core components and therefore is added to the total calculated temperature uncertainty. In addition, the increased coolant temperature has a small effect on flow distribution between assemblies, and on the heat transfer coefficient.

Axial and Circumferential Variation of the Heat Transfer Coefficient: Axial variation is due to the ribbed profile of the fuel rod and results in axial variation of the cladding temperature over one rib-pitch length, the effect being large on the rod surface and being damped by cladding conduction toward the rod inside diameter. The circumferential variation depends on the rod pitch-to-diameter ratio. Again, the temperature variation is not as large at the midwall or inside diameter surface as on the outside diameter surface. 
TABLE 4-I

Hot Spot Factors for 300-MW(e) GCFR Fuel Cladding (Full-power steady-state turbulent flow conditions)

\begin{tabular}{|c|c|c|c|c|}
\hline & $\begin{array}{l}\text { Uncertainty } \\
\text { 3o }\end{array}$ & $\begin{array}{c}\text { Channel } \\
\text { Factor } \\
F_{c}\end{array}$ & $\begin{array}{c}\text { Film } \\
\text { Factor } \\
F_{f}\end{array}$ & $\begin{array}{c}\text { Cladding } \\
\text { Factor } \\
F_{c l}\end{array}$ \\
\hline \multicolumn{5}{|l|}{ STATISTICAL } \\
\hline \multicolumn{5}{|l|}{ Tolerances } \\
\hline Fuel rod pitch & $05 \%$ & 1011 & 1001 & 1000 \\
\hline Grid spacer & $10 \%$ & $1000^{\mathrm{a}}$ & $1000^{\mathrm{a}}$ & $1000^{\mathrm{a}}$ \\
\hline Bowing & $11 \%$ & $1000^{\mathrm{a}}$ & $1000^{\mathrm{a}}$ & $1000^{\mathrm{a}}$ \\
\hline \multicolumn{5}{|l|}{ Cladding } \\
\hline outside diameter & $027 \%$ & 1003 & $1000^{\mathrm{a}}$ & 1000 \\
\hline 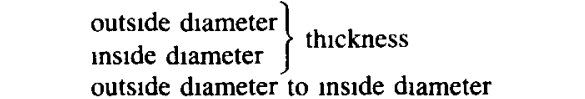 & $\begin{array}{l}027 \% \\
031 \%\end{array}$ & 1000 & 1000 & 1034 \\
\hline eccentricity & $48 \%$ & 1000 & 1000 & 1030 \\
\hline \multicolumn{5}{|l|}{ Pellet } \\
\hline outsıde diameter & $064 \%$ & 1015 & 1015 & 1014 \\
\hline density (fissile content) & $35 \%$ local & 1000 & 1035 & 1035 \\
\hline enrichment (fissile content) & $05 \%$ zonal & 1006 & 1000 & 1000 \\
\hline Orifice calıbration error & $50 \%$ & 1050 & 1040 & 1000 \\
\hline Rib height & $100 \%$ & 1016 & 1000 & 1000 \\
\hline $\left.\begin{array}{l}\text { Swelling } \\
\text { Creep and duct dilation }\end{array}\right\} \begin{array}{l}\text { Negligible at location } \\
\text { of hot spot }\end{array}$ & & 1000 & 1000 & 1000 \\
\hline \multicolumn{5}{|l|}{$\begin{array}{l}\text { Correlattons and Properties } \\
\text { Coolant }\end{array}$} \\
\hline specıfic heat & $05 \%$ & 1000 & 1002 & 10 \\
\hline density & $05 \%$ & 1000 & 1002 & 1000 \\
\hline viscosity & $45 \%$ & 1000 & 1030 & 1000 \\
\hline conductivity & $72 \%$ & 1000 & 1040 & 1000 \\
\hline
\end{tabular}


TABLE 4-I (continued)

Hot Spot Factors for 300-MW(e) GCFR Fuel Cladding

(Full-power steady-state turbulent flow conditions)

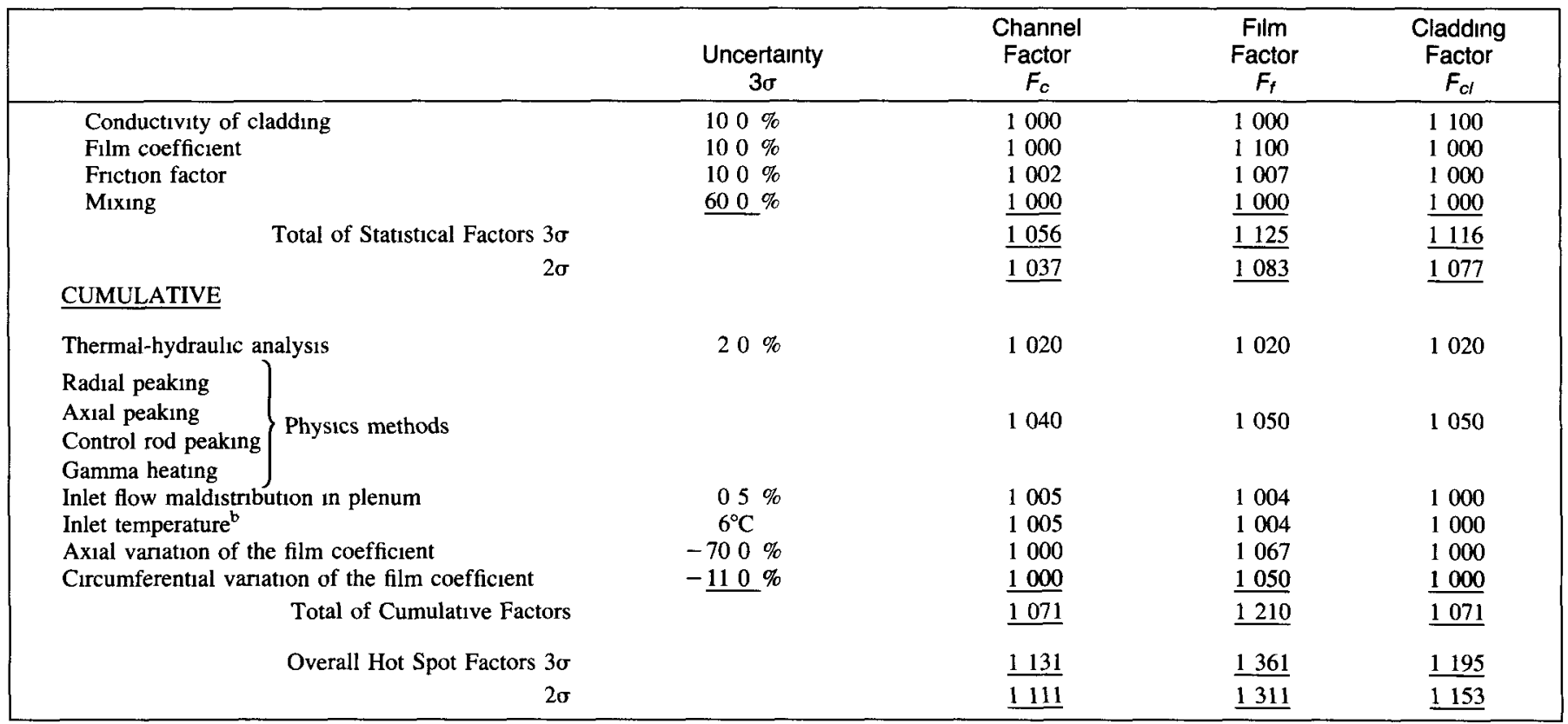

${ }^{\mathrm{a}}$ Values very close to 1

${ }^{b}$ In addition to the hot spot subfactor effect, calculated hot spot temperatures must be rassed by $6^{\circ} \mathrm{C}$ to account for coolant inlet temperature uncertainty 
Inlet Flow Maldistribution: Because of the resistance provided by a considerable amount of equipment in the inner plenum, there is little flow maldistribution to the GCFR core assemblies.

Flow Duct and Grid Spacer Clearance: The GCFR fuel and radial blanket assemblies are designed such that the edge rods adjacent to the duct wall are overcooled and the cladding hot spot occurs on interior rather than edge rods. For the fuel assembly, this design objective is achieved with a fuel rod-to-duct clearance that is $80 \%$ of the rod-to-rod clearance. The duct-to-spacer clearance resulting from fabrication and assembly requirements permits the bundle to shift to one side of the flow duct, which results in a small edge channel on one side and a large edge channel on the other side. Analysis has shown that even the small edge channel results in cladding temperatures lower than the hot spot temperature of interior rods. Because of this analytical finding, duct and spacer clearance is not part of the hot spot factors. However, duct-to-spacer clearance enters into rod temperature calculations for specific radiation-induced rod bowing calculations and fuel rod life evaluations.

\section{4-2 Coolant Mixing in Rod Bundles}

In rod bundle type fuel elements, there is a possibility that coolant temperature differences can occur along the axial length between adjacent subchannels. These temperature differences are possible because of geometrical tolerances and a nonuniform power distribution across the radial dimension of the rod bundle. Temperature differences due to geometrical tolerances are normally quite small but temperature differences due to a nonuniform radial power distribution can be sizable. Coolant temperature differences across the radial dimension lead to differences in cladding and fuel temperatures, which can affect the ability of the rod bundle to operate within the prescribed fuel and cladding temperature limitations.

Coolant mixing between adjacent subchannels will tend to reduce temperature differences. There are two mechanisms for coolant mixing: a net exchange of coolant flow between subchannels and the turbulent diffusivity of heat. The latter mechanism is by far the most important one for coolant temperature smoothing within rod bundles and is the subject of this section.

There are two limiting cases that are useful to analyze in order to establish bounds on the temperature distribution of the coolant, cladding, and fuel within a rod bundle having a nonuniform radial power distribution. The first limiting case assumes complete coolant mixing at each axial position, while the second limiting case assumes no mixing at all. These two cases can be analyzed using the methods of Chapter 3.

The heat exchange between adjacent subchannels may be expressed by

$$
q^{\prime \prime}=\left(k+\rho C_{p} \varepsilon_{H}\right) \frac{d T}{d y} .
$$

The first term in the parentheses, $k$, is the thermal conductivity of the fluid while 
the group of terms, $\rho C_{p} \varepsilon_{H}$, represents the turbulent diffusivity for heat. For gases under conditions expected in reactor fuel elements, turbulent diffusion is far greater than molecular conduction, $\rho C_{p} \varepsilon_{H} \gg k$, so Eq. (4.7) can be approximated with good accuracy by

$$
q^{\prime \prime}=\rho C_{p} \varepsilon_{H} \frac{d T}{d y} .
$$

This equation can then be used to formulate an approximate expression for the heat transferred per unit length due to turbulent diffusion between adjacent coolant subchannels $i$ and $j$ :

$$
q^{\prime}=Y\left(\rho C_{p} \varepsilon_{H}\right) g_{i j} \frac{T_{i}-T_{j}}{\delta_{i j}},
$$

where $g_{i j}$ is the gap width between the subchannels and $\delta_{i j}$ is the distance between the centroids of subchannels $i$ and $j$ (see Fig. 4-1). The term $Y$ in Eq. (4.9) is called the "mixing factor" and is an empirically determined quantity. Reynolds
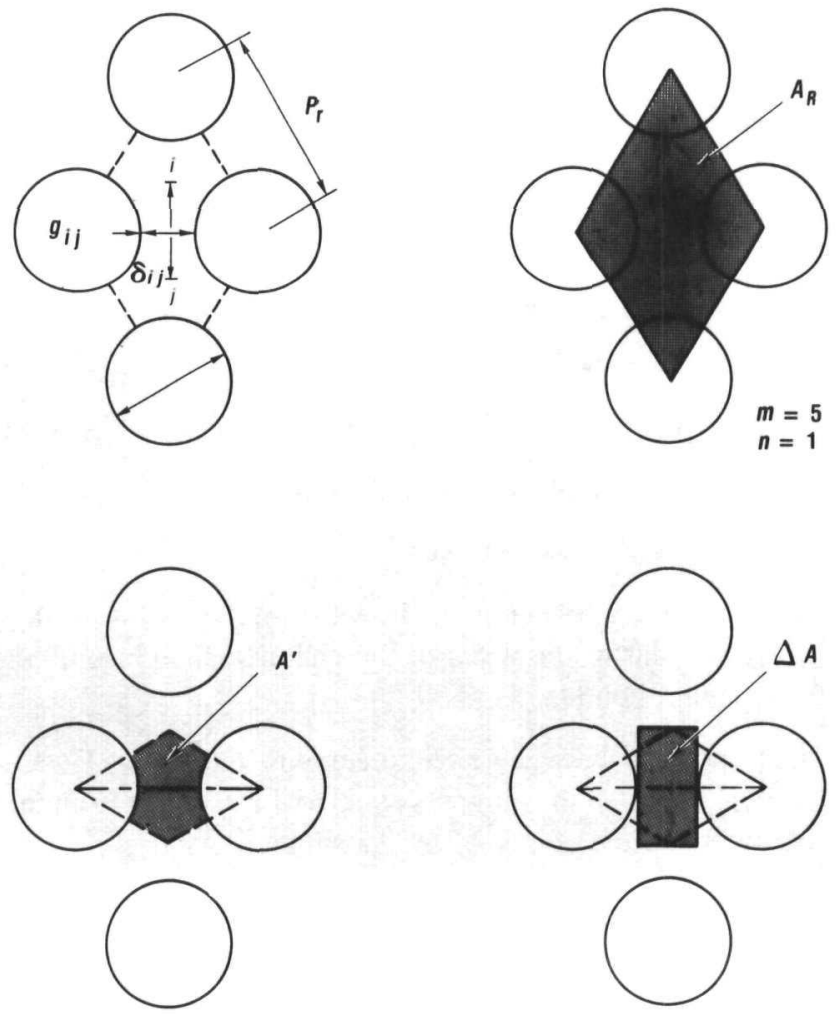

Fig. 4-1. Dimensions and areas used in turbulent coolant mixing models. 
analogy, which states that the diffusivities for the turbulent interchange of momentum and heat are nearly equal for gases, is used in the equation. Therefore, $\varepsilon_{M}=\varepsilon_{H}$ and $\varepsilon_{M}$ is given by the Nikuradse values:

$$
\varepsilon_{H}=\varepsilon_{M}=\frac{\mu}{\rho} \frac{\operatorname{Re}}{20} \sqrt{\frac{f}{2}} .
$$

Ingesson and Hedberg ${ }^{6}$ and later Ingesson ${ }^{7}$ experimentally determined the mixing factor and collected data from various authors. Ingesson ${ }^{7}$ recommended that the data be correlated by

$$
Y=C_{M}\left(\frac{\frac{\operatorname{Pr}}{d}}{\frac{\operatorname{Pr}}{d}-1}\right)^{1 / 2}\left(\frac{\operatorname{Pr}}{d} \frac{\operatorname{Pr}}{D_{H}}\right)^{3 / 2},
$$

where $C_{M}=1.158$ for a square array of rods and $C_{M}=0.933$ for a triangular array of rods.

Ingesson further analyzed the available data and arrived at a slightly modified expression for the mixing factor. Kjellström reported ${ }^{8}$ the modified expression for $Y$ as

$$
Y=1.14\left(\frac{n_{l}+n_{j}}{\sum_{m_{i}} \frac{\Delta A}{A^{\prime}}+\sum_{m_{J}} \frac{\Delta A}{A^{\prime}}}\right)^{1 / 2}\left(\frac{A_{R}}{A}\right)^{2},
$$

where

$m=$ number of gaps and $n=$ number of open gaps for the two subchannels

$A=$ actual flow area of the two subchannels

$A_{R}=$ flow area with rods removed

$A^{\prime}=$ area enclosed between lines drawn from the center of the subchannels perpendicular to the walls of the channel, the channel walls, and the subchannel boundary

$\Delta A=$ area enclosed between two tangents to the channel walls in the gap and the length of the tangents equal to the distance from the subchannel boundary to the center of the subchannel itself.

In a subsequent paper by Kjellström, ${ }^{9}$ some doubts were raised concerning the rather large values of $Y$ given by Eqs. (4.11) and (4.12). New experiments were performed at Würenlingen ${ }^{10}$ which confirmed that the Ingesson $Y$ values were too large and it was recommended that the expressions for $Y$ be multiplied by the correction factor 0.5 for the GCFR rod bundle fuel element. 
Another formulation for coolant mixing between subchannels has been used. In this second formulation, a turbulent cross flow, $w_{l y}$, between subchannels is introduced; it is defined as the mass interchange between channels $i$ and $j$ per unit time and per unit length. There is no net mass flow interchange so $w_{l j}=w_{l l}$. Heat is exchanged between subchannels according to

$$
q_{i j}^{\prime}=w_{l j} C_{p}\left(T_{\imath}-T_{J}\right) .
$$

Rowe and Angle ${ }^{11}$ correlated experimental results for the cross-flow factor by

$$
w_{l j}=0.04 \bar{D}_{H} \overline{\dot{M}} \sqrt{\frac{\bar{f}}{2}} \text {, }
$$

where $\bar{D}_{H}, \overline{\dot{M}}$, and $\bar{f}$ are average values of the hydraulic diameter, mass flow, and friction factor for subchannels $i$ and $j$, respectively.

The cross-flow formulation for mixing between subchannels of a rod bundle has been used for the design of the GCFR fuel element using the COBRA*GCFR computer program. ${ }^{11}$ This computer program is discussed in Sec. 4 of Chapter 10.

Calculational results by the method of Eq. (4.9) and (4.13) have been compared for the GCFR fuel element design and the results were found to agree within $\sim 10 \%$.

The empirical relations for coolant mixing between subchannels do not include the influence of fuel rod spacers on coolant mixing. It is estimated that the effect of spacers on coolant mixing can be an order of magnitude greater than the effect of turbulent diffusivity due to fully developed flow in rod bundle subchannels. Coolant mixing in rod bundles is an area of reactor thermal hydraulics requiring considerably more research and development.

\section{4-3 Core Temperature Shaping}

It was indicated in the previous chapter that the performance of the reactor core is limited by a maximum temperature. This performance limitation is, of course, true for any thermodynamic machine. The maximum temperature in a nuclear reactor may be limited by the moderator, by a structural component such as the fuel cladding, or by the fuel. For a reactor core designed on the basis of a uniform fuel loading and a fuel element configuration that is the same for each radial position and also uniform along the axial length, the maximum fuel element surface and maximum fuel temperature occur at one spot in the core. In effect, the entire fuel element is designed to operate within the maximum temperature limit that occurs at the one hot spot while the remainder of the core is operating below its capability at lower temperatures. Ideally, it is desirable to design the core so that all or the vast majority of the core operates at the maximum temperature limit with proper compensation for various uncertainties (hot spot factors). A more optimum reactor core design can be achieved by eliminating the restraint that the fuel be uniformly loaded and that the fuel element geometry be the same for each 
radial location and uniform along the axial length. In this discussion, means for achieving a more optimum core design by programming the axial fuel element shape and the axial fuel loading are considered. Extending these same ideas to the radial direction to achieve a more optimum design is not elaborated on but becomes obvious from what is said about axially programming the parameters. Radial flattening of the power distribution and/or orificing of channels for proper distribution of mass flow is found in most gas-cooled reactors. ${ }^{12}$

The first parameter considered is the axial fuel loading distribution, which in turn determines the axial heat flux distribution. In Sec. 3-3A, an equation for the axial surface temperature distribution was derived in the form

$$
\frac{T_{S}(\zeta)-T_{1}}{T_{2}-T_{1}}=\frac{\phi(\zeta)}{\sigma}+\int_{0}^{\zeta} \phi(\zeta) d \zeta,
$$

where

$T_{S}(\zeta)=$ surface temperature as a function of the dimensionless axial length, $\zeta$

$T_{1}=$ coolant inlet temperature

$T_{2}=$ coolant outlet temperature

$\phi(\zeta)=$ dimensionless axial flux distribution.

Also, $\sigma$ is the heat transfer parameter:

$$
\sigma=\operatorname{St}\left(\frac{P L}{A}\right)
$$

In this last expression, $S t$ is the Stanton number, $P$ the fuel element heated perimeter, $L$ the core length, and $A$ the fuel element cross-sectional flow area.

It is easy to demonstrate that an exponential flux distribution, for example,

$$
\phi(\zeta)=\phi(0) \exp (-\sigma \zeta)
$$

yields a constant surface temperature when substituted into Eq. (4.15). The magnitude of the temperature is determined by the value of the flux at the core inlet, $\phi(0)$, the value of the heat transfer parameter, $\sigma$, and the values of the coolant inlet and outlet temperatures. Figure 4-2 illustrates the flux and surface temperature distribution for this case.

The previous illustration for a constant axial surface temperature can be extended to a constant maximum fuel temperature along the axial core length if the heat transfer coefficient $h$ is replaced by a constant overall heat transfer coefficient, $U$, which represents the thermal conductance from the bulk coolant to the location of the maximum fuel temperature. Even if the overall heat transfer coefficient varies somewhat along the axial length, the exponentially decreasing power generation from core entrance to core exit will result in a more uniform fuel temperature throughout the core. In fact, any axial power generation that 


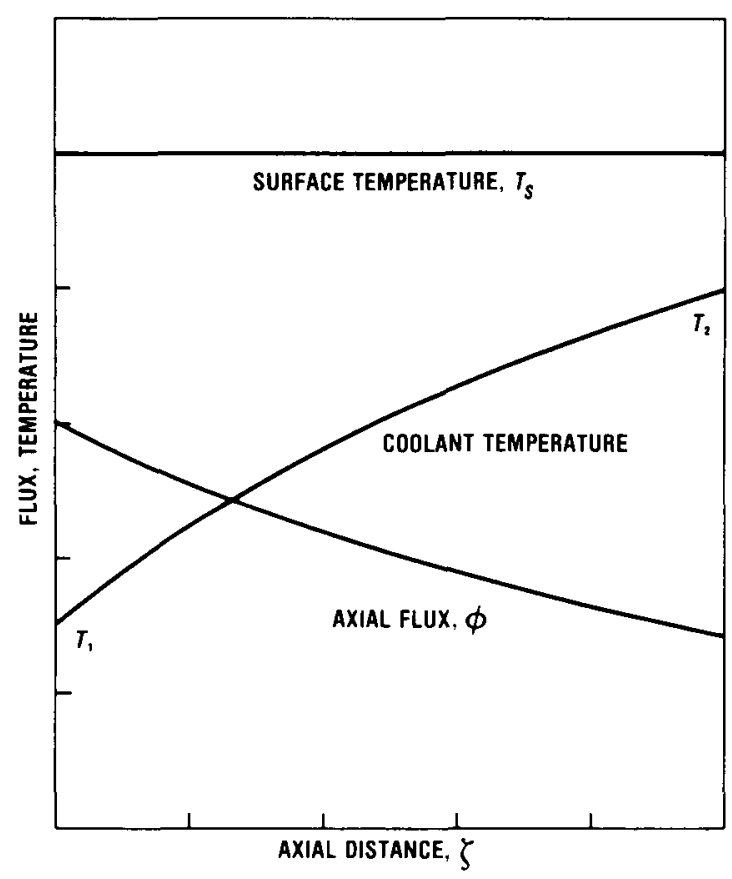

Fig. 4-2. Temperature shaping by fuel loading distribution.

decreases from core entrance to core exit will result in a flattened axial fuel temperature profile. This concept is used in the HTGR, which is designed with three axial fuel loading zones. The resulting core temperatures with this fuel loading strategy are discussed in Chapter 7.

Another core design concept once proposed to flatten the axial fuel cladding surface temperature while still employing a uniform fuel loading was to have the coolant enter the core at the center of the reactor then split and flow toward both ends. Both halves of the core then have a power distribution that is half of a chopped-cosine distribution, being a maximum at the inlet and decreasing toward the exit. The structural design of such a reactor core is obviously very complicated; it was only used in some early gas-cooled reactors.

Another means of flattening the axial temperature profile is to insert control rods from the exit (hot) end of the core, which causes the neutron flux to peak nearer the core entrance for a core with uniform fuel loading. A similar effect is achieved in a pebble bed reactor where fresh (high-power) fuel is introduced at the top and burned (low-power) fuel leaves at the bottom of the core (Once Through and Then Out cycle), with downflow in the core.

A way to achieve a more uniform surface or fuel temperature without resorting to a variable fuel loading is to vary the fuel element geometry along the axial length. Looking at Eq. (4.15), it can be seen that for any flux distribution it should 
be possible in principle to vary the heat transfer parameter $\sigma$ to produce a uniform surface temperature, $T_{s}$. Varying $\sigma$ implies varying either the heat transfer perimeter, $P$, the cross-sectional flow area, $A$, or the Stanton number, St. All of these parameters can be varied to achieve the same result, e.g., a flattened surface and fuel temperature. No serious attempt has been made to program the heat transfer perimeter to achieve a flattened temperature profile. On the other hand, flattening the core axial temperature profile by varying the cross-sectional flow area has received some attention. ${ }^{13,14}$ It was found that varying the fuel element crosssectional flow area not only could be used to obtain a more uniform axial temperature distribution but also resulted in a lowering of the coolant pumping power.

Varying the fuel element heat transfer perimeter or cross-sectional flow area along the axial length to achieve a flattened core temperature distribution results in a complex fuel element design. However, employing surface roughness as a means of increasing the Stanton number, that is, increasing the surface heat transfer coefficient, is a very effective way to achieve temperature flattening. Surface roughness is equivalent to a change in fuel element geometry but is a much more subtle change than either a perimeter or cross-sectional flow area change. Various roughness forms may be used, from regular rib elements to random sand-type roughness. Various manufacturing techniques can also be implemented to form the roughness elements.

A one-step, regular rib, surface roughness scheme is used in the design of

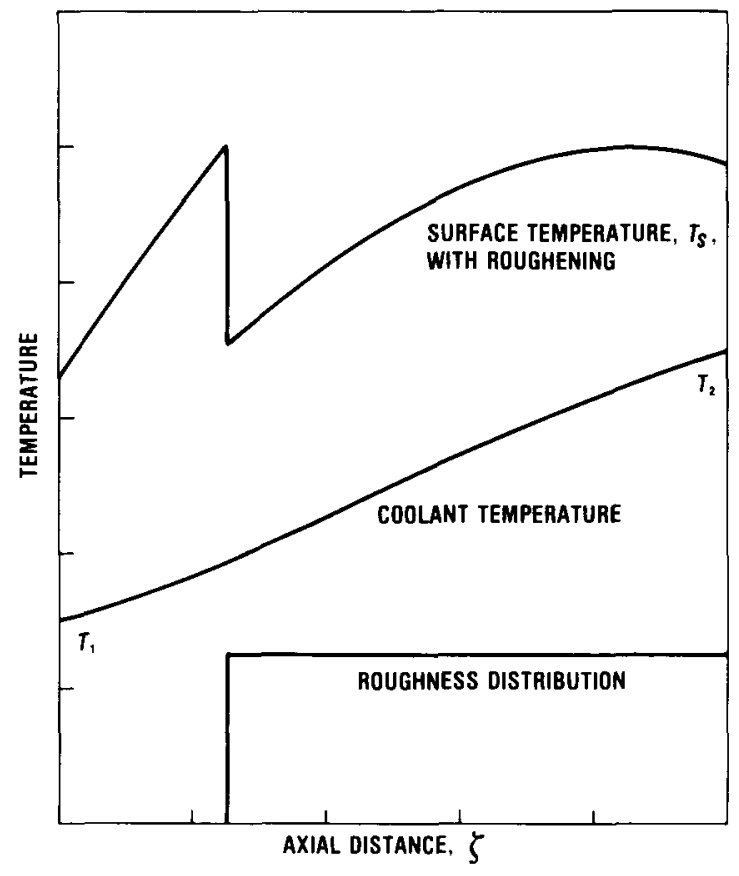

Fig. 4-3. Temperature shaping by one-step surface roughness. 
the GCFR and British gas-cooled reactors In this design, the inlet portion of the fuel element is smooth and the remainder rough The surface temperature distribution has the form shown in Fig 4-3

In the one-step surface-roughening design, the extent of roughening is adjusted so that the maximum temperature occurs at two points instead of just one Note that more of the surface operates near the maximum temperature Also, with this design, the average linear heat ratıng can be increased over that possible without surface roughening

Rather than using just one degree of surface roughness to produce a constant increase in the Stanton number, it is a conceivable extension to program the distribution of surface roughness along the axial fuel element length By doing this it is possible to achieve a flat temperature profile over a large part of the element as depicted in Fig 4-4 The distributed surface roughness achieves the desired temperature flattening and does so with less coolant pumping power than the one-step surface roughness approach Manufacturing the distributed roughness is more difficult than the one-step roughness but not significantly so

This discussion of core temperature flattening is not meant to be exhaustive or to cover the many interrelated problems of neutronics, heat transfer, and structural design However, this discussion indicates what can be accomplished by removing certain design restrictions that were imposed implicitly, if not explicitly, in Chapter 3

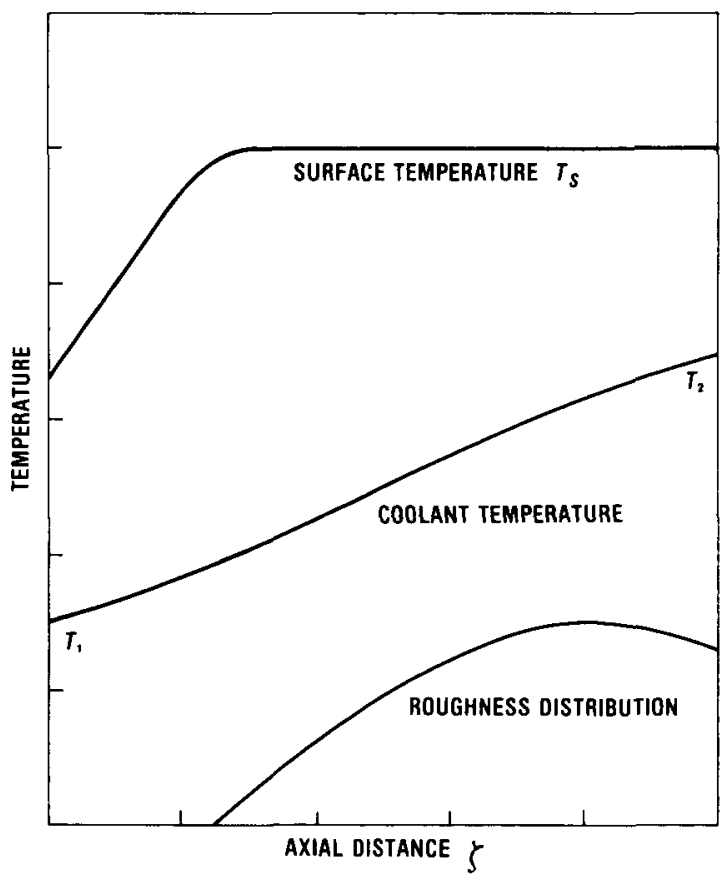

Fig 4-4 Temperature shapıng by distributed surface roughness 


\section{4-4 Choice of Gas Coolants}

Even though the subject of this monograph is helium-cooled reactors, it would be incomplete without a discussion of the possible gases that might be selected for use as a reactor coolant. In the early days of the development of gas-cooled reactors in the United States, there was considerable debate over the choice of coolant for a closed thermodynamic cycle nuclear reactor plant. Of course, air was the only choice for an open thermodynamic cycle.

The factors that need to be considered when choosing a cooling gas for a closed thermodynamic cycle nuclear reactor are: neutron absorption and activation, chemical stability and activity, structural material compatibility, availability, cost, and thermodynamic effectiveness. Thermodynamic effectiveness includes both consideration of heat transfer and coolant pumping. The following discussion concentrates on the choice of a gas coolant from the standpoint of the thermodynamic cycle.

A simplified analysis has been developed to bring out the salient points. Consider the simplest of reactor cores-a cylinder of length $L$ and frontal area $A_{c}$, containing a single coolant hole with diameter $D$ and flow area $A$. The total heat transfer surface is $S=\pi D L$ and the void fraction is $\varepsilon=A / A_{c}$. The conservation of mass, energy, and momentum for the gas flowing through the core are, respectively:

$$
\begin{gathered}
\dot{m}=\rho V A, \\
Q=\dot{m} C_{p} \Delta T,
\end{gathered}
$$

and

$$
\Delta p=\frac{1}{2} \rho V^{2}\left(\frac{4 f L}{D}\right)
$$

In Eq. (4.19), $Q$ is the total core power, $\Delta T$ the coolant temperature difference across the core, and $C_{p}$ the coolant specific heat capacity. The momentum equation is simply the coolant pressure drop, $\Delta p$, across the core with $f$ as the friction coefficient. Other pressure losses such as entrance, exit, spacer, and other parasitic losses are neglected in this development.

The core power can also be written as

$$
Q=h S \Delta t \text {, }
$$

where $h$ represents the effective heat transfer coefficient and $\Delta t$ the log-mean effective temperature difference. The heat transfer coefficient will be assumed to be obtained from an empirically determined Stanton number, St, defined by

$$
\mathrm{St}=\frac{h}{\rho V C_{p}}
$$

The core pumping power can be approximated by 


$$
P_{p}=\frac{\Delta p}{\rho} \dot{m} .
$$

In keeping with the simplicity of this development, the gas will be assumed to obey the perfect gas equation

$$
p=\frac{\rho R T}{M},
$$

where $R$ is the universal gas constant and $M$ the molecular weight. The gas density, $\rho$, in the momentum and pumping power equations is found from the perfect gas equation.

Combining the above equations in a straightforward, but lengthy, algebraic manner yields the expression

$$
\frac{Q}{A_{c}}=\varepsilon \frac{p}{R} \frac{\Delta T}{T}\left(\frac{P_{p}}{Q} \frac{\mathrm{St}}{f / 2} \Delta t\right)^{1 / 2} M C_{p}^{3 / 2} .
$$

This equation, or variations of it, has been used to compare gas coolants. Although it was derived for a very simple core configuration, it is actually independent of the configuration.

To make a direct comparison of gas coolants, assume that the core characteristics of void fraction, pressure, coolant and surface temperatures, and the ratio of pumping power-to-core thermal power are all fixed. The quantity $Q / A_{c}$ is the ratio of core thermal power to frontal area and is one measure of merit. The term $Q / A_{c} L$ is the core power density so it is desirable that $Q / A_{c}$ be maximized. The properties of gas coolants enter via St/(f/2) and $M C_{p}{ }^{3 / 2}$. However, for turbulent flow of all gases, the quantity St/(f/2) is nearly constant (Reynolds analogy). Therefore, the influence of the gas coolant can be expressed by

$$
\frac{Q}{A_{c}} \propto M C_{p}^{3 / 2}
$$

or by introducing the molar specific heat capacity, $c_{p}=\frac{C_{p}}{M}$ :

$$
\frac{Q}{A_{c}} \propto\left(\frac{c_{p}^{3}}{M}\right)^{1 / 2} .
$$

This last relation indicates that the best gas coolant is one with a large molar heat capacity and a small molecular weight. These two requirements tend to be contradictory. The kinetic theory of gases indicates that the molar heat capacity increases with the complexity of the gas or, more precisely, with the number of degrees of molecular freedom: translation, rotation, and vibration. The high molecular weight gases are complex and have more degrees of freedom than the low molecular weight gases. However, overall, the low molecular weight gases are better choices for coolants based on the above performance parameter. Hydrogen 
TABLE 4-II

Thermal Performance Comparison of Selected Gas Coolants

Relative to Helium*

\begin{tabular}{|lccc|}
\hline Gas & $\begin{array}{c}\text { Power for } \\
\text { Fixed Frontal } \\
\text { Area }\end{array}$ & $\begin{array}{c}\text { Heat Transfer } \\
\text { Area for Fixed } \\
\text { Flow Area }\end{array}$ & $\begin{array}{c}\text { Pressure op } \\
\text { for a Given } \\
\text { System Pressure }\end{array}$ \\
\hline Helium & 100 & 100 & 100 \\
$\mathrm{CO}_{2}$ & 122 & 132 & 252 \\
$\mathrm{H}_{2}$ & 241 & 109 & 142 \\
Steam & 118 & 160 & 196 \\
Alr & 070 & 124 & 153 \\
\hline
\end{tabular}

${ }^{*}$ Gas properties were evaluated at $345 \mathrm{MPa}(500 \mathrm{psia})$ and $540^{\circ} \mathrm{C}\left(1000^{\circ} \mathrm{F}\right)$ Same ratio of pumping power to thermal power

as the lowest molecular weight gas turns out to be the best choice for a gas coolant based only on heat transfer considerations and is indeed a good choice for certain applications, such as space power for instance, but hydrogen is not acceptable in nuclear power stations for safety reasons.

Table 4-II is a comparison of a few potential gases for nuclear reactor application. It is seen from this table that the ratio $Q / A_{c}$, power for fixed frontal area, is greater for $\mathrm{CO}_{2}, \mathrm{H}_{2}$, and steam and less for air compared to helium. However, this is not the only figure of merit for comparing gases. ${ }^{15}$ For example, in comparing gases on the basis of the required heat transfer area for a fixed flow area, which is indicative of the complexities of mechanical design such as fuel rod spacing, helium is favored over the other gases, as also seen in Table 4-II. Another parameter of interest is $\Delta p / p=\left(1-\frac{1}{\gamma}\right)^{-1} \frac{\Delta T}{T_{1}} \frac{P_{p}}{Q}$, which relates to pressure loads on grid plates, etc., and it is seen again from Table 4-II that helium is favored over the other gases.

The choice of gas coolants usually reduces to carbon dioxide and helium for large-scale nuclear power plants. Studies ${ }^{16}$ have shown that helium is to be preferred over carbon dioxide on the basis of turbomachinery design. Compared to $\mathrm{CO}_{2}$, helium will lead to

1. a smaller frontal area for the same blade efficiency

2. lower exit diffuser losses

3. less sensitivity to off-design operation.

On the other hand, for large pressure ratio turbomachinery, helium requires more blade rows than a turbomachine designed for $\mathrm{CO}_{2}$. Helium turbomachinery is limited by blade stresses while $\mathrm{CO}_{2}$ turbomachinery is limited by the Mach number.

The choice between helium and $\mathrm{CO}_{2}$ for natural circulation cooling for afterheat removal has also been studied. ${ }^{17}$ While the use of a heavy gas is normally preferable, especially in the laminar flow regime, with an acceptable design for 
the natural circulation loop, pressurized helium can remove the afterheat for the HTGR and the GCFR.

The choice of helium as a coolant for nuclear reactors is a good one when based on considerations other than thermodynamic ones:

1. There is no significant neutron interaction at practical pressures for nuclear power plants.

2. Helium is chemically inert.

3. Although proper design precautions need to be taken to prevent helium leakage, tests on and operation of helium-cooled reactors have demonstrated that acceptable design leakage rates can be achieved. ${ }^{18}$

4. The availability of helium in the United States is assured for the foreseeable future. ${ }^{19}$

5. Although self-welding of metal components at high temperatures was once thought to present a problem, this has not turned out to be the case.

6. Although the cost of helium can be expected to increase in the future, it should remain a very small cost of reactor operation for any acceptable leakage rate.

\section{4-5 Pebble Bed Reactor Thermal Hydraulics}

In the case of pebble beds, the pressure drop may be written as

$$
\Delta p=\psi \frac{L}{d_{p}}\left(\frac{1-\varepsilon}{\varepsilon^{3}}\right) \frac{\rho V^{2}}{2} .
$$

If $V_{p}$ is the mean velocity between the particles, the mean velocity, $V$, corresponding to the free cross section of the pebble bed is simply

$$
V=\varepsilon V_{p},
$$

where $\varepsilon$ is the void fraction in the bed. The hydraulic diameter, $D$, is related to the pebble diameter, $d_{p}$, by the relation,

$$
D=d_{p}\left(\frac{\varepsilon}{1-\varepsilon}\right) \text {. }
$$

Defining a Reynolds number by

$$
\operatorname{Re}=\left(\frac{1}{1-\varepsilon}\right) \frac{\rho V d_{p}}{\mu},
$$

experimental results are correlated up to $\operatorname{Re}=5 \times 10^{4}$ by $^{20}$

$$
\psi=320 \operatorname{Re}^{-1}+6 \operatorname{Re}^{-01} \text {, }
$$

where the two terms on the right side correspond to laminar and turbulent flow, respectively. Uncertainties come mainly from the actual value of the voidage of 
the random packing of equal spheres, which is 0.375 for an infinite bed and varies with distance from the wall.

Experimental results for heat transfer can be correlated as ${ }^{20}$

$$
\mathrm{Nu}=\frac{h d_{p}}{k}=\frac{1-\varepsilon}{\varepsilon} \operatorname{Re}^{0.6} \operatorname{Pr}^{1 / 3} \text { for } 500<\operatorname{Re}(1-\varepsilon)<10^{4} \text {. }
$$

Other correlations have been proposed, such as ${ }^{21}$

$$
\begin{gathered}
\mathrm{Nu}=2+\frac{1-\varepsilon}{\varepsilon} \mathrm{Re}^{0.5}+5 \times 10^{-3} \frac{1-\varepsilon}{\varepsilon} \mathrm{Re} \\
\quad \text { for } 250<\operatorname{Re}(1-\varepsilon)<5.5 \times 10^{4}
\end{gathered}
$$

or $^{22}$

$$
\begin{aligned}
& \mathrm{Nu}^{2}=0.35 \frac{\operatorname{Pr}^{0.6}}{\varepsilon^{3.34}} \operatorname{Re}^{0.877}+0.00316 \frac{\operatorname{Pr}}{\varepsilon^{2.05}} \operatorname{Re}^{1.67} \\
& \text { for } 10^{2} \leqslant \operatorname{Re} \leqslant 10^{5}, \text { and } 0.26 \leqslant \varepsilon \leqslant 0.476
\end{aligned}
$$

For low Reynolds numbers, several correlations have been proposed such as

$$
\begin{gathered}
\mathrm{Nu}=1.04[(1-\varepsilon) \mathrm{Re}]^{0.5} \\
\text { for } 10<(1-\varepsilon) \mathrm{Re}<200,
\end{gathered}
$$

but the problem is not yet solved.

Effective radial and axial heat conductivities in the packed bed must also be derived taking into account anisotropic convection, conduction, and radiation.

Transverse energy transport in a pebble bed is usually described by defining an effective thermal conductivity of the bed:

$$
k_{\mathrm{eff}}=k_{s}+k \frac{\mathrm{Pe}}{m},
$$

where

$$
\begin{aligned}
k_{s} & =\text { conductivity of the bed without flow } \\
k & =\text { coolant thermal conductivity } \\
\mathrm{Pe} & =\operatorname{Re} \times \operatorname{Pr}, \text { Peclet number } \\
m & =\text { parameter equal to } \sim 8.5 \text { for a large reactor. }
\end{aligned}
$$

The second term on the right in Eq. (4.37), which corresponds to forced flow, is much larger than the first term during normal operation but the first term is important for accident conditions.

Significant cross flow occurs in a pebble bed; the flow resistance in the transverse direction should be calculated with the same correlation as in the vertical direction in the fully turbulent regime. Some other specific problems occurring 
with pebble beds are wall effects, radial variations of void fraction and velocity, effects of free convection, and heat transfer from the pebbles at the surface of the bed Finally, under accident conditions, and loss of forced cooling, natural convection and radiation heat transfer become very important Experımental results have been reported on model tests for those two phenomena For instance, the effective conductivity of graphite spheres is found ${ }^{23}$ to increase from $\sim 12$ to $50 \mathrm{~W} / \mathrm{m} \mathrm{K}$ when the temperature of the bed increases from 1000 to $2500^{\circ} \mathrm{C}$

\section{NOMENCLATURE}

Symbol

$A \quad=$ cross-sectional area of flow channel

$A_{c} \quad=$ cross-sectional area of reactor core

$A_{R} \quad=$ flow area in coolant mixing parameter [Eq $(4$ 12)]

$A^{\prime} \quad=$ flow area in coolant mixing parameter [Eq $\left.(412)\right]$

$C_{M} \quad=$ coolant mixing parameter [Eq $\left(\begin{array}{ll}4 & 11\end{array}\right)$ ]

$C_{p}=$ specific heat capacity

$c_{p} \quad=$ molar specific heat capacity

$D \quad=$ hydrauhc diameter

$d \quad=$ fuel rod diameter

$d_{p} \quad=$ pebble diameter

$F \quad=$ overall hot spot factor

$F_{c} \quad=$ coolant temperature rise hot spot factor

$F_{c} \quad=$ total cumulative hot spot subfactor [Eq (4 3)]

$F_{c l} \quad=$ cladding temperature rise hot spot factor

$F_{f} \quad=$ film temperature nse hot spot factor

$F_{s} \quad=$ total statistical hot spot subfactor [Eq (4 2)]

$f \quad=$ Fanning friction factor

$f_{c b} \quad=$ hot spot deterministic subfactor for component $b$

$f_{s b} \quad=$ hot spot statistical subfactor for component $b$

$g=$ gap width between subchannels [Eq (4 9)]

$h \quad=$ heat transfer coefficient

$k=$ thermal conductivity

$k_{\text {eff }} \quad=$ effective thermal conductivity

$k_{s} \quad=$ conductivity in pebble bed without flow

$L \quad=$ core length

$M \quad=$ molecular weight

$\dot{M} \quad=$ total mass flow rate

$m \quad=$ number of total gaps [Eq $\left.\left(\begin{array}{ll}4 & 12\end{array}\right)\right]$

$\dot{m} \quad=$ channel mass flow rate

$N \quad=$ number of fuel rods in core

$\mathrm{Nu}=$ Nusselt number

$n \quad=$ number of fuel rods in fuel element assembly

$n \quad=$ number of open gaps [Eq $\left.\left(\begin{array}{ll}4 & 12\end{array}\right)\right]$

$P \quad=$ heat transfer perimeter

$P_{p} \quad=$ coolant pumping power 


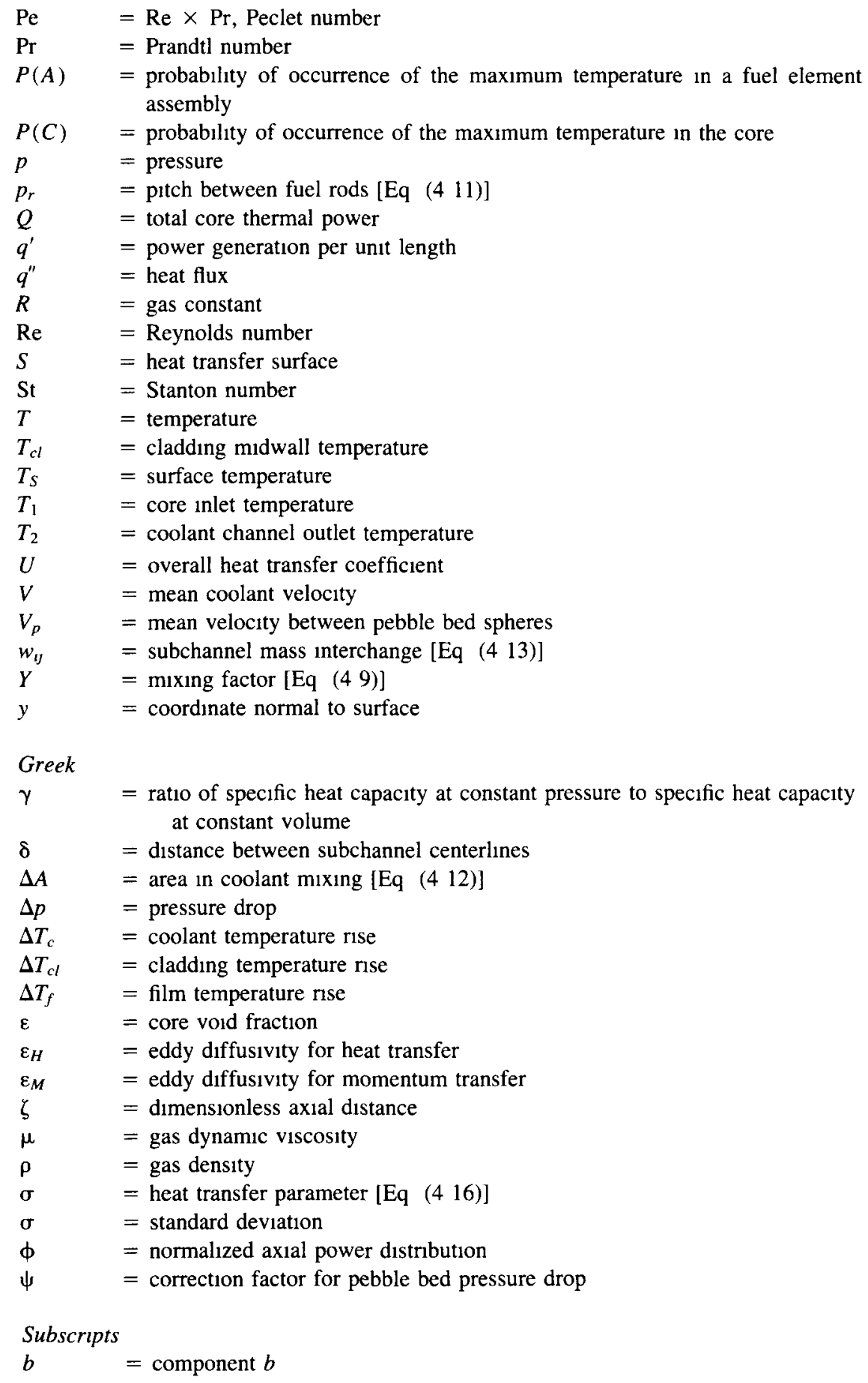




$\begin{array}{ll}\imath & =\text { index for } \imath^{\prime} \text { th subchannel or } \imath^{\prime} \text { th hot spot subfactor } \\ J & =\text { index for } J^{\prime} \text { th subchannel } \\ \lim & =\text { limiting temperature }\end{array}$

Superscripts

$\begin{array}{ll}- & =\text { mean quantity } \\ & =\text { maximum quantity }\end{array}$

\section{REFERENCES}

1 C B Baxı, C J Burhop, and F O Bennett, "COBRA*GCFR, A Computer Code for Thermal-Hydraulic Analysis of GCFR Fuel Assembly," Trans Am Nucl Soc, 30, 543 (1978)

$2 \mathrm{~K}$ H Chen and G D Hoover, "PACT-2 Probabilıstic Analysıs of Coolant and Claddıng Temperatures," GEFR-00417, General Electric Co (Oct 1978)

3 "CRBRP Assemblıes Hot Channel Factors Prelıminary Analysıs," WARD-D-0050, Westınghouse Electric Corp (Oct 1974)

4 A Amendola, "SHOSPA Advanced Statistıcal Hot Spot Analysis," KfK-1843, EUR 3979, Kernforschungszentrum Karlsruhe (1968)

5 J Nikuradse, "Gesetzmazigkeit der Turbulenten Stromung in Glatten," Rohren Forschungsheft (1932)

6 L Ingesson and S Hedberg, "Heat Transfer Between Subchannels in a Rod Bundle," Proc 4th Int Heat Transfer Conf, Versalles, Parı, August 31-September 5, 1970, U Grigull and E Hahne, Eds, Vol III, p FC7 11, Elsevier, Amsterdam (1970)

7 L Ingesson, "Heat Transfer Between Subchannels in a Rod Bundle A Comparison Between Existıng Correlations,' Proc 5th GCFR Heat Transfer Specialists Mtg , Wurenlıngen, Switzerland, May 14-16, 1979, OECD Nuclear Energy Agency

8 B KJellstrom, “Mixing in Clusters," Proc Heat Transfer Specialıts Mtg, Windscale, England, OECD Nuclear Energy Agency (1972)

9 B Kjellstrom, "Studies of Turbulent Flow Parallel to a Rod Bundle of Triangular Array,' AE-487, Aktiebolaget Atomenerg1, Sweden (May 1974)

10 U Stiefel, Swiss Federal Institute for Reactor Research, Private Communication (1976)

11 D W Rowe and C W Angle, "Experımental Study of Mixıng Between Rod Bundle Fuel Element Flow Channels During Boilıng," Trans Am Nucl Soc , 10, 665 (Nov 1967)

12 G Melese-d'Hospital, "Sımplıfied Analysis of Coolant Flow and Outlet Temperature in Gas-Cooled Nuclear Reactor Cores," Nucl Scl Eng , 35, 165 (1969)

13 G Melese-d'Hospital, "Comparison of Partial Roughening of the Surface of Fuel Elements with Other Ways of Improving Thermal Performance of a Nuclear Reactor," Trans Am Nucl Soc, 6, 337 (1963)

14 K Ichımiya and S Hasegawa, "Studies of Flattenıng of Axıal Temperature Distrıbutıon of a Fuel Element and Optımızation of Pumping Power,' $N$ Cl Eng Des, 31, 363 (1974)

15 G Melese-d'Hospital, "Influence of the Choice of Coolant Gas on Reactor Thermal Performance,' Nucl Appl , 2, 205 (June 1966)

16 W D Rannie, "Prelımınary Consideratıons Relatıng to Selection of Coolants for Closed-Cycle Gas Coolants," internal memorandum, GA Technologies (July 1958) 
17 G Melese-d'Hospital, “On Natural Circulation in High-Temperature Gas-Cooled Reactor and Pebble Bed Reactors for Different Flow Regimes and Various Coolant Gases," Proc 2nd Int Topl Mtg Nuclear Reactor Thermal Hydraulics, Santa Barbara, Calıfornia, January 11-14, 1983, Vol II, p 858, American Nuclear Society (1983)

18 A J Neylan et al , "Leaktightness in HTGRs-Experience at Fort St Vrain," GAA13383, GA Technologies (June 1975)

19 E Cook, "The Helium Question," Science, 206, 1141 (Dec 7, 1979)

20 E Achenbach, "Forced Convective Heat Transfer and Pressure Drop of a Randomly Packed HTGR Core,' NUREG-CP0014, U S Nuclear Regulatory Commission (Oct 1980)

21 K R Stroh et al , "A Steady-State Thermal-Hydraulic Model for Gas-Cooled Pebble Bed Reactor Cores,', NUREG-CP0014, U S Nuclear Regulatory Commission (Oct 1980)

22 Gysler and Haque, "On the Thermal Hydraulics of Pebble Bed Reactors," NUREGCP0014, U S Nuclear Regulatory Commission (Oct 1980)

23 K Petersen et al , "Thermal Hydraulıcs of the Pebble Bed High Temperature Reactor Under Accident Conditions,' NUREG-CP0014, U S Nuclear Regulatory Commission (Oct 1980) 


\section{RELATED MECHANICAL PROBLEMS*}

\section{5-1 Introduction}

The thermal and fluid dynamic design of a reactor is dependent upon the structures that enclose the flow, the designs for both should be considered s1multaneously The mechanical designs of the core and the nuclear steam supply system structures generally limit the reactor overall performance For example, the outlet temperature of the reactor and, hence, reactor efficiency are limited by the ablity of the core structures and the steam supply system structures to withstand the thermal stress induced as the plant cycles between high-temperature full-power operation and a cold shutdown Indeed, the history of energy development parallels the creation of alloys that will withstand ever-increasing temperatures and pressures with ever-ıncreasing lifetimes

Three aspects of the mechanical design analysis of helium-cooled reactor structures are reviewed in this chapter flow-induced vibration, sound-induced vibration, and thermal stress analysis Flow-induced vibration is defined as the vibration of relatively flexible structures, such as fuel rods or heat exchangers, due to the passage of helium over the structures The helium flow can cause vibration that can damage a flexible structure etther by high cycle fatigue or by fretting wear at the supports Acoustic analysis is concerned with acoustic waves traveling at the speed of sound through the reactor circuit These sound waves are generated primarily by the circulators but they can also be induced by abrupt changes in the flow direction of the helium and within the heat exchanger tube banks Acoustic noise can damage plates and shells lining the ducts and cavities of the flow circuit Thermal stresses are induced in any restrained component by the tendency of materials to expand as they are heated If the temperature is uniform and there is no restraint on the structure, then heating results in an expansion but no resultant stress Thermal stresses are generated as components attempt to expand against restraints provided by adjacent structural supports or as a result of a nonuniform temperature distribution within the body For example, heat exchanger tubes that are cooled by the internal flow of boiling water do not expand as much as their supportıng plates, which run at nearly the helium coolant

*This chapter was contributed by $\mathrm{R}$ D Blevins 
temperature, and a differential thermal stress is induced between the heat exchanger tubes and their support plates.

\section{5-2 Flow-Induced Vibration}

\section{5-2A Dimensional Analysis, Classification, and Testing}

In general, flow-induced structural vibrations are driven by a highly energized flow that contacts a relatively flexible structure. In nuclear reactors, flow-induced vibrations are nearly always the result of the reactor coolant impinging on flexible reactor internals, fuel rods, shielding, or heat exchanger tubes. The resultant vibrations are undesirable and often unanticipated. They are frequently the unfortunate by-product of the tendency of structures to become more flexible and flows to increase in velocity as reactors are scaled up.

Consider the two-dimensional, spring-supported, damped cross section exposed to a uniform low Mach number flow, as shown in Fig. 5-1. The fluid flow exerts a force on the structure in the flow. The force causes the structure to deform. The magnitude of the deformation depends on the magnitude of the fluid force relative to the mass, stiffness, and damping of the structure and the manner in which the force is applied. The flow and the structure can be characterized by the parameters listed in Fig. 5-2. From these parameters, the following nondimensional groups can be formed:
Reynolds number: $\frac{\rho U D}{\mu}$
Mass ratio: $\frac{m}{\rho D^{2}}$
Reduced velocity: $\frac{U}{f D}$
Damping: $\zeta$
Geometry: $\frac{L}{D}$
Amplitude: $\frac{Y}{D}$

The well-known Buckingham $\Pi$ theorem implies that any one of these parameters
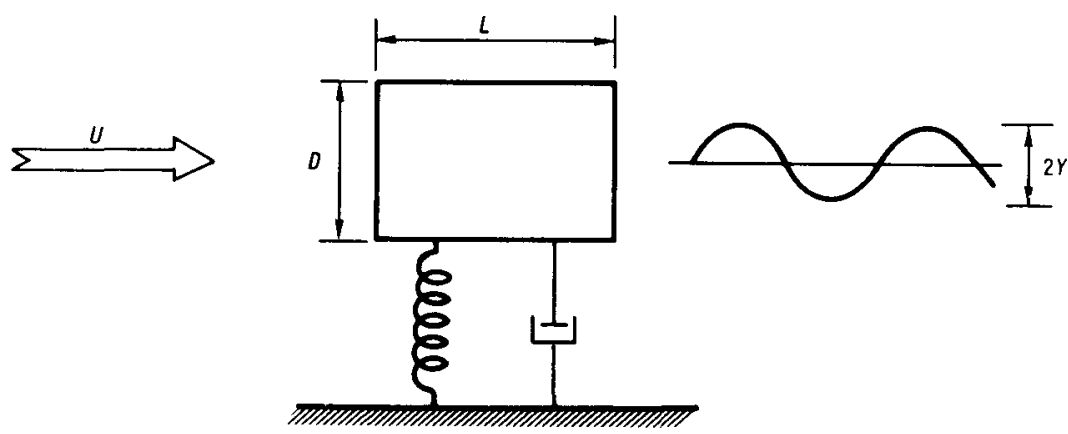

Fig. 5-1. A spring-mounted structure exposed to a fluid flow. 


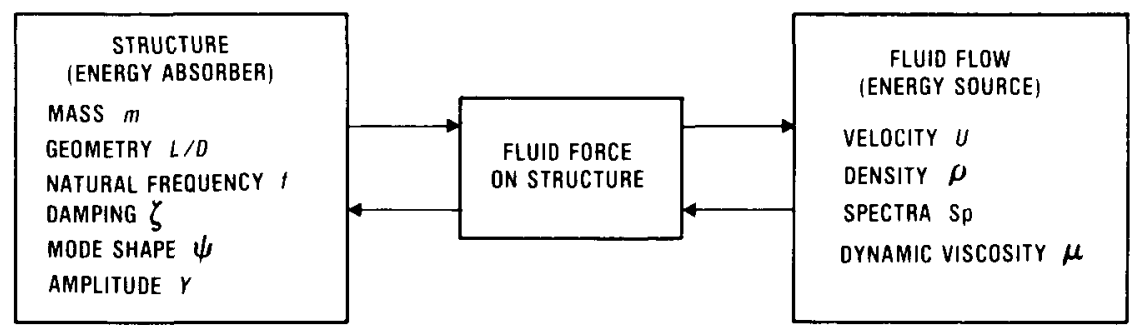

Fig 5-2 Fluid/structure interaction

can be expressed as a function of the remaining parameters Thus, the nond1mensional amplitude can be expressed functionally as (see Nomenclature, $p$ 174)

$$
\frac{Y}{D}=F\left(\frac{\rho U D}{\mu}, \frac{U}{f D}, \frac{L}{D}, \frac{m}{\rho D^{2}}, \zeta\right)
$$

Of course, additional parameters could be added to the right side of Eq (5 1), such as mode shape, higher modes, or nondimensional turbulence spectra, but as it stands, the right side factor of Eq (5 1) is a minimal list of nondimensional parameters needed to begin a flow-induced vibration analysis The need for nondimensional analysis is justified as the only engineering approach at the present tıme

Thus, at the least, the following seven quantities must be determined before beginning a flow-induced vibration analysis

1 fluid velocity

2 fluid density

3 fluid kinematic viscosity

4 structural geometry

5 structural natural frequency (ordinarily fundamental mode)

6 structural damping

7 structural mass and mass distribution

In general, establishıng these seven quantitıes requires a rigorous dynamic analysis of fluid and structural performance Certain quantities, such as damping, ordinarily are not known with sufficient accuracy even in cases where dynamic measurements are made However, an error in any of these seven quantities will be reflected by an error in the calculated vibration [Eq (5 1)]

Flow-induced vibration phenomena are generally classified by the nature of the fluid force and by the type of system affected by the vibrations The classification given in Table 5-I is only a partial list of the known flow-induced vibration phenomena Transient mechanisms such as water hammer and pıpe whip have been omitted, as have vibrations due to internal flow, such as pipe instabilities and vibrations forced by pump oscillations However, all of these phenomena are practically important in the sense that they have been observed in industry, all 


\section{TABLE 5-I}

Classification of Flow-Induced Vibrations

\begin{tabular}{|c|c|c|c|}
\hline & Phenomena & $\begin{array}{l}\text { Instantaneous Fluid } \\
\text { Force Is Explicitly } \\
\text { Dependent On }\end{array}$ & $\begin{array}{l}\text { Systems Subject to } \\
\text { the Phenomena }\end{array}$ \\
\hline 1 & $\begin{array}{l}\text { Vortex-induced } \\
\text { structural vibration }\end{array}$ & $\begin{array}{l}\text { Time, amplitude of structural } \\
\text { vibration }\end{array}$ & $\begin{array}{l}\text { Slender bluff structures in a } \\
\text { cross-flow }\end{array}$ \\
\hline 2 & $\begin{array}{l}\text { Galloping and } \\
\text { flutter }\end{array}$ & $\begin{array}{l}\text { Translational velocity of } \\
\text { structure, rotation of structure, } \\
\text { rate of rotation of structure }\end{array}$ & $\begin{array}{l}\text { Slender structures in a cross } \\
\text { flow, tubing, plates, and shells } \\
\text { in a parallel flow (rare) }\end{array}$ \\
\hline 3 & Whirling & $\begin{array}{l}\text { Position of one tube relative to } \\
\text { adjacent tubes }\end{array}$ & $\begin{array}{l}\text { Closely spaced tube arrays in a } \\
\text { cross flow }\end{array}$ \\
\hline 4 & $\begin{array}{l}\text { Turbulence-induced } \\
\text { vibration }\end{array}$ & Time (random) & $\begin{array}{l}\text { Any structure subject to a } \\
\text { turbulent flow }\end{array}$ \\
\hline 5 & $\begin{array}{l}\text { Vortex-induced } \\
\text { acoustic vibration }\end{array}$ & Time & $\begin{array}{l}\text { Acoustic cavities containıng } \\
\text { bluff structures in a cross fiow }\end{array}$ \\
\hline
\end{tabular}

can occur in nuclear reactors, and a body of literature has developed about each of them. Note that in Table 5-I, the forces are explicitly time dependent in vortexinduced vibration (items 1 and 5) and turbulence-induced vibration (item 4). This dependence results because both of these phenomena depend on eddies that exist in the flow regardless of the presence or absence of structural vibration. However, in galloping and flutter (item 2 ) and whirling (item 3), the fluid forces are primarily dependent on the position and velocity of the structure relative to the flow; consequently, time does not explicitly appear in the associated fluid forces. As a result, the mathematical models used to analyze galloping, flutter, and whirling are self-excited while those employed for vibration induced by vortex shedding and turbulence are forced.

In the remainder of this section, it is assumed that the velocity, density, and Reynolds number of the flow are known and that the geometry, mass, natural frequencies, and mode shapes of the structure have been either measured or calculated. Knowledge of the flow velocity and density implies that a performance analysis has been completed. The natural frequencies and mode shapes can be calculated using finite element techniques or can be found from analytical solutions. The natural frequencies of a very wide range of structural and fluid systems are compiled in Refs. 1 and 2. A more detailed exploration of flow-induced vibration with sample problems and references through 1975 can be found in Ref. 3.

The analysis of flow-induced vibration of a structure has not developed to the point that the vibrations of an arbitrary structure can be predicted accurately. For a few structures, notably heat exchanger tube banks and fuel rods that match the body of experience gained by analysis and testing, vibrations can often be predicted. However, for many structures, there is no alternative to testing to 
confirm the adequacy of the structure for flow-induced vibration. Considering Eq. (5.1), it can be seen that full-scale testing will fulfill all the dimensional requirements; indeed, full-scale testing is the preferred form of any testing. However, the expense of full-scale tests generally precludes their use except for verification.

Model testing is a valid measure of the full scale only if each of the nondimensional parameters given in Eq. (5.1) is modeled exactly. Since temperature does not explicitly appear in Eq. (5.1), the first simplification from full-scale testing would be to make the flow-induced vibration tests at room temperature. A second simplification would be to substitute atmospheric air for pressurized helium. However, since density does explicitly appear in the mass ratio term, $m / \mathrm{\rho} D^{2}$, it can be seen that the use of atmospheric air is not acceptable unless (a) the air is pressurized to the helium density or (b) the mass of the structure is reduced by the ratio of air density to the reactor helium density (ordinarily about one-third). This mass reduction would be done, for example, by substituting an aluminum model for the steel original. A third simplification in testing would be to use a small-scale model in place of the full-scale structure. This geometric scaling is very difficult to achieve in practice because as a flexible structure is reduced in size, its natural frequencies increase as the square of the inverse of the scale factor. Thus, a one-third scale structure has a natural frequency nine times that of the original and hence the model is considerably more resistant to vibration than the original. For this reason, scale model structures are rarely adequate for vibration testing unless a particular flow mechanism is being studied and the model is especially constructed to properly scale this mechanism.

\section{5-2B Flow-Induced Vibration in Cross Flow}

A closely spaced array of tubes or rods in a cross flow can be subject to a number of flow-induced vibration phenomena that have the potential for damaging the tubes. These flow-induced vibration phenomena are listed in Table 5-II.

Vortex-induced vibration can exist in closely spaced arrays. However, turbulence and the close proximity of tubes evidently discourage the establishment of a regular vortex street. In addition, resonance with vortex shedding occurs at lower flow velocities in arrays than in single tubes. As a result, heat exchangers and fuel rods often operate successfully in the range of flow velocities that produces vortex resonance, whereas the same tubes would fail if they were exposed to the same flow but were widely separated.

Turbulence-induced vibration in tube arrays will occur at any flow velocity when the flow is in the turbulent regime. However, these vibrations tend to be benign in the sense that they do not ordinarily induce excessive wear. Ordinarily, the amplitude of turbulence-induced vibration increases with flow velocity raised to a power between 1 and 2 and is relatively insensitive to small changes in design.

The jet switch mechanism arises from the coupling and uncoupling of fluid jets issuing between tubes in a regular tube array. However, this mechanism has 
TABLE 5-II

Classification of Flow-Induced Vibrations in Heat Exchanger Tube Arrays Exposed to a Cross Flow

\begin{tabular}{|c|c|c|c|}
\hline & Phenomena & $\begin{array}{l}\text { Range of } \\
U /(f D)^{\mathrm{a}}\end{array}$ & $\begin{array}{l}\text { Nature of } \\
\text { Phenomena }\end{array}$ \\
\hline 1 & $\begin{array}{l}\text { Vortex-induced } \\
\text { vibration }\end{array}$ & $1<\frac{U}{f D}<10$ & Vibration forced by vortices in the flow \\
\hline 2 & $\begin{array}{l}\text { Turbulence-induced } \\
\text { vibration }\end{array}$ & All & Vibration forced by turbulent eddies \\
\hline 3 & Whırlıng & $\frac{U}{f D}>5$ & Fluid elastic instability \\
\hline 4 & Jet switchung & $\frac{U}{f D}>75$ & $\begin{array}{l}\text { Coupling and uncoupling of jets behind a tube } \\
\text { array }\end{array}$ \\
\hline
\end{tabular}

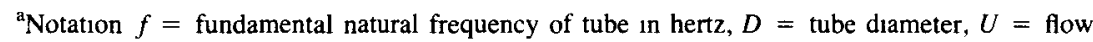
velocity in minumum gap between tubes

been observed to be active on only one occasion and the whirling mechanism generally furnishes a more conservative criterion.

Whirling instability is the most practically important flow-induced vibration mechanism in tube arrays, and it is discussed in more detail in the remainder of this section.

When a tube or fuel rod array is subject to a high-velocity cross flow, then the fluid is accelerated into the gaps between tubes. The mean fluid force on the tubes is largely a function of these gaps between tubes. If a tube moves slightly from its nominal position, then the dimension of the gaps between it and neighboring tubes will change and hence the fluid force will change, not only on the tube that moved but also on the neighboring tubes. If a tube moves in two dimensions (both parallel and perpendicular to the mean flow) in sympathy with neighboring tubes, then it is possible for the tube to extract energy from the flow. If the energy extracted from the flow exceeds the energy expended in damping as the tube moves, then the amplitude of vibration will increase dramatically and the tubes are said to be unstable.

The minimum flow velocity for the onset of this whirling instability is

$$
\frac{U}{f D}=K\left[2 \pi \zeta\left(\frac{m}{\rho D^{2}}\right)\right]^{1 / 2},
$$

where

$K=$ dimensionless instability constant with $K \approx 3$

$D=$ tube outside diameter

$f=$ tube natural frequency in hertz

$m=$ mass per unit length of the tube, including added mass 
$U=$ velocity for the onset of instability measured at the minımum flow area between tubes

$\zeta=$ damping factor (ordınarily measured in stıll fluid)

$\rho=$ fluid density

This equation was first derived in 1970 using a semiempincal approach and can also be obtained from a theoretical analysis ${ }^{34}$ Both derivations are based on a quasi-steady analysis that required $U /(f D)$ to be above the vortex shedding resonance and on interactions within a tube row, not a tube array

At velocities below that given by Eq (5 2), the tubes' vibrations are primarily due to turbulence- or vortex-induced vibration The turbulence-induced vibration is charactenzed by steady increases in tube amplitude Once the critical velocity of Eq (5 2) is exceeded, the tube amplitude increases very sharply with increasing velocity, with amplitude proportional to $U^{n}$ where $n=4$ or more These large amplitudes are characterized by clusters of tubes vibratıng at their natural frequency in oval orbits

The whirlıng instability of Eq ( 52$)$ has been observed by a large number of experimenters workıng independently with both tube rows and tube arrays and operating in both water and arr The interest in this phenomenon lies not only in the relative simplicity by which the instability may be calculated but in its ability to correlate industrial tube fallures over very wide ranges of $m /\left(\mathrm{p} D^{2}\right)$ and $U /(f D)$ For example, Fig 5-3 shows industrial heat exchanger failures in comparison with

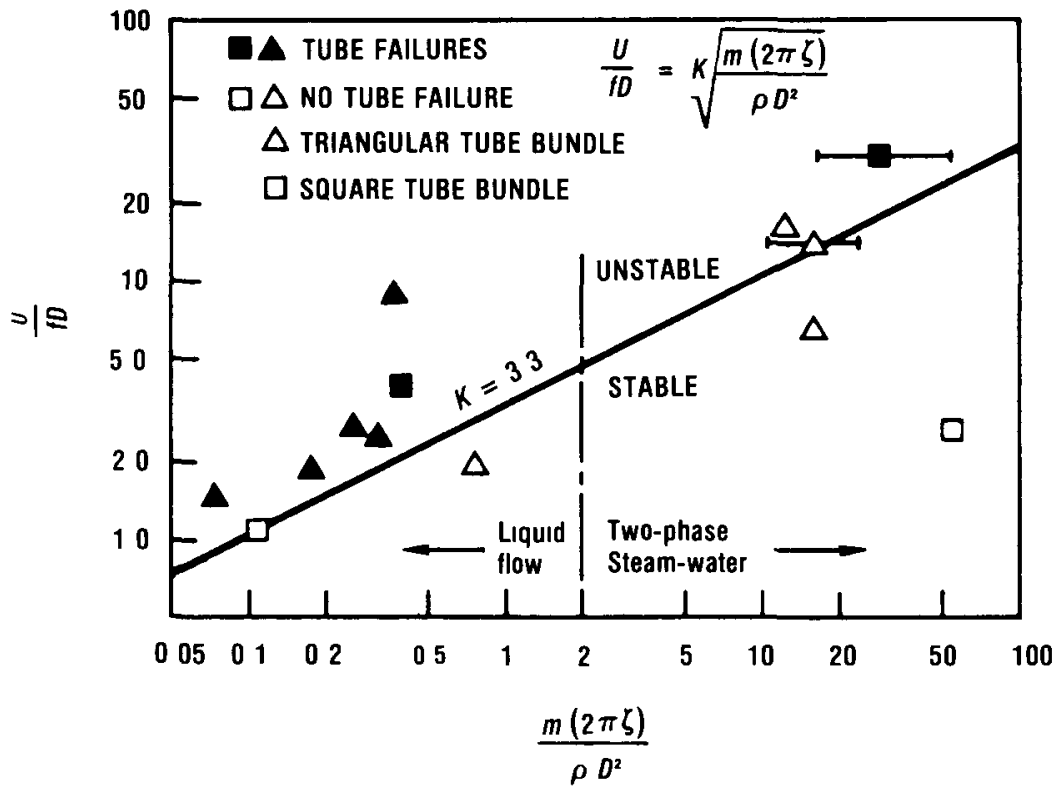

Fig 5-3 Fluid elastic vibration analysis of field experiences with heat exchanger components in a cross flow 
Eq. (5.2). Note that Eq. (5.2), in the absence of other criteria, proves to be an excellent predictor of the tube failures.

The only parameter appearing in Eq. (5.2) that cannot be determined from a fluid performance analysis and structural dynamic analysis is the dimensionless instability constant, $K$. There are two methods of determining $K$. The first is to determine the change in fluid forces as a tube moves, by either theory or experiment. The second, which is more popular, is to observe the instability and correlate the results with Eq. (5.2). The initially reported value of $K$ was $K=9.9$ for a tube row. ${ }^{5}$ Pettigrew and Gorman ${ }^{4}$ have recommended a value of $K=3.3$ as a conservative estimate for tube arrays. However, as more and more experimental evidence has been accumulated, it has become clear that $K$ is a function of the details of the tube array. ${ }^{6}$

\section{5-2C Turbulence-Induced Vibration in Parallel Flow}

When a turbulent flow is bounded by a structure, the turbulent energy in the flow results in fluctuating pressures on the surface of the structure. These surface pressures are random in the sense that (a) they oscillate over a broad band of frequencies, (b) they vary in amplitude over the surface of the structure, and (c) they are coherent only over small areas. These variations in time and space make it impossible to treat turbulence-induced vibrations deterministically; probabilistic methods must be employed.

Generally, two rational approaches to the random vibrations of structures have been employed in the literature. The first is to employ random vibration theory and estimate the power spectra and joint acceptance of the turbulence to determine the mean square response. The second approach is to bypass the theory of random vibrations and empirically correlate observed vibration levels with known system parameters such as flow velocity and hydraulic diameter. The weakness of the random vibration approach is that accurate estimates of power spectra and joint acceptance are rarely available for a particular system. The principal shortcoming of the empirical approach is that it often neglects a parameter of fundamental importance, such as damping, and so can lead to erroneous results when applied to new systems. Both approaches are hampered by uncertainties in the nature of the turbulent forcing function, which, unlike vortex shedding, flutter, or whirling, depends on the details of upstream turbulence generators rather than the structure itself.

In many fuel rod and heat exchanger designs, the mean flow is parallel to the tubes over the majority of the tube span. This parallel turbulent flow can induce vibrations that are of considerable practical importance. At very high flow velocities, it is possible for large-amplitude unstable vibrations to be induced by a parallel flow. However, the metallic rods and tubes in practical heat exchangers are generally too stiff to be influenced by this instability, which has apparently never been observed in an operating heat exchanger. On the other hand, smallamplitude turbulence-induced tube vibrations occur in virtually every fuel rod and 
shell-and-tube heat exchanger, and considerable effort has been made to predict these vibrations analytically.

The theories of turbulence-induced vibration of circular cylinders in a parallel turbulent flow can generally be placed in a power law form. For example, the prediction of Wambsganss and Chen with the modification by Blevins can be expressed as $^{3}$ :

$$
\frac{\hat{Y}}{D}=0.036 K\left(U D^{2}\right)^{1 / 2}\left(\frac{\rho D^{2}}{m}\right)\left(\frac{U}{f D}\right)^{15}\left(\frac{d}{D}\right)^{15}\left(\frac{D}{L}\right)^{05}\left(\frac{1}{\zeta}\right)^{05} \sin \frac{\pi z}{L},
$$

where $\hat{Y}$ is the root-mean-square displacement of a cylinder of diameter $D$ and length $L$ which is simply supported and is vibrating in its fundamental mode. Of course, the maximum displacement occurs at the mid-span, $z=L / 2$. The term $K$ is a dimensioned constant having the value $K=5.8 \times 10^{-3} \mathrm{~s}^{1 / 2} / \mathrm{m}^{3 / 2}$. The term $f$ is the natural frequency of the fundamental mode; $m$ is the mass of the cylinder per unit length, including the added mass of the fluid; $\zeta$ is the damping, both structural and fluid; $U$ is the mean flow velocity; $\rho$ is the fluid density; and $d$ is the hydraulic diameter of the passage in which the cylinder is situated. In general, the theories express the characteristic vibration amplitude $Y$ in the form

$$
Y=K \rho^{t} U^{\jmath} d^{k} D^{l} m^{m} f^{n} \zeta^{o},
$$

where superscripts $i$ through $o$ are dimensionless exponents whose values depend on the theory. The effect of cylinder length is accounted for through the natural frequency, $f$, which is a function of length.

It can be easily seen that the variations of the exponents will result in large differences in the predictions of the various theories. Paidoussis has concluded ${ }^{7}$ that the best accuracy one can hope to achieve in the prediction of vibration amplitudes with these theories is about one order of magnitude. Since the turbulent forces in a parallel flow are largely dependent on upstream turbulence generators, improvements in the theoretical work are unlikely to yield substantial improvements in accuracy unless the theories are tied to a specific flow for which the turbulence level can be accurately identified.

\section{5-3 Acoustic Vibration}

\section{5-3A Acoustics of the Coolant Circuit}

The primary coolant circuit of a gas-cooled reactor can be considered to be a series of interconnected ducts and cavities, as shown in Fig. 5-4. Acoustic waves can propagate through the circuit. An acoustic wave is defined as a disturbance that causes fluctuations in pressure to propagate at the speed of sound through an unbounded gas. The speed of sound in a gas at relatively low pressure and high temperatures, in comparison to the critical temperature and pressure required for 


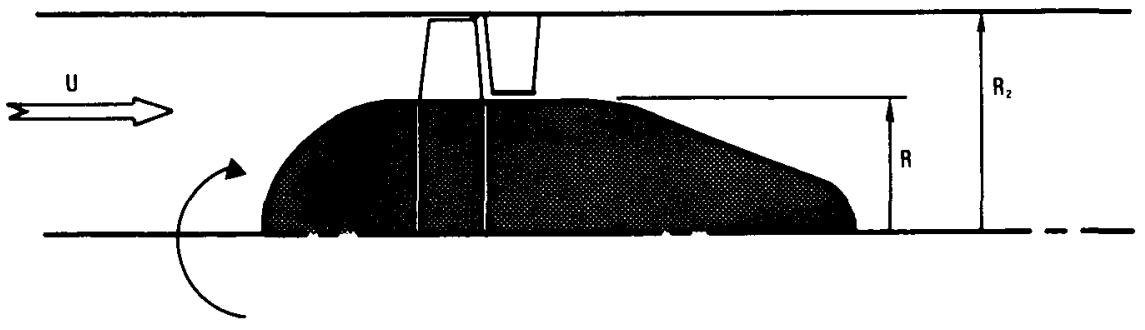

Fig 5-4 A longitudinal section of a single-stage fan, consıstıng of an inlet contraction, a rotatıng blade row (rotor), a stationary row (stator), and a diffuser expansion

liquification of the gas, varies with the square root of the absolute temperature ${ }^{2}$

$$
c=\left(\frac{\gamma \mathscr{R} T}{M}\right)^{1 / 2},
$$

where

$\gamma=$ ratio of the specific heat at constant pressure to that at constant volume, $\gamma=1667$ for helium

$\mathscr{R}=$ universal gas constant, $\mathscr{R}=8315 \mathrm{~J} / \mathrm{kg} \mathrm{mol} \mathrm{K}$

$T=$ absolute temperature in degrees Kelvin

$M=$ molecular weight, $M=4$ for helium

For example, at $600^{\circ} \mathrm{C}\left(1110^{\circ} \mathrm{F}\right)$, the speed of sound in helium is $\sim 1700 \mathrm{~m} / \mathrm{s}$ and it is substantially independent of the reactor pressure

Since acoustic waves travel at the speed of sound relative to the gas, the flow of gas through the reactor will augment the speed of sound waves traveling with the flow However, since the speed of sound is much greater than typical flow velocities through the reactor, the shift in the speed of travel of an acoustic wave from the speed of sound [Eq (5 5)] is usually insignificant in a heliumcooled reactor It can be significant in test rigs operating in air due to the much lower speed of sound in air compared to helium

Sound waves are reflected by rigid walls The criteria for rigidity is that the density of the wall material times the speed of sound in the wall be much greater than the corresponding quantity in the gas Thus, thick walls comprised of concrete and steel qualify as nigid with respect to a gas However, if the walls are surfaced by relatively thin sheet metal cover plates, which are supported by fibrous thermal insulation, then the sound waves can dynamically interact with the cover plates and energy can travel from the sound waves into the cover plates and back again into the coolant circuit This is the typical reactor case It has proven too complex to analyze the detals of compliant walls of a reactor circuit within the framework 
of an overall acoustic circuit analysis so the following simplified methodology is ordinarily employed:

1. A rigid wall acoustic model for the circuit is constructed. Impedance or damping may be incorporated to model acoustic dissipation.

2. The model is coupled to sources of sound, such as circulators. The sound levels through the coolant circuit are predicted.

3. The responses of cover plates and shrouds to the predicted sound levels are determined based on the assumption that the vibration of the plates does not influence the sound.

In the remainder of this section, the first point is explored. Sections 5-3B and 5-3C cover the second and third points, respectively.

A rigid-walled model of the coolant circuit can be assembled from onedimensional duct models and three-dimensional cavity models. Since the equations governing sound propagation are easier to solve for one-dimensional ducts than for three-dimensional cavities, the coolant circuit is modeled by ducts whenever possible. A one-dimensional duct is defined here to be a duct small enough in cross section that the wave length of sound, $\lambda$, propagating through the duct is much larger than the duct circumference, $\lambda>2 \pi D$, so that only longitudinal modes of the duct are excited. Since the wave length is equal to the speed of sound, $c$, divided by the frequency of vibration, $f=\omega / 2 \pi$, the above criteria become

$$
\frac{2 \pi c}{\omega}>2 \pi D
$$

and the cutoff frequency for the validity of a one-dimensional duct model is then

$$
\omega<\frac{c}{D} \text {. }
$$

As an example, for one-dimensional duct analysis to be valid, for a speed of sound $c=1700 \mathrm{~m} / \mathrm{s}$ and duct diameter $D=1 \mathrm{~m}$, the frequency of the sound waves must be $<270 \mathrm{~Hz}$. This limits the duct analysis to the low-frequency components of the sound. Fortunately, those components are of primary interest because the structural modes of the plates and shells in the coolant circuit that are most susceptible to vibration generally have fundamental natural frequencies below $200 \mathrm{~Hz}$.

For duct analysis, the sound propagating through a rigid-walled duct with flow velocity much less than the speed of sound is simply governed by the onedimensional wave equation:

$$
\frac{\partial^{2} p}{\partial x^{2}}=\frac{1}{c^{2}} \frac{\partial^{2} p}{\partial t^{2}}
$$

where $p$ is sound pressure traveling in the $x$ direction with the speed of sound, $c$. 
The wave equation for sound waves is derived from the continuity and momentum equations, which can be expressed in the form

$$
\frac{\partial m}{\partial x}=-\frac{A}{c^{2}} \frac{\partial p}{\partial t}
$$

and

$$
\frac{\partial m}{\partial t}=-A \frac{\partial p}{\partial x}
$$

where $m$ is the mass flow and $A$ is the duct cross-sectional area. The sound pressure and mass flow are found by simultaneously solving the two first-order partial differential equations, Eqs. (5.8) and (5.9), rather than solving the second-order equation, Eq. (5.7).

Both $m$ and $p$ will oscillate in time with circular frequency, $\omega$, and these quantities can be written as

$$
m=m_{0}(x) \exp (i \omega t)
$$

and

$$
p=p_{0}(x) \exp (i \omega t),
$$

where $m_{0}(x)$ and $p_{0}(x)$ are expressions for the spatial dependence and $\exp (i \omega t)$ is the complex notation for the time dependence of these quantities. The term $i$ is the imaginary constant, $i=\sqrt{-1}$. The simultaneous solution of Eqs. (5.8) and (5.9) with the duct outlet conditions expressed as a function of the duct inlet conditions is ${ }^{8}$ :

$$
\left(\begin{array}{l}
m \\
p
\end{array}\right)_{\text {out }}=\left(\begin{array}{cc}
\cos \frac{\omega L}{c} & \frac{A}{i c} \sin \frac{\omega L}{c} \\
-i \frac{c}{A} \sin \frac{\omega L}{c} & \cos \frac{\omega L}{c}
\end{array}\right)\left(\begin{array}{l}
m \\
p
\end{array}\right)_{\mathrm{in}} .
$$

By similarly proceeding around the circuit, the conditions across the various ducts can be established in terms of matrix equations of the same form as Eq. (5.10).

A cavity is defined as a volume in the acoustic circuit for which Eq. (5.6) is not satisfied. The plenums above and below the core are cavities. The cavities can be described in terms of the natural frequencies and mode shapes of the volume enclosed by blocking all entrances and exits from the cavity. For example, the natural acoustic frequencies of a cylindrical, rigid-walled cavity are ${ }^{2}$ :

$$
f_{j k l}=\frac{c}{2 \pi}\left[\left(\frac{\lambda_{k l}}{R}\right)^{2}+\left(\frac{j \pi}{L}\right)^{2}\right]^{1 / 2} \quad \text { for } j, k, l=0,1,2,3, \ldots
$$

where

$f=$ natural frequency of the mode described by integers $j, k$, and $l$ 
$R=$ radius of the cavity

$L=$ length of the cavity

$c=$ speed of sound

$\lambda_{k l}=\mathrm{a}$ dimensionless parameter that describes the radial-circumferential dependence of the natural frequency and is tabulated in Ref. 2.

By considering any ducts connected to the cavities to be point sources of mass and pressure, the duct acoustic equation can be coupled to the cavity acoustic modes resulting in an overall matrix equation for the sound in the reactor circuit:

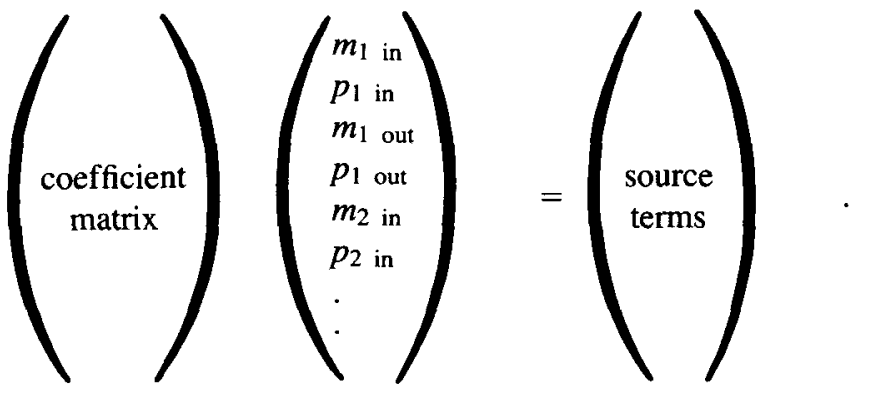

Once the sources of mass or pressure fluctuation are identified, then this matrix equation can be solved for the fluctuation in acoustic pressure throughout the reactor circuit.

\section{5-3B Acoustic Sources of Sound}

A single-stage axial fan (circulator) is shown in Fig. 5-4. Near the blades, the helium velocities are higher than anywhere else in the reactor. It follows that fluctuating pressures are usually large on the blades in spite of the considerable effort expended to reduce friction losses and turbulence levels in circulators. An irreducible minimum of turbulence is maintained in thin boundary layers that line the surfaces. Somewhat more important is the wake turbulence from rotors, which washes into the stators. Boundary layer and wave turbulence contain a broad range of frequencies. The resulting turbulence-induced fluctuating pressure spectrum is smooth and broad; however, there is a second component of the pressure spectrum due to periodic interaction of the blades and the stators. Figure 5-5 illustrates a typical pressure spectrum for a centrifugal fan. The blade passing frequency is the rate at which a rotor blade passes a single stator blade and is given by $n N$ where $n$ is the number of blades and $N$ is the rotational speed. In Fig. 5-5, $n=19$ and $N=1450 \mathrm{rpm}$, giving a blade passing frequency (BPF) of $460 \mathrm{~Hz}$. Blade passage creates extremely periodic fluctuating pressures at whole multiples of the BPF, which are shown in Fig. 5-5 as lines in the spectrum. The rest of the spectrum is due to turbulence generated in wakes and boundary layers. The lowfrequency portion of the curve is strongly influenced by the details of the test rig and instrumentation. 


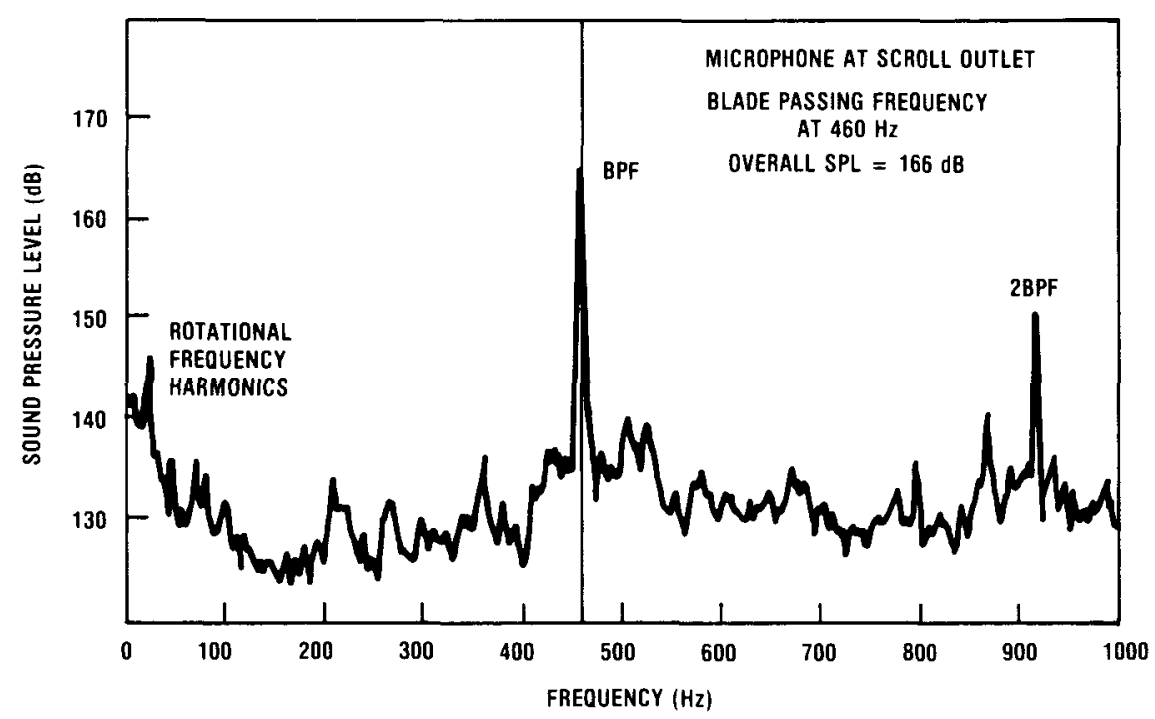

Fig. 5-5. Typical noise spectrum at circulator scroll outlet of the Dungeness B AGR during commissioning tests (Ref. 9).

The total sound power is obtained by integrating the smooth curve in Fig. $5-5$, and then adding in the power contained in the spectrum lines. For example, a blower might radiate $20 \mathrm{~W}$ "broadband" plus $6,2,3$, and $1 \mathrm{~W}$ at the first, second, third, and fifth BPFs, respectively. The total power radiated would then be $20+6+2+3+1=32 \mathrm{~W}$.

There are two common empirical formulas used to predict the total acoustic output of single-stage ducted blowers operating in air at standard temperature and pressure. Most widely used is the Peistrup and Wesler correlation. As corrected by Beranek, it is usually stated as follows ${ }^{10}$ :

$$
\text { sound power level }=93.3+17.7 \log _{10} \frac{\mathrm{HP}}{N^{0.15}} \mathrm{~dB} \text { (re } 10^{12} \text { watts) , }
$$

where $\mathrm{dB}$ represents decibels and $\mathrm{HP}$ is the blower power at the shaft in horsepower. A more revealing form of the relation is

$$
\Pi_{a}=1.8 \times 10^{-8} \Pi_{b}^{1.77} N^{-0.27} \text { (air) , }
$$

where the acoustic power, $\Pi_{a}$, and blower power, $\Pi_{b}$ are both in watts. The second widely used formula is the Allen correlation ${ }^{11}$ :

sound power level $=93+10 \log _{10}(\mathrm{HP} \cdot \Delta P) \mathrm{dB}$ (re $10^{-12}$ watts),

where $\Delta P$ is the total pressure change across the blower in inches of water. Experience has shown that these correlations can be in error by as much as $10 \mathrm{~dB}$. Accurate estimates can only be obtained from model tests or tests on a similar machine. 
Once the power is obtained and an estimate of the spectra is made, usually from tests, the equivalent mean square pressure that the sound will radiate into a uniform duct can be estimated from:

$$
\frac{\Pi_{a}}{2}=\frac{A\left\langle p^{2}\right\rangle}{\rho c},
$$

where $A$ is the area of the duct, $\left\langle p^{2}\right\rangle$ is the mean square oscillating pressure, $\rho$ is the gas density, and $c$ is the speed of sound. The factor of 2 has been introduced to allow for the fact that the power will be transmitted into both directions of the duct. Once $\left\langle p^{2}\right\rangle$ is found from the above formula, an estimate of the frequency can be obtained from the spectra and an acoustic analysis of the sound propagation through the coolant circuit can be made using the technique described in Sec. 5-3A. If a root-mean-square pressure $p_{e}$ is emitted in both directions, the source strength is then $p_{s}=2 p_{e}$. Using $p_{e}=\sqrt{\left\langle p^{2}\right\rangle}$ and Eq. (5.16) gives

$$
p_{s}=2 p_{e}=\sqrt{\frac{2 \rho c \Pi_{a}}{A}} \text {. }
$$

\section{5-3C Acoustic Excitation of Cover Plates}

A cover plate is a plate of uniform thickness that is fixed to the pressure vessel and holds a thickness of fibrous insulation between itself and the pressure vessel (see Fig. 5-6). The purpose of the insulation is to protect the pressure vessel from the high-temperature gas. The purpose of the cover plate is to hold the insulation in place and protect it from the flowing helium and, in particular, acoustic noise.

Acoustic plate vibration analysis is generally made under the following simplifying assumptions:

1. The acoustic pressure field is not influenced by the cover plate vibration with the exception that radiation damping of the cover plate is included in the analysis.

2. The low-frequency components of the acoustic pressure field are completely coherent over the surface of the cover plate.

3. The acoustic pressure field is a stationary random process.

4. The acoustic pressure is uniform over the surface of the plate.

Rather than make a deterministic analysis of the cover plate response to each component of the acoustic pressure field, it is far simpler to apply random vibration theory to the cover plate. If the acoustic field is modeled as a narrow-band random process then, it can be shown that the cover plate root-mean-square displacement in response to an oscillating pressure at the plate natural frequency is ${ }^{12}$ :

$$
\left\langle Y_{i}^{2}\right\rangle=\frac{\left\langle p^{2}\right\rangle J_{i}^{2}}{\zeta_{i}^{2} \omega_{i}^{4}(\mu h)^{2}}
$$




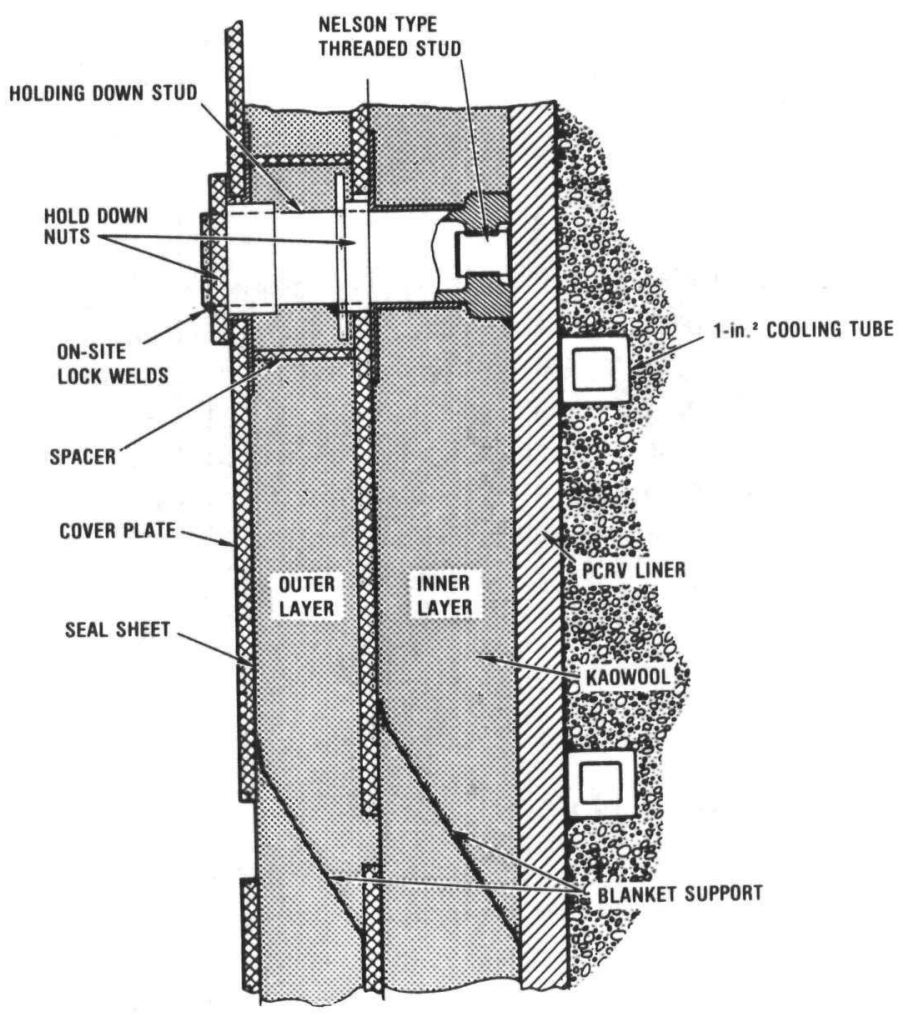

Fig. 5-6. Cover plates on the inner walls of the reactor pressure vessel.

$\left\langle Y_{i}^{2}\right\rangle$ is the mean square plate response in the $i$ 'th mode to the mean square pressure, $\left\langle p^{2}\right\rangle$, which has been evaluated at the plate circular natural frequency, $\omega_{i}$, which has damping $\zeta_{i} ; \mu$ is the density of the plate material; $h$ is the thickness of the plate; and $J_{i}$ is the joint acceptance, which for a uniform pressure field is:

$$
J_{i}^{2}=\left(\int \tilde{z}_{i} d x d y\right)^{2} /\left(\int \tilde{z}_{i}^{2} d x d y\right)^{2},
$$

where $\tilde{z}_{i}$ is the mode shape (displacement normal to the plane of the plate) of the $i$ 'th mode. The joint acceptance is a measure of the tendency of a mode to be acoustically excited.

If an equivalent static pressure is defined that produces the same modal displacement when applied statically as does the dynamic pressure,

$$
p_{s}=\frac{\left\langle p^{2}\right\rangle^{1 / 2}}{\zeta_{i}},
$$

then the maximum displacement of the cover plate due to an equivalent static load is 


$$
y_{m}=\frac{K_{1} p_{s} J_{l}}{\mu h \omega_{l}^{2}}
$$

in the $i$ 'th mode. It can be shown from thin plate theory that the natural frequency of a thin plate of modulus of elasticity, $E$, Poisson's ratio, $v$, and side length, $L$, can be expressed in hertz as ${ }^{2}$ :

$$
f_{l}=\frac{\lambda_{l}^{2}}{2 \pi L^{2}}\left(\frac{E h^{2}}{12 \mu\left(1-\nu^{2}\right)}\right)^{1 / 2},
$$

where the dimensionless constant $\lambda_{l}$ is a function of the mode number, $i$, and the plate geometry, and $\mu$ is the density of the plate material. Similarly, thin plate theory can be used to express the maximum stress in the plate as a function of the maximum displacement of the plate:

$$
S_{m}=K_{2} \frac{E}{1-v^{2}} \frac{h}{L^{2}} y_{m}
$$

Substituting Eq. (5.21) into this equation to eliminate the variable $y_{m}$ and substituting Eq. (5.22) in turn to eliminate the natural frequency $\omega=2 \pi f$ yields the maximum stress in the plate as a function of only the equivalent static pressure, $p_{s}$, the plate thickness, $h$, the plate length, $L$, and the nondimensional factors:

$$
S_{m}=\left(\frac{12 K_{1} K_{2} J_{l}}{\lambda_{l}^{4}}\right) p_{s}\left(\frac{L}{h}\right)^{2}
$$

This equation implies that the stress in the cover plate is substantially independent of the plate material. The dimensionless factors $K_{1}, K_{2}, J_{l}$, and $\lambda_{l}^{4}$ are ordinarily evaluated from finite element analysis since the complexity of most cover plates precludes a closed form solution. The factors are determined by applying Eqs. (5.19) through (5.23) to the output of the finite element analysis with $L$ chosen as a characteristic plate length, typically the length of one side of the plate. Once $K_{1}, K_{2}, J_{l}$, and $\lambda_{l}^{4}$ are identified, the $S_{m}$ can be set equal to the stress allowable for the plate material high cycle vibration (vibration in excess of $10^{6}$ cycles) and Eq. (5.24) can be solved for the permissible ranges of plate thickness and plate length. Note from Eq. (5.24) that the stress declines as the plate is thickened ( $h$ increases) or its area is reduced ( $L$ decreases).

\section{5-4 Thermal Stress Analysis}

\section{5-4A General Aspects of Thermal Stress and Strain}

Nearly all materials expand as they are heated as the result of the thermal energy of atoms vibrating about their equilibrium positions in the crystal lattice. The thermal expansion is single valued and reversible for heating to temperatures well below the melting temperature. As the temperatures approach the melting 
temperature, the material begins to creep and a permanent deformation results. With relatively amorphous, isotropic materials, such as cast or forged metals, the expansion is almost independent of direction, while for highly anisotropic materials, such as various forms of graphite, the expansion is a function of orientation relative to the crystal lattice.

If the length of a structural element at temperature, $T$, is $u\left(T_{1}\right)$, and at temperature $T_{2}$ its length is $u\left(T_{2}\right)$ with $T_{2}>T_{1}$, then the thermal strain is defined as the fractional increase in the original length:

$$
\varepsilon=\frac{u\left(T_{2}\right)-u\left(T_{1}\right)}{u\left(T_{1}\right)} .
$$

This expansion is ordinarily specified in terms of the slope of the expansion curve using the instantaneous coefficient of thermal expansion,

$$
\alpha_{\text {inst }}=\frac{d u(T)}{u d T} .
$$

It may also be specified in terms of the thermal strain due to heating above a reference temperature using the mean coefficient of thermal expansion,

$$
\alpha_{\text {mean }}=\frac{u(T)-u\left(T_{\text {ref }}\right)}{\left(T-T_{\text {ref }}\right) u\left(T_{\text {ref }}\right)} .
$$

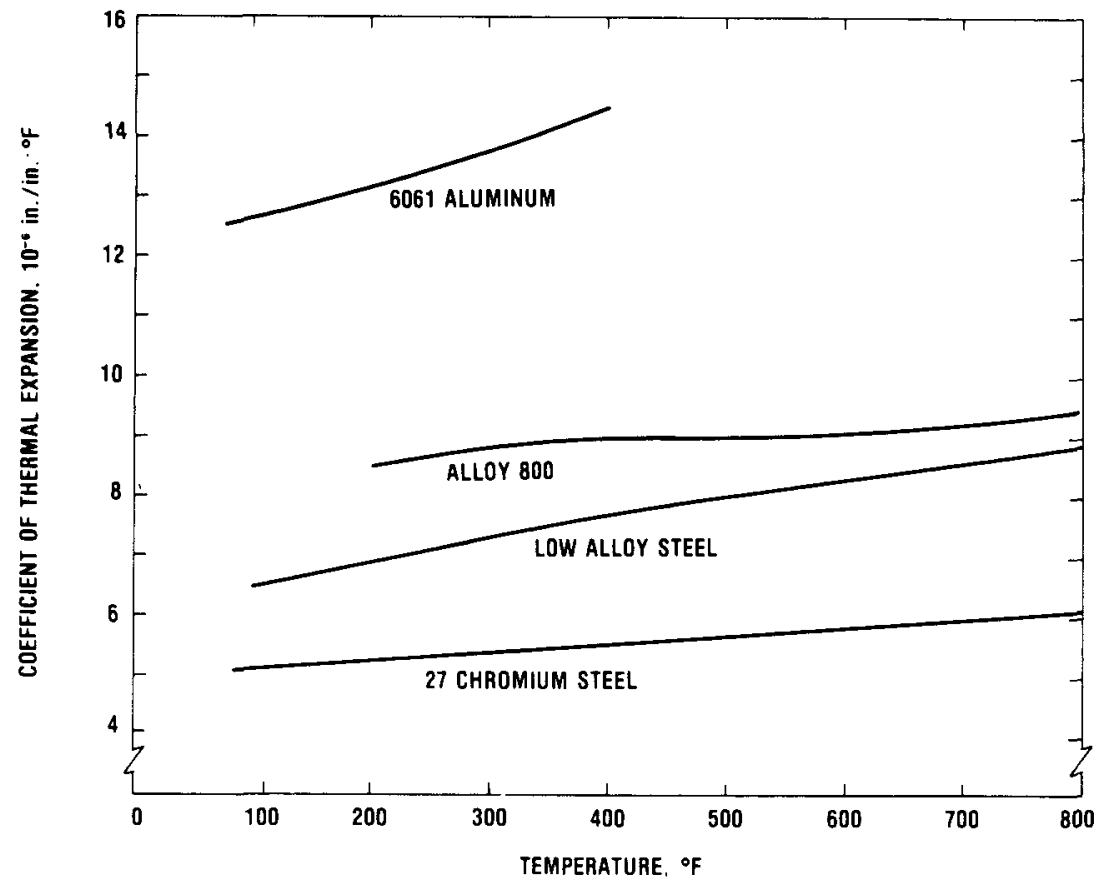

Fig. 5-7. Instantaneous coefficients of thermal expansion for several common alloys. 
Both $\alpha_{1 \text { nst }}$ and $\alpha_{\text {mean }}$ are functions of temperature and material expressed in $\mathrm{mm} / \mathrm{mm}-{ }^{\circ} \mathrm{C}$. Figure 5-7 shows the instantaneous coefficient of thermal expansion for several structural metals used in the high-temperature gas-cooled reactor (HTGR). The coefficients are taken from the American Society of Mechanical Engineers Boiler and Pressure Vessel Code. Note the large differences between the various materials and that the coefficients vary with temperature. Thus it is not sufficient in general to apply a single coefficient of thermal expansion regardless of temperature.

\section{5-4B Thermal Stress}

For small thermal strains, the equations describing the relationship between stress and strain in a homogenous elastic media are ${ }^{13,14}$ :

where

$$
\begin{gathered}
\varepsilon_{\imath}-\alpha \Delta T=\frac{1}{E}\left[\sigma_{\imath}-v\left(\sigma_{J}+\sigma_{k}\right)\right] \\
\text { for } i, j, k=1,2,3 \text { and } i \neq j \neq k,
\end{gathered}
$$

$$
\begin{aligned}
\varepsilon_{t} & =\text { normal strain in } i \text { direction } \\
\sigma_{l} & =\text { normal stress in } i \text { direction } \\
E & =\text { modulus of elasticity } \\
\alpha & =\text { coefficient of thermal expansion } \\
\Delta T & =\text { difference between strain free temperature and temperature of interest } \\
\nu & =\text { Poisson's ratio. }
\end{aligned}
$$

A solution to these equations for the stress-free case is

$$
\left.\begin{array}{l}
\varepsilon_{l}=\alpha \Delta T \\
\sigma_{t}=0
\end{array}\right\},
$$

e.g., if a material is heated to a uniform temperature and no restraint is placed on the material, then the material freely expands stress free.

Thermal stress is induced in a homogenous material only if (a) the material is restrained from expanding or (b) if the temperature field is nonlinear. If the material is restrained from expanding in the direction $i=1$ but is otherwise free, then the solution to Eq. (5.28) gives a thermal stress:

$$
\begin{aligned}
& \sigma_{1}=-E \alpha \Delta T, \\
& \sigma_{2}=\sigma_{3}=0, \\
& \varepsilon_{1}=0,
\end{aligned}
$$

and

$$
\varepsilon_{2}=\varepsilon_{3}=(1+\nu) \alpha \Delta T .
$$


Solutions to Eq. (5.28) for two and three degrees of restraint are given in Table 5-III. Note that the stress increases with the degree of restraint. These simple restraint solutions are useful for bounding thermal stresses due to a given temperature difference. For example, if a coolant hot streak induces a hot spot in a thermal barrier plate, then the local thermal stress can be estimated by considering that the cool portion of the plate restrains the hot spot in two dimensions.

Thermal stress is induced in heat-conducting members as a result of both the temperature variation through the member and the restraint provided by the member itself. The temperature variation through the wall of a tube that is heated on one wall and cooled on the other is logarithmic. However, for thin-walled tubes, the deviation from a linear distribution through the wall is slight and the tangential, $t$, and longitudinal, $z$, stresses at the inner and outer tube wall are ${ }^{15}$ :

$$
\underset{\substack{\sigma_{t_{\text {outer }}} \\ \text { wall }}}{ }=\sigma_{\substack{z_{\text {outer }} \\ \text { wall }}}=-\sigma_{\substack{t_{\text {tnner }} \\ \text { wall }}}=-\frac{\alpha E\left(T_{o}-T_{l}\right)}{2(1-\nu)},
$$

where $T_{o}$ is the temperature of the outside tube wall and $T_{1}$ is the temperature of the inside wall. If the outer wall is heated and the inner wall is cooled, then the outer fibers are forced into compression and the inner fibers are in tension.

Thermal stress can result from heat generation within a member. A fuel pin may be modeled as a solid cylinder of radius $R$ with uniform heat generation $q^{\prime \prime \prime}$ per unit volume. If the fuel pin is cooled externally, then the temperature of the fuel pin decreases quadratically from the center to the surface at temperature $T_{s}$ (see Sec. 3-4D):

$$
T-T_{s}=\frac{q^{\prime \prime \prime}}{4 k}\left(R^{2}-r^{2}\right),
$$

where $r$ is radial distance from the axis of the fuel pin and $k$ is the thermal conductivity of the fuel pin. The corresponding stresses in the fuel pin radial, tangential, and axial directions are (Ref. 13, p. 568):

$$
\begin{aligned}
\sigma_{r r} & =\frac{\alpha E q^{\prime \prime \prime}}{16 k(1-v)}\left(r^{2}-R^{2}\right) \\
\sigma_{\theta \theta} & =\frac{\alpha E q^{\prime \prime \prime}}{16 k(1-v)}\left(3 r^{2}-R^{2}\right) \\
\sigma_{z z} & =\frac{\alpha E q^{\prime \prime \prime}}{16 k(1-v)}\left(4 r^{2}-2 R^{2}\right) .
\end{aligned}
$$

At the surface $r=R$, the tangential and axial stresses are a maximum:

$$
\sigma_{\theta \theta}=\frac{\alpha E q^{\prime \prime \prime} R^{2}}{8 k(1-v)}=\frac{\alpha E \Delta T_{\max }}{2(1-v)}=\sigma_{z z}
$$

For a given internal heat generation rate, $q^{\prime \prime \prime}$, the thermal stress is proportional to 
TABLE 5-III

Thermal Stress*

\begin{tabular}{|lll|}
\hline 1 & One-dımensional restraint & $\sigma_{\max }=-E \alpha\left(T_{2}-T_{1}\right)$ \\
2 & $n$-dımensional restraint & $\sigma_{\max }=\frac{-E \alpha\left(T_{2}-T_{1}\right)}{1-(n-1) v}, n=1,2,3$ \\
3 & $\begin{array}{l}\text { Thin-walled tube with outside wall temperature, } \\
T_{o}, \text { and inside wall temperature, } T_{t}\end{array}$ & $\sigma_{\max }=\frac{\alpha E\left(T_{o}-T_{i}\right)}{2(1-v)}$ \\
4 & $\begin{array}{l}\text { Solid cylinder with heat generation, } q^{\prime \prime \prime}, \text { per unit } \\
\text { volume and conductivity, } k\end{array}$ & $\sigma_{\max }=\frac{\alpha E q^{\prime \prime \prime} R^{2}}{8 k(1-v)}=\frac{\alpha E \Delta T_{\max }}{2(1-v)}$ \\
\hline
\end{tabular}

*From Refs 13 and 14

the material parameter $\frac{\alpha E}{k(1-v)}$. These stresses are tensile. Note that the expression for these thermal stresses is comparable to that of a thin tube heated on one side and cooled on the other [Eq. (5.31)].

In all problems of heat generation and heat conduction, the temperature difference and hence the stress is inversely proportional to the conductivity $k$ and proportional to the heat flux. Thus by choosing materials of high conductivity or alternately by minimizing heat flux, thermal stress can be minimized. For example, welds between two different metals are prone to failure due to thermal stress and material degradation at the interface. The welds can be protected to a degree by placing them in regions of stagnant fluid so that there is no heat transfer-hence, no temperature gradient and associated thermal stress - through the weld.

\section{5-4C Strength of Materials Under Thermal Stress}

\section{Low-Temperature Analysis}

Below $\sim 450^{\circ} \mathrm{C}$, creep and creep rupture effects are usually negligible in steels and nickel-chromium-iron alloys used in HTGRs. The loads placed on pressure vessels are categorized into primary and secondary stresses. Primary stresses include membrane stresses, such as those due to internal pressure, and bending stresses. These primary stresses will produce gross distortion or failure if sufficient thickness is not provided. Thermal stresses are secondary stresses. Secondary stresses can produce only limited strain. As a consequence, the allowable stress resulting from secondary (thermal) stress may be much higher than that allowed from primary stress.

Consider the stress/strain diagram for an idealized elastic, perfectly plastic material shown in Fig. 5-8. The stress is proportional to strain, $\sigma=E \varepsilon$, where $E$ is the modulus of elasticity for all stresses in the range $-\sigma_{y}<\sigma<\sigma_{y}$ and $\sigma_{y}$ is the yield stress. Higher stress produces strain but no greater stress. Thus, if a primary stress exceeds $\sigma_{y}$, the structure must fail as the material yields until it 


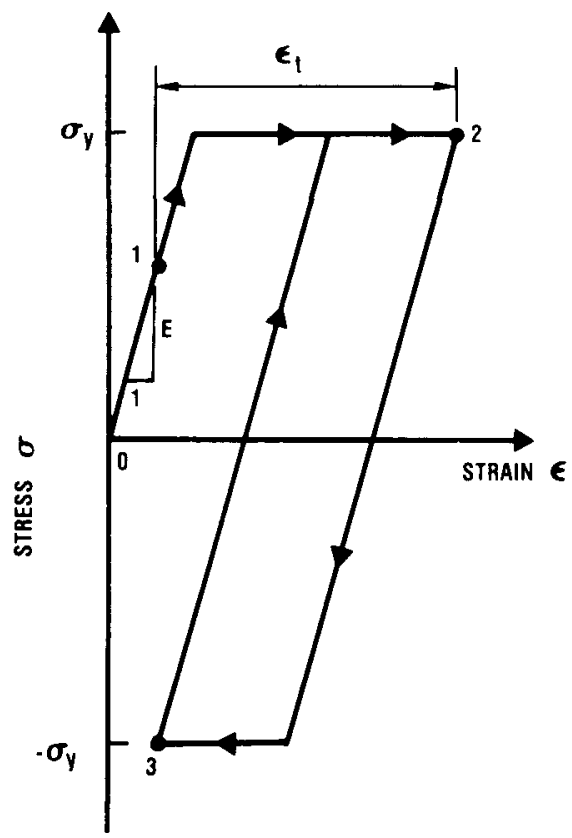

Fig 5-8 Thermal cycling at low temperatures

ruptures Consider a case where the material is loaded elastically to point 1 on Fig 5-8 by primary stress Since this is well below yield, the material will not fall Now the material is heated to a thermal stran, $\Delta \varepsilon_{t 1}=\alpha \Delta T$ The material yields plastically to point 2 Yielding stops at this point because of the self-limiting nature of thermal strain If the material now cools to its original temperature, a negatıve increment of thermal strain, $\Delta \varepsilon_{t_{2}}=-\alpha \Delta T$, develops The material returns elastically and then deforms plastically to point 3 on Fig 5-8 Further thermal cycling traces out the 2 to 3 cycle Thus, the material experiences a steady limited cycle If the thermal strain is less than twice the yield strain, $\sigma_{t}<2 \sigma_{y}$, the material undergoes a purely elastic cycle with no plastic deformation regardless of the initial starting point Thus, to avoid fallure, the limit on primary stress is the yield stress and the limit on the thermal stress range is twice the yield stress for an idealızed elastıc, perfectly plastic material

Real materials can withstand some repeated plastic deformation Thermal fatigue life can be expressed as a function of the total plastic strain range per cycle by the Coffin-Manson relatıonshıp ${ }^{1617}$

$$
N^{1 / 2} \Delta \varepsilon_{p}=F(T),
$$

where $N$ is the number of cycles to produce failure at a plastic strain range of $\Delta \varepsilon_{p}$ The lower the number of cycles, the greater the plastic strain range to produce farlure 


\section{High Temperature}

As the temperature of metallic components is increased beyond $450^{\circ} \mathrm{C}$, the yield stress rapidly decreases to the point where it is not practical to design structures in the purely elastic stress ranges. Some degree of plastic deformation is permissible in high-temperature reactor metallic structures. However, in the high-temperature plastic range, materials are subject to continual elongation to rupture as a result of two phenomena called "ratcheting" and "creep."

Ratcheting is the result of both thermal stress and a mechanical load. A twobar linkage model of ratcheting is shown in Fig. 5-9. Each bar has its own temperature history but together they support the mechanical load $P$. This linkage could represent the inner and outer fibers of a tube wall. The ratcheting sequence is:

1. Both bars are at the same temperature and they bear in tension the load $P$ corresponding to the elastic tensile stress $\sigma$.

2. Bar 1 is cooled while bar 2 is maintained at its same temperature. As bar 1 attempts to contract, it experiences an increasing tensile stress. The stress passes the tensile yield stress and yields in tension. At the same time the stress in bar 2 becomes compressive.

3. Bar 2 now cools, and it develops tensile stress and yields in tension.

4. Now both bars are returned to the condition of step 1. But now, since both bars have yielded in tension, the linkage is longer than at step 1 . Repeating the cycle will again incrementally increase the elongation. The cycle is irreversible because of the tensile load $P$. This is called "ratcheting" and eventually it must lead to failure.

The regimes where materials creep or ratchet are dependent on temperature, stress, and material properties. They are further discussed in Refs. 18 and 19. Creep in reactor fuel elements is discussed in Ref. 20.

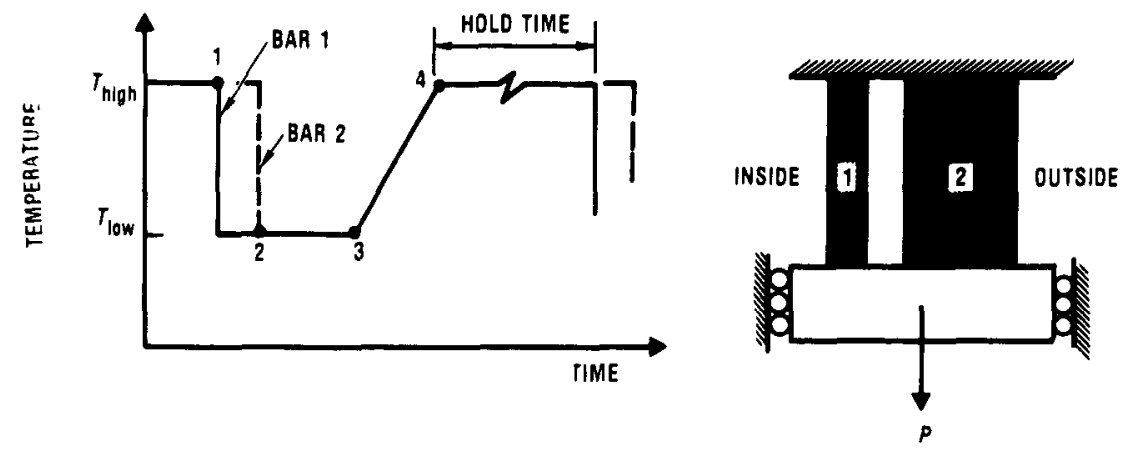

Fig. 5-9. Simple example of conditions leading to elevated temperature ratcheting. 


\section{NOMENCLATURE}

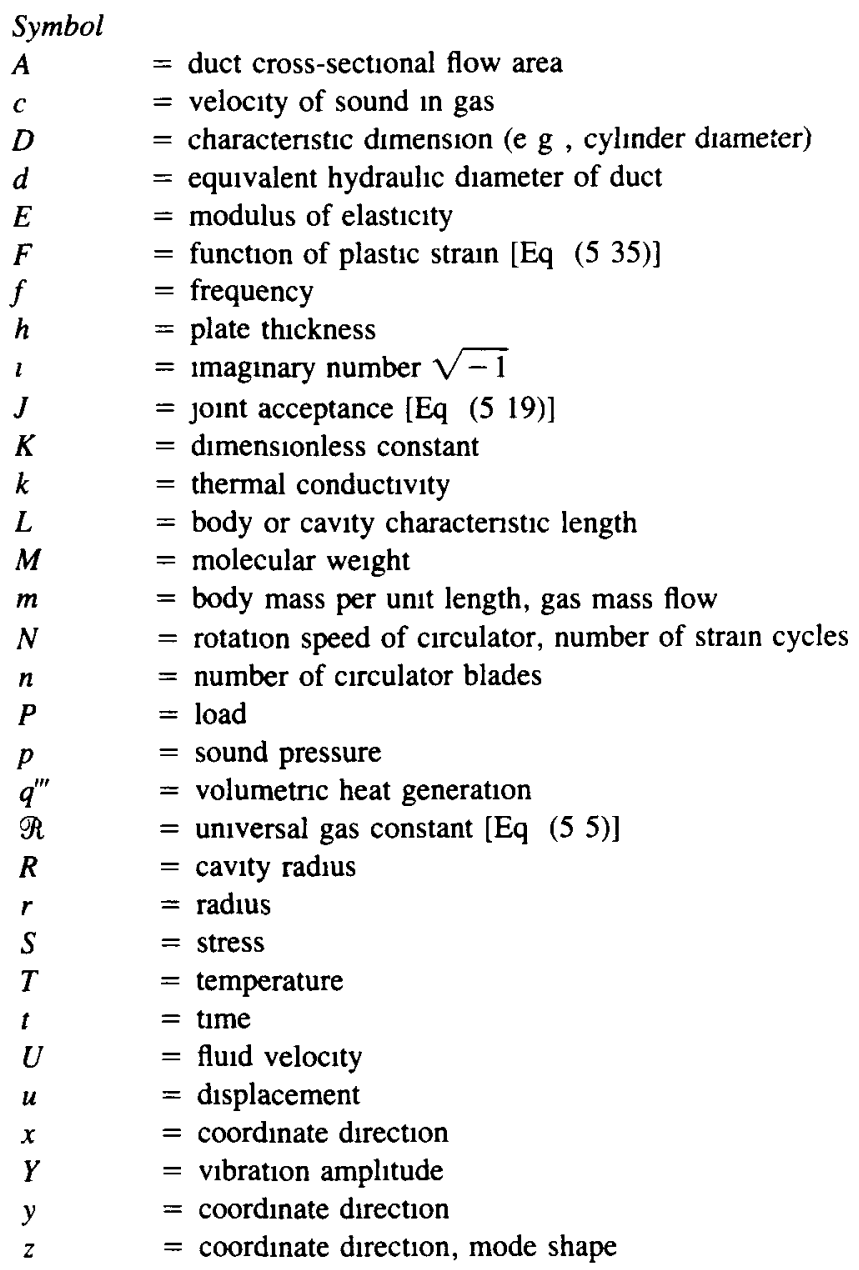

\section{Greek}

$\alpha \quad=$ coefficient of thermal expansion

$\gamma=$ ratio of gas specific heat at constant pressure to specific heat at constant volume

$\Delta \quad=$ difference

$\varepsilon \quad=$ strain

$\zeta \quad=$ damping factor

$\lambda=$ wave length of sound, eigenvalue of cavity natural frequency

$\mu \quad=$ fluid dynamic viscosity, plate density

$v=$ Poisson's ratio

$\Pi \quad=$ acoustic power

$\rho=$ fluid density 


$$
\begin{array}{ll}
\sigma & =\text { stress } \\
\omega & =\text { circular frequency }
\end{array}
$$

\section{Subscripts}

$l, \jmath, k=$ coordinate direction

$J, k, l=$ mode integers

$r r, \theta \theta, z z=$ radial, circumferentıal, and axıal direction, respectively

$t \quad=$ tangential

$0 \quad=$ reference value

$1,2,3=$ coordinate directions

\section{REFERENCES}

1 D J Gorman, Free Vibration Analysts of Beams and Shafts, John W1ley \& Sons, New York (1975)

2 R D Blevins, Formulas for Natural Frequency and Mode Shape, Van Nostrand Reinhoid Co , New York (1979)

3 R D Blevıns, Flow-Induced Vibratıon, Van Nostrand Reınhold Co , New York (1977)

4 M J Pettıgrew and D J Gorman, "Vibration of Heat Exchange Components in Liquid and Two-Phase Cross Flow," Proc Int Conf on Vibration in Nuclear Plant, Keswick, United Kingdom, May 9-12, 1978, paper 2 3, Vol 1,p 215, Britısh Nuclear Energy Society (1979)

5 H J Connors, "Fluidelastic Vibration of Tube Arrays Excited by Cross Flow," Proc Symp Flow-Induced Vibration in Heat Exchangers, ASME 91st Annual Winter Meeting, New York City, New York, November 29-December 3, 1970, p 42, American Society of Mechanical Engineers (1971)

6 M P Paidoussis, "A Review of Flow-Induced Vibrations in Reactors and Reactor Components," Nucl Eng Des, 74, 31 (1983)

7 M P Paidoussis, "The Dynamical Behavior of Cylındncal Structures in Axial Flow," Ann Nucl Sct Eng, 1, 83 (1974)

8 G Baylac, R J Gibert, and M Livolant, "Calcul de l'Amplification Acoustıque dans les Circuits Complexes,"' Houlle Blanche, 5, 407 (1971)

9 B Bickers, "An Assessment of Noise and Vibration Measurements Taken Durnng the Commissioning of Dungeness B,' Proc 3rd Keswick Int Conf Vibration in Nuclear Plant, Keswick, United Kingdom, May 11-14, 1982, Vol 1, p 518, Britısh Nuclear Energy Society (1983)

10 L L Beranek, G W Kamperman, and C H Allen, "Norse of Centrifugal Fans," $J$ Acoustic Soc Am, 27, 217 (1955)

11 C H Allen, "Noise Control in Ventılatıng Systems," in Nolse Reductıon, L Beranek, Ed, McGraw-Hill Book Co , New York (1960)

12 T E Burton, "Vibration of HTGR Plates and Shells," GA-A 13942, GA Technologies (Aug 1977)

13 C F Bonilla, Ed, Nuclear Engineering, McGraw-Hill Book Co , New York (1957)

14 S Timoshenko and J N Goodier, Theory of Elasticity, 2nd ed, McGraw-Hill Book Co , New York (1957)

15 J F Harvey, Pressure Vessel Desıgn, p 65, D Van Nostrand Co, New York (1963) 
16 S S Manson, Thermal Stress and Low-Cycle Fatıgue, McGraw-Hill Book Co, New York (1966)

17 L E Coffin, "Introduction to High-Temperature Low-Cycle Fatıgue," Exp Mech , 8, 218 (May 1968)

18 J Bree, "Incremental Growth Due to Creep and Plastıc Yielding of Thin Tubes Subjected to Internal Pressure and Cyclic Thermal Stress,' J Strain Analysis, 3, 122 (1968)

19 Criteria for the Design of Elevated Temperature Class 1 Components, Amencan Society of Mechanical Engineers, New York (1976)

20 D R Olander, "Fundamental Aspects of Nuclear Reactor Fuel Elements," TID26711-P1 (1976) 


\section{6}

\section{HTGR DESIGN BASES}

This chapter is an overview of the main design features of high-temperature gas-cooled reactors (HTGRs) and their design bases. After some discussion of the HTGR fuel cycle and fuel management, the choice of materials for the HTGR is considered. Properties of graphite, coated particles, fuel rods, control rod materials, and primary circuit materials are presented. Finally, the thermal design bases for HTGR cores are given. This chapter serves as an introduction to Chapter 7 , which deals with the detailed configuration of the core and the thermal design.

\section{6-1 HTGR Design Features}

The HTGR was originally conceived as a nuclear heat source capable of providing the high temperatures necessary to obtain modern steam conditions for electricity generation and, at the same time, capable of extending the applications of nuclear power to high-temperature industrial processes. The use of thorium as a fertile material, rather than ${ }^{238} \mathrm{U}$, has also been proposed since the beginning in order to match the extended fuel element lifetime inherent in the moderatordiluted design with the excellent neutronic properties of the bred ${ }^{233} U$ fuel. Graphite was chosen as the moderator, fuel containment material, and core structure because of its good neutronic, irradiation, and high-temperature properties, and helium as the coolant was preferred since helium is inert, does not interact with neutrons, and has satisfactory heat transfer and transport properties at modest pressures, say, $\sim 2$ to $5 \mathrm{MPa}$ ( 20 to $50 \mathrm{~atm}$ ), with acceptable pumping power. Finally, the development of the impervious coated particle fuel has led to very high burnups ( 100 to $200 \mathrm{MWd} / \mathrm{kg}$ ) and a clean primary circuit without a metallic fuel cladding or even a fission gas purging system as in the Peach Bottom HTGR. The safety features of the HTGR resulting from its high-temperature capabilities and the large thermal inertia of its graphite structures are further increased by the utilization of a prestressed concrete reactor pressure vessel (PCRV) to contain the whole primary system for all large HTGR systems.

The basic HTGR concept has a number of variants for its fuel cycle, fuel design, thermodynamic cycle, and industrial applications. The reactor can utilize highly enriched ${ }^{235} \mathrm{U}$ with thorium as the fertile material, or it can operate on a low-enriched uranium cycle. Makeup fuel, to supplement recycle ${ }^{233} \mathrm{U}$ for the thorium cycle, could be ${ }^{235} \mathrm{U},{ }^{239} \mathrm{Pu}$, or preferably ${ }^{233} \mathrm{U}$ coming from other HTGRs or from fast breeders. The fuel elements could be cylindrical, as in the Dragon 
or Peach Bottom reactors; spherical, like the pebbles in the AVR and THTR reactors; or prismatic, as in the Fort St. Vrain power station. The detailed design of the fuel elements and coated particles can be readily modified in order to reach specific goals, such as an increase in the outlet temperature or the conversion ratio.

Up to now, electricity generation with nuclear energy has been provided by steam cycle systems. Increased cycle efficiency and modern steam conditions may be obtained from advanced nuclear systems, breeders, AGRs, and of course HTGRs. The high helium outlet temperature in the HTGR has allowed a considerable reduction in the required boiler surface, even for modern steam conditions of 520 to $540^{\circ} \mathrm{C}$. Typically, the power per unit boiler surface area has increased by a factor of 4 from the Magnox to the AGR, and by another factor of 2.5 for the HTGRs. Further improvements in steam conditions and/or a drastic reduction in steam generator surface area are not economically justifiable in HTGR systems, but a different type of power cycle deriving real benefits from the high-temperature source, namely, the gas turbine, could be an ideal match for the HTGR core. Instead of exchanging its heat with water and steam in a steam generator, helium leaving the reactor may be expanded in a closed-cycle gas turbine that drives both a helium compressor and a generator for electricity production. Potential advantages of this advanced system, which is described in Chapter 8, are its compactness, since the steam plant is eliminated; its potential for high thermal efficiency with the higher top gas temperatures obtainable from HTGR cores; and also the fact that its high reject heat temperature greatly facilitates the use of dry cooling towers.

Besides electricity generation, with either a steam cycle or a direct gas turbine cycle, the HTGR could be utilized to broaden the applications of nuclear energy to a number of industrial processes. Because of the low temperatures of light water reactors, their industrial applications are limited to the production of low quality steam, or the use of reject heat for district heating, at the cost of a decrease in plant efficiency. High-temperature and high-pressure steam available from HTGRs with proven operating conditions could be utilized in a number of industries, such as chemical plants, pulp and paper plants, and oil refineries, or for tar sand mining or in situ recovery of tar sands, or for cogeneration of electricity and steam. As is seen in Chapter 9, the higher helium temperatures obtainable from HTGR cores, for example $950^{\circ} \mathrm{C}$ in the AVR system, would make possible the production of synthetic gaseous and liquid fuels from coal, and even direct production of hydrogen by thermochemical decomposition of water. These unique capabilities of the HTGR system could significantly extend the applications of nuclear energy to $75 \%$ of the total U.S. energy requirements above and beyond electric power generation.

\section{6-2 HTGR Nuclear Fuel Cycle}

From a nuclear analysis viewpoint, the HTGR core is characterized by a semi-homogeneous design (where the fuel particles are dispersed in the graphite 
moderator), by the absence in the core of metallic materials that could absorb neutrons, and by the use of both highly enriched ${ }^{235} U$ and bred (or recycle) ${ }^{233} U$ as the fissile material, with ${ }^{232} \mathrm{Th}$ as the fertile material. The helium coolant has insignificant interaction with the core neutronics, and with low impurities, it does not become activated. The thorium cycle was chosen initially because of the neutronic properties of ${ }^{233} \mathrm{U}$, which is the best fissile material for thermal reactors, $\sim 10 \%$ more neutrons per absorption than ${ }^{235} U$. Graphite was chosen as the moderator (and reflector) material because of its excellent structural and thermal properties at high temperatures, good irradiation behavior compared to BeO (Refs. 1 and 2), and its much lower cost. The optimum conversion ratio with $\mathrm{BeO}$ moderation and ${ }^{235} \mathrm{U}$ fuel is $\sim 10 \%$ higher than for graphite, but the $\mathrm{C} /{ }^{233} \mathrm{U}$ system could also lead to a conversion ratio close to unity if needed, and graphite is a satisfactory moderating material.

The conventional fuel cycle in all existing HTGRs utilizes $93 \%$ enriched ${ }^{235} \mathrm{U}$ as the fissile material and ${ }^{232} \mathrm{Th}$ as the fertile material. Some of the ${ }^{233} \mathrm{U}$ bred in ${ }^{232} \mathrm{Th}$ is used (burned) in situ, i.e., produces fissions together with ${ }^{235} \mathrm{U}$. At the end of a cycle, typically 4 to $6 \mathrm{yr}$, the fuel removed from the reactor still contains a sizable amount of ${ }^{233} \mathrm{U}$, which can be either stored or recycled in the reactor, and a mixture of ${ }^{235} \mathrm{U}$ and ${ }^{236} \mathrm{U}$, which can be sold or recycled once. The use of two different sizes of coated particles, for instance 0.46 to $0.57 \mathrm{~mm}$ for the fissile particles and 0.71 to $0.82 \mathrm{~mm}$ for the fertile particles, facilitates separation of fuels during reprocessing. In an equilibrium recycle condition, onequarter or one-sixth of the core would be replaced every year by fuel containing recycle ${ }^{233} \mathrm{U}$, with some makeup ${ }^{235} \mathrm{U}$ (93\% enriched) since the conversion ratio of the reactor is $<1$ (i.e., more fuel is consumed than is produced). The most desirable mode of operation in the HTGR involves ${ }^{233} \mathrm{U}$ recycle because of the neutronic advantage of ${ }^{233} \mathrm{U}$ in thermal spectrum reactors, as shown in Table 6-I (Ref. 3). The quantity $\eta_{\text {eff }}$ is the average number of fission neutrons produced per neutron absorbed in the fissile material, while $\eta_{\text {eff }}-1$ indicates the number of neutrons available for purposes other than just maintaining the chain reaction. As can be seen, the excess neutron production capability of ${ }^{233} \mathrm{U}$ is $25 \%$ better than that of ${ }^{235} \mathrm{U}$ and $\sim 45 \%$ better than that of ${ }^{239} \mathrm{Pu}$. The relative value that a reactor operator could afford to pay for bred fuels is found to be substantially higher for ${ }^{233} U$ than for ${ }^{235} U$ (see the last column of Table 6-I). In the "reference" fuel cycle, the bred ${ }^{233} \mathrm{U}$ is recycled continuously while the discharged feed uranium, now $\sim 30 \%$ enriched, is recycled once more through the reactor. After

TABLE 6-I

Relative Neutron Production Capabilities for ${ }^{233} \mathrm{U},{ }^{235} \mathrm{U}$, and ${ }^{239} \mathrm{Pu}$

\begin{tabular}{|cccc|}
\hline Isotope & $\eta_{\text {eff }}$ & $\eta_{\text {eff }}-1$ & $\begin{array}{c}\text { Relative Value as } \\
\text { Fissile Material }\end{array}$ \\
\hline${ }^{233} \mathrm{U}$ & 2.25 & 1.25 & 1.4 \\
${ }^{235} \mathrm{U}$ & 2.00 & 1.00 & 1.00 \\
${ }^{239} \mathrm{Pu}$ & 1.85 & 0.85 & 0.8 \\
\hline
\end{tabular}


an additional reactor cycle, the recycle ${ }^{235} U$ enrichment is only $\sim 4 \%$, the remainder being largely ${ }^{236} \mathrm{U}$. The fuel value of this retired ${ }^{235} \mathrm{U} /{ }^{236} \mathrm{U}$ mixture is assumed to be zero.

Over the lifetime of a given plant, the HTGR fuel cycle could include several modes of operation, ${ }^{4-6}$ for example:

1. Nonrecycle. The fuel loaded in the reactor consists of enriched ${ }^{235} \mathrm{U}$ and ${ }^{232} \mathrm{Th}$. Spent fuel removed from the core is placed in storage to await reprocessing, refabrication, and recycle.

2. Recycle operation. The fuel removed from the core is reprocessed and the ${ }^{233} \mathrm{U}$ is fed back into the reactor together with highly enriched ${ }^{235} \mathrm{U}$ makeup.

Besides the different strategies for the ${ }^{235} \mathrm{U} /{ }^{232} \mathrm{Th} /{ }^{233} \mathrm{U}$ cycle, other HTGR cycles with different types of fissile and fertile materials have been proposed; for instance, a low-enrichment ${ }^{235} \mathrm{U} /{ }^{238} \mathrm{U}$ cycle proposed in Europe (refer to Table 2-III).

For a given type of fuel cycle, the most important independent fuel management variables are the moderator-to-fertile material ratio $(\mathrm{C} / \mathrm{Th})$, power density, and fuel lifetime. The fissile loading in the initial core and for reloads is determined by criticality and burnup requirements for a given value of $\mathrm{C} / \mathrm{Th}$. A reduced thorium loading leads to a reduction of two components of fuel cycle cost: reduced working capital costs because of a smaller fissile inventory, and reduced fabrication and reprocessing costs because of smaller fertile and fissile loadings. However, fuel depletion costs will be increased because of the resultant lower conversion ratio, and higher power peaking factors lead to high fuel temperatures.

The product of power density and fuel lifetime is proportional to the fast fluence, limiting for neutron irradiation damage. A lower power density will permit a longer fuel lifetime for a given design limit. For instance, a 6-yr fuel lifetime and $6 \mathrm{~W} / \mathrm{cm}^{3}$ average power density for the Fort St. Vrain reactor core lead to about the same maximum fast fluence as that of the fuel for large HTGR designs with a 4-yr lifetime and $8.4 \mathrm{~W} / \mathrm{cm}^{3}$ density. An increase in power density would decrease both capital costs and fuel cycle costs for the same fuel lifetime and $\mathrm{C} / \mathrm{Th}$; but the fast fluence would be increased and new design criteria (or other materials) would be required. Obviously, the detailed design of the fuel element, i.e., the relative number of coolant holes and their size in the prismatic block design, ${ }^{7}$ has to be adjusted to the chosen value of the power density for a given maximum fuel temperature.

Semiannual refueling would lead to a gain of up to 0.05 in the conversion ratio because of the reduction in reactivity, which has to be compensated by burnable poisons. A shorter fuel lifetime slightly increases the conversion ratio, by $\sim 0.02$ from a 4 - to a 3-yr lifetime because of the decrease in fission product poisons held in the core. A reduction in power density leads to an increase in the conversion ratio because of better neutron thermalization (added moderator) and, more importantly, because more volume is made available for heavier fuel loadings. The conversion ratio increases from 0.66 to 0.74 when the power density 
is decreased from 8.4 to $6 \mathrm{~W} / \mathrm{cm}^{3}$. Obviously, the plant must be designed for a given power density, since it involves both reactor core dimensions and coolant conditions, such as pressure drop. Thus the capital costs of the plant must be included in the economic optimization studies of the fuel cycle.

Since only a fraction of the core is replaced every year (one-sixth in Fort St. Vrain, one-quarter in other designs), at any time the core contains a distribution of fuel of different ages. The fissile density of new fuel being higher than the core average, the fission power density is also higher than average, leading to a higher fuel temperature in the new fuel compared to the average fuel. This effect is called the "age peaking factor," which is increased by a long fuel lifetime and a high $\mathrm{C} / \mathrm{Th}$ ratio, both of which lead to lower conversion ratios and therefore a larger relative difference in the fission rate in fuel of different ages (see Chapter 7).

Studies of various possible fuel cycles have shown the great flexibility available to HTGRs, which may be designed for different cycles without major changes or even adapted to accept different fuel cycles during the reactor lifetime. ${ }^{8}$ For instance, it is possible to start an HTGR on a low-enriched uranium cycle (i.e., $<20 \%$ enrichment) and gradually switch it over to the thorium cycle after several years of operation. ${ }^{9}$ A low-enriched uranium cycle could be designed for the same conditions as the thorium cycle, i.e., same outer dimensions of prismatic fuel block, same coolant flow area, same temperatures and power density, and same overall core dimensions and number of control rods. The detailed design of the coated particles, fuel sticks, coolant holes, fuel lifetime, and fuel loadings will obviously be different for the two cycles. For instance, the low-enriched uranium cycle benefits from a more heterogeneous fuel arrangement and higher moderation leading to a fewer number of fuel rods (or bodies) with an initial ${ }^{235} \mathrm{U}$ enrichment of $\sim 6 \%$.

\section{6-3 HTGR Materials}

Overall plant design optimization includes choice of coolant flow, pressure, temperature, pressure drop, fuel and fuel element geometry, core dimensions, etc. Some basic decisions have to be made from engineering judgments or safety arguments, and other limitations arise from the properties and irradiation behavior of the chosen core materials. Even though helium is chemically inert, the level of impurities must be kept low enough to prevent significant reactions with ceramic materials in the core, or metals in the primary coolant loop. The top helium temperature is limited, generally by the metallic parts in the primary system. The graphite moderator and structure must be designed in such a way as to minimize thermal and radiation-induced stresses and the radiation-induced dimensional changes must be limited to acceptable values, so as not to introduce unacceptable deformation in the core. Fuel elements and coated particles are subject to burnup and temperature effects and must be able to last their design life without unacceptable damage or release of fission products. Even for steady-state reactor operation, a detailed time history of the temperature and flux distribution in the core is needed 
to study its behavior, i.e., temperatures and stresses. Furthermore, transient behaviot must be understood in order to verify that no damage to fuel elements or structures is done, for instance, by repeated scrams. Finally, safety design margins must be established in the thermal and mechanical design so that accidental conditions could be sustained without damage to the system and, of course, to the public.

After basic choices have been made for the gaseous coolant and metals in the primary system, design criteria have to be set for the coolant chemistry, the type of graphite, the fluence, temperatures and stress levels, and the detailed fuel composition, geometry, and operating conditions. Experiments in- and out-of-pile under representative conditions and experience with actual reactors since the mid1960 s have yielded a great wealth of data on the behavior of fuels, the moderator, and structural and other materials for HTGR applications.

\section{6-3A Graphite}

In HTGR cores, graphite is used as a structural material, i.e., for core support columns, the reflector, and of course also as the main structure of the prismatic (or spherical) fuel elements. Graphite has been used in nuclear reactors from the very beginning, so a great deal of information on the properties of graphites for nuclear applications is available, particularly from France, West Germany, the United Kingdom, and the United States. ${ }^{10,11}$ The graphite temperature was limited to $\sim 300$ to $400^{\circ} \mathrm{C}$ for the early reactors and stored energy created by fast neutron irradiation was a serious problem. For advanced graphite-moderated reactors like HTGRs, graphite temperatures during operation range from 350 to $400^{\circ} \mathrm{C}$ to 1200 to $1300^{\circ} \mathrm{C}$ and little energy is stored, but irradiation effects by fast neutrons cause dimensional changes, changes in thermal conductivity, and irradiation-induced creep. ${ }^{2}$ Nuclear graphites are of three basic types, according to the selection of filler cokes and processing, which determine the crystalline structure and the associated porosity and, therefore, the properties and irradiation behavior: anisotropic petroleum needle-cokes, near-isotropic petroleum or Gilsonite cokes, and high-strength isotropic graphites. While the first two kinds can be manufactured in large quantities at relatively low cost, the third kind cannot be manufactured in large quantities and is more expensive.

Dimensional changes of graphite at high temperature due to fast neutron irradiation given in Fig. 6-1 show the great difference in behavior of isotropic and non-isotropic graphites. Since the graphite moderator in HTGRs is replaced with the fuel elements every 4 to $6 \mathrm{yr}$, the maximum fast neutron fluence is on the order of $8 \times 10^{21} \mathrm{n} / \mathrm{cm}^{2}(E>0.18 \mathrm{MeV})$ or $11 \times 10^{21} \mathrm{n} / \mathrm{cm}^{2}(E>0.05 \mathrm{MeV})$. For near-isotropic graphite (H-451), a shrinkage is first observed to increase with increasing fluence and temperature, both parallel and perpendicular to graphite extrusion, to $\sim 1$ to $1.5 \% \Delta l / l$ at $1000^{\circ} \mathrm{C}$. Then the shrinkage decreases and eventually becomes expansion with increasing fluence. For needle-coke graphite (H-327), the shrinkage parallel to the extrusion direction increases with fluence 


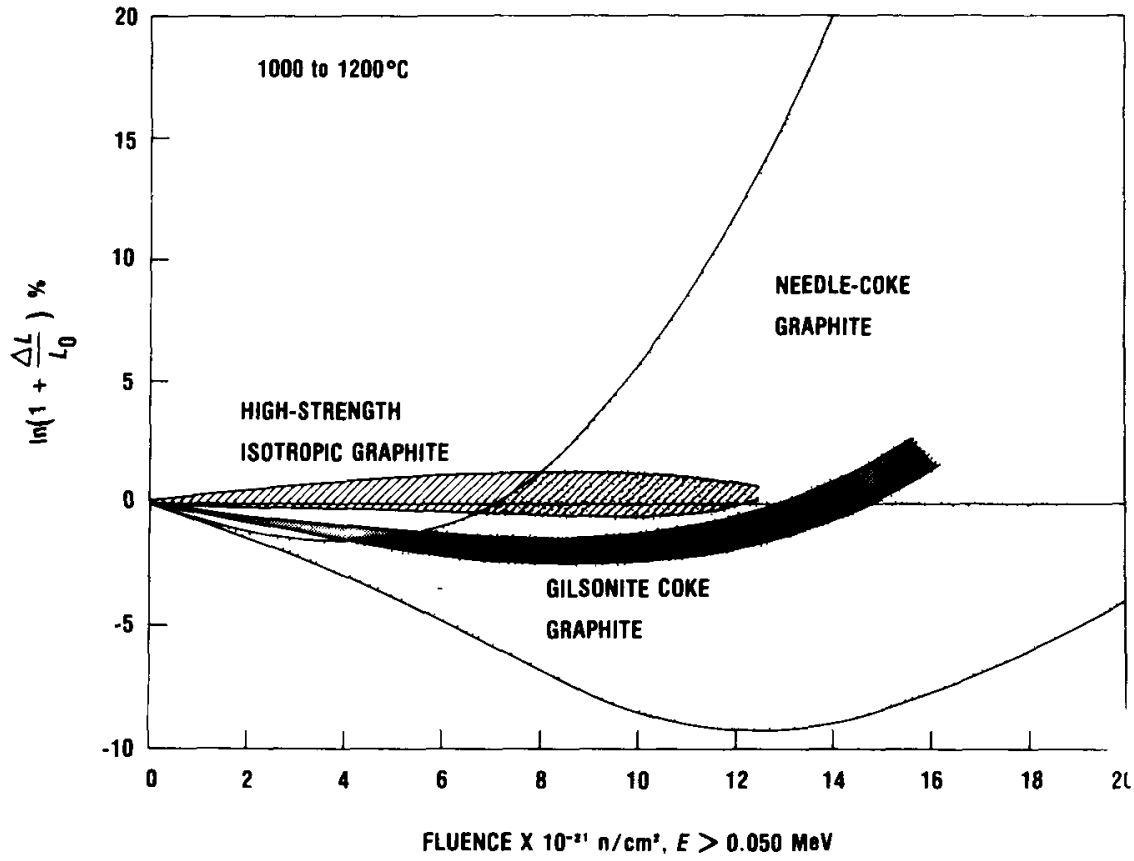

Fig. 6-1. Dimensional changes versus fast neutron fluence at 1000 to $1200^{\circ} \mathrm{C}$ for needlecoke, near-isotropic (or Gilsonite coke), and high-strength isotropic graphites.

and temperature (above $\sim 700^{\circ} \mathrm{C}$ ), up to $\sim 5 \% \Delta l / l$ at $8 \times 10^{21} \mathrm{n} / \mathrm{cm}^{2}(E>$ $0.18 \mathrm{MeV}$ ). But for this graphite, dimensional changes perpendicular to extrusion could be either shrinkage or expansion depending on fast fluence and irradiation temperature as shown in Fig. 6-2.

Desirable properties in core graphites are: minimal dimensional changes, high thermal conductivity in the radial direction (for good heat transfer from fuel rod to coolant), low thermal expansion, low elastic modulus, high tensile strength, low impurity content, and acceptable oxidation resistance. The graphite should also be relatively inexpensive and readily machinable. Developments in Europe and in the United States in the 1970s with near-isotropic graphites indicate satisfactory behavior for use in HTGRs. ${ }^{12}$

Thermal conductivity values in the radial direction are comparable for needlecoke graphite and for near-isotropic graphite. They are found first to decrease with increasing fast fluence and then remain constant up to values of 7 to $8 \times$ $10^{21} \mathrm{n} / \mathrm{cm}^{2}(E>0.18 \mathrm{MeV}$ ). As can be seen in Fig. 6-3, the thermal conductivity of unirradiated graphite decreases with increasing temperature, from $\sim 83.5$ $\mathrm{W} / \mathrm{m} \cdot{ }^{\circ} \mathrm{C}$ at $500^{\circ} \mathrm{C}$ to $48.1 \mathrm{~W} / \mathrm{m} \cdot{ }^{\circ} \mathrm{C}$ at $1400^{\circ} \mathrm{C}$. This trend is reversed after irradiation at $\sim 10^{21} \mathrm{n} / \mathrm{cm}^{2}$, and the thermal conductivity increases from $25 \mathrm{~W} / \mathrm{m} \cdot{ }^{\circ} \mathrm{C}$ at $500^{\circ} \mathrm{C}$ to $\sim 42 \mathrm{~W} / \mathrm{m} \cdot{ }^{\circ} \mathrm{C}$ at $1400^{\circ} \mathrm{C}$ for fluences from $\sim 4$ to $8 \times 10^{21} \mathrm{n} / \mathrm{cm}^{2}$. It must be 

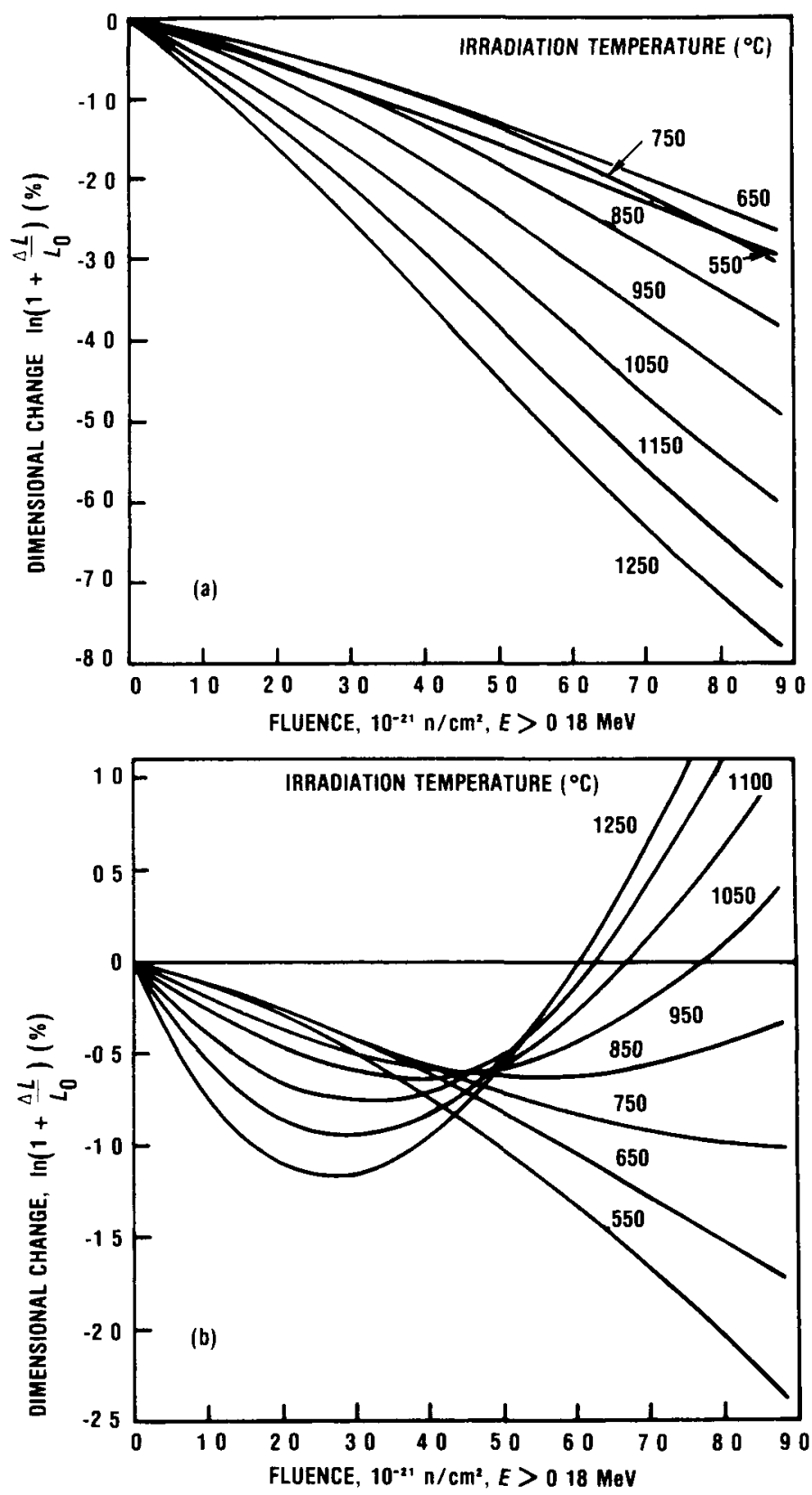

Fig 6-2 Needle-coke graphite (H-327) dımensıonal changes in (a) parallel and (b) perpendicular directions 

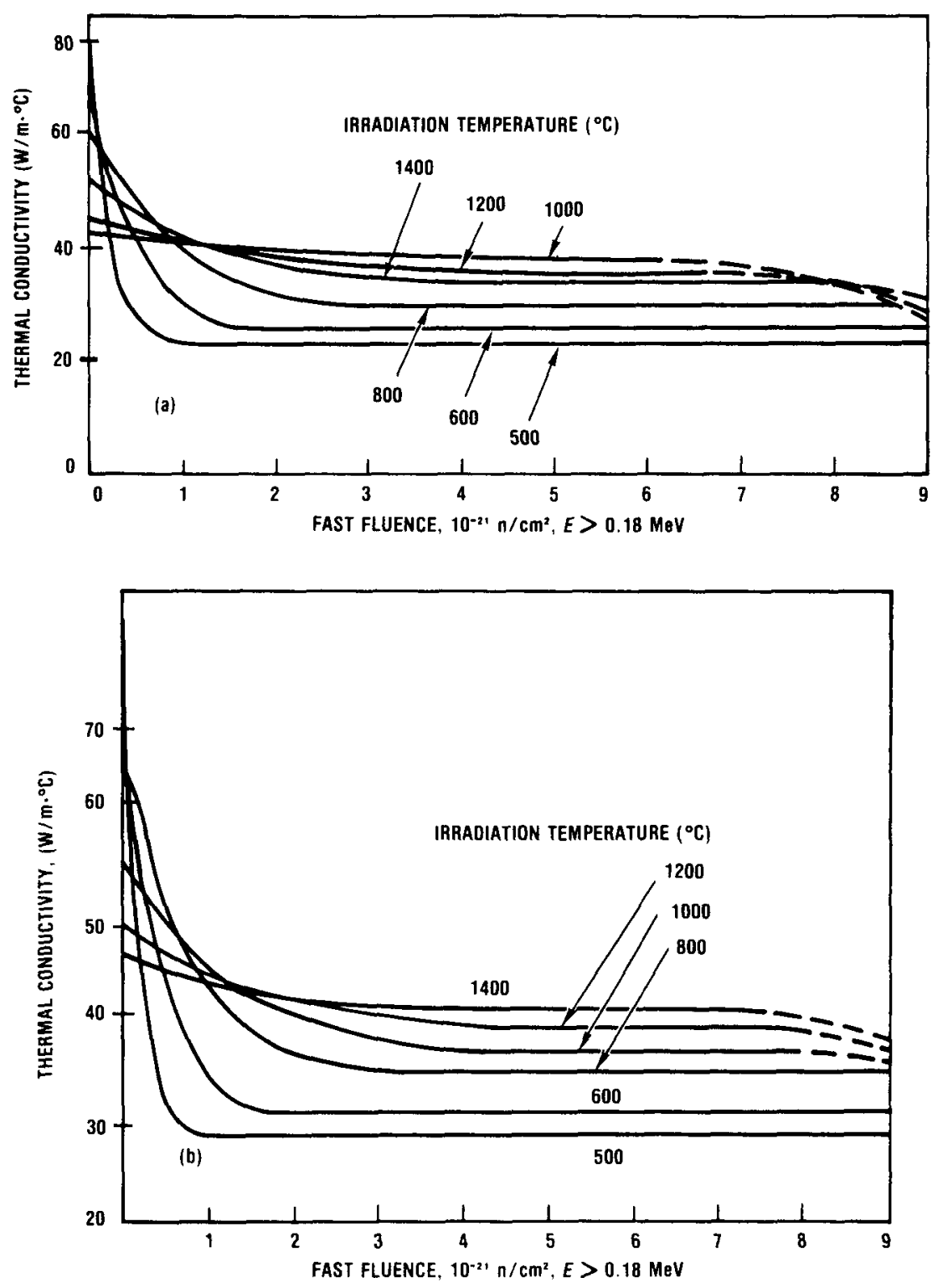

Fig. 6-3. Thermal conductivity of (a) $\mathrm{H}-327$ graphite and (b) $\mathrm{H}-451$ graphite, both perpendicular to extrusion, as a function of irradiation temperature and fluence.

remembered that, in an HTGR fuel element, the graphite temperatures change with time because of variable rates of heat generation.

The values of the thermal expansivity (or coefficient of thermal expansion) of graphite are needed to calculate dimensional changes due to temperature in 
both radial and axıal directions and also for thermal stress calculations The thermal expansion in the perpendicular direction, which depends on the graphite type, increases with increasing temperature as shown in Fig 6-4 The coefficient of thermal expansion in the perpendicular direction remains nearly unchanged by fast neutron irradiation The specific heat of graphite, quite important for transient response of HTGR cores, is found to be an increasing function of temperature as shown in Fig 6-5 Graphite thermal emissivity is needed for calculations of radiation heat transfer, for instance, across the gap between fuel rod and fuel holes, or for safety studies Graphite emissivity for unpolished surfaces is generally found to be 085 to 090

Both ultımate tensile strength and Young's modulus increase with increasing fast neutron fluences up to $\sim 3 \times 10^{21} \mathrm{n} / \mathrm{cm}^{2}$ for $\mathrm{H}-327$ and $\mathrm{H}-451$ graphites a 30 to $60 \%$ increase in strength at irradiation temperatures increasing from 650 to $1350^{\circ} \mathrm{C}$, with a corresponding 60 to $130 \%$ increase in modulus Average minımum tensile strength values for fluences up to $\sim 3 \times 10^{21} \mathrm{n} / \mathrm{cm}^{2}$ at 860 to $1080^{\circ} \mathrm{C}$ were found to be

\section{H-327 parallel \\ H-327 perpendicular \\ H-451 parallel \\ $\mathrm{H}-451$ perpendicular}

$$
\begin{array}{r}
146 \pm 195 \mathrm{MPa} \\
665 \pm 135 \mathrm{MPa} \\
1635 \pm 185 \mathrm{MPa} \\
1825 \pm 185 \mathrm{MPa}
\end{array}
$$

Thermally induced creep of graphite is significant only above $2000^{\circ} \mathrm{C}$, but irradiation-induced creep becomes important at temperatures as low as $300^{\circ} \mathrm{C}$ The transient creep strain and the steady-state creep constant both increase with increasing irradiation temperature over the interval 500 to $1200^{\circ} \mathrm{C}$ For different graphites, these values are nearly inversely proportional to Young's modulus Creep strains up to $25 \%$ in tension and $5 \%$ in compression have been reported But compressive creep in isotropic graphites appears to stop when the strain reaches 2 to $3 \%$, and more experimental data are still needed

\section{6-3B Coated Particles}

All HTGR fuels are based on the coated fuel particle concept in which a small kernel, consisting of oxides, carbides, or oxycarbides of heavy metals $\left({ }^{232} \mathrm{Th}\right.$ or ${ }^{238} \mathrm{U}$ as fertile material, ${ }^{233} \mathrm{U},{ }^{235} \mathrm{U}$, or ${ }^{239} \mathrm{Pu}$ as fissile material), is coated with a number of layers, typically two to four, of ceramic materials, $1 \mathrm{e}$, pyrolytic carbon (PyC) or silicon carbide ( $\mathrm{SiC}$ ) Two main types of coated fuel particles have been developed

1 BISO partıcles The heavy metal kernel is first coated with an inner buffer layer of low-density PyC to attenuate the recolls of fission products and provide enough void to accommodate fission gases and the swelling of the fuel kernel An outer layer of dense isotropic PyC provides hightemperature containment for fission gases and mechanical strength for 


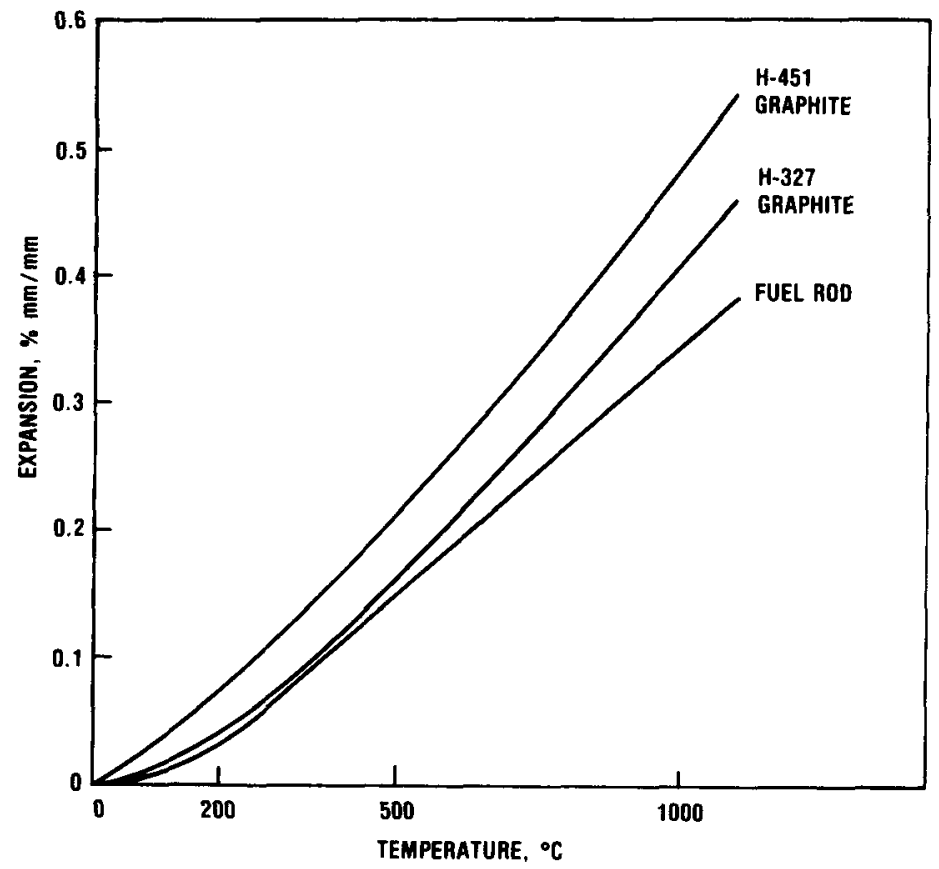

Fig. 6-4. Thermal expansion design curve for $\mathrm{H}-327$ and $\mathrm{H}-451$ graphite and a fuel rod.

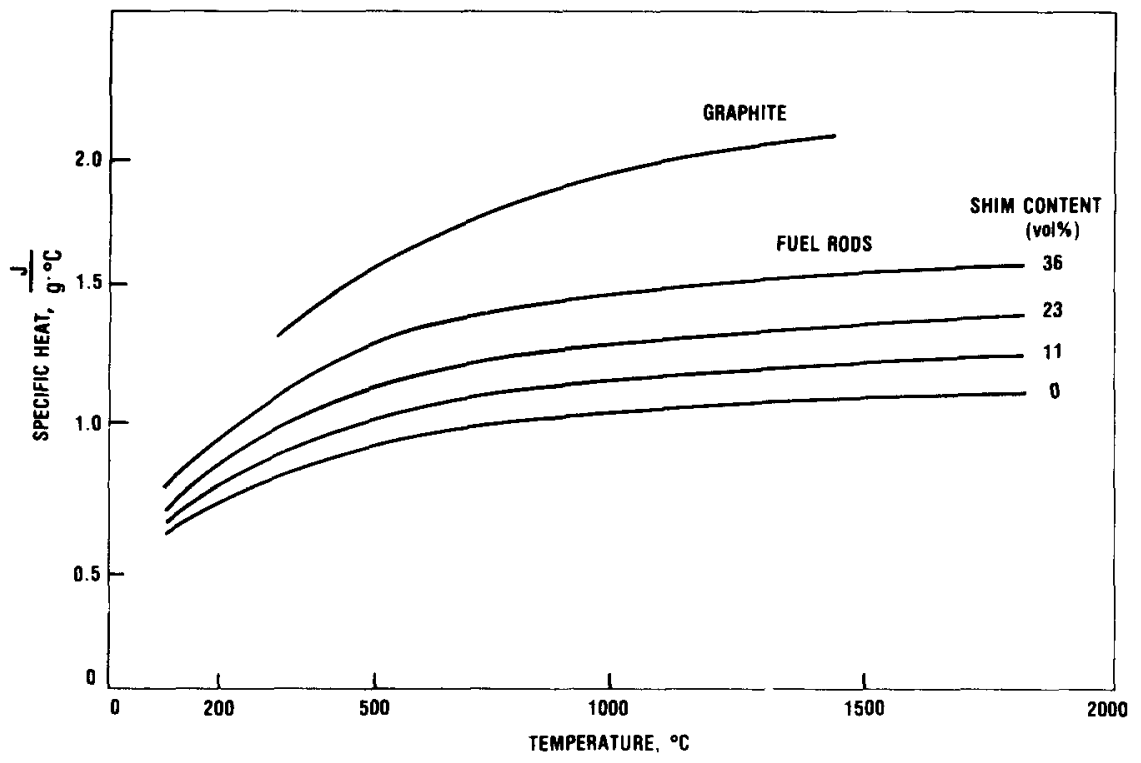

Fig. 6-5. Specific heat of graphite and fuel rods as a function of temperature. 


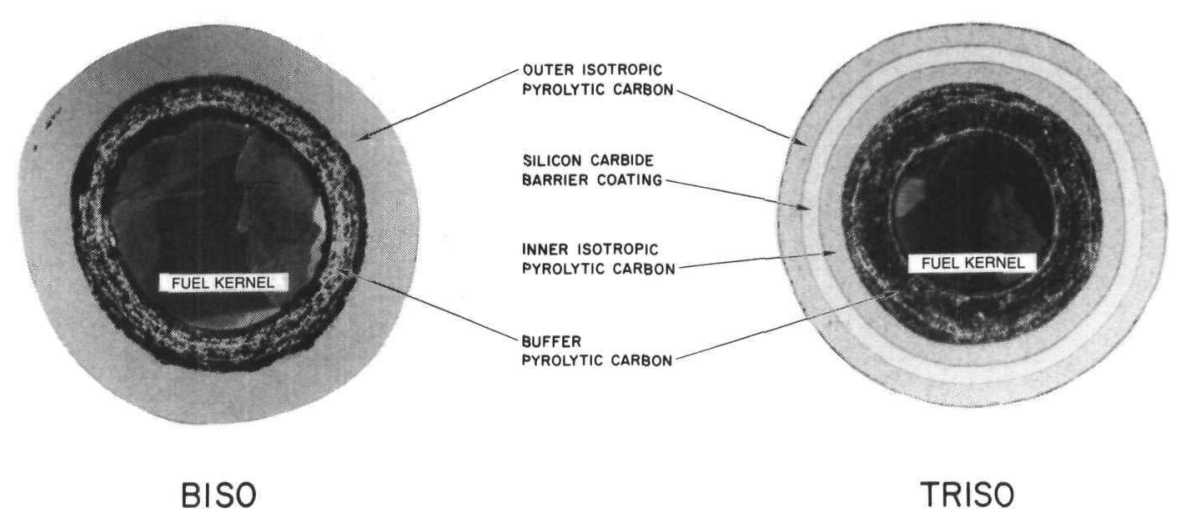

Fig. 6-6. Reference thorium cycle HTGR fuel particles irradiated beyond peak design exposure.

the particles. However, the more volatile fission product metals such as cesium and strontium will gradually diffuse through the PyC layers over a long period of time. In operating HTGRs such as the Peach Bottom reactor, it has been found that a fraction of the cesium and strontium diffusing out of the fuel rods is usually held in the graphite structure of the fuel element.

2. TRISO particles. A thin layer of $\mathrm{SiC}$ is deposited on the first layer of dense PyC to stop the escape of all metallic fission products from the particle. An outer layer of dense isotropic PyC provides mechanical support to the $\mathrm{SiC}$ layer and acts as backup containment.

Typically, TRISO particles are used in HTGRs for fissile fuel kernels, which consist of $93 \%$ enriched ${ }^{235} \mathrm{U}$ carbide $\left(\mathrm{UC}_{2}\right)$ or of UCO (chosen more recently), while BISO coatings may be used for fertile particles of $\mathrm{ThO}_{2}$. Figure 6-6 shows pictures of the two types of particles after irradiation, with their characteristic dimensions. ${ }^{13}$ Typical operating conditions for HTGR fuel are given in Table 6-II. A large number of in- and out-of-pile tests have shown that performance of coated particles is generally limited by four mechanisms:

1. Kernel migration or "amoeba effect."' Fuel kernels have a tendency to migrate toward the hot side of the particle in a temperature gradient. Generation of heat within a fuel rod with cooling at the outside induces a temperature gradient between the hotter center and cooler outer surface. As the kernel moves through the PyC buffer layer into the structural $\mathrm{PyC}$ or $\mathrm{SiC}$ layers, the particle coating is weakened.

2. High coating stresses. High coating stresses, which may lead to failure, are related to the particle geometry and irradiation effects. Failure of the composite pressure vessel could occur because of increasing fission gas 
TABLE 6-II

Service Conditions for 3000-MW(t) HTGR Fuel

\begin{tabular}{|lcc|}
\hline & Maxımum & Average \\
\hline Fuel temperature $\left({ }^{\circ} \mathrm{C}\right)$ & 1350 & 850 \\
Fuel rod thermal gradient $\left({ }^{\circ} \mathrm{C} / \mathrm{cm}\right)$ & 340 & 120 \\
Power density & 120 & 43 \\
$\quad$ Fuel rod $(\mathrm{kW} / l$ fuel rod) & 01 & 002 \\
$\quad$ Fuel particle $(\mathrm{W} /$ particle $)$ & & \\
Fuel rod linear heat rate & 230 & 82 \\
$\quad(16 \mathrm{~cm}$ diameter) $(\mathrm{W} / \mathrm{cm})$ & $8 \times 10^{21}$ & $5 \times 10^{21}$ \\
Fast neutron fluence $\left(\mathrm{n} / \mathrm{cm}^{2}\right)(E>018 \mathrm{MeV})$ & 78 & 72 \\
Burnup & 7 & 4 \\
Fissile $(\%$ fima & \\
Fertile $(\%$ fima $)$ & & \\
\hline
\end{tabular}

${ }^{a}$ Fissions of initial metal atoms

pressure and coatıng densification Coatıng stresses are influenced by design parameters, kernel diameter, coatıng dimensions and properties, and by reactor parameters, particle temperature, neutron fluence, and heavy metal burnup in the kernel ${ }^{14}$ Irradiation-induced creep helps avold exceeding fracture stress

3 Fission product-coating reactions In $\mathrm{UC}_{2}$ TRISO particles at high burnup, $1 \mathrm{e}$, above $50 \%$ FIMA, and at high temperature, 1600 to $1760^{\circ} \mathrm{C}$, the rare earth fission products migrate from the kernel and react with $\mathrm{SiC}$ on the cool side of the particle This effect is generally not a limiting factor in present HTGR designs, since the coating attack becomes important only after high burnup, at which time the fuel temperature in the element is below that necessary to cause reaction, but, it can be limiting for accident conditions

4 Manufacturing defects A small number of particles in some coatıng batches receive incomplete or defective coatings Particles with defective coatings are expected to fall progressively with increasing burnup, and therefore the fraction of defective particles is strictly regulated by fuel specifications and quality control procedures

These four problems are discussed in detall in Ref 15

\section{6-3C Fuel Rods}

In HTGRs, coated particles are incorporated into fuel rods with a matrix consisting of an organic binder and graphite filler, which is carbonized and heattreated to yield a carbonaceously bonded rod Typical rod dimensions are $157 \mathrm{~mm}$ in diameter and $635 \mathrm{~mm}$ long for large HTGRs and $127 \mathrm{~mm}$ and $508 \mathrm{~mm}$, respectively, for Fort St Vrain fuel Since variable fissile and fertle fuel loadings are used to flatten the power generation within the HTGR core, fuel rods may 
contain different quantities of fissile, fertile, and shim (graphite) particles; this affects their physical properties. Properties of the fuel rods are also influenced by their operating temperature and fast neutron fluence. Data required for thermal design are mainly:

1. Fuel rod thermal conductivity, ${ }^{16}$ as shown in Fig. 6-7, decreases slightly with increasing temperature in the range of 900 to $1300^{\circ} \mathrm{C}$. For the same total volume occupied by particles-fissile, fertile, and shim (graphite) in the fuel rod-the thermal conductivity increases with an increasing volume fraction of shim particles. This increase is to be expected, since thermal conductivity of graphite is higher than that of heavy metal-coated particles and matrix. Fast neutron irradiation is not expected to affect the thermal conductivity of fuel rods very much in the temperature range of 1000 to $1400^{\circ} \mathrm{C}$, which is of interest for HTGR designs.

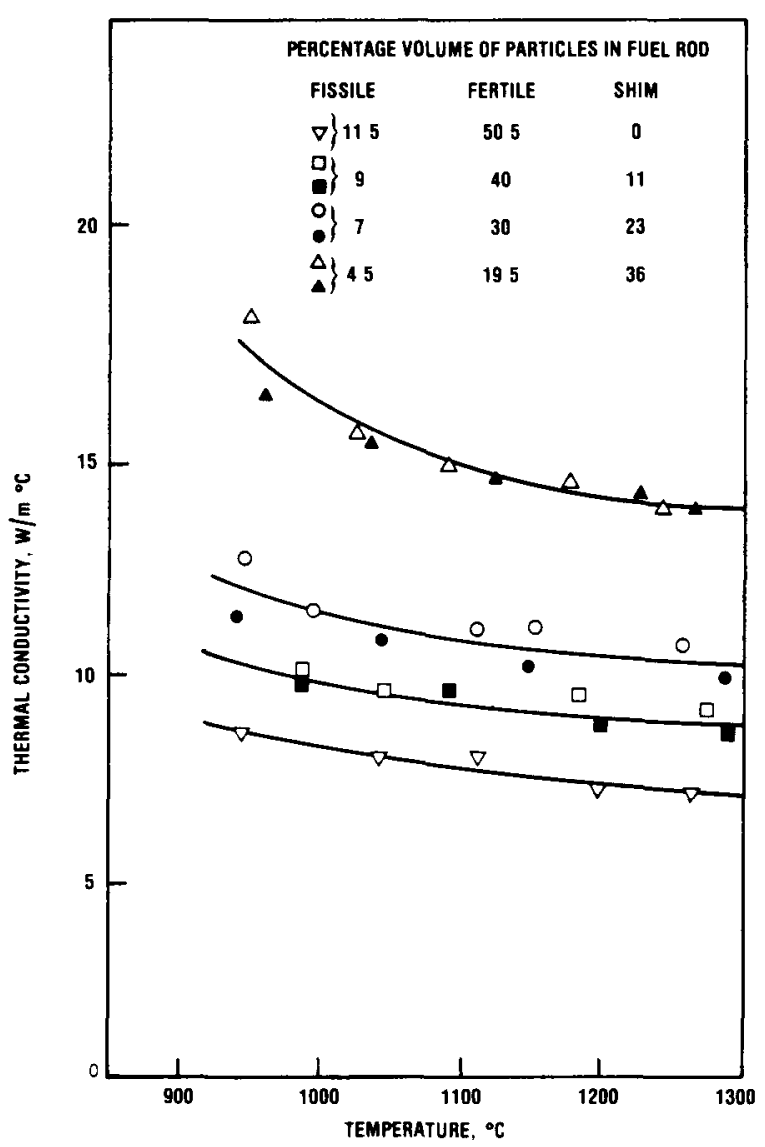

Fig. 6-7. Thermal conductivity of typical HTGR fuel rods as a function of temperature. 
2. Fuel rod thermal expansivity increases with increasing temperature and is very close to the corresponding value for graphite (see Fig 6-4). Thermally induced dimensional changes are found to be much less important than irradiation-induced dimensional changes in affecting the gap between fuel rod and fuel hole, which itself determines the heat transfer between rod and graphite.

3. Fuel rod emissivity values measured to be in the range of 0.86 to 0.92 are comparable to the values for graphite.

4. Fuel rod specific heat can be calculated from specific heat values for its components. As shown in Fig. 6-5, the specific heat is found to increase rapidly from room temperature to $\sim 500^{\circ} \mathrm{C}$; above $\sim 500^{\circ} \mathrm{C}$, it increases at a slower rate. As expected, the fuel rod specific heat increases with an increasing fraction of graphite shim particles.

5. Fuel rod density has been measured for rods made from different blends of particles. As shown in Table 6-III, the rod density vartes from 1.73 to $\sim 2.03 \mathrm{~g} / \mathrm{cm}^{3}$ for the loadings envisaged for the initial core and reloads.

6. Irradiation-induced dimensional changes have been measured in a series of 16 high-exposure instrumented capsule experıments. ${ }^{17}$ Enough data are now avallable on the effects of particle, matrix, and process variables

TABLE 6-III

Fuel Rod Metal Density and Volume Percentage of Fuel Particles in Different Blends of HTGR Fuel Rods

\begin{tabular}{|c|c|c|c|c|c|}
\hline \multirow[b]{2}{*}{ Segment } & \multirow[b]{2}{*}{ Fuel Zones } & \multicolumn{3}{|c|}{$\begin{array}{l}\text { Metal Density } \\
\left(\mathrm{g} / \mathrm{cm}^{3}\right)\end{array}$} & \multirow{2}{*}{$\begin{array}{c}\text { Fuel Rod } \\
\text { Densıty } \\
\left(\mathrm{g} / \mathrm{cm}^{3}\right)\end{array}$} \\
\hline & & Thorıum & Ura & & \\
\hline \multirow{4}{*}{$\begin{array}{l}\text { Initial } \\
\text { core }\end{array}$} & Top four layers & 0577 & 0 & & 1876 \\
\hline & Middle three layers & 0504 & & & 1804 \\
\hline & Bottom layer & 0429 & & & 1740 \\
\hline & Buffer zone & 0812 & & & 2035 \\
\hline \multirow[t]{6}{*}{ Reloads } & Top four layers & 0575 & & & 1954 \\
\hline & Middle three layers & 0459 & & & 1814 \\
\hline & Bottom layer & 0374 & & & 1731 \\
\hline & Buffer zone & 0653 & & & 1931 \\
\hline & & \multicolumn{4}{|c|}{ Partıcles by Volume Fraction } \\
\hline & & $\begin{array}{l}\text { Fissile } \\
\text { Particles }\end{array}$ & $\begin{array}{c}\text { Fertıle } \\
\text { Partıcles }\end{array}$ & $\begin{array}{l}\text { Shim } \\
\text { Content }\end{array}$ & $\begin{array}{c}\text { Matrıx } \\
\text { Content }\end{array}$ \\
\hline \multirow{4}{*}{$\begin{array}{l}\text { Initual } \\
\text { core }\end{array}$} & Top four layers & 0057 & 0298 & 0225 & 042 \\
\hline & Middle three layers & 0046 & 0260 & 0274 & 042 \\
\hline & Bottom layer & 0038 & 0221 & 0321 & 042 \\
\hline & Buffer zone & 0036 & 0419 & 0125 & 042 \\
\hline \multirow[t]{4}{*}{ Reloads } & Top four layers & 0109 & 0297 & 0174 & 042 \\
\hline & Middle three layers & 0076 & 0237 & 0267 & 042 \\
\hline & Bottom layer & 0059 & 0193 & 0328 & 042 \\
\hline & Buffer zone & 0054 & 0337 & 0189 & 042 \\
\hline
\end{tabular}


on irradiation performance to specify fuel rod properties and fabrication processes General criteria for successful rod performance are good rod integrity and acceptable shrinkage values at operatıng temperature and design fast fluences Successful capsule tests have been performed up to $1500^{\circ} \mathrm{C}$ and $106 \times 10^{21} \mathrm{n} / \mathrm{cm}^{2}, 1 \mathrm{e}$, far beyond design conditions Large numbers of fuel rods have been successfully irradiated under representative HTGR conditions in test elements in the Peach Bottom reactor Satısfactory irradiation results of a mock-up prismatic German fuel element in the Dragon reactor have also been reported ${ }^{18}$ Discussion of HTGR fuel development and testıng for the Belgian, Englısh, French, German, and U S programs have been reported in Refs 19 and 20 For tıme-varying fuel element temperatures, the irradiation history is divided into short time operation at constant temperature during which irradiationinduced dimensional shrinkage is calculated using curves as given in Fig 6-8, for instance, for the four top fuel element layers of an eightlayer HTGR core A review of design and operating experience for HTGR fuel elements is presented in Ref 21

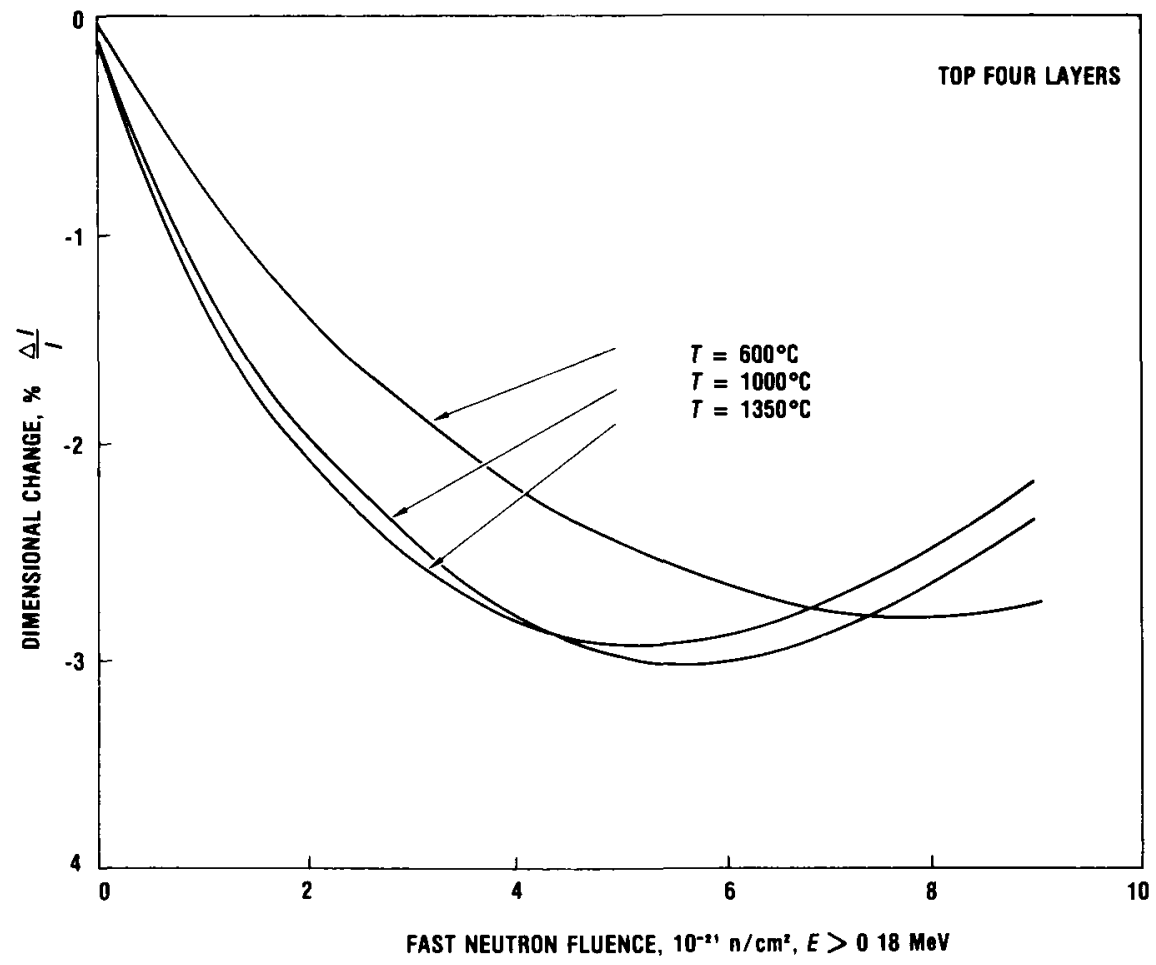

Fig 6-8 Radiatıon-ınduced dimensıonal changes of HTGR fuel rods 
TABLE 6-IV

HTGR Control Rod Design Parameters

\begin{tabular}{|c|c|c|c|}
\hline Geometry & & Heat transfer parameters & \\
\hline Cladding thickness (mm) & 127 & Cladding conductivity $\left(\mathrm{W} / \mathrm{m}{ }^{\circ} \mathrm{C}\right.$ ) & 019 \\
\hline Compact/cladding gap (mm) & 152 & Compact conductivity $\left(\mathrm{W} / \mathrm{m}^{\circ} \mathrm{C}\right)^{\mathrm{a}}$ & 42 \\
\hline Compact outside dameter $(\mathrm{mm})$ & 833 & Mass flow rates $(\mathrm{kg} / \mathrm{s})$ & \\
\hline Compact insıde diameter (mm) & 521 & Fully rodded & \\
\hline Spine outside diameter $(\mathrm{mm})$ & 952 & inner channel & 013 \\
\hline $\begin{array}{l}\text { Total control rod } \\
\text { outside diameter }(\mathrm{mm})\end{array}$ & 889 & outer channel & 0087 \\
\hline $\begin{array}{l}\text { Control rod channel } \\
\text { inside diameter }(\mathrm{mm})\end{array}$ & 1016 & Unrodded & 0235 \\
\hline
\end{tabular}

${ }^{\mathrm{a}}$ Irradiated to fluences between 1 and $6 \times 10^{25} \mathrm{n} / \mathrm{m}^{2}$ at $\sim 600^{\circ} \mathrm{C}$

\section{6-3D Control Rod Materials}

Control rods for HTGRs consist of absorber sections held together by a metal spine passing through the center of the assembly, with a total absorber length of $638 \mathrm{~m}$ The neutron absorber section consists of two concentric Incoloy 800 sleeves closed at each end, enclosing graphite compacts containing boron carbide The control rod parameters are indicated in Table 6-IV, which gives the flow rates through the control rod channels in the graphite fuel elements Irradiation effects and properties of boron carbide/graphite bodies developed for HTGR control materials ( $40 \mathrm{wt} \%$ boron) are reported in Refs 22 and 23 The $\mathrm{B}_{4} \mathrm{C}$ is also used as burnable poison each prismatic HTGR fuel element has six 126 -mm-diam burnable poison holes located at the corners of the hexagon The burnable poison rods, $125 \mathrm{~mm}$ in diameter with a total length of $756 \mathrm{~mm}$ (in each hole), weigh $\sim 09 \mathrm{~kg}$ per fuel element Incoloy 800 , which is used as sleeve and spine material for the control rods, melts at $1370^{\circ} \mathrm{C}$ and undergoes significant creep above $1100^{\circ} \mathrm{C}$ Incoloy 800 is a high-strength material that is resistant to carburization at its maxımum operating temperature of $\sim 790^{\circ} \mathrm{C}$ in the control rod

Reserve shutdown material is designed to drop into the closed bottom channel in the control rod fuel columns in the remote event that shutdown cannot be achieved with control rods This reserve shutdown material consists of small boronated graphite spheres of the same type as for the control rods Tests have shown that boron migration out of this material will not occur below $\sim 2800^{\circ} \mathrm{C}$ and that migration above that temperature would be very slow

\section{6-3E Primary Circuit}

In addition to good heat transfer properties, helium is chemically inert when pure and, therefore, it can be used at very high temperatures But, durnng normal operation in an HTGR, even with a continuous purification system, a number of impurities are present in the helium coolant The coolant gas of a large HTGR may contain levels of impurities as high as ${ }^{24} 10 \mathrm{ppm}$ of total oxidants $\left(\mathrm{CO}, \mathrm{CO}_{2}\right.$, 
$\mathrm{H}_{2} \mathrm{O}$ ); $80 \mathrm{ppm}$ of hydrogen; and $2 \mathrm{ppm}$ of hydrocarbons (mainly $\mathrm{CH}_{4}$ ), although typical contamination levels are expected to be much lower. Significant reactions between the coolant (impure helium) and components in the primary circuits (graphite and metals) must be avoided during normal operating conditions. Therefore, a good understanding of radiolytic reactions in the coolant ${ }^{25}$ and of the behavior of core and structural materials in helium containing impurities is necessary. Most of the early studies of the effects of impurities in helium on structural materials were performed with about equal amounts of $\mathrm{CO}$ and $\mathrm{H}_{2}$. They showed no significant adverse interactions, for example, with ferritic steels up to $595^{\circ} \mathrm{C}$; austenitic materials were only slightly carburized at 595 and $745^{\circ} \mathrm{C}$. However, the small but finite level of $\mathrm{CH}_{4}$ found in the coolant has the potential for carburization. Since creep ductility and rupture life could be reduced by higher levels of impurities than expected in normal service, long-term experiments have been performed on HTGR pressure boundary materials in a contaminated helium atmosphere in order to ensure the integrity of these materials for the life of the reactor.

Results from postoperation destructive examination of various components of the Peach Bottom I HTGR, which had operated at elevated temperatures for $7 \mathrm{yr}$, have shown construction materials, such as carbon steels and Incoloy 800 , to be in excellent condition, thus confirming predictions of their behavior in impure helium. Similarly, Nimonic 75 removed from the hottest region of the Dragon reactor was in excellent condition after $30000 \mathrm{~h}$ of operation. ${ }^{26}$ Various experiments were carried out by the Dragon project; corrosion of graphite in the Dragon reactor can differ in rate and in form from that expected from out-of-pile experiments. The importance of time, temperature, and impurity concentrations (mainly of $\mathrm{CO}$ and $\mathrm{H}_{2}$ ) regarding the attack of alloy constituents of primary circuit materials and subsequent determination of their physical properties has been shown experimentally.

Due to outgassing of impure graphites used in the reflector region, higher impurity levels have been observed in the pebble bed reactor AVR than in the Dragon or Peach Bottom reactors. ${ }^{27}$ It has been observed that there is hardly any corrosive attack of the core with low moisture content, but accident conditions must be considered with a large ingress of water and sizable formation of water/ gas $\left(\mathrm{CO}+\mathrm{H}_{2}\right)$. It has been shown experimentally that a mixture of $22 \mathrm{vol} \%$ of water/gas in helium cannot be ignited, no matter how great the infiltration of air. After accidental water ingress and rapid reactor shutdown, the endothermic reaction $\left(\mathrm{C}+\mathrm{H}_{2} \mathrm{O} \rightarrow \mathrm{CO}+\mathrm{H}_{2}\right)$ cools off the fuel elements and the water/gas reaction decreases because of lower graphite temperature. Under normal conditions, oxidation of graphite could affect its strength. For instance, fracture toughness of $\mathrm{H}-451$ graphite is found ${ }^{28}$ to decrease $\sim 50 \%$ when oxidation increases porosity from 18 to $25 \%$.

The wear behavior of steels in helium is more complex than in oxidizing atmospheres. Both wear and coefficients of friction and adhesion are likely to be higher, according to static tests at high temperature. In a relatively inert environ- 
ment at high temperature, surfaces in sliding contact can gall, self-weld, and undergo surface damage. Wear rate coefficients are dependent on alloy composition and structure, temperature, surface roughness, surface films, load, and rubbing distance. No marked effect of specimen geometry has been found at $800^{\circ} \mathrm{C}$ with ceramics or cermets. To protect sliding surfaces, various surface treatments are employed such as nitriding, application of plasma spray chromium carbide coatings, or the use of molybdenum disulfide coatings. While these treatments definitely improve the wear and friction behavior in helium atmospheres, the long-term behavior of these coatings at high temperatures must be confirmed. ${ }^{29}$

Table 6-V indicates the principal construction materials used in major components of HTGR steam cycle reactors, PCRVs, thermal barriers, helium circulators, and steam generators. The design temperatures for the materials shown in Table 6-V vary all the way from $\sim 80^{\circ} \mathrm{C}$ for the PCRV liners to $950^{\circ} \mathrm{C}$ for core structural graphite. The materials are chosen in such a way as to ensure satisfactory long-term behavior in the temperature, stress, radiation, and corrosion environment. For instance, Incoloy 800 was found to be very satisfactory for the superheater of Peach Bottom I. Alloy $800 \mathrm{H}$, Inconel 600, and Type 304 stainless steel coupons exposed for two years at $720^{\circ} \mathrm{C}$ in the Fort St. Vrain reactor were found to be in excellent condition. ${ }^{28}$ Discussion of the uses of steels and high-temperature alloys in HTGRs is given in Ref. 30 .

\section{TABLE 6-V}

Service Conditions and Structural Materials for HTGR-SC/C Components*

\begin{tabular}{|c|c|c|}
\hline Component & $\begin{array}{c}\text { Maximum } \\
\text { Temperature } \\
\text { Durıng Normal } \\
\text { Operatıon }\left({ }^{\circ} \mathrm{C}\right)\end{array}$ & Materials of Construction \\
\hline Core structures & 950 & Graphte (H-451) \\
\hline Core support & & Graphite (2020 and PGX/TS-1621) \\
\hline graphite & 810 & \\
\hline ceramics & 810 & Alumına, sılıca \\
\hline Core restraints & 560 & Inconel 718 , Alloy $800 \mathrm{H}$ \\
\hline Control rods & 750 & Alloy $800 \mathrm{H}, \mathrm{B}_{4} \mathrm{C} /$ graphite \\
\hline Class B thermal barrier & 760 & $\begin{array}{l}\text { Hastelloy X, Saffil alumina, and Kaowool } \\
\text { fibrous insulation }\end{array}$ \\
\hline Class A thermal barner & 340 & Carbon steel, Kaowool \\
\hline Steam generators & & $\begin{array}{l}\text { Alloy } 800 \mathrm{H}, 21 / 4 \mathrm{Cr}-1 \mathrm{Mo} \text {, Type } 304 \\
\text { stainless steel }\end{array}$ \\
\hline structures & 700 & \\
\hline tubes & 635 & \\
\hline Core auxiliary heat exchanger & & Carbon steel, $2 \frac{1}{4} \mathrm{Cr}-1 \mathrm{Mo}$, Alloy $800 \mathrm{H}$ \\
\hline $\begin{array}{l}\text { structures } \\
\text { tubes }\end{array}$ & $\begin{array}{l}340 \\
340\end{array}$ & \\
\hline Circulators & 340 & $\begin{array}{l}12 \% \text { chromium martensitic stainless steels } \\
\quad(410,422)\end{array}$ \\
\hline PCRV & 80 & Concrete, rebar, prestressing tendons \\
\hline
\end{tabular}

*From Ref $28 \mathrm{SC} / \mathrm{C}=$ steam cycle/cogeneration 


\section{6-4 Thermal Design Bases for HTGR Cores}

Core thermal design bases are defined as a function of four categories of plant conditions; the first two of them being anticipated modes of operation, the other two being conceivable modes of operation expected to occur infrequently ${ }^{31}$ :

1. Normal operating transients. Normal conditions are any conditions in the course of system startup, operation in the design power range, load following, hot standby, and system shutdown.

2. Upset transients. Upset operating conditions are defined as any deviations from normal operating conditions that are anticipated to occur often enough that the design should include a capability to withstand the conditions without impairing operation.

3. Emergency transients. Emergency operating conditions are defined as those deviations from normal conditions that may require shutdown for correction of the conditions or repair of damage in the system. The conditions have a low probability of occurrence but are included to provide assurance that no gross loss of structural integrity will result as a concomitant effect of any damage developed in the system.

4. Faulted transients. Faulted operating conditions are defined as those combinations of conditions associated with extremely low probability postulated events whose consequences are such that the integrity and operability of the nuclear energy system may be impaired to the extent that considerations of public health and safety are involved. Such events are not expected to occur over the life of the plant but are postulated only to set the safety design of the plant.

Representative plant transients during the life of an HTGR are given in Table 6-VI, while Table 6-VII summarizes the thermal-hydraulic design bases for the reactor for the four categories of plant conditions. The design must satisfy each of the individual bases given for fuel, coolant, and other components for any of those conditions. Table 6-VIII gives a summary ${ }^{32}$ of temperature limits for core or component damage and critical safety limits for thermal transients. It can be seen that critical safety limits are not imposed by fuel failure because, following reactor shutdown, the fuel temperature rapidly drops to the average moderator temperature.

While the primary helium coolant is a chemically inert and single-phase fluid, which does not contribute to reactivity, its temperature must be limited as shown on Table 6-VII to keep the core, support structure, and components in the PCRV within acceptable temperature conditions.

Fuel and reflector elements must maintain their integrity to allow heat to be removed from the core with an acceptable coolant flow geometry. Graphite strength increases to a maximum at $2500^{\circ} \mathrm{C}$ and remains acceptable at higher temperatures. Graphite sublimation rates become significant above $3000^{\circ} \mathrm{C}$ and reach $1 \mathrm{~atm}$ pressure at $\sim 4000^{\circ} \mathrm{C}$. 
Temperature limits of metallic core components must also be established. Table 6-VII and 6-VIII show, for example, temperature limitations on the flow control valve and plenum element so that no blockage of control rod insertion or coolant channel flow would occur that would result in violation of fuel design bases. Similarly, temperature limits are imposed on the control rod metallic cladding and spine: the control rod should be removable following an emergency transient, and the integrity of the poison compacts should be maintained in control rod channels following a faulted condition.

\section{TABLE 6-VI \\ Representative Plant Transients in 3000-MW(t) HTGR During 40-yr Plant Life}

\begin{tabular}{|c|c|}
\hline & $\begin{array}{l}\text { Number of } \\
\text { Occurrences } \\
\text { per Plant }\end{array}$ \\
\hline \multicolumn{2}{|l|}{ Normal Transtents } \\
\hline Startup from refuelıng status & 145 \\
\hline Startup with full helium inventory & 255 \\
\hline Shutdown to refuelıng status & 81 \\
\hline Shutdown with full helum inventory & 44 \\
\hline Rapid load increase $(5 \% / \mathrm{mm})$ & 2000 \\
\hline Normal load increase $(3 \% / \mathrm{min})$ & 18000 \\
\hline Rapıd load decrease $(5 \% / \mathrm{m} ı)$ & 2000 \\
\hline Normal load decrease $(3 \% / \mathrm{min})$ & 18000 \\
\hline Step load increase $(+10 \%)$ & 2000 \\
\hline Step load decrease $(-10 \%)$ & 2000 \\
\hline \multicolumn{2}{|l|}{ Upset Transients (from full load) } \\
\hline Loop shutdown & 90 \\
\hline Reactor trip & 100 \\
\hline Turbine trip and load rejections & 120 \\
\hline Sudden reduction of feedwater flow & 30 \\
\hline Steam leak to PCRV with correct protective action & 30 \\
\hline \multicolumn{2}{|l|}{ Emergency and Faulted Transients } \\
\hline Slow primary system depressurization & 3 \\
\hline Rod withdrawal with high flux trip & 3 \\
\hline Loop shutdown with helium valve fallure & 3 \\
\hline Shutdown with three auxiliary cooling loops-up to 10$\}$ & 10 \\
\hline Shutdown with two auxiliary cooling loops-up to 10$\}$ & \\
\hline Sudden depressurization and shutdown with two auxiliary cooling loops $\mathrm{a}^{\mathrm{a}}$ & 1 \\
\hline
\end{tabular}

${ }^{\mathrm{a}}$ Faulted 
TABLE 6-VII

Thermal Design Bases for HTGR Core

\begin{tabular}{|c|c|c|c|c|c|c|c|c|}
\hline \multirow[b]{2}{*}{$\begin{array}{l}\text { Category } \\
\text { Condition }\end{array}$} & \multirow[b]{2}{*}{ Definition } & \multirow[b]{2}{*}{ Description } & \multirow[b]{2}{*}{ Fuel } & \multirow[b]{2}{*}{ Graphite } & \multicolumn{2}{|c|}{ Coolant } & \multirow{2}{*}{$\begin{array}{l}\text { Flow Control } \\
\text { Valve and } \\
\text { Plenum } \\
\text { Elements }\end{array}$} & \multirow{2}{*}{$\begin{array}{c}\text { Control Rod } \\
\text { Cladding and } \\
\text { Spıne }\end{array}$} \\
\hline & & & & & $\begin{array}{l}\text { Average Core } \\
\text { Outlet }^{\mathrm{a}}\end{array}$ & $\begin{array}{c}\text { Average Regıon } \\
\text { Outlet }^{\mathrm{b}}\end{array}$ & & \\
\hline Normal & $\begin{array}{l}\text { Conditions occurring durıng } \\
\text { normal plant operation, } \\
\text { startup, rated power load } \\
\text { changes, shutdowns, and } \\
\text { refuelıng }\end{array}$ & $\begin{array}{l}\text { No damage } \\
\text { tolerated } \\
\text { that }\end{array}$ & $\begin{array}{l}\text { The calculated number of } \\
\text { falled fuel particle coatings } \\
\text { shall be limited to be } \\
\text { consistent while not } \\
\text { exceeding the "expected" } \\
\text { circulating coolant fission }\end{array}$ & $2400^{\circ} \mathrm{C}$ & $\begin{array}{l}770^{\circ} \mathrm{C} \text { for } \\
\text { steady state, } \\
790^{\circ} \mathrm{C} \text { for } \\
\text { transients up } \\
\text { to } 15 \text { min }\end{array}$ & $\begin{array}{l}825^{\circ} \mathrm{C} \text { for steady } \\
\text { state, } 885^{\circ} \mathrm{C} \\
\text { for transients } \\
\text { up to } 24 \mathrm{~h} \text {, } \\
965^{\circ} \mathrm{C} \text { for } \\
\text { transients up to }\end{array}$ & $\begin{array}{l}538^{\circ} \mathrm{C} \text { for } \\
\text { steady } \\
\text { state }\end{array}$ & $\begin{array}{l}870^{\circ} \mathrm{C} \text { for } \\
\text { steady state } \\
\text { and } \\
\text { transients } \\
>1 \mathrm{~h} \text {, }\end{array}$ \\
\hline Upset & $\begin{array}{l}\text { Deviations from normal } \\
\text { conditions that are } \\
\text { expected with moderate } \\
\text { frequency }{ }^{c}\end{array}$ & $\begin{array}{l}\text { requires } \\
\text { reactor } \\
\text { shutdown }\end{array}$ & $\begin{array}{l}\text { product activity level as } \\
\text { specified }\end{array}$ & & & $15 \mathrm{mmn}$ & $\begin{array}{l}760^{\circ} \mathrm{C} \text { for } \\
\text { transients } \\
<10 \mathrm{~h}\end{array}$ & $\begin{array}{l}1095^{\circ} \mathrm{C} \text { for } \\
\text { transients } \\
<1 \mathrm{~h} \\
\text { integrated } \\
\text { over control } \\
\text { rod lifetime }\end{array}$ \\
\hline Emergency & $\begin{array}{l}\text { Conditions having low } \\
\text { probability of occurrence } \\
\text { that are included to } \\
\text { provide assurance that no } \\
\text { gross loss of structural } \\
\text { integrity will result }\end{array}$ & $\begin{array}{l}\text { Some repair } \\
\text { to system } \\
\text { may be } \\
\text { required } \\
\text { before } \\
\text { restart }\end{array}$ & $\begin{array}{l}\text { The reactor can be shut down } \\
\text { to a safe condition with a } \\
\text { small amount of fuel } \\
\text { damage }^{d}\end{array}$ & $2500^{\circ} \mathrm{C}$ & $\begin{array}{l}915^{\circ} \mathrm{C} \text { for } \\
\text { steady state }\end{array}$ & $\begin{array}{l}915^{\circ} \mathrm{C} \text { for steady } \\
\text { state }\end{array}$ & $\begin{array}{l}760^{\circ} \mathrm{C} \text { for } \\
\text { transients } \\
<10 \mathrm{~h}\end{array}$ & $1095^{\circ} \mathrm{C}$ \\
\hline Faulted & $\begin{array}{l}\text { Extremely low probability, } \\
\text { postulated conditions } \\
\text { whose consequences may } \\
\text { be such that considerations } \\
\text { of public safety may be } \\
\text { involved }^{\mathrm{c}}\end{array}$ & $\begin{array}{l}\text { Safe reactor } \\
\text { shutdown } \\
\text { and } \\
\text { contınued } \\
\text { core } \\
\text { cooling } \\
\text { capability } \\
\text { required }\end{array}$ & $\begin{array}{l}\text { The reactor can be shut down } \\
\text { and kept subcritical, an } \\
\text { adequate cooling geometry } \\
\text { shall be maintained }{ }^{\mathrm{d}}\end{array}$ & $3000^{\circ} \mathrm{C}$ & $\begin{array}{l}1040^{\circ} \mathrm{C} \text { for } \\
4 \mathrm{~h}, 1095^{\circ} \mathrm{C} \\
\text { for } 1 \mathrm{~h}\end{array}$ & $\begin{array}{l}1040^{\circ} \mathrm{C} \text { for } 4 \mathrm{~h} \\
1095^{\circ} \mathrm{C} \text { for } 1 \mathrm{~h}\end{array}$ & $870^{\circ} \mathrm{C}$ & $2370^{\circ} \mathrm{C}$ \\
\hline
\end{tabular}

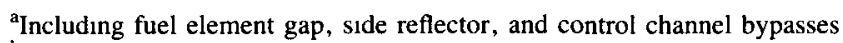

${ }^{b}$ Including fuel element gap and control channel bypasses

'ASME III, Par NA 2110 NB 3113

${ }^{\mathrm{d}}$ Limits are based on 10CFR 100 


\section{TABLE 6-VIII}

\section{Summary of Component Damage Temperature Limits and Reactor Safety Temperature Limits for HTGRs}

\begin{tabular}{|c|c|c|}
\hline & $\begin{array}{l}\text { Component Damage } \\
\text { Limit Temperature }\end{array}$ & $\begin{array}{l}\text { Critıcal Safety } \\
\text { Lımıt Temperature }\end{array}$ \\
\hline Fuel particle coating & $\begin{array}{l}1650^{\circ} \mathrm{C} \text { for falure of fuel } \\
\text { particle coating in } \\
\text { shutdown condition }\end{array}$ & $\begin{array}{l}>2370^{\circ} \mathrm{C} \text { for loss of fixed } \\
\text { fuel-graphite matrix } \\
\text { integrity }\end{array}$ \\
\hline $\begin{array}{l}\text { Control rod cladding and } \\
\text { spine }\end{array}$ & $\begin{array}{l}870^{\circ} \mathrm{C} \text { for transient exposure } \\
\text { of long duration } \\
1095^{\circ} \mathrm{C} \text { for transient exposure } \\
\text { of short duration }(1 \mathrm{~h})\end{array}$ & $\begin{array}{l}\sim 2815^{\circ} \mathrm{C} \text { for possible boron } \\
\text { migration }\end{array}$ \\
\hline $\begin{array}{l}\text { Core region flow control } \\
\text { onfice }\end{array}$ & $\begin{array}{l}1095^{\circ} \mathrm{C} \text { for transient exposure } \\
\text { of }>1 \mathrm{~h}\end{array}$ & $1315^{\circ} \mathrm{C}$ allowable for $1 \mathrm{~h}$ \\
\hline $\begin{array}{l}\text { Thermal barrier cover plates } \\
\text { upper plenum and cross- } \\
\text { ducts }\end{array}$ & $\begin{array}{l}538^{\circ} \mathrm{C} \text { for transients of } \\
>10 \mathrm{~h}\end{array}$ & $665^{\circ} \mathrm{C}$ allowable for $1 \mathrm{~h}$ \\
\hline $\begin{array}{l}\text { lower plenum and cross- } \\
\text { ducts }\end{array}$ & $982^{\circ} \mathrm{C}$ for transient of $>10 \mathrm{~h}$ & $1095^{\circ} \mathrm{C}$ allowable for $1 \mathrm{~h}$ \\
\hline $\begin{array}{l}\text { Ambient gas temperature of } \\
\text { auxiliary circulator }\end{array}$ & $\begin{array}{l}\text { Temperature transient } \\
\text { allowable from } 338 \text { to } \\
663^{\circ} \mathrm{C} \text { in } 40 \mathrm{~min}\end{array}$ & $\begin{array}{l}\text { Temperature transient } \\
\text { allowable from } 338 \text { to } \\
663^{\circ} \mathrm{C} \text { in } 40 \mathrm{~min}\end{array}$ \\
\hline $\begin{array}{l}\text { Ambient gas temperature of } \\
\text { pnmary closure in upper } \\
\text { plenum penetration }\end{array}$ & $\begin{array}{l}504^{\circ} \mathrm{C} \text { for transient exposure } \\
\text { of } 10 \mathrm{~h}\end{array}$ & $\begin{array}{l}504^{\circ} \mathrm{C} \text { for transient exposure } \\
\text { of } 10 \mathrm{~h}\end{array}$ \\
\hline $\begin{array}{l}\text { Gas inlet temperature to } \\
\text { steam generator and } \\
\text { auxiliary heat exchanger }\end{array}$ & $\begin{array}{l}805^{\circ} \mathrm{C} \text { steady state for the } \\
\text { steam generator } \\
915^{\circ} \mathrm{C} \text { steady state for the } \\
\text { auxilary heat exchanger }\end{array}$ & $\begin{array}{l}1038^{\circ} \mathrm{C} \text { allowable exposure } \\
\text { for } 4 \mathrm{~h} \text { or } 1095^{\circ} \mathrm{C} \\
\text { allowable exposure for } 1 \mathrm{~h}\end{array}$ \\
\hline
\end{tabular}

\section{REFERENCES}

1. H. B. Stewart, C. L. Rickard, and G. B. Melese, "Gas-Cooled Reactor Technology," pp. 15-23 in Advances in Nuclear Science and Technology, Vol. 4, Academic Press, Inc., New York (1968).

2. M. Simnad and J. Howe, "Materials for Nuclear Fission Power Reactor Technology," in Energy and Materlals, Academic Press, Inc., New York (1977)

3. H. B. Stewart, "Thorium Utilization Reexamined," Proc. American Power Conf., Chicago, Illinois, April 20-22, 1976, Vol. 38, p. 131, Illinois Institute of Technology (1977).

4. R. C. Dahlberg et al., "HTGR Fuel and Fuel Cycle,' Nucl. Eng. Des., 26, 58 (Jan. 1974).

5. R. C. Dahlberg et al., "HTGR Fuel Cycle Status in the USA," Proc ANS/ENS 1st 
European Nuclear Conf, Parıs, France, April 21-25, 1975, pp 413-414, Pergamon Press (1976)

6 A Lotts and J Coobs, "HTGR Fuel and Fuel Cycle Technology," Proc ANS/ASME Joint Int Conf Advanced Nuclear Energy Systems, Pittsburgh, Pennsylvania, March 14-17, 1976, CONF-760303, p 585, American Society of Mechanical Engineers (1976)

7 "History and Summary of General Atomic Studies of HTGR Plutonıum Utılization," EPRI 84-2, Electric Power Research Institute (Dec 1975)

8 P Kasten et al , "Overview of Gas-Cooled Reactor Systems Their Importance and Their Interactions,' Proc IAEA Int Mtg Gas-Cooled Reactors, Julich, FRG, October 13-17, 1975, CONF-751007, SM-200/85, Vol II, p 347, International Atomic Energy Agency (1976)

9 H Gutmann et al , "The High-Temperature Reactor in the Future Fuel Market," Ann Nucl Energy, 3, 113 (1976)

10 G Engle, M R Everett, and W P Eatherly, "Status of Graphite Technology and Requirement for HTGRs,"' Proc ANS Topl Mtg Gas-Cooled Reactors HTGRs and GCFBRs, Gatlınburg, Tennessee, May 7-10, 1974, CONF-740501, p 288, National Technical Information Service (1974)

11 B T Kelly, "Radiation Damage in Graphite and Its Relevance to Reactor Design," Prog Nucl Energy, 2, 4, (1978)

12 G Engle et al , "Development Status of Near-Isotropic Graphites for Large HTGRs," UC-77, U S Atomic Energy Commission (June 1974)

13 O M Stansfield, "HTGR Fuel Design and Performance,' Proc AlChE 78th National Mtg , Salt Lake City, Utah, August, 1974, American Institute of Chemical Engineers (July 1974)

14 T D Gulden et al , "The Mechanical Design of TRISO Coated Particle Fuels for the Large HTGR," Nucl Technol, 16, 100 (1972)

15 T D Gulden and H Nickel, Eds , "Coated Particles Fuel," Nucl Technol, 35, 2, special issue (Sep 1977)

16 W R Johnson, “Thermal Conductıvity of Large HTGR Fuel Rods,' GA-LTR-9 (UC77), GA Technologies (Mar 1974)

17 D P Harmon et al, "HTGR Fuel Performance," GA-A13506, GA Technologies (Oct 1975)

18 D F Leushacke et al, "Irradiation of an HTGR Fuel Element," Proc IAEA Int Mtg Gas-Cooled Reactors, Julich, FRG, October 13-17, 1975, CONF-751007, SM200/33, Vol I, p 291, International Atomic Energy Agency (1976)

19 T D Gulden et al , "Present Th-Cycle Fuel Concepts and Performance Limitations," p 176, E Balthesen et al , "HTGR Fuel Development and Testıng," p 201, and L W Graham et al , "HTR Fuel Development and Testıng in the Dragon Project," p 218, Proc ANS Topl Mtg Gas-Cooled Reactors HTGRs and GCFBRs, Gatlinburg, Tennessee, May 7-10, 1974, CONF-740501, Natıonal Technical Information Service (1974)

20 E Balthesen et al , "State and Development of HTGR Fuel Elements in the FRG," p 268, M Gaube et al , "Operation Capabılity of Standard HTR Fuel at High Temperature,"' p 270, and C Cunningham and A N Knowles, “Design of HTR Fuel for Endurance,"' p 272, Trans Am Nucl Soc, Vol 20 (1975)

21 A J Goodjohn et al , "HTGR Fuel and Fuel Cycle Expenence in the United States,' Trans Am Nucl Soc , 40, 256 (1982) 
22 O Stansfield, "Irradiation Effects in Boronated Graphite," GA-A12035, GA Technologies (1972)

23 L Beavan, "Control Materials in LHTGR Desıgn," GA-A13260, GA Technologies (1974)

24 P Hedgecock and P Patriarca, "Materials Selectıon for Gas-Cooled Reactor Components," Proc ANS Topl Mtg Gas-Cooled Reactors HTGRs and GCFBRs, Gatlinburg, Tennessee, May 7-10, 1974, CONF-740501, p 525, National Technical Information Service (1974)

25 G Tingey and W Morgan, "Radiolytic Reactions in the Coolant of Helium-Cooled Reactors,' Proc IAEA Int Mtg Gas-Cooled Reactors, Julich, FRG, October 13-17, 1975, CONF-751007, SM-200/55, Vol I, p 309, International Atomic Energy Agency (1976)

26 R Nieder and R Wischnewsk1, "Coolant Chemistry in HTRs Under Normal and Accident Conditions," Trans Am Nucl Soc, 20, 185 (1975)

27 V S Boyer et al , "High Temperature Reactors," Nuclear Energy Maturity, Proc Paris Conf, Progress in Nuclear Energy Serles, Plenary Sessions, p 223, Pergamon Press (1976)

28 P L Rittenhouse and D Roberts, "HTGR Structural Materials Efforts in the USA," Proc BNES Conf Gas-Cooled Reactors Today, Bnstol, United Kingdom, September 20-24, 1982, Vol 4, p 163, British Nuclear Energy Society (1982)

29 D Roberts and J Watson, "Plant Materials for Advanced Gas-Cooled Reactors," Trans Am Nucl Soc , 24, 160 (1976) 


\section{7 \\ HTGR CORE THERMAL DESIGN*}

\section{7-1 Introduction}

This chapter presents an application of the previously discussed design techniques and design critena to a specific high-temperature gas-cooled reactor (HTGR) core The example chosen is the core of an 1160-MW(e) [3000-MW(t)] HTGR offered commercially to electrical utilities in the early 1970s The core of this large HTGR is in concept and design quite similar to the earlier Fort St Vrain HTGR

Only an overview of the thermal design is given in this chapter, but the details may be found in a series of topical reports covering various aspects of the large HTGR thermal design ${ }^{1-4}$ After describing some of the important features of the core in Sec 7-2, the nuclear design is discussed and the power distributions are introduced in Sec 7-3 Core coolant flow is the subject of Sec 7-4, where flow control values, flow paths, core pressure, and flow distribution are discussed

Core temperature distributions and some transient thermal analyses are presented in Sec 7-5 Because they are important in predicting the performance of the fission product barners, the fission products, the fuel element stresses, and the core temperature histories are presented in Sec 7-6, the final section of this chapter

\section{7-2 Core Description}

\section{7-2A Reactor Core}

The active core of a large HTGR has the approximate shape of a right-circular cylinder It is surrounded by graphite reflector elements above, below, and around the active core The core is contanned within the central cavity of the prestressed concrete reactor vessel (PCRV) Figure 7-1 shows the reactor core in relation to the other main components in the nuclear steam supply systems A 3000-MW(t) plant has six primary coolant loops and three auxiliary coolant loops that surround the core Helium from the upper cross-ducts flows into the plenum above the core, then downward through the core, removing the energy generated in the core In

*This chapter was contributed by D W McEachern 


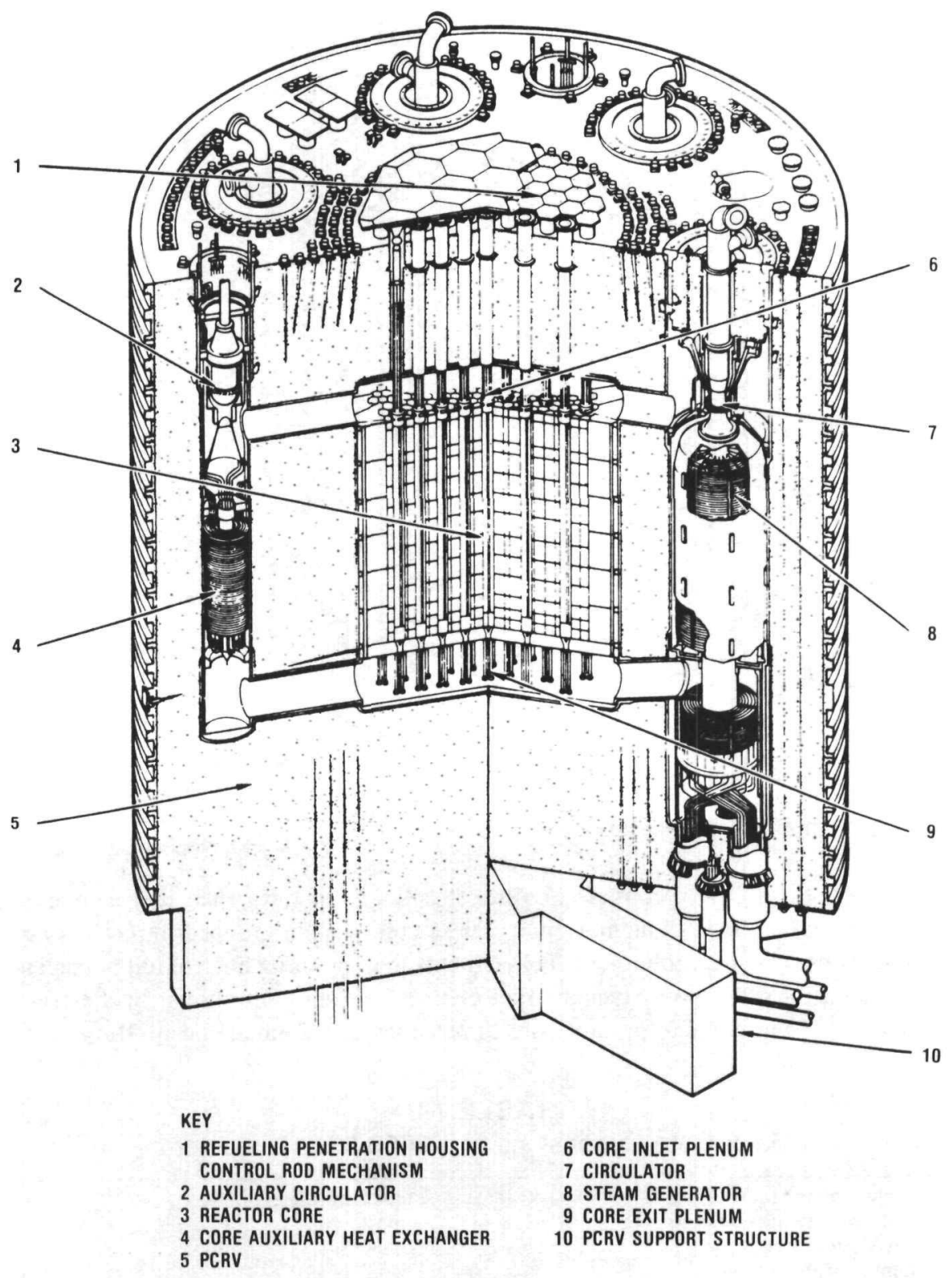

Fig. 7-1. General arrangement for a 3000-MW(t) HTGR.

the lower plenum of the core, the coolant flows radially outward into the six steam generators where the energy is transferred to the secondary coolant to produce high-pressure high-temperature steam. 


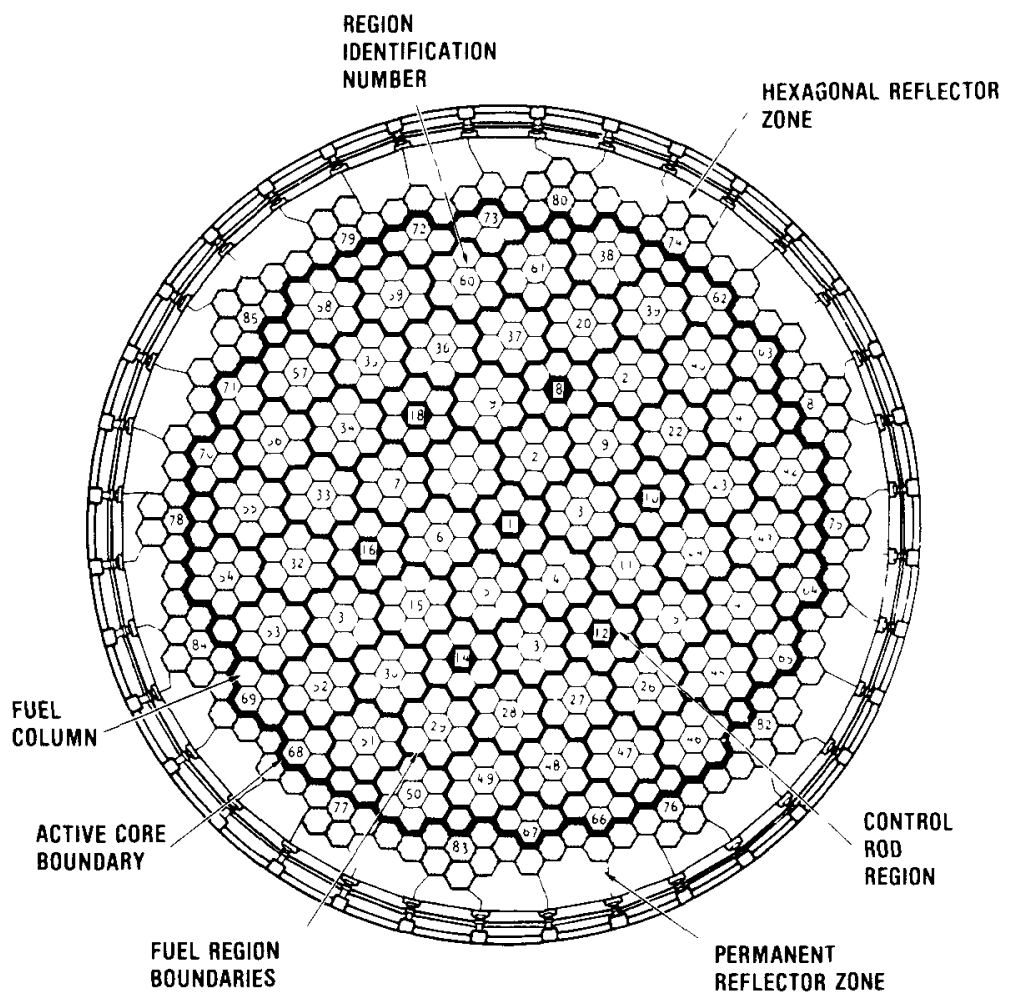

Fig. 7-2. A $3000-\mathrm{MW}(\mathrm{t})$ core plan.

The core assembly consists of vertical columns of hexagonal fuel elements arranged on a uniform triangular pitch. These columns are grouped into refueling regions consisting of a column of fuel elements incorporating control rod passages surrounded by six or less standard fuel element columns, as shown in the core plan view in Fig. 7-2. Important core dimensions are summarized in Table 7-I.

TABLE 7-I

Major Core Dimensions of a $3000-\mathrm{MW}(\mathrm{t})$ Reactor

\begin{tabular}{|lc|lr|}
\hline Thermal power [MW(t)] & 3000 & Reflector thickness (m) & \\
Effective core diameter $(\mathrm{m})$ & 8.47 & top & 1.19 \\
Active core height $(\mathrm{m})$ & 6.34 & bottom & 1.19 \\
Number of fuel elements & 3944 & side (mean) & 1.37 \\
Number of fuel elements per column & 8 & Number of flow regions & \\
Number of fuel columns & & full seven-column & 61 \\
$\quad$ standard & 420 & partial four-column & 12 \\
control & 73 & single fixed-orifice columns & 18 \\
Core support block height $(\mathrm{m})$ & 0.88 & total & 91 \\
& & Number of control rod drives & 73 \\
& & Number of control rods & 146 \\
\hline
\end{tabular}


The 3000-MW(t) reactor has 61 refueling regions containing seven columns of fuel elements, 12 refueling regions containing four columns, and 18 single columns at the outer edge of the core that form the approximately circular core. Large HTGRs use a highly enriched uranium-thorium 4-yr fuel cycle. Approximately $25 \%$ of the core (called a "segment") is refueled annually. The four segments of the core are distributed in the core to give a symmetric radial and azimuthal power distribution.

\section{7-2B Refueling Region}

A refueling region consists of seven columns of fuel elements. The columns rest on a single, large, graphite core support block having the same outline as the seven-column region. The vertical columns that make up the refueling region include fuel, control, and reflector elements, as shown by the schematic diagram in Fig. 7-3. A typical fuel or control column consists of two bottom reflector elements, eight fuel elements, two top reflector elements, and a metallic plenum element. The elements within the central column of each region are displaced axially downward relative to the elements in the surrounding six columns. This axial offset is a mechanical design feature that prevents the possibility of a continuous shear plane at element interfaces across the core. Each refueling region is located directly below a refueling penetration that, during operation, contains a control rod drive assembly. Two parallel channels are provided for inserting two control rods into the central column of each refueling region. A third channel is provided in the same column for inserting reserve shutdown absorber material. The seven-column regions are keyed at the top by metal plenum elements, which provide a plenum chamber and a valve body for the variable flow control valve (orifice valve). The flow control valve assembly rests on the control column and admits coolant flow into the top of the control column and, through openings in each of the top plenum elements, to the surrounding six standard fuel columns. The valve is shown in Fig. 7-4.

Four thermocouples, two of which provide readings of region average helium outlet temperature to the operator at all times during operation, are located in a horizontal graphite probe held in the core support block, as shown in Fig. 7-3. During operation of the reactor, the operator uses the average coolant temperature reading from each of the regions as a basis for adjusting the region's coolant flow rate using the region's flow control valve.

\section{7-2C Fuel Elements}

Individual fuel elements are right-regular prisms $0.79 \mathrm{~m}$ ( $31.3 \mathrm{in}$.) high with a hexagonal cross section of $0.36 \mathrm{~m}$ (14.17 in.) across flats. A standard fuel element is depicted in Fig. 7-5. Fuel elements with this hole pattern are sometimes called "eight-row elements," derived by counting half the rows of fuel and coolant holes and omitting the middle row. Perhaps "17-row element" would be more 


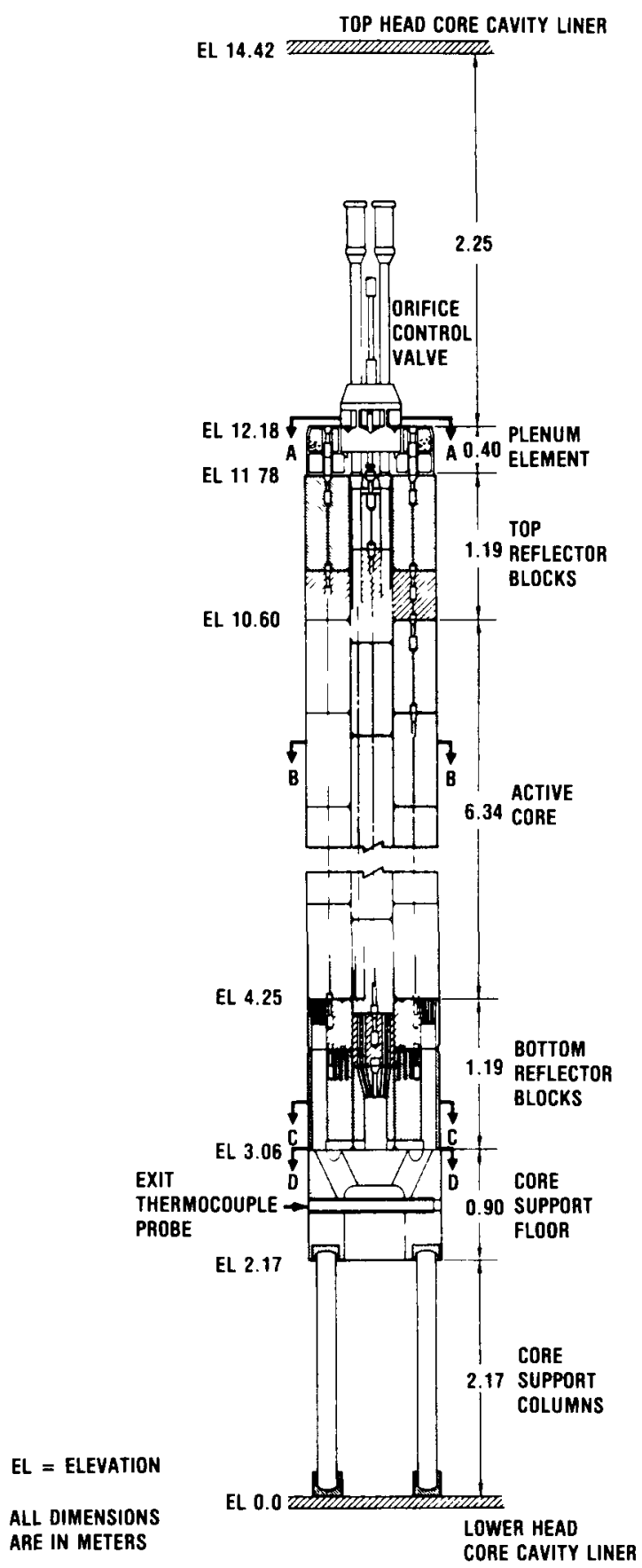

Fig. 7-3. Seven-column refueling region. 


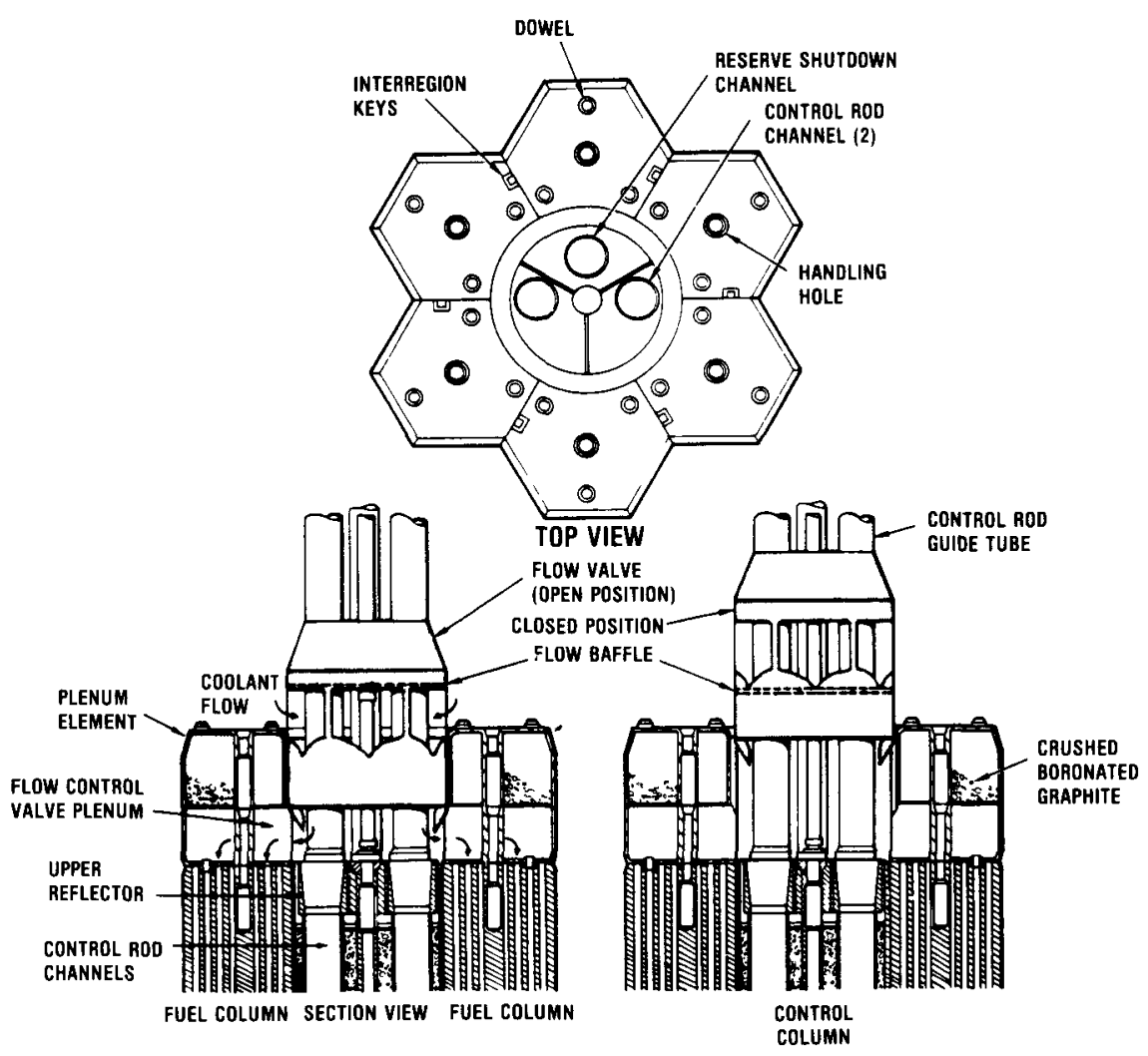

FLOW VALVE IN OPEN POSITION FLOW VALVE IN CLOSED POSITION

Fig. 7-4. Flow control valve and plenum arrangement.

descriptive. Coolant channels extending through each element align with coolant channels in the elements above and below. The active fuel is contained in an array of holes that is parallel to the coolant channels. The fuel holes are drilled blind from the top face of the element and are filled with bonded fuel rods of coated fuel particles. The fuel rods and coolant channels are distributed on a triangular array with an ideal ratio of two fuel rods for each coolant channel. Table 7-II gives fuel element geometrical parameters needed in the thermal design.

Figure 7-6 shows the control rod fuel element used in the center column of each region. This element is similar to the standard element but contains enlarged channels for the two control rods and the reserve shutdown absorber material. The major control fuel block parameters are given in Table 7-III.

Three graphite dowels are located on the top face of each element. These dowels fit into mating socket holes in the bottom face of the element above to keep the coolant channels aligned at all times. Located in the center of each fuel 


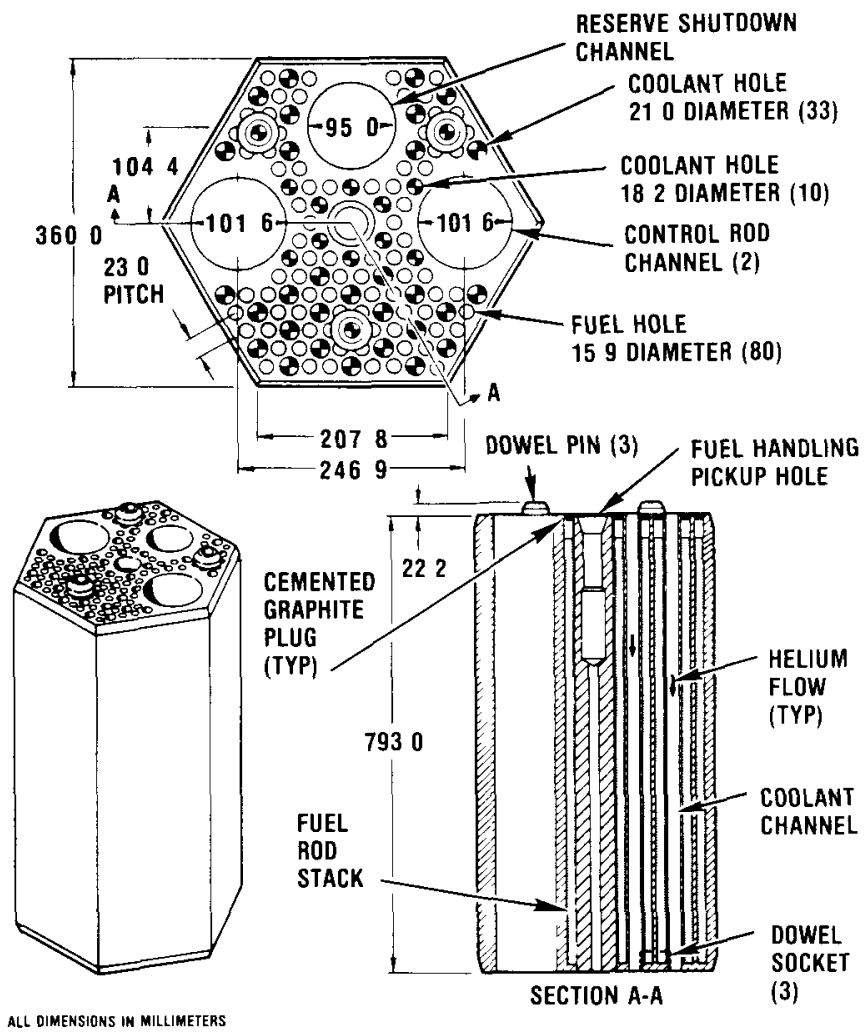

Fig 7-6 Control fuel element

TABLE 7-II

Standard Fuel Element Design Parameters*

\begin{tabular}{|c|c|c|c|}
\hline Length of fuel element (mm) & 793 & Web thicknesses & \\
\hline Distance across the flats (mm) & 360 & coolant coolant $(\mathrm{mm})$ & 188 \\
\hline Number of fuel holes & 132 & coolant-fuel (mm) & 455 \\
\hline Number of coolant holes & & fuel-fuel (mm) & 711 \\
\hline larger $210-\mathrm{mm}$ holes & 66 & Rod diameters & \\
\hline smaller $182-\mathrm{mm}$ holes & 6 & fuel $\operatorname{rod}(\mathrm{mm})$ & 156 \\
\hline Number of burnable poison holes & 6 & burnable porson rods $(\mathrm{mm})$ & 126 \\
\hline Hole diameters & & Fuel rod length $(\mathrm{mm})$ & 630 \\
\hline fuel hole (mm) & 158 & Fuel stack height & \\
\hline larger coolant hole $(\mathrm{mm})$ & 210 & standard stack (12 rods) (mm) & 756 \\
\hline smaller coolant hole (mm) & 182 & under dowel (11 rods) $(\mathrm{mm})$ & 693 \\
\hline burnable poison hole $(\mathrm{mm})$ & 127 & Mass of an average element & \\
\hline Pitches & & graphite fuel element $(\mathrm{kg})$ & 835 \\
\hline coolant-coolant (mm) & 398 & fuel rods $(\mathrm{kg})$ & 349 \\
\hline coolant-fuel (mm) & 230 & burnable poison $(\mathrm{kg})$ & 09 \\
\hline fuel-fuel $(\mathrm{mm})$ & 230 & total assembly $(\mathrm{kg})$ & 1193 \\
\hline
\end{tabular}

*Many of these parameters have variations within the core, and the values used in thermal design are given All dimensions are for beginning-of-life at ambient temperature 


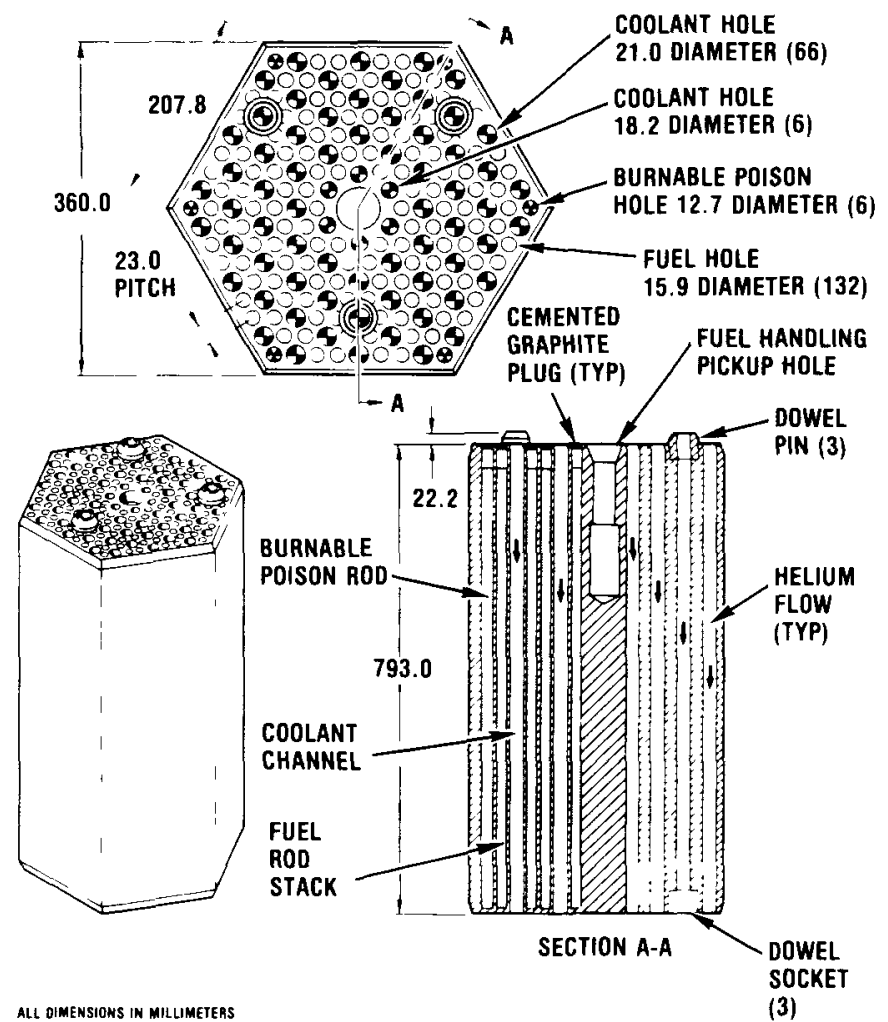

Fig. 7-5. Standard fuel element.

TABLE 7-III

Control Fuel Element Design Parameters*

\begin{tabular}{|c|c|c|c|}
\hline Length of fuel element (mm) & 793 & Web thickness & \\
\hline Distance across the flats (mm) & 360 & coolant-coolant (mm) & 18.8 \\
\hline Number of fuel holes & 80 & coolant-fuel (mm) & 4.55 \\
\hline Number of coolant holes & & fuel-fuel (mm) & 7.11 \\
\hline larger $21.0-\mathrm{mm}$ holes & 33 & Fuel rod diameter (mm) & 15.6 \\
\hline smaller $18.2-\mathrm{mm}$ holes & 10 & Fuel rod length (mm) & 63.0 \\
\hline Hole diameters & & Fuel stack height & \\
\hline fuel hole $(\mathrm{mm})$ & 15.8 & seven top fuel elements & \\
\hline larger coolant hole $(\mathrm{mm})$ & 21.0 & standard stack (12 rods) $(\mathrm{mm})$ & 756 \\
\hline smaller coolant hole $(\mathrm{mm})$ & 18.2 & under dowel (11 rods) $(\mathrm{mm})$ & 693 \\
\hline control rod hole $(\mathrm{mm})$ & 101.6 & bottom-most fuel element & \\
\hline reserve shutdown channel $(\mathrm{mm})$ & 88.9 & standard stack ( 9 rods) $(\mathrm{mm})$ & 567 \\
\hline Pitches & & under dowel (8 rods) $(\mathrm{mm})$ & 504 \\
\hline coolant-coolant $(\mathrm{mm})$ & 39.8 & Mass of average element & \\
\hline coolant-fuel $(\mathrm{mm})$ & 23.0 & top seven fuel elements & \\
\hline fuel-fuel $(\mathrm{mm})$ & 23.0 & graphite fuel element $(\mathrm{kg})$ & 81.2 \\
\hline & & fuel rods $(\mathrm{kg})$ & 20.9 \\
\hline & & total assembly $(\mathrm{kg})$ & 102.1 \\
\hline
\end{tabular}

*Many of these parameters have variations within the core. 


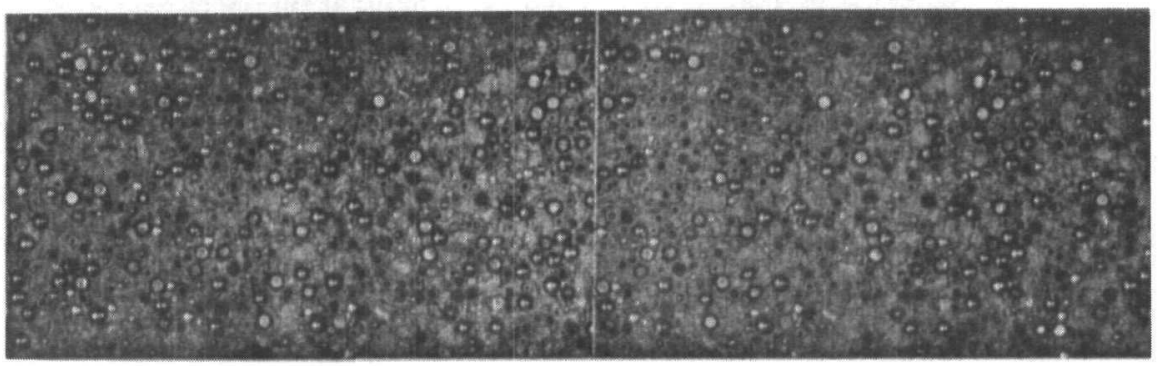

Fig. 7-7. Metallographic cross section of a typical HTGR fuel rod.

and reflector element is a handling hole, and at the six corners of each standard fuel element there are blind holes for burnable poison rods containing boron carbide.

\section{7-2D Fuel Rods and Particles}

The HTGR fuel consists of BISO- and TRISO-coated particles incorporated into fuel rods with a matrix consisting of an organic binder and graphite filler that is carbonized and heat treated to yield a carbonaceously bonded rod. The metallographic cross section of a typical fuel rod is shown in Fig. 7-7. In the HTGR core design, fissile and fertile materials are zoned within the core in both the radial and axial directions. This zoning is achieved by using fuel elements containing different masses of fissile and fertile material distributed uniformly within the fuel rods. The fuel rods in all fuel elements have the same dimensions. Varying amounts of high-conductivity granulated graphite are used as shim to make the volume of all the fuel rods equal regardless of metal loading. The shim is uniformly mixed with the fissile and fertile particles before the rod is formed to produce a homogeneous distribution of particles.

The large HTGR is designed to operate on the highly enriched ${ }^{235} \mathrm{U}^{232} \mathrm{Th}$ fuel cycle. ${ }^{5}$ HTGRs have also been designed ${ }^{6}$ using $20 \%$ enriched U/Th and in Europe using low-enriched ${ }^{235} \mathrm{U}$ but no thorium. Also, some designs have included once-through feeding and others use recycled ${ }^{233} \mathrm{U}$ and plutonium. Fissile fuel particles for the HTGR consist of spherical $\mathrm{UC}_{2}$ kernels coated with layers of pyrolytic carbon (PyC) and silicon carbide ( $\mathrm{SiC})$. This combination of $\mathrm{PyC}$ and $\mathrm{SiC}$ is referred to as a "TRISO" coating. The fissile fuel kernels are $93 \%$ enriched in ${ }^{235} \mathrm{U}$. The fertile fuel consists of spherical $\mathrm{ThO}_{2}$ kernels coated with two layers of PyC. This type of coating is referred to as a "BISO" coating. The two particle types are illustrated in Fig. 6-6, p. 188. The coated particle design parameters are summarized ${ }^{3}$ in Table 7-IV.

\section{7-2E Control Rod System}

Core reactivity is controlled by pairs of control rods inserted into the central column of each refueling region. These rod pairs are moved in and out by the 
TABLE 7-IV

Coated Particle Design Parameters

\begin{tabular}{|lc|lc|}
\hline & $\begin{array}{c}\text { Dimensions } \\
(\mu \mathrm{m})\end{array}$ & & $\begin{array}{c}\text { Dimensions } \\
(\mu \mathrm{m})\end{array}$ \\
TRISO & 200 & BISO & \\
fuel kernel diameter $\left(\mathrm{UC}_{2}\right)$ & fuel kernel diameter $\left(\mathrm{ThO}_{2}\right)$ & 500 \\
buffer coating thickness & 100 & buffer coating thickness & 85 \\
Inner isotropic PyC thickness & 25 & isotropic PyC thickness & 75 \\
$\mathrm{SlC}_{1}$ thickness & 25 & & \\
outer isotropic PyC thickness & 35 & & \\
\hline
\end{tabular}

reactor operators who activate electrically powered control rod drives located in PCRV penetrations above the central column of each region. Each control rod consists of a series of absorber sections held together by a metal spine passing through the center of the assembly, as shown in Fig. 7-8. The major design parameters of the control rod system are given in Table 6-IV.

The neutron absorber rod section consists of two concentric sleeves, which are closed at each end. The sleeves enclose graphite compacts containing boron in the form of boron carbide granules. During reactor operation, primary coolant flows down the control rod channels in the core to cool the rods. This flow, from the upper core plenum, enters the channels through holes drilled in the walls of the control rod guide tube. Part of the flow passes down the annular space between the wall of the fuel element channel and the outside of the control rods. The remainder of the flow passes through the center of the control rods, cooling the rods' central spines. The exit passage for the cooling gas from the control rod channels is in the lower reflector of the control column. The flow through the control rod channels is controlled by a short circular passage machined in the bottom reflector of the control column. The helium flow in the control rod channel is not strongly dependent on whether or not the control rod is inserted into the core since most of the pressure loss occurs at the short circular passage in the bottom reflector.

\section{7-3 Nuclear Design}

\section{7-3A Definition of Power Peaking Factor}

Thermal analyses carried out for the HTGR core (a) evaluate temperature conditions and coating integrity throughout the core for rated-power steady-state operation over core lifetime, (b) estimate the response of core temperature to transient operations varying from normal startup and load-following to emergency and faulted transient conditions, and (c) establish detailed temperature distributions within the fuel elements and core components.

A detailed understanding of the nuclear design is required to supply the heat source terms for the thermal calculations. The nuclear design data required for the steady-state core survey calculation are discussed below. 


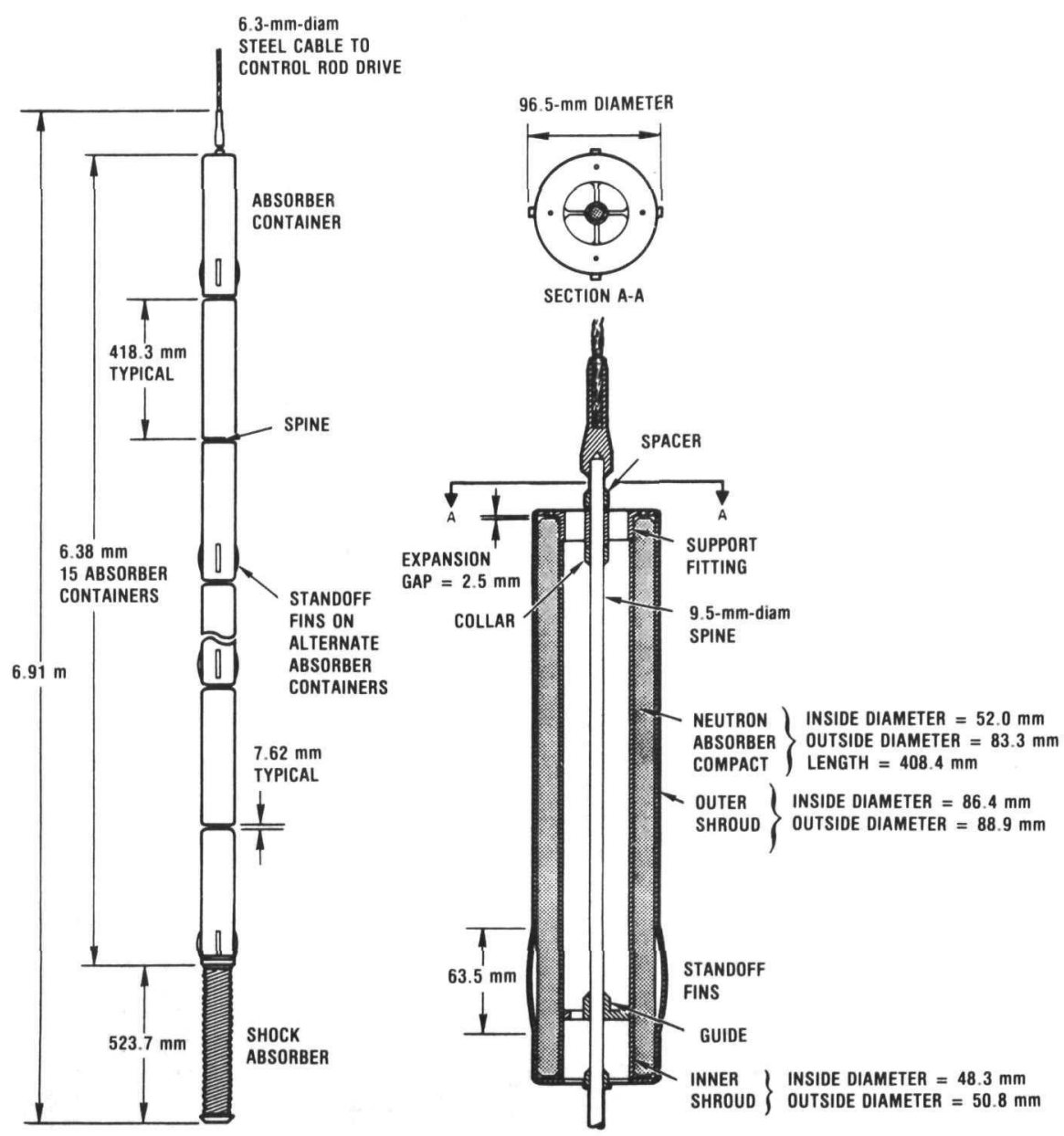

Fig. 7-8. Control rod assembly and absorber container details.

To carry out the core survey calculations, (a) a history of the power distribution within the core is required to specify local heat fluxes and power densities, (b) a history of the fast neutron fluence is required to enable the fast neutroninduced dimensional change in graphite and fuel rods and the coating integrity to be calculated, and (c) the burnup distribution history is required to allow fuel particle coating integrity to be evaluated. Each of these quantities depends on the refueling sequence, the fissile and fertile metal distribution throughout the core, the control rod programming used, and the detailed operating history of the plant.

The power distributions in the HTGR have been described in a report covering nuclear design of the 3000-MW(t) HTGR core. ${ }^{2}$ Only a brief discussion of the nuclear design is given below to show how results of the nuclear design are used in the thermal analyses. 


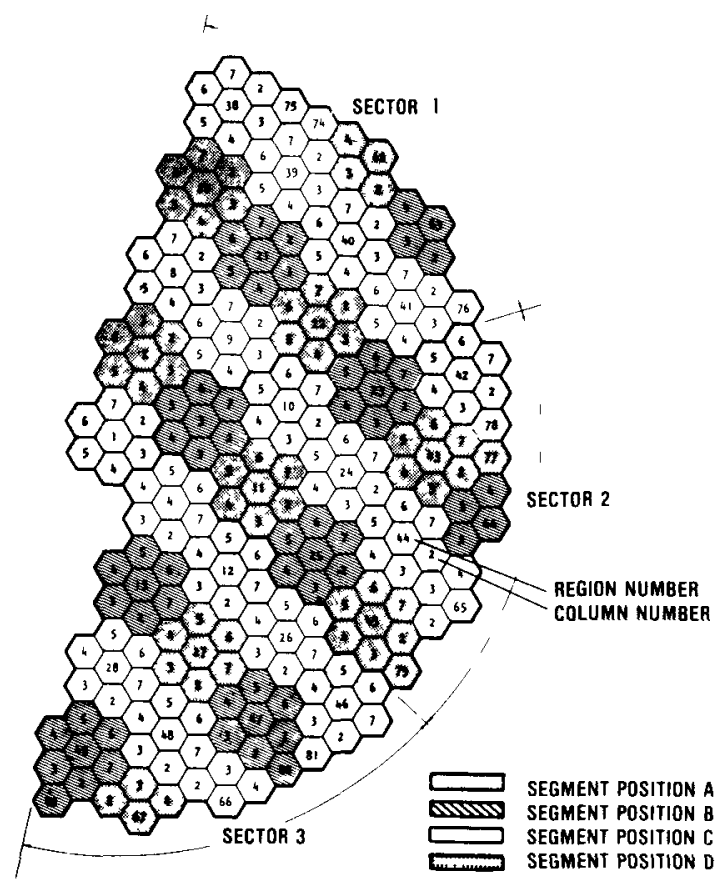

Fig. 7-9. Refuelıng sequence and Identification map.

Distributions of the fuel and burnable poison material within the core are two of the primary core parameters that are controlled by the core designer. These parameters are used to shape core power distribution. Since the fissile and fertile material zoning and the control rod patterns all strongly influence the power distribution, the design of each must be coordinated with the other.

The ideal power distribution is one that is radially and azimuthally as uniform as possible, and is combined with an axial power distribution strongly skewed toward the coolant inlet end of the core. These distributions must be reasonably stable with burnup and reasonably insensitive to control rod motion. Axial and radial zoning are accomplished by varying the quantity of ${ }^{235} \mathrm{U}$ and the $\mathrm{U} / \mathrm{Th}$ ratio in the fuel rods.

Large HTGRs employ a 4-yr fuel cycle in which about one-quarter of the fuel is replaced each year. For rated-power operation, a seven-rod pattern is used wherein the control rod pair in region 1 is used under automatic control to regulate main steam temperature, and six-rod pairs in regions $60 \mathrm{deg}$ apart in the ring containing regions 8 through 19 are used as manually operated shim rods (see Fig. 7-2). A core with 180-deg symmetry results from this combination of reload sequence and control rod pattern. Figure 7-9 depicts one of the symmetric halves and notes the "segment positions" A, B, C, and D. 
Power distributions are calculated for the design of the HTGR core with a number of one-, two-, and three-dimensional codes. These codes use either neutron diffusion or transport theory principles. ${ }^{2}$

A method for describing the power distribution in the fuel rods in the core is needed for the thermal design calculations. HTGR designers use power density peaking factors much like those used by other reactor designers. A peaking factor, $P(l, z)$, defined at each point in the core is used. Each core location is defined by a combination radial/azimuthal parameter, $l$, giving the location in a cross-sectional core plane and a core axial distance, $z$, from the coolant inlet end of the core. All of the following peaking factors express the component of the power distribution with respect to the core average power density.

The power peaking factor at any point in the reactor core is expressed by (see Nomenclature, p. 247):

$$
P(l, z)=P(r) \cdot \alpha(l, r) \cdot A(l, z),
$$

where $P(r)$ is the region radial power peaking factor, $\alpha(l, r)$ is the local radial intraregion tilt factor, and $A(l, z)$ is the relative axial power factor.

The power peaking factor is normalized such that

$$
\sum_{\substack{\text { core } \\ \text { volume }}} P(l, z) \Delta l \Delta z=1,
$$

where $\Delta l \Delta z$ is an element of the total core volume. A summation is used rather than an integration since the nuclear codes calculate the power peaking factors at discrete elements.

The local radial power peaking factor, $P(l)$, is found by summing the point power peaking factor over the core height:

$$
P(l)=\sum_{\substack{\text { core } \\ \text { height }}} P(l, z) \Delta z .
$$

An average region power peaking factor, $P(r)$, is found by summing the radial power peaking factor over a region:

$$
P(r)=\sum_{\text {region } r} P(l) \Delta l .
$$

The accumulative axial power peaking factor, $F\left(l, z_{I}\right)$, is a useful parameter and is defined by:

$$
F\left(l, z_{I}\right)=\sum_{\substack{\text { core } \\ \text { height } z l}} A(l, z) \Delta z
$$

The summation in the accumulative axial power peaking factor is carried out from the core inlet, $z=0$, to the core height, $z_{I}$. The accumulative axial power peaking factor is normalized so that when the summation is carried out over the full core length, $z_{l}=1$, then $F(l, 1)=1$. 
Examples of these power peaking factors are illustrated in the following sections.

The power distribution used in the HTGR thermal designs is calculated using several one-, two-, and three-dimensional diffusion codes developed especially for HTGR application. A three-dimensional nuclear analysis using the diffusion code GATT (Ref. 7) provides the local power peaking factor $P(l, z)$ at each radial and axial location of the core. However, these three-dimensional calculations are expensive. Without much sacrifice in accuracy, the three-dimensional power distribution is synthesized from a two-dimensional diffusion code GAUGE (Ref. 8) radial power distribution, and one-dimensional axial power shapes from FEVER (Ref. 9) and BUG, $R-z$ (Ref. 10). The GAUGE code provides the region peaking factors, $P(r)$, and radial intraregion power tilt, $\alpha(l, r)$. The final axial shapes are calculated using an $r-z$ model of the core by the BUGTRI code (Ref. 10) as a function of control rod position.

\section{7-3B Fuel Rod Metal Loading}

The fissile and fertile material in large HTGR cores is zoned both radially and axially to control the power distribution. The resulting fuel rod metal loadings required to implement the zoning determine the volume fractions of TRISO-UC ${ }_{2}$, BISO- $\mathrm{ThO}_{2}$, and graphite shim particles in fuel rods in four of the major fuel zones.

\section{7-3C Control Rod Program}

Most of the control rod motion occurs ${ }^{2}$ between core shutdown and about three days into full-power operation. During this period of operation, the majority of the rod pairs will be withdrawn to compensate for reactivity losses that arise from the temperature defect from the cold shutdown condition to the hot operating conditions, and from the buildup of rapidly saturating fission product neutron poisons such as ${ }^{135} \mathrm{Xe}$ and ${ }^{149} \mathrm{Sm}$. At the end of three days, about seven fully or partially inserted rod pairs provide the control over the remainder of the cycle. Figure 7-2 gives a typical seven-rod configuration for the $3000-\mathrm{MW}(\mathrm{t})$ core.

Burnable poison is used to compensate for most of the reactivity loss from long-term operating effects. Boron in the form of $\mathrm{B}_{4} \mathrm{C}$ is dispersed in graphite rods, which are placed in some holes in the corners of the fuel elements. The burnable poison rod size and composition are designed in such a way that during the first period of each annual cycle, which is $\sim 200$ days of full-power operation, there is minimum control rod motion. The reactivity loss due to depletion of fissile material is compensated for by reactivity gain due to the burnable poison depletion. During the remaining 100 days of a cycle, the seven control rods are slowly withdrawn to balance further loss of reactivity from depletion of fissile material.

Using this scheme, a 7-yr burnup study can be made at full power, during which the control rod pair in the central region 1 is used as a regulating rod. 
During the first $2 \mathrm{yr}$ of core operation, regions $9,11,13,15,17$, and 19 are rodded, for all subsequent years, regions $8,10,12,14,16$, and 18 are rodded

\section{7-3D Core Radial Power Distribution}

The relative power generated in a region is expressed by the region radial peakıng factor, $P(r)$, defined in Eq $(74)$ Flow control valves are manipulated so the flow in each of the refueling regions is proportional to the total power generated in the region Radial peakıng factors for the regions, $P(r)$, in a symmetric half of the core are shown in Fig 7-10 for four time points during a typical annual cycle

It can be seen that the power distribution changes little during the first 200 days, then, as the control rods in the core interior are withdrawn, the power shifts sharply toward the center region The range of $P(r)$ from 06 to 14 in the example is also typical ${ }^{2}$ The power within a refueling region is not spatially uniform, but

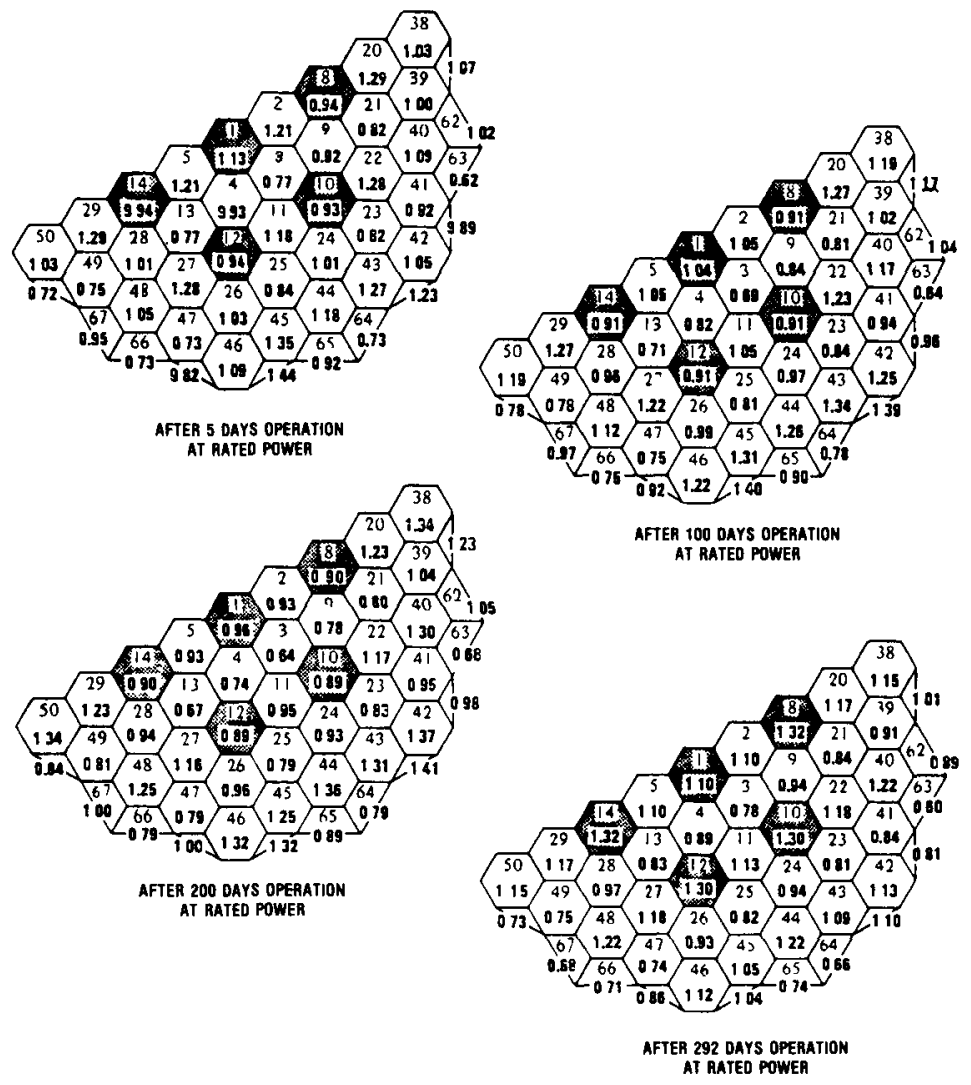

Fig 7-10 Full-power regıon peakıng factors, $P(r)$ for a typıcal annual cycle 
varies with location due to the thermal neutron flux gradients and nonuniform burnup and conversion existing within the region. Neutron flux gradients within regions are determined by fuel composition in the region and neighboring regions, the control rod pattern, and neutron leakage and reflection at the core periphery. The intraregion power tilt factor, $\alpha(l, r)$, from Eq. (7.1) is used to describe this nonuniform power within a refueling region. Local power tilts cause variations in helium, graphite, and fuel temperatures among local channels within the region.

Even though the basic design criteria given in Chapter 6 address fuel particle integrity, hot helium temperature, and control rod cladding temperature, it is convenient to set guidelines that limit various features of the radial power distribution. These guidelines are used in developing a nuclear design that has a high probability of meeting all thermal design bases. Radial power design guidelines are guidelines based on limiting fuel temperatures, core pressure drop, guiding flow valve design, and fixed orifice design.

Maximum region power peaking factor. The maximum allowable region power generation is set to keep the core pressure drop below an upper limit. The core pressure drop limit is based on efficient plant operation and not on safety. Since the flow valves are operated to yield an approximately equal coolant temperature rise in each core region, the core pressure loss is dictated by the coolant flow requirement of the highest powered region. In operation, the flow control valve for this maximum powered region is set wide open and the remaining valves are closed to bring the coolant exit temperature of the other regions equal to the same value. A high maximum region power requires that the flow control valves on other regions be closed to divert sufficient flow to the high-power region. For the $3000-\mathrm{MW}(\mathrm{t})$ reactor, the maximum region peaking factor during steady-state full-power operation is 1.6 .

Minimum region peaking factors. A requirement for a minimum region peaking factor is made to provide a low limit on the range of region flow required in the design of the flow control valve. For the $3000-\mathrm{MW}(\mathrm{t})$ reactor, the minimum region peaking factor during steady-state full-power operation is 0.5 .

\section{7-3E Core Axial Power Distribution}

The ideal axial power distribution, which would result in an axially constant fuel temperature, is an exponential distribution peaked toward the top of the core (see Chapter 4). The continuous zoning of heavy metal required for such an ideal distribution, however, is not practical, and in the current core design, three axial fuel zones are used to shape the axial power. In this zonal scheme, the four topmost fuel elements in a region of the core all have the same fuel composition and constitute the top zone. The next three elements are in the middle zone, and the bottom element is the bottom zone. One additional criterion that the axial power distribution must meet is that it should be stable with core burnup. A core average axial power shape and the effect of burnup are shown in Fig. 7-11. A small shift in power shape occurs in each of the axial zones during the first year 


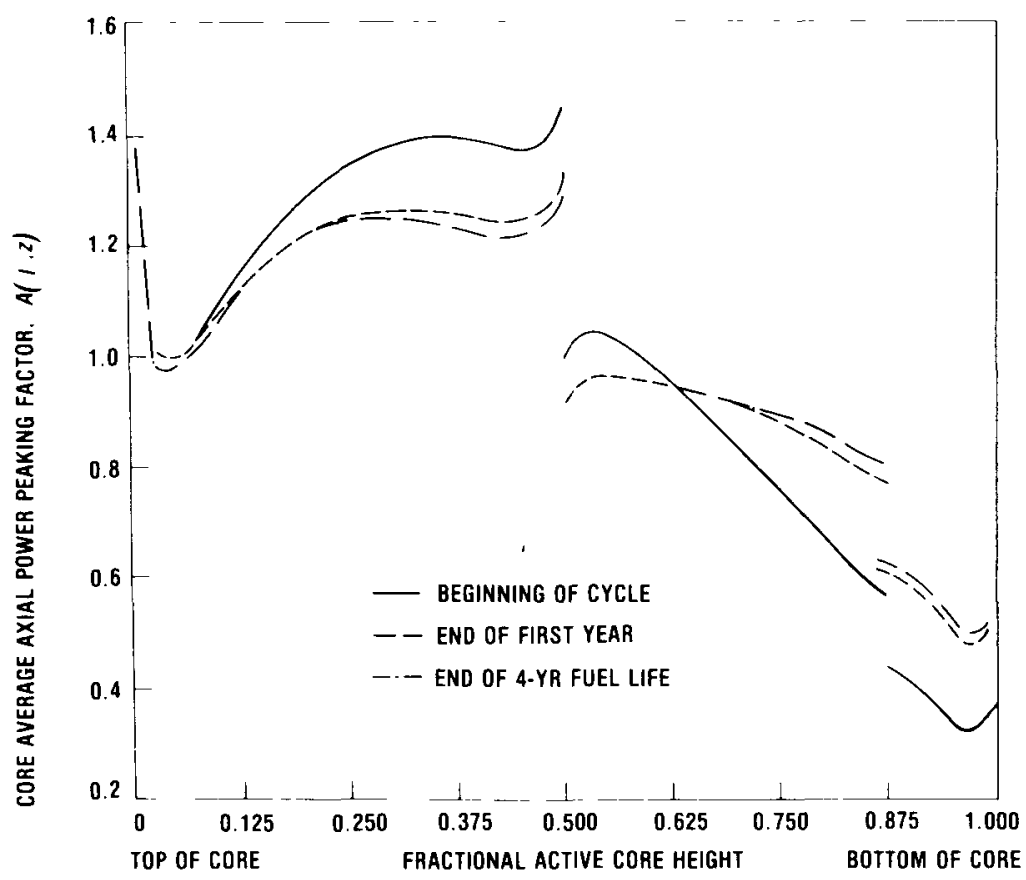

Fig. 7-11. Effect of burnup on core average axial power distribution.

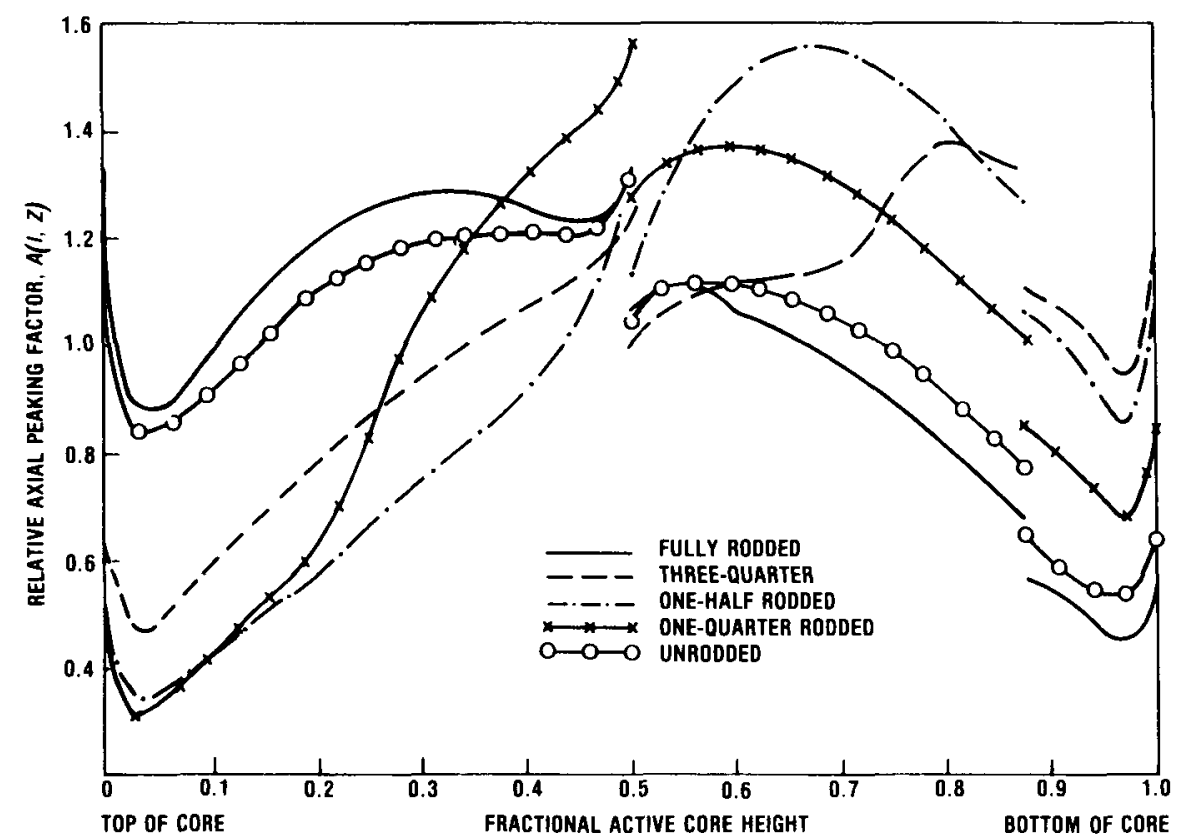

Fig. 7-12. Effect of control rod motion on axial power distribution in rodded regions. 


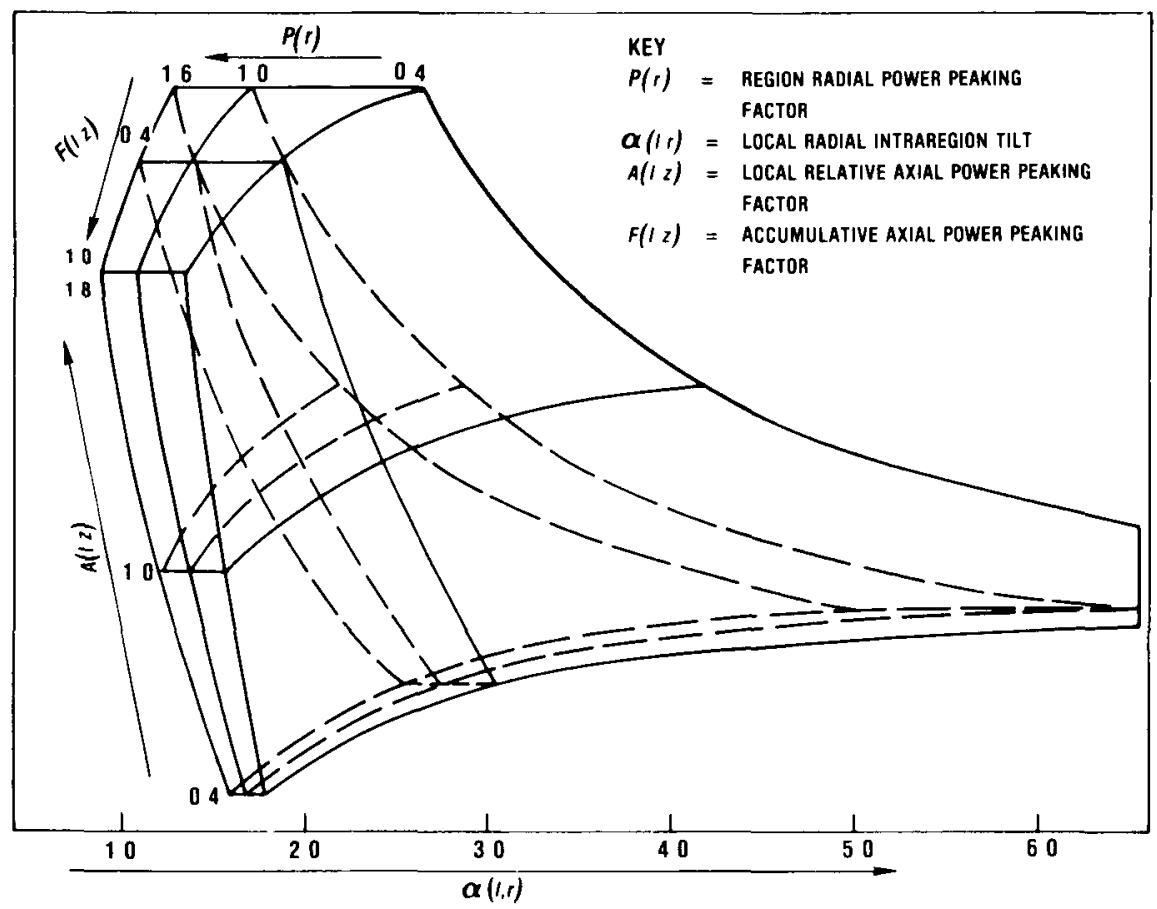

Fig. 7-13. Combination of radial and axial peakıng factors that results in a peak fuel temperature of $1400^{\circ} \mathrm{C}\left(2550^{\circ} \mathrm{F}\right)$

as the lumped burnable poison is depleted; the shape remains essentially unchanged thereafter.

One of the important effects of control rod movement within a region is to perturb the axial power shape in the refueling region and in regions surrounding it. Figure 7-12 shows the axial power distribution in a rodded region as a function of rod insertion distance. The axial power shapes for the radial region in Fig. $7-12$, from the BUG code, ${ }^{11}$ indicate that as the rod pair is inserted, the power is pushed toward the bottom of the core and the axial power has a characteristic bulge just below the tip of the rods. The axial power shape in regions adjacent to rodded regions is also perturbed. When the rod is fully inserted in the region, the axial power shape is nearly the same as when the rod is fully withdrawn.

\section{7-3F Dependence of Fuel Temperature on the Power Peaking Factors}

Local fuel temperatures depend on all four of the power peaking factors defined earlier in this section, $P(r), \alpha(l, r), A(l, z)$, and $F(l, z)$. Using an idealized core thermal model ${ }^{1}$, the dependence of fuel temperature on these four power distribution characteristics has been generated and is presented in Fig. 7-13. The figure is an isothermal solid; all points within the solid yield values of the four peaking factors, which produce a maximum centerline fuel temperature of $1400^{\circ} \mathrm{C}$ 
$\left(2550^{\circ} \mathrm{F}\right)$ For example, the following three combinations of peakıng factors yield a $1400^{\circ} \mathrm{C}$ fuel rod centerline temperature as read from the sothermal solid in Fig $7-13$

\begin{tabular}{lccc} 
& \multicolumn{4}{c}{ Peakıng } & \multicolumn{2}{c}{ Combination Number } \\
Factors & 1 & 2 & 3 \\
\hline$P(r)$ & 16 & 10 & 04 \\
$\alpha(l, r)$ & 12 & 20 & 16 \\
$A(l, z)$ & 10 & 10 & 04 \\
$F(l, z)$ & 10 & 04 & 10
\end{tabular}

\section{7-4 Core Flow Distribution}

The helium coolant is delivered from the circulators to the large plenum above the core through four large ducts From the upper plenum, the coolant flows downward in various paths through the core The principal paths are coolant channels, core gaps, internal and external, control rod channels, and side reflector gaps

Flow distribution control in the core of the HTGR is used because the helium coolant temperature rise in the HTGR core is large under normal operating conditions and because the graded fuel cycle management results in relatıvely large differences in radial power generation in the core The flow distribution through the core is controlled by remotely operable flow control valves A sketch of these valves is shown in Fig 7-4 In the HTGR, all valves are identical, each region with four or more columns is fitted with a valve It is the effect of these valves along with the design of the core flow paths that controls the core pressure and flow distribution

Core operating procedures dictate that the flow should be controlled so that regions have nearly equal measured coolant exit temperatures This procedure produces maximum fuel temperatures in the regions withın $\sim 55^{\circ} \mathrm{C}\left(\sim 100^{\circ} \mathrm{F}\right)$ of one another and provides an operating environment for downstream components free from large-scale hot gas streaks

Design of the core flow paths must recognize

1 the cooling requirements of the individual core components

2 the temperature limits of the reactor components in contact with hot coolant

3 the core component dimensional change induced by temperature and fast neutron flux

4 the requirement to refuel the core

The general rules are that as much as possible of the core cavity flow should remove heat from the fuel, and the flow resistances of each individual coolant hole should be as nearly identical as possible 
Ideally, all core cavity components should be designed to discharge coolant at the same helium temperature into the lower plenum. If components such as the side reflector are designed to require a large quantity of coolant that is heated relatively little, other components such as the core will necessarily have to supply helium at temperatures above the average hot helium temperature. This leads to temperature differences ("hot streaks") entering a steam generator, thus complicating its design.

Fuel element cooling paths are provided by holes drilled through the blocks and by the thin gaps around the periphery of the blocks. The ideal design of a core is to fit the fuel elements into the core with a limited fraction of the flow in the gaps surrounding the fuel elements.

Dimensions of fuel elements and other components increase slightly when they are heated, so this dimensional change must be accommodated by the design. For the level of fast neutron fluence in the HTGR core, the graphite fuel and reflector elements shrink a little under $1 \%$ radially and just over $1 \%$ axially on the average during their 4-yr life. This means that the across-flats dimension of a fuel element will decrease $\sim 3.5 \mathrm{~mm}(0.14 \mathrm{in}$.) and a fuel element will on the average decrease $5.1 \mathrm{~mm}(0.2 \mathrm{in}$.) in length. Core structural designers have devised a number of techniques to control gaps between elements including: elaborately keyed elements, mechanical core clamping devices, and use of the coolant inlet pressure to hold elements together. The technique proposed for large HTGR cores utilizes a spring-actuated clamping device. Springs force the large side reflector blocks inward to form a ring of blocks defining the active core cavity. This design fixes the total across-core gaps between fuel elements. The springs at the level of the core support blocks force these blocks together, shutting off the core gap flow paths at the level of the core support floor. This "tight core support floor" design tends to raise the pressure in the core and refiector gap system. The inlet plenum elements provide only a small inlet flow area to the core gaps; the core gap flow is $<10 \%$ of the core cavity flow at the inlet and $\sim 2.6 \%$ at the core exit.

Fuel columns are positioned at the bottom by dowels on their core support blocks. The dowels allow only small initial hot gaps between the sides of the blocks in the region and with surrounding regions. With increasing region age, these gaps increase in size and the size varies axially due to fast neutron-induced dimensional change in the fuel and reflector elements. To limit in-region gap width, the columns within a fuel region are also keyed together at the top.

\section{7-4A Core Flow Paths}

Most of the coolant entering the upper core plenum passes through the coolant channels within the fuel elements of the core, and a small fraction of the flow bypasses these coolant channels and passes through alternate flow paths to provide cooling to fuel elements and other components within the reactor core cavity. Each of the flow passages that exists in the $3000-\mathrm{MW}(\mathrm{t})$ core cavity is briefly discussed below. 


\section{Coolant Channel Flow}

Almost all of the coolant entering the refueling region through the variable flow control valves flows through the coolant channels within the top reflector, active core, and bottom reflector hexagonal graphite blocks. In the lower reflector, the helium from the coolant channels in the standard fuel column merges into three large 12.7- $\mathrm{cm}$-diam coolant holes as shown in Fig. 7-3. Large holes are used in the lower reflector to reduce pressure loss. The coolant then passes through the full-length reflector element with the matching coolant holes and then into the core support block. The coolant from individual coolant channels in the control column is collected into a single plenum within the bottom reflector element just above the core support block. Horizontal slots in the bottom faces of the control column bottom reflector block and matching slots in neighboring elements in the standard columns allow the coolant to be routed to the adjacent standard columns and into the core support block as shown in Fig. 7-3. This prevents the coolant from the central region from impinging directly on the region exit thermocouple assembly, which would influence the reading more than its small flow rate would merit.

A variable flow control assembly is located at the inlet to each refueling region to provide on-line control of coolant flow distribution among the refueling regions of the core. Thermocouples are located, as shown in Fig. 7-3, in a graphite sleeve penetrating the core support block beneath each of the regions that is fitted with flow control valves. These thermocouples indicate the region-averaged coolant outlet temperatures, which are used as a basis for distributing the coolant flow using the flow valves.

In the $3000-\mathrm{MW}(\mathrm{t})$ reactor, 18 fuel columns located around the periphery of the core have been fitted with fixed orifices to control flow through these columns. These fixed orifices can be changed only at the time when the penetration used to refuel the column is opened.

\section{Bypass Flows}

The core cavity flow that does not pass through the fuel element coolant holes is called "bypass flow." This bypass flow varies with fuel age and with axial position in the core. Bypass flow increases as spaces between elements increase due to fast neutron-induced fuel element shrinkage. The bypass flows provide cooling to components of the core as follows:

1. Control rod channel. Control rod cooling flow passes through the control rod channel, cooling the control rods that are inserted into the core as well as removing heat from the control column fuel elements. Control rod flow is limited by a small diameter flow passage in the control column bottom reflector. The control rod flow merges with the coolant channel flow in the bottom reflector region. The reserve absorber hole in the central fuel column has a blind bottom. Flow can pass through this hole only by crossflow in and out to surrounding coolant paths. 
2. Flow in gaps between fuel columns and crossflow. A fraction of the core cavity flow bypasses the fuel element coolant holes and passes through the gaps between fuel columns. Two kinds of fuel element gaps have been defined: external gaps and internal gaps. External gaps are those between fuel columns of adjacent refueling regions. A vertical flow path from the upper core plenum to the external gaps is afforded by the spaces between fuel columns within a refueling region. The inlet to the internal gaps is only from the flow control valve plenum, or from lateral flow that occurs between the internal and external gaps of refueling regions. The coolant in the gaps between fuel columns (external gaps) flows downward and exits at the bottom reflector through the flow windows between the control and standard fuel column reflector elements. There it mixes with the coolant hole and control rod channel flow. A small portion of the external gap flow exits through the vertical spaces between core support floor blocks. In the reactor core, small lateral pressure differences that develop between the gap flow and coolant channel flow provide the potential for an exchange of coolant between the bypass gaps and coolant channels. This flow is termed "crossflow" and is discussed in Sec. 7-4C.

3. Side reflector and reflector gaps. Helium coolant flows through spaces between graphite reflector blocks. This flow removes the heat deposited in the side reflector. Helium flow also passes between the permanent reflector and the core cavity liner but is limited by a core peripheral seal near the level of the core support floor.

\section{7-4B Flow Resistance of Coolant Paths}

The flow distribution within the core depends on the dimensions and flow resistances of the numerous flow paths.

The pressure drop equation for a single coolant channel serves to illustrate the various losses experienced by the helium coolant as it passes through the core:

$$
\begin{gathered}
\Delta p_{T}=\frac{1}{2 \rho}\left(\frac{\dot{m}}{A}\right)^{2}\left[K_{v}+K_{1}+\frac{4 f L}{D}\left(\frac{\bar{T}}{T_{1}}\right)+\frac{T_{2}-T_{1}}{T_{1}}\right. \\
\left.+\sum_{J=1}^{n} K_{J}\left(\frac{T_{J}}{T_{1}}\right)+K_{2}\left(\frac{T_{2}}{T_{1}}\right)\right] .
\end{gathered}
$$

The pressure drop equation is similar to Eq. (3.100) of Chapter 3. In Eq. (7.6), $K_{v}$ is the loss coefficient of the flow control valve, $K_{J}$ is the loss coefficient due to the offset at element interfaces, and $T_{j}$ is the temperature at the bottom of the core element block $j$.

Early designs were carried out using flow resistances taken directly from handbooks or derived from handbook information; e.g., Table 7-V shows ap- 
TABLE 7-V

Flow Resistances as a Function of the Region Power Factor

\begin{tabular}{|lccc|}
\hline \multicolumn{1}{|c}{ Region Power Factor, $P(r)$} & 1.6 & 1.0 & 0.4 \\
\hline Velocity head $^{\text {a }}$ in top reflector coolant holes $(\mathrm{kPa})$ & 38 & 15 & 024 \\
Orifice coefficient, $K_{v}$ & 347 & 350 & 3073 \\
Entrance loss coefficient, $K_{1}$ & 036 & 036 & 036 \\
Frictional resistance & 1235 & 1307 & 1657 \\
{$\left[\frac{4 f L}{D} \times \frac{\bar{T}}{T_{1}}\right]$} & & & \\
Acceleration due to temperature rise & 074 & 074 & 074 \\
{$\left[\frac{T_{2}-T_{1}}{T_{1}}\right]$} & & & \\
Element interface offset loss coefficients & & & \\
$\sum_{j=1}^{n} K_{J}\left(\frac{T_{J}}{T_{1}}\right)$ & 050 & & \\
Exit loss coefficient & & 330 & \\
{$\left[K_{2}\left(\frac{T_{2}}{T_{1}}\right)\right]$} & 334 & \\
\hline
\end{tabular}

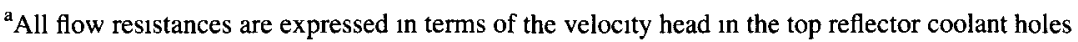

proximate values of resistances to flow through the coolant holes. The major influence on the pressure distribution is the inlet flow control valve, which can take on values of $K_{v}$ between 3.47 and 307 inlet coolant channel velocity heads, depending on the position at which the operator sets the valve. Frictional resistance of the coolant hole accounts for the next largest pressure loss. The coolant holes drilled in graphite are initially quite rough and friction factors $30 \%$ higher than those for smooth tubes have been measured.

The exit loss term represents the irrecoverable pressure losses in the lower reflector blocks and the core support block.

Extensive measurements of flow loss coefficients and flow distribution in HTGR components have been made and detailed results can be found in Refs. 12 through 19.

\section{7-4C Crossflow}

Flow passing horizontally between the active core gaps and the coolant holes is called "crossflow." This flow may be through spaces between the horizontal faces of blocks or, to a lesser extent, through the slightly porous graphite of the fuel element. The amount of crossflow between core gaps and coolant channels depends on the potential pressure difference. The pressure drop across the inlet 
orifices in regions generating less than maximum power varies between $\sim 10$ to $70 \mathrm{kPA}(\sim 1.5$ to $10 \mathrm{psi})$ depending on the flow valve setting and core power distribution. This pressure drop through the valve determines the coolant hole pressure in the regions. The helium pressure in coolant channels of a region with a partially closed valve is lower than that in the surrounding gaps. This pressure difference will cause flow to enter the coolant holes through fuel element interface gaps. In high-power regions with open-flow control valves, the pressure in the coolant holes in the upper reffector and some portions of the active core is higher than the pressure in the coolant flowing in spaces between fuel elements. This pressure difference can induce flow to leave coolant holes in a high-power region through the small horizontal interfacial gaps that may develop between fuel blocks. The external and internal gap pressures and flow distribution are affected by many variables, but one of the dominant influences is the design of the core support floor. The core side restraint system is designed so that at full power, when the core exit coolant temperature reaches a maximum, the core support blocks are all in contact and the gap spaces between the blocks are closed. This means that little flow can escape through the floor. The "tight" floor increases the gap pressure resulting in a tendency for crossflow to be from the gaps into the coolant holes. Internal gap dimensions are fixed by the placement of dowels on the core support blocks, which aligns the lower ends of the fuel columns. External gaps are controlled by these dowels, the dimensions of the core support blocks, and the core side restraint design.

Preliminary designs and core survey calculations requiring design and performance calculations often use a representation of the core flow, such as Eq. (7.6), which does not include the possibility of crossflow.

Crossflow effects on core flow and pressure distributions can be determined with one of the core network flow codes used in core design: FLAC (Ref. 20), SPIFFS (Ref. 21), and SNIFFS (Refs. 22, 23, and 24). The basic network flow path capabilities are similar in the three codes, but each has special features. Flow measurements of core components and full regions have been made and results are reported in Ref. 19.

\section{7-4D Core Flow Distribution}

Results from two cases are included to demonstrate the influence of core crossflow gaps caused by fuel element dimensional change and bowing induced by fast neutron irradiation. First, results of calculations made for the initial core when all the graphite elements are new and can be assembled to give nearly zero interfacial gaps are discussed. This limiting case is referred to as the "no crossflow" case. For the second case, crossflow gaps of $0.25 \mathrm{~mm}(0.01 \mathrm{in}$.) are included at the interface between each fuel and reflector element. This second illustrative case is referred to as the "crossflow" case.

Figure 7-14 shows the pressure distribution in coolant holes, gaps between fuel columns, and side reflector gaps for the no crossflow case. The pressure in 


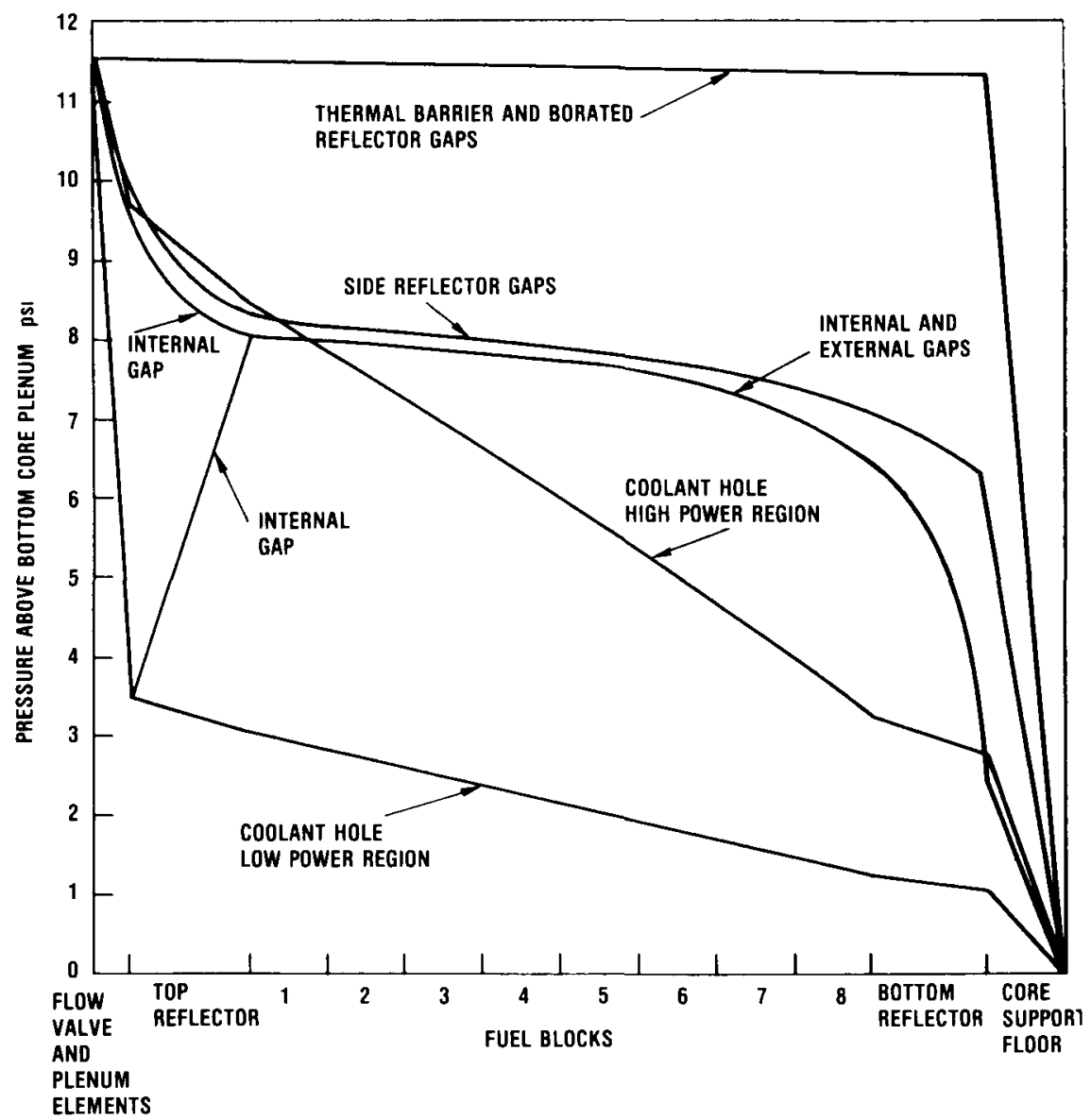

Fig 7-14 Core coolant pressure distribution in no crossflow case

the boronated reflector and thermal barrier gaps is kept high by the core peripheral seal flow restrictor located at the level of the core support floor (only $1 \%$ bypass flow) Therefore, flow passes from the thermal barrier and reflector gaps laterally into the permanent side reflector gaps and inward to the core gaps Also as a result of this lateral flow, the axial coolant flow decreases in the side reflector gaps and increases in the core gaps with distance from the coolant inlet

The coolant pressure in the upper reflector internal gaps depends on the region flow control valve position In regions with fully open flow control valves, the internal and external gap pressures are nearly identical However, in regions with nearly closed flow control valves, the internal gap pressure is low because the helium at the entrance to these internal gaps experiences the full pressure drop across the flow control valve Flow is driven horizontally from the external gaps to the internal gaps in these low-flow regions Also, in these low-flow regions, 
an upward helium flow is possible in the internal gaps in the top reflector blocks. The flow transferred from the external gaps horizontally to the internal gaps and upward to the flow control valve plenum represents a leak around the closed valve.

At the core support floor, the internal gaps, external gaps, and side reflector flows are effectively blocked by the narrow spaces between support blocks. Thus, most of these gap flows pass into the lateral slots in the lower reflector blocks, join the coolant channel flow, and together it all passes through the core support block into the lower plenum. If crossflow is not present, the flow in coolant holes and control rod channels is constant along the length of the core.

Helium coolant passing through the core cavity flow passages removes the thermal energy generated in the fuel elements, control rods, and reflector elements. The core flow, power, and helium temperature distributions if no crossflow is present are shown in Fig. 7-15. About $95 \%$ of the heat is removed by the helium flowing through the coolant channels. The helium flowing through the reflector gaps removes the relatively small fraction $(0.8 \%)$ of the total heat deposited there by gamma and neutron attenuation. About $2.8 \%$ of the helium leaving the narrow

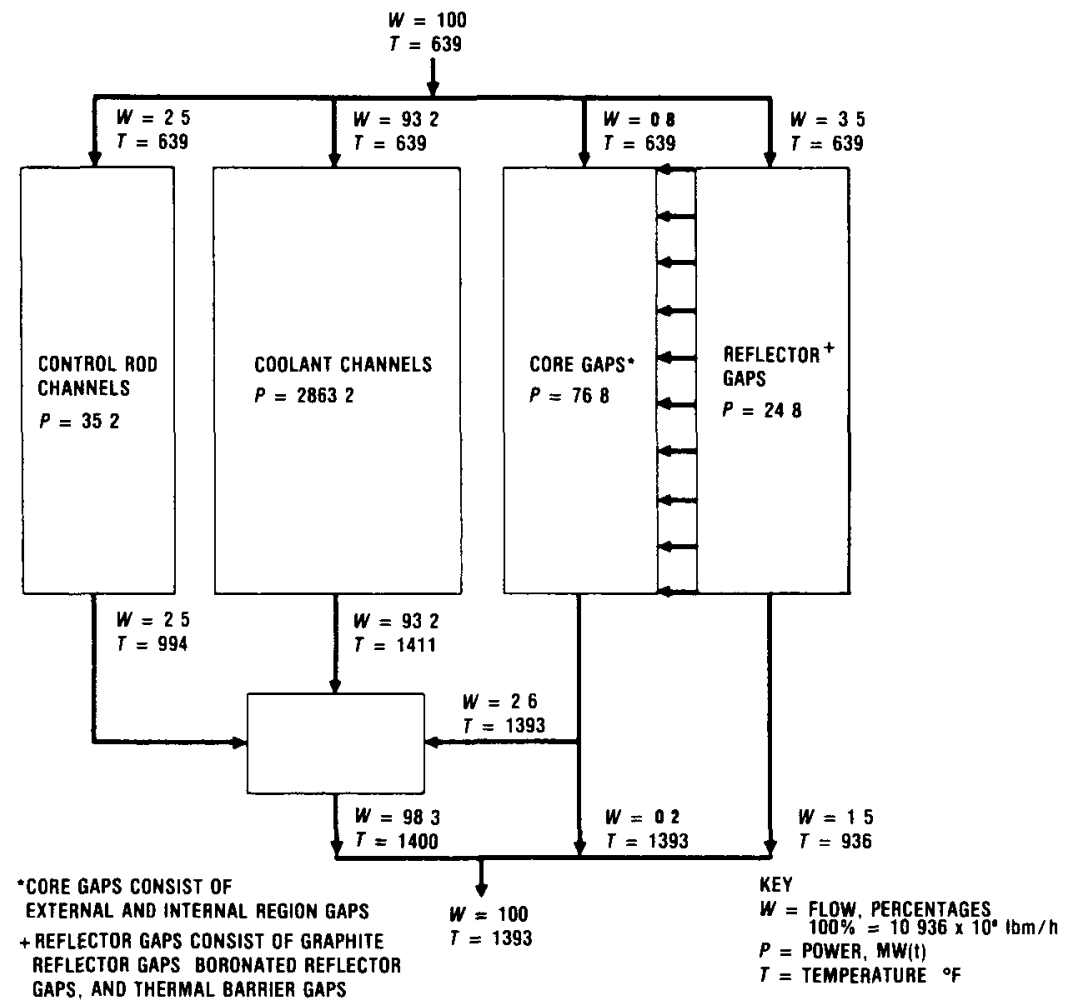

Fig. 7-15. Core power, flow, and coolant temperature distributions in a 3000-MW(t) core "no crossflow" case. 
core gaps between fuel columns removes $2.5 \%$ of the total heat load and emerges at the approximate core average gas exit temperature. The $2.5 \%$ of helium flowing through the control rod coolant channels removes $\sim 1.2 \%$ of the total heat. This is enough flow to maintain the control rod cladding and compact temperature within design limits.

Generally, the crossflow paths occur near the core reflector boundary, where a fast neutron flux gradient exists due to neutron leakage into the side reflector. However, in the flow distribution calculations with crossflow, a horizontal flow path of $0.25 \mathrm{~mm}(0.01 \mathrm{in}$.) was included between all fuel blocks in the core. These crossflow paths connect the internal and external gaps directly with the coolant channels at each horizontal interface between fuel blocks. ${ }^{19}$ Figure 7-16 shows the pressure distribution in several of the core cavity flow paths when

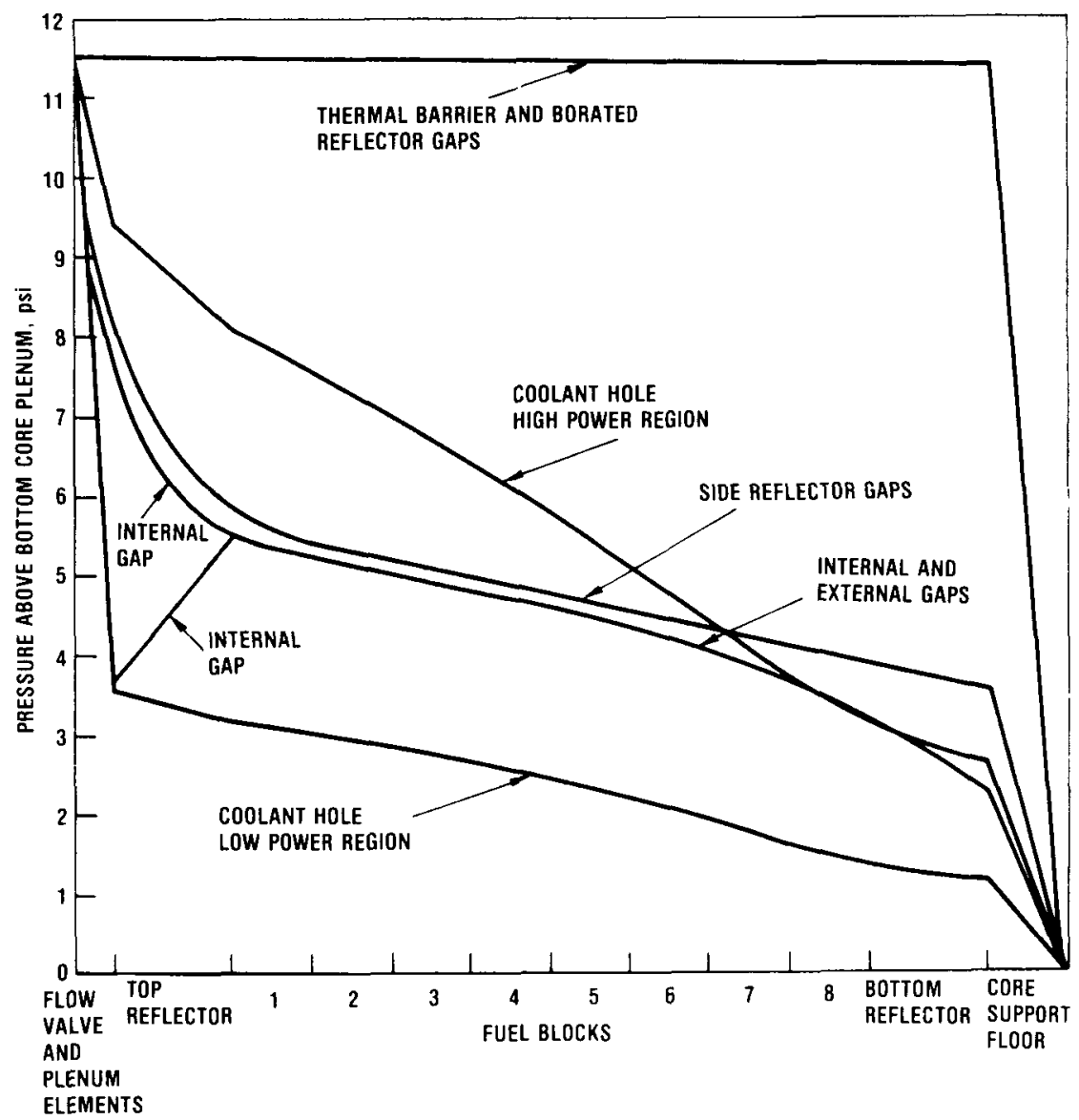

Fig. 7-16. Core coolant pressure distribution in "crossflow" case. 
crossflow is present. When the horizontal crossflow gaps are present, there is an overall inward flow from the reflector gaps and core internal and external gaps into coolant holes. The flow distribution among the core flow paths when crossflow is present is given in Fig. 7-17. The total flow entering the reflector and core gap system from the core plenum is higher than for the no crossflow case and the helium flow entering the coolant channels through the flow valves is lower than the no crossflow case. Gap flow enters the coolant channels at different axial levels increasing the coolant channel helium flow as it passes through the core. The control rod channel flow is also decreased in the lower portion of the core as a result of crossflow from the control rod channel into the coolant channel. The decreased internal and external gap pressures resulting from crossflow produce an increased inward flow from the borated reflector and thermal barrier gaps.

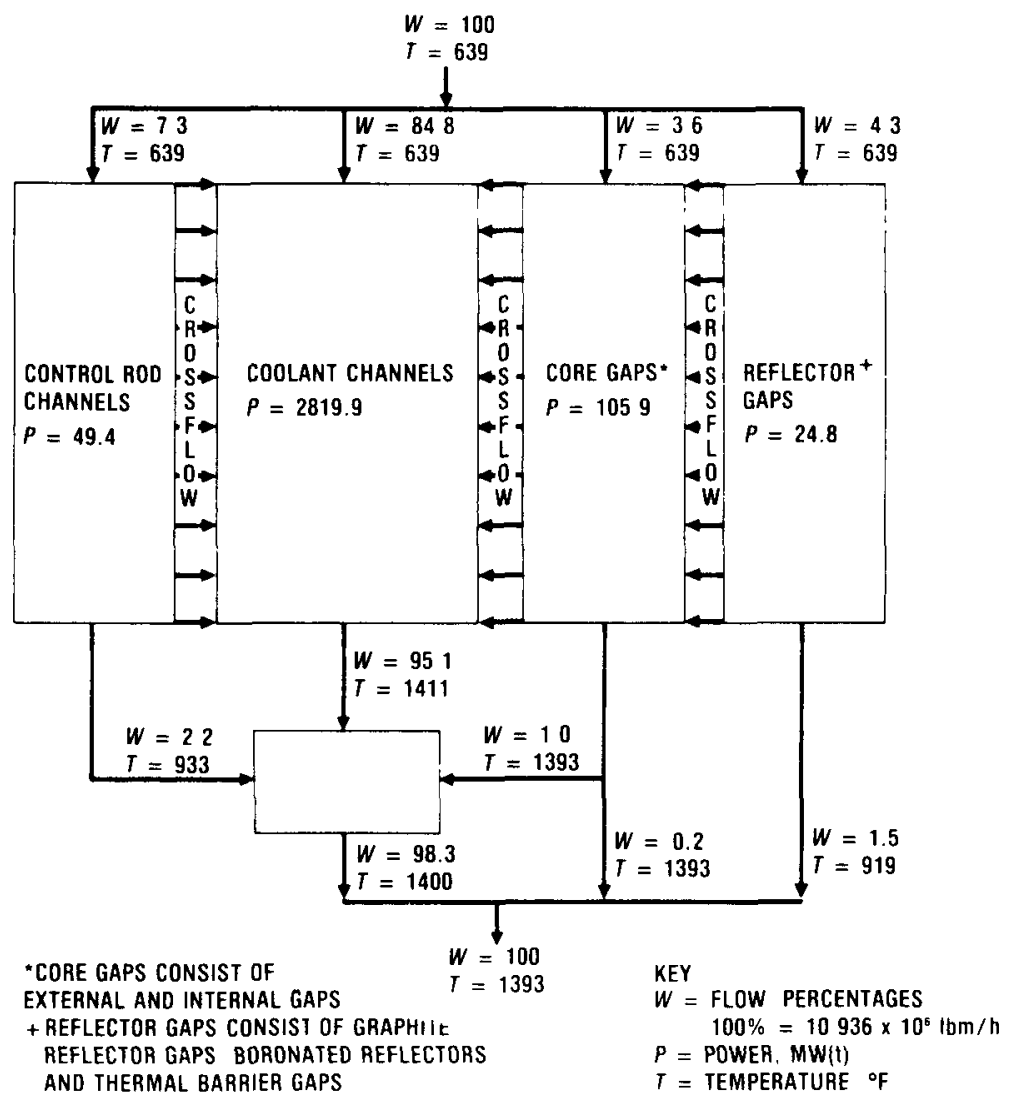

Fig. 7-17. Core power, flow, and coolant temperature distributions in a $3000-\mathrm{MW}(\mathrm{t})$ core "crossflow" case. 


\section{7-4E Laminar Instability}

When a gas enters a heated channel at a Reynolds number just above but near the isothermal laminar-turbulent transition value, there is a tendency for transition from turbulent flow to laminar flow to occur. For a collection of parallel channels connected between two constant pressure plenums, such as an HTGR core or an HTGR region, flow in channels that undergo this turbulent-to-laminar transition have been observed to receive decreasing flow even though the external pressure difference is maintained across the plenums. This instability, referred to as "laminar instability" has been observed experimentally ${ }^{25,26}$ and explained theoretically. ${ }^{25,27}$ The instability has been associated with negative values of the rate of change of pressure drop with flow rate $(\partial P / \partial m<0)$; that is, a decrease in mass flow through the channel can yield an increase in pressure drop.

This laminar instability cannot occur during normal power operation in the HTGR because Reynolds numbers and heating rates are in the stable regime. However, laminar instabilities can occur in the HTGR core during core startup when the flow is low. Therefore, a minimum flow rate has been specified and orifice adjustment is delayed until all channels are well away from the instability range. ${ }^{11}$

\section{7-5 Core Temperatures}

The temperatures in the core have to be kept below values that begin to cause damage to fission product barriers, produce structural material weakness, and lead to excessive chemical reaction rates. These temperature limitations in the HTGR are defined quantitatively in Table 6-VII, which gives the core thermal design criteria.

In addition to the thermal limits of Table 6-VII, the temperature distribution must not produce thermal or temperature-dependent stresses from fast neutroninduced dimensional changes that prevent the core components from performing their function.

A plethora of degrees of freedom are available that allow the temperature limit and distribution to be controlled by the core designer. The problem is in selecting the most cost-effective ones and at the same time meet the design criteria.

\section{7-5A Unit Cell Models of Heat Flow in Fuel Elements}

To understand some basic aspects of heat transfer in the prismatic HTGR fuel element, simple models are helpful. In fact, a great number of useful core design calculations are made with these models.

To develop a simple model of the fuel element, it is necessary only to notice that the regular area in the interior of the fuel element of the large HTGR can be made up from triangular-shaped unit cells as shown in Fig. 7-18b. To proceed with the model, it is necessary to assume that the unit cell is a symmetry section 


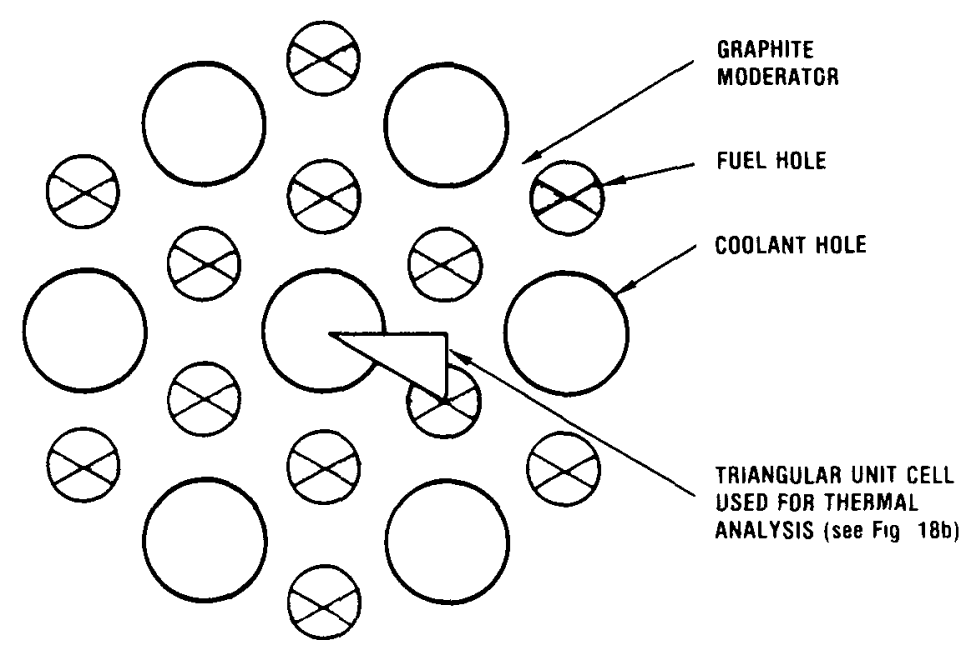

Fig. 7-18a. Fuel element coolant hole pattern.

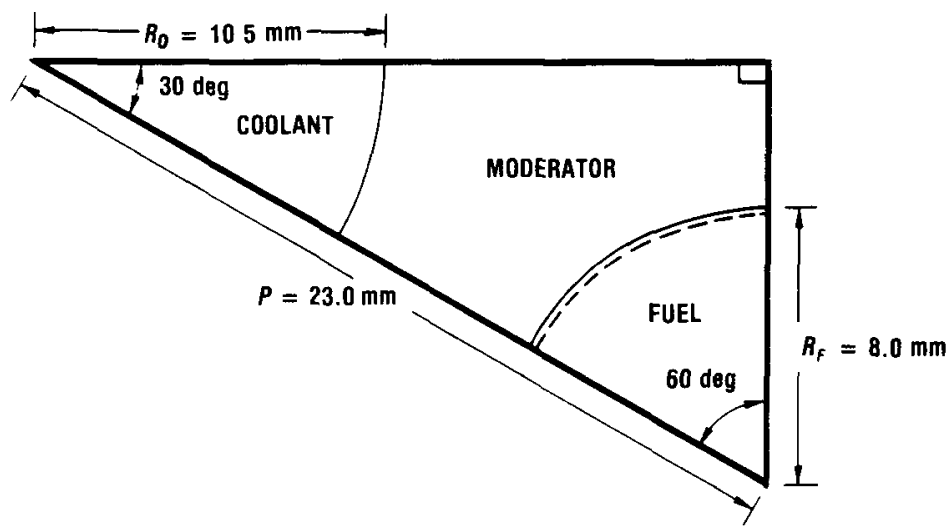

Fig. 7-18b. Triangular unit cell element used in thermal analysis.

such that only the heat generated in the fuel and reflector in the triangular region is removed by the coolant flowing in the coolant hole of the triangle. This means that heat conduction radially across the fuel element is ignored. Even though the model is obviously not accurate in every part of the core, various correction factors to this basic model have been devised to account for these special effects. For the hottest locations in the core, the temperatures calculated by the model are conservative since conduction of heat is away from the hot location to surrounding cooler spots.

Using the unit cell model, it is possible to determine the temperatures of the coolant, graphite, and fuel throughout the core as outlined in Chapter 3. For 
example, the fuel centerline temperature, $T_{f c l}$, in a particular unit cell at any axial location, $z$, is given by:

$$
\begin{aligned}
T_{f c l}(z)= & T_{\text {coolant }}(z)+\Delta T_{\text {film }}(z)+\Delta T_{\text {graphte }}(z) \\
& +\Delta T_{\text {gap }}(z)+\Delta T_{\text {fuel }}(z),
\end{aligned}
$$

where

$$
\begin{gathered}
T_{\text {coolant }}(z)=T_{1}+\frac{\bar{q}^{\prime} F(l, z)}{\dot{m} C_{p}}, \\
\Delta T_{\text {film }}(z)=\frac{q_{c}^{\prime \prime}(z)}{h_{\text {film }}}, \\
\Delta T_{\text {graphtte }}(z)=\frac{q_{c}^{\prime \prime}(z)}{h_{\text {graphite }}}, \\
\Delta T_{\text {gap }}(z)=\frac{q_{f}^{\prime \prime}(z)}{h_{\text {gap }}},
\end{gathered}
$$

and

$$
T_{\text {fuel }}(z)=\frac{q_{f}^{\prime \prime \prime}(z) R_{f}^{2}}{4 k_{f}} .
$$

In the above expressions, $\bar{q}^{\prime}$ is the average linear heat rating of the fuel given by

$$
\bar{q}^{\prime}=\frac{Q P(l)}{N L},
$$

where $Q$ is the total core thermal power ( $2746.3 \mathrm{MW}$ ) removed by the helium flowing in the coolant holes of the variable orifice region, $N$ is the number of coolant holes, $L$ is the active core length, and $P(l)$ is the local radial peaking factor previously described in Sec. 7-3A.

The term $q_{c}^{\prime \prime}$ is the heat flux at the coolant hole and for any position in the core is given by

$$
q_{c}^{\prime \prime}(l, r, z)=\bar{q}^{\prime \prime} \cdot P(r) \cdot \alpha(l, r) \cdot A(l, z) .
$$

The power peaking factors have been previously defined in Sec. 7-3A. The average heat flux, $\bar{q}^{\prime \prime}$, is evaluated from the total core thermal power, $Q$, and the total heat transfer surface of the coolant holes adjusted by small correction factors ${ }^{1}$ to account for unfueled core length, non-ideal fuel hole-to-coolant hole ratio, and bypass flow.

The term $q_{f}^{\prime \prime}$ is the heat flux at the fuel surface and is found in a manner similar to $q_{c}^{\prime \prime}$ except that the fuel heat transfer surface is used rather than the coolant heat transfer surface.

The fuel volumetric heat generation term, $q_{f}^{\prime \prime \prime}$, in Eq. (7.12) is related to the 
fuel surface heat flux by

$$
q_{f}^{\prime \prime}=q_{f}^{\prime \prime \prime} \cdot \frac{R_{f}}{2}
$$

The heat transfer coefficient, $h_{\mathrm{film}}$, in Eq. (7.9) is a function of axial position because of the temperature-dependent helium properties. The heat transfer coefficient is determined from correlations given in Sec. 3-3B. The term $h_{\text {graphite }}$ is the equivalent conductance from the coolant surface through the graphite web (Fig. 7-18) to the fuel surface. The evaluation of this parameter is described in Sec. 3-4I. A computer program, HEXT, was written to facilitate obtaining the equivalent graphite thermal conductance from the series form of the solution for the unit cell temperatures.

\section{7-5B Effect of Power Distribution on Core Temperatures}

The region-to-region variation of the core radial power is compensated for by radial flow distribution control using core inlet flow control valves. However, the variation of the radial power distribution within the refueling regions results in some localized high coolant, graphite, and fuel temperatures in a small volume of the core. The variation of the radial power peaking within the regions is represented quantitatively by the intraregion power tilt factor, $\alpha(l, r)$. In addition to the intraregion power tilt, the axial variation of the local temperature is also dependent on the variation of axial power peaking, $A(l, z)$. The unit cell model is used to calculate local channel axial coolant, graphite, and fuel temperatures within the refueling regions.

The influence of the radial region peaking factor $P(r)$, the intraregion tilt factor $\alpha(l, r)$, and the axial power peaking factor $A(l, z)$ on coolant, graphite, and fuel temperature is demonstrated below using results from the $\mathrm{BACH}$ code. Figure 7-19a depicts the axial distribution of coolant, graphite, and fuel temperatures in an average power channel $[P(r)=1.0, \alpha(l, r)=1.0]$. Corresponding temperatures in a high-temperature channel $[P(r)=1.3, \alpha(l, r)=1.4]$ are shown in Fig. 7-19b. Fuel temperatures in both these channels are low in the inlet half of the core length, and a nearly constant fuel centerline temperature is exhibited in the lower half of the core due to shaping of the axial power.

In the average-power channel, the coolant exit temperature is about equal to the core average coolant channel exit temperature, $787^{\circ} \mathrm{C}\left(1448^{\circ} \mathrm{F}\right)$. In the higher power region $P(r)=1.3$ (Fig. $7-19 \mathrm{~b}$ ), the operator will have adjusted the core flow control valves so that the coolant flow will be $30 \%$ greater than in the average power region and the measured exit temperatures will be equal to that in the average power region. However, in the local unit cell with $\alpha(l, r)=1.4$, the power is an additional $40 \%$ greater. But there is no control of flow distribution within the region, so the coolant hole in a unit cell with high intraregion power tilt will receive just a little less than the region average flow. Then the helium 


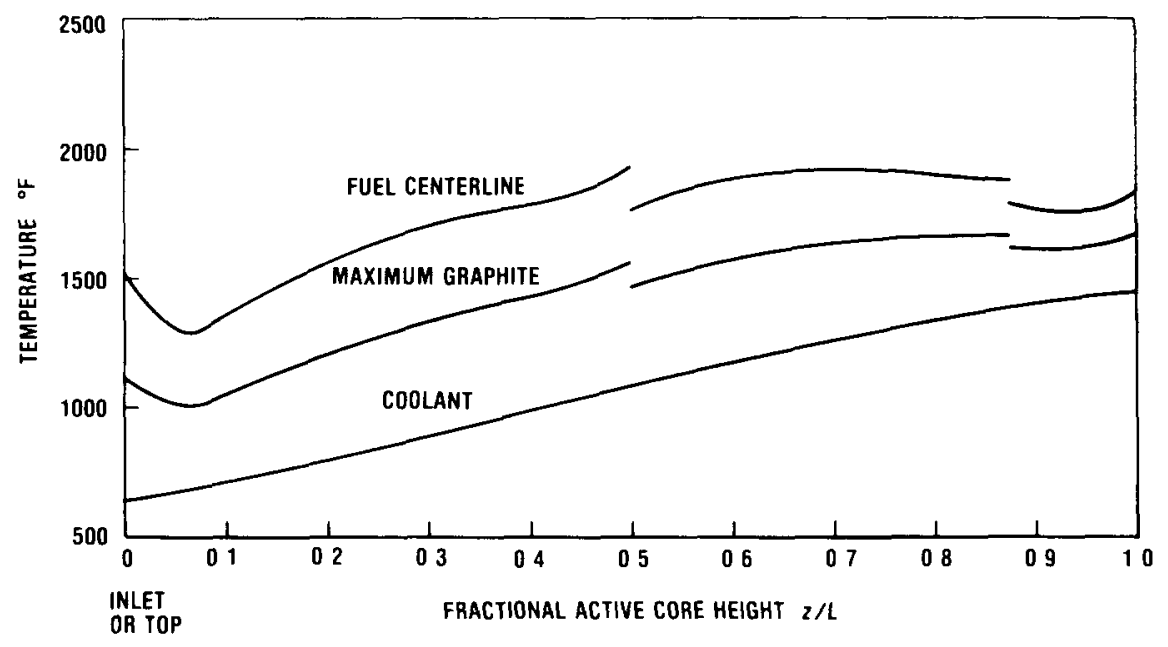

Fig 7-19a Axial distribution of coolant, graphite, and fuel temperatures in an average power channel with $P(r)=\alpha(l, r)=10$

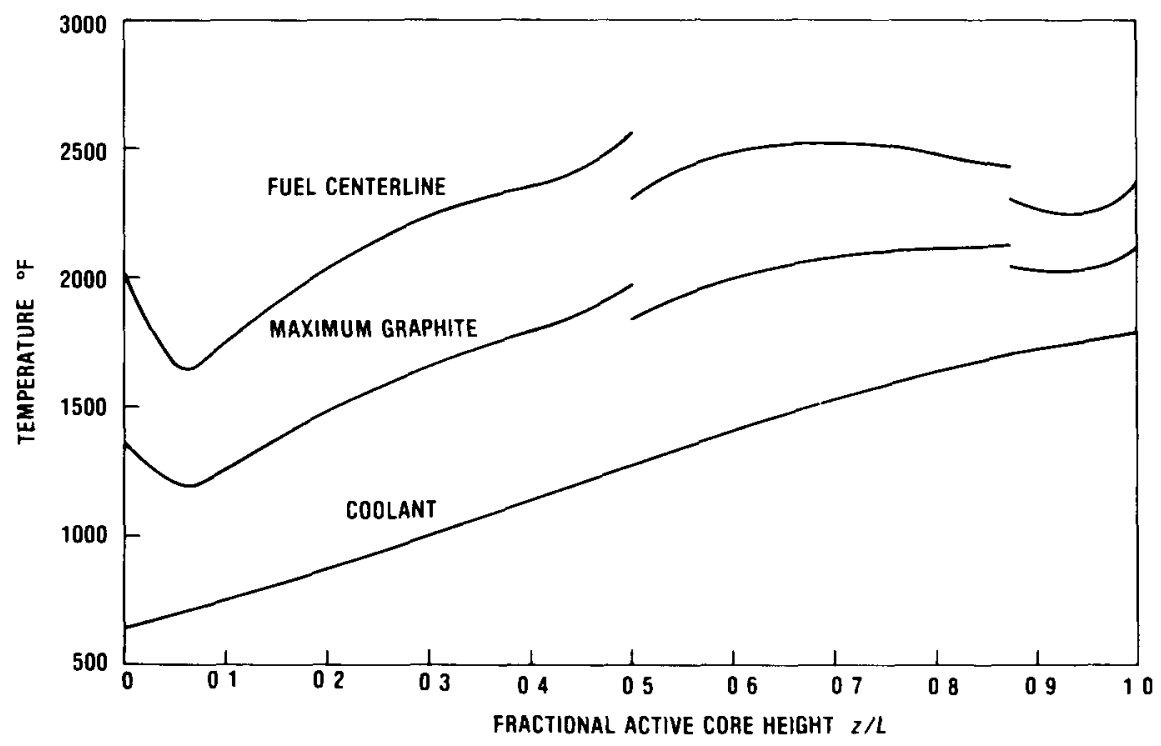

Fig 7-19b Axial distribution of coolant, graphite, and fuel temperatures in the high-temperature local channel with $P(r)=13$ and $\alpha(l, r)=14$ 
flowing in the high-temperature channel with $\alpha(l, r)=14$ will experience an $\sim 40 \%$ greater coolant temperature rise, which is seen in Fig 7-19b, and it will exit at $971^{\circ} \mathrm{C}\left(1780^{\circ} \mathrm{F}\right)$

In the high-temperature unit cell, all of the temperature rises in the fuel element are also higher than the average because the heat flux is higher The combination of higher gas temperature rise and higher solıd temperature nse yields a fuel temperature $\sim 278^{\circ} \mathrm{C}\left(500^{\circ} \mathrm{F}\right)$ greater than in the average power channel

A plot in Fig 7-20 shows the local maximum fuel centerline temperature at core midheight as a function of region peaking factor $P(r)$ and intraregion tilt $\alpha(l, r)$ These temperatures correspond to the core operatıng at rated power and the same coolant exit temperature from each region

Figure 7-20 clearly demonstrates the effectiveness of the flow control valves in controlling fuel temperature For a $60 \%$ increase in the region peakıng factor, the maximum fuel temperature increases by $\sim 178^{\circ} \mathrm{C}\left(320^{\circ} \mathrm{F}\right)$ For a similar percentage increase in the local tilt, $\alpha(l, r)$, for which there is no coolant flow control, the maximum temperature increase is nearly twice as large

Figure 7-21 presents a radial temperature distribution from the fuel centerlıne to the bulk coolant temperature at core midheight for the region with $P(r)=13$

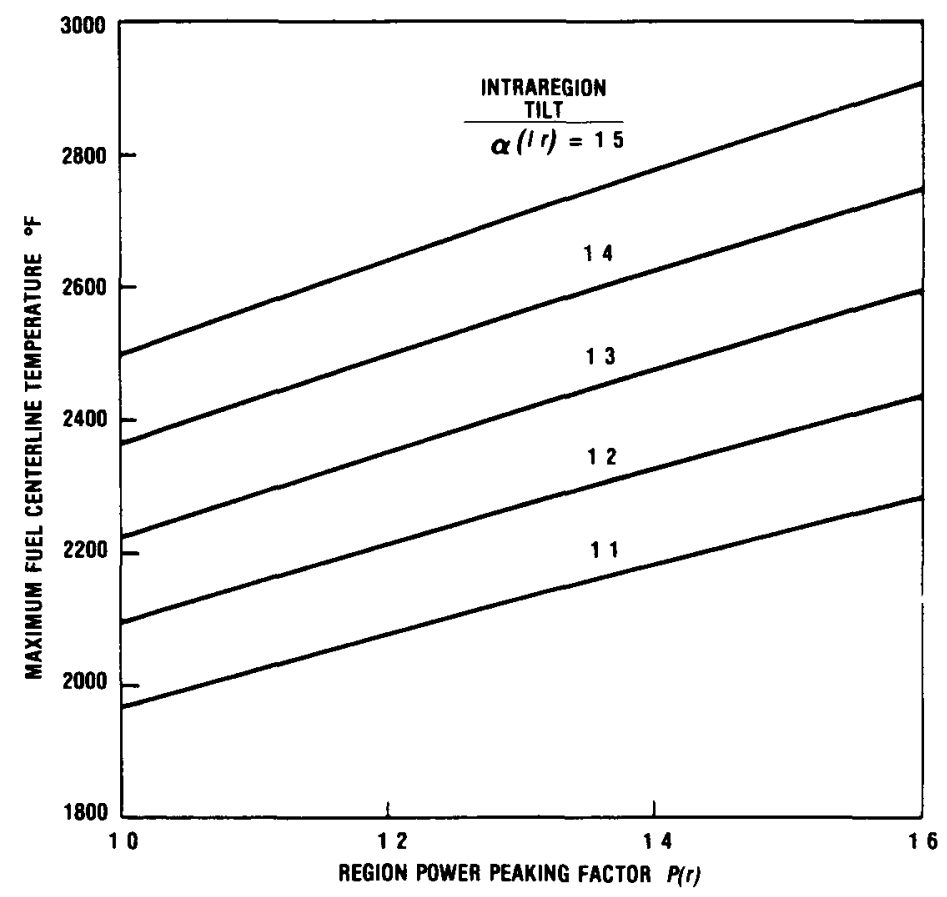

Fig 7-20 Fuel centerline temperature as a function of regıon peakıng factor and intraregıon tılt at core midheight in unrodded regions 


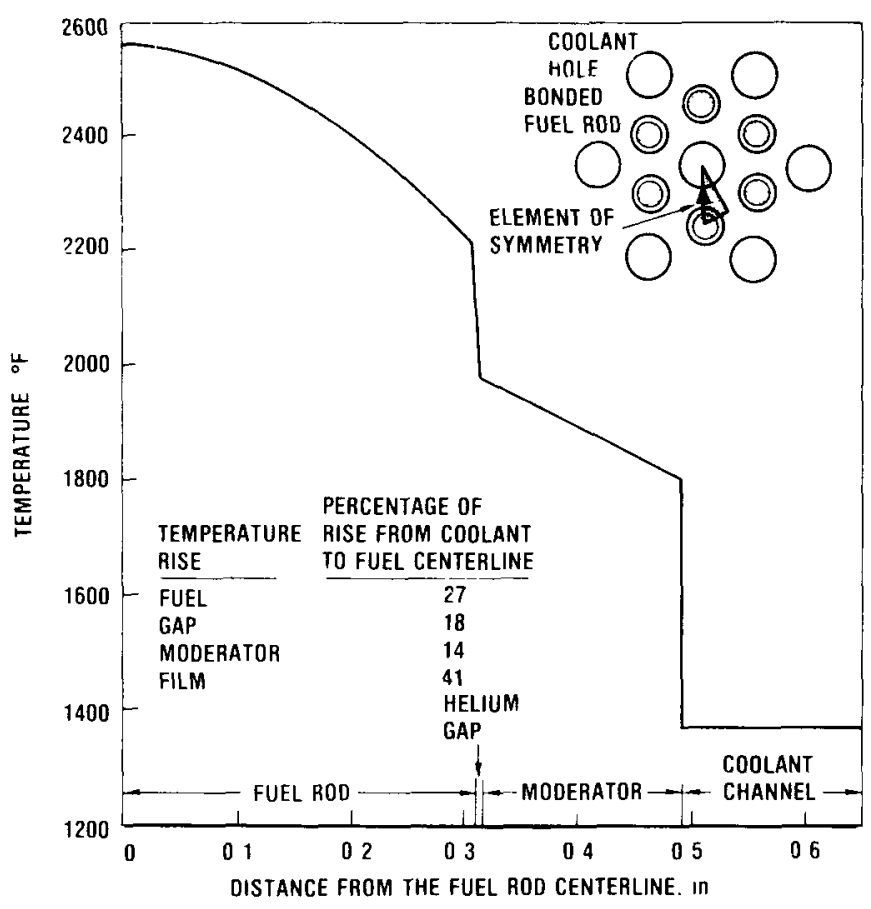

Fig. 7-21. Radial temperature profile in the high-temperature local channel with $P(r)=1.3$ and $\alpha(l, r)=1.4$.

and $\alpha(l, r)=1.4$. Under these conditions, the largest heat flow resistances are in the fuel rod and in the film.

As for the effect of axial power distribution, at full-power operation, the control rod pairs are slowly withdrawn during the last 100 days of each cycle to balance the core reactivity. As the rods are withdrawn, the region peaking factor $P(r)$ in rodded regions increases, the region's intraregion tilt $\alpha(l, r)$ tends to decrease, and the axial power shape $A(l, z)$ peaks near the lower end of the core. Figure 7-22 shows the combined effect of these power distribution changes during the withdrawal of the rod on fuel centerline temperature in a typically rodded region for four rod positions. The axial profiles for regions where rods are partially inserted are taken from Fig. 7-12.

\section{7-5C Fuel Element Temperature Distribution}

The unit cell models ignore heat flow within the fuel element. Therefore, a three-dimensional heat transfer model of the fuel element using the CINDA code ${ }^{28}$ has been used for more detailed analysis. This model, called DEMISE (Ref. 1), shows the effect of the fuel element geometry and the power distribution on temperature distribution within a fuel element. It is used to obtain detailed tem- 


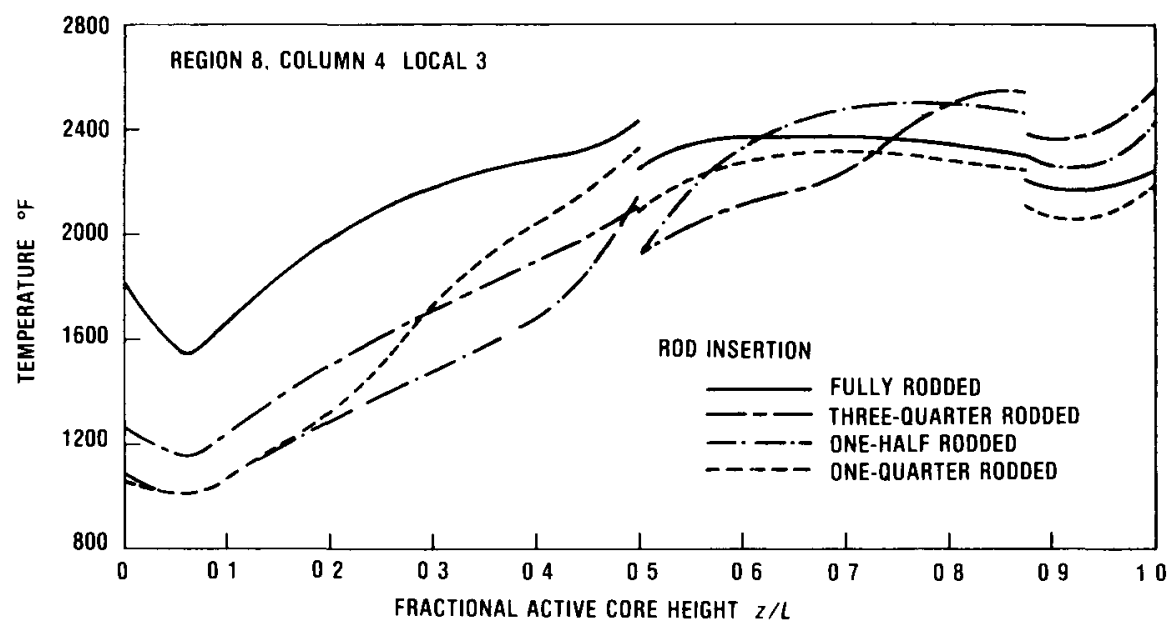

Fig. 7-22. Axial fuel temperature distribution in one-quarter, one-half, three-quarter, and fully rodded regions.

perature distributions within half-column portions of the core. It is then possible to compute the effect on fuel element temperature of variation in power across the fuel element and the effect of departure from the unit cell geometry at the edges of the fuel elements and in the area around the fuel handling hole. This code has also been used in studies to determine the amount of heat removed by the flow in the internal and external gaps and the temperature distributions in coolant flowing in these gaps. To illustrate the performance of the fuel elements under various operating conditions the following two cases are presented:

1. a column of standard fuel elements with a uniform, radially flat, power distribution operating in a region with $P(r)=1.0$ and $\alpha(l, r)=1.0$

2. a column of standard fuel elements operating in a high-power region with a tilted power distribution; the region peaking factor $P(r)=1.557$ and a maximum value of intraregion power tilt $\alpha(l, r)=1.2$.

\section{Column of Standard Fuel Elements with Flat Power Distribution}

Figure 7-23 gives fuel and coolant temperatures in a horizontal plane of onehalf of a standard fuel element at the end of the sixth axial fuel layer. The other half of the element is symmetric. Fuel rods are noted by " $F$ " nodes, coolant by " $C$ " nodes, gaps by " $G$ " nodes, and burnable poison rods by " $B$ " nodes. At this axial level, the maximum fuel temperatures occur in the central portion of the fuel element in the area near the fuel handling hole. The fuel rods in this area exhibit higher temperatures because they experience a reduction in total effective heat transfer area due to the presence of the smaller diameter $[18.2 \mathrm{~mm},(0.717 \mathrm{in})$. 


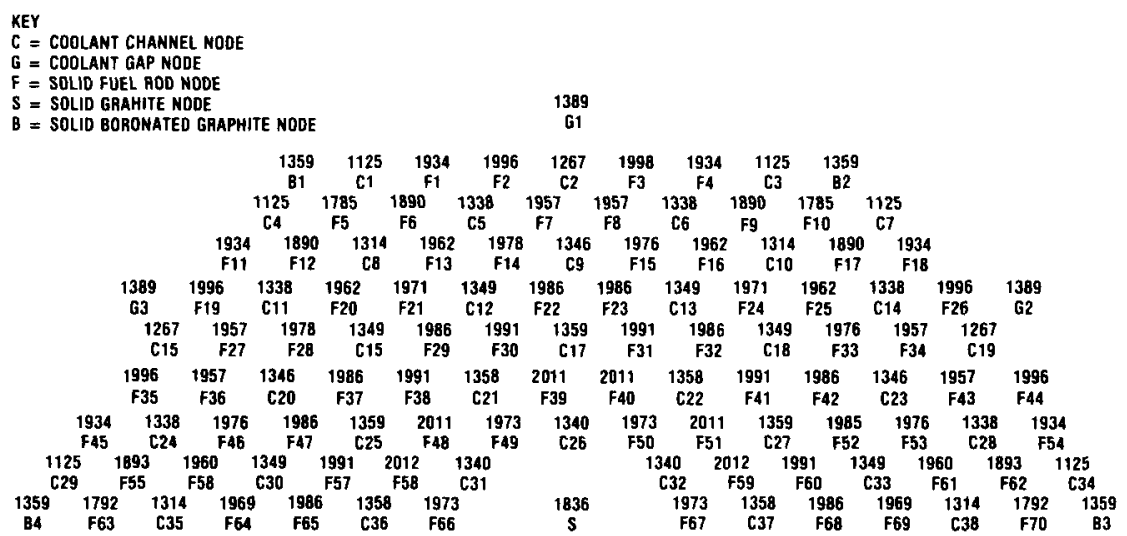

Fig. 7-23. Temperature distribution in a horizontal plane of the sixth fuel element in a standard column calculated using block average axial power and flat radial power with $P(r)=1.0$ and $\alpha(l, r)=1.0$.

coolant holes in the central portion of the element. This indicates that the diameter of these coolant holes could be increased slightly to improve the temperature distribution within the fuel element. Higher fuel temperatures are also observed at boundary fuel pins (e.g., F2 and F3).

\section{Standard Column with Tilted Power Distribution}

Results for a column of standard fuel elements located on the periphery of a region with a tilted power distribution are presented in this section. These fuel elements are representative of those that have been operating in the reactor for $1 \mathrm{yr}$. The column selected for analysis is in a region with a power factor of 1.557, and the column includes fuel rods with an intraregion tilt of 1.2. This combination is close to the maximum power conditions at rated power observed in the reactor.

Lines of constant power tilt are shown in Fig. 7-24. Values of $\alpha(l, r)$ for each fuel rod were taken from the top half of the column and used along with the region power factor, the total mass flow for the half-block, and the proper axial power profile. The temperatures calculated for the upper half of the column are shown in Fig. 7-25 at the end of the fourth fuel block. The highest fuel temperatures occur at the boundary of the fuel element because the fuel rods with the highest intraregion tilts are located there. The maximum fuel temperature is $1426^{\circ} \mathrm{C}\left(2600^{\circ} \mathrm{F}\right)$ compared to $1121^{\circ} \mathrm{C}\left(2050^{\circ} \mathrm{F}\right)$ for the column in Fig. $7-24$ with $P(r)=\alpha(l, r)$ $=1$. Fuel temperatures are lower at points closer to the central portion of the fuel element since the tilt decreases radially inward.

\section{7-5D Transient Thermal Analysis}

Transients for which the HTGR is designed are divided into several categories depending on their expected frequency or probability of occurrence as described 


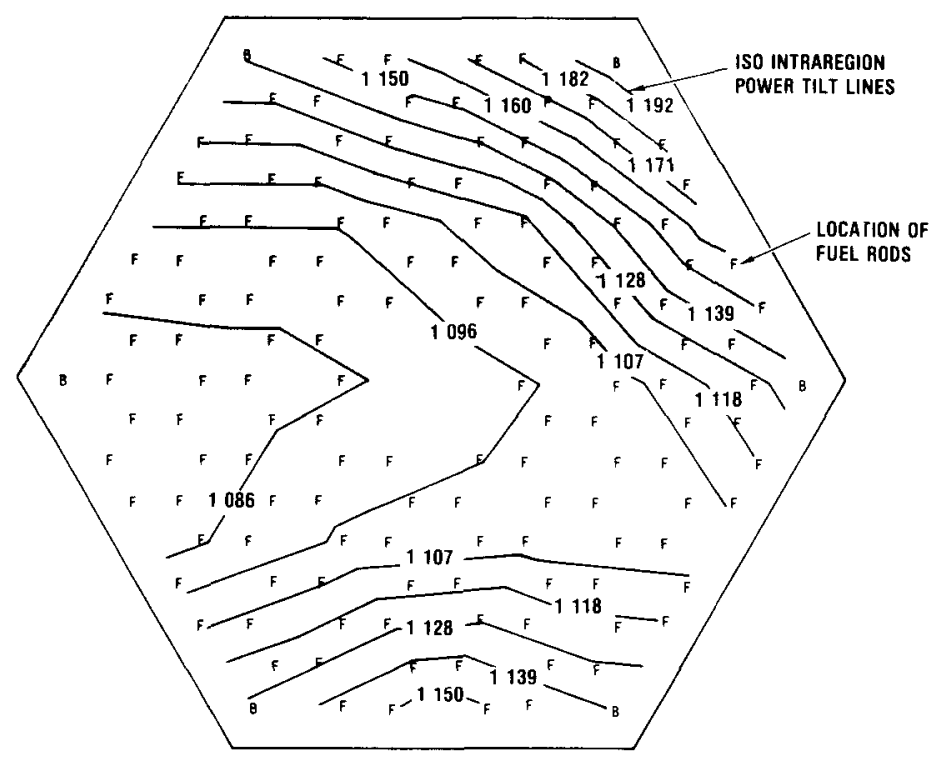

Fig. 7-24. The BUGTRI radial power distribution in column 5 of region 25 at the end of reload 2.

KEY

$C=$ COOLANT CHANNEL NODE

$G=$ COOLANT GAP NODE

$F=$ SOLID FUEL ROD NODE

$S$ = SOLID GRAPHITE NODE

$B=$ SOLIO BORONATED GRAPHITE NODE

136

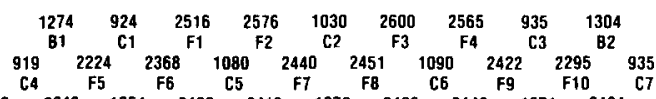

$2460{ }_{2340}{ }_{1054}{ }_{2400}{ }_{2419}{ }_{1076}{ }_{2438}{ }_{2442}{ }_{1071}{ }_{2424}{ }_{2567}$

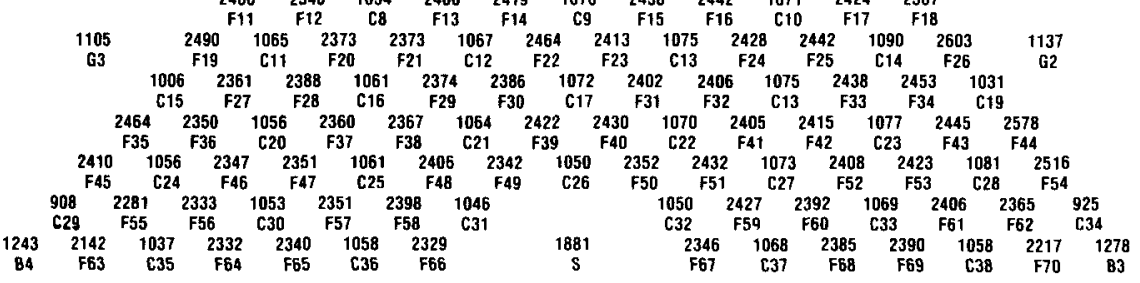

Fig. 7-25. Temperature distribution in a horizontal plane of the fourth fuel element in a standard column operating in a high-power region with a tilted power distribution with $P(r)=1.557$ and $\alpha(l, r)=1.199$.

in Chapter 6. Table 6-VI summarizes the normal, upset, emergency, and faulted transients for which the HTGR is designed. Of the normal transients in Table 6-VI, the first four (startup and shutdown) are sufficiently slow, compared to the thermal time constant of the core, so that the thermal analysis can be performed using steady-state codes. The remaining normal transients are faster and require 
transient thermal analysis. The upset transient in Table 6-VI results in fuel temperatures that are lower than the normal transients discussed above. ${ }^{11}$ The emergency and faulted transients can result in some high core average fuel temperatures but they are not expected to occur frequently and, in general, result in lower fuel temperatures when the appropriate corrective action is taken. Emergency and faulted transients are discussed in Sec. 15 of Ref. 11.

For normal operating transients, the peak temperatures occur during a transient that results in a simultaneous increase in core power-to-flow ratio and a perturbation in core radial and axial power distributions. Plant transients that include all of these effects and result in local fuel temperatures above steady state are the load-following transients. The transient presented is a 100-60-100\% loadfollowing transient with a $5 \% / \mathrm{min}$ return to full load after the $60 \%{ }^{135} \mathrm{Xe}$ concentration in the fuel has reached steady state.

The plant response for a 100-60-100\% load-following transient is shown in Figs. 7-26, 7-27, and 7-28 as calculated by the plant transient code TAP. The load reduction at $5 \% / \mathrm{min}$ begins at $100 \mathrm{~s}$ and continues until $60 \%$ load is achieved. The $60 \%$ load condition is maintained for $1000 \mathrm{~s}$ to allow the system to equilibrate thermally, and then the return to full load begins at $1580 \mathrm{~s}$. The main and reheat

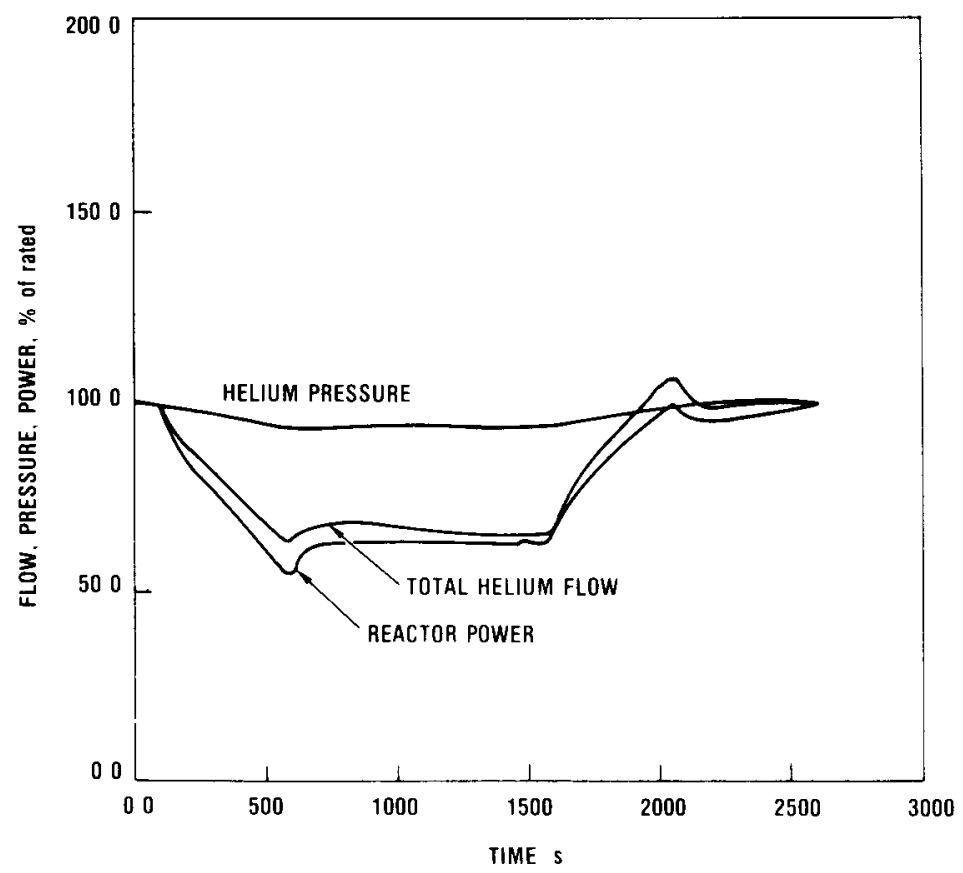

Fig. 7-26. Time history of core power, flow, and helium pressure during a 100-60-100 loadfollowing transient. 

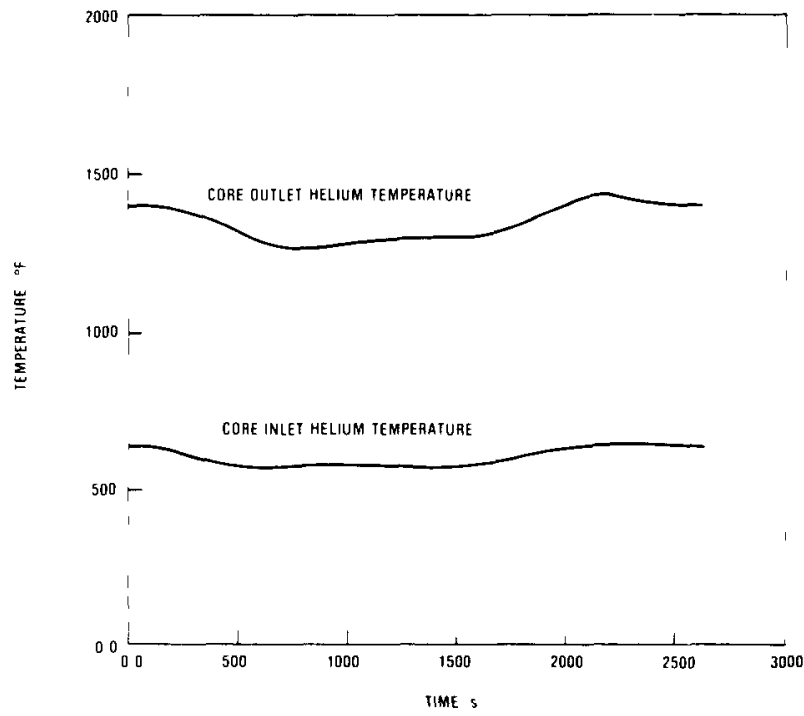

Fig. 7-27. Time history of core helium inlet and outlet helium temperatures during a 100-60100 load-following transient.

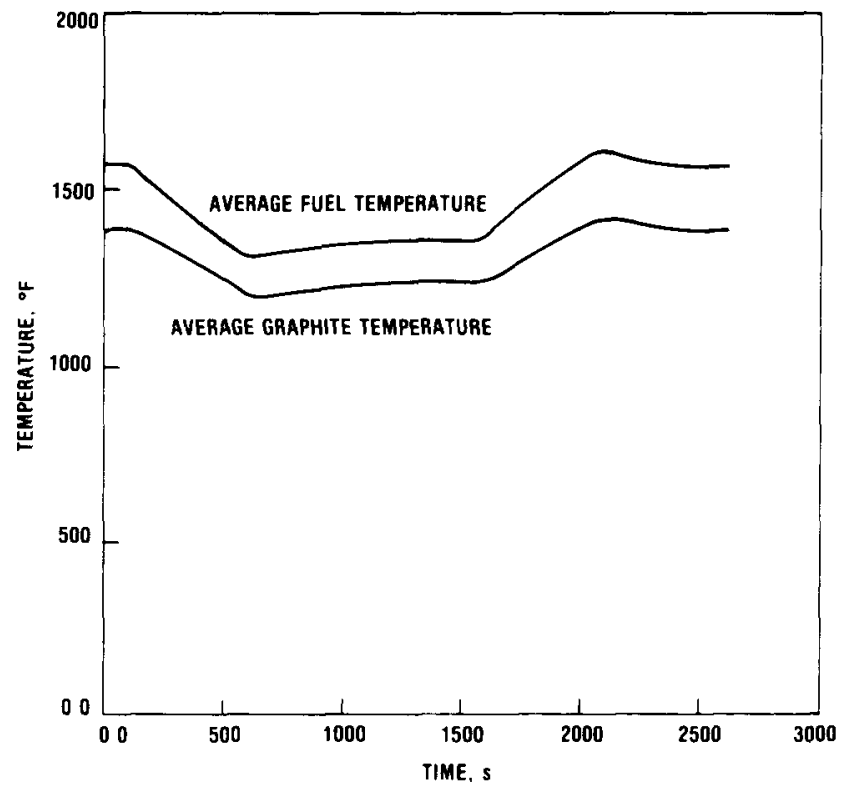

Fig. 7-28. Time history of core average fuel and graphite temperatures during a 100-60-100 load-following transient. 
steam flows follow the load requirement during the transient. The power undershoot during the load decrease and overshoot during the load increase drive the volume average fuel temperature (Fig. 7-28) such that the total energy removal from the reactor core is sufficient to deliver the required steam conditions.

The major system transient response parameters obtained from the TAP computer code, including the core-average graphite and fuel temperatures, are used to obtain the core reactivity changes due to temperature. The iodine-xenon transient equations are solved for the ${ }^{135} \mathrm{Xe}$ component of reactivity. To evaluate the performance of graphite and fuel components during the transient, a detailed thermal analysis of the core is required that includes the effect of changes in local radial and axial power distribution. Detailed transient analyses are performed to evaluate the short-term coolant, graphite, and fuel temperature increases above the steady-state conditions.

\section{7-5E Core Response to Accidents}

The HTGR core responds particularly well to accidents involving reduced cooling because of the large core heat capacity and the use of a single-phase coolant. This can be illustrated by looking at an accident involving the loss of primary system coolant pressure. This hypothetical accident is referred to as the design-basis depressurization accident (DBDA). The DBDA can occur only in the extremely unlikely case of multiple failures in the structure of a large closure of the PCRV.

Assuming a failure in the largest penetration, the primary coolant pressure would decrease rapidly, attaining atmospheric pressure in just over $100 \mathrm{~s}$. The reactor would trip because of reduced coolant pressure after $10 \mathrm{~s}$ and the main circulator speed would reduce to $4 \%$ of its rated value in $100 \mathrm{~s}$. Under these conditions, the main circulator can operate on nuclear steam for $\sim 10 \mathrm{~min}$.

During the time when the main circulator is operating, the core behaves as shown in Fig.7-29. Following the reactor trip at $10 \mathrm{~s}$, the power generation falls quickly to afterheat level. Steep temperature gradients in the fuel rod and graphite seen in Fig. 7-21 disappear within a few minutes and the graphite and fuel temperatures become nearly equal. As heat flows from the hotter fuel rod to the cooler graphite, the fuel temperatures fall $\sim 166^{\circ} \mathrm{C}\left(300^{\circ} \mathrm{F}\right)$ and the graphite temperature increases by $\sim 55^{\circ} \mathrm{C}\left(100^{\circ} \mathrm{F}\right)$. This redistribution of sensible heat within the fuel elements reduces the temperature of the particle coating (fission product barrier) by $\sim 166^{\circ} \mathrm{C}\left(\sim 300^{\circ} \mathrm{F}\right)$. Because of the large flow reduction and increase in the graphite temperature, the average exit temperature increases $\sim 28^{\circ} \mathrm{C}\left(\sim 50^{\circ} \mathrm{F}\right)$.

If auxiliary steam is available or if the core auxiliary cooling system (CACS) is started, the fuel temperature and hot helium temperature remain hundreds of degrees below the values expected to cause damage (see Table 6-VIII). However, if it is assumed that after 10 min the main circulators stop and the CACS startup is delayed, then the core temperature will only increase very slowly because of the large core heat capacity. The heat capacity of all the fuel elements in the 


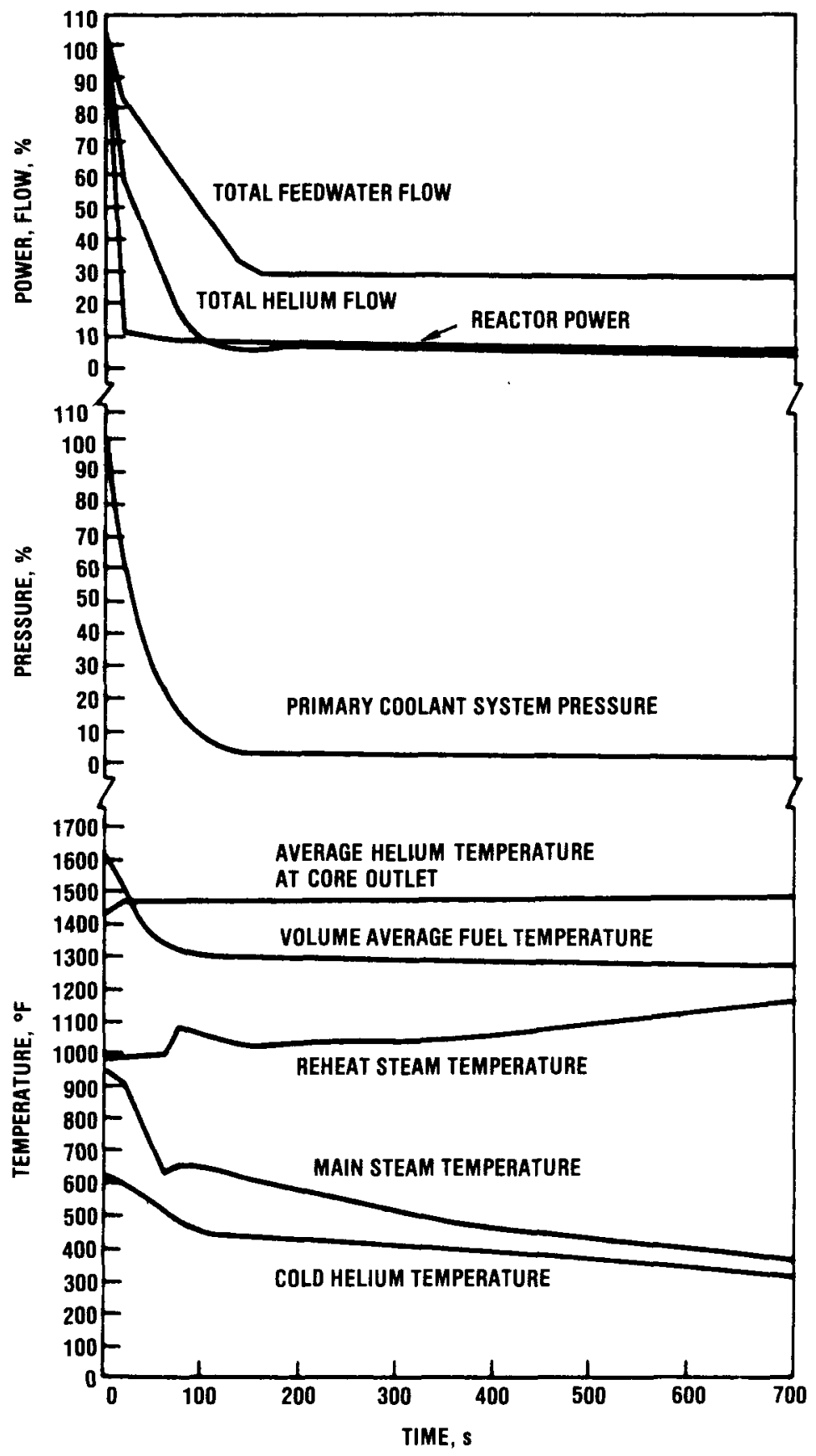

Fig. 7-29. Main loop cooling performance following a DBDA at a 3000-MW(t) plant. 
$3000-\mathrm{MW}(\mathrm{t})$ core is $\sim 760 \mathrm{MW}-\mathrm{s} /{ }^{\circ} \mathrm{C}\left(1420 \mathrm{MW}-\mathrm{s} /{ }^{\circ} \mathrm{F}\right)$. At this rate of core temperature increase, startup of the CACS can be delayed 4 to $5 \mathrm{~h}$ before any fuel damage would occur. But, because the lower thermal barrier is sensitive to extended exposure to gas at temperatures exceeding $1100^{\circ} \mathrm{C}\left(2000^{\circ} \mathrm{F}\right)$ the CACS must be restarted in 2 to $3 \mathrm{~h}$ to avoid damage to this thermal barrier.

Even though the core responds slowly to reduced cooling accidents, fuel temperature responses to fast reactivity accidents can be quite rapid as is illustrated for rod withdrawal accidents in Ref. 11 .

\section{7-6 Time-Temperature History}

A number of important phenomena affecting the performance of the fuel elements, the integrity of the fuel particle coatings, the stresses in the fuel element graphite, and the release of metallic fission products from the core are dependent on the long-term history of core temperature, fast neutron fluence, and burnup of fissionable material. Reference 3 describes the fuel particle behavior quantitatively in terms of these core environmental parameters, Ref. 29 the fuel element stresses, and Ref. 30 the behavior of metallic fission products. Dimensional changes in graphite and fuel rods and progressive oxidation of graphite and metallic fission product transport in the fuel elements ${ }^{1,11}$ are time and temperature dependent. Fuel temperatures are calculated during the design which allow a survey of the entire core to find areas where design parameters are near their limits and, therefore, where more careful attention to local effects is merited. The TREVER code ${ }^{1}$ was developed to carry out the temperature survey of the entire core quickly, using simple but accurate approximations. Capability has been included in the TREVER code to facilitate the use of temperature histories in order to define fuel particle coating failure, fuel element stresses, and fission products release.

Time-dependent thermal analysis. The TREVER code is based on quasisteady thermal models. Time-dependent conditions are determined by changing the flow and heat transfer geometry as core dimensions change during operation. In addition, the power distribution is changed by fuel burnup and control rod motion and core material thermal properties are changed due to fast neutroninduced changes. These latter effects are factored into the TREVER code.

The heat transfer model used in the TREVER code is the one-dimensional unit cell model also used in the BACH code ${ }^{31}$ and described in Sec. 7-5A.

For steady-state rated-power operation, temperature history calculations are made for coolant, graphite, and fuel components at numerous locations within the core. The spatial resolution of these survey calculations depends on the mesh size of the nuclear code used to calculate the fission and fast neutron history. In the following example, the nuclear data were calculated by the GAUGE code, ${ }^{8}$ which uses a mesh size of one-sixth of a fuel element. To illustrate the fuel temperature behavior, a typical high-temperature fuel channel is presented in Fig. 7-30. Complete 4-yr histories of the fuel centerline temperature, fuel hole surface graphite temperature, coolant helium temperature, and fuel rod surface temperature gradient 


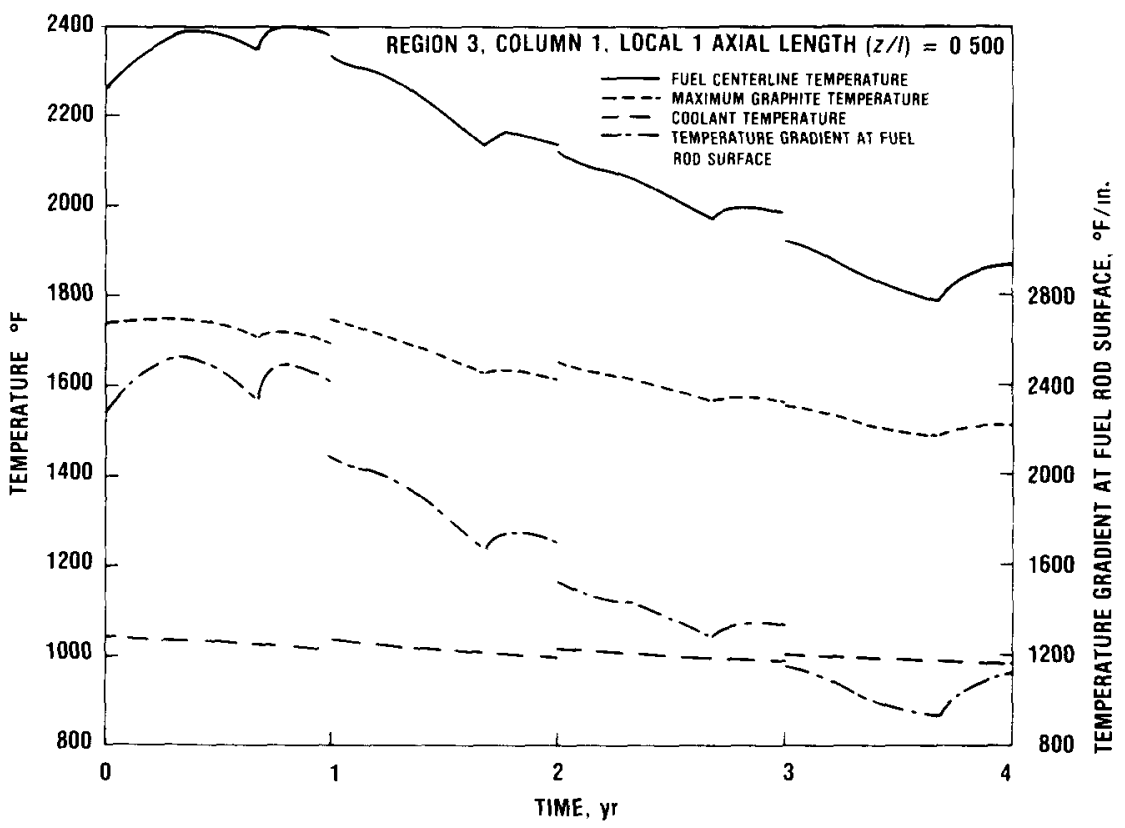

Fig. 7-30. Temperature histories in a typical unrodded region adjacent to a rodded region.

are shown for an unrodded region. These temperatures are plotted for the axial location having maximum fuel temperatures and are typical of an equilibrium cycle.

The temperature histories in Fig. 7-30 are for a typical fuel rod stack in an unrodded region adjacent to a rodded region. The region shown, region 3 , is located near the center of the core in the first ring of refueling regions (see Fig. 7-2). The abscissa indicates the time since the region was reloaded. The fuel temperature increases slowly during the first 125 days (an $80 \%$ load factor is assumed for all data presented) as the burnable poison is depleted. This is followed by a slight radial shift in power from the center of the core toward the periphery. This radial shift at 125 days into the initial annual cycle occurs as a result of the radial zoning of the fuel and burnable poison. This shift in power toward the core periphery and depletion of the fuel tends to cause the rates of temperature change to decrease slightly. At $\sim 200$ days into the cycle interval, the operator begins to withdraw the control rods from the core. As the rods are withdrawn, the power level and temperatures increase in regions near the rodded regions.

This same general pattern of temperature behavior is repeated for subsequent reload intervals. However, the burnable poison in a region is essentially depleted after the region's first year in the core. Continued depletion of the fissile material tends to cause the fuel temperature pattern to exhibit a slight downward trend with time. But as the fuel depletes, the power density decreases, which in turn results 
in a decrease in the rate of depletion. Hence, during the last year of the 4-yr cycle, the fuel temperature is relatively constant except for the perturbation resulting from the motion of control rods. During the 4-yr history, the graphite and fuel temperatures slowly decrease while the coolant temperature is held relatively constant by the adjustment of flow control valves.

From detailed core survey calculations including all regions of the core, the following general conclusions can be made:

1. The initial core has relatively low temperatures that only change gradually at all locations of the core.

2. The regions that are loaded at the end of the first year have higher temperatures as a result of higher "age peaking."

3. In general, the highest temperatures are experienced during the first year of the fuel's life in the core, then there is a gradual decline in temperature throughout the remaining $3 \mathrm{yr}$.

4. In various locations of the core, significant and discontinuous temperature reductions occur at the end of each year as a result of shifts in power caused by refueling of adjacent regions.

5. The impact of both radial and axial power distribution caused by control rod motion is most apparent in rodded regions, and also to a lesser extent in regions adjacent to rodded regions. Even the regions near the core boundary experience a small radial perturbation of local power due to control rod motion near the center of the core.

6. During the part of the year when the shim rods are being withdrawn, fuel temperatures increase in the bottom portion of the partially rodded region as a result of the rod-induced axial power shift.

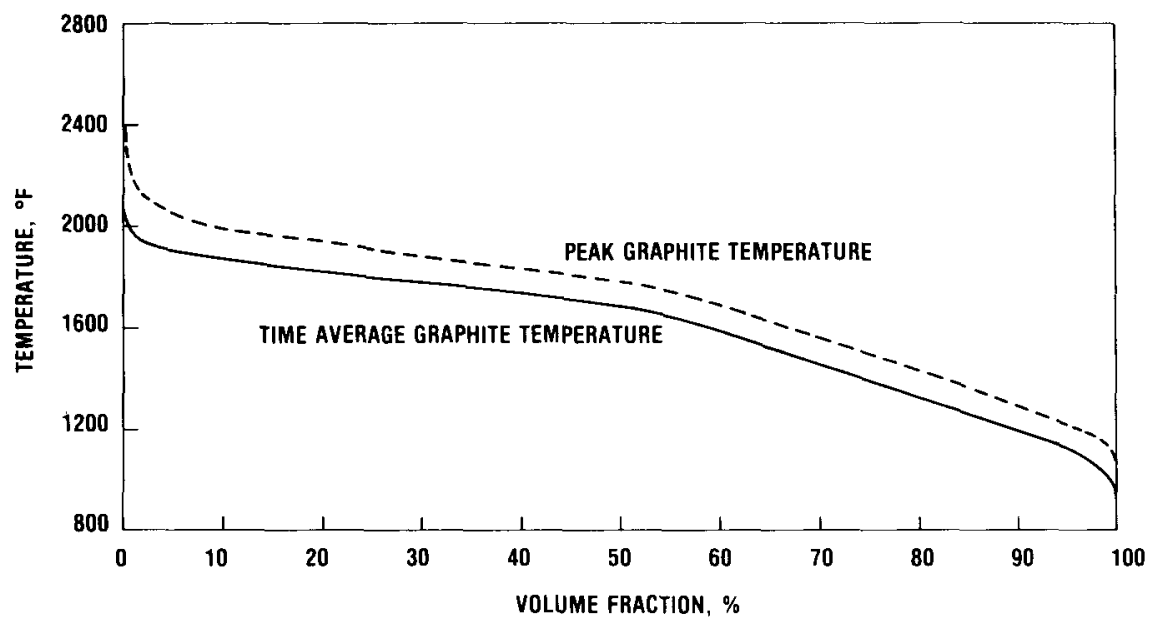

Fig. 7-31. Volume distribution of peak and time-average temperatures of graphite in segment 5 . 
Temperatures of fuel rods and fuel element graphite throughout the core are relatively uniform for a core with a $415^{\circ} \mathrm{C}\left(750^{\circ} \mathrm{F}\right)$ coolant temperature rise and a factor of 35 variation in local power density in the fuel rods Figure 7-31 shows the distribution of lifetıme peak values of graphite temperature and graphite tımeaveraged temperature The time-averaged temperature for the largest portion of the graphite is within $870 \pm 140^{\circ} \mathrm{C}\left(1600 \pm 250^{\circ} \mathrm{F}\right)$ Peak graphite temperatures are 110 to $165^{\circ} \mathrm{C}$ ( 200 to $300^{\circ} \mathrm{F}$ ) higher than the time-averaged values The peak temperature curve shows the fraction of the graphite whose peak temperature exceeds $1093^{\circ} \mathrm{C}\left(2000^{\circ} \mathrm{F}\right)$, that is, the peak temperature of $<10 \%$ of the graphite exceeds $1093^{\circ} \mathrm{C}\left(2000^{\circ} \mathrm{F}\right)$

\section{NOMENCLATURE}

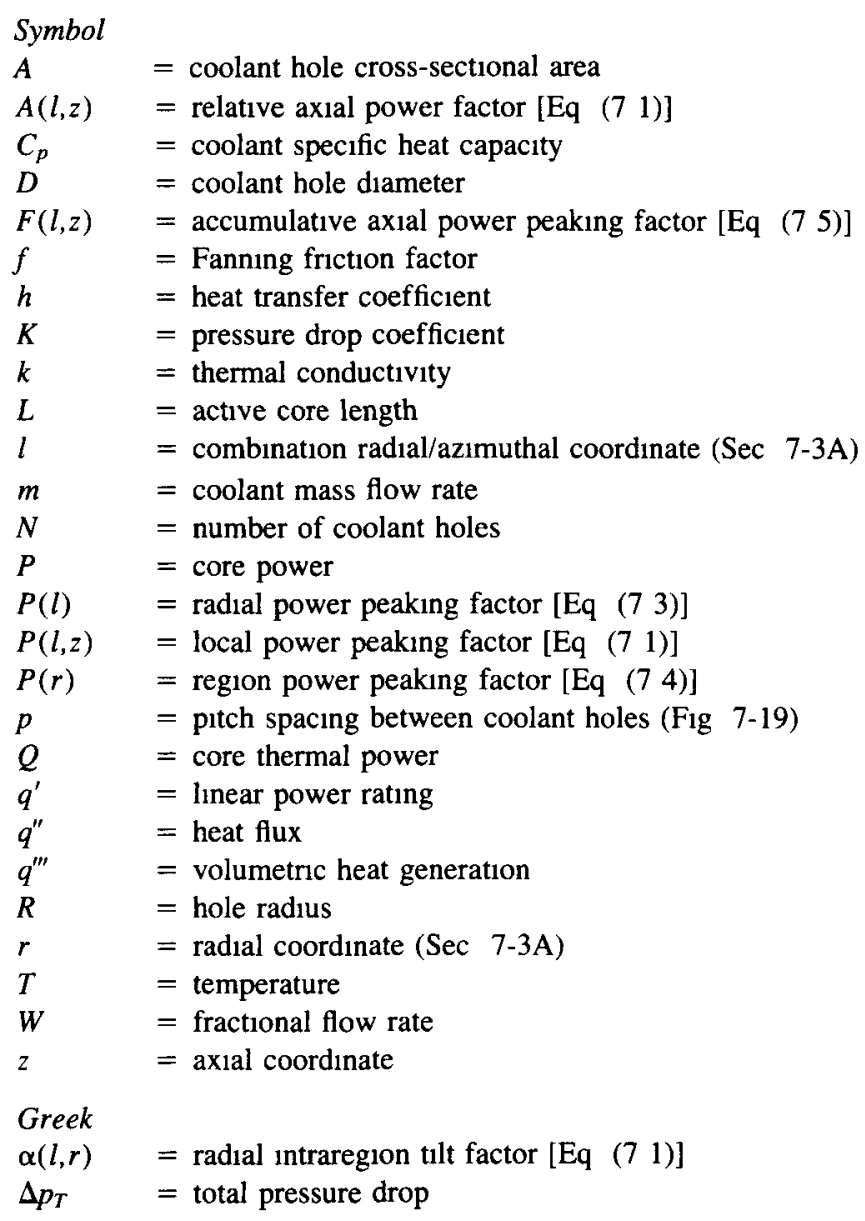



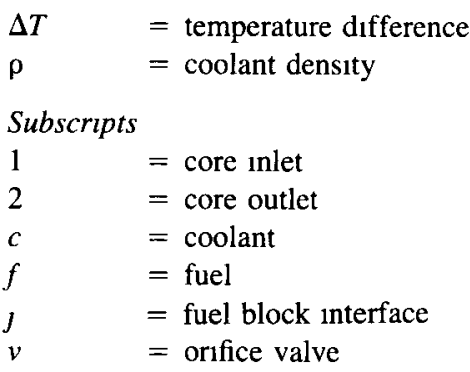

Superscript

- $\quad=$ average

\section{REFERENCES}

1 A S Shenoy and D W McEachern, "HTGR Core Thermal Design Methods and Analysıs," GA-A12985, GA Technologies (Dec 31, 1974)

2 C J Hamilton, "HTGR Power Distributions," GA-A13007, GA Technologies (Dec 1974)

3 C L Smith, "Fuel Particle Behavior Under Normal and Transient Conditions," GAA12971, GA Technologies (Oct 1974)

4 M J Haire and D W McEachern, "Gaseous Radioactivity Levels in the Primary Coolant of an HTGR,' GA-A12946, GA Technologies (Oct 1, 1974)

5 R C Dahlberg, R F Turner, W V Goeddel, "HTGR Fuel and Fuel Cycle Summary Description," GA-A12801 (revision), GA Technologies (Jan 21, 1974)

6 M H Merrill and R K Lane, "Medium-Enniched Uranium/Thorium Fuel Cycle Parametric Studies for the HTGR," GA-A 14659, GA Technologies (Dec 1977)

7 R Kraetsch and M R Wagner, "GATT A Three-Dimensional Few-Group Neutron Diffusion Theory Program for a Hexagonal-3 Mesh,' GA-8547, GA Technologies (Jan 1, 1969)

8 M R Wagner, "GAUGE A Two-Dimensional Few-Group Neutron Diffusion-Depletion Program for a Unıform Triangular Mesh,' GA-8307, GA Technologies (Mar $15,1968)$

9 F W Todt and L J Todt, "FEVER/M1 A One-Dimensional Program for Reactor Fuel Cycle Analysıs,' GA-9780, GA Technologies (Oct 22, 1969)

10 J P Dorsey, R Froelich, and F W Todt, "BUG-2/BUGTRI Two-Dimensional Multigroup Burnup Codes for Rectangular and Hexagonal Geometry," GA-8272, GA Technologies (Aug 22, 1969)

11 "GASSAR General Atomic Standard Safety Analysıs Report," GA-A13200, GA Technologies (1975)

12 P A Iyer and J Sauerwein, "Individual Component CEA Tests-Analysıs Report," GA-A13906, GA Technologies (June 1, 1976)

13 P A lyer and D W Doll, "Development of Flow Control Valve and Plenums for the HTGR Core,' GA-A13863, GA Technologies (Oct 8, 1976)

14 P A Iyer, "Evaluation of Performance of Fixed Area Port Plenum Elements from SCL-1 Test,' GA-A14403, GA Technologies (Apr 14, 1977) 
15 P A Iyer, "Evaluation of Performance of Flow Control Valves and Plenum Elements from SCL-1 Tests," GA-A14708, GA Technologies (Jan 1978)

16 P A Iyer, "Evaluation of the Refueling Region Pressure Drop Characteristics from SCL-1 Test," GA-A14733, GA Technologies (Feb 1978)

17 P A Iyer, "Evaluation of Control Rod Flow Performance from SCL-1 Test," GAA14280, GA Technologies (Mar 1978)

18 P A Iyer, "Evaluation of the Performance of Bottom Reflector and Core Support Blocks from SCL-1 Tests,' GA-A14784, GA Technologies (July 1978)

19 J-C LeMaitre, "Crossflow Between Two HTGR Blocks Test Procedure and Final Test Report,' CEA EMT/SYST/TCR/80/F E 525050000 054, Commıssariat á l'Energie Atomique (Apr 1981)

20 G J Malek, "Development of the Flow Analysis Code FLAC," GA-9482, GA Technologies (June 1969)

21 D H Welty, "SPIFFS Single-Phase Non-Isothermal Fluid Flow Simulator," P-1380038, Shell O1l Co (Aug 1973)

22 G M Baccaglın, "SNIFFS Single-Phase Non-Isothermal Fluid Flow Simulator, User's Manual," GA-A14501, GA Technologies (June 1977)

23 G M Baccaglını, "Verification of the SNIFFS Computer Code," GA-A14703, GA Technologies (Oct 1977)

24 G M Baccaglın, "SNIFFS Single-Phase Non-Isothermal Fluid Flow Simulator, Computer Program Manual,' GA-A14736, GA Technologies (Jan 1978)

25 D P Harry, "A Steady-State Analysis of the Laminar-Instability Problem Due to Heatıng Para-Hydrogen in Long, Slender Tubes," NASA-TND-2084, Natıonal Aeronautics and Space Administration Lewis Research Center (Feb 1964)

26 C A Bankston, "The Transition from Turbulent to Laminar Gas Flow in a Heated Tube,' J Heat Transfer, 92, 569 (Nov 1970)

27 E Reshotko, "An Analysis of the Laminar-Instability Problem in Gas-Cooled Nuclear Reactor Passages," AIAA J , 5, 9, 1606 (Sep 1967)

28 D R Lewis et al , "CINDA-Chrysler Improved Numerical Differencing Analyzer," TN-AP-67-287, Chrysler Corp Space Division (Oct 20, 1967)

29 P D Smith and P Y Tang, "The Isolation and Analysis of Critical Stress Areas in Graphite Fuel Elements," Trans 4th Int Conf Structural Mechantcs and Reactor Technology, San Francisco, Calıfornia, August 14-20, 1977, paper D 5/2 (1978)

30 D Alberstein et al , "Metallic Fission Product Release from the HTGR Core," GAA13258, GA Technologies (May 15, 1975)

31 H Fenech, "Heat Transfer and Fluid Flow in Nuclear Systems," pp 346-347, Pergamon Press (1981) 


\section{8 \\ THE HTGR GAS TURBINE*}

\section{8-1 Introduction}

Ever since the onset of the development of nuclear reactors for energy production, especially reactors using a gaseous coolant, the idea of the use of a closed-cycle gas turbine to provide the power conversion function for a gas-cooled reactor has appeared attractive to many engineers It was realistically recognized, however, that introduction of a new heat source and prime-mover would be a formidable task, and accordingly, initial deployment of the high-temperature gascooled reactor (HTGR) in the United States and Europe was based on a state-ofthe-art steam turbine power conversion system With successful demonstration of the initial HTGR systems (1 e , Dragon, Peach Bottom I, and AVR) and a seemingly establıshed market for large commercial HTGR steam cycle plants, groups of advanced technology engineers directed their attention to the study of the nuclear gas turbine ${ }^{1}$

During the 1970s, design studies, assessments, and evaluations were carried out on an advanced direct-cycle HTGR option The motivation for this effort included furthering the exploitation of an increased reactor outlet temperature (above the current $700^{\circ} \mathrm{C}$ value) to achieve high efficiency, taking full advantage of the favorable Brayton cycle characteristics related to economic dry-cooling capabilities, examıning the potential for very high efficiency in a combined-cycle mode, and examınıng projected plant sımplifications and their attendant economic benefits

As with all advanced technology endeavors, several iterations were required to establish a reference $800-\mathrm{MW}$ (e) plant concept, and this chapter outlines these systems and design iterations with particular emphasis on thermal-hydraulic considerations

\section{8-1A HTGR Deployment}

This chapter is not intended to explain the characteristics of the HTGR, since these have been covered previously, ${ }^{2}$ but rather to outline the currently perceived

*This chapter was contributed by Colın F McDonald 
deployment strategy to put the role of the gas turbine (HTGR-GT) plant into perspective.

The aforementioned design studies led to the following conclusions in 1980:

1. Extensive development was necessary to establish a technically viable HTGR-GT plant to satisfy demanding safety and licensing criteria.

2. New cycle studies and innovation were necessary to identify features for improved economics.

3. The study findings were not regarded as being consistent with the goal of having a commercial-size HTGR plant operational in the mid-1990s.

Accordingly, the steam cycle HTGR (HTGR-SC/C) was designated as the lead plant and the HTGR-GT classed as a long-term, advanced technology, follow-on HTGR plant option. Figure 8-1 shows the evolution of the HTGR and portrays advancement to the more complex high-temperature systems in an orderly manner. Following the initial deployment of the HTGR-SC/C plant with a reactor outlet temperature on the order of $700^{\circ} \mathrm{C}\left(1292^{\circ} \mathrm{F}\right)$, Fig. 8-1 shows that the more advanced systems such as the gas turbine and process heat applications require a higher temperature of $\sim 850^{\circ} \mathrm{C}\left(1562^{\circ} \mathrm{F}\right)$. These conditions are beyond current technology in terms of material behavior for commercial life components. As pointed out

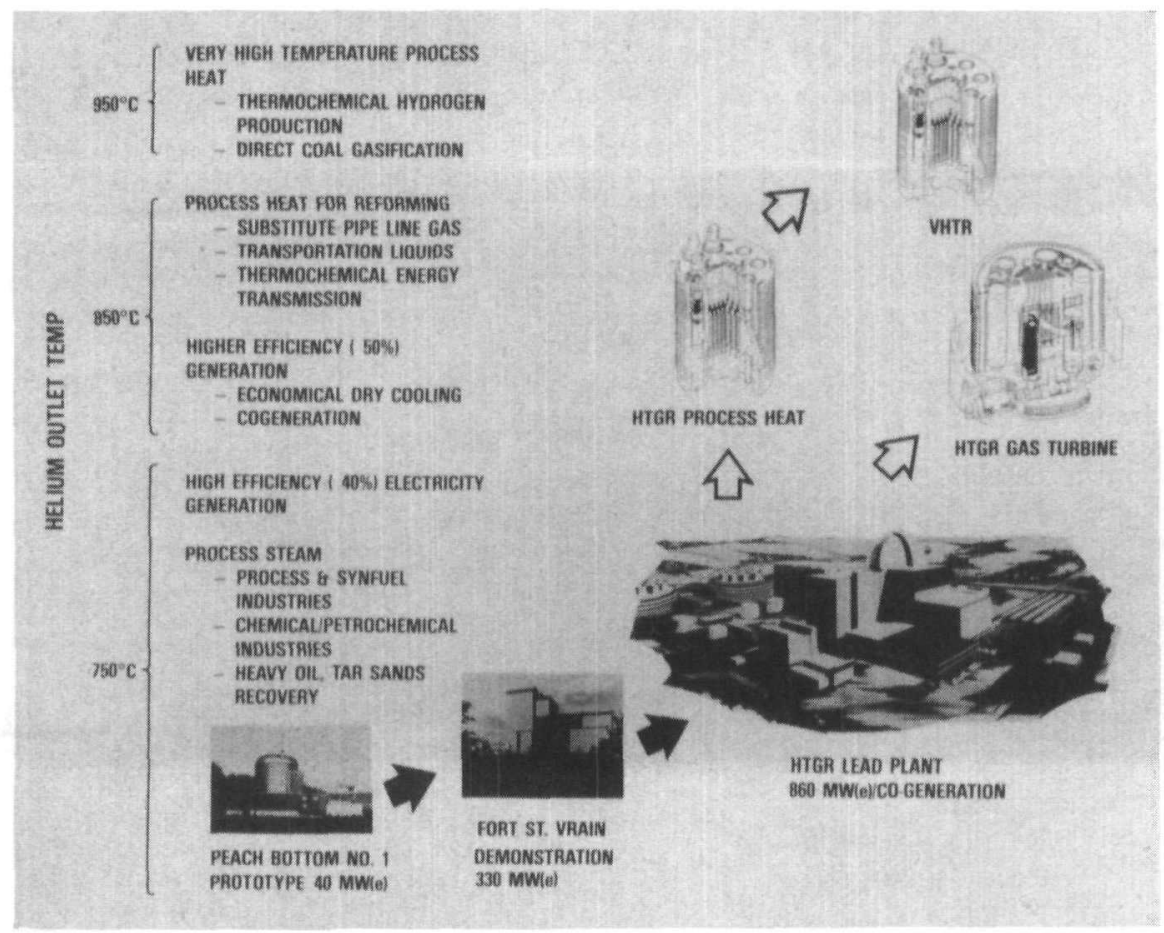

Fig. 8-1. HTGR systems and national energy roles. 
later in this chapter, the gas turbine can take advantage of considerably higher temperatures; up to $1000^{\circ} \mathrm{C}\left(1832^{\circ} \mathrm{F}\right)$. At this temperature level, it would be necessary to either cool the turbine blades (state-of-the-art technology) or utilize advanced uncooled turbine blade materials such as ceramics or carbon-carbon fiber composites. Similarly, advanced materials would be necessary in the reactor system (i.e., thermal barriers, hot-gas ducts, etc.). Following initial deployment of the gas turbine at $850^{\circ} \mathrm{C}\left(1562^{\circ} \mathrm{F}\right)$, there is clearly an incentive to advance to higher temperature variants as the technology becomes available.

Table 8-I outlines the salient features of the various HTGR systems covering core outlet temperatures from $700^{\circ} \mathrm{C}\left(1292^{\circ} \mathrm{F}\right)$ to $950^{\circ} \mathrm{C}\left(1742^{\circ} \mathrm{F}\right)$. The data in this table essentially portray a progression of technology from the state-of-the-art HTGR-SC/C plant, which is ready for commercialization, to the envisioned advanced reactor systems. While the technology transfer from the HTGR-SC/C plant to the advanced plants, including the gas turbine, is significant, a considerable development effort must be expended for the higher temperature systems embodying advanced technology features. The above deployment strategy led to the conclusion that the gas turbine development be essentially allied to process heat applications where very high temperatures must be realized. ${ }^{3}$

\section{8-1B HTGR-GT Background}

The closed-cycle gas turbine (CCGT), not well known in the United States, has been proven in Europe with over 40 years of operating experience. ${ }^{4}$ The CCGT is well suited to nuclear, coal-fired, and solar heat sources, ${ }^{5}$ but the application that has received the most attention in the last decade has been the study of CCGT coupling with an HTGR.

\section{TABLE 8-I}

Comparison of Salient Features for Different HTGR Options

\begin{tabular}{|c|c|c|c|c|}
\hline & \multirow[b]{2}{*}{$\begin{array}{l}\text { Lead Plant } \\
\text { HTGR-SC/C }\end{array}$} & \multicolumn{3}{|c|}{ Advanced Follow-on Options } \\
\hline & & $\begin{array}{c}\text { Process Heat } \\
\text { HTGR Indirect } \\
\text { Cycle }\end{array}$ & $\begin{array}{l}\text { Process Heat } \\
\text { HTGR Direct } \\
\text { Cycle }\end{array}$ & HTGR-GT \\
\hline $\begin{array}{l}\text { Reactor outlet } \\
\text { temperature } \\
\left({ }^{\circ} \mathrm{C}\right)\left[{ }^{\circ} \mathrm{F}\right]\end{array}$ & $693[1279]$ & $850[1562]$ & $950[1742]$ & $850[1562]$ \\
\hline $\begin{array}{l}\text { Reactor inlet } \\
\text { temperature }\left({ }^{\circ} \mathrm{C}\right) \\
{\left[{ }^{\circ} \mathrm{F}\right]}\end{array}$ & $318[609]$ & $438[820]$ & $500[932]$ & $494[922]$ \\
\hline $\begin{array}{l}\text { Reactor core thermal } \\
\text { rating }[\mathrm{MW}(\mathrm{t})]\end{array}$ & 2240 & 1170 & 1170 & 2000 \\
\hline $\begin{array}{l}\text { Core power density } \\
\left(\mathrm{W} / \mathrm{cm}^{3}\right)\end{array}$ & 715 & 66 & 66 & 66 \\
\hline $\begin{array}{l}\text { Core power/flow } \\
\text { ratio }(\mathrm{J} / \mathrm{kg}) \\
{[\mathrm{W} \cdot \mathrm{h} / \mathrm{lb}]}\end{array}$ & $\begin{array}{c}194 \times 10^{6} \\
{[245]}\end{array}$ & $\begin{array}{c}214 \times 10^{6} \\
{[270]}\end{array}$ & $\begin{array}{c}233 \times 10^{6} \\
{[294]}\end{array}$ & $\begin{array}{c}173 \times 10^{6} \\
{[219]}\end{array}$ \\
\hline
\end{tabular}


TABLE 8-I (continued)

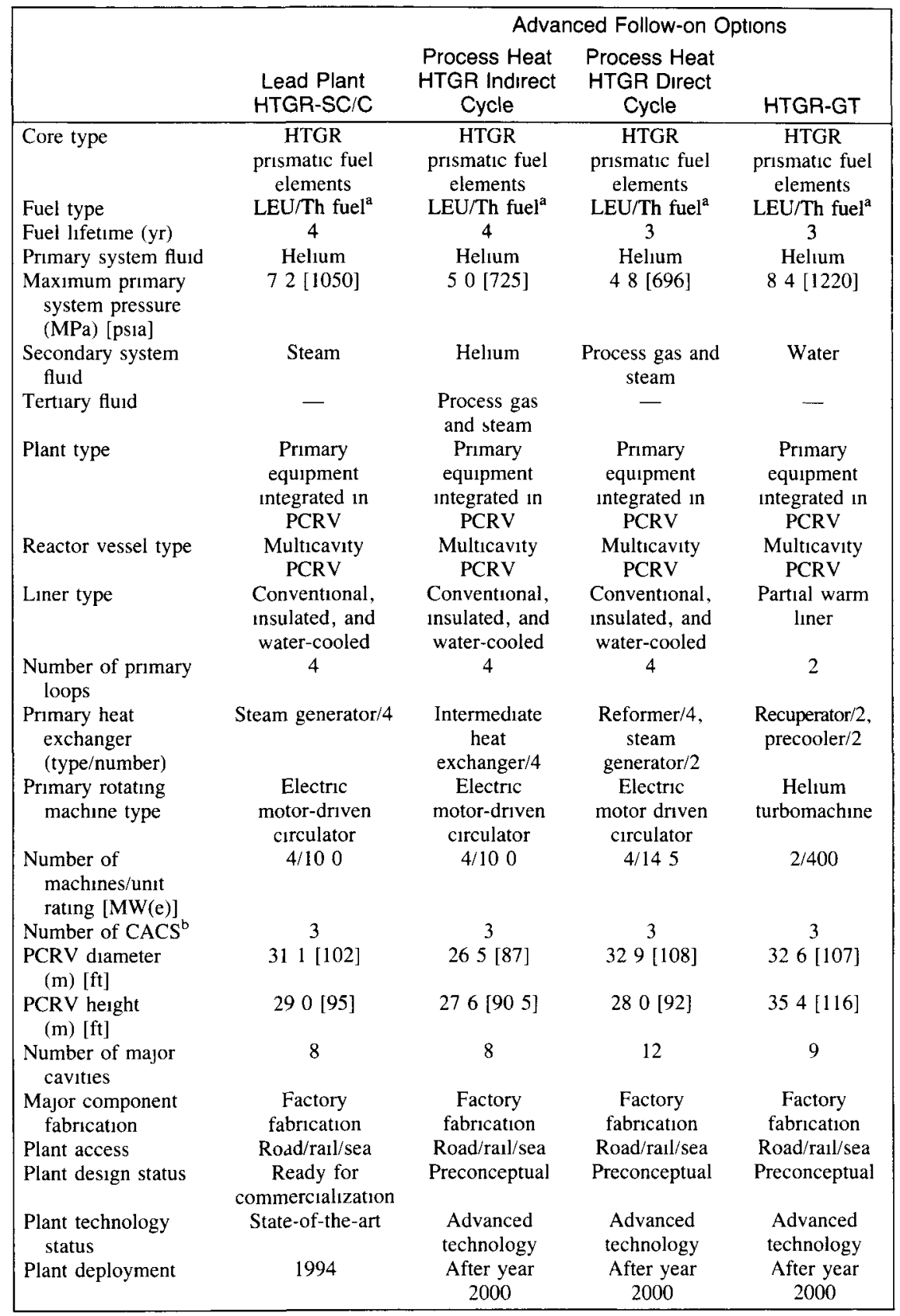

${ }^{a}$ LEU/Th $=$ low-enriched uranium/thorium

${ }^{\mathrm{b}} \mathrm{CACS}$ - core auxiliary coolıng system 
As HTGR-GT plant design studies progressed since initiation in 1971, the thermodynamic cycle and plant configuration evolved from investigating the best means to satisfy the various performance, economic, safety, and operational goals. These studies, done over the course of a decade, have been well documented in the open literature, both in the United States ${ }^{6-9}$ and Europe. ${ }^{10-12}$

Early in the studies, efforts were directed toward the design, performance, and economic assessment of a multiloop plant in the 1200-MW(e) class that could be adapted to both smaller and larger units. A $1200-\mathrm{MW}(\mathrm{e})$ reference plant established in 1977-1978 based on a non-intercooled cycle and embodying three power conversion loops (PCLs) has been described. ${ }^{13}$

Over the last few years, plant layout studies have been done for a wide range of power levels. These studies have consisted essentially of varying the number of PCLs, sizing the major components, evaluating the impact of component ori-

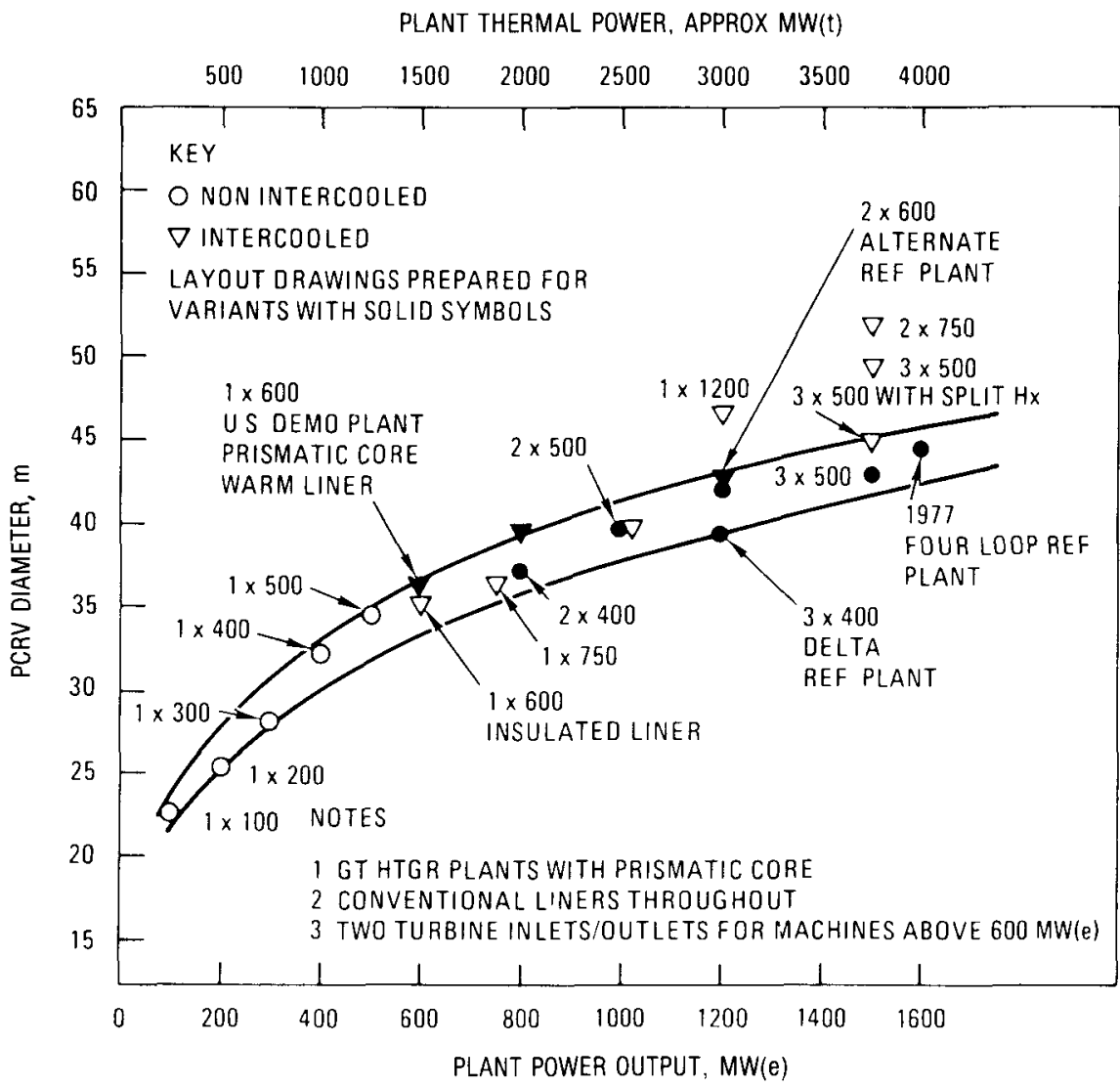

Fig. 8-2. The impact of HTGR-GT plant power rating on PCRV diameter for different layout concepts. 
entation on the prestressed concrete reactor vessel (PCRV) diameter, computing plant efficiency, and estimating costs (capital and power generation costs). Figure 8-2 shows the range of plants studied in a conceptual manner and the impact on PCRV diameter, which is regarded as a major capital cost indicator.

Inputs from the utilities in 1979 indicated a trend away from the larger plants envisioned for the end of this century. Accordingly, efforts were directed toward a plant in the $800-\mathrm{MW}(\mathrm{e})$ class, and details of the reference plant concept are given in $\mathrm{Sec} .8-3$.

\section{8-2 Thermodynamic Cycles and Performance}

In the quest for high overall plant efficiency, analyses and design studies were carried out for plant variants with varying thermodynamic cycles; particular emphasis was placed on the direct cycle because studies of the indirect cycle utilizing an intermediate heat exchanger (IHX) showed it to be unattractive for the following reasons: (a) it necessitated a $50^{\circ} \mathrm{C}$ higher reactor outlet temperature to keep the same turbine inlet temperature, (b) questionable integrity of the IHX, and (c) a considerable capital cost penalty and resultant unattractive power generation costs. In the case of the process heat plant, the IHX is pressure balanced for the bulk of its operating conditions. In the case of the gas turbine, this is not possible, since the IHX pressures become unbalanced as the power level changes. With this situation, a viable IHX was not identified based on today's technology (in particular, materials capability). It was concluded that the best indirect cycle was in fact the steam cycle plant. Accordingly, only direct-cycle variants were addressed, which are outlined below.

\section{8-2A Thermodynamic Cycles}

The attractive features of the Brayton (gas turbine) cycle are compared with the Rankine (steam) cycle in the simplified temperature/entropy diagram in Fig. 8-3. The Brayton cycle plant heat rejection occurs over a wide range of temperatures rather than at the one temperature of a condensing vapor. This range departs from one thermodynamic cycle efficiency criterion, but conversely, it means that the higher average heat rejection temperature can greatly ease the practical problem of reject heat dissipation. Indeed, as outlined in Sec. 8-5, a higher mean rejection temperature can become valuable for industrial use or for binary-cycle power production.

The decision of whether or not to incorporate an intercooler is important to the thermodynamic cycle, since it affects both the plant layout and the heat rejection characteristics. Figure 8-4 compares the two cycles. In any operation involving gas compression by multistage machines, the process efficiency can be improved by cooling the gases in an intercooler between the stages. Intercooling offers a cycle efficiency gain of about three percentage points, but this gain must be 


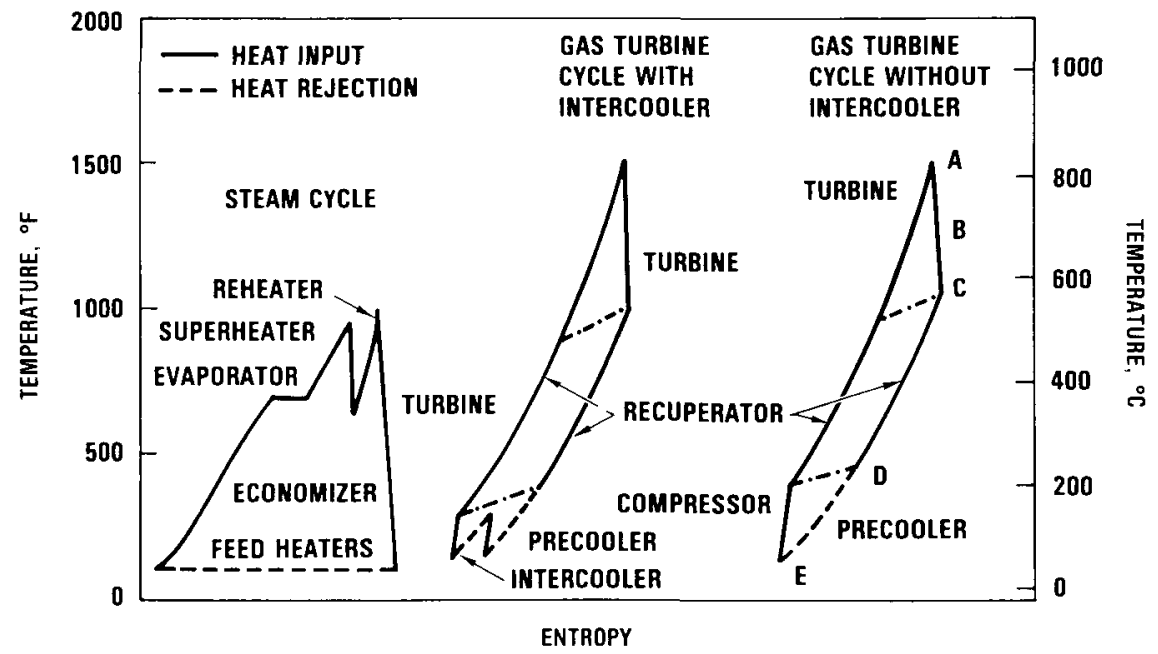

Fig 8.3 Comparıson of thermodynamic cycles for steam and gas turbıne plants

(a) NON INTERCOOLED CYCLE

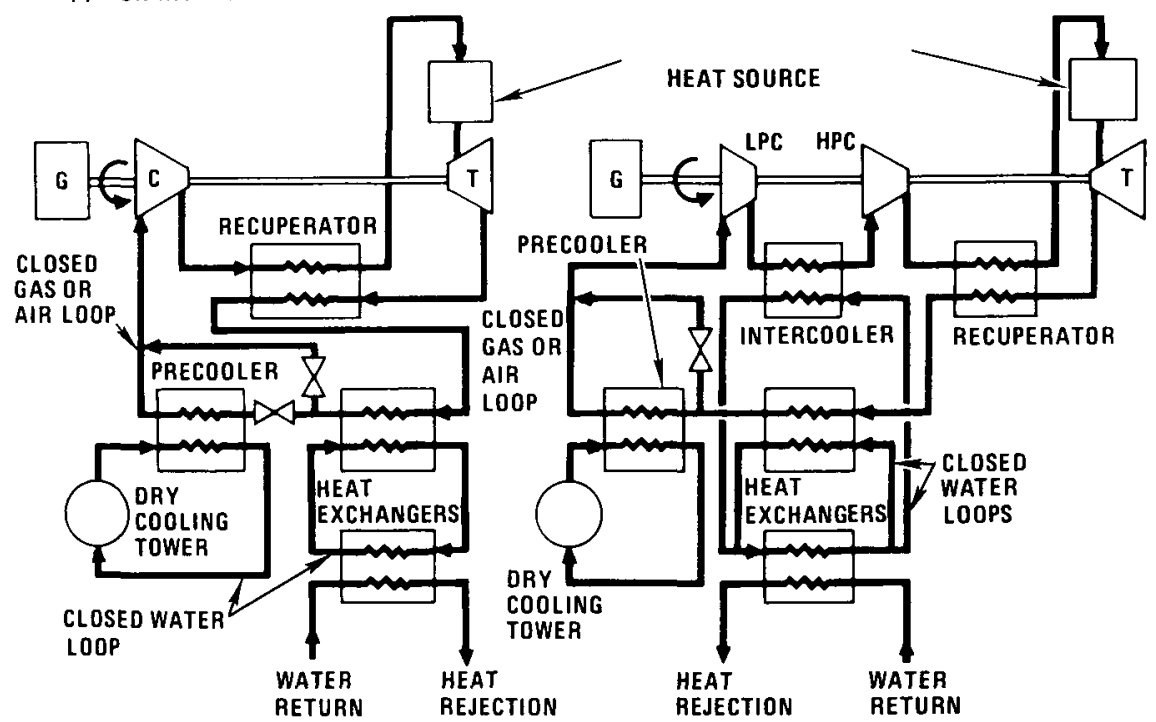

Fig. 8-4. Comparison of two thermodynamic cycles for combıned power and heat CCGT plants. 
weighed against the differing heat rejection temperatures and the power plant complexity.

In the HTGR-GT plant studies in the United States, there has been a strong motivation to use the non-intercooled cycle for the following reasons: (a) plant simplicity in both the turbomachine and primary systems and (b) a high reject temperature for the economical dry cooling and optional bottoming cycle (discussed in Sec. 8-5). In Europe, on the other hand, the intercooled cycle has always been favored because (a) it has a higher efficiency, (b) the reject water temperature is well suited to district heating, and (c) there is a carryover from the European fossil-fired CCGT plants, which have all been intercooled. ${ }^{14}$ Some of the major factors involved in the issue of intercooling versus non-intercooling are outlined in Table 8-II.

\section{8-2B Gas Turbine Plant Performance}

In parallel with the plant component and design layout work, performanceoptimization studies have been performed. ${ }^{15,16} \mathrm{~A}$ design and cost evaluation computer code was developed and used to identify the parameters to give the mınımum power generating cost. System parameter selection, accomplished during optimization, dramatically affects conceptual design by influencing overall plant performance, availability, safety, and economics. Therefore, sensitivity of these

\section{TABLE 8-II}

\section{Summary of Major Factors Relating to the Issues of Intercooling}

\section{Non-Intercooled Plant}

Simpler turbomachine (shorter rotor, less duct connections)

Simpler gas flow paths and primary system layout

Less complex system implies improved avalability and reliability

High reject temperature well surted for cogeneration ( $1 \mathrm{e}$, binary cycle, process steam, district heating, etc )

Reduced plant construction time (simpler PCRV)

Reduced complexity and risk

\section{Intercooled Plant}

Increased cycle thermodynamic efficiency

Reduced helium mass flow rate ( $\mathrm{e}$ e, smaller components)

Source of cooler high-pressure gas avalable for cavity liner cooling

Reduced core inlet gas temperature

Possible use of additional water-to-helium heat exchanger (intercooler) for decay heat removal

Heat rejection split between two water-to-helium exchangers (precooler and intercooler) results in smaller unit assemblies

Utilization of European experience from the small fossil-fired CCGTs

Water outlet temperature well suited for district heating

Additional maintenance requirements

Increased plant capital cost

Additional potential source of water ingress to primary system 
factors to changes in plant parameters should be determined at the earliest design stages.

System optimization and design evaluations were performed during the conceptual design stage to identify: (a) an optimized set of parameters for further design development, (b) sensitive areas where additional design definition or improvements would be effective, and (c) where margins can most effectively be applied to achieve the desired probability of performance success at minimum cost.

The most important parameter affecting performance of a gas turbine is turbine inlet temperature. Figure 8-5 shows the progression in inlet temperature for fossil-fired CCGT plants that have been in operation. For the HTGR-GT reference plant, a turbine inlet temperature of $850^{\circ} \mathrm{C}\left(1562^{\circ} \mathrm{F}\right)$ was selected. This temperature is modest compared to that for most industrial gas turbine practice,

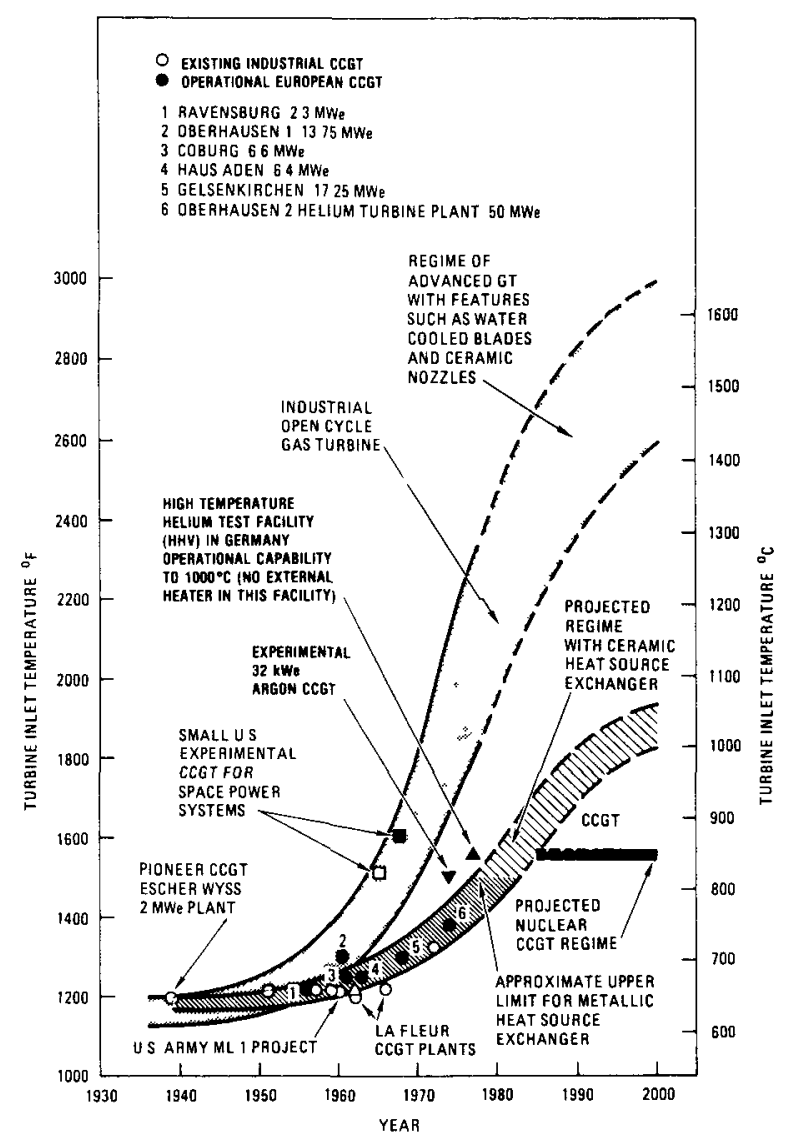

Fig. 8-5. Turbine inlet temperature trends for closed- and open-cycle industrial gas turbines. 
it is below the level where turbine blade cooling is necessary, and it facilitates utılization of an existing nickel-base alloy (for the turbine blades), which is used extensively in industrial gas turbınes In commercial arlıne service, the gas turbine engines (turbojets and turbofans) operate with turbine inlet temperatures on the order of $1200^{\circ} \mathrm{C}\left(2192^{\circ} \mathrm{F}\right)$, and for military applications even higher temperatures are used

Other important parameters in the CCGT are the compressor pressure ratio and recuperator effectiveness Figure 8-6 shows the effect of these parameters on the efficiency of a non-intercooled cycle with a turbıne inlet temperature of $850^{\circ} \mathrm{C}$ $\left(1562^{\circ} \mathrm{F}\right)$ To explore the effect of temperature, a family of curve plots (like those shown in Fig 8-6) was prepared and the maxımum efficiency loci were determıned These are shown in Fig 8-7, which relates the important cycle parameters with cycle efficiency for a non-intercooled cycle A similar performance carpet plot for an intercooled plant is shown in Fig 8-8 with turbine inlet temperatures from 750 to $1050^{\circ} \mathrm{C}$ For this array, the compressor pressure ratio was fixed at 30 , a value that has been shown to be near optımum for the intercooled plants operated in Europe From these performance arrays, it is clear that the HTGR-GT offers

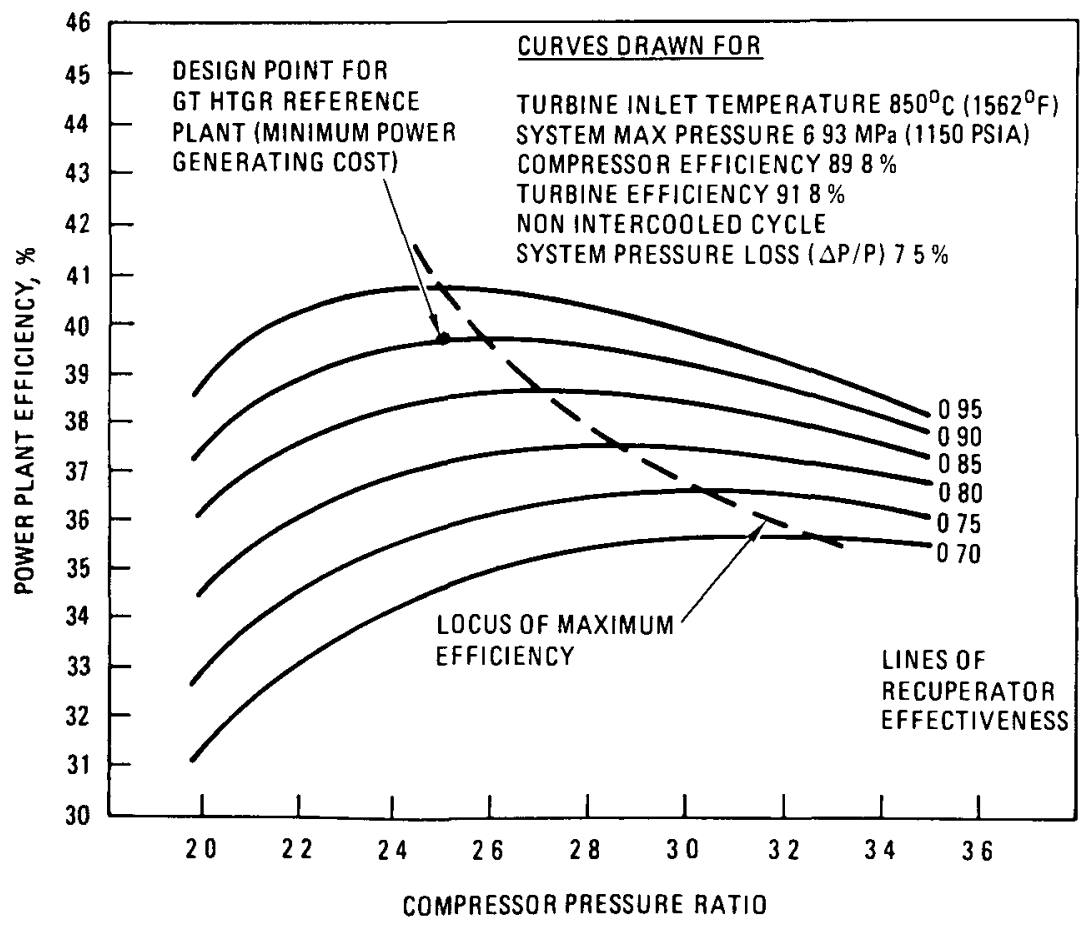

Fig 8-6 Influence of compressor pressure ratio and recuperator effectiveness for a helium CCGT based on a non-intercooled cycle 


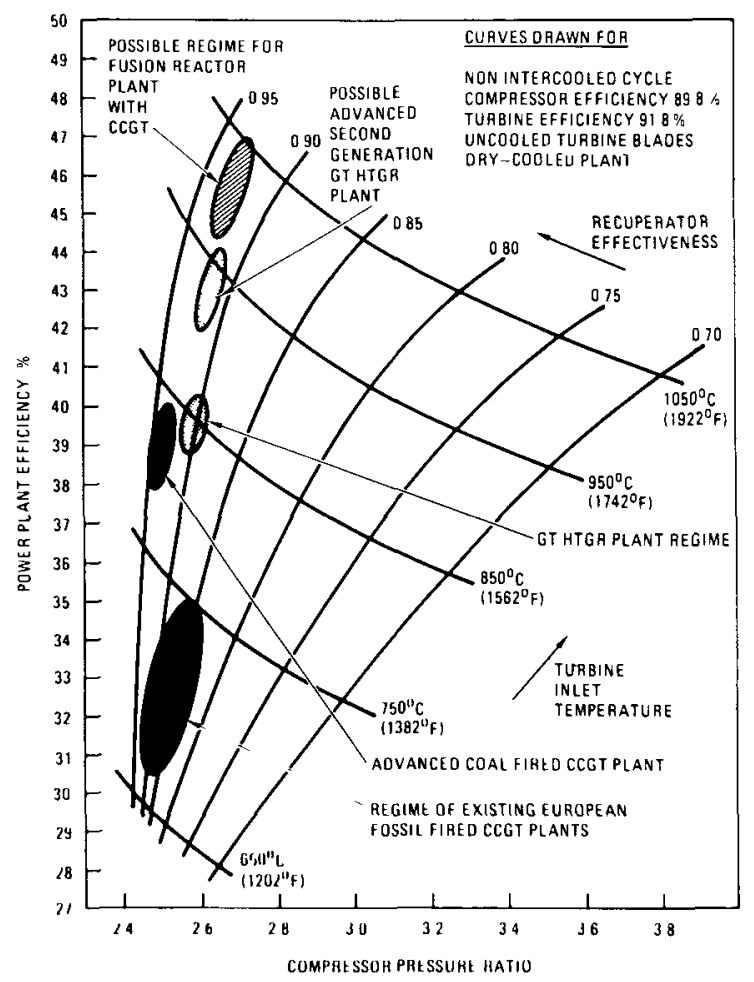

Fig. 8-7. Representative cycle parameter array for a non-intercooled HTGR-GT plant.

significant potential for high levels of efficiency, which is discussed in Sec. 8-5.

The performance studies indicated that high efficiencies can be realized but with ever-increasing plant complexity. However, the U.S. utility companies believed that the attendant complexity inherent with the higher efficiency variants was not appropriate for the first-of-a-kind plant involving new technologies and that the associated increased development effort and possible improvement in plant operability (because of the additional complexity) detracted from the overall goal of seeking plant simplicity. Accordingly, efforts were concentrated on the basic non-intercooled Brayton cycle (albeit highly "recuperated"), with emphasis on a dry-cooling mode of heat rejection.

Figure 8-9 shows the parameters selected for the reference plant from the optimization study with a reactor outlet temperature of $850^{\circ} \mathrm{C}\left(1562^{\circ} \mathrm{F}\right)$. A maximum system pressure of $8.4 \mathrm{MPa}$ (1220 psia) was selected from the sensitivity studies. This pressure level, which gives high gas density and compact turbomachinery, heat exchangers, and ducts, is only a modest extension of PCRV structural design practice. Unlike the steam cycle plant that requires an external source of power to drive the circulators, the term "pumping power" is not used 


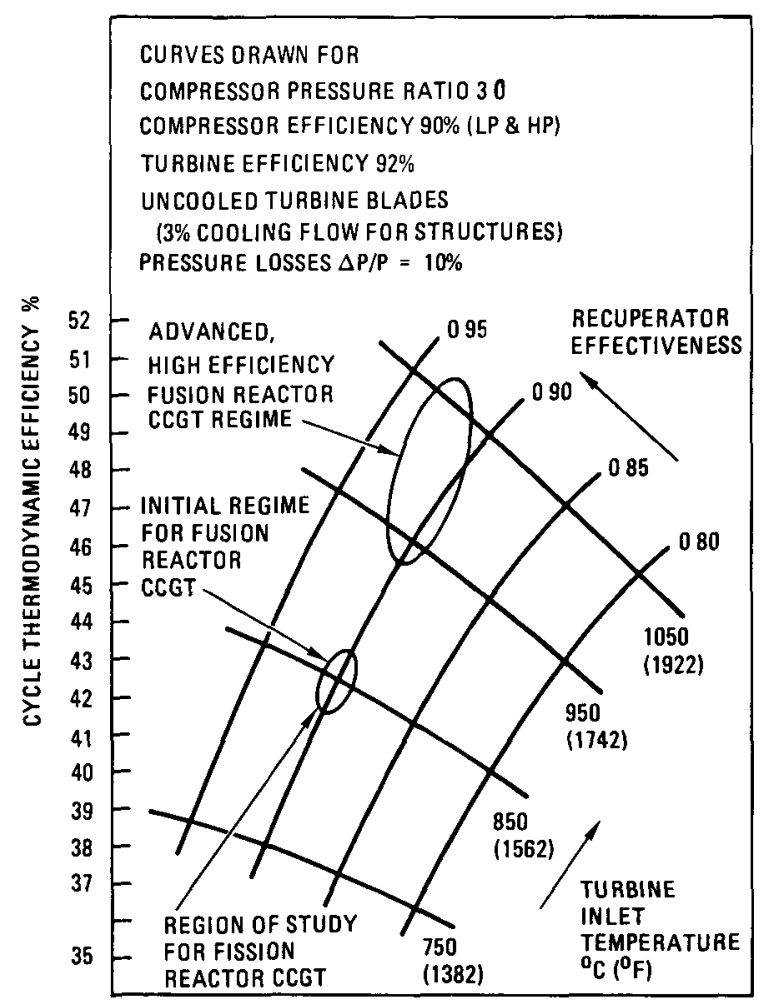

Fig 8-8 Performance array for a helium CCGT plant based on an intercooled cycle

in the gas turbine A substantial amount of power is necessary to drive the compressors and this is provided by the gas turbine The net power output is, of course, the gross turbine power minus the power required by the compressor For a given compressor pressure ratı, $R_{c}$, it is important to maximize the turbine expansion ratio, $R_{t}$, since these are related by the expression

$$
R_{t} / R_{c}=1-\sum(\Delta P / P),
$$

where $\Sigma(\Delta P / P)$ represents the summation of the non-dimensional pressure losses in the circuit A good guide for a CCGT is for the total pressure losses not to exceed $10 \%$, leading to the ratio $R_{t} / R_{\mathrm{c}} \geqslant 090$ With a reactor outlet temperature of $850^{\circ} \mathrm{C}\left(1562^{\circ} \mathrm{F}\right)$, a compressor pressure ratio of 26 was selected, which together with the recuperator effectiveness of 090 , resulted in a plant efficiency of $40 \%$ for the non-intercooled cycle with dry cooling The parameters shown in Fig 8-9 formed the basis for the conceptual design of the reference plant, which is briefly described in $\operatorname{Sec} 8-3$ 


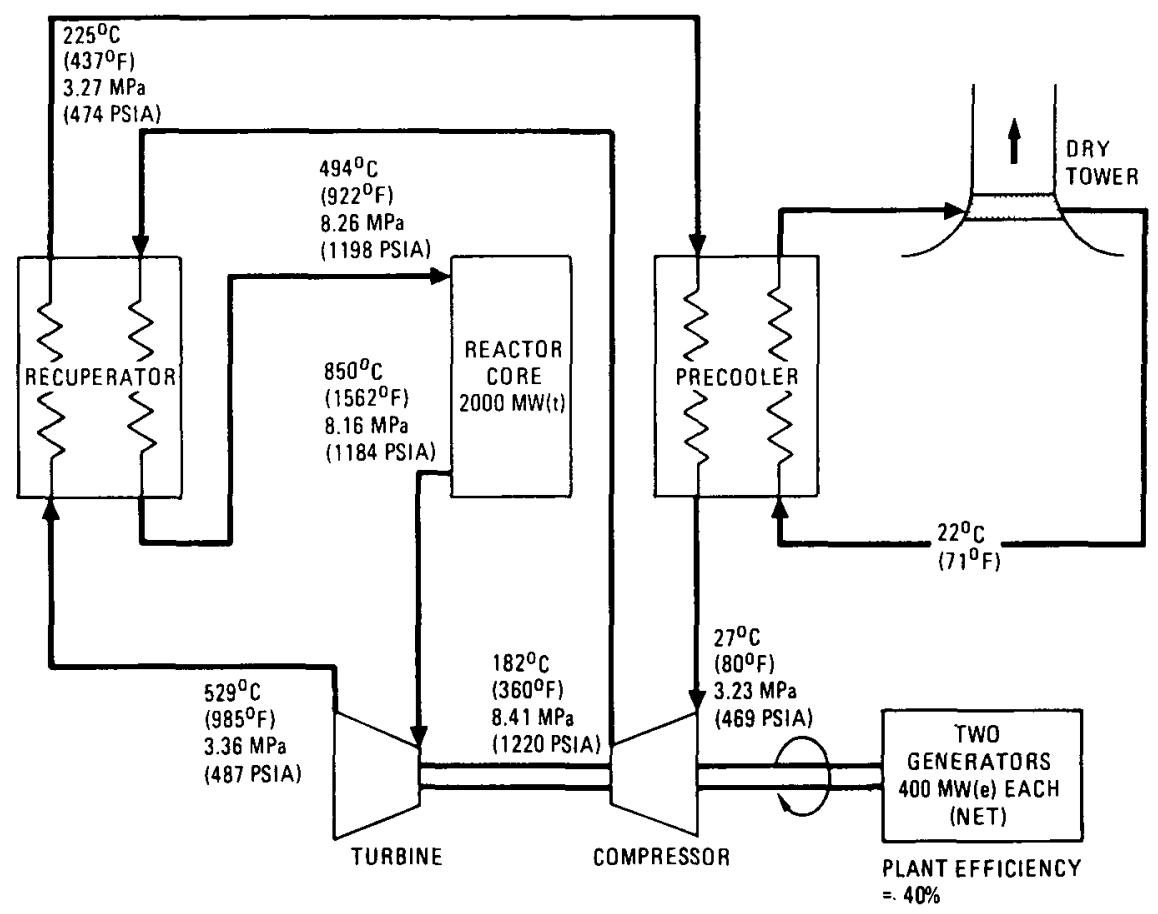

Fig. 8-9. Flow path diagram showing salient parameters for an HTGR-GT plant reference design.

\section{8-3 Reference 2000-MW(t) HTGR-GT Plant Design Concept}

The reactor turbine system consists of power conversion loops (PCLs), the reactor core, and auxiliary cooling loops. The plant ${ }^{17}$ embodies two PCLs rated at $400 \mathrm{MW}(\mathrm{e})$ each and consisting of a turbomachine, a recuperator, a precooler, and control valves. As shown in the reactor turbine system arrangement in Fig. 8-10, all of the primary system equipment is installed in the PCRV to give an integrated plant configuration.

The two turbomachines are installed in horizontal cavities toward the base of the PCRV. The helium turbomachine is rated at $400 \mathrm{MW}(\mathrm{e})$ and consists of a simple and rugged arrangement with a single shaft and direct drive to the generator. The turbomachine drive to the generator is from the compressor end of the turbomachine, and the thrust bearing is located external to the PCRV to facilitate inspection and maintenance.

The heat exchangers (recuperator and precoolers) are installed in vertical cavities in the PCRV, as shown in Fig. 8-10. The recuperator, which contributes significantly to the high cycle efficiency, is a helium-to-helium heat exchanger of high effectiveness. The reference design is based on a straight-tube, axial counter- 


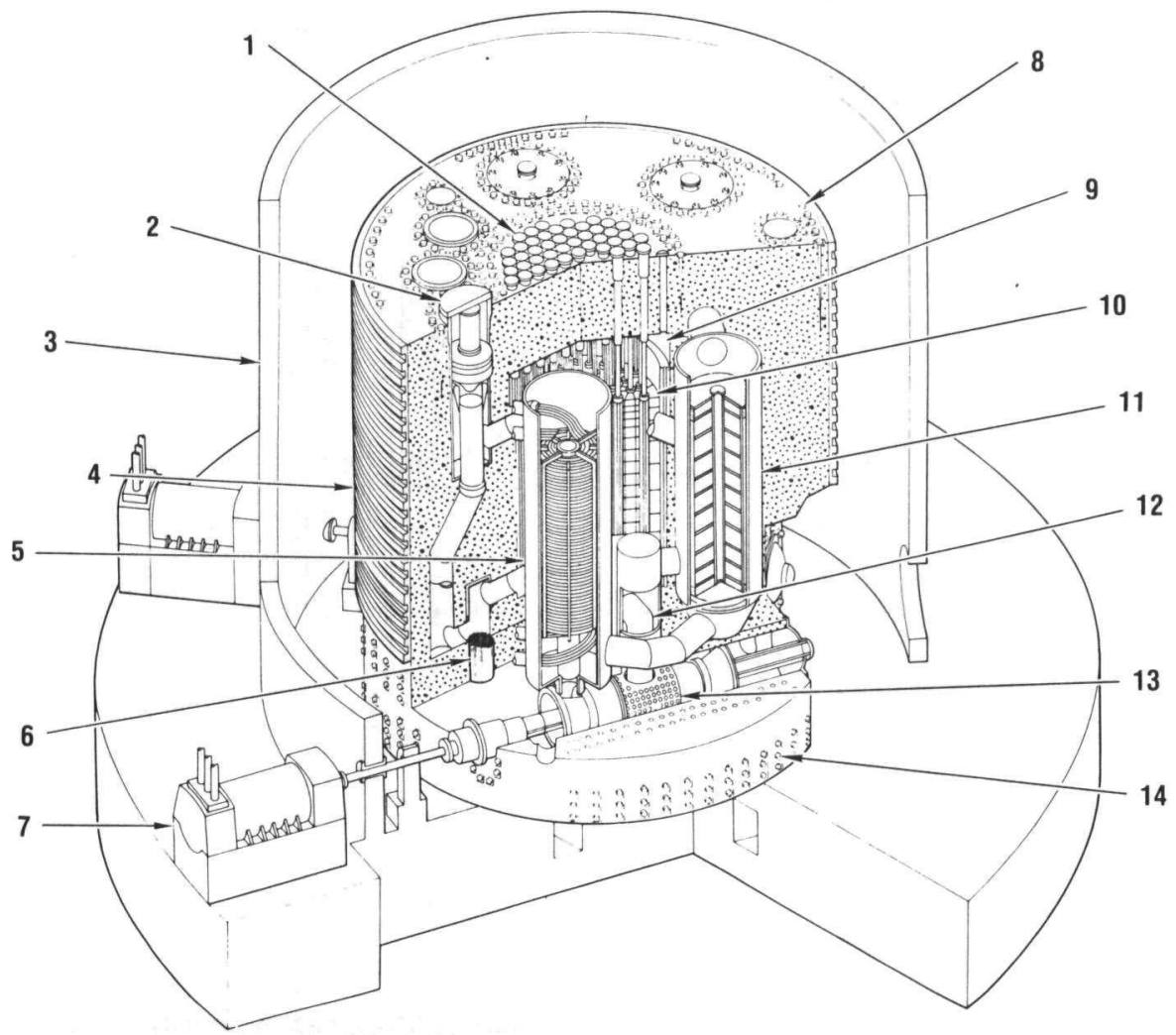

KEY

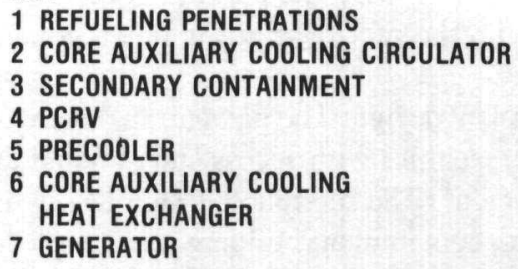

8 VERTICAL PRESTRESS TENDONS

9 REFUELING PLENUM

10 CORE

11 RECUPERATOR

12 CORE OUTLET DUCT

13 TURBOMACHINERY

14 HORIZONTAL PRESTRESSED TENDONS

Fig. 8-10. A two-loop 800-MW(e) direct-cycle HTGR-GT power plant concept.

flow configuration and has a provision for in-service inspection. The precooler, which is used to remove reject heat from the cycle, is a helium-to-water heat exchanger of very high thermal effectiveness. The reference design has a helical bundle of cross-counterflow geometry. Both of these heat exchangers are regarded as state-of-the-art technology and, with modest metal temperatures and pressure differentials (compared with modern steam generators), utilize code-approved lower grade alloys of reduced cost.

The core auxiliary cooling system consists of three separate and independent 


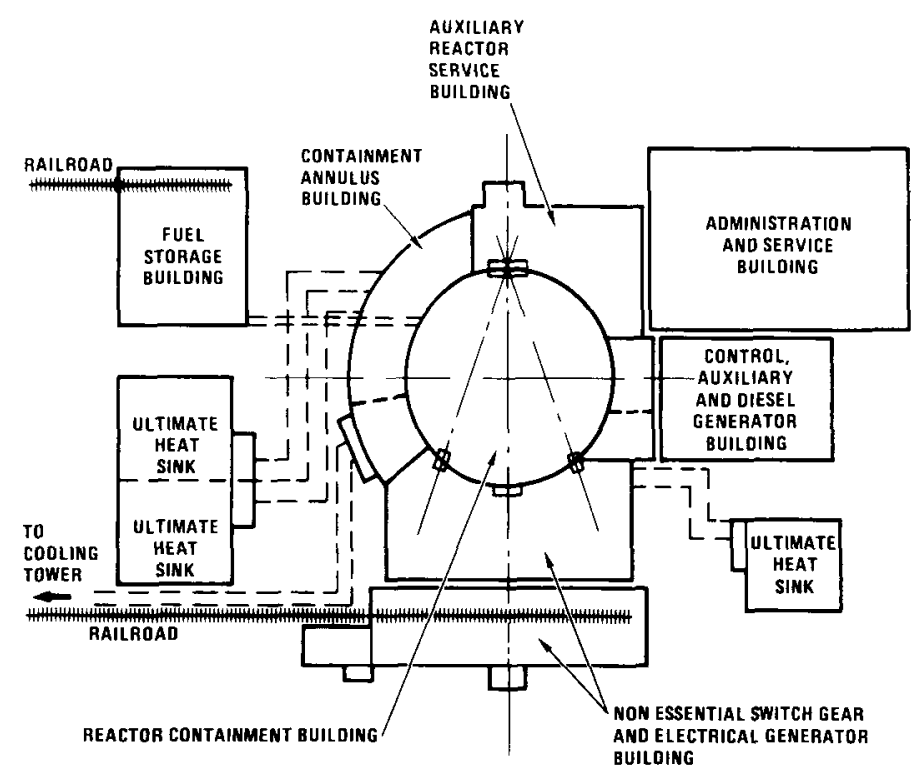

Fig. 8-11. Overall plant arrangement for a two-loop reference design.

cooling loops comprised of auxiliary circulators, core auxiliary heat exchangers, and ultimate heat sink rejecting heat to the atmosphere. The system can remove the core residual decay heat for cooldown following the loss of helium circulation in the main power conversion loops with the reactor in a shutdown conditioneither pressurized or depressurized.

Figure 8-11 shows the balance-of-plant design. The plant arrangement utilizes horizontal electric generators and turbomachines with access and removal through grade-level penetrations in the containment. The reference design has hydrogencooled generators located outside of the containment building and coupled to the turbomachine via a shaft penetration through the building. The major features of the plant are summarized in the last column of Table 8-I.

\section{8-4 Component Design Considerations}

For an integrated plant, the PCL components cannot be treated as isolated units, and indeed, their design and also resolution of the interconnecting gas flow path geometries must be considered during the establishment of the plant primary system configurations. ${ }^{18}$ The main PCL components that have a strong influence on the primary system design are the PCRV, reactor core, turbomachine, and heat exchangers. The PCRV and reactor core ${ }^{19}$ are very similar to those of the steam cycle HTGR. 


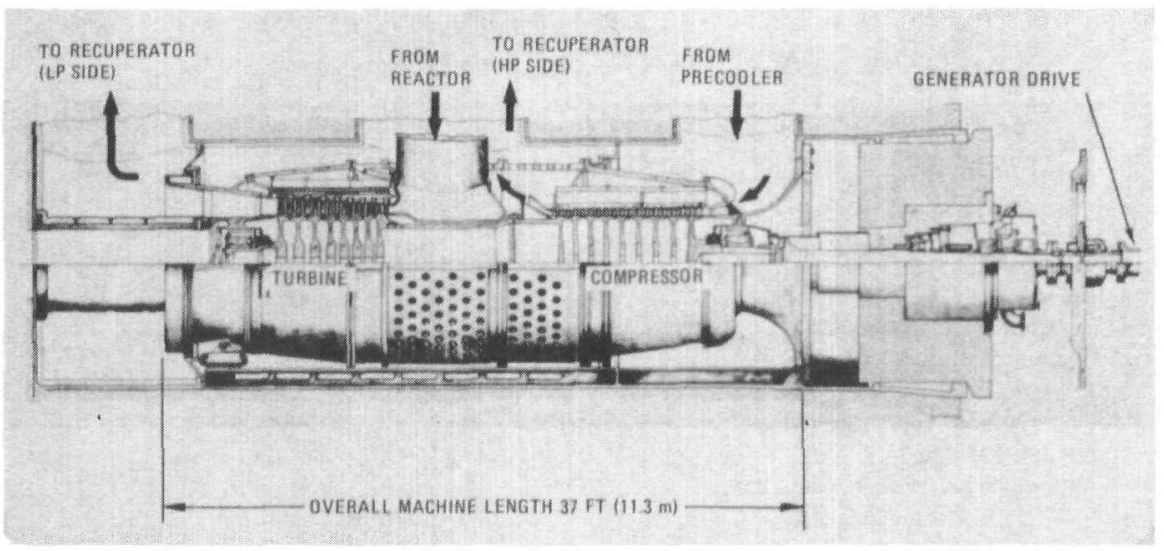

Fig. 8-12. A 400-MW(e) non-intercooled turbomachine for an HTGR-GT plant.

\section{8-4A Helium Turbomachine}

A simple and rugged arrangement ${ }^{20-22}$ consisting of a single-shaft directdrive turbomachine was chosen for the HTGR-GT plant and details are given in the simplified cross section of the $400-\mathrm{MW}$ (e) $60-\mathrm{Hz}$ machine shown in Fig. 8-12. The salient features of the turbomachine are given in Table 8-III. The 400-MW(e) helium turbomachine has 18 compressor stages (for a pressure ratio of 2.6 with the low molecular weight helium gas) and 8 turbine stages.

The aerodynamic procedures used for the helium turbomachine are essentially identical to conventional air-breathing gas turbine practice. Substitution of helium for air greatly modifies aerodynamic requirements by removing Mach number limitations; the problem then becomes that of trying to induce the highest possible gas velocities that stress-limited blades will allow. Helium compressors for closedcycle gas turbines are characterized by small blade heights, high hub-to-tip ratios, and low aspect ratios. For a representative helium compressor, the typical salient aerodynamic parameters, together with the effects of varying the blade and gas velocities, are shown in Fig. 8-13. An important parameter is the hub-to-tip ratio, and an accepted upper limit for high efficiency compressors is $\sim 0.90$.

The properties of helium affect the turbine in very much the same way as they affect the compressor. That is, for a given overall expansion ratio, the total number of stages for a helium machine will be greater than for an air-breathing gas turbine. Performance analysis of a large number of turbine test rigs produces an empirical relationship between stage loading factor, axial velocity (mean blade speed), and efficiency. Figure 8-14, constructed from test data from many different rig turbines, shows this relation in simplified form. The eight-stage helium design has the necessary combination of aerodynamic parameters to give an overall design in the "maximum efficiency" regime. Although the efficiency values shown in Fig. 8-14 do not include allowances for tip clearance, leakage losses, and disk 
TABLE 8-III

Details of HTGR-GT Turbomachine Design

\begin{tabular}{|c|c|}
\hline Turbomachine Ratıng [MW(e)] & 400 \\
\hline Machıne type & Non-intercooled \\
\hline Machıne arrangement & Single-shaft \\
\hline Frequency $(\mathrm{Hz})$ & 60 \\
\hline Number of turbine inlet ducts & 1 \\
\hline Turbıne inlet temperature $\left({ }^{\circ} \mathrm{C}\right)$ & 850 \\
\hline Compressor pressure ratıo & 250 \\
\hline Number of compressor stages & 18 \\
\hline Maxımum compressor tıp diameter $(\mathrm{m})$ & 183 \\
\hline Blade height $(\mathrm{mm})[\mathrm{min} / \mathrm{max}]$ & $800 / 1257$ \\
\hline $\begin{array}{l}\text { Compressor adiabatic } \\
\text { efficiency (across blading) (\%) }\end{array}$ & 898 \\
\hline Number of turbine stages & 8 \\
\hline Maxımum turbıne tıp diameter (m) & 218 \\
\hline Blade height $(\mathrm{mm})[\mathrm{min} / \mathrm{max}]$ & $1257 / 2972$ \\
\hline $\begin{array}{l}\text { Turbine isentropic efficiency } \\
\text { (across blading) }(\%)\end{array}$ & 918 \\
\hline Blading life $(\mathrm{h})$ & 280000 \\
\hline Blade coolıng & No \\
\hline Turbıne blade material & Nickel-base alloy, IN-100 \\
\hline Generator drive end & Compressor \\
\hline Rotor burst shield & Yes, integral part of machıne structure \\
\hline Thrust bearing position & External to PCRV \\
\hline Number of journal bearings & 2 \\
\hline Journal bearing man access & Yes \\
\hline Type of rotor construction & Welded rotor \\
\hline Machine casing diameter $(\mathrm{m})$ & 40 \\
\hline Machine length $(\mathrm{m})$ & 113 \\
\hline Machıne weight (kg) & 276770 \\
\hline Design technology base & Large industrial open-cycle gas turbınes \\
\hline
\end{tabular}

cooling losses, the position of the efficiency contours is not changed by these factors and the figure is useful as a preliminary design tool to establish a practical design.

The performance prediction for the 400-MW(e) helium turbomachine is based on established design methodology, and the high compressor and turbine efficiency values shown in Fig. 8-15 reflect the influence of technology from demonstrated advanced technology industrial gas turbines. The sensitivity of plant efficiency to small changes in compressor and turbine efficiencies can be seen clearly from Fig. 8-15.

The rotor is of welded construction. Welded rotors have a long successful history in Europe for both gas and steam turbines. The stress levels in the turbine blades are commensurate with a life of 280000 h (i.e., $40 \mathrm{yr}$ at an $80 \%$ capacity factor). For the turbine inlet temperature of $850^{\circ} \mathrm{C}\left(1562^{\circ} \mathrm{F}\right)$, blade cooling is not necessary, and an existing nickel-base alloy (IN-100), which has been used extensively in open-cycle industrial gas turbines, was selected for the turbine blading.

The turbine has the advantage of being able to utilize cast alloys, which are very strong at elevated temperature, for the blading. Turbine materials at an $850^{\circ} \mathrm{C}$ 


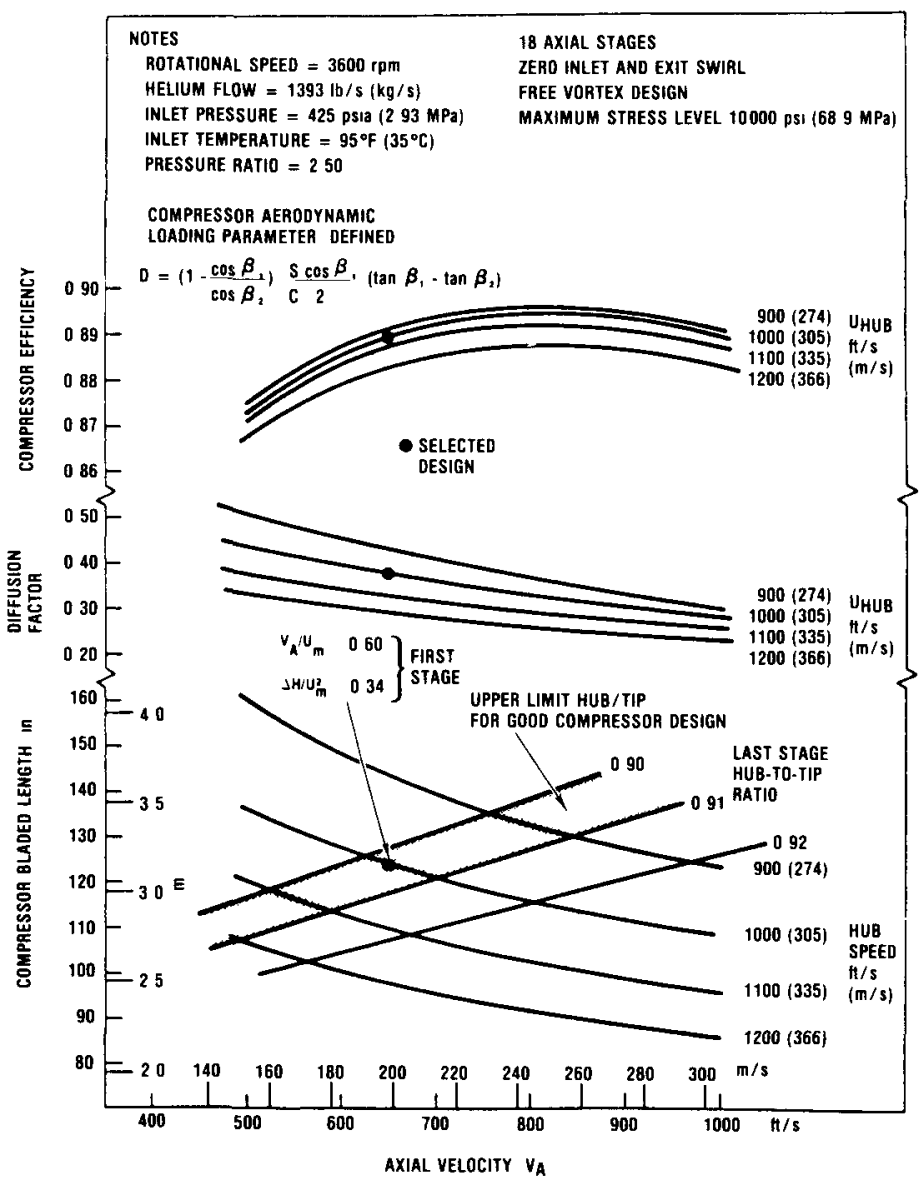

Fig. 8-13. Representative axial compressor design parameters for a 400-MW(e) helium turbomachine.

operating temperature are not regarded as a major developmental item. [In the case of the other major components (i.e., heat exchangers, ducts, thermal barrier, etc.), their geometries necessitate the use of wrought materials and do require characterization for elevated temperature service in the reactor primary system.] With the $60,800-\mathrm{kg}$ (67-ton) rotor supported on two journal bearings, the overall length of the turbomachine is $11.3 \mathrm{~m}(37 \mathrm{ft})$. The overall diameter of $3.5 \mathrm{~m}$ $(11.5 \mathrm{ft})$ is a design constraint to facilitate rail transportation of a contaminated turbomachine installed in a shielded cask. The weight of the overall machine is $277000 \mathrm{~kg}$ (305 tons).

Since the turbomachine is installed inside the reactor vessel, rotor burst protection is incorporated in the machine design in the form of containment rings around the compressor and turbine rotor bladed sections and around the com- 


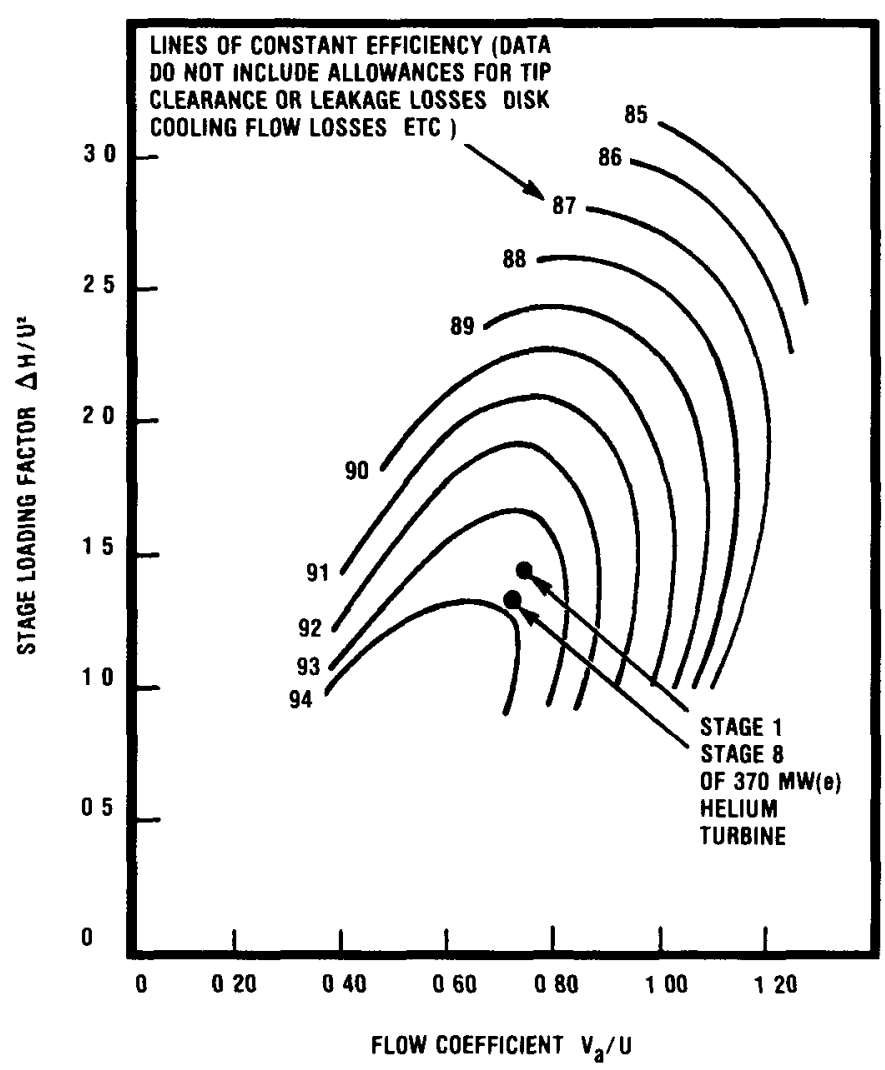

Fig 8-14 Generalized axial turbine blading efficiency contours

pressor-to-turbine shaft Man-access provisions are provided in the PCRV for inspection and limited maintenance work on the journal bearıngs, which are of the multiple, tilting pad, orl-lubricated type The spaces in which the bearings are located are isolated from the main cycle working fluid by shielding (purge gas from the plant helium storage system is used to give an acceptable radiological environment for man-access) The drive to the generator is from the compressor end of the turbomachine, and the thrust bearng is located external to the PCRV to facilitate inspection and maintenance and to limit the number of oil systems in the primary system to a minımum Diagnostic condition monitoring, in situ inspection, and maintenance features are designed into the turbomachine system ${ }^{23}$

For a single-shaft turbomachine with a net power output of $400 \mathrm{MW}(\mathrm{e})$, the rotating section is compact and substantially smaller than an equivalent air-breathing machine because of the high degree of pressurızation (particularly at the turbine exit) and because the enthalpy drop in the helium turbine is many times greater (1 e , increased specific power) The external dimensions of the 400-MW(e) helium 


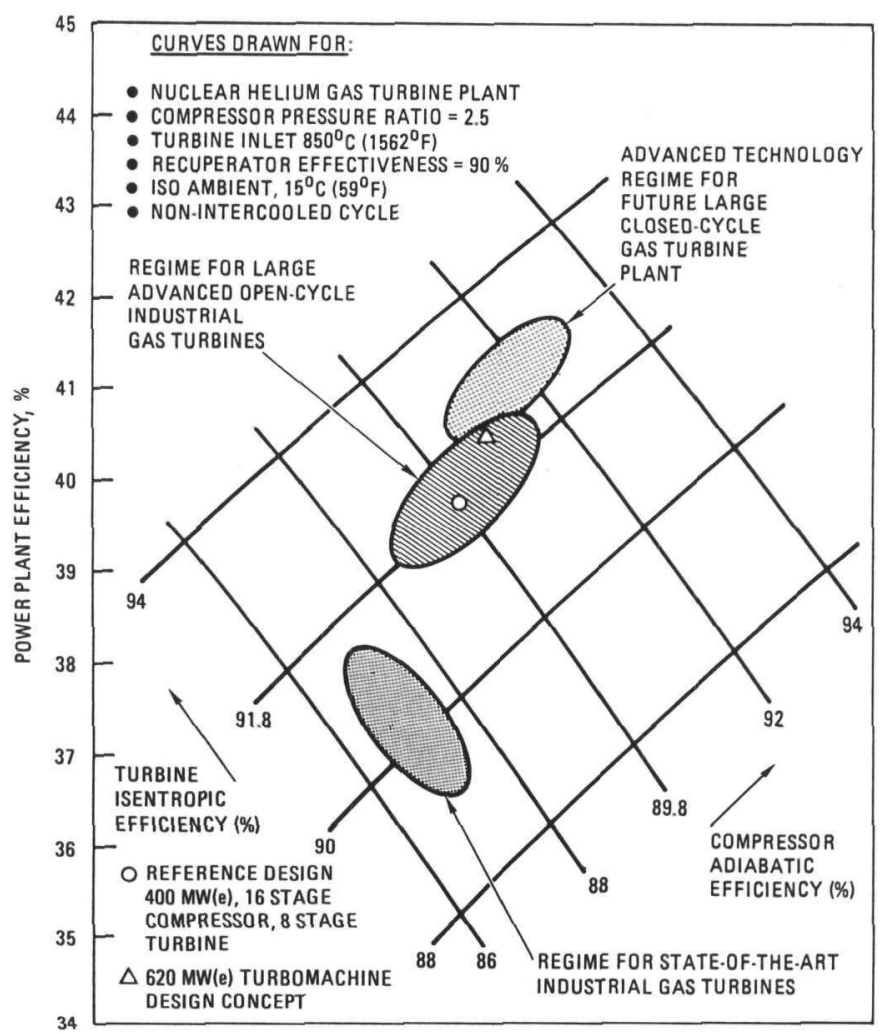

Fig. 8-15. An array showing the influence of compressor and turbine efficiencies on an HTGRGT nuclear closed-cycle power plant.

gas turbine are similar to those of an air-breathing, advanced, open-cycle industrial gas turbine in the $100-\mathrm{MW}(\mathrm{e})$ range.

Studies have been done on the power rating potential for a $60-\mathrm{Hz}$ helium turbomachine. The main point of interest for a given turbine inlet temperature $\left(850^{\circ} \mathrm{C}\right)$ is the influence of machine power on the life expectancy (i.e., stress level in the blading) for a given material. For the $850^{\circ} \mathrm{C}$ turbine inlet temperature and a candidate turbine blade material (IN-100), the interrelationship between firststage blade centrifugal stress and creep rupture life is shown in Fig. 8-16. It can be seen that for the full operating life of $280000 \mathrm{~h}$ (i.e., $40 \mathrm{yr}$ at $80 \%$ utilization), the non-intercooled machine upper limit is $\sim 600 \mathrm{MW}(\mathrm{e})$. The equivalent number for the intercooled machine (with lower helium mass flow) is $\sim 700 \mathrm{MW}(\mathrm{e})$. Higher power ratings are possible with cooled turbine blades, but for the initial HTGR-GT, the simplicity of uncooled blades is preferred.

The industrial technology bases from which the nuclear plant turbomachinery can benefit are shown in Fig. 8-17, which illustrates existing hardware. The 
turbomachine and other PCL components are designed for a 40-yr life; however, they are also designed to be replaceable.

The aforementioned helium turbomachine design considerations relate to the

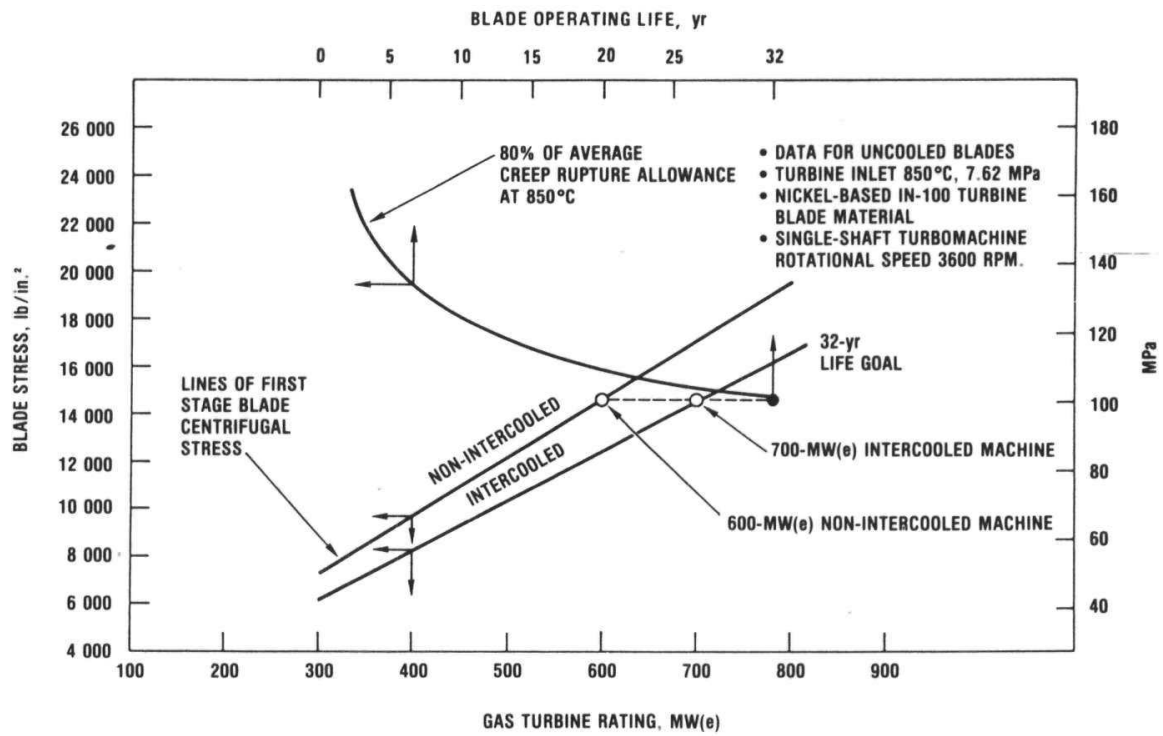

Fig. 8-16. The rating potential for a $60-\mathrm{Hz}$ helium turbomachine with existing nickel-based alloy turbine blading.

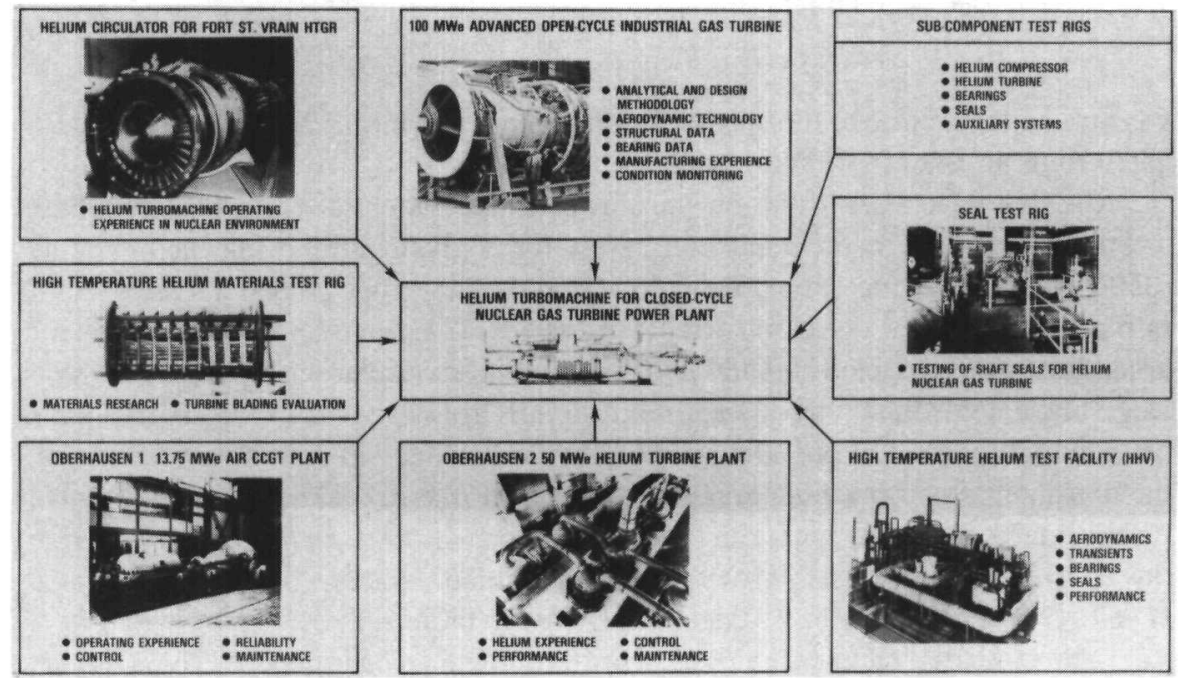

Fig. 8-17. Technology bases for a nuclear closed-cycle helium turbomachine. 
HTGR-GT plant for the U.S. market (i.e., 60-Hz system); however, it should be pointed out that a large effort has also been expended in Europe for the HHT plant ${ }^{12}$ and details of the turbomachine for this $50-\mathrm{Hz}$ system have been reported. ${ }^{24-26}$

\section{8-4B Heat Exchangers}

The heat exchangers, ${ }^{27-29}$ which involve a significant thermal-hydraulic design effort, are large components and have a great influence on the integrated primary system. The combined effects of size constraint (integration in the PCRV side-wall cavities), in-service inspection, in situ repair, and maintenance and fabrication considerations have a significant effect on the choice of surface geometry, flow configuration, and mechanical design. The major heat exchangers in the power conversion system are the recuperator and precooler, and salient features of these units are given in Table 8-IV. The core auxiliary cooling system embodies a core auxiliary heat exchanger, but since this unit is regarded as a generic HTGR component, and has been reported previously, ${ }^{30}$ it is not discussed here.

TABLE 8-IV

Details of HTGR-GT Plant Heat Exchanger Designs

\begin{tabular}{|c|c|c|}
\hline \multirow{2}{*}{$\frac{\text { PCL Ratıng }}{\text { Exchanger }}$} & \multicolumn{2}{|c|}{$\begin{array}{c}400-M W(e) \\
\text { Non-Intercooled }\end{array}$} \\
\hline & Recuperator & Precooler \\
\hline Exchanger configuration & Counterflow & $\begin{array}{c}\text { Multıpass } \\
\text { cross-counterflow }\end{array}$ \\
\hline Construction type & Stratght tube modular & Helical bundle \\
\hline Heat duty/unit $[\mathrm{MW}(\mathrm{t})]$ & 918 & 581 \\
\hline Log mean temperature difference $\left({ }^{\circ} \mathrm{C}\right)$ & 425 & 305 \\
\hline Effectiveness & 0898 & 0972 \\
\hline Tubes per exchanger & 66483 & 827 \\
\hline Tube outside diameter $(\mathrm{mm})$ & 111 & 286 \\
\hline Wall thıckness (mm) & 11 & 29 \\
\hline Modules per exchanger & 83 & 1 \\
\hline Exchanger diameter (m) & 564 & 472 \\
\hline Effective tube length (m) & 122 & 105 \\
\hline Effective bundle height (m) & 122 & 125 \\
\hline Exchanger assembly height (m) & 204 & 198 \\
\hline Exchanger assembly weight (tonnes) & 726 & 435 \\
\hline Maximum metal temperature $\left({ }^{\circ} \mathrm{C}\right)$ & 515 & 177 \\
\hline Maxımum internal $\Delta \mathrm{P}(\mathrm{MPa})$ & 462 & 183 \\
\hline Materials & $\begin{array}{c}\text { Ferritic } \\
2-1 / 4 \mathrm{Cr}-1 \mathrm{Mo}\end{array}$ & Low-alloy \\
\hline In-service inspection/repair level & $\begin{array}{l}\text { Module } \\
\text { Modo }\end{array}$ & Individual tubes \\
\hline Assembly location & Factory/optional & Factory \\
\hline Transportation mode & Barge & Barge \\
\hline ASME code class & Section VIII & Section VIII \\
\hline Design status & Con & \\
\hline Technology status & State-of-the & chnology \\
\hline
\end{tabular}


The heat exchanger types selected for the HTGR-GT plant conceptual design have a sound technology base, and in this regard can be considered conservative Extensive thermal-hydraulic analyses have been performed to identify the optimum configurations and surface geometries for the gas turbine plant, these are summarized below

The helium-to-helıum recuperator concept shown in Fig 8-18 is a straighttube counterflow arrangement, with an overall assembly made up from a mult1plicity of contıguous hexagonal elements Establishing the thermal size of the recuperator entalled scanning parametric surveys for the combination of surface geometry, heat exchanger frontal area (diameter), and effective tube length that fits the avallable PCRV cavity envelope at an acceptable pressure loss The results of a typical thermal-hydraulic analysis for a recuperator embodying plain tubular surfaces is shown in Fig 8-19 The selection of the reference design involves the evaluation of performance (pressure loss), considerations of installation (envelope avalable in PCRV), and fabrication (tube pitch), together with the satisfaction of the goal of minımizing cost In the quest for a design solution that satisfies all of

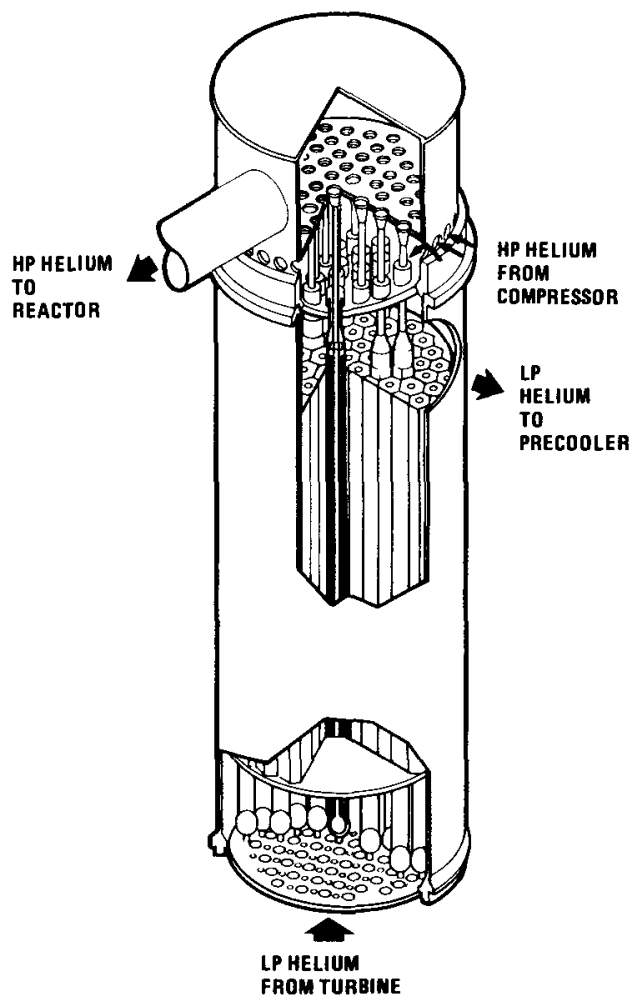

Fig 8-18 The straight-tube, modular, counterflow recuperator concept for an HTGR plant 


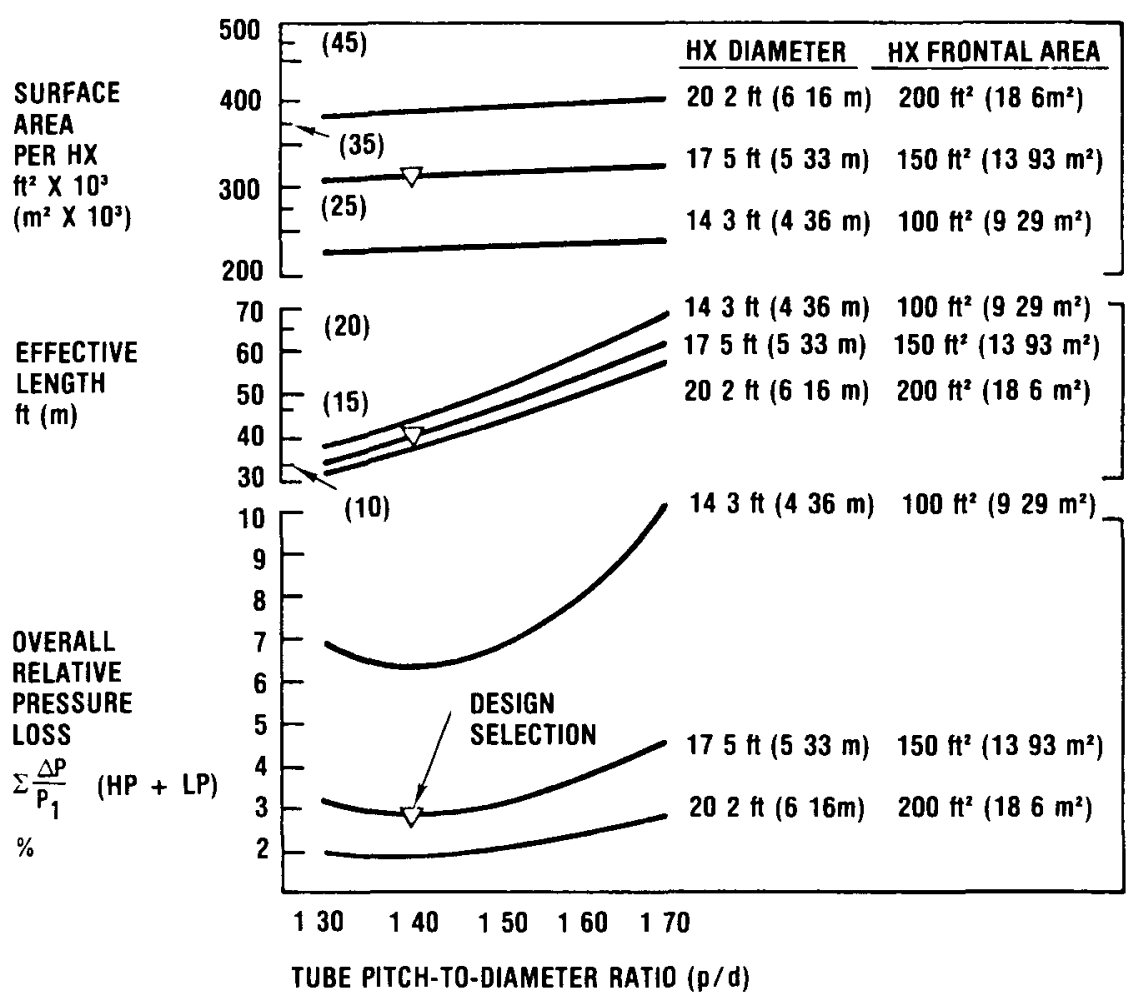

Fig 8-19 Thermal sizing data for an HTGR-GT plant recuperator

the safety, cost, and performance goals, enhanced tubular geometries have been studied Since the PCRV is obviously a major plant cost item, it was thought that PCRV size reductions obtainable through the use of enhanced surface geometries in the heat exchangers might present an avenue by which overall plant costs could be reduced, even though higher heat exchanger costs may result Studies were performed that included an evaluation of finned tubes, artificially roughened tubes, and other enhanced surface geometries These indicated that the overall volume of the heat exchanger could be reduced, but at the expense of frontal area $(1 \mathrm{e}$, an increased diameter accompanied by reduced length) It was concluded that plain tube geometries were satısfactory for the recuperator design

A useful array for comparative purposes, during the prelımınary design ${ }^{28}$ stage that relates heat exchanger thermal-hydraulic parameters, is shown in Fig 8-20 The two curve arrays are related through the common parameter of surface compactness $\left(\mathrm{m}^{2} / \mathrm{m}^{3}\right)$ for lines of different heat flux $\left(W / \mathrm{cm}^{2}\right)$ The plot on the right shows the relationship between tube diameter, normalized pitch parameter, and surface compactness ( $1 \mathrm{e}$, thermal-hydraulic considerations) Design points for various helium heat exchangers are shown superımposed on the curve array 
To achieve high thermal density (for integration in the PCRV) and low flux (for low thermal stress), it is necessary to utilize quite compact surfaces (i.e., tubes of a small diameter, closely pitched), and studies have indicated that straight-tube designs offered practical solutions (fabrication and performance). As can be seen

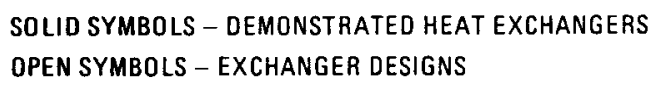

REGIME FOR ADVANCED TECHNOLOGY COMPACT TUBULAR HEAT EXCHANGERS FOR POWER PLANT APPLICATION

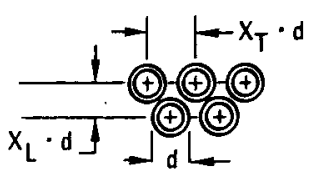

SURFACE GEOMETRY DETAILS DATA PRESENTED FOR PLAIN TUBULAR SURFACE GEOMETRIES

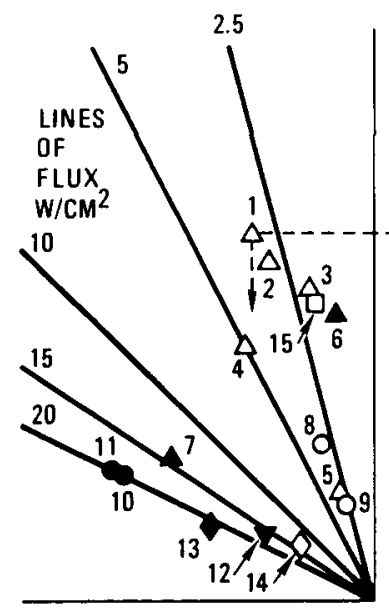

$\begin{array}{lllllllll}16 & 14 & 12 & 10 & 8 & 6 & 4 & 2 & 0\end{array}$

THERMAL DENSITY, MW/M ${ }^{3}$

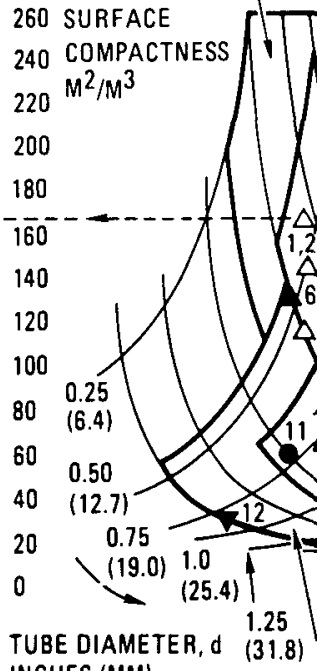

INCHES (MM)

\subsection{5}

STATE.OF-THE.ART INDUSTRIAL HEAT EXCHANGER REGIME STRAIGHT-TUBE HELIUM HEAT EXCHANGER REGIME FOR ADVANCED HTG $R$ POWER PLANTS HELICAL GEOMETRY HEAT EXCHANGER REGIME

KEY

$\triangle$ STRAIGHT-TUBE HELIUM EXCHANGERS

1. HTGR-GT MODULAR RECUPERATOR

2. HTGR.PH IHX CONCEPT

3. MONOLITHIC RECUPERATOR CONCEPT

4. IHX DESIGN CONCEPT

5. IHX DESIGN CONCEPT

6. OBERHAUSEN 2 HELIUM TURBINE PLANT RECUPERATOR

7. PEACH BOTTOM HTGR U.TUBE STEAM GENERATOR
- HELICAL GEOMETRY EXCHANGERS

8. IHX DESIGN CONCEPT

9. IHX DESIGN CONCEPT

10. FORT ST. VRAIN HTGR STEAM GENERATOR

11. DRAGON HTR STEAM GENERATOR

ADDITIONAL DATA POINTS

$12,13,14$, POWER PLANT STEAM GENERATORS

15. HTGR-GT HELICAL HELIUM-TO. WATER PRECOOLER DESIGN CONCEPT

Fig. 8-20. Thermal and surface density relationships for tubular heat exchangers. 
from Fig 8-20, the data point for the proposed recuperator is in the regime where the above requirements are realized

The helium-to-water precooler concept shown in Fig 8-21 is a multipass cross-counterflow helical bundle arrangement The waterside of this unit is pressurized only to the point at which bolling is suppressed, and if leaks develop, the water would not enter the reactor primary system because of the higher level of pressure on the gas side of the exchanger

With single-phase fluids on both sides of the precooler, only modest heat transfer coefficients are realızable for the constraints imposed on pressure loss for both the helium and water circuits The large thermal conductance for this exchanger can be seen clearly in Fig 8-22

In the thermal-hydraulic analysis of the precooler, both plain tube and en-

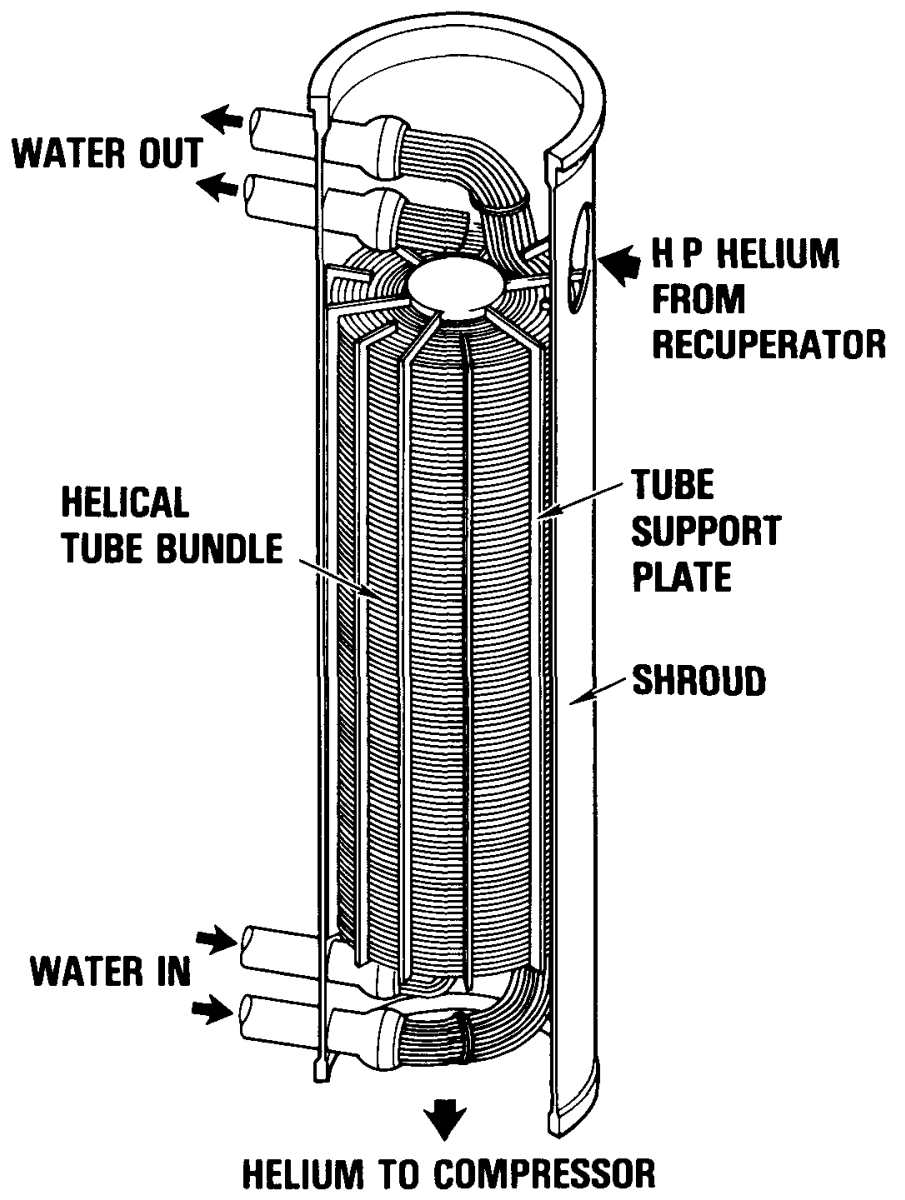

Fig 8-21 The helical-bundle, cross-counterflow, hellum-to-water heat exchanger concept 


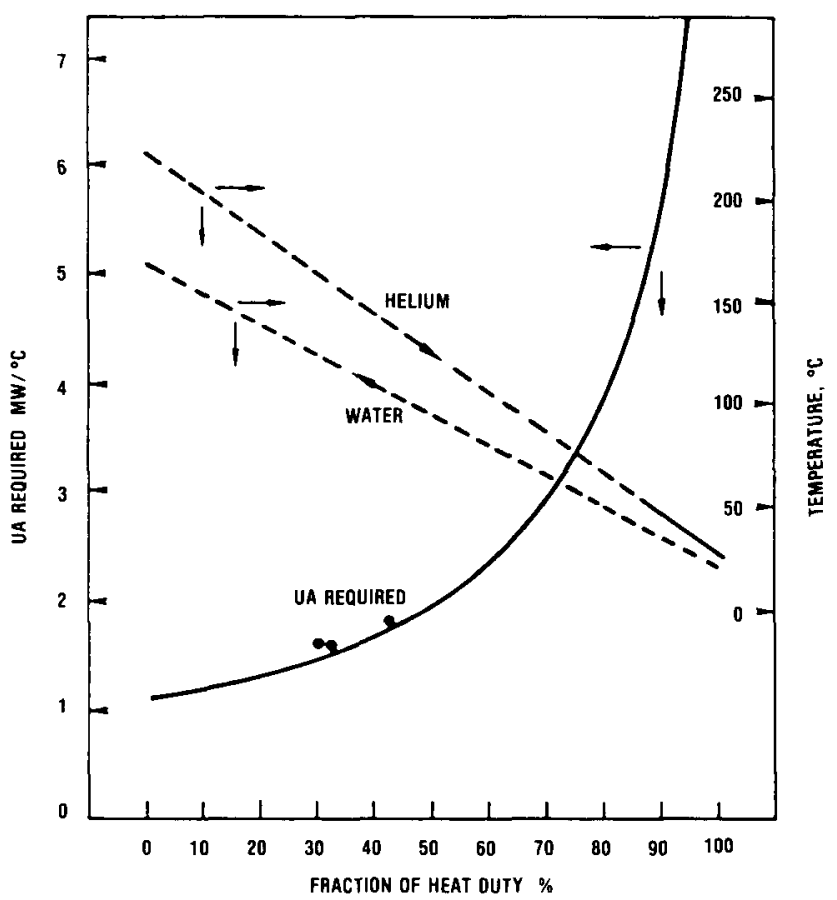

Fig 8-22. Precooler thermal requirements.
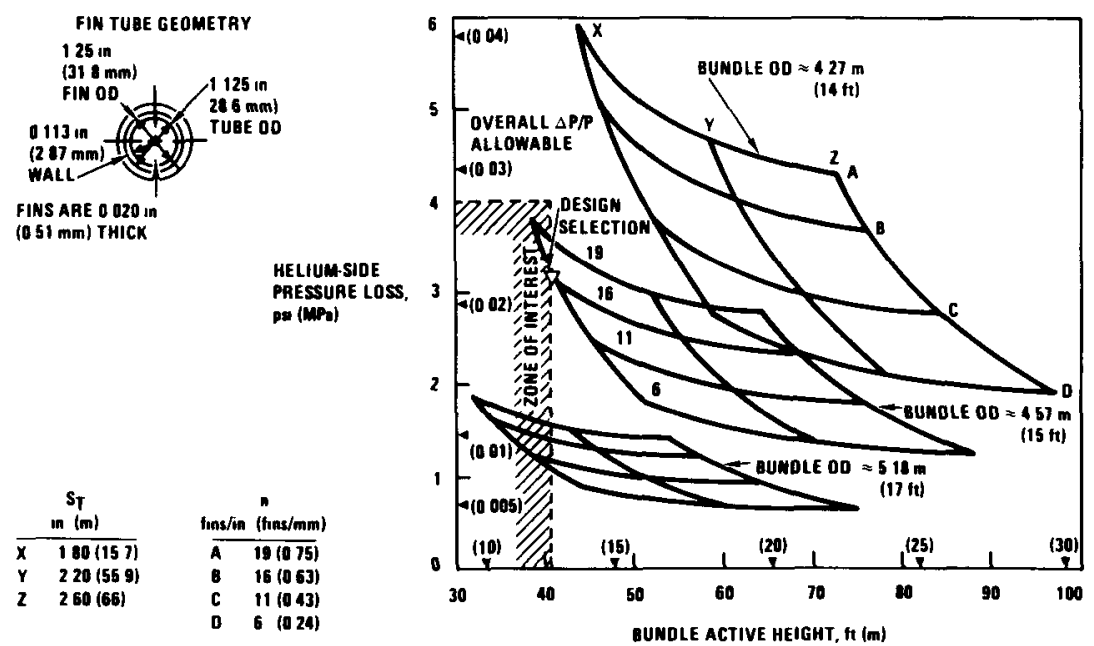

Fig 8-23. Precooler thermal size options. 
hanced surface geometries were evaluated. The large heat exchange requirement and PCRV envelope restrictions virtually necessitated using externally finned tubes. While the gas side is controlling, it was necessary to establish a flow geometry with an acceptable waterside velocity. In the study of various configurations, the optimum (in terms of performance and envelope) was found to be a helical bundle with a multipass cross-counterflow arrangement.

Figure 8-23 presents a typical parametric survey of precooler thermal size options. Helium pressure loss and tube bundle height are shown as functions of tube pitch and fin count for three separate "islands" of precooler diameter. The thermal size selection falls within a "zone of interest" defined by the allowable bundle pressure loss and the bundle height limit, as established by PCRV layout considerations.

The recuperator and precooler assemblies are integrated in the PCRV, and the interfaces have received attention during the conceptual design phase to ensure the viability of the selected mechanical design approaches. The axial counterflow recuperator (embodying tubes of small diameter) bears a close resemblance to units that have operated trouble-free for over half a million hours in the European fossil-fired CCGT plants. The multipass cross-counterflow helical bundle approach selected for the precooler has been used extensively for steam generators in gascooled reactors. From Fig. 8-24 it can be seen that a substantial technology base exists for the design of helium heat exchangers.

Another obvious issue related to the size and weight of the heat exchangers is the technology for handling, transporting, and installing the units in the reactor

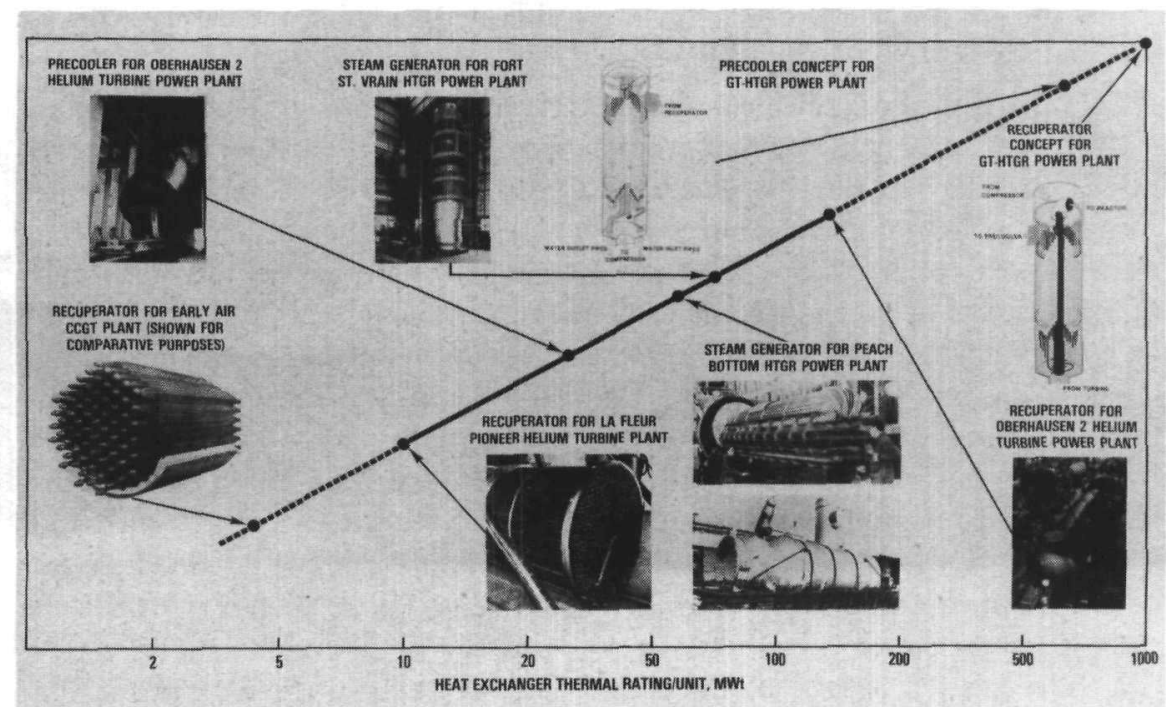

Fig. 8-24. Helium heat exchanger design evolution. 
vessel. In this regard, it should be noted that the heat exchangers for the HTGR-GT are, in fact, no longer or heavier than units being built for contemporary steam plants, and that existing and proven methods of handling and transportation are indeed applicable.

A large effort has also been expended in Europe for the heat exchangers of HHT plants. ${ }^{31-34}$

\section{8-4C Systems Studies in Support of Component Design}

In-depth systems analyses have been performed on the HTGR-GT in support of design activities. Establishing the system transients is a vital task for a complex plant such as the gas turbine. Operation, control, and protective system transient analyses have been performed. ${ }^{35-39}$ A major difference between the steam cycle and gas turbine variants of the HTGR is that in the direct-cycle plant, the primary system has essentially two pressure levels (i.e., compressor inlet and outlet) that are on the order of $5 \mathrm{MPa}$ (50 bars) apart. If a failure should occur, in the turbomachine for example (i.e., turbine deblading or rotor failure), there will be a rapid equilibration of system pressure: detailed transient analyses of this event have been made. ${ }^{39}$ Such transient data are necessary to design the primary system, particularly the core support structure and the thermal barrier. ${ }^{40}$ With a highenergy turbomachine in the reactor primary system, the impact of the high acoustic level on critical components has also been investigated. ${ }^{41}$

\section{8-5 Waste Heat Utilization}

\section{8-5A Cogeneration Possibilities}

In the United States, the waste heat discharged from utility power plants is $\sim 10 \%$ of the energy consumed each year, and currently this thermal energy is merely discharged to the environment (often in a controversial manner). In coming decades, the intrinsic economic worth of power plant reject heat will be too valuable to be merely discharged to the environment, and plants of the 21 st century are projected to operate in a combined power-plus-heat mode (i.e., cogeneration).

Utilizing high-grade reject heat for district heating, process steam production, desalination, etc. must be part of a national program to conserve resources. Establishing users and operators involves long-term planning, and in many cases, overcoming institutional barriers. Pressured by the coming period of energy consciousness and possible era of energy shortage, power plant waste heat utilization is projected to become a reality on a wide scale in the 21 st century and may well be in concert with a future very high efficiency second-generation HTGR, namely, the gas turbine option.

Cogeneration aspects of the HTGR-GT have been discussed previously. ${ }^{42}$ Figure 8-25 illustrates several ways in which the waste heat from an HTGR-GT plant could be utilized. Although an owner/operator may not want multiple heat 


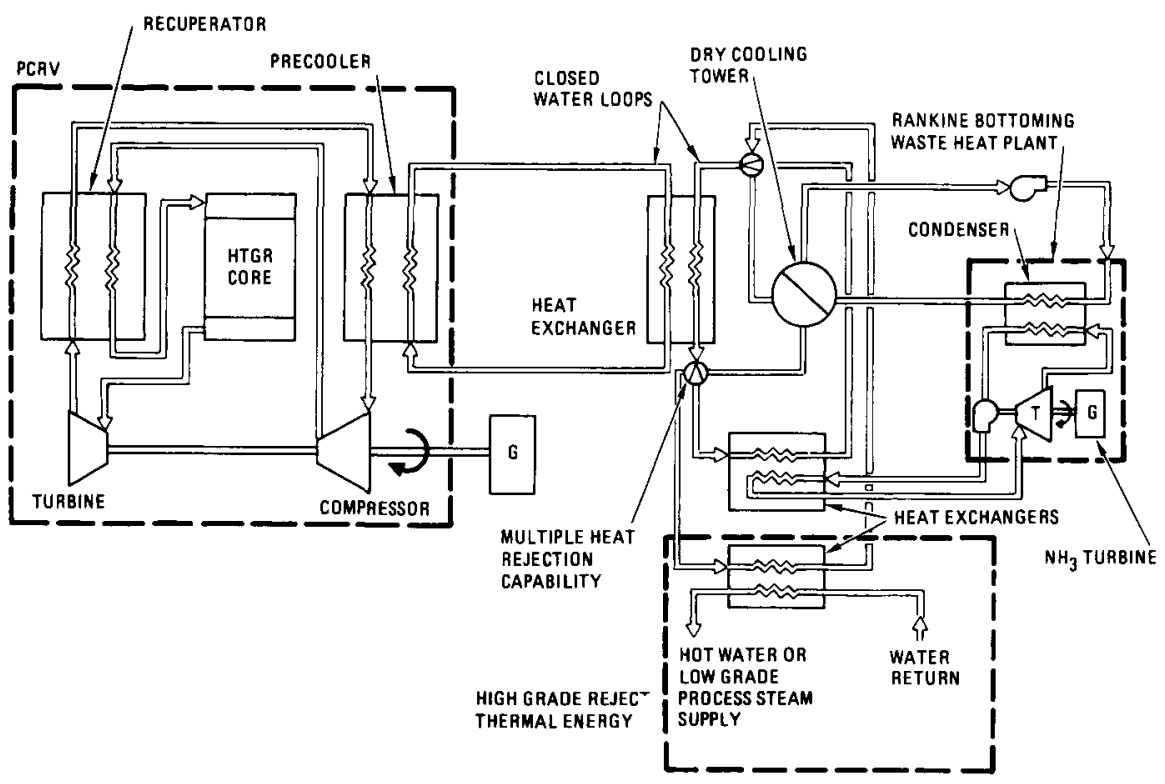

Fig 8-25 Flow schematic showing cogeneration options for an HTGR-GT plant

rejection capability, Fig 8-25 illustrates the operational flexibılity Heat rejection alternatives are briefly discussed below

\section{8-5B Dry Cooling}

Concern has been expressed over the avalability of cooling water for power plants (nuclear and fossil), the lack of water (in certain regions of the United States), together with ever-increasing environmental demands, may no longer permit plant sitıng near existıng bodies of water ( $1 \mathrm{e}$, lakes, nvers, oceans) The heat rejection characteristic of the CCGT is conducive to economic dry cooling, and the use of natural-draft dry-cooling towers can provide good performance over a wide range of temperatures in virtually any region desired Plant siting flexibility is one of the factors motivatıng the study of the CCGT for fission reactors

In dry cooling, the CCGT naturally rejects its heat over a wide range of temperatures, since the heat is derived from the sensible, rather than the latent, heat of the single-phase working fluid This temperature range is about an order of magnitude higher than permissible condensate temperature rise (see Figs 8-3 and 8-9), meaning that dry towers for a Brayton cycle plant could be designed for about a tenth of the airflow needed for the alternative Rankine cycle steam plant The towers are therefore smaller (also related to the higher efficiency of the Brayton cycle) and the higher exit air temperature induces greater buoyancy, 

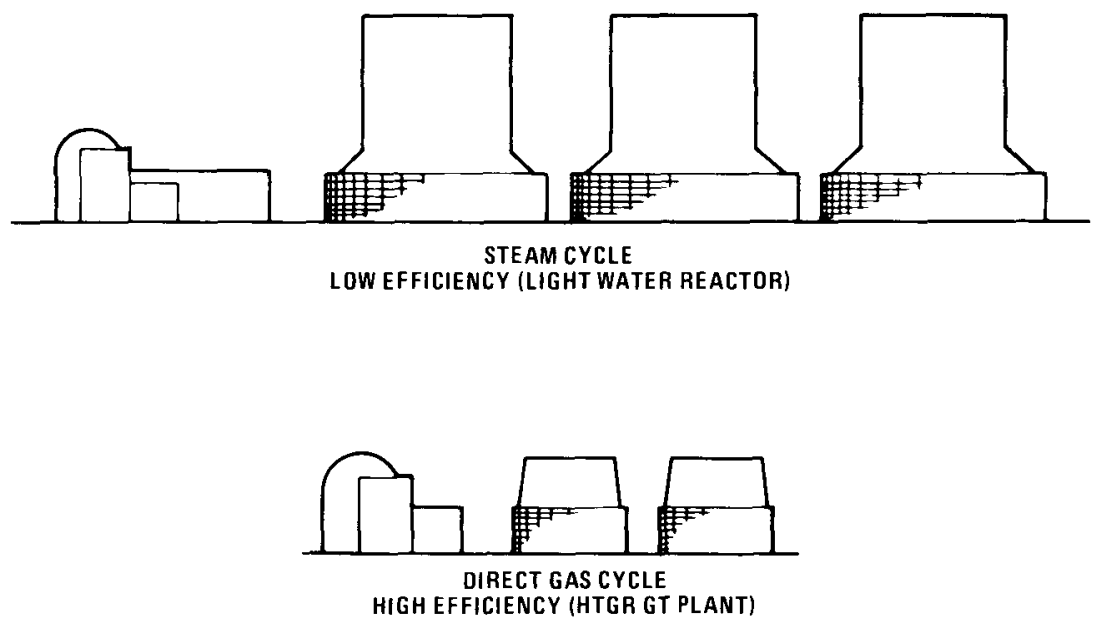

Fig 8-26 Simplified comparıson of steam cycle (Rankıne) and gas turbıne (Brayton cycle) plant skyline profiles for dry cooling

causing an almost threefold increase in air velocity to aid heat transfer and further reduce the tower size A comparison of plant cooling requirements is dramatically shown in the skyline profile of Fig 8-26 The savings in water consumption for a dry-cooled gas turbıne plant are significant Studies related to dry coolıng have been performed, ${ }^{43}$ and the gas turbine plant can take advantage of advanced cooling concepts, currently in the research stage, including the use of ammonia as the heat transport medium ${ }^{45}$ Flexibility of siting for an economical dry-cooled fission plant in the early decades of the 21 st century could be a motıvating factor in the selection of the high-efficiency HTGR gas turbine variant

\section{8-5C District Heating}

Many small installations already supply district heatıng in U S cities, but switching to large centralized facilities for urban and industrial heating can only be regarded as a long-term goal, and, indeed, would require a dedicated natıonal program

For the CCGT, combined power and heat production has been thoroughly discussed previously ${ }^{46} 47$ Possibilities for district heatıng using nuclear power plants have been reported ${ }^{48} 49$ particularly for a nuclear CCGT ${ }^{50-52}$

Another important feature of the HTGR-GT power conversion system is the flexibility with regard to combined electrical power and heat production Figure 8-27 shows that the electrical power is not very sensitive to the amount of heat produced, for example, when process heat production is doubled, the electrical power is only reduced by $\sim 25 \%$ This contrasts with a steam turbine plant with steam extraction (for water heatıng, etc) or backpressurıng, where a significant 


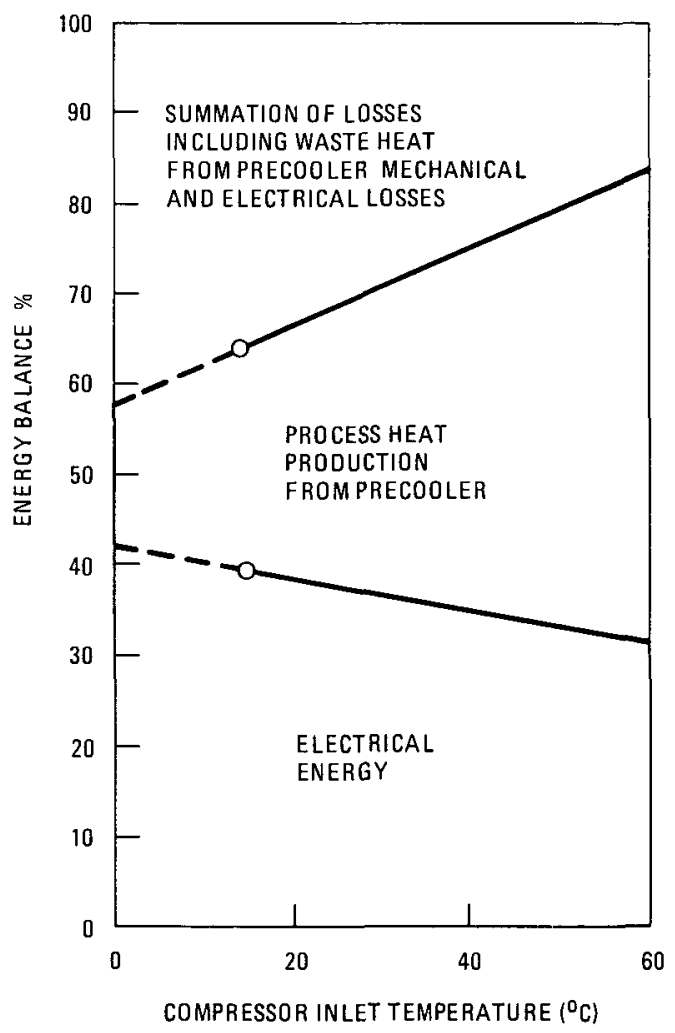

Fig 8-27 Energy balance as a function of compressor inlet temperature for a CCGT to illustrate the combined power and heat production capability

penalty is paid in electrical output Figure 8-27 shows that simply changing the compressor inlet temperature can control the plant heat-to-power ratio

District heatıng, particularly of the HTGR-GT magnitude, requires a large transmission and distribution system The heat is removed and used in the transfer heat exchangers as sensible rather than latent heat European practice indicates that pressurized water, because of its efficient heat transfer properties and high specific heat, is probably the best fluid Figure 8-25 shows that the reject thermal energy could be in the form of hot water or process steam A CCGT plant advantage is that its high water reject temperature could allow air to be heated at the enduser point The expense of conversion would be minımized for the end user since a large number of the present residential, commercial, and industrial installations now use air systems Another advantage of the high water temperature is that it could be used for air conditioning, which would increase the annual system utilization

The avallable reject heat from even a small HTGR-GT plant [single-loop, 
400-MW(e)] is still sufficient for a population of $\sim 50000$ living in a winter climate as severe as that of Chicago, a city in the midwestern United States. The $50-\mathrm{MW}(\mathrm{e})$ Oberhausen 2 (fossil-fired) helium turbine plant in West Germany ${ }^{14}$ with a reject thermal heat of $54 \mathrm{MW}(\mathrm{t})$ is currently the largest CCGT combined power and heating plant.

\section{8-5D Process Steam Production}

Of the total U.S. energy requirement, $\sim 16 \%$ is used to produce industrial process steam. Even with conservation measures, overall industrial steam consumption is expected to increase more than $2 \% / y r$ over the next decades and at a much higher rate in some industries.

Most industrial steam-generating equipment is fired by natural gas or oil and is usually of small capacity. In the coming decades, these two clean fossil fuels will be too valuable to burn for electricity and process steam production, and will be needed for chemical feed stocks and transportation. Forty-five percent of the energy used by American industry goes into producing process steam, which is typically used at $\sim 177^{\circ} \mathrm{C}\left(350^{\circ} \mathrm{F}\right)$. This quality of steam can be generated from the heat leaving the precooler of the HTGR-GT plant $\left(225^{\circ} \mathrm{C}\right)$. The electrical output from the plant would be essentially unaffected by the process steam generation, and the efficiency and power costs would not be compromised.

\section{8-5E Desalination}

Although small-to-medium-sized fossil-fired desalination plants are operating in several countries, available technology has rarely been extrapolated to the scale required for coupling to large plants.

For the range of temperatures available from the reject-heat side of the HTGR-GT plant, the basic multistage flash-evaporation process arrangement typically used for desalination can be adopted. Preliminary studies for the HTGRGT plant ${ }^{53}$ indicate that several progressively shorter parallel sections of the typical heat recovery modules should be used, as shown in Fig. 8-28. The condenser brine is successively fed from the largest train down to the shortest train, with product water leaving each module. Use of the multiple-heat-recovery principle, which is made possible by the high reject-heat temperature, requires slightly larger brine recycling pumps compared to a conventional unit with a constant temperature input. The economic impact of this is more than offset by the $\sim 80 \%$ increase in distilled water output for equivalent heat input.

\section{8-5F Hybrid Plant Operation}

The well-established process of hydrogen generation by electrolysis can be considered for a high-efficiency plant such as the HTGR-GT. During off-peak electrical and heat demand periods, the plant could operate as a combined cycle 


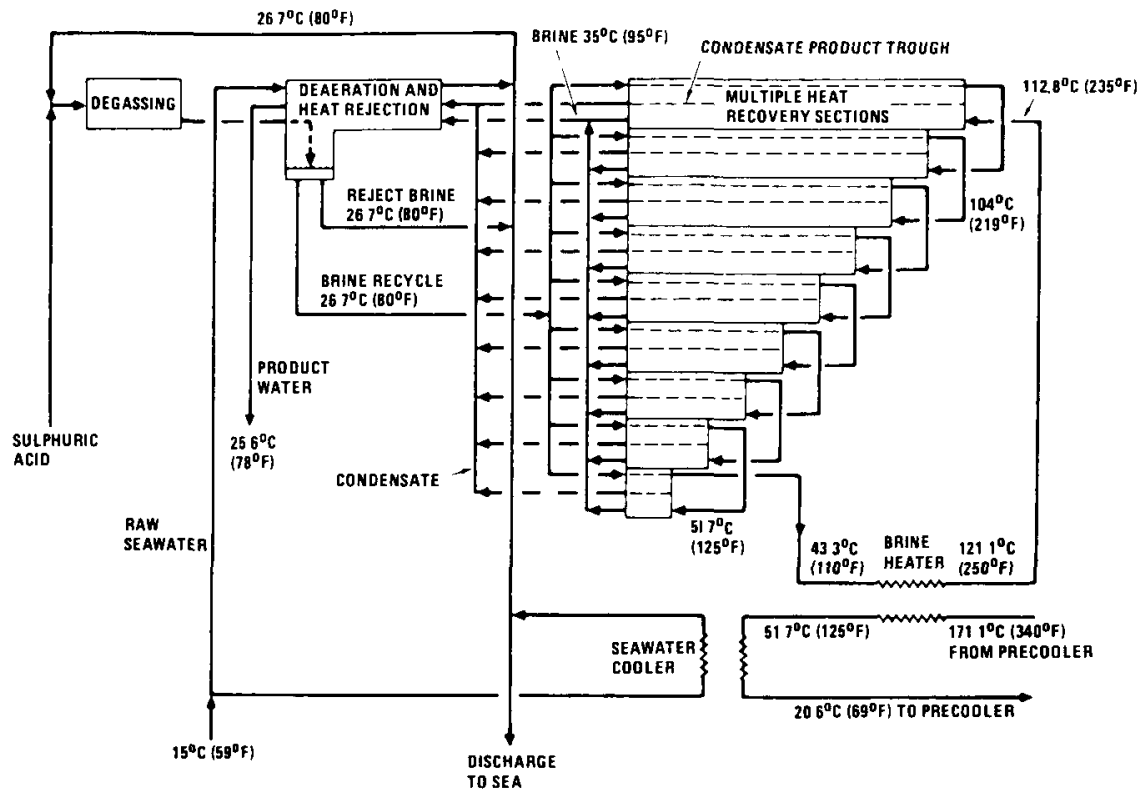

Fig. 8-28. Desalination module for coupling to an HTGR-GT power plant.

plant with an overall efficiency of $\sim 50 \%$ (see the following section), and the plant output could be used for hydrogen production by electrolysis. ${ }^{54}$ This capability is not, of course, unique to the HTGR-GT, but it will most likely be realized only for high-efficiency systems.

Hydrogen has a lower transmission cost than electricity or hot water. It can be pumped to the end-user site, used as a feedstock for petrochemical processes, stored as a gas, or liquified. Operation of the plant in a hybrid mode adds flexibility for changing consumer demands, and provides high availability of the nuclear heat source. Operation of nuclear plants in a hybrid mode [with a reactor outlet temperature perhaps as high as $\left.1000^{\circ} \mathrm{C}\left(1832^{\circ} \mathrm{F}\right)\right]$ has been projected for advanced HTGR complexes of the future. ${ }^{55}$

\section{8-5G Bottoming Rankine Cycles}

With added emphasis on fuel conservation and minimum environmental impact, cogeneration studies ${ }^{42}$ have examined the waste heat utilization from the HTGR-GT plant secondary cycle. Figure 8-29 shows a simplified bottoming cycle. As shown, the bottoming cycle only entails substituting a vaporizable liquid (e.g., ammonia or steam) for the water normally in the reject heat exchanger (associated with an external vapor turbine, pump, and condenser). The approximately triangular-shaped bottom cycle diagram in Fig. 8-29 should best fit the "space" available for the bottom cycle operation; this is influenced by the choice of working 


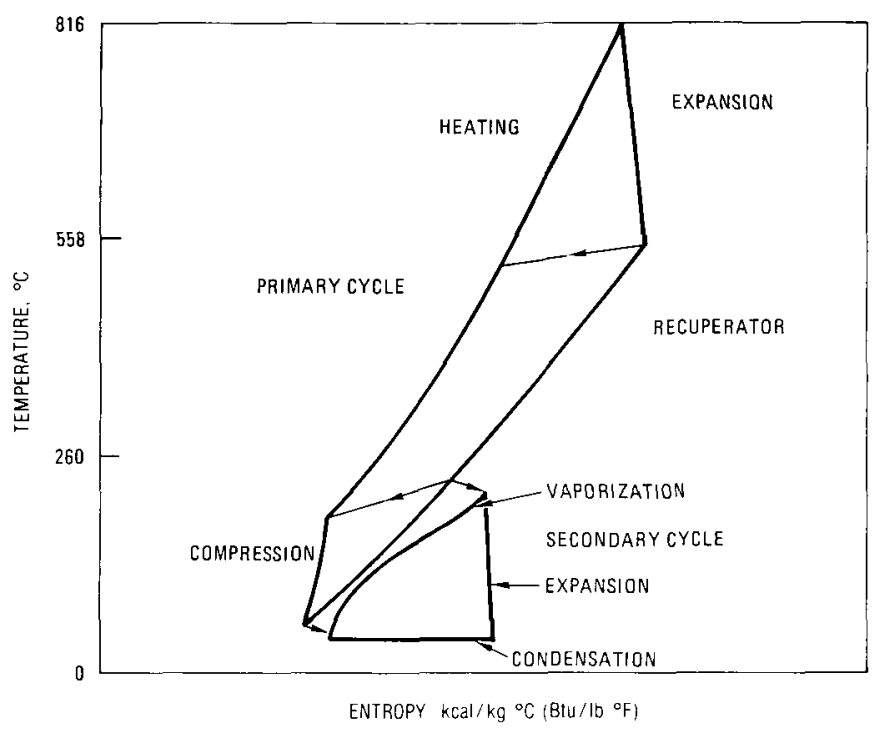

Fig. 8-29. A simple temperature/entropy diagram for an HTGR-GT binary cycle.

fluid. Irreversibility in the secondary cycle heat source exchanger should be minimized by utilizing a supercritical cycle, which can match well the HTGR-GT plant heat rejection characteristics. Initially, a supercritical ammonia cycle was studied $^{56}$ to determine the performance potential of the system, recognizing that steam is preferred by plant operators because it is the conventional medium and existing equipment could be used.

System studies ${ }^{57}$ and equipment conceptual designs helped evaluate the economic and performance potential of an ammonia bottoming cycle. The classical temperature plateau associated with normal evaporation (in the temperature/entropy diagram) was flattened to give an ammonia heat input characteristic well matched to the heat source (see Fig. 8-30a). Conceptual design work on the major components $^{58}$ and ammonia turbine ${ }^{59}$ was performed in sufficient detail to establish feasibility and cost.

Experimental programs are under way in France ${ }^{60}$ to study ammonia bottoming cycles for pressurized water reactors. An old fossil-fired steam plant in Paris will be retrofitted with an ammonia bottoming turbine and is scheduled ${ }^{61}$ for initial operation in the early 1980s. Use of ammonia rather than water in the dry-cooling tower is more economical because (a) phase change is nearly isothermal, permitting a closer approach temperature with the air; (b) the high product of heat vaporization and density gives a greater heat rejection capacity per unit volume than water; and (c) freezing problems in the tower are eliminated. ${ }^{62}$

To answer utility concerns about the use of exotic fluids, two steam cycles have also been evaluated. Both involve variants to established and conventional steam cycles to match the HTGR-GT characteristics. 

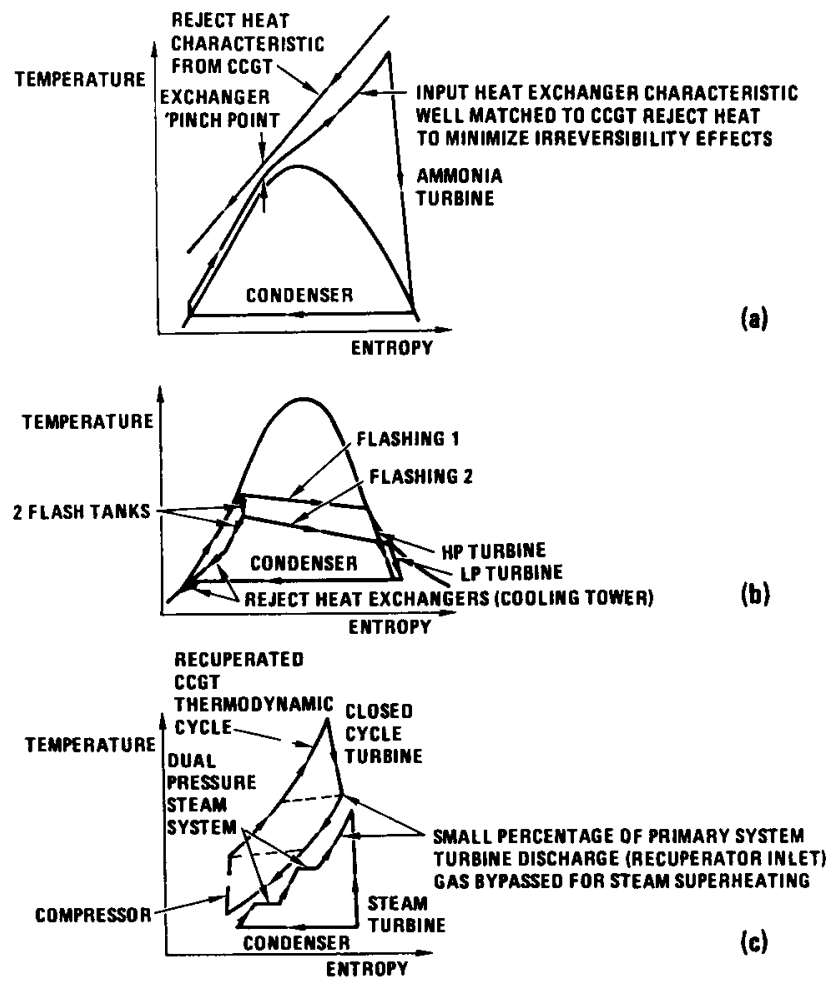

Fig 8-30 Thermodynamic diagrams for candidate CCGT bottomıng cycies (a) supercritical ammonia bottomıng cycle, (b) flashıng steam bottomıng cycle (two stages of flashıng shown) based on utilization of conventional low-pressure steam equipment, and (c) pseudo temperature/entropy diagram for Tilliette steam cycle showing dual-pressure and superheatıng system to match CCGT heat rejection characteristic

One system (Fig 8-30b) involves generatıng additional electrical power by simply flashing the reject heat exchanger water outlet to steam and passing it through low-pressure turbines The system thermodynamics are dependent on water temperature and the number of flashing stages (two are shown in Fig 8-30b) This approach means that exıstıng steam flashıng/separatıng equipment, turbines, condenser, and pıpıng/valves can be used While these equipment items will be large, because of the high volume flow, they are regarded as technically simple and state-of-the-art

The second system ( $\mathrm{F} 1 \mathrm{~g} \quad 8-30 \mathrm{c}$ ) involves bypassing a small percentage of the high-temperature gas at the turbine exit conditions to superheat the steam ${ }^{63} \mathrm{By}$ utılızıng a dual pressure steam system, the bottomıng cycle characteristics can be well matched to the primary system This system offers the potential for high thermodynamic efficiency from the bottoming cycle, but this efficiency is paid for by substantial plant complexity and a large number of components 
In Fig. 8-31, the plant performance projections for various HTGR-GT cycles are shown. As mentioned in an earlier section, the reference plant (dry-cooled) has an efficiency of $40 \%$ with a reactor outlet temperature of $850^{\circ} \mathrm{C}\left(1562^{\circ} \mathrm{F}\right)$. Incorporating a bottoming cycle (as outlined above) in the reference plant would increase the overall efficiency to $\sim 47 \%$. With plant operation in the combinedcycle mode at currently perceived process-heat HTGR core outlet temperatures $\left(950^{\circ} \mathrm{C}\right)$, a utility power plant with a $50 \%$ efficiency should be realizable in the long term.

Efficiency levels $>50 \%$ can be projected with the use of exotic working fluids such as dissociating nitrogen tetroxide. While work in the United States has not proceeded beyond thermodynamic studies ${ }^{64,65}$ for chemically reacting gases, there does exist significant potential for Brayton/Rankine cycle systems.

\section{8-6 Gas Turbine Plant Development}

\section{8-6A Technical Issues}

The technical issues have been reported previously, ${ }^{3}$ and those presented below are essentially related to having the helium turbine in the reactor system and do not include generic HTGR issues:

1. helium turbomachine integrity (safety and licensing concern)

2. turbomachine structural integrity verification

3. reactor system pressure transients

4. lubrication oil ingress

5. seal design

6. primary system acoustic level

7. materials considerations

8. maintenance considerations.

It is recognized that a large development effort is necessary to resolve these issues.

\section{8-6B Safety Considerations}

The safety philosophy and criteria developed for the steam cycle plant are largely applicable to the gas turbine variant, a major exception being the installation of the turbomachine within the reactor vessel. In-depth systems and safety analyses addressed the issue of having a very high energy rotating machine in close proximity to the reactor core. These studies led to the decision that failure of the turbomachine rotor, concurrent with a "safe shutdown" earthquake, be considered a design-basis event. Studies of the gas turbine indicated that the worst case was a failure of the rotor in one revolution of the machine. Transients associated with this failure mode are severe and have necessitated redesign of the core support floor to take the high-pressure loading.

In 1981 , at the time gas turbine plant studies were discontinued in the United 


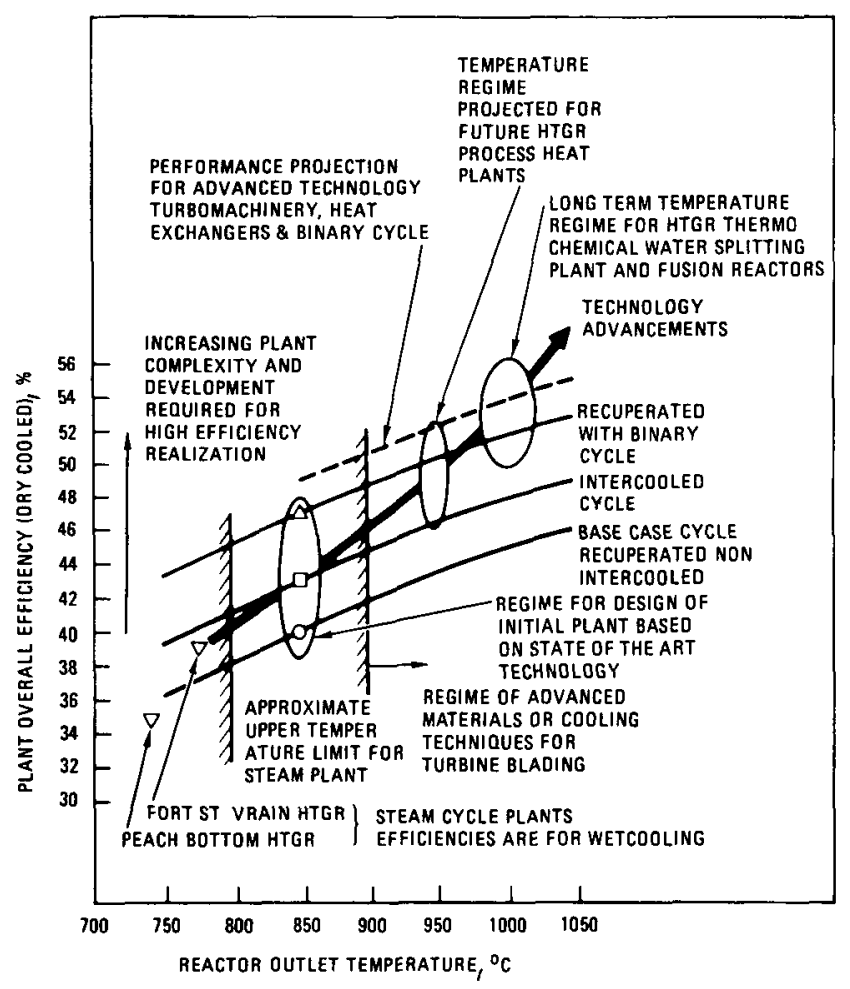

Fig. 8-31. Performance trends for CCGT plants with differing thermodynamic cycles.

States, all of the safety issues were not resolved. In light of increasingly demanding safety goals, it is likely that new criteria would have to be developed for a gas turbine in the future, and these would surely have a considerable influence on the plant design features.

\section{8-6C Development}

Various development approaches have been reported, ${ }^{66,67}$ having recognized that the singular most important component requiring development is the turbomachine. It is germane to discuss the enormous technology base and ongoing development activities that are supportive of the introduction of a large helium turbomachine.

For over 40 years, CCGT plants in Europe have operated in a combined power and heat production mode with fossil-fired sources. The wide range of existing CCGTs is illustrated in Fig. 8-32. The largest unit in utility service is the fossil-fired Oberhausen 2 helium turbine plant in West Germany, which was designed for $40 \mathrm{MW}(\mathrm{e})$ and $54 \mathrm{MW}(\mathrm{t})$ for district heating. 


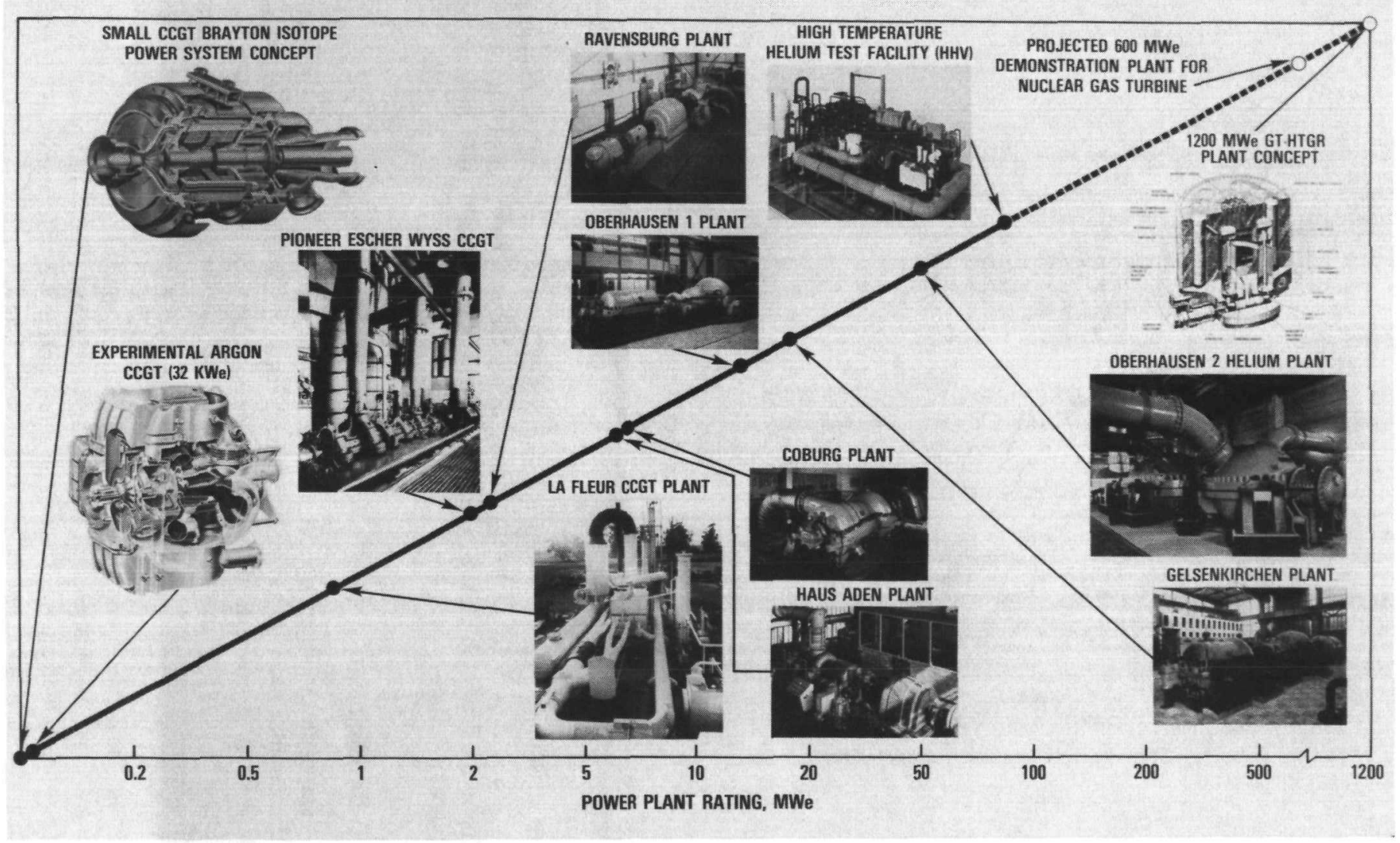

Fig. 8-32. An array showing the wide power range of existing CCGT gas turbine plants with extrapolation to nuclear CCGTs of the future. 
The increasing activity in the nuclear gas turbine field has resulted in intensive helium turbomachinery design studies, and it is pertinent to review the related technology in this field. The portrayal of data in Fig. 8-33 shows that there is an established technology base for the design of helium turbomachinery, there having been several multistage axial flow turbomachines designed and operated over a wide power range. While the properties of helium are different from air, the established aerodynamic analytical design techniques from open-cycle air turbomachinery are directly applicable.

Two large helium facilities, which are regarded as key elements in the development effort for the HTGR-GT plant, are operational in West Germany:

1. 50-MW(e) Oberhausen 2 Helium Turbine Plant. The EVO utility helium turbine power plant in West Germany (discussed in Ref. 68 and shown in Fig. 8-34) is fired with fossil fuel and was designed with the objective, in addition to the production of electric power and district heating, of acquiring from this prototype system experience useful in the design, construction, and operation of large-scale helium turbine systems. The selection of a relatively low primary system pressure of $28 \mathrm{bar}$, and a turbine inlet temperature of $750^{\circ} \mathrm{C}$ yields a large volumetric flow of the helium working fluid, which is of the same order of magnitude as largescale systems. Thus, the major components in the power conversion system, namely, the turbomachine, heat exchangers, and ducting, are similar to those for the HTGR-GT plant.

Recognizing the "first-of-a-kind" nature of this large helium turbine plant, some difficulties were experienced in its initial operation. Thermal expansion problems in some of the large casings necessitated redesign of the bearing and buffer systems. Incorrect heat treatment of the rotor resulted in a permanent bow that limited rotational speed and power output. This was remedied by installing a new rotor, and the plant was put into service as a cogeneration unit (i.e., electric power plus hot water production for district heating). Pressure losses in the system were higher than estimated, and this resulted in a power output less than the rated value of $50 \mathrm{MW}(\mathrm{e})$.

2. High-Temperature Helium Test Facility (HHV). The HHV facility at Kernforschungsanlage in Jülich, West Germany, is for experimental and developmental purposes only, and is designed for testing specific components of a nuclear gas turbine under representative operating conditions. The helium gas is circulated in the system by means of a turbomachine driven by an electric motor. As a result of the compressor work, the helium can be heated up to $1000^{\circ} \mathrm{C}$ so that a heater fired by fossil fuels has been eliminated. The facility has operated successfully for $600 \mathrm{~h}$ with a turbine inlet temperature of $850^{\circ} \mathrm{C}$. The turbomachine consists of two turbine stages that produce $\sim 46 \mathrm{MW}(\mathrm{e})$ and an eight-stage compressor that absorbs $90 \mathrm{MW}(\mathrm{e})$, the difference being supplied by a 


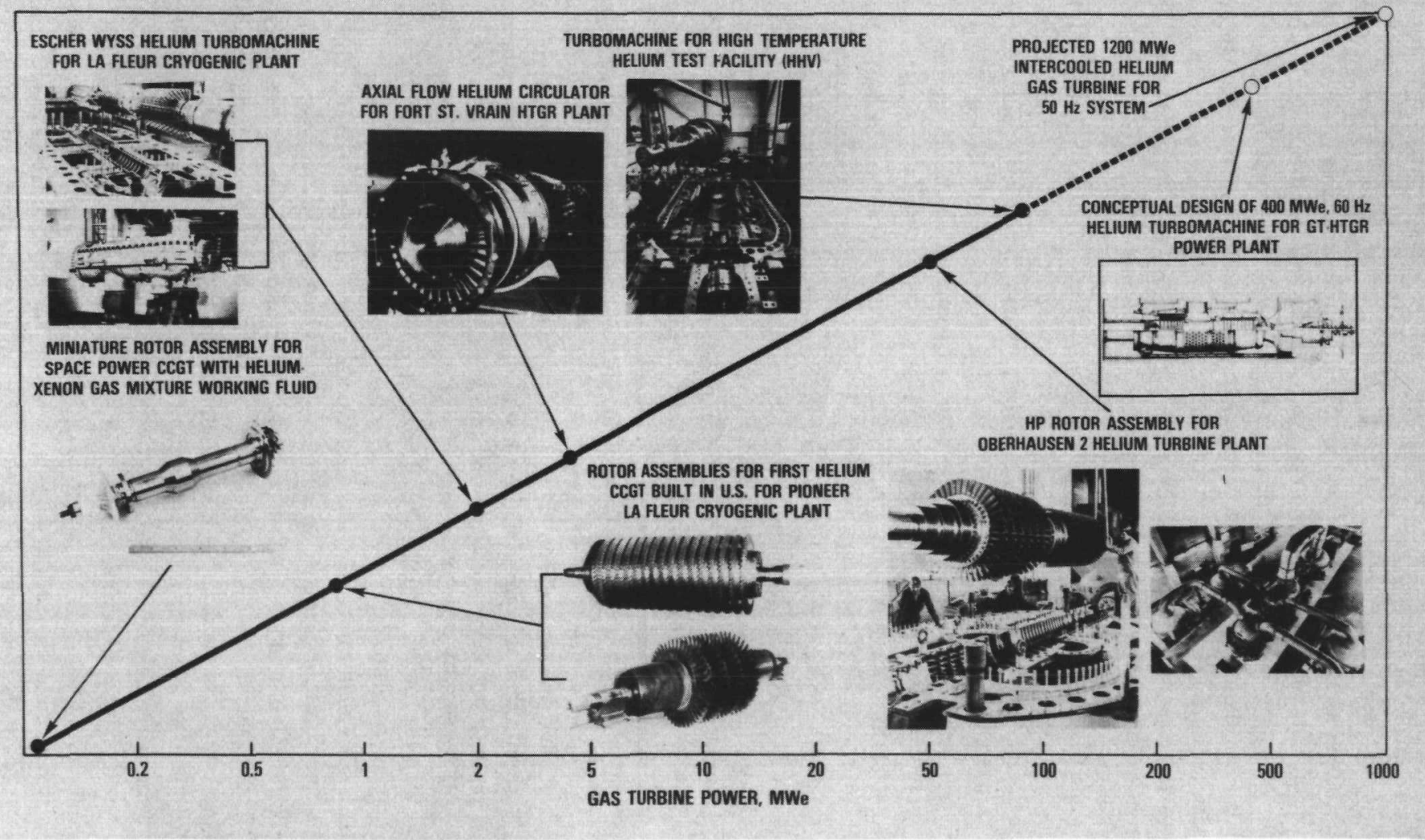

Fig. 8-33. Helium gas turbomachinery design evolution. 


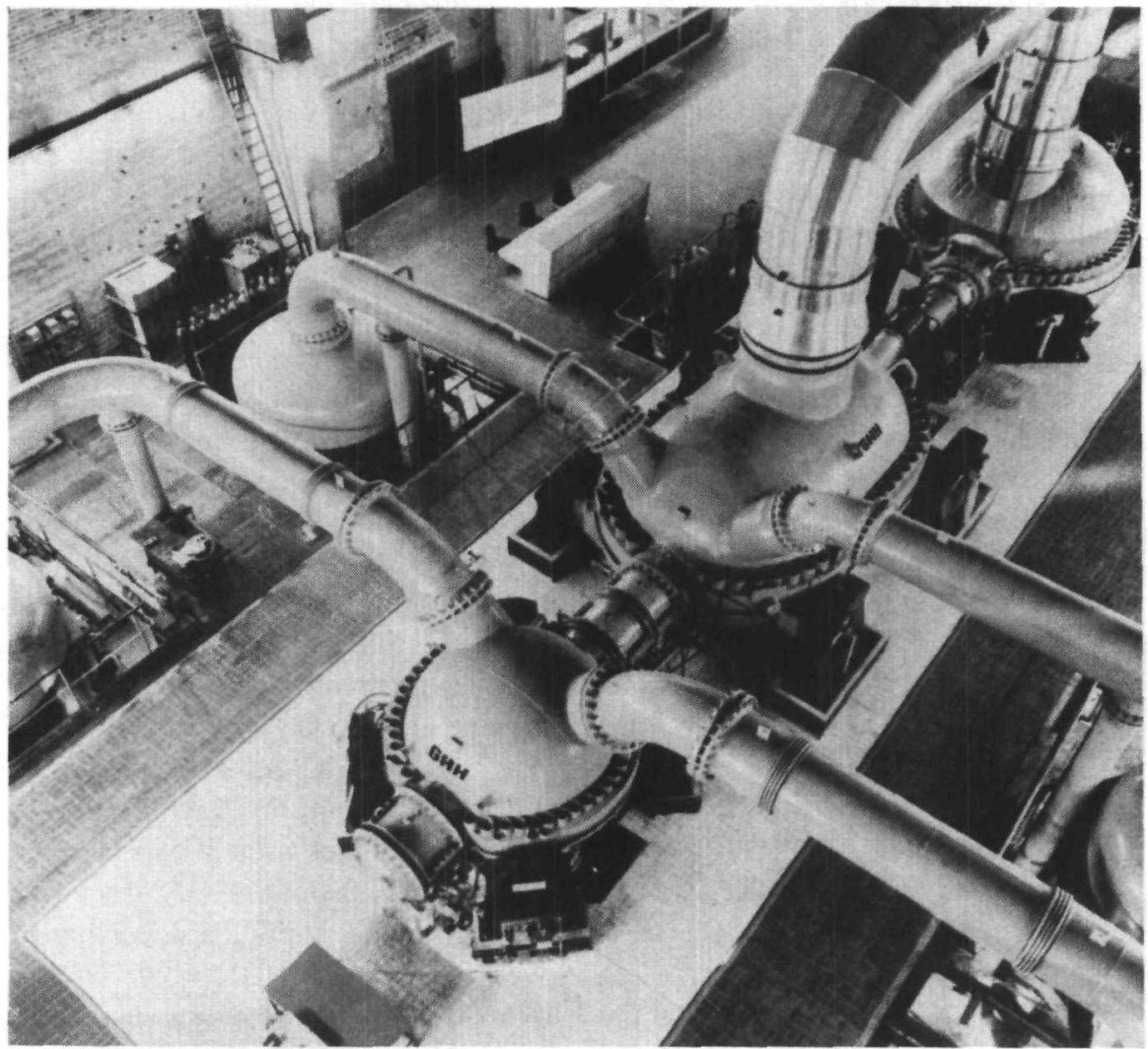

Fig. 8-34. View of the 50-MW(e) Oberhausen 2 helium turbine plant for combined power plus heat production.

45-MW(e) synchronous motor. While shown as a 90-MW(e) plant in Fig. 8-33, the dimensions of the helium turbine are equivalent to a machine rating of $300 \mathrm{MW}(\mathrm{e})$. The facility has the capability for testing hot gas ducts, heat exchanger modules, valves, and thermal insulation. ${ }^{69}$

During initial operation of the HHV facility, an oil-ingress event occurred while the machine was in a cold condition. This was diagnosed as being a result of faulty machining of the large turbomachine castings. The oil penetrated the fibrous insulation in the ducting, and its removal proved to be a difficult and time-consuming operation. This experience could have lasting effects in that for future studies of helium turbomachinery for a nuclear gas turbine plant, alternative bearings (gas or magnetic) would have to be considered to obviate the oil-ingress problem. 


\section{8-7 Conclusions}

As outlined in this chapter, the efficiency potential of the HTGR-GT has hardly been exploited, while the steam turbine has possibly reached the final stages of development. For the Rankine cycle plant, efficiency levels above $\sim 42 \%$ can be realized only with more complex steam turbine cycles. During the last two centuries, steam temperatures and pressures in the steam Rankine cycle have increased to $\sim 566^{\circ} \mathrm{C}\left(1050^{\circ} \mathrm{F}\right)$ and $24.1 \mathrm{MPa}(3500 \mathrm{psia})$, respectively. These conditions essentially represent upper limits as dictated by current economic factors for both the turbine and steam generator.

In contrast to the above, Table $8-\mathrm{V}$ clearly shows the temperature potential for the gas turbine (although now only four decades old). The gas turbine is a modern prime-mover and is expected to play a significant role in future electrical power generation with coal-fired (fluidized bed), solar, and nuclear (fission and fusion) heat sources. The data on Table $8-\mathrm{V}$ are clearly not meant to imply obsolescence for the steam turbine; in fact, it will remain the mainstay of the utility industry in the foreseeable future.

The CCGT power conversion system has been demonstrated in small plants in Europe over 40 years of operation in a cogeneration mode.

The deployment of the high-efficiency HTGR, which can offer operational flexibility not possible with other reactor types, could contribute significantly to national energy goals. The HTGR steam cycle plant, with or without cogeneration features, could be demonstrated in a commercial size in the mid-1990s. The more advanced higher temperature HTGR options that require additional development are projected for initial demonstration in the early decades of the 21 st century. An extended period of development (particularly in the materials area) is necessary to make the higher temperature systems viable, and the benefits of a gas turbine plant operating in a combined power and heat mode (e.g., for large-scale district heating, process steam production, desalination, etc.) require institutional changes and a dedicated program of resource conservation. As mentioned in the text, the gas turbine is an ideal cogeneration plant and studies of an advanced $950^{\circ} \mathrm{C}$ variant have shown superior characteristics when operating in a combined electric power and process steam production mode. ${ }^{70}$

This chapter addressed the coupling of a large nuclear heat source with a helium gas turbine power conversion system. This coupling is clearly not limited to large systems; in fact, recent studies have been made on a $10-\mathrm{MW}(\mathrm{e})$ plant. ${ }^{71}$ For special applications such as defense-related installations, where high-power plant efficiency is paramount (to permit extended operation with no environmental contact), the small nuclear gas turbine plant was shown to be an attractive power source.

The ultimate application of the CCGT is projected to be its coupling to a fusion reactor. ${ }^{72}$ As the HTGR-GT plant clearly benefits from prior steam cycle plant operation, the technology base for a fusion gas turbine plant would be its fission direct-cycle predecessor. 
TABLE 8-V

Comparison of Turbine Power Conversion Systems

\begin{tabular}{|c|c|c|c|}
\hline \multirow[b]{2}{*}{ Prime Mover } & \multirow[b]{2}{*}{ Utility Steam Turbıne } & \multicolumn{2}{|c|}{ Gas Turbınes } \\
\hline & & $\begin{array}{l}\text { Industrial Open- } \\
\text { Cycle Turbıne }\end{array}$ & $\begin{array}{c}\text { Nuclear Gas Turbıne } \\
\text { (CCGT) }\end{array}$ \\
\hline Desıgn/operatıonal status & $\begin{array}{l}\text { Two centuries of steam } \\
\text { system operation }\end{array}$ & $\begin{array}{c}\text { Four decades of } \\
\text { operation }\end{array}$ & Conceptual desıgn \\
\hline Machune type & Multsstage axıal flow & Multistage axıal flow & Multıstage axıal flow \\
\hline Power levels [MW(e)] & Up to 1300 & Up to 100 & Up to 600 \\
\hline Maxımum pressure $(\mathrm{MPa})$ [psia] & $24][3500]$ & $172[250]$ & $827[1200]$ \\
\hline Turbine inlet temperature $\left({ }^{\circ} \mathrm{C}\right)\left[{ }^{\circ} \mathrm{F}\right]$ & up to $566[1050]$ & up to $1149[2100]$ & 850 [1562] \\
\hline Maxımum blade temperature $\left({ }^{\circ} \mathrm{C}\right)\left[{ }^{\circ} \mathrm{F}\right]$ & $<538[1000]$ & $816[1500]$ cooled & $816[1500]$ uncooled \\
\hline Blade tip speed $(\mathrm{m} / \mathrm{s})[\mathrm{ft} / \mathrm{s}]$ & $\begin{array}{c}>610[2000] \text { in } \\
\text { low-pressure rear stages }\end{array}$ & $457[1500]$ & $366[1200]$ \\
\hline Blade material & Forged ferritic stanless steel & Cast nickel-base alloy & Cast nıckel-base alloy \\
\hline Operatıng environment & Erosion, solıds bulldup & $\begin{array}{l}\text { Oxıdızıng combustion } \\
\text { products }\end{array}$ & Inert helium \\
\hline Expected overhaul interval (h) [yr] & 35000 to $45000[4$ to 514$]$ & $\cong 40000[46]$ & Projected 53000 [6] \\
\hline Plant efficiency $(\%)$ & Up to 42 & 30 to 35 & 43 \\
\hline Combined cycle efficiency $(\%)$ & - & $>40$ & $>50$ \\
\hline Performance improvement potential & Small & $\begin{array}{l}\text { Significant potential, } \\
\text { high temperatures, } \\
\text { utilization of ceramics } \\
\text { and water-cooled } \\
\text { blades }\end{array}$ & $\begin{array}{l}\text { Significant for long- } \\
\text { term project }\end{array}$ \\
\hline Long-term status/viability & $\begin{array}{l}\text { Will continue as mainstay } \\
\text { utility prime mover in } \\
\text { forseeable future }\end{array}$ & $\begin{array}{l}\text { Increasing industrial } \\
\text { utilization, particularly } \\
\text { for combustion of } \\
\text { dirty fuels (1n a } \\
\text { fluidized bed } \\
\text { combustor) }\end{array}$ & $\begin{array}{l}\text { Significant incentives } \\
\text { for CCGT plant with } \\
\text { operation through } 21 \text { st } \\
\text { century for fusion, } \\
\text { solar, and coal-fired } \\
\text { heat sources }\end{array}$ \\
\hline
\end{tabular}

Power levels [MW(e)]

Maxımum pressure $(\mathrm{MPa})$ [psia]

Turbine inlet temperature $\left({ }^{\circ} \mathrm{C}\right)\left[{ }^{\circ} \mathrm{F}\right]$

Maxımum blade temperature $\left({ }^{\circ} \mathrm{C}\right)\left[{ }^{\circ} \mathrm{F}\right]$

Forged ferritic stamless stee

$$
\text { Up to } 42
$$

$$
\text { - }
$$

combustor heat sources 


\section{REFERENCES}

1 Proc Int Conf on Nuclear Gas Turbines, London, United Kingdom, April 8-9, 1970, Britısh Nuclear Energy Society (1970)

2 H M Agnew, "Gas-Cooled Nuclear Power Reactors," Scl Am, 244, 6, 55 (June 1981)

3 C F McDonald and C O Peınado, "The Nuclear Gas Turbıne-A Perspectıve on a Long Term Advanced Technology HTGR Plant Option," paper 82 GT-289, Amer Ican Society of Mechanical Engineers (1982)

4 C Keller, "Forty Years of Experience on Closed-Cycle Gas Turbınes," Ann Nucl Energy, 5, 8-10, 405 (1978)

5 C F McDonald, "The Closed-Cycle Gas Turbıne-Present and Future Prospectıves for Fossil and Nuclear Heat Sources," paper 78-GT-102, American Society of Mechanıcal Engineers (1978)

6 C F McDonald, "Large Closed-Cycle Gas Turbıne Plant," paper presented at NATOsponsored lecture series on Closed-Cycle Gas Turbınes, Von Karman Institute for Fluıd Dynamıcs, Brussels, Belgium, May 9-13, 1977

7 C F McDonald, "The Nuclear Closed-Cycle Gas Turbıne (HTGR-GT)-A Utılity Power Plant for the Year 2000," paper 79-0191, American Institute of Aeronautics and Astronautics (1979)

8 C F McDonald and J M Krase, "Nuclear Gas Turbıne Power Plant Actıvities in the United States," paper 77-JPGC-GT-5, American Society of Mechanical Engıneers (1977)

9 C F McDonald and C R Boland, "The Nuclear Closed-Cycle Gas Turbine (HTGRGT)-Dry-Cooled Commercıal Power Plant Studıes," J Eng Power, 103, 1, 89 (Jan 1981)

10 A Hodzic et al, "Design Concept of the $3 \times 360$ MWe HHT Reference Nuclear Power Plant,' Proc IAEA Int Mtg Gas-Cooled Reactors, Julıch, FRG, October 1317, 1975, CONF-751007, SM-200/64, Vol II, p 179, International Atomic Energy Agency (1976)

11 A Hodzic et al , "Reference Design of the HTGR Nuclear Gas Turbine Power Plant," Nuclear Energy Maturity, Progress in Nuclear Energy Series Vol 1, p 599, Pergamon Press (1976)

12 E Arndt et al , "HHT Demonstration Power Plant," Trans Am Nucl Soc, 31, 22 (May 1979)

13 C F McDonald et al , "Prımary System Desıgn Studıes for Advanced Direct Cycle Nuclear Gas Turbıne Plant," paper 77-GT-25, American Society of Mechanical Engineers (1977)

14 D Weber, "Total Energy Applications for Closed-Cycle Gas Turbınes," paper presented at Int Total Energy Congress, Copenhagen, Denmark, October 4-8, 1976

15 L L Kammerzell and J W Read, "HTGR-GT Systems Optımızation Studies," paper 80-WA/GT-3, American Society of Mechanical Engineers (1980)

16 N Gregory and E Zollinger, "Optımızation of the HHT 1640 MWt Demonstration Nuclear Power Plant (HHT Project),' paper 81-GT-13, American Society of Mechanical Engineers (1981)

17 C O Peinado et al , "Design of the 800-MWe HTGR Gas Turbıne Power Plant," Proc American Power Conf, Chicago, Illinoıs, April 21-23, 1980, Vol 42, p 130, Illınoıs Instıtute of Technology (1980) 
18 C F McDonald et al, "Component Desıgn Consıderations for Gas Turbıne HTGR Power Plant," paper 75-GT-67, American Society of Mechanical Engineers (1975)

19 R Rao and A Baxter, "Core Desıgn Consıderatıons for a Large Gas Turbıne HTGR," paper 79 GT-117, American Society of Mechanical Engıneers (1979)

20 R G Adams and F H Boenig, "The Design of the Turbomachinery for the Gas Turbıne HTGR Plant,'” paper 77-GT-38, American Society of Mechanical Engineers (1977)

21 R G Adams et al , "Bearıng Compartment Seal System for Turbomachinery in Direct Cycle HTGR Power Plant,' paper 78-GT-38, American Society of Mechanical Engineers (1978)

22 C F McDonald and M J Smith, "Turbomachınery Design Consıderations for the Nuclear HTGR-GT Power Plant,"' $J$ Eng Power, 103, 1, 65 (Jan 1981)

23 C F McDonald and J A Paget, "Maintenance Considerations in the Design of the Direct Cycle Nuclear Gas Turbıne Power Plant," paper 79-GT-116, Amencan Society of Mechanical Engineers (1979)

$24 \mathrm{H}$ Haselbacher and A Eierman, "Development of Helium Gas Turbıne Systems in the Nuclear Field," paper 74-GT-123, American Society of Mechanical Engineers (1974)

25 W Endres, "Large Helıum Turbınes for Nuclear Power Plants," paper 70-GT-99, American Society of Mechanical Engıneers (1970)

26 H Haselbacher et al " "HHT Helium Turbine and the HHV Plant," paper A4/21 presented at NUCLEX 1978 5th Int Fair of Nuclear Industries and Technical Meetings, Basel, Switzerland, October 3-7, 1978

27 T H Van Hagan et al, "Heat Exchanger Designs for Gas Turbıne HTGR Power Plant," paper 79-WA/GT-2, American Society of Mechanical Engineers (1979)

28 C F McDonald et al, "Heat Exchanger Design Considerations for High-Temperature Gas-Cooled Plants,' paper 80-HT-62, American Society of Mechanical Engineers (1980)

29 C F McDonald et al, "Heat Exchanger Desıgn Consıderatıons for Gas Turbıne HTGR Power Plant," J Eng Power, Series A, 99, 2, 237 (Apr 1977)

30 E J Hurn and D P Carosella, "Prımary Loop Heat Exchanger for HTGR Plant Resıdual Heat Removal and Auxılıary Coolıng System," paper 81 -JPGC-NE 10, Amencan Society of Mechanical Engineers (1981)

31 R Naegelin and G Varadı, "Thermohydraulic Design of Heat Exchangers for Direct Cycle Integrated Gas Turbine Plants," Proc IAEA Int Mtg Gas-Cooled Reactors, Julıch, FRG, October 13-17, 1975, CONF-751007, SM-200/6, Vol II, p 51, International Atomic Energy Agency (1976)

$32 \mathrm{H}$ Bieri et al , "Designing the Heat Exchangers for Integrated Gas Turbıne Cycles of High-Temperature Reactors," Sulzer Tech Rev, special issue NUCLEX 75, 71 (1975)

33 H Fischli et al , "Recuperators for the HHT Demonstration Plant," paper 80-GT-3, American Society of Mechanical Engineers (1980)

34 R Naegelın et al , "Heat Exchangers for HHT Plants," paper A4/16 presented at NUCLEX 1978 5th Int Fair of Nuclear Industries and Technical Meetıngs, Basel, Switzerland, October 3-7, 1978

35 F L Openshaw and T W Chan, "Operational, Control, and Protective System Transient Analyses of the Closed-Cycle GT-HTGR Power Plant,' paper 80-WA/GT-1, American Society of Mechanıcal Engineers (1980) 
36 T Chan et al, "HTGR-GT and Electrical Load Integrated Control," paper 80 WA/ DSC-25, American Society of Mechanical Engineers (1980)

37 F L Openshaw et al , "Control of a Gas Turbine HTGR," paper 76 GT 97, American Society of Mechanical Engıneers (1976)

38 A Bardıa, "Dynamics and Control Modeling of the Closed-Cycle GT-HTGR Power Plant," Proc 4th Power Plant Dynamics, Control, and Testing Symp , Gatlinburg, Tennessee, March 17-19, 1980, p 21, University of Tennessee Nuclear Engineering Dept (1980)

39 G J Cadwallader and R K Deremer, "HTGR-GT Primary Coolant Transient Resultıng from Postulated Turbıne Debladıng," paper 81-GT-19, American Society of Mechanical Engineers (1981)

40 S Lightner and W S Betts, "The Venting Characterıstics of a Fibrous Thermal Barrier System Durıng a Rapid Depressurization Accident (Rotor Fallure) in an HTGRGT,' paper 81-GT-14, American Society of Mechancal Engineers (1981)

41 W S Betts and R D Blevins, "The Response of a Thermal Barrier System to Acoustic Excitation in a Gas Turbine Nuclear Reactor," paper 81-GT-16, Amencan Society of Mechanıcal Engineers (1981)

42 C F McDonald, "The HTGR-GT Closed-Cycle Gas Turbıne-A Power Plant Concept with Inherent Cogeneration (Power Plus Heat Production) Capability,' Proc 15th Intersociety Energy Conversion Engineering Conf, Seattle, Washington, August 1822, 1980, Vol 1, p 667, American Institute of Aeronautics and Astronautics (1981)

43 A Montakhab, "Prelıminary Design of Dry Coolıng Tower for Closed-Cycle Gas Turbine HTGR,' paper 81-GT-20, American Society of Mechanical Engineers (1981)

44 A R Foster et al , "Design of Dry Cooling Towers for Use with a Direct Cycle HTGR," paper 73-Pwr-7, American Society of Mechanical Engineers (1973)

45 B M Johnson et al , "Development of an Advanced Concept of Dry/Wet Cooling for Power Plants,' Proc American Power Conf, Chicago, Illınoıs, April 27-29, 1981, Vol 43, p 428, Illinois Institute of Technology (1981)

46 H U Frutschı, "The Relationship of Power and Heat Production with Closed-Cycle Gas Turbines," paper 79-GT-103, American Society of Mechanical Engineers (1979)

47 F Taygun and H U Frutschı, "Conventional and Nuclear Gas Turbınes for Combıned Power and Heat Production," paper 70-GT-22, American Society of Mechanical Engineers (1970)

48 P Margen, “The Use of Nuclear Energy for District Heatıng," Prog Nucl Energy, 2, 1, (1978)

49 “'Germany Looks Towards Nuclear District Heatıng," Energy Int , 12, 8, 17 (1975)

50 H U Frutsch1 and W Muller, "Hıgh-Temperature Reactor with Helıum Turbine Special Operational Properties, Controllability, Waste Heat Recovery, and Dry Coolıng Tower,' paper A3/10 presented at NUCLEX 1978 5th Int Fair of Nuclear Industries and Technical Meetıngs, Basel, Switzerland, October 3-7, 1978

51 K Bammert et al , "Nuclear Power Plants with Closed-Cycle Helium Turbine Supply," paper 70-GT-93, American Society of Mechanıcal Engıneers (1970)

52 H Bonnenberg and H V Schlenker, "Waste Heat of HTR Power Stations for District Heatıng," Proc BNESInt Conf High-Temperature Reactor and Process Applications, London, United Kıngdom, November 26-28, 1974, CONF-741144, p 37 1, Britısh Nuclear Energy Society (1975)

53 L Meyer and J W Holland, "Gas Turbıne HTGR as a Thermal Energy Source for 
Desalınation and District Heatıng," paper presented at Int Total Energy Congress, Copenhagen, Denmark, October 4-8, 1976

54 W J D Escher and T D Donakowsk1, "Competıtıvely Priced Hydrogen Vid HighEfficiency Nuclear Electrolysis," Proc Ist World Hydrogen Energy Conf, Miamı Beach, Florıda, March 1-3, 1976, CONF 760334, Vol 1, p 2A-1, T N Vezıroglu, Ed , University of Miamı (1976)

55 C F McDonald and A Hodzic, "Conceptual Engineering Features of a Very Advanced HTGR Plant Projected to Meet Energy Needs in the Middle Decades of the 21 st Century,' Proc 4th Int Conf Alternative Energy Sources, Miamı Beach, Flonda, December 14-16, 1981, paper 1-1, Vol 5, p 3, Ann Arbor Science Publishers (1982)

56 T W Schoene et al, "The Gas Turbıne HTGR Plant with a Binary Cycle," Proc Conf IEEE Power Engineering Soclety, Portland, Oregon, July 18-23, 1976, Institute of Electronics and Electrical Engineers (1976)

57 J R Schuster et al , "Binary Plant Cycle Studies for the Gas Turbıne HTGR," paper 76-GT-39, American Society of Mechanical Engineers (1976)

58 C F McDonald and D L Vrable, "Component Design Considerations for Gas Turbıne HTGR Waste Heat Power Plants," Proc 11th Intersociety Energy Conversion Engineering Conf, Lake Tahoe, Nevada, September 12-17, 1976, Vol 1, p 192, American Institute of Chemical Engineers (1976)

59 C F McDonald and K Vepa, "Ammonia Turbomachinery Design Consıderations for the Direct Cycle Nuclear Gas Turbıne Waste Heat Power Plant," paper 77-GT75, American Society of Mechanical Engineers (1977)

60 "Les Cycles Bınarres Eau-Ammoniac Applıcation aux Centrales Thermiques de Grande Puissance," paper presented at Societe Francaise des Thermiciens, Feb 20, 1980

61 J Fleury, "Ammonia Bottoming Cycle Development at Electricite de France for Nuclear Power Plants," paper 81-GT-178, American Society of Mechanıcal Engıneers (1981)

62 “Water, Water Everywhere But ,"EPRI J , 4, 8, 6 (1979)

63 Z P Tilliette and B P1erre, "Improvement to Recuperative Gas Cycles by Means of a Heat Generator Partly Bypassing Recuperator-Applications to Open and Closed Cycles and to Various Kinds of Energy," paper 79-GT-115, American Society of Mechanical Engineers (1979)

64 R J Stochl, "Potential Performance Improvement Using a Reactıng Gas (Nitrogen Tetroxıde) as the Workıng Fluid in a Closed Brayton Cycle," TM-79322, National Aeronautics and Space Administration (Dec 1979)

$65 \mathrm{~K}$ Kesavan and J F Osterle, "Split-Flow Nuclear Gas Turbıne Cycle Using Dissocratıng $\mathrm{N}_{2} \mathrm{O}_{4}$," paper 82-GT-181, American Society of Mechanical Engineers (1982)

66 "High Temperature Gas-Cooled Reactor-Gas Turbıne Application Study," Gas-Cooled Reactor Associates, La Jolla, Calıfornıa (Dec 1980)

67 P Fortescue, "Nuclear Gas Turbine Development," Power Eng 80, 50 (Dec 1976)

68 P Zenker, "The Oberhausen 50-MWe Helium Turbıne Plant," Combustion, 47, 10 21 (1976)

69 G Noack et al, "Significance of the Helium Turbine Plant at Oberhausen (EVO) and of the High Temperature Test Facility at Julıch (HHV) for the Development of the HTGR Direct Cycle System (HHT),' Proc IAEA Int Mtg Gas-Cooled Reactors, Julich, FRG, October 13-17, 1975, CONF-751007, SM-200/26, Vol II, p 189, International Atomic Energy Agency (1976) 
70 C F McDonald, T H Van Hagan, and D Kapıch, "Performance Potential of an Advanced Nuclear Gas Turbıne/Cogeneration System (HTGR-GT/C)," paper 83-GT101, American Society of Mechanical Engineers (1983)

71 C F McDonald et al , "Very High Efficiency Small Nuclear Gas Turbıne Power Plant Concept (HTGR-GT-BC) for Special Applications, paper presented at 29th Int ASME Gas Turbine Conf , Amsterdam, Netherlands, June 3-7, 1984

72 C F McDonald and C P C Wong, "Closed Cycle Gas Turbıne Applicatıons for Fusion Reactors,'” paper 81-GT-17, American Society of Mechanical Engineers (1981) 


\section{9 \\ PROCESS HEAT HTGRS*}

\section{9-1 Introduction}

The high-temperature capabilities of the high-temperature gas-cooled reactor (HTGR) offer a unique heat source for process heat applications not readily obtainable with other types of nuclear reactors Fossil-fuel shortages and escalating costs provide incentıves for developing a nuclear process heat source and create an increased interest in synthetic fuels

Most energy-intensive industrial processes require considerable steam and electric power Cogeneration of electricity and steam is an advantageous blending of two well-developed technologies-electric power generation with its hightemperature high-pressure inlet steam and condensing cycle and industrial steam characterized by moderate pressures and temperatures with productive use of the heat of condensation

The HTGR is well suited for the cogeneration option, since the present HTGR can deliver steam at temperatures up to $540^{\circ} \mathrm{C}\left(1000^{\circ} \mathrm{F}\right)$ and $17 \mathrm{MPa}(2500 \mathrm{psia})$ The direct substitution of nuclear energy for fossil energy as the heat source would result in a dally savings of $\sim 16000$ barrels of oil ${ }^{a}$ (energy equivalent) for each 1170-MW(t) HTGR plant This chapter discusses design studies of systems that have the potential to achieve these goals by utllizing a nuclear heat source for this application as well as other uses in the nonelectric field

As shown in Table 9-I, U S energy demands rely heavily on petroleum and natural gas Over $70 \%$ of the bulk energy demands are met by these fuels at present

*This chapter was contributed by Robert $\mathrm{N}$ Quade

${ }^{\mathrm{a}}$ One barrel $=42 \mathrm{gal}=016 \mathrm{~m}^{3}$

TABLE 9-I

U S Energy Consumption in 1980

\begin{tabular}{|lcr|}
\hline Resources & Joules $\times 10^{18}$ & $\%$ \\
\hline Petroleum & 360 & 45 \\
Natural gas & 217 & 27 \\
Coal & 162 & 20 \\
Hydropower, other & 40 & 5 \\
Nuclear & $\underline{24}$ & $\frac{3}{100}$ \\
\hline
\end{tabular}


TABLE 9-II

Estımated Total Remaining Recoverable Fossil Fuel Resources In the United States

\begin{tabular}{|c|c|c|}
\hline Resources & Joules $\times 10^{18}$ & $\%$ \\
\hline Coal & 37700 & 794 \\
\hline Shale oll & 6300 & 133 \\
\hline Crude oll & 2200 & 46 \\
\hline Natural gas & 1200 & 25 \\
\hline \multirow[t]{2}{*}{ Natural gas liquids } & 100 & 02 \\
\hline & 47500 & 1000 \\
\hline
\end{tabular}

As shown in Table 9-II, over three-quarters of the estımated total remanning recoverable fossil fuels in the United States is in the form of coal However, coal currently accounts for only $20 \%$ of the energy consumed in the United States

It is unlikely that natural gas, which produces almost $30 \%$ of U S energy, can maintain its hold over such a large share of the energy produced in the United States Since oll is the predominant fuel used in the United States, it would be a logical alternative to take up most of the burden caused by reduced natural gas usage However, domestic resources are inadequate to meet the increased demand Coal and nuclear power remain among proven energy sources for meetıng U S energy requirements

With the many possibilities of application and the different HTGR configurations under consideration, a general deployment strategy has evolved The chronology starts at steam cycle cogeneration plants (HTGR-SC/C) that are based on the proven technology of Peach Bottom and Fort St Vrain Core outlet temperatures are in the range of 700 to $750^{\circ} \mathrm{C} \mathrm{Higher}$ core outlet temperatures of $850^{\circ} \mathrm{C}$ follow with application to process heat (HTGR-PH) and the gas turbine (HTGR-GT) These conditions are somewhat beyond current technology in terms of material behavior for commercial life components Beyond this range, the very high temperature reactor (VHTR) at a temperature of $950^{\circ} \mathrm{C}$ can be considered At each of these levels, new processes are presented for potential coupling to the nuclear heat source A summary of these applications by reactor type is shown in Fig 8-1, p 251

\section{9-2 HTGR Applications and Design Commonality}

Clearly, it is impractical to talor a reactor design for each use Three HTGR designs will handle most uses, as shown in Fig 9-1 HTGR-I is the steam cycle HTGR developed for electric power generation with a portion of the turbine plant removed HTGR-II and III represent successively higher temperature versions that 


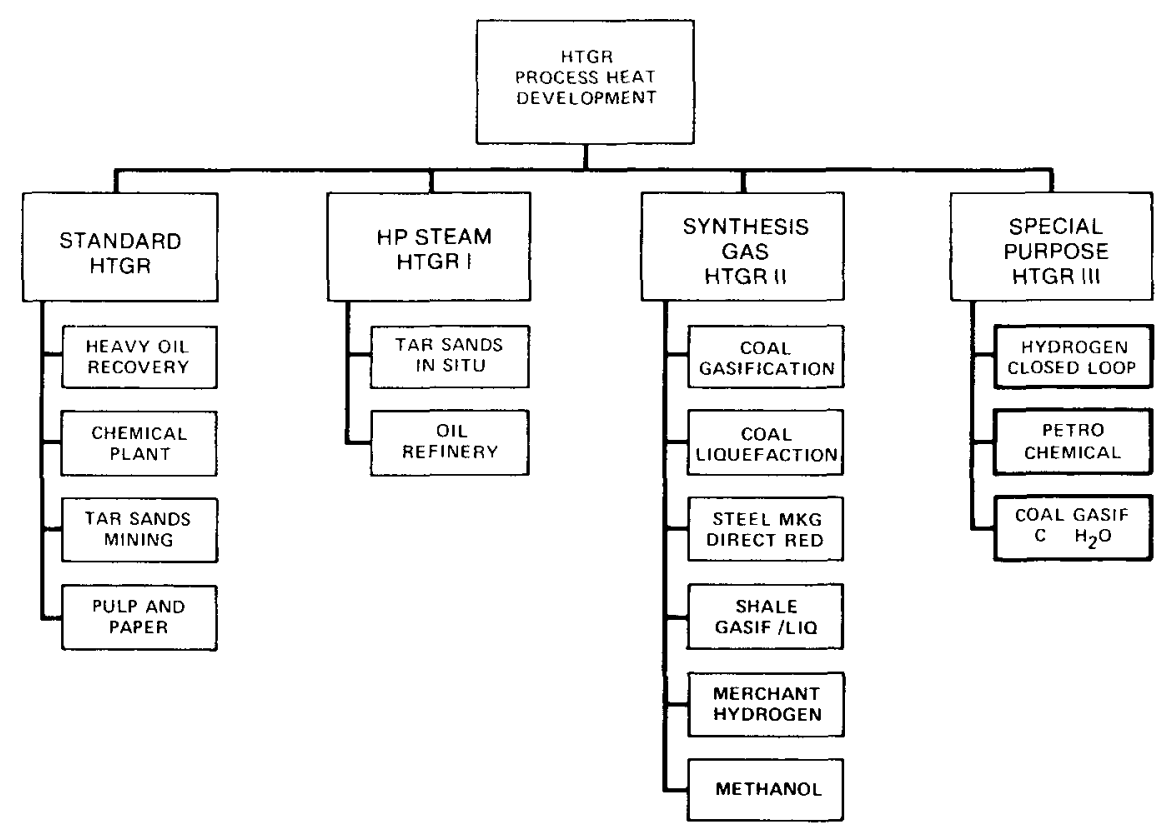

Fig 9-1 HTGR models for study of process applications

TABLE 9-III

Materials Development Required for Various

HTGR Helium Outlet Temperatures

\begin{tabular}{|c|c|}
\hline $\begin{array}{c}\text { Helium Outlet } \\
\text { Temperature }\end{array}$ & \multicolumn{1}{c|}{ Development Areas } \\
\hline $760^{\circ} \mathrm{C}$ & $\begin{array}{c}\text { Current steam cycle HTGR } \\
\text { no new materials development required }\end{array}$ \\
850 to $950^{\circ} \mathrm{C}$ & $\begin{array}{l}\text { HTGR-II development } \\
\text { thermal barner materials } \\
\text { metallic heat exchanger materials }\end{array}$ \\
$950+{ }^{\circ} \mathrm{C}$ & $\begin{array}{l}\text { HTGR-III development } \\
\text { 1mproved fuel particles } \\
\text { fuel management techniques } \\
\text { thermal barner designs and ceramic materials } \\
\text { ceramic heat exchangers } \\
\text { refractory metals or ceramics for process heat exchanger }\end{array}$ \\
\hline
\end{tabular}

have the capability of producing $\mathrm{H}_{2}$ by light hydrocarbon reforming (II) and water splitting, or steam carbon reaction (III).

As the temperature rises, material problems become much greater. Table 9-III summarizes the major areas that are affected. 


\section{9-2A Process Steam/Cogeneration}

A study ${ }^{1}$ to estimate the potential process steam market in the United States showed that by the year 2000 a total of 52 sites could use steam equivalent to the output of an 1170-MW(t) cogeneration plant, 10 sites could use $2 \times 1170 \mathrm{MW}(\mathrm{t})$ [or a 2240-MW(t) plant], and 11 sites could use $3 \times 1170 \mathrm{MW}(\mathrm{t})$ [or a 3360$\mathrm{MW}(\mathrm{t})$ plant]. These numbers are upper limits because site-specific factors would reduce the usable number.

\section{9-2B Process Heat}

Synfuel production plants will have large process energy requirements and represent a large potential market for HTGR units. The process energy requirements can be fulfilled by either fossil fuel or nuclear fuel. The nuclear fuel cycle costs are clearly lower than the fossil fuel costs-ranging from 25 to $70 \%$ of the fossil value. However, the other life cycle costs, e.g., capital charges and operations/maintenance costs, must also be considered. The economic objective of application studies is to determine if the apparent economic advantages can be maintained when all other factors are considered.

Major synfuel processes are coal liquefaction, coal gasification, and oil recovery from shale. All of the synfuel processes basically involve the addition of $\mathrm{H}_{2}$ to the parent hydrocarbon.

Liquefaction processes may be "direct" such as solvent refined coal (SRC), H-coal, or Exxon's donor solvent, or "indirect" such as coal gasification to make synthesis gas followed by catalytic recombination. Coal gasification to make a substitute natural gas (SNG) generally involves production of a synthesis gas $\left(\mathrm{H}_{2}+\mathrm{CO}\right)$ followed by a methanation step to convert the syngas to methane $\left(\mathrm{CH}_{4}\right)$.

Oil recovery from shale involves the retorting of the shale rock to release the kerogen and subsequent hydrogen addition to make a syncrude product.

Table 9-IV shows an estimate for the potential synthetic fuel market. By the year 2000, coal liquids production is projected to range from 32 to $112 \times 10^{3}$ $\mathrm{m}^{3} /$ day [200 to $700 \times 10^{3}$ barrels per day (bpd)], and could increase to 320 to $800 \times 10^{3} \mathrm{~m}^{3} /$ day $\left(2\right.$ to $\left.5 \times 10^{6} \mathrm{bpd}\right)$ by the year 2020 .

Shale oil is projected to have the greatest near-term potential because the technology is well developed and its product cost is nearly competitive at current oil prices. Its longer term potential, however, lags that of coal liquids primarily because the shale resource is concentrated and environmental constraints may hold production down.

Synthetic "high-Btu" gas from coal is expected to play a less important role in the United States since the major demand for synthetic fuels is projected to be for liquids rather than gas. Recent increases in natural gas reserves and the good prospects for deep gas and enhanced recovery are expected to lower the demand. 
TABLE 9-IV

Synthetic Fuel Forecast for September 1981 (Production in $\mathrm{m}^{3} /$ day and bpd crude oil equivalent)

\begin{tabular}{|c|c|c|c|c|}
\hline & 1990 & 2000 & 2010 & 2020 \\
\hline \multicolumn{5}{|l|}{ Coal Liquids } \\
\hline $10^{3} \mathrm{~m}^{3} /$ day & 8 to 32 & 32 to 112 & 160 to 480 & 320 to 800 \\
\hline $10^{3}$ bpd & 50 to 200 & 200 to 700 & 1000 to 3000 & 2000 to 5000 \\
\hline equivalent number of $\mathrm{HTGRs}^{\mathrm{a}}$ & 1 to 4 & 4 to 13 & 18 to 55 & 36 to 90 \\
\hline \multicolumn{5}{|l|}{ Shale Oll } \\
\hline $10^{3} \mathrm{~m}^{3} /$ day & 16 to 48 & 96 to 192 & 160 to 288 & 224 to 480 \\
\hline $10^{3}$ bpd & 100 to 300 & 600 to 1200 & 1000 to 1800 & 1400 to 3000 \\
\hline equivalent number of HTGRs ${ }^{b}$ & 2 to 6 & 12 to 24 & 20 to 36 & 28 to 60 \\
\hline \multicolumn{5}{|l|}{ High Btu Coal Gas } \\
\hline $10^{3} \mathrm{~m}^{3} /$ day & 64 & 64 to 48 & 128 to 80 & 24 to 160 \\
\hline $10^{3}$ bpd & 40 & 40 to 300 & 80 to 500 & 150 to 1000 \\
\hline equivalent number of $\mathrm{HTGRs}^{\mathrm{c}}$ & 1 & 1 to 7 & 2 to 12 & 4 to 23 \\
\hline
\end{tabular}

${ }^{a} A$ A 1170-MW(t) HTGR, $8800 \mathrm{~m}^{3} /$ day (55 000 bpd)

${ }^{\mathrm{b}} \mathrm{A} 1170-\mathrm{MW}(\mathrm{t})$ HTGR, $8000 \mathrm{~m}^{3} /$ day $(50000 \mathrm{bpd})$

${ }^{\mathrm{c} A} 1170-\mathrm{MW}(\mathrm{t}) \mathrm{HTGR}, 6880 \mathrm{~m}^{3} /$ day (43 $\left.000 \mathrm{bpd}\right)$

\section{9-3 Process Steam/Cogeneration Plant}

\section{9-3A Reactor Plant Description}

To maximize the advantage of scale, but also provide sizes that can reach a large number of industrial sites, a modular approach has been adopted for the HTGR. An 1170-MW(t) plant has two steam generator/helium circulator loops, a $2240-\mathrm{MW}(\mathrm{t})$ plant has four loops, and a $3360-\mathrm{MW}(\mathrm{t})$ plant has six. The 1170MW(t) HTGR plant size is similar to the operating $842-M W(t)$ Fort St. Vrain HTGR plant.

Flexibility in the process steam temperature and pressure conditions is provided by several possible combinations of turbine arrangements (topping, condensing). A steam cycle diagram for the reference multipurpose plant is shown in Fig. 2-15, p. 63. Helium leaves the reactor core at a temperature of $693^{\circ} \mathrm{C}$ and goes to the steam generators. Steam is produced at $16.6 \mathrm{MPa}$ and $538^{\circ} \mathrm{C}$ and passes through the high-pressure turbine. For a cogeneration mode, the process steam is extracted here and sent to the process. A fraction of the steam is sent through the intermediate- and low-pressure turbines and used for feedwater heating. Considerable flexibility is obtained with the operation of the HTGR from cogeneration mode to noncogeneration mode by adding a low-pressure condensing turbine, as shown in the dotted portion of Fig. 2-15. This portion of the plant could be built initially if the process steam load is projected to occur well after plant construction, or could be added later if the initial process steam load should drop off. The HTGR plant operating in a cogeneration mode is identified as an HTGR-steam cycle/cogeneration (HTGR-SC/C) plant. 
TABLE 9-V

HTGR Applications Survey

\begin{tabular}{|c|c|c|c|}
\hline & $\begin{array}{l}\text { Commercial } \\
\text { Plant Size }\end{array}$ & $\begin{array}{l}\text { Process } \\
\text { Steam } \\
\text { Requirements } \\
{[\mathrm{MW}(\mathrm{t})]}\end{array}$ & $\begin{array}{c}\text { Electrical } \\
\text { Power } \\
\text { Requirements } \\
{[\mathrm{MW}(\mathrm{e})]}\end{array}$ \\
\hline \multicolumn{4}{|l|}{ Existing Industries } \\
\hline petrochemical plants (Geısmar, LA) & - & 2745 & 582 \\
\hline refinery plant & $390000 \mathrm{bpd}^{\mathrm{a}}$ & 1929 & 111 \\
\hline aluminum mill (Grammercey, LA) & 720000 tonne/yr & 317 & 94 \\
\hline steel mill & $65 \times 10^{6}$ tonne $/ y r$ & 296 & 240 \\
\hline \multicolumn{4}{|l|}{ Petroleum Products Recovery } \\
\hline in situ heavy oll recovery & $35000 \mathrm{bpd}$ & 993 & 1 \\
\hline in situ oll sands recovery & $46000 \mathrm{bpd}$ & 1090 & 83 \\
\hline in situ shale oil recovery & 33000 bpd & 1090 & $\begin{array}{c}\text { To be } \\
\text { determined }\end{array}$ \\
\hline \multicolumn{4}{|l|}{ Synfuel Processes } \\
\hline catalytic coal gasıfication-high-Bu gas (e g, Exxon process) & $43000 \mathrm{bpd}$ & 1116 & 187 \\
\hline coal liquids-SRC-II & $80000 \mathrm{bpd}$ & 989 & 122 \\
\hline coal liquids-H-Coal & 81000 bpd & 755 & 251 \\
\hline coal liquids-Exxon donor solvent & $60000 \mathrm{bpd}$ & $577^{\mathrm{b}}$ & $260^{\mathrm{b}}$ \\
\hline syngas (slagging Lurg1)-methanol add-on & $72000 \mathrm{bpd}$ & 371 & 105 \\
\hline
\end{tabular}

${ }^{\mathrm{a}} 1 \mathrm{bpd} \cong 016 \mathrm{~m}^{3} / \mathrm{day}$

${ }^{\mathrm{b}}$ Prelımınary 


\section{9-3B HTGR Applications}

Table 9-V shows representative energy-intensive industries/operations and their energy requirements

A review of the energy requirements of the applications surveyed suggests that the HTGR and the liquid-metal fast breeder reactor are the only nuclear energy sources capable of supplying industrial high-temperature steam requirements The light water reactor primary steam is limited to $288^{\circ} \mathrm{C}\left(550^{\circ} \mathrm{F}\right)$

\section{9-3C HTGR-SC/C Comparative Assessment}

There are three main areas for comparison of HTGR-SC/C plants with other energy alternatives economics, the environment, and conservation

Table 9-VI shows an economic comparison of the HTGR-SC/C with a coalfired cogeneration plant of comparable size and a No 2 oll-fired plant (noncogeneration) The comparison indicates that the HTGR-SC/C has a significant $(60 \%)$ steam cost advantage over the reference coal plant when both operate at a $70 \%$ capacity factor Although the nuclear plant has a higher initial capital cost, the fuel cycle costs are considerably lower over the life of the plant than for nonnuclear systems The economic advantage of a nuclear plant will depend on the particular cost of coal in the area and how this cost may vary relative to nuclear fuel in the future

Another key economic consideration is the distance of energy transmission and the associated cost Remote siting of the HTGR from the user area may be required in some situations and would decrease the energy cost advantage due to

\section{TABLE 9-VI}

Comparison of HTGR-SC/C with Coal- and Oil-Fired Plants* (Costs in millions of 1980 dollars levelızed over $30 \mathrm{yr}$ )

\begin{tabular}{|c|c|c|c|}
\hline & $\begin{array}{c}\text { HTGR } \\
\text { Multıpurpose }\end{array}$ & $\begin{array}{c}\text { Coal } \\
\text { Multıpurpose }\end{array}$ & $\begin{array}{l}\text { Existıng } \\
\text { No } 2 \text { Oil }\end{array}$ \\
\hline Heat input to cycle (MW) & 1170 & 1230 & \\
\hline Heat output in process steam (MW) & 1000 & 1000 & 1000 \\
\hline Net electncal power output (MW) & 150 & 157 & 0 \\
\hline Total capital cost $\left(1980 \$ \times 10^{6}\right)$ & 738 & 531 & Existing \\
\hline \multicolumn{4}{|l|}{$\begin{array}{c}\text { Annual Costs }\left(1980 \$ \times 10^{6}\right. \\
\text { levelized over } 30 \mathrm{yr})\end{array}$} \\
\hline fixed charges & 61 & 44 & - \\
\hline fuel & 30 & 96 & 281 \\
\hline operatıons and maintenance & 25 & 32 & 25 \\
\hline credit for electric power & $(35)$ & (37) & 0 \\
\hline total annual costs & 81 & 135 & $\overline{306}$ \\
\hline Steam cost $\left(\$ / 10^{6} \mathrm{Btu}\right)$ & 394 & 654 & 1488 \\
\hline Unt steam cost (normalızed to HTGR) & 10 & 16 & 38 \\
\hline
\end{tabular}

*O1l $1000 / 082=1219 \mathrm{MW}(\mathrm{t})$ input $\times 3413 \times 10^{6} \times 8760 \times 070=255 \times 10^{12}$ Btu/yr Cost $=\$ 1102 / 10^{6} \mathrm{Btu} \times 255 \times 10^{12} \mathrm{Btu}=\$ 281 \times 10^{6} / \mathrm{yr}$ 
the higher energy transmission cost. Space limitations or environmental restraints in the vicinity of a process plant may also require the remote siting of a coal-fired plant.

Although significantly larger environmental issues exist for a coal-fired plant in comparison with an HTGR, quantitative data for comparison with an HTGR are yet to be developed. The environmental advantages of the HTGR will become more apparent when data are developed on $\mathrm{CO}_{2}$ effects, ash and sludge disposal, land use, atmospheric pollution, and other aspects.

In an earlier cogeneration study, ${ }^{2}$ the energy savings due to cogeneration with an HTGR at a large petrochemical complex were estimated. The total estimated oil savings at the chemical complex were $2.34 \times 10^{6} \mathrm{~m}^{3} / \mathrm{yr}(14.6$ million barrels/yr). Of this, $1.5 \times 10^{6} \mathrm{~m}^{3} / \mathrm{yr}(9.4$ million barrels $/ \mathrm{yr})$ resulted from using a cogeneration plant and the remainder resulted from using an HTGR-SC/C plant.

Other cogeneration applications offer similar possibilites for energy savings and for substitution of large volumes of fossil fuels. The petroleum recovery applications (heavy oil or oil sands) in particular require between 35 and $50 \%$ of produced oil as process fuel for steam production. Use of an HTGR would save this valuable oil for more beneficial uses.

\subsection{Issues}

There are several key issues that must be resolved to deploy nuclear cogeneration projects, including project schedule length, backup power, siting, and institutional matters. New coal plants have long schedules ( 6 to $8 \mathrm{yr}$ ) for deployment, and nuclear plants require even longer schedules. These long schedules present problems, particularly since industrial owners/users find it difficult to project energy needs over such long periods. Also the long schedules require large sums for interest during construction-a particular problem with high interest rates. Uncertainties due to licensing, leading to schedule delays and inflation, which lead to higher interest rates, have been a significant problem for current nuclear plants.

Backup power provisions (for steam and electric power) are essential for cogeneration applications. These requirements can be met in several ways: by additional nuclear or fossil units that normally produce electric power but can be switched to the cogeneration mode, by use of existing fossil units, and possibly by energy storage systems such as the sensible energy transport system (SETS) using heat transfer salt. The SETS system uses a binary or ternary salt (potassium and sodium nitrate and sodium nitrite) heated by a secondary helium loop as the heat transport and storage system. The salt is usable in the range of $565^{\circ} \mathrm{C}\left(1050^{\circ} \mathrm{F}\right)$ to $200^{\circ} \mathrm{C}\left(390^{\circ} \mathrm{F}\right)$ and may be stored in quantities sufficient for outages up to $24 \mathrm{~h}$.

There are several options regarding siting of HTGR-SC/C plants. In general, close-in siting is preferred, and the unique safety features of the HTGR should be of benefit in this respect. Piping of the steam up to $32 \mathrm{~km}$ ( 20 miles) appears feasible in many cases.

Institutional issues are a major consideration in the use of HTGR cogeneration 


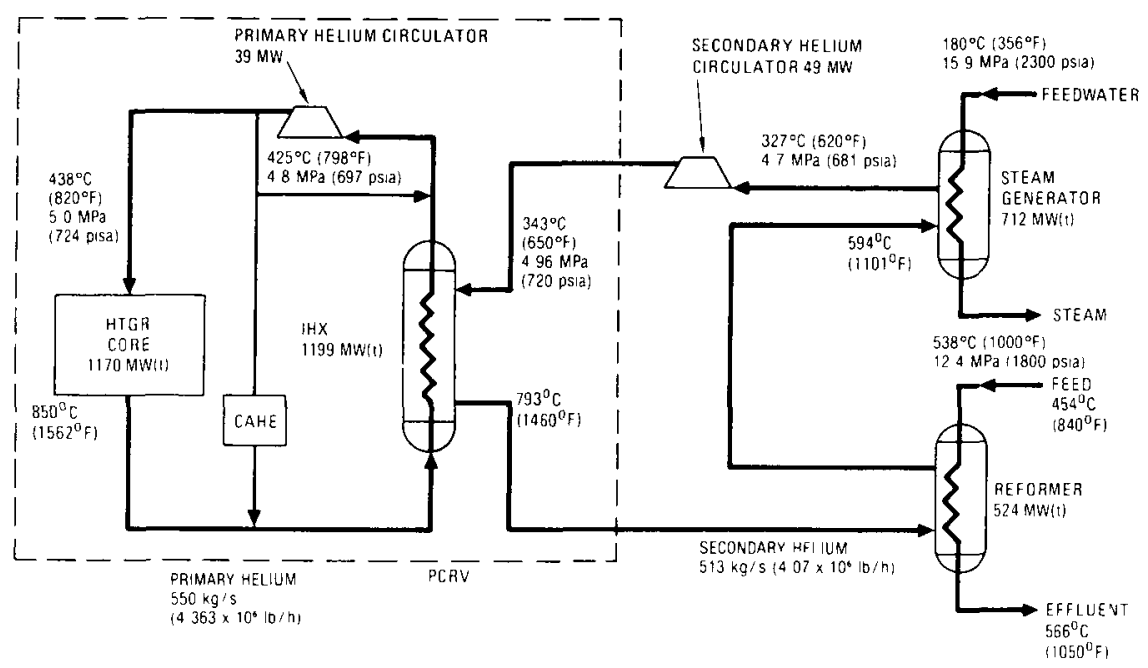

Fig. 9-2. Flow diagram for $850^{\circ} \mathrm{C}$ indirect-cycle HTGR process heat plant.

plants. The institutional barriers in the United States for small non-utility-owned units have been substantially reduced and incentives defined by recent legislation and rulemaking. Some utility participation is now allowed in cogeneration projects. Changes allowing additional utility participation and a clear definition of what portions of the plant or product fall under price regulation need to be developed.

\section{9-4 Process Heat Plants}

\section{9-4A $850^{\circ} \mathrm{C}$ Indirect-Cycle HTGR-PH Plant}

In this variant of the process heat plant, the reactor thermal energy is transferred to the process plant via a secondary helium heat transfer loop; hence, the "indirect-cycle" designation. For the indirect-cycle concept, as for other HTGRs, the entire primary coolant system is contained in a prestressed concrete reactor vessel (PCRV). The steam generators are now replaced by intermediate heat exchangers within the PCRV. With the higher core outlet temperature, a lower core power density is used to limit the fuel temperature. The basic flow diagram for steady-state operating conditions is shown in Fig. 9-2. In the primary circuit, the thermal energy from the 1170-MW(t) reactor core is removed by four independent loops. Each loop includes an intermediate heat exchanger (IHX), an electric-motor-driven helium circulator, and related instrumentation and controls. The primary helium temperature conditions (particularly the core outlet temperature of $850^{\circ} \mathrm{C}$ ) were established to meet the requirements of the chemical process while staying within the structural limits of the Inconel-617 material used in the IHX. The pressure level of $5 \mathrm{MPa}$ (725 psia) is consistent with approaches followed in the Fort St. Vrain design. The pressure level of the secondary helium is maintained only slightly above that of the primary system (thus preventing 
leakage of reactor helium into the secondary circuit) in order to minimize the longterm loading on the IHX, in which the combination of high temperature and material limitations requires a near-pressure-balanced operation for structural integrity.

The four secondary helium loops each consist of an IHX, reformer, steam generator, secondary helium circulator, and related piping, valves, and instrumentation. During normal operation, secondary helium is heated to $793^{\circ} \mathrm{C}$ in the IHX and routed outside the PCRV to the reformer and then to the steam generator, which extracts the heat necessary for the process and auxiliary power generation. The secondary loop equipment (eight reformers, four steam generators, and four circulators) is installed in four prestressed concrete pressure vessels (PCPVs). The PCPV closely resembles the PCRV with regard to structural and construction features.

\section{9-4B $950^{\circ} \mathrm{C}$ Direct-Cycle HTGR-PH Plant}

In this variant of the process heat plant, the reactor thermal energy is transferred directly to the process in the primary system. As in the previous case, the nuclear heat is used for the reforming process and to generate high-quality steam in sufficient quantities to satisfy both the process and electrical generation needs for operation of the nuclear plant and the reforming process. For this higher core outlet temperature application, the fuel cycle is reduced from 4 to $3 \mathrm{yr}$.

The basic flow diagram for steady-state operating conditions is shown in Fig. 9-3. To investigate the maximum potential of the VHTR, the direct-cycle reforming concept under discussion has a core outlet temperature of $950^{\circ} \mathrm{C}$. This temperature increase from $850^{\circ} \mathrm{C}$ for the indirect cycle necessitates the use of more advanced technology in the nuclear heat source, which implies a longer schedule for realization of the first commercial-size plant.

In the direct-cycle plant, all of the nuclear heat source and heat exchanger equipment is installed in the PCRV. In the plant discussed, four reformers, two steam generators, and four circulators are utilized for the $1170-\mathrm{MW}(\mathrm{t})$ variant. From Fig. 9-3, it can be seen that the reactor outlet gas flows directly to the convectively heated reformer, transferring $650 \mathrm{MW}(\mathrm{t})$ to the process gas. After leaving the reformer, the primary helium flows through the steam generator and, via the circulator, is transported back to the reactor inlet at a temperature of $500^{\circ} \mathrm{C}$. The maximum primary system pressure of $4.8 \mathrm{MPa}$ (696 psia) is slightly less than for the indirect-cycle case, and selection was based on process plant considerations (particularly the reforming operation). A comparison of plant features for all of the HTGR designs is given in Table 8-I, p. 252. The material problems due to high temperature were outlined in Table 9-III.

\section{9-4C Components}

Two components are peculiar to the process heat reactor, the IHX in the indirect-loop version and the reformer in both versions. Current designs are described here. 


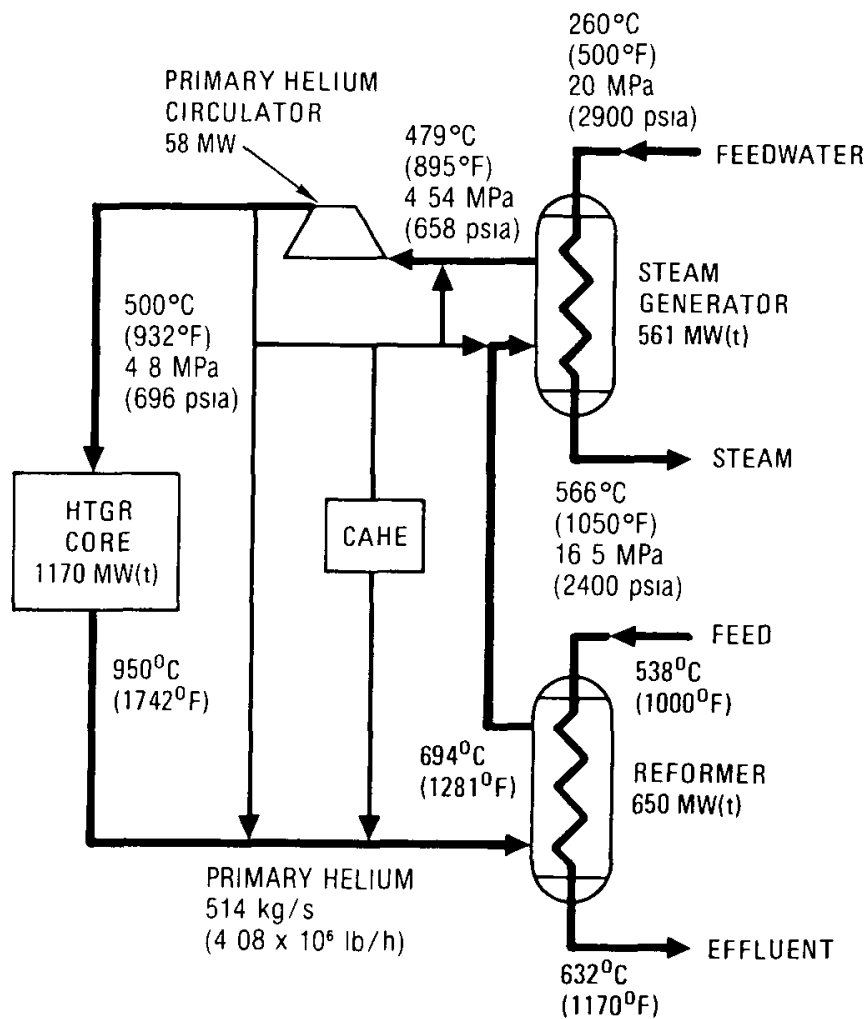

Fig. 9-3. Flow diagram for $950^{\circ} \mathrm{C}$ direct-cycle HTGR process heat plant.

\section{Intermediate Heat Exchanger}

The function of the IHX is to transfer heat from a primary coolant loop to a secondary loop and, in addition, to provide a barrier to egress of fission products (possibly circulating within the reactor primary coolant) into the secondary helium loop. The IHX has been designed as a straight-tube heat exchanger with the primary helium flowing in a single pass inside the tubes and the secondary helium flowing across the bundle in a multipass cross-counterflow configuration. As shown in Fig. 9-4, the IHX is located entirely within the PCRV and is welded at the lower end to a liner extension support. (The upper end of the unit is attached to a primary/ secondary gas boundary dome via a bellows/seal assembly, which compensates for IHX axial thermal expansion.)

Although normal operation is in a near-pressure-balanced condition, the design basis is predicated on the loss of the secondary loop pressure. The current selection of tubing material for the $850^{\circ} \mathrm{C}$ plant design is Inconel-617. An extensive high-temperature materials program is in progress to obtain high-temperature data for potential materials in this application. The material selection and design of the IHX represent a substantial technical development effort. 


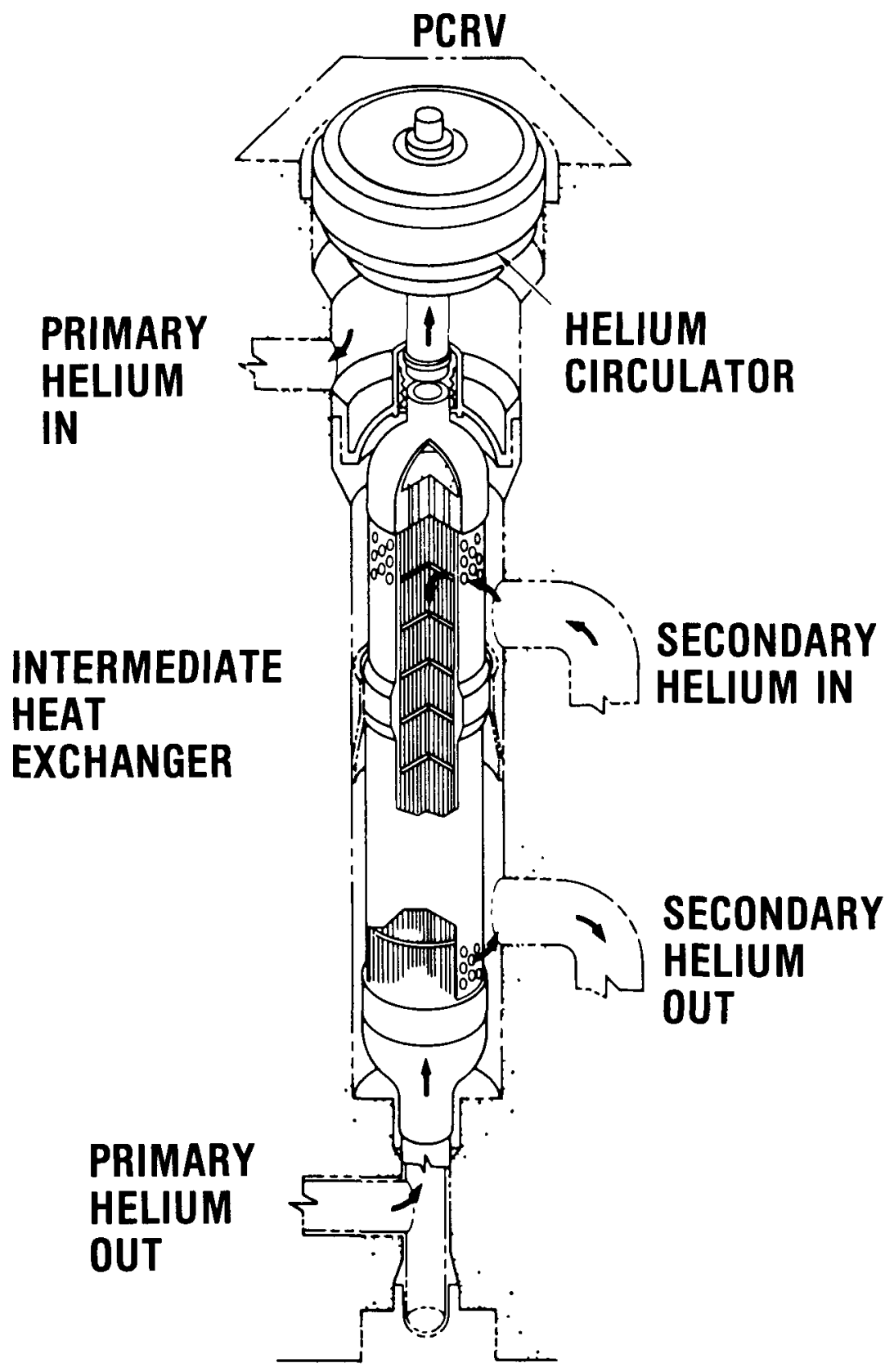

Fig. 9-4. The IHX concept. 


\section{Steam-Methane Reformers}

The steam-methane reformer transfers the heat from the helium loop to the reformer feedstock in the presence of a nickel catalyst. It is, in effect, an axial counterflow convective heat exchanger, but with space provided on the tube side for the inclusion of the catalyst material. A shell-and-tube heat exchanger is utilized, which has tubes large enough to contain the catalyst material in stacked particle form. The feedstock is introduced on the tube side of the exchanger and flows over the catalyst particles while being heated by helium through the tube walls. The conversion reaction takes place during passage through the bed, requiring that heat be convectively supplied to the tubes over the entire bundle length.

In the case of the indirect-cycle plant, the reformers are installed in PCPVs; the hot secondary helium is introduced on the shell side at the hot end of the catalyst tubes, flows counter to the product gas around the tubes, and is discharged at the cold end. In the direct cycle, as the name implies, the high-temperature reactor helium flows directly into the reformer. The reformer is a bayonet tube design where the hot process gas is returned to the inlet end of the reformer via a central tube withın the reformer tube. This arrangement permits regenerative heat transfer with the process stream being reformed. The chemical process of reforming will not be reversed since no catalyst is present in the return tube.

One of the major unresolved issues for process heat applications using reforming is whether the reformer can be located within the primary coolant circuit. As described, both designs are being pursued. Table 9-VII shows a comparison of the advantages of each design. The conclusion may well be that it depends on the particular application.

\section{9-5 Process Heat Applications}

A large number of potential process heat applications can be envisioned for a nuclear reactor with a core outlet temperature of $800^{\circ} \mathrm{C}\left(1472^{\circ} \mathrm{F}\right)$ and above.

TABLE 9-VII

Internal Versus External Reformers

\begin{tabular}{|c|c|}
\hline Internal & External \\
\hline $\begin{array}{ll}\text { Advantages } \\
1 & \text { lower overall cost } \\
2 & \text { lower operating costs } \\
3 & \text { smaller reformers, smaller inventory of } \\
& \text { catalyst } \\
4 & \text { fewer operating parts } \\
5 & \text { less power required } \\
6 & \text { higher temperatures avallable } \\
7 & \text { helium loop protected by PCRV } \\
8 & \text { more compact plant }\end{array}$ & $\begin{array}{ll}\text { Advantages } \\
1 & \text { greater accessibility } \\
2 & \text { simpler reformer design } \\
3 & \text { fewer licensing problems } \\
4 & \text { versatility of external loop } \\
5 & \text { permits use of naphtha feed } \\
6 & \text { minimizes shutdowns } \\
7 & \text { faster plant construction } \\
8 & \text { double barner for hydrogen/tritium } \\
\text { diffusion }\end{array}$ \\
\hline
\end{tabular}




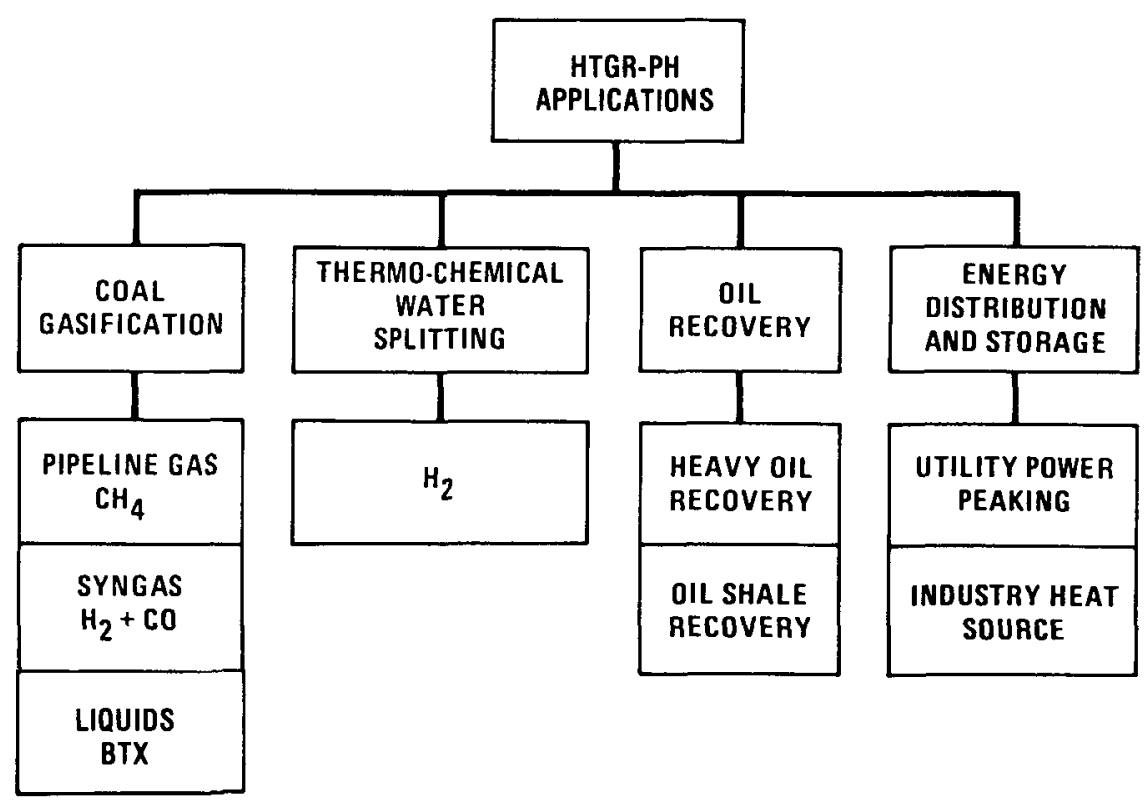

Fig. 9-5. Nuclear process heat applications.

These applications can be broken into four categories, as shown in Fig. 9-5, which represent the bulk of the possibilities. These categories are discussed below.

\section{9-5A Synfuel Using Coal as a Feedstock}

Pipeline gas, reducing gas $\left(\mathrm{H}_{2}+\mathrm{CO}\right)$, or light liquids (benzene, diesel, fuel oil) can be produced. A considerable number of processes are under development to produce synfuels from coal. These processes are basically of the hydrogencarbon type or the steam-carbon type. Most of the coal liquefaction processes are of the former (SRC-II, donor solvent, H-coal), whereas most of the gasification processes are of the latter (Lurgi, Koppers-Totzek). The HTGR-II with a core outlet temperature of 800 to $850^{\circ} \mathrm{C}\left(1472\right.$ to $\left.1562^{\circ} \mathrm{F}\right)$ fits well with the hydrogencarbon processes since steam-light hydrocarbon reforming can be used for hydrogen production. The steam-carbon reaction will require core outlet temperatures in the $950^{\circ} \mathrm{C}\left(1742^{\circ} \mathrm{F}\right)$ range.

\section{9-5B Nuclear-Chemical Energy Center}

To illustrate how the HTGR could effectively participate in the nuclear energy field for the intermediate time frame (1995 and onward), an example of a nuclearchemical energy center utilizing coal as a feedstock has been developed. Figure 9-6 shows how the nuclear-chemical energy center can be integrated to serve the 
needs of various users. The basic HTGR-PH plant receives coal liquids, uranium in the form of fuel elements, and water at the plant site. The basic chemical equations involved are:

$$
\begin{array}{ll}
\mathrm{C}^{*}+2 \mathrm{H}_{2} & \mathrm{CH}_{4}+\text { heat } \\
\mathrm{CH}_{4}+\mathrm{H}_{2} \mathrm{O}+\text { heat } \longrightarrow & \mathrm{CO}+3 \mathrm{H}_{2} \text { (steam reforming) } \\
\mathrm{CO}+\mathrm{H}_{2} \mathrm{O} & \mathrm{H}_{2}+\mathrm{CO}_{2} \text { (shift reaction) } \\
& { }^{*} \mathrm{Coal} \text { liquids are represented by carbon. }
\end{array}
$$

The process plant output products shown in Fig. 9-6 are then sent to the users. Aromatics produced, primarily benzene, would be shipped off-site via pipeline or tank car. Liquid hydrogen could also be shipped via special truck or tank car. The direct reduction plant could include an electric furnace for the downstream production of steel with a portion of the HTGR electric output directed toward that end.

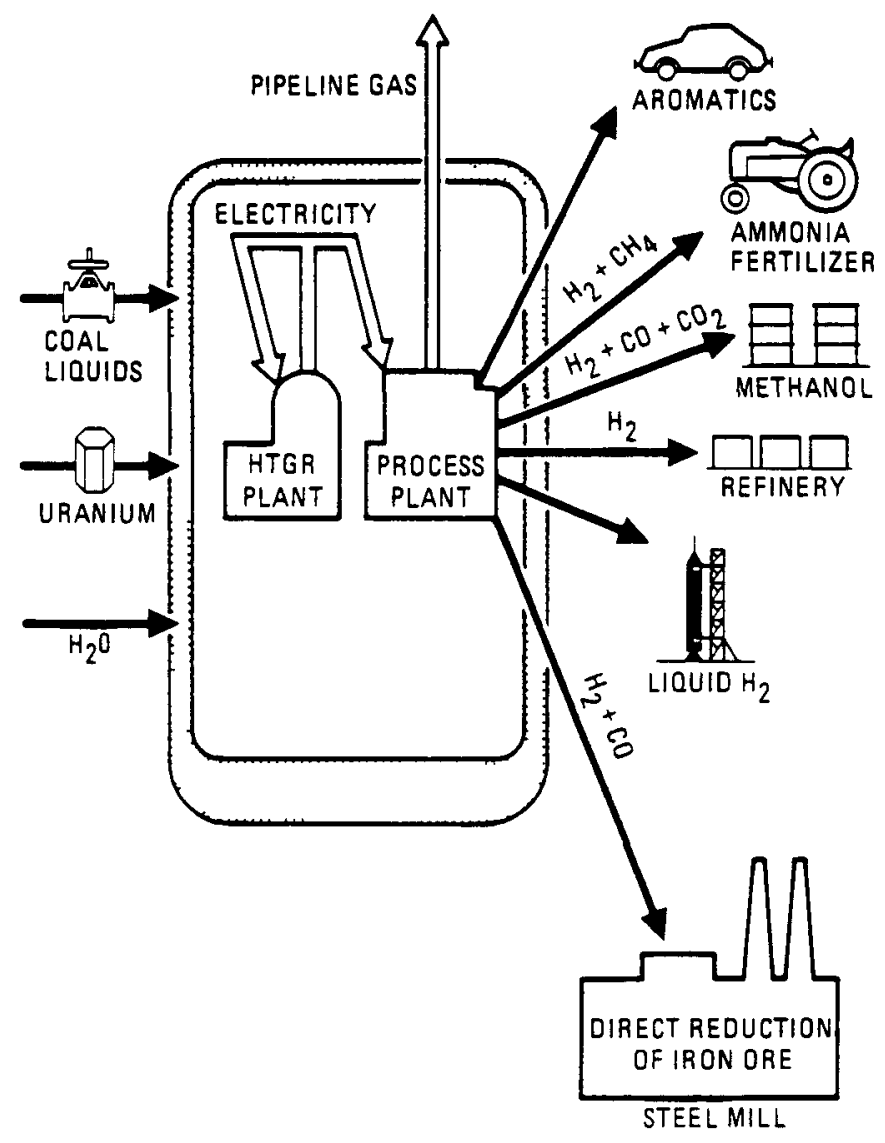

Fig. 9-6. The nuclear-chemical energy center. 


\section{TABLE 9-VIII}

Typical Plant Products for a Twin 842-MW(t) HTGR

\begin{tabular}{|c|c|c|c|c|c|c|}
\hline Fınal Product & $\begin{array}{l}\text { Electrıcity } \\
(\mathrm{MW})\end{array}$ & $\begin{array}{l}\text { Ener } \\
\mathrm{CH}_{4}\end{array}$ & $\begin{array}{l}\text { Center Prod } \\
\mathrm{H}_{2}+\mathrm{CO} \\
\text { (MMSCFD) }^{\mathrm{b}}\end{array}$ & $\mathrm{CO}_{2}$ & $\begin{array}{l}\mathrm{C}_{6} \mathrm{H}_{6} \\
\text { (bpd) }\end{array}$ & $\begin{array}{c}\text { Customer } \\
\text { Plant Capacity }\end{array}$ \\
\hline Oll refinery & 46 & & 72 & & \multirow{7}{*}{11400} & $160000 \mathrm{bpd}^{\mathrm{c}}$ \\
\hline Ammonıa & 49 & 15 & 78 & 13 & & 1500 ton/day \\
\hline Aromatics & & & & & & $11400 \mathrm{bpd}^{\mathrm{c}}$ \\
\hline Methanol & 30 & & 113 & 28 & & 1500 ton/day \\
\hline $\begin{array}{l}\text { Reduced iron ore } \\
\text { pellets }\end{array}$ & & 5 & 113 & & & 1170000 ton/yr \\
\hline Pipeline gas & & 154 & 20 & & & $154 \mathrm{MMSCFD}^{\mathrm{b}}$ \\
\hline Electricity for sale & $\underline{256}$ & & & & & $256 \mathrm{MW}(\mathrm{e})$ \\
\hline Total & 381 & 174 & 396 & 41 & 11400 & \\
\hline
\end{tabular}

${ }^{\mathrm{a}}$ Energy center input

Liquid coal $22 \times 10^{6}$ metric ton/yr (37 $500 \mathrm{bpd}$ )

Uranium 648 metnc ton/yr $\left(712\right.$ ton/yr) $\mathrm{U}_{3} \mathrm{O}_{8}$ (recycle)

$\mathrm{H}_{2} \mathrm{O} 49 \mathrm{~kg} / \mathrm{s}\left(112 \times 10^{6} \mathrm{gal} /\right.$ day $)\left(\mathrm{H}_{2}\right.$ production only)

${ }^{\mathrm{b}} 1 \mathrm{MMSCFD}=283 \times 10^{3}$ (standard) $\mathrm{m}^{3} /$ day

${ }^{\mathrm{c}}$ bpd $=016 \mathrm{~m}^{3} /$ day

Reasonable plant sizes, commensurate with today's technology, are shown for these uses in Table 9-VIII, which gives a breakdown of customer facilities, the approximate output quantity, and the quantities of gas sent to customer faclities These values are matched by a twin 842-MW(t) HTGR This arrangement gives a very high degree of avallability A representatıve heat balance on the nuclear-chemical energy center shows that the nuclear heat represents $35 \%$ of the heat input, with the remainder being supplied from the liquid coal as the chemical feedstock

\section{9-5C Oil Shale Recovery}

A commercial-scale installation has been studied to determine its total energy load in evaluating the applicability of an HTGR to a commercial facility The study was based on surface retortıng operations producing $8000 \mathrm{~m}^{3} /$ day $(50000$ bpd) of raw shale o1l from $113 \times 10^{-3} \mathrm{~m}^{3}$ per ton ( $30 \mathrm{gal} /$ ton) of shale The kerogen (organic part of shale) was hydrotreated at the site using steam-methane reforming of the off-gas Table 9-IX shows overall energy demand which is in line with practical reactor sizes The advantages of using a nuclear reactor he in the production of hydrogen from a fraction of the resource that otherwise would not be fully utılized, increased process efficiency, and reduced air pollution

\section{9-5D Alternate Heat Transmission and Storage Systems}

The high-temperature capability of the HTGR-PH enables it to be coupled to several possible energy transport media for transport over long distances and 
TABLE 9-IX

Energy Demand for a Surface Shale Oil Operation with Hydrotreating* ${ }^{\dagger}$

\begin{tabular}{|lcc|}
\hline & $\mathrm{MW}(\mathrm{e})$ & $\mathrm{MW}(\mathrm{t})$ \\
\hline Mnnng/crushing/retortıng & 726 & 492 \\
Reformung & 6.7 & 256 \\
Hydrotreatung & $\underline{136}$ & $\frac{49}{929}$ \\
Total & 929 & 797 \\
\hline
\end{tabular}

*From Ref 3

${ }^{\dagger}$ Based on $8000 \mathrm{~m}^{3} /$ day ( 50000 bpd).

still provide good thermodynamic efficiency at the user end. Several transport fluids and systems have been examined. One is a chemical energy system wherein an endothermic reaction (steam-methane reforming) takes place at the nuclear heat system end and an exothermic reaction (methanation) at the user end. ${ }^{4} \mathrm{~A}$ second is the use of a sensible heat salt system that is heated to $540^{\circ} \mathrm{C}\left(1000^{\circ} \mathrm{F}\right)$ at the reactor end and transported to the user. The cooled salt is returned to the reactor. This system has the potential for relatively inexpensive energy storage and may be useful for electric power peaking applications. ${ }^{5} \mathrm{~A}$ third system would be a direct steam line to the users if distances are $<30 \mathrm{~km}$. A comparison of these alternate energy transport systems is shown in Fig. 9-7.

\section{9-5E Hydrogen Production by a Closed-Loop Thermochemical Process}

Extensive development work is proceeding in the United States and abroad on hydrogen production processes that utilize a series of chemical steps to separate

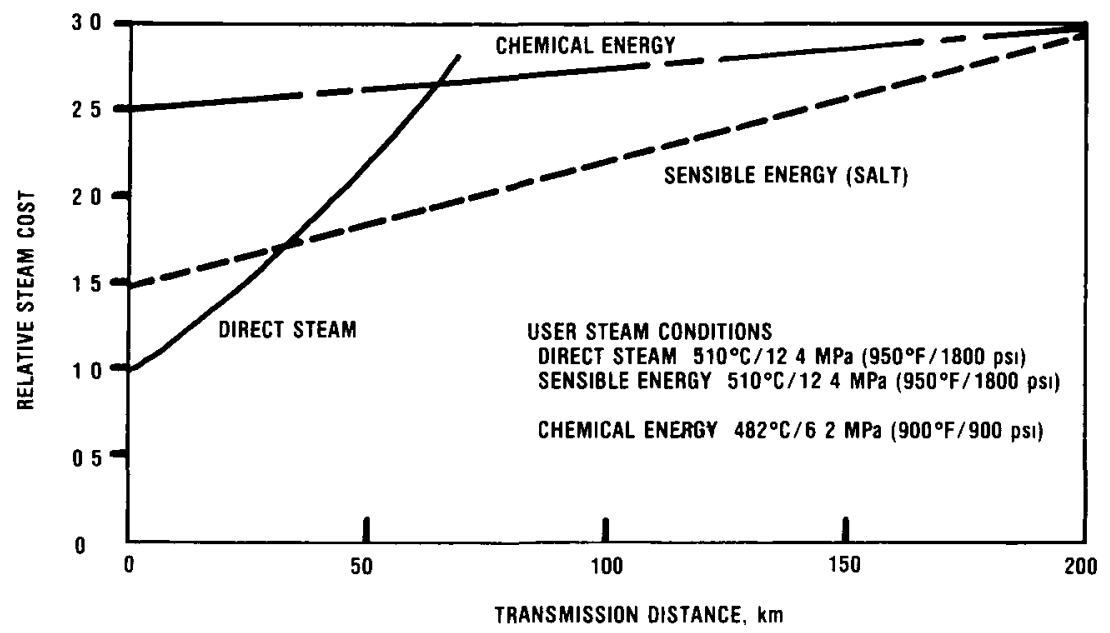

Fig. 9-7. Comparison of the cost of steam versus distance for varıous energy transport systems. 
TABLE 9-X

Pebble Bed and Prismatic Fuel Element Reactor Features

\begin{tabular}{|c|c|c|}
\hline & Prismatıc Element Core & Pebble Bed Core \\
\hline Fuel element form and dımensions & $\begin{aligned} \text { Right hexagonal prism, } & \sim 360 \mathrm{~mm} \text { across flats } \\
& \sim 790 \mathrm{~mm} \text { height }\end{aligned}$ & 60-mm-diam sphere \\
\hline Fuel management & $\begin{array}{l}\text { Graded-cycle, off-line refueling, one-fourth to } \\
\text { one-third core annually for typical large unit }\end{array}$ & $\begin{array}{l}\text { Optıonal, once-through-then-out (OTTO) or } \\
\text { multıple-pass cycle, on-line fueling, } \sim 3 \text {-yr in- } \\
\text { core fuel life }\end{array}$ \\
\hline $\begin{array}{l}\text { Control and shutdown } \\
\text { primary control }\end{array}$ & $\begin{array}{l}\text { Gravity control rods inserted into in-core } \\
\text { channels }\end{array}$ & $\begin{array}{l}\text { High-thrust, rigid control rods drive into pebble } \\
\text { bed }\end{array}$ \\
\hline backup shutdown & $\begin{array}{l}\text { Gravity feed of absorber granules into in-core } \\
\text { channels }\end{array}$ & $\begin{array}{l}\text { Gravity feed of absorber spheres }(<10-\mathrm{mm} \\
\text { diameter) into interstices between fuel elements }\end{array}$ \\
\hline Reflector & $\begin{array}{l}\text { Core boundary reflector elements can be replaced } \\
\text { dunng normal refueling }\end{array}$ & $\begin{array}{l}\text { Core boundary reflector elements not routinely } \\
\text { accessible for replacement }\end{array}$ \\
\hline \multirow[t]{4}{*}{ Core performance } & $\begin{array}{l}\text { On-line adjustable fuel region flow-control } \\
\text { onfices to compensate for radıal age-peaking of } \\
\text { graded cycle }\end{array}$ & $\begin{array}{l}\text { Low radial power peaking factors due to axial } \\
\text { flow and on-line refueling }\end{array}$ \\
\hline & $\begin{array}{l}\text { Core } \Delta P \text { is dictated by core orficing to achieve } \\
\text { power/flow matching in the highest power region }\end{array}$ & $\begin{array}{l}\text { Pebble bed core is not orificed but inherently } \\
\text { high pressure drop characteristics result in core } \\
\Delta P \text { similar to a prismatic core }\end{array}$ \\
\hline & In-core instrumentation for power mapping & $\begin{array}{l}\text { Core instrumentation must be external to active } \\
\text { core }\end{array}$ \\
\hline & $\begin{array}{l}\text { Block-type fuel elements are subject to internal } \\
\text { stresses due to fluence and temperature } \\
\text { differences within the block envelope }\end{array}$ & $\begin{array}{l}\text { A very small fraction of fuel elements are } \\
\text { expected to be broken by control rod insertion } \\
\text { into the bed }\end{array}$ \\
\hline
\end{tabular}


water into hydrogen and oxygen by thermal means. Most of these processes need a high-temperature heat input step, which is often the decomposition of sulfuric acid. For instance, the sulfur-iodine process for thermochemical watersplitting is now under development. A bench-scale unit demonstrating all the major steps in this process has been constructed and is operating. ${ }^{6}$

Watersplitting methods, when coupled to a nuclear heat system, provide a way of more than doubling synfuel production from a fixed quantity of fossil feedstock. These savings occur since none of the fossil source is used to provide heat for the process and no $\mathrm{CO}_{2}$ is produced in the hydrogen production process itself. In the longer term, hydrogen is a likely candidate for replacement of current liquid and gaseous fuels.

\section{9-6 Comparison of Prismatic and Pebble Bed HTGRs for Process Heat Applications}

As seen in previous chapters, an HTGR with a pebble bed core [pebble bed reactor (PBR)] has been developed in the Federal Republic of Germany, with one reactor in operation [the 15-MW(e) AVR] and another one to be commissioned in 1984 [the $300-\mathrm{MW}(\mathrm{e}) \mathrm{THTR}$ ]. In view of the satisfactory experience with hightemperature operation of the AVR $\left(950^{\circ} \mathrm{C}\right.$ top helium temperature), a number of studies of PBR designs for high-temperature process heat applications have been performed. $^{7,8}$

A comparison of some of the different features of pebble bed and prismatic fuel element cores is given in Table 9-X. Comparison of the heat transfer characteristics of the pebble and prism fuel concepts shows no significant overall heat conductance advantage for the pebble bed system. The larger pebble surface heat transfer area and higher coolant-to-surface heat transfer film coefficient for the pebble bed are offset by the higher solid conductance characteristic of the prismatic geometry. However, some fuel temperature performance advantage for the PBR can be anticipated due to the radially flat power distribution, lower age peaking factor, and nearly ideal axial power shape achievable by a continuously fueled OTTO fuel management cycle (see Chapters 4 and 6).

Some mechanical questions with large PBRs, such as insertion of control rods in the core or radiation damage to the radial graphite reflector, are as yet unsolved or unproven (before operation of the THTR in 1984-1985). It is, thus, too early to tell whether some of the advantages of the PBR, such as on-line refueling and flatter temperature profiles, could make the PBR as advantageous for process heat applications with larger plants as it could be with small modular systems.

\section{REFERENCES}

1. "High-Temperature Gas-Cooled Reactor Steam Cycle/Cogeneration Application Study," Gas-Cooled Reactor Associates, La Jolla, California (Dec. 1980). 
2 "Cogeneration Feasibility Study in the Gulf States Utilities Service Area," ORNL/ SUB-7317/1, Oak Ridge National Lab (July 1979)

3 “Applications for an HTGR in Oil Shale Processing," Pace Co, Denver (Nov 1979)

4 K Kugeler et al , "Transport of Nuclear Heat by Means of Chemical Energy," Nucl Eng Des, 34, 1, 65 (1975)

5 R N Quade, D L Vrable, and D D Peterman, "Energy Distribution and Storage Alternates with a Centralized Heat Source," Proc 13th Intersociety Energy Conversion Engineering Conf, San Diego, Calıfornia, August 20-25, 1978, Vol 2, p 1016, Society of Automotive Engineers (1979)

6 G E Besenbruch et al , "Status of the Development of the General Atomic Thermochemical Water-Splittıng Cycle," paper presented at 2nd Miamı Int Conf on Alternative Energy Sources, Miamı Beach, Flonda, December 10, 1979

7 ' 'High-Temperature Reactor for Process Heat Applications,' Nucl Eng Des, 34, 1, special issue (1975)

8 "Comparatıve Evaluation of Pebble-Bed and Prismatıc Fueled High-Temperature GasCooled Reactors,' ORNL-5694, Oak Ridge National Lab (Jan 1981) 


\section{GAS-COOLED FAST BREEDER REACTOR THERMAL HYDRAULICS*}

\section{0-1 Introduction}

Two basic types of fast breeder reactors (FBRs) have been considered: the sodium-cooled liquid-metal fast breeder reactor (LMFBR) and the gas-cooled fast breeder reactor (GCFR), which is helium cooled (see Table 10-I). The reference fuel for both systems is a mixture of $\mathrm{PuO}_{2}$ and $\mathrm{UO}_{2}$, and at a later date will possibly be a mixture of PuC and UC. The specific power, or fissile loading, is comparable for LMFBRs and GCFRs, but the latter enjoys a higher breeding ratio and a lower "doubling time," the time required to double the initial fissile inventory. The compound doubling time of the GCFR system is expected to be less than the historical doubling time of electricity generation $(\sim 12 \mathrm{yr}$ overall). A large number of energy strategy studies have been performed to look at the impact of various policies on ore requirements with various assumptions for nuclear power growth. ${ }^{1-7}$ It has been shown that high-gain breeders are required to terminate the consumption of uranium to feed a given nuclear program, ${ }^{4}$ and to limit the

TABLE 10-I

Comparison of Thermal and Fast Breeders ${ }^{\star}$

\begin{tabular}{|l|ccl|c|}
\hline & \multicolumn{3}{|c|}{ Fast } & Thermal \\
\hline & $\begin{array}{c}\text { LMFBR } \\
\mathrm{PuO}_{2}\end{array}$ & $\begin{array}{c}\text { LMFBR } \\
\text { PuC }\end{array}$ & $\begin{array}{l}\mathrm{GCFR}^{2} \\
\mathrm{PuO}_{2}\end{array}$ & $\begin{array}{c}\text { MSBR }^{\mathrm{a}} \\
\text { Thorium }^{2}\end{array}$ \\
\hline Breeding gain & 02 & 03 & 045 & 007 \\
Doubling time (yr) & 15 & 10 & 8 & 20 \\
Specific power (MW(e)/kg] & 0335 & 0335 & 032 & 0665 \\
Conservation coefficient $^{\mathrm{c}}$ & 0022 & 0033 & 0046 & 0031 \\
\hline
\end{tabular}

*From Ref 1

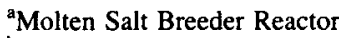

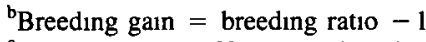

${ }^{c}$ Conservation coefficient $=$ breeding gain $\times$ (specific power) $^{2}$ (inversely proportional to total amount of uranium required)

*Chandu B Baxi contributed to this chapter 
TABLE 10-II

Simplified Comparison of Reactor Coolants

\begin{tabular}{|l|c|cc|c|}
\hline & \multicolumn{4}{|c|}{ Coolant } \\
\cline { 2 - 5 } & Water & \multicolumn{2}{|c|}{ Helium } & Sodium \\
\hline Reactor type & PWR & HTGR & GCFR & LMFBR \\
Average temperature $\left({ }^{\circ} \mathrm{C}\right)$ & 300 & 550 & 450 & 450 \\
Average pressure $(\mathrm{MPa})$ & 15 & 5 & 10 & 05 \\
Coolant temperature rise $\Delta T\left({ }^{\circ} \mathrm{C}\right)$ & 30 & 420 & 300 & 165 \\
Density $\rho\left(\mathrm{g} / \mathrm{cm}^{3}\right)$ & 070 & 0003 & 00068 & 080 \\
Specific heat $C_{p}\left(\mathrm{~J} / \mathrm{g} \cdot{ }^{\circ} \mathrm{C}\right)$ & 5.3 & 52 & 52 & 125 \\
Flow velocity $V(\mathrm{~m} / \mathrm{s})$ & 45 & 50 & 80 & 6 \\
Heat transport per unit core & & & & 100000 \\
$\quad$ frontal area $p u C_{p} \Delta T\left(\mathrm{~W} / \mathrm{cm}^{2}\right)$ & 50000 & 33000 & 84000 & 10 \\
Rod surface heat transfer & & & & 20 \\
$\quad$ coefficient $h\left(\mathrm{~W} / \mathrm{cm}^{2}{ }^{\circ} \mathrm{C}\right)$ & 3 & 025 & 15 & 200 \\
Average film drop $\Delta T\left({ }^{\circ} \mathrm{C}\right)$ & 20 & 120 & & \\
Heat transfer per unit rod surface & & & & \\
area $h \Delta T\left(\mathrm{~W} / \mathrm{cm}^{2}\right)$ & 60 & 30 & 150 & \\
\hline
\end{tabular}

total uranium consumption of the Western World to a value close to the expected uranium reserves. $^{5-7}$

A simplified comparison of thermodynamic and heat transfer and transport properties of the three main reactor coolants is given in Table 10-II. Water and helium are typical coolants for thermal reactors, while sodium and helium are the two fast reactor coolants that have been primarily considered. In Table 10-II, typical operating pressures and temperatures have been chosen to represent conditions for pressurized water reactors (PWRs), high-temperature gas-cooled reactors (HTGRs), GCFRs, and LMFBRs, respectively. It can be seen that the heat transport per unit core frontal area with helium is $\sim 85 \%$ of the value for sodium, requiring a core diameter $\sim 10 \%$ larger for the GCFR. Since the core dimensions of an FBR are extremely small compared to the total plant size, this is not a real penalty. In fact, a lower power density may be desirable in FBRs for safety reasons. Similar reasoning would apply for a comparison of helium and water in thermal reactors, showing that the cooling performance of pressurized helium is satisfactory. As a matter of fact, cooling properties that are too good could be a penalty in some cases. For instance, thermal shock problems are very severe in sodium-cooled reactors because of the excellent thermal conductıvity of sodium; this is not the case with gas cooling.

A broader comparison of sodium and helium as FBR coolants is shown in Table 10-III. It can be seen that the main advantages of sodium are its excellent thermal-hydraulic properties: low operating pressure, a maximum of $\sim 1 \mathrm{MPa}$ (10 atm), and good natural convection properties for emergency decay heat removal. The main problems with sodium are its high induced radioactivity, requiring heavy shielding and an intermediate sodium heat transfer loop; its high chemical activity and its change of phase with three possible phases in case of incidents; its opacity, leading to complex inspection, maintenance, and refueling; 
TABLE 10-III

Ranking of Sodium and Helium as Fast Breeder Coolants

\begin{tabular}{|c|c|c|c|}
\hline & Excellent & Adequate & Poor \\
\hline \multicolumn{4}{|l|}{ Nuclear Reaction Cross Sections } \\
\hline Effect on breeding ratio & Helium & Sodium & \\
\hline Doubling tıme & Helium & Sodium & \\
\hline Induced radioactivity & Helium & & Sodium \\
\hline Radiation stabılity & Helıum, Sodıum & & \\
\hline \multicolumn{4}{|l|}{ Thermal-Hydraulıc Propertıes } \\
\hline Heat transfer & Sodrum & Helıum & \\
\hline Pumping power & Sodrum & & Helium \\
\hline \multicolumn{4}{|l|}{ Systems Complexity } \\
\hline Operatıng pressure & Sodium & Helıum & \\
\hline Number of systems (loops) & & Helıum & Sodium \\
\hline Materials compatibility & Helıum & Sodium & \\
\hline Refuelıng system & & Helium & Sodium \\
\hline \multicolumn{4}{|l|}{ Safety, as affected by } \\
\hline Loss of coolant & Sodıum & Helıum & \\
\hline Loss of flow & Sodium & & Hehum \\
\hline Possible coolant change & Helium & & Sodium \\
\hline Potential chemical reactivity & Helium & & Sodium \\
\hline
\end{tabular}

and its propensity to induce high thermal stresses, particularly under transient conditions. In spite of all these problems, sodium-cooled FBRs have been built in a number of countries as prototypes or demonstration plants, but no commercialsize reactor yet exists except for the 1200-MW(e) Superphenix, under construction in France, with expected startup in 1985.

Liquid metals such as mercury, sodium, and $\mathrm{NaK}$, were chosen as coolants for the first fast reactors, which had small, high power density cores, without enough room for cooling with other coolants. When the core size of FBRs increased from a few liters to thousands of liters, the fraction of the core occupied by the coolant grew to $\sim 50 \%$ and other coolants could be considered besides sodium; namely, steam $^{8}$ or gases. Superheated steam has good heat transfer properties at high pressure, but acts as a moderator and thus leads to a low breeding ratio. Besides, it is highly corrosive at high temperatures and no cladding material is available. Therefore, only pressurized gases have been studied in the past few years as alternative coolants for FBRs. Helium appears to be the preferred coolant for FBRs, although $\mathrm{CO}_{2}$ (Refs. 9 and 10) and even dissociating gases $\left(\mathrm{N}_{2} \mathrm{O}_{4} \rightleftarrows 2 \mathrm{NO}_{2} \rightleftarrows \mathrm{N}_{2}+2 \mathrm{O}_{2}\right)$ with a direct cycle have also been suggested in Europe. ${ }^{10-12}$

Table 10-IV shows the various designs proposed for GCFRs. Besides the choice of coolant, two main types of fuels have been considered: metal-clad fuel very similar to fuel for LMFBRs, and advanced fuel using coated fuel particles similar to those employed ${ }^{13-15}$ in HTGRs. Both the indirect (or steam) cycle and 


\section{TABLE 10-IV}

Main Types of GCFRs

\begin{tabular}{|c|c|c|c|c|c|c|}
\hline Coolant & \multicolumn{4}{|c|}{ Helium } & $\mathrm{CO}_{2}$ & $\mathrm{~N}_{2} \mathrm{O}_{4}$ \\
\hline Fuel & \multicolumn{2}{|c|}{$\begin{array}{c}\mathrm{Metal} \mathrm{clad}_{\left(\mathrm{PuO}_{2}-\mathrm{UO}_{2}\right)} \\
\text { Cycle }\end{array}$} & $\begin{array}{c}\text { Coated } \\
\text { particle }\end{array}$ & Metallic & $\begin{array}{c}\text { Coated } \\
\text { particle }\end{array}$ & $\begin{array}{c}\text { Metal clad } \\
\left(\mathrm{PuO}_{2}-\mathrm{UO}_{2}\right)\end{array}$ \\
\hline Country & $\begin{array}{c}\text { SBRA } \\
\text { FRG } \\
\text { Japan } \\
\text { Switzerland } \\
\text { US }\end{array}$ & $\begin{array}{c}\text { FRG } \\
\text { Switzerland } \\
\text { or direct }\end{array}$ & Steam & Steam & Direct \\
\hline
\end{tabular}

${ }^{a}$ Gas Breeder Reactor Association, association of European industries headquartered in Brussels, Belgium

the direct (or gas turbine) cycle have been studied for GCFRs as for thermal reactors. To obtain the most benefit from ongoing developments in thermal and fast reactor programs, the quasi-universal choice for GCFR designs is a reactor cooled by helium, using metal-clad $\left(\mathrm{UO}_{2}-\mathrm{PuO}_{2}\right)$ fuel and producing electricity through a steam cycle. ${ }^{10,16}$ Such a system is discussed in this chapter.

\section{0-2 GCFR System Design Description}

As indicated in Sec. 10-1, most designs utilize the same type of fuel elements as LMFBRs, i.e., metal-clad mixed $\left(\mathrm{UO}_{2}-\mathrm{PuO}_{2}\right)$ rods within hexagonal metal ducts. The nuclear steam supply system for a GCFR is similar to advanced gascooled reactor (AGR) and HTGR systems, i.e., the reactor core, steam generators, helium circulators, and core auxiliary cooling systems are all contained within a prestressed concrete reactor vessel (PCRV). Since the metallic fuel cladding is limited in temperature to 700 to $750^{\circ} \mathrm{C}$, as opposed to an all-ceramic core in the HTGR, the outlet coolant temperature in GCFRs may be somewhere between 550 and $600^{\circ} \mathrm{C}$ and a direct cycle would not be efficient. Therefore, reference GCFR designs utilize an indirect steam cycle, although there is the potential for helium gas turbine applications with advanced metallic or ceramic claddings.

Studies have been made in various countries on GCFR demonstration plants, in the range of 300 to $750 \mathrm{MW}(\mathrm{e})$, and of full-size plants from 1000 to $1500 \mathrm{MW}(\mathrm{e})$. Most of the design work in the United States has been performed for a 300- to 350-MW(e) plant, while a 1200-MW(e) six-loop concept has been studied by the Gas-Cooled Breeder Reactor Association (GBRA) in Europe, to be preceded by a three-loop 600-MW(e) demonstration plant. For all GCFR designs in Western Europe and the United States, the reactor core, blanket, and shielding are contained in a central cavity of the PCRV; steam generators, helium circulators, and core auxiliary cooling systems are located in pods within the concrete walls of the 
PCRV. The active core is made up of hexagonal assemblies of stainless steel-clad fuel rods with artificial surface roughening to enhance heat transfer from the cladding to the coolant, as in AGRs. To balance the pressure between the inside of the cladding and the outside, a fuel venting system has been designed to operate under all steady-state and transient conditions. A coolant pressure of $\sim 10 \mathrm{MPa}$ has been chosen in European and U.S. GCFR designs, which is higher than that for thermal gas-cooled reactors because of the higher core power density in all FBRs. This helium pressure can be compared to the water pressure of $15 \mathrm{MPa}$ in PWRs.

Table 10-V gives the main characteristics for typical 350- and 1200-MW(e) plants designed by General Atomic. The hot spot mid-cladding temperature of 700 to $750^{\circ} \mathrm{C}$ and the maximum linear rating of $\sim 40 \mathrm{~kW} / \mathrm{m}$ for the $350-\mathrm{MW}(\mathrm{e})$ GCFR are comparable to the corresponding values for the LMFBR demonstration plants such as Phenix in France ${ }^{18}$ or the Prototype Fast Reactor in the United Kingdom, ${ }^{19}$ while the breeding gain of 0.35 is much larger for GCFRs than for LMFBRs (0.1 to 0.2). A larger breeding ratio is expected in GCFRs since helium does not slow down appreciably or absorb neutrons compared to sodium; this leads to a harder neutron spectrum, preferable for $\mathrm{PuO}_{2}-\mathrm{UO}_{2}$ fuel. If one compares the performance of large GCFRs to large LMFBRs, such as the 1200-MW(e) Superphenix now under construction in France, ${ }^{20}$ one finds about the same reactor rating; but the breeding gain of Superphenix is only $\sim 0.20$, instead of 0.4 to 0.5 , which leads to a compound fuel doubling time of some $25 \mathrm{yr}$ while it could be

TABLE 10-V

Main Characteristics of GCFR Plants* (Mixed oxide fuel)

\begin{tabular}{|lcc|}
\hline & $360 \mathrm{MW}(\mathrm{e})$ & $1200 \mathrm{MW}(\mathbf{e})$ \\
\hline Thermal power $(\mathrm{MW})$ & 1090 & 3600 \\
Helium pressure (MPa) & 105 & 10 to 12 \\
Maximum mid-clad temperature $\left({ }^{\circ} \mathrm{C}\right)$ & $750^{\mathrm{a}}$ & 750 \\
Reactor inlet temperature $\left({ }^{\circ} \mathrm{C}\right)$ & 298 & 310 \\
Top helium temperature $\left({ }^{\circ} \mathrm{C}\right)$ & 524 & 565 \\
Number of main loops & 3 & 6 \\
Net cycle efficiency $(\%)$ & 33 & 33 \\
Active core & & \\
volume $\left(\mathrm{m}^{3}\right)$ & -7 & 20 to 125 \\
length $(\mathrm{m})$ & 20 & 12 to 106 \\
Fuel rod diameter $(\mathrm{mm})$ & 8 & 8 \\
Average fuel enrichment $(\%)$ & 20 & -13 \\
Reactor ratıng [MW(t)/kg fissile] & -05 & 059 to 084 \\
Average core power density $\left(\mathrm{MW} / \mathrm{m}^{3}\right)$ & 155 & 180 to 290 \\
Maximum linear rating $(\mathrm{kW} / \mathrm{m})$ & 33 to 40 & 35 to 49 \\
Breeding ratio (average) & 135 & 138 to 157 \\
Compound doubling time $(\mathrm{yr})$ & 25 & 159 to 83 \\
\hline
\end{tabular}

*From Ref 17

${ }^{\mathrm{a}} 700^{\circ} \mathrm{C}$ for initial operation at $300 \mathrm{MW}(\mathrm{e})$ 
$\sim 8$ to 16 yr for large GCFRs. In general, the power density of LMFBRs is larger than for GCFRs (i.e., $300 \mathrm{MW} / \mathrm{m}^{3}$ for Superphenix) since too large a volume fraction of sodium in the core would decrease the neutronic performance of LMFBRs; therefore the fuel rods must be on a rather close pitch. The rods can be further apart in GCFRs and the clearance between fuel assemblies can also be larger than for LMFBRs in order to accommodate bowing and irradiation swelling of the metal ducts without significant neutronic penalty.

The nuclear steam supply system (NSSS) for a 350-MW(e) GCFR plant is shown $^{21}$ in Fig. 10-1. Helium flows up through the reactor core located in the central cavity of the PCRV, then flows down through the three steam generators located in separate cavities within the PCRV concrete walls. Helium then flows back to the 14-MW electric-motor-driven circulators mounted below the steam generators before returning to the core. Three core auxiliary cooling loops are located in separate cavities within the PCRV, each with its own heat exchanger and electrically driven helium circulator. These loops are used for long-term shutdown cooling, backup for the main loops, or for emergency cooling.

The PCRV is similar in design to the vessels of the Hartlepool and Heysham AGRs with prestressing by longitudinal tendons and circumferential wire wrapping, and reinforcement by steel rods. The major penetrations are closed by concrete closures designed to always be in compression and held in place by two structurally independent and redundant means. Flow restrictors are designed to

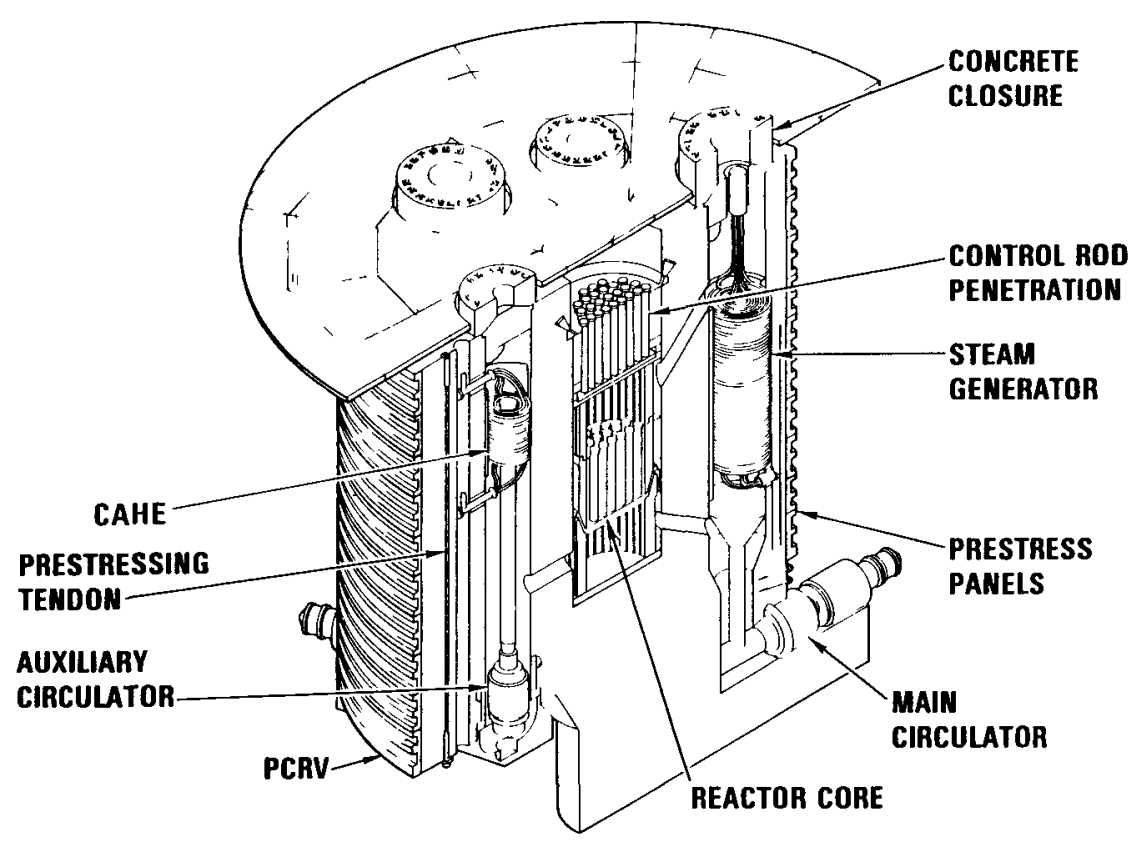

Fig. 10-1. GCFR demonstration plant nuclear steam supply system. 


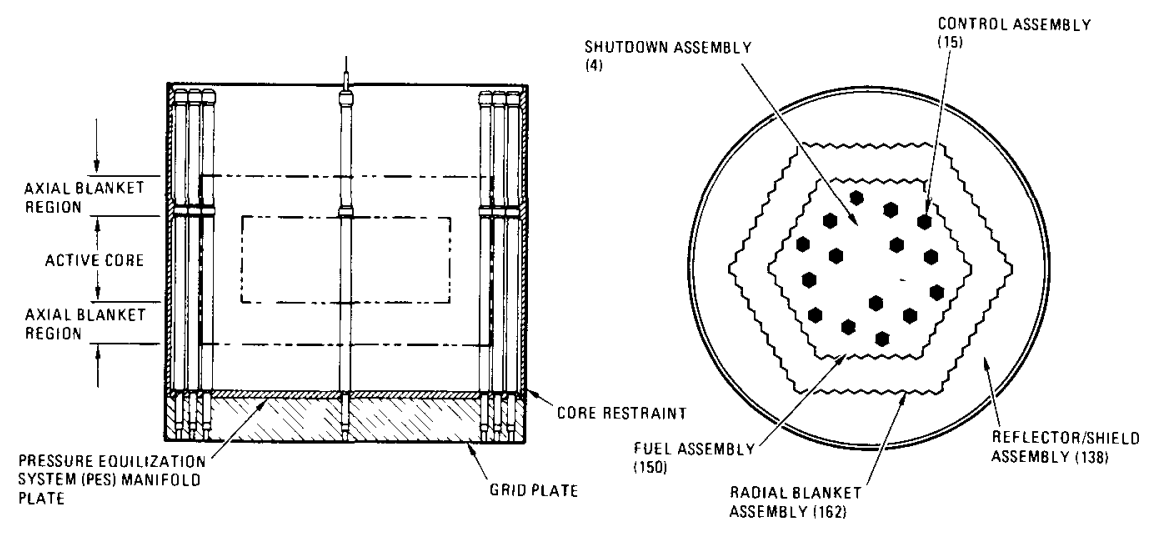

ELEVATION VIEW

PLAN VIEW

Fig. 10-2. GCFR upflow-core demonstration plant general configuration.

provide an acceptable maximum rate of leakage in case of failure of such closures. Furthermore, a leaktight secondary containment building made of reinforced concrete provides a backpressure of $0.16 \mathrm{MPa}$ ( $1.6 \mathrm{~atm}$ absolute) after thermal equilibration. The steel liner of the PCRV is insulated on the helium side by a thermal barrier similar to that of HTGRs (although operating at higher pressure and lower temperature). Cooling of the liner and penetrations is provided by cooling tubes on the concrete side, as in all PCRVs.

The configuration of the 350-MW(e) GCFR reactor core is shown in Fig. 10-2. The active core of the GCFR consists of 169 assemblies; 150 of these are fuel assemblies, 15 are control assemblies, and 4 are shutdown assemblies.

The central core region is surrounded by a radial blanket region of fertile material. The radial blanket consists of 162 hexagonal blanket assemblies arranged in three concentric rows around the active core. Fertile blanket material is also included in the fuel assemblies, above and below the active core (upper and lower axial blankets). The radial blanket is surrounded by 138 hexagonal reflector/shield assemblies arranged in two concentric rows.

The control and shutdown rod assemblies are located on the centers of regions that consist of a central control (or shutdown) assembly surrounded by six fuel assemblies. Removal and replacement of assemblies during refueling is accomplished through the penetration in the closure plug provided for the drive mechanisms. Each seven-assembly region is serviced by one of the penetrations. In the regions out-board of the control and shutdown assembly locations, additional penetrations are provided in the closure plug to service the blanket and reflector/ shield assemblies.

The GCFR fuel assembly design is similar to designs employed in LMFBRs, particularly the fuel rod design. The fuel rod employs the same materials and has similar geometry and operating conditions as those being developed in international 


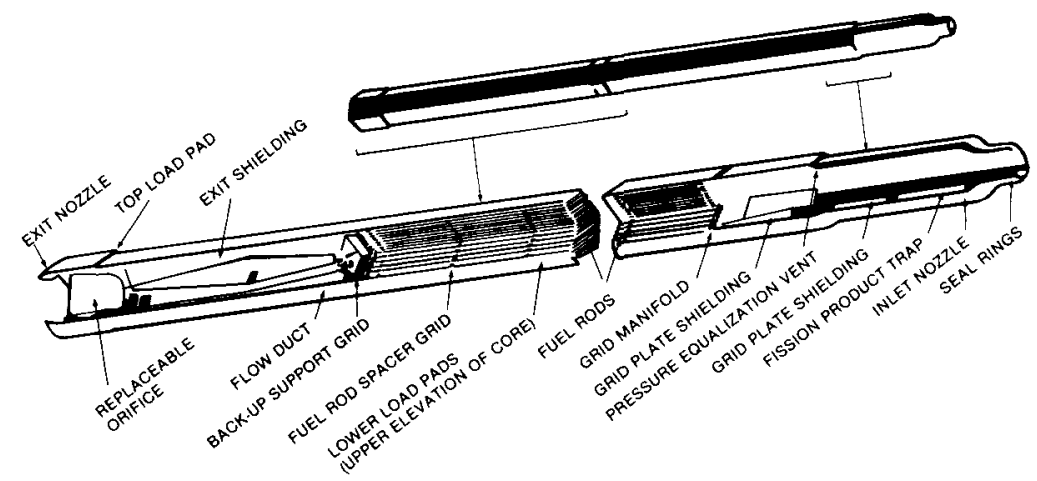

Fig. 10-3. GCFR fuel assembly.

LMFBR programs. The unique characteristics incorporated in the GCFR fuel assembly design include the following:

1. roughened fuel rod cladding to enhance heat transfer to the helium coolant

2. pressure-equalized and vented fuel rods, which essentially eliminate any pressure-induced stresses on the cladding from either the primary coolant system pressure or from fission gases generated within the rods

3. a large fuel rod pitch-to-diameter ratio relative to that commonly employed in the LMFBR designs, which gives an acceptable pressure drop with helium.

The fuel assembly is hexagonally shaped, $194 \mathrm{~mm}$ across flats and $5 \mathrm{~m}$ long. A cylindrical inlet nozzle, $172 \mathrm{~mm}$ in diameter by $\sim 675 \mathrm{~mm}$ long, is located at the bottom end. The inlet nozzle fits into a mating hole in the core support grid plate. The assembly rests on the conical surface, which forms the transition between the cylindrical and hexagonal shapes (see Fig. 10-3).

Contained within the assembly is a 2870 -mm-long fuel bundle consisting of 265 fuel rods. The fuel rods are $8 \mathrm{~mm}$ in diameter and are located on an $11-\mathrm{mm}$ triangular pitch. The rods are fastened to a grid manifold at their lower ends and are laterally spaced by 12 spacer grids positioned at selected axial locations along the length of the rods. The spacer grids are retained in position by means of six hanger rods. The hanger rods are structural members containing no fuel material. A hexagonal flow duct is provided around the rod bundle for channeling the coolant flow through the rod bundle.

An exit end nozzle is provided on the top end of the assembly. The exit 
nozzle is used for handling the assembly and contains a fixed-area replaceable orifice. The orifice is designed to be changed at refueling outages.

The blanket assembly design is essentially the same as the fuel assembly, except that the blanket rod bundle consists of a smaller number of larger rods. Other than the rod bundle, the radial blanket assembly is designed to use the same major components as the fuel assembly. These major components include the inlet nozzle, grid plate shielding, assembly charcoal trap, exit shielding, flow duct, and exit nozzle. The fixed-area replaceable orifice would be specific to the blanket assembly and would contain mechanical discrimination characteristics to prevent a blanket orifice from being assembled on a fuel assembly.

The blanket rod bundle consists of 61 rods, $21.7 \mathrm{~mm}$ o.d. by $2880 \mathrm{~mm}$ long. Each rod consists of a cladding tube, a stack of depleted $\mathrm{UO}_{2}$ cylindrical pellets, a pellet holddown spring at the top of the pellet stack, and end plugs. The blanket rods are pressure-equalized and vented in the same manner as the fuel rods, except that, due to the low fission product yield, a fission product trap is not included in each blanket rod. An assembly trap is, however, included in the inlet nozzle region.

The blanket rods are arranged on a much smaller pitch-to-diameter ratio than the fuel rods. As a result, a wire-wrap spacer system, rather than spacer grids, as used in the fuel assembly design, is used to maintain spacing in the rod array.

The control and shutdown assemblies have the same external configuration as the fuel and blanket assemblies, and many of the major components are the same or are only slightly modified. The flow duct and inlet nozzle structures are the same as used in the fuel and blanket assemblies, and the grid plate shielding and exit nozzle design are slightly modified.

The control rod consists of a bundle of control pins contained within a guide duct having upper and lower end fittings. The composite, consisting of the guide duct, control pins, and end fittings, is designed to move up and down in the flow duct, while always remaining wholly within the flow duct.

The control pin bundle consists of 55 pins, $16.8 \mathrm{~mm}$ o.d. by $1300 \mathrm{~mm}$ long. Each pin consists of a cladding tube, a stack of $\mathrm{B}_{4} \mathrm{C}$ poison pellets, a pellet holddown spring, and end plugs. The control pins are attached to the upper end fitting and are laterally spaced by five spacer grids. Six tie rods are provided in hexagonal corners of the bundle to maintain the axial spacing of the spacer grids. The control pins are vented directly to the helium coolant.

The reflector/shield rod bundle consists of 19 rods, $40.1 \mathrm{~mm}$ o.d. by $3180 \mathrm{~mm}$ long. Each rod consists of a cladding tube, a boronated graphite column, and end plugs. The rods are attached to a grid at their lower end and are laterally spaced by wire wraps. The reflector/shield rods are vented directly to the helium coolant.

\section{0-3 Surface Roughening}

Artificial surface roughness has been used in gas-cooled reactors, first in the United Kingdom for the AGRs and later in GCFR designs, to improve heat transfer. 
The surface roughness increases the friction factor and the heat transfer coefficient from the rod surface to the coolant.

\section{0-3A Performance Index}

The thermal performance of surface-roughened GCFR fuel elements can be defined as the ratio of the thermal power to the pumping power (see Nomenclature on p. 357):

$$
\frac{Q}{N}=\frac{Q}{\left(M \Delta p / \rho_{1} \eta\right)}
$$

Since

$$
\begin{aligned}
Q & =M C p\left(T_{2}-T_{1}\right)=\alpha\left(T_{W}-\bar{T}\right) P L, \\
\Delta p & =\frac{M^{2}}{\bar{\rho} A^{2}} \frac{f L}{2 D_{h}},
\end{aligned}
$$

and

$$
\text { St }=\frac{\alpha A}{M C p} \text {, }
$$

Eq. (10.1) reduces to:

$$
\frac{Q}{N}=\frac{8 \eta P^{2} L^{2}\left(T_{W}-\bar{T}\right)^{3}}{Q^{2}} \rho_{1} \bar{\rho} C p^{3} \frac{\mathrm{St}^{3}}{f}
$$

Equation (10.2) shows that for a given heat transfer surface area, $P L$, a given thermal power, $Q$, a given film temperature drop, $T_{W}-\bar{T}$, and a given coolant, $\rho_{1} \bar{\rho} C p^{3}$, the thermal performance is proportional to $\mathrm{St}^{3} / f$. Thus, the increase in Stanton number due to roughness is more important than the increase in friction factor $f$ (Ref. 22).

\section{0-3B Types of Roughness}

The roughness on the fuel rods of the GCFR consists of ribs $\sim 0.13 \mathrm{~mm}$ in height (see Sec. 10-6H), with a pitch-to-height ratio of $\sim 12$, and a width-toheight ratio of 3.5. Various types of roughness have been considered for the GCFR. These are:

1. transverse versus multistart spiral ribs

2. square versus trapezoidal ribs

3. ribs manufactured by various manufacturing processes, such as electrochemical etching, mechanical grinding, and electrochemical grinding ${ }^{23}$

4. two- or three-dimensional roughening. ${ }^{24}$

Figure 10-4 shows how the Stanton number multiplier $\left(\mathrm{St}_{R} / \mathrm{St}_{S}\right)$ and friction 


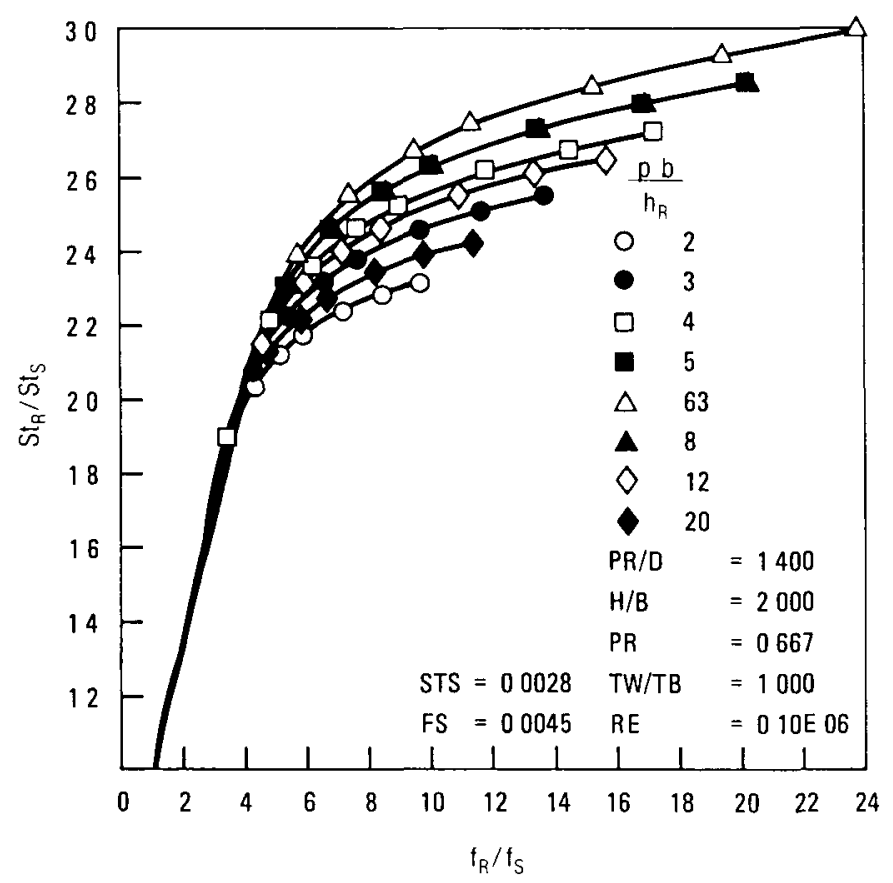

Fig 10-4 Stanton number versus friction factor for roughened rod bundles (referred to values for smooth rods) (Ref 25)

factor multiplier $\left(f_{R} / f_{S}\right)$ vary with the geometry of the roughness rib, defined as the ratio of distance between nbs compared to rib height $(p-b) / h_{R}$

After considering the manufacturing, economic, and performance aspects, transverse ribs of a trapezoidal section (F1g 10-5), manufactured by a mechanical grinding process, were selected ${ }^{26}$ for GCFRs

\section{0-4 Thermal-Hydraulic Codes}

Two principal codes are used in the thermal-hydraulic design of the GCFR core assemblies The first code, ${ }^{27}$ CALIOP, is used for core parametric and scoping studies The second code, ${ }^{28}$ COBRA*GCFR, is for detailed thermal-hydraulic analysis and design of the assemblies

\section{0-4A CALIOP Code}

The CALIOP computer program is a design tool for fast breeder core systems that considers core system geometries, thermal hydraulics, and reactor physics The code is used for initial core parametric and scoping studies, core assembly coolant onfice evaluations, and initial fuel management calculations 

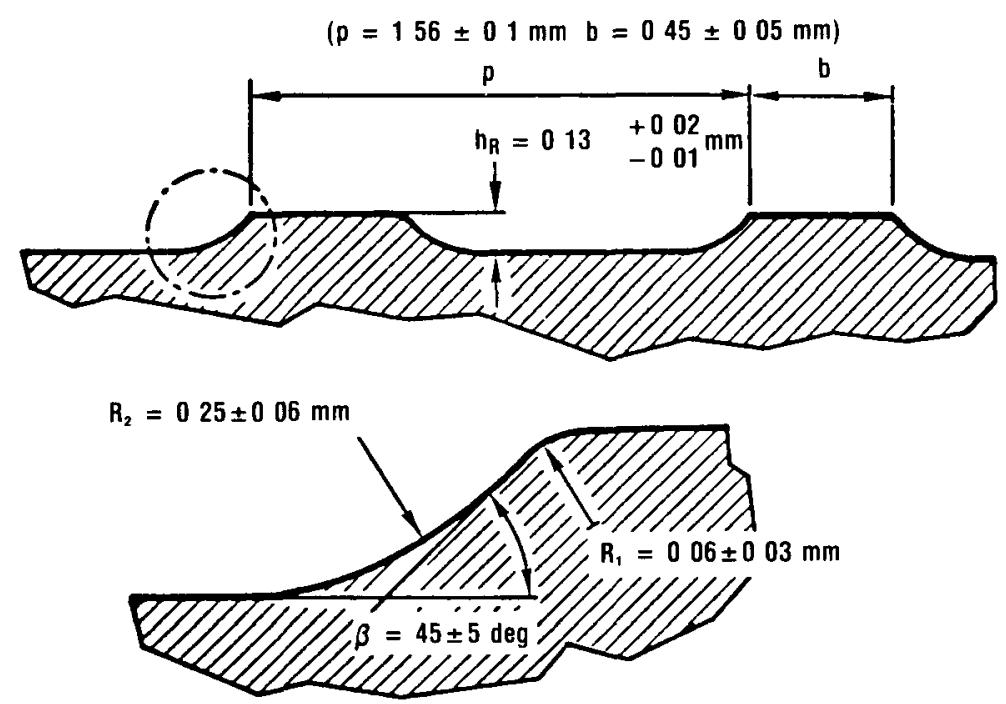

Fig 10-5 Roughness configuration for GCFR fuel rods

The thermal hydraulics and neutronics included in CALIOP are simplified representations of rather complex phenomena and core characteristics The intent of the simplified and analytical approach is to provide a fast and economic means for studying the impact of a large number of different core design and performance objectives This means that calculational accuracy has been somewhat compromised in favor of calculational speed and cost Still, high confidence in the calculated results is required to reach conclusions that should remain valid when more detailed thermal-hydraulic and physics calculations become avalable on specific core designs

A number of options are available in the CALIOP code For example, for a given power level, core $\Delta P$, number of fuel elements, number of rods per element, core length, blanket thickness, and maximum permissible hot spot temperature, CALIOP will determine the fuel rod pitch-to-diameter ratio and the core outlet temperature The preliminary configuration of the core assemblies obtained by the CALIOP code is analyzed in detall by the thermal-hydraulic subchannel code COBRA*GCFR

\section{0-4B COBRA*GCFR Code}

The COBRA*GCFR code ${ }^{28}$ is a thermal-hydraulic subchannel analysis code that has been adapted for GCFR applications from the COBRA-IV code ${ }^{29}$ developed for light water reactors (LWRs) and LMFBRs The code calculates flow, pressure, and temperature distributions by subdividing the assembly into sub- 


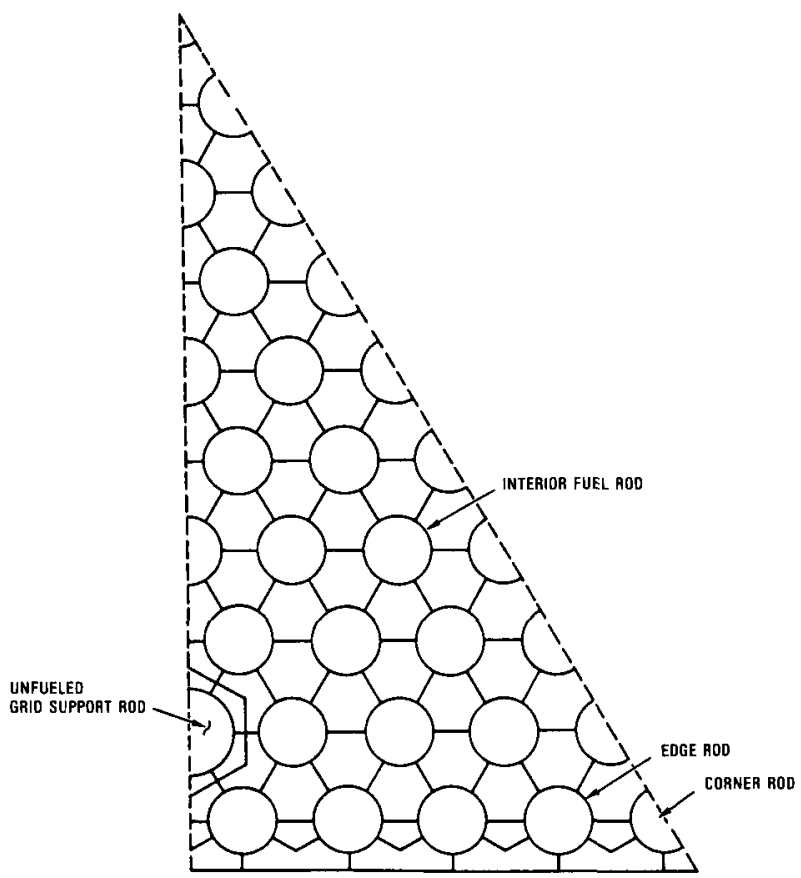

Fig. 10-6. One-twelfth-scale section model of the GCFR fuel assembly.

channels. Figure 10-6 shows a subdivision used for GCFR fuel assembly analyses. The principal features of the COBRA*GCFR code include thermal-hydraulic treatment of smooth, rough, and wire-wrapped bundles; rod circumferential heat conduction; radiation heat transfer; and buoyancy effects.

The preliminary verification of the COBRA*GCFR code was achieved through a series of benchmark calculations where code calculations were compared to those of other existing codes and experimental results. The COBRA*GCFR results have shown good agreement at all flow ranges in these benchmark calculations. Figure 10-7 shows one such comparison with the 12-rod BR-2 calibration experiments conducted at the Institute of Neutron Physics and Reactor Research in Karlsruhe, West Germany. ${ }^{30}$ These experiments are out-of-pile thermal-hydraulic tests, conducted in pressurized helium, for calibrating a 12-rod bundle used for radiation tests in the BR-2 test reactor at Mol, Belgium.

\section{0-5 Thermal-Hydraulic Correlations}

An extensive review of thermal-hydraulic correlations for GCFR assemblies is presented in Ref. 25 . The following is only a brief summary. 

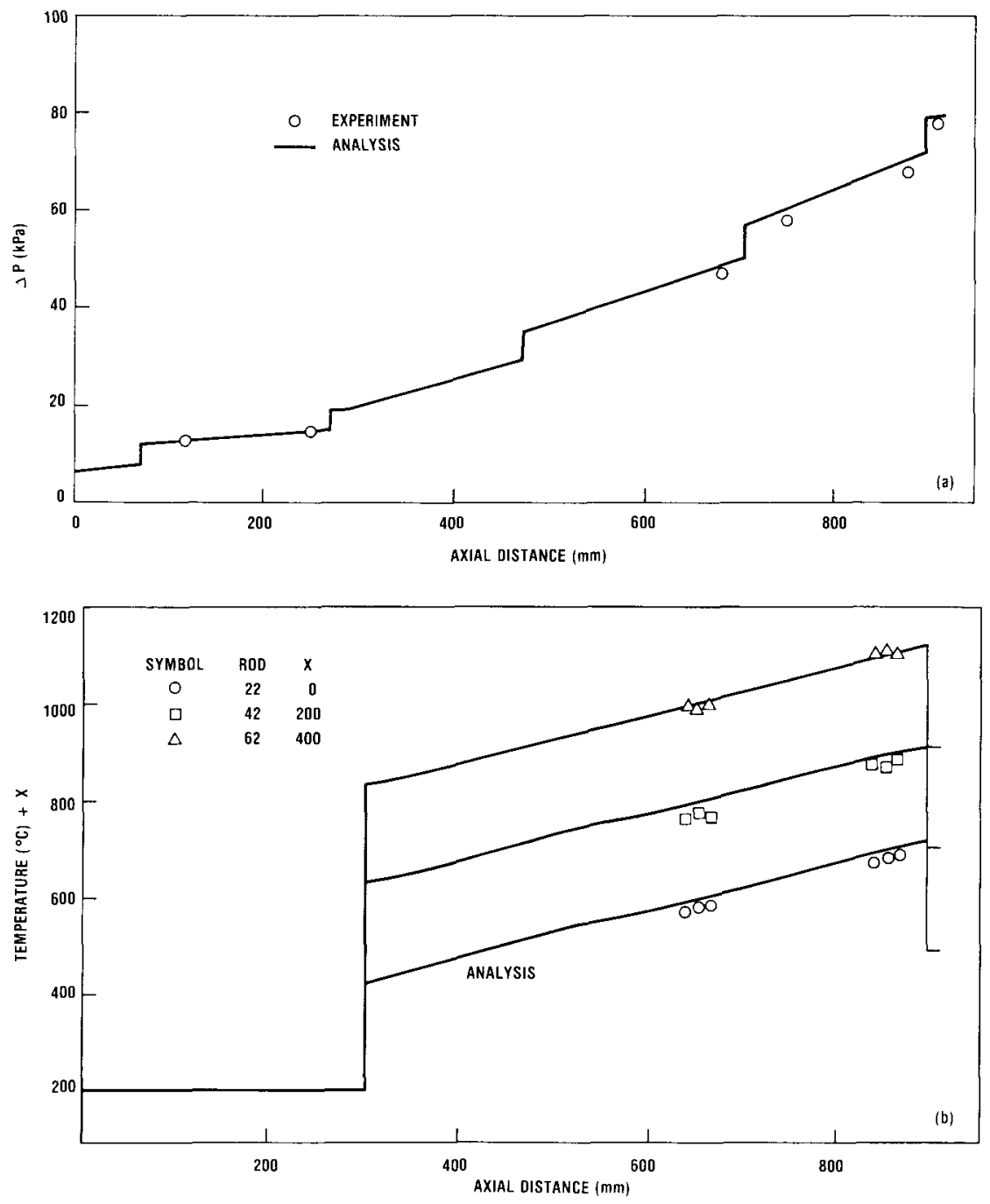

Fig 10-7 Comparıson of BR-2 calibration experıments and COBRA*GCFR analysis (a) bundle pressure drop and (b) rod surface temperatures

\section{0-5A Laminar Flow}

For GCFR-type rod bundles, the Darcy friction factor is given by ${ }^{31}$

$$
f=\frac{K}{\operatorname{Re}} \frac{T_{W}}{T_{B}},
$$

where $K$ depends on the pitch-to-diameter ratio $(p / d)$ 


$$
K=-128+260(p / d)-60(p / d)^{2} .
$$
by $^{25}$ :

Similarly, for fully developed laminar flow, the Nusselt number is given

$$
\mathrm{Nu}=-13.7+24.1(p / d)-5(p / d)^{2} .
$$

\section{0-5B Turbulent Flow}

During turbulent flow ( $\operatorname{Re}>10000$ ), different correlations apply for smooth and for rough surfaces.

\section{Smooth Surface}

The following correlation is recommended for smooth bundles in the p/d range from 1.3 to 1.5 (Ref. 25):

$$
f=1.04\left[0.0056+0.5(\operatorname{Re})^{-032}\right] .
$$

The Nusselt number in the smooth region is calculated by the Petukov-Roizen correlation. ${ }^{32}$ However, acceptable $( \pm 10 \%)$ results are obtained by using the Dittus-Boelter correlation ${ }^{33}$ :

$$
\mathrm{Nu}=0.023 \operatorname{Re}^{08} \operatorname{Pr}^{04} .
$$

\section{Rough Surface}

The friction factor and Stanton number in the rough portion of the bundle are calculated by integration of the logarithmic velocity and temperature profiles (Ref. 25):

$$
u^{+}=2.5 \ln \left(y^{+} / h_{w}^{+}\right)+R\left(h_{w}^{+}\right)
$$

and

$$
t^{+}=2.5 \ln \left(y^{+} / h_{w}^{+}\right)+G\left(h_{w}^{+}\right) .
$$

The $R\left(h_{w}^{+}\right)$and $G\left(h_{w}^{+}\right)$functions depend on the microscopic description of the roughness (i.e., type of roughness, pitch, width, and height of the roughness, etc.). For the GCFR roughness shown in Fig. 10-5, these functions are ${ }^{34}$ :

$$
\begin{aligned}
R\left(h^{+}\right)=R_{01} & +0.4 \ln \left[\frac{h_{R}}{0.01\left(r_{0}-r_{1}\right)}\right] \\
& +\frac{5}{\sqrt{h_{w}^{+}}}\left(\frac{T_{W}}{T_{B}}-1\right)^{2},
\end{aligned}
$$

with

$$
R_{01}=4.0+\frac{2.75}{\left(h_{w}^{+}\right)^{0256}},
$$




$$
R\left(h^{+}\right) \leqslant 5.5+2.5 \ln \left(h_{B}^{+}\right)
$$

and

$$
G\left(h_{w}^{+}\right)=g_{0} \operatorname{Pr}^{0.44}\left(\frac{T_{W}}{T_{B}}\right)^{n}\left[\frac{h_{R}}{0.01\left(r_{2}-r_{1}\right)}\right]^{0.053},
$$

with

$$
g_{0}=4.45\left(h_{w}^{+}\right)^{0.24}+\frac{10.3}{\left(h_{w}^{+}\right)^{0.7}}
$$

and

$$
\begin{aligned}
& n=0.5 \text { helium and air } \\
& n=0.0 \text { for } \mathrm{CO}_{2} .
\end{aligned}
$$

The integration of the velocity profile, Eq. (10.8), for an internal channel of a rough rod bundle with triangular pitch gives the following relation between the friction factor and $R\left(h_{w}^{+}\right)$(Ref. 35):

$$
\sqrt{\frac{8}{f}}=R\left(h_{w}^{+}\right)+2.5 \ln \frac{r_{0}-r_{1}}{h}-B
$$

where

$$
B=\frac{3.75+1.25 r_{0} / r_{1}}{1+r_{0} / r_{1}}
$$

and

$$
r_{0}=p\left(\frac{\sqrt{3}}{2 \pi}\right)^{1 / 2}
$$

Similarly, integration of the velocity and temperature profile gives the relation ${ }^{35}$ :

$$
\mathrm{St}=\frac{\mathrm{Nu}}{\operatorname{Re} \cdot \operatorname{Pr}}=\frac{f / 8}{1+\sqrt{f / 8}\left[G\left(h_{w}^{+}\right)-R\left(h_{w}^{+}\right)\right]} .
$$

Typical relations for $f$ and $\mathrm{Nu}$ versus Re for rough and smooth surfaces in the GCFR fuel assembly bundle are shown in Figs. 10-8 and 10-9, respectively.

\section{0-5C Transition Flow}

It is recommended that laminar flow correlations be used for rough and smooth surfaces for a Reynolds number $<2000$. The respective correlations suggested for smooth and rough surfaces should be used for fully turbulent flow for a Reynolds number $>10000$. In the range of $2000<\operatorname{Re}<10000$, it is recommended that a linear interpolation between the laminar and turbulent values for $f$ and St be used. 


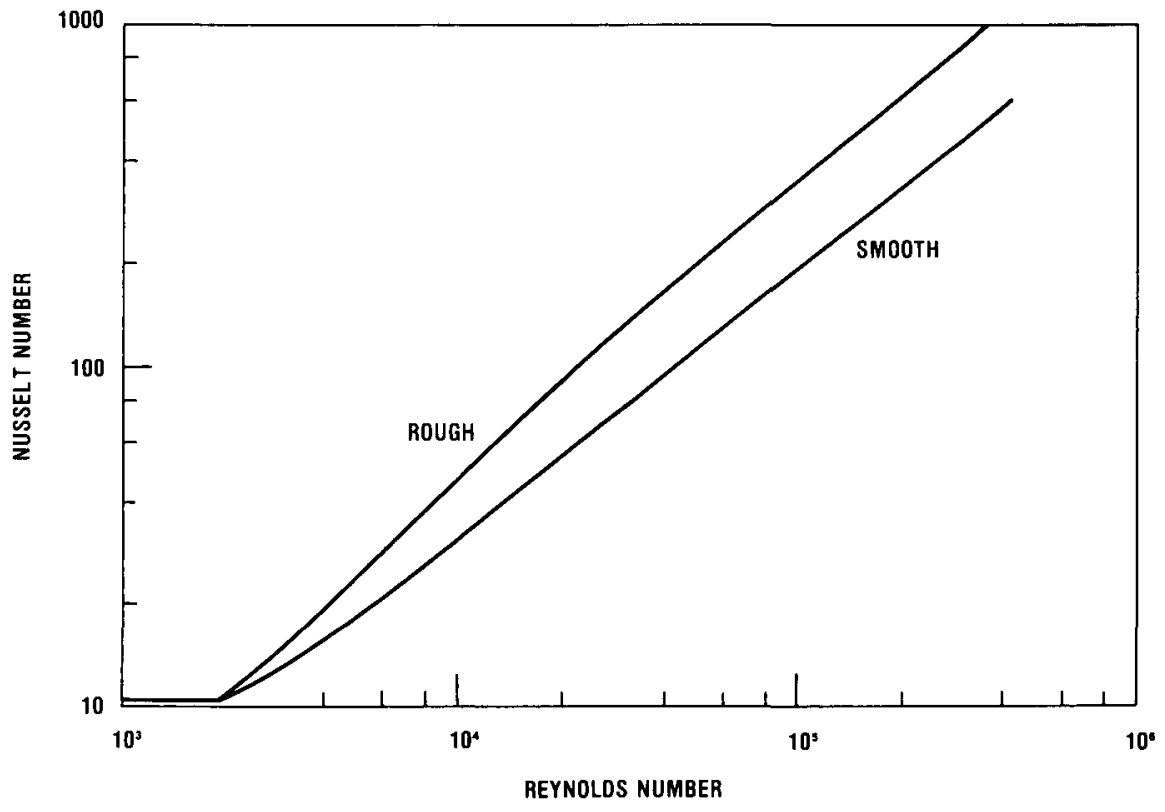

Fig 10-8 Relation between the Nusselt number and Reynolds number for a typical GCFR fuel assembly geometry

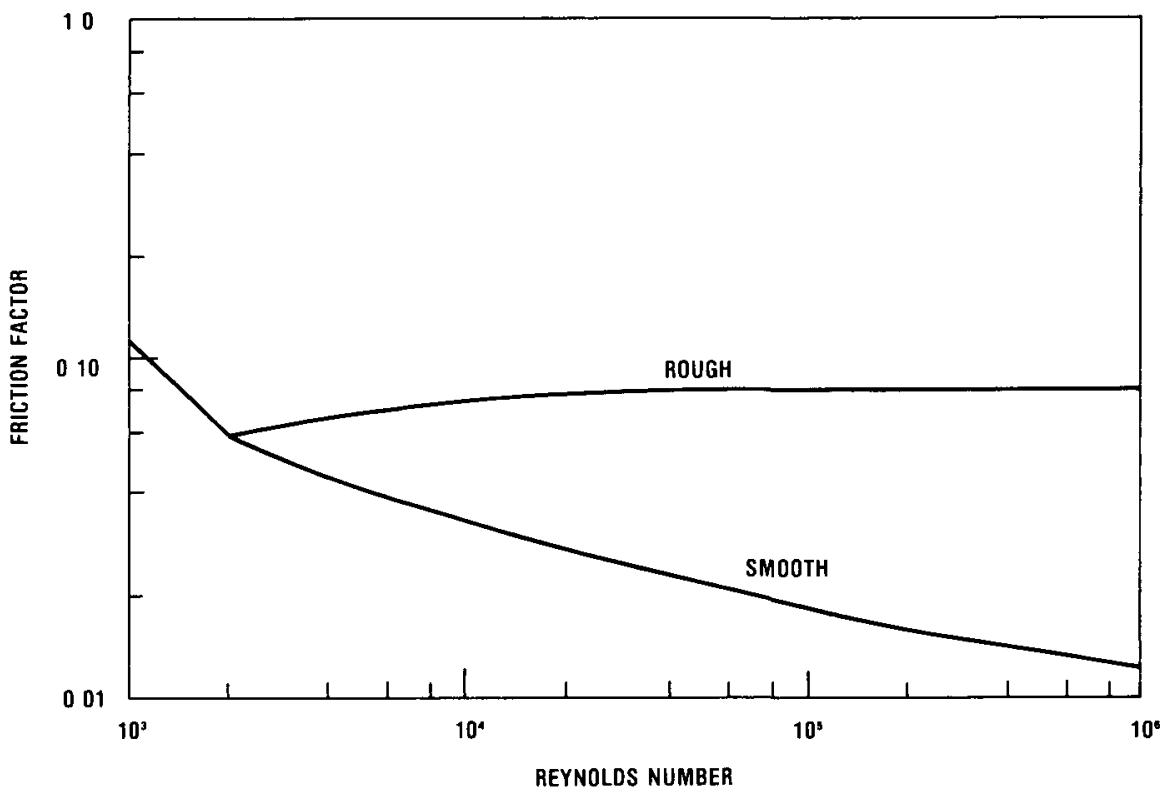

Fig 10-9 Relation between the Darcy friction factor and Reynolds number for a typical GCFR fuel assembly geometry 


\section{0-5D Other Considerations}

Due to the gas coolant and the roughening of the fuel rods, some considerations other than the direct use of thermal-hydraulic correlations enter into the analysis of GCFR assemblies. Some of these are discussed below.

\section{Effect of Spacers on Heat Transfer Coefficient}

Due to disturbance of the boundary layer and an increase in the level of turbulence in the immediate vicinity of the spacers, the heat transfer coefficient is enhanced. The effect is of differing magnitudes for rough and smooth rods and is also a function of the spacers. The correlations for this effect are available in Ref. 25.

\section{Biot Number Effect}

The enhancement of the heat transfer coefficient due to roughness is not uniform axially across the rib pitch, but varies by a large factor. The values of the Stanton number obtained from Eq. (10.16) are the average values over a pitch of the rib for a case with very large conductivity of the cladding (or very small conductivity of the gas). For the real cases, the Stanton number is modified with the Biot number, Bi, defined as:

$$
\mathrm{Bi}=\frac{\alpha h_{R}}{k_{c}},
$$

where

$$
\begin{aligned}
\alpha & =\text { heat transfer coefficient } \\
h_{R} & =\text { rib height }
\end{aligned}
$$

For the GCFR rib described in Sec. 10-3B, the Stanton number for finite conductivity is obtained by:

$$
\mathrm{St}=(1-C \times \mathrm{Bi}) \mathrm{St}_{\infty},
$$

where

$$
\begin{aligned}
\mathrm{St} & =\text { actual Stanton number } \\
\mathrm{Bi} & =\text { Biot number } \\
\mathrm{St}_{\infty} & =\text { Stanton number obtained from Eq. (10.16) } \\
C & \simeq 1.2 .
\end{aligned}
$$

\section{0-6 Thermal-Hydraulic Design Considerations}

Some important aspects of thermal-hydraulic design considerations for GCFR core assemblies are discussed below. 


\section{0-6A Hot Spot Analysis}

Nominal temperatures are predicted by thermal-hydraulic analysis of GCFR assemblies using subchannel codes. Uncertainties such as a change in geometry from nominal dimensions or uncertainties in thermal-hydraulic correlations, properties, physics calculations, etc. are not included. All of these uncertainties can be accounted for by defining hot spot factors that are applied to the nominal temperatures to calculate the hot spot temperatures. For the GCFR demonstration plant, the hot spot midwall cladding temperature is limited to $750^{\circ} \mathrm{C}$ by material considerations.

To calculate the midwall hot spot cladding temperature, three hot spot factors are defined:

$$
\begin{aligned}
F_{c h} & =\text { channel hot spot factor } \\
F_{f} & =\text { film hot spot factor } \\
F_{c l} & =\text { cladding hot spot factor. }
\end{aligned}
$$

The midwall hot spot cladding temperature is obtained as follows:

$$
T_{c}=T_{l n}+(\Delta T)_{c h} \times F_{c h}+(\Delta T)_{f} \times F_{f}+(\Delta T)_{c l} \times F_{c l},
$$

where

$T_{c}=$ hot spot midwall cladding temperature

$T_{\text {in }}=$ coolant inlet temperature

$(\Delta T)_{c h}=$ channel temperature rise to the location of hot spot

$(\Delta T)_{f}=$ film temperature drop at the location of hot spot

$(\Delta T)_{c l}=$ nominal temperature drop from midwall cladding to surface at the location of hot spot.

The hot spot factors are calculated by using a semi-statistical method. In this method, the uncertainties are divided into two groups: (a) uncertainties that occur randomly (e.g., manufacturing and assembling tolerances, material properties, and correlations), which are treated as statistical subfactors and (b) those that occur nonrandomly (uncertainties in calculations and measurements), which are directly added as cumulative subfactors. The subfactors are combined by a method similar to the one used for the Clinch River FBR. Table 10-VI summarizes the hot spot factors calculated for the GCFR fuel assembly. The $2 \sigma$ deviations are used for all but faulted operating conditions (see Sec. 4-1D).

\section{0-6B Plant Size}

The plant size is selected depending on plant purpose (i.e., reactor experiment, demonstration, commercial application) and component feasibility. For GCFR demonstration plants, sizes of 800 to $1100 \mathrm{MW}(\mathrm{t})$ have been considered; 


\section{TABLE 10-VI}

Hot Spot Factors for GCFR Fuel Assembly

\begin{tabular}{|cccc|}
\hline & $\begin{array}{c}\text { Channel } \\
F_{c}\end{array}$ & $\begin{array}{c}\text { Film } \\
F_{f}\end{array}$ & $\begin{array}{c}\text { Claddıng } \\
F_{c l}\end{array}$ \\
\hline Turbulent flow & 1131 & 1361 & 1195 \\
$3 \sigma^{a}$ & 1111 & 1311 & 1.153 \\
$2 \sigma$ & 1236 & 1212 & 1138 \\
Laminar flow & 1187 & 1173 & 1116 \\
$3 \sigma$ & $\sigma \sigma$ & 111 & \\
\hline
\end{tabular}

${ }^{a} \sigma=$ standard deviation, thus, $2 \sigma$ indicates $9772 \%$ confidence level and $3 \sigma$ indicates $9987 \%$ confidence level.

for commercial plants, usually six loops with $\sim 600 \mathrm{MW}(\mathrm{t})$ each have been evaluated.

\section{0-6C Component Technology}

Component technology has an impact on key components that results in limits on major operating conditions. For example, the pressure containment capability of the reactor vessel introduces an upper limit for the primary system pressure; the circulator power limit influences the allowable core pressure drop; and fuel handling and assembly duct dilation considerations impose limits on fuel assembly size.

\section{0-6D Fuel Life Goals}

Fast breeder fuel economics require long fuel in-pile times and have resulted in fuel life goals equivalent to burnups of $\sim 100 \mathrm{MWd} / \mathrm{kg}$ heavy metal. This goal has a direct impact on fuel assembly components, such as assembly and duct size and duct wall thickness. For the GCFR demonstration plant, $70 \mathrm{MWd} / \mathrm{kg}$ has been recommended.

\section{0-6E Material Limitations}

Overall plant economics dictate high temperatures for the working fluid, which results in fuel and fuel cladding temperatures as high as feasible. Both temperatures are limited by material properties. For proper fuel performance, the centerline temperature must stay below the melting point; for the cladding temperature, long-term effects of radiation at high temperatures and interaction with the fuel are important. Cladding irradiation tests for the LMFBR and GCFR have focused on feasibility demonstrations of a maximum cladding temperature of 700 to $750^{\circ} \mathrm{C}$; maximum linear ratings range from 329 to $395 \mathrm{~W} / \mathrm{cm}(10$ to $12 \mathrm{~kW} / \mathrm{ft}$ ) for the GCFR, which results in centerline fuel temperatures well below the melting point of mixed oxide fuel. 
For the GCFR demonstration plant core, a hot spot cladding temperature of $750^{\circ} \mathrm{C}$ had been selected. This is higher than the $730^{\circ} \mathrm{C}$ indicated in the Clinch River breeder reactor analysis. However, it should be remembered that the hot spot temperature is the maximum temperature considering all possible uncertainties. The nominal maximum temperatures should be compared for the different breeder concepts; this temperature is lower for the GCFR as shown in Table 10-VII.

TABLE 10-VII

Comparison of Cladding Temperatures

\begin{tabular}{|ccc|}
\hline & LMFBR & GCFR \\
\hline $\begin{array}{c}\text { Maximum hot spot cladding } \\
\text { temperature }\left({ }^{\circ} \mathrm{C}\right)\end{array}$ & 730 & 700 to 750 \\
$\begin{array}{c}\text { Maximum nominal cladding } \\
\text { temperature }\left({ }^{\circ} \mathrm{C}\right)\end{array}$ & 660 & 600 to 640 \\
\hline
\end{tabular}

\section{0-6F Core Configuration and Core Assembly Designs}

A large number of core design and operating parameters are dictated by plant economics and component technology. Key parameters that remain to be determined are: fuel and radial blanket rod diameter, rod pitch, number of rods per assembly, and core length. These parameters strongly affect the thermal as well as the nuclear performance, which is measured by breeding ratio and doubling time. The parameters are selected based on sensitivity studies.

\section{0-6G Thermal-Hydraulic Core Assembly Design and Performance}

Using the nominal operating data obtained with CALIOP in the scoping study, detailed assembly analyses are conducted using the subchannel analysis code COBRA. A typical fuel assembly model for COBRA analyses is shown in Fig. 10-6. This detailed design analysis results in determination of parameters such as edge channel size; location and diameter of grid spacer support rods; flow, pressure, and temperature distributions; and wire-wrap pitch for the radial blanket.

The description of the thermal-hydraulic design of fuel and radial blanket assemblies is given in Table 10-VIII. During the evolution of core assembly design, careful attention must be given to an efficient use of the pressure drop in various portions of the assembly. Although a very compact assembly design is desirable, the pressure drop associated with each component has to be minimized. The pressure drop distribution obtained for the current fuel assembly design is shown in Table 10-IX. The largest portion of the pressure drop ( $\sim 45 \%)$ is caused by the rough rod bundle; a rather large fraction is caused by the grid spacers $(\sim 22 \%)$. The pressure drops in the inlet and outlet regions are caused mainly by shielding requirements. 
TABLE 10-VIII

GCFR Core Assembly Design and Performance

\begin{tabular}{|lc|}
\hline Fuel Assembly & 1200 \\
\hline Active core height $(\mathrm{mm})$ & 265 \\
Number of fuel rods per assembly & 8 \\
Fuel rod & 115 \\
$\quad$ diameter $(\mathrm{mm})$ & 287 \\
pitch (mm) & 013 \\
Duct-to-rod clearance (mm) & 156 \\
Roughness height $(\mathrm{mm})$ & 66 \\
Roughness pitch (mm) & 90300 \\
Maximum assembly flow (kg/s) & 293 \\
Reynolds number & 561 \\
Inlet temperature $\left({ }^{\circ} \mathrm{C}\right)$ & \\
Outlet temperature, maximum assembly $\left({ }^{\circ} \mathrm{C}\right)$ & \\
Radıal Blanket Assembly & 222 \\
Rod & 242 \\
diameter (mm) & 300 \\
pitch (mm) & 15 \\
Wire-wrap pitch (mm) & 40000 \\
Maximum assembly flow (kg/s) & \\
Reynolds number & \\
\hline
\end{tabular}

TABLE 10-IX

Pressure Drop in Various Parts of the GCFR Fuel Assembly*

\begin{tabular}{|lr|}
\hline \multicolumn{1}{|c|}{ Region } & $\Delta P(\%)$ \\
\hline Inlet & 83 \\
Lower axial blanket & 49 \\
Core region (rough) & 438 \\
Upper axial blanket & 71 \\
Spacers & 226 \\
Acceleration & 21 \\
Outlet & 112 \\
\hline
\end{tabular}

*For a three-loop demonstration plant

\section{0-6H Fuel Rod Roughness Configuration}

Through an extensive research program at the Federal Institute of Reactor Research in Switzerland, the optimum roughness configuration has been determined. ${ }^{24}$ The thermal-hydraulic correlations for the optimum roughness shape are applied when fuel rod diameter and pitch are selected. Subsequently, a calculation is performed to determine the optimum roughness height. Results of these rib height calculations for the current demonstration plant core are shown in Fig. 10-10. 


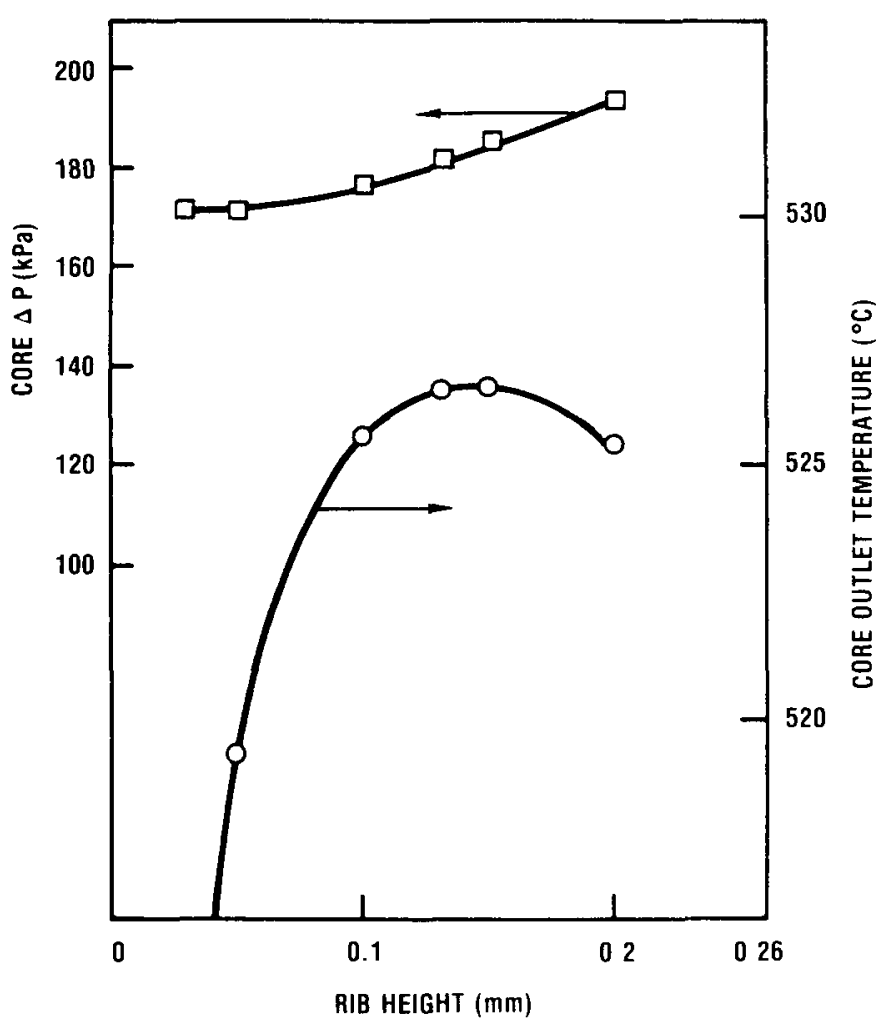

Fig. 10-10. Effect of rib height on three-loop GCFR demonstration plant performance.

\section{0-6I Edge Channel Design}

In the GCFR reference design, the fuel assembly edge channel is composed of rough fuel rods and a smooth flat duct wall. For this design, a large edge channel is required because:

1. Under low power and flow conditions, the relative heat input to the edge channel increases while the relative flow rate is reduced. These disadvantages are slightly counterbalanced by overcooling under normal operating conditions.

2. In-pile creep causes the duct to dilate more midway along the flats than at the corners. The relative impact of this dilation can be reduced by making the channel large and by including flow resistances to avoid excessive overcooling of the edge channels.

3. Mechanical design requirements of the grid spacers require a relatively thick edge band, which results in a flow blockage in the edge channel that tends to be larger than that in interior subchannels. This, in turn, 
leads to flow redistributions with modification of the heat transfer at the spacer level, and creates sawtooth-type fuel rod temperature distributions, as shown in Fig. 10-11 for the temperature difference between two diametrically opposite sides of a rod. From a flow and temperature distribution point of view, uniform relative flow blockages are desirable. This can be achieved by large edge channels.

4. Due to fabrication tolerances of duct inner diameter and outer spacer dimensions, the possible edge channel geometry covers a wide range. The fractional variation of the edge channel due to the fabrication tolerances can be minimized by using large edge channels.

The above findings have led to the recommendation of a large nominal edge channel. The duct-to-rod clearance selected is $80 \%$ of the rod-to-rod clearance. However, this large edge channel would lead to a temperature difference across the edge rods of $\sim 75^{\circ} \mathrm{C}$ and a temperature difference swing associated with the sawtooth temperature distribution of $32^{\circ} \mathrm{C}$, which, together with radiation-induced differential metal swelling, would lead to unacceptable fuel rod bowing and to a fuel rod life equivalent to $\sim 80 \%$ of the life goal of $70 \mathrm{MWd} / \mathrm{kg}$. Analytical studies

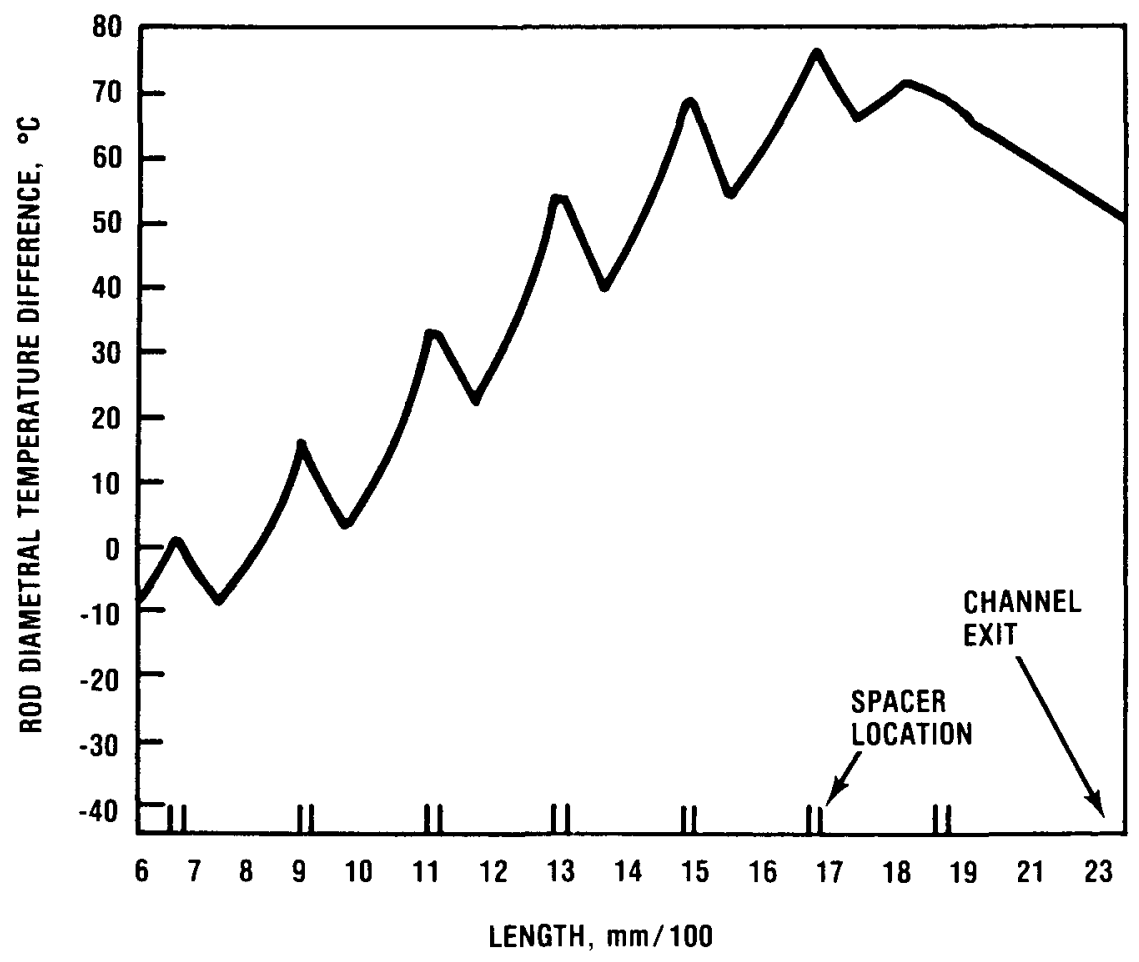

Fig. 10-11. Rod diametral temperature difference along the length of the fuel rod. 
have shown that roughening of the inner duct surface results in additional flow resistance sufficient to reduce the temperature difference and the difference swing to 53 and $24^{\circ} \mathrm{C}$, respectively, and reduce bowing such that a rod life equivalent to a burnup of $70 \mathrm{MWd} / \mathrm{kg}$ could be reached. The need for a roughened duct strongly depends on the fast fluence and on the metal swelling correlation; both are associated with a relatively large uncertainty.

\section{0-6J Effect of Fabrication Tolerances on Fuel Rod Life}

The temperature gradients across edge and corner fuel rods are strongly affected by the fabrication tolerances. Deviations from nominal design due to fabrication tolerances lead to large positive and negative flow area deviations in the edge channel and to unacceptable rod bowing and fuel life reduction effects. In the case of stacking of positive tolerances, a large temperature gradient develops across the edge rods; and in the case of stacking of negative tolerances, the temperature gradient swing due to spacer solidity ${ }^{a}$ effects reduces the fuel life. In addition, the negative-tolerance case develops excessive temperatures during lowflow operation.

A comparison of data from Table $10-X$ shows that selections of $80 \%$ edge spacing and roughened duct surfaces alone do not sufficiently correct the detrimental effects of fabrication tolerances on the edge rod performance. Depending on the ultimate swelling correlations and the fast fluence at end of fuel life, a drastic reduction of duct and spacer fabrication tolerances may be required.

\section{TABLE 10-X}

Effect of Fabrication Tolerances on GCFR Edge Fuel Rod Temperature Distribution (Smooth duct wall, $80 \%$ nominal edge spacing)

\begin{tabular}{|lcc|}
\hline $\begin{array}{l}\text { Stack-up of } \\
\text { Fabrication }\end{array}$ & $\begin{array}{c}\text { Fuel Rod } \\
\text { Temperature } \\
\text { Difference } \\
\left({ }^{\circ} \mathrm{C}\right)\end{array}$ & $\begin{array}{c}\text { Temperature } \\
\text { Difference } \\
\text { Swing } \\
\left({ }^{\circ} \mathrm{C}\right)\end{array}$ \\
\hline Tolerances & 107 & - \\
Plus & 763 & 32 \\
Nominal & 44 & 44 \\
\hline
\end{tabular}

\section{0-6K Advanced Design Considerations}

Because of the different hydraulic characteristics of the different flow channels within the rod bundle, uniform temperature distributions at all flow conditions cannot be achieved. Advanced design alterations have been proposed to compen-

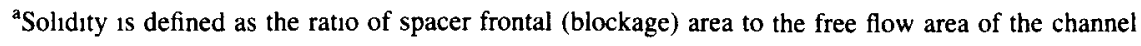


sate for, or to correct, nonuniform rod temperature distributions. The introduction of roughness on the inner surface of the flow duct represents a substantial improvement in the thermal-hydraulic assembly design and performance. A further design improvement is seen with flow mixing vanes, which are successfully employed in LWR cores. The use of mixing vanes in the GCFR fuel assembly may enhance coolant mixing and result in more uniform coolant temperatures at all flow conditions.

Both design features have been proposed because of their potential for reducing temperature differences within fuel assemblies at all flow conditions. In addition to increasing the fuel rod life expectancy, there are several other attractive advantages. Because of smaller differences between maximum and average temperatures, the mixed mean core outlet temperature will be increased and coolant flow and pumping power requirements will be decreased. In addition, mixing vanes may have a favorable impact on hot spot factors.

\section{0-6L Fuel and Blanket Assembly Orificing}

Depending on the life of the core assemblies and their location in the core, the fuel and blanket assembly power vary by a large factor from the average values. To obtain a maximum mixed mean core outlet temperature, the assemblies are orificed to control the flow through the individual assembly. Ideally, each core

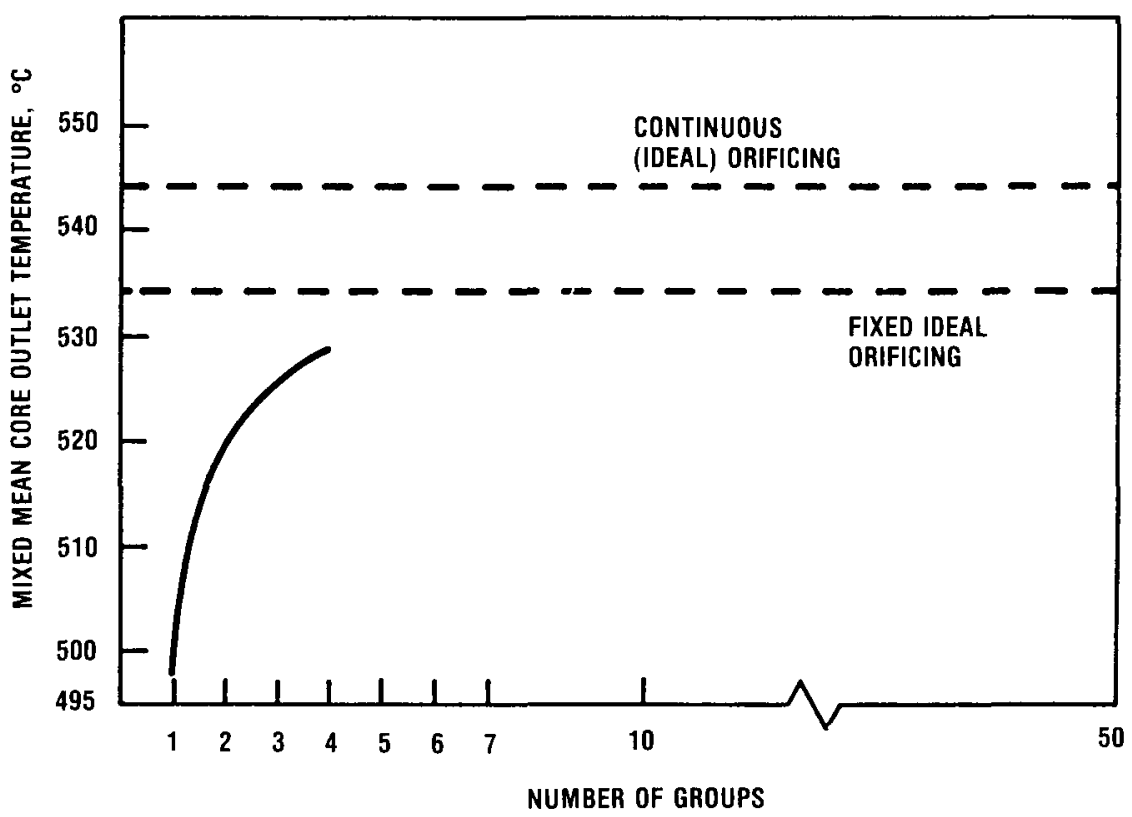

Fig. 10-12. Effect of the number of fuel orificing groups on outlet temperature (assumes ideal flxed blanket orifices). 
assembly can be orificed so that the mass flow through the assembly is just enough to keep the midwall hot spot temperature below $750^{\circ} \mathrm{C}$ during a particular cycle. However, this requires a large number of orifice sizes; hence, a trade-off must be made between the number of orifice sizes and the thermal performance.

Figure 10-12 shows the results of such a study for the GCFR fuel assemblies. With a continuously adjustable ideal orificing, a mixed mean core outlet temperature of $544^{\circ} \mathrm{C}$ is possible. With fixed but ideal orificing, the mixed mean outlet temperature is reduced by $10^{\circ} \mathrm{C}$ to $534^{\circ} \mathrm{C}$. Neither of these options is feasible due to the large number of orifices required. Reducing the number of orifices for the fuel assemblies reduces the outlet temperature. Since the reduction in the mixed mean outlet temperature, by using 5 types of orifices compared to 50 , is quite small (i.e., $3^{\circ} \mathrm{C}$ ), the GCFR demonstration core would have only 5 orifice groups for the fuel assemblies. A similar study indicates the choice of 5 groups for the radial blanket assemblies.

\section{0-7 Safety Analyses}

The GCFR has several characteristics that enhance its safety. The following design features are of particular interest:

1. a single-phase, nonradioactive, transparent coolant, helium, which has a small reactivity effect and is chemically inert (as in an HTGR)

2. an integrated primary circuit in a PCRV without exposed large primary coolant piping, like all recent gas-cooled reactors in Europe and the United States

3. vented fuel, which removes any significant pressure drop across the cladding and greatly reduces the radioactivity in the primary coolant circuit

4. upflow through the core, which has been incorporated to provide natural circulation residual heat removal (RHR) as a backup to the three forcedcirculation RHR systems.

Since one of the significant differences between GCFRs and LMFBRs is the use of a pressurized coolant, depressurization accidents, although of low probability, must be considered for GCFRs, rather than loss-of-coolant accidents. Also, because of the low core heat capacity, coolant flow must be maintained to remove the residual heat, either with forced circulation or possibly with natural circulation.

We therefore discuss two thermal-hydraulic aspects of the GCFR connected with its safety: transient problems during rapid depressurization and the role of natural circulation for RHR.

\section{0-7A Residual Heat Removal Following Depressurization Accidents}

If a postulated leak were to occur, the primary coolant would start to flow into the containment building, which contains air of $\sim 20$ times the PCRV 
volume ${ }^{36,37}$ A signal that there is low primary coolant pressure, high containment pressure, or high containment radioactivity actuates the reactor trip and the containment isolation. The safety-related event sequence assumed here includes lossof-site power (LOSP), which simultaneously disables the main loop cooling system (MLCS). An LOSP accident results in coastdown of main circulators and startup of emergency diesel generators. The primary coolant pressure decreases exponentially, and the leakage flow is choked during most of the blowdown period. When the coolant pressure decreases below a set value [e.g., 2.07 MPa (300 psia)], the plant protection system (PPS) logic initiates the core auxiliary cooling system (CACS) that is designed for all RHR systems including the design-basis depressurization accident (DBDA).

For a slower depressurization in which the pressure [2.07 MPa (300 psia)] to switch on the CACS is reached later, the PPS initially selects the safety cooling system (SCS), one of the two safety RHR systems. The SCS pony motors are powered to prevent the main circulator speed from coasting down and to maintain a prescribed value for the SCS operation. As pressure decays, the pony motor accelerates, providing a roughly constant mass flow rate, until the maximum pony motor speed is reached. When the pressure reaches a value below the setpoint value [2.07 $\mathrm{MPa}$ (300 psia)], the cooling mode is automatically transferred to the CACS.

When the CACS is called upon, the full design torque is applied to the auxiliary circulators. The auxiliary circulator pressure head forces the auxiliary loop isolation valve open and the main loop isolation valve closed. Thus, the helium circulation loop switch is accomplished. Also, the water pumps are started for the pressurized water loop between the core auxiliary heat exchanger (CAHE) and the auxiliary loop cooler (ALC). The core decay heat, carried by helium to the CAHE and transported by water to the ALC, is ultimately dissipated into the atmosphere by a fan or natural draft of air through the ALC.

The typical core flow rate, core thermal power, and the pressure transients following the DBDA are shown in Fig. 10-13 (Ref. 38). Figure 10-14 shows the maximum hot spot temperatures for the fuel and the blanket rods following this transient.

The primary coolant pressure becomes equal to the containment pressure after $\sim 3 \mathrm{~min}$ of blowdown. The typical temperatures and pressure responses of the containment atmosphere following the DBDA are shown in Fig. 10-15. Following the blowdown stage, air ingress occurs gradually into the primary coolant due to inhalation of the containment air mixture as the coolant inside the PCRV cools and contracts.

The transient responses of the reactor system to depressurization accidents were analyzed with the FASTRAN computer program. This program simulates dynamics of the GCFR primary and secondary coolants of the main cooling systems as well as the auxiliary safety systems under pressurized and depressurized conditions. For the blowdown phase of depressurization, the primary coolant system is modeled with gas volumes that respond according to the perfect gas law and 


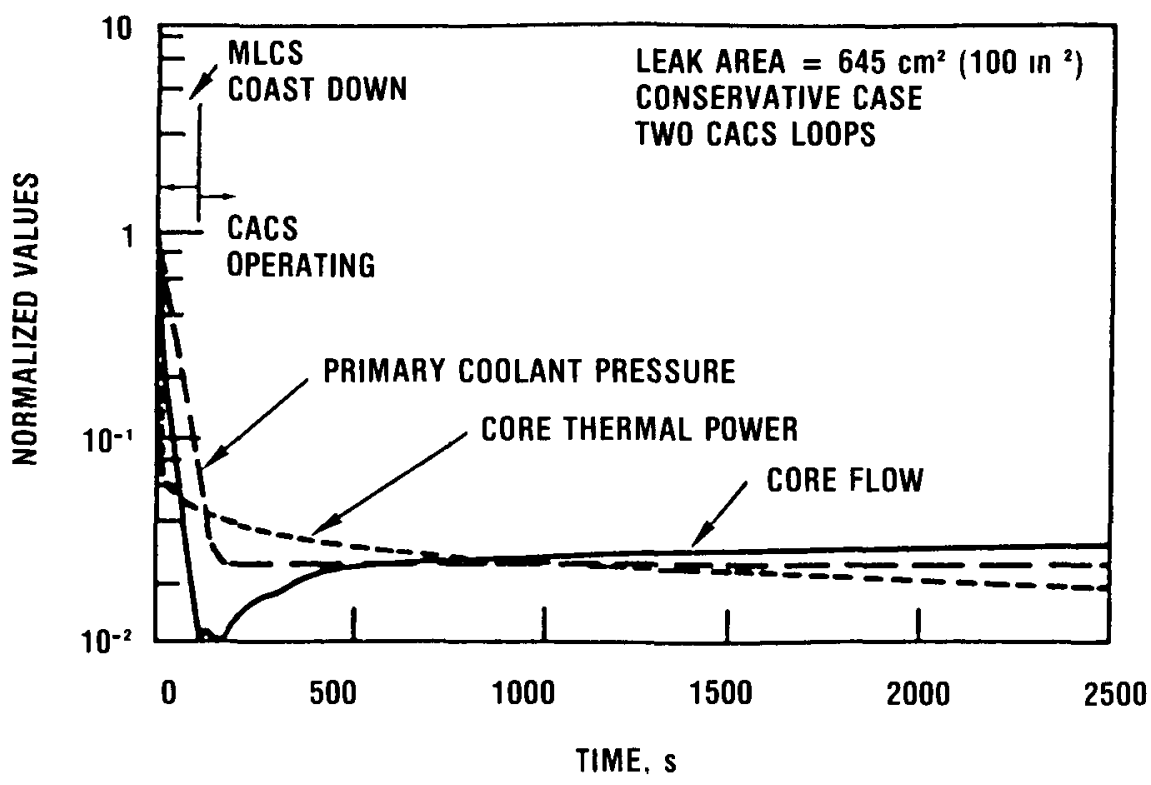

Fig 10-13 Typical OBDA transient for core power, flow, and pressure

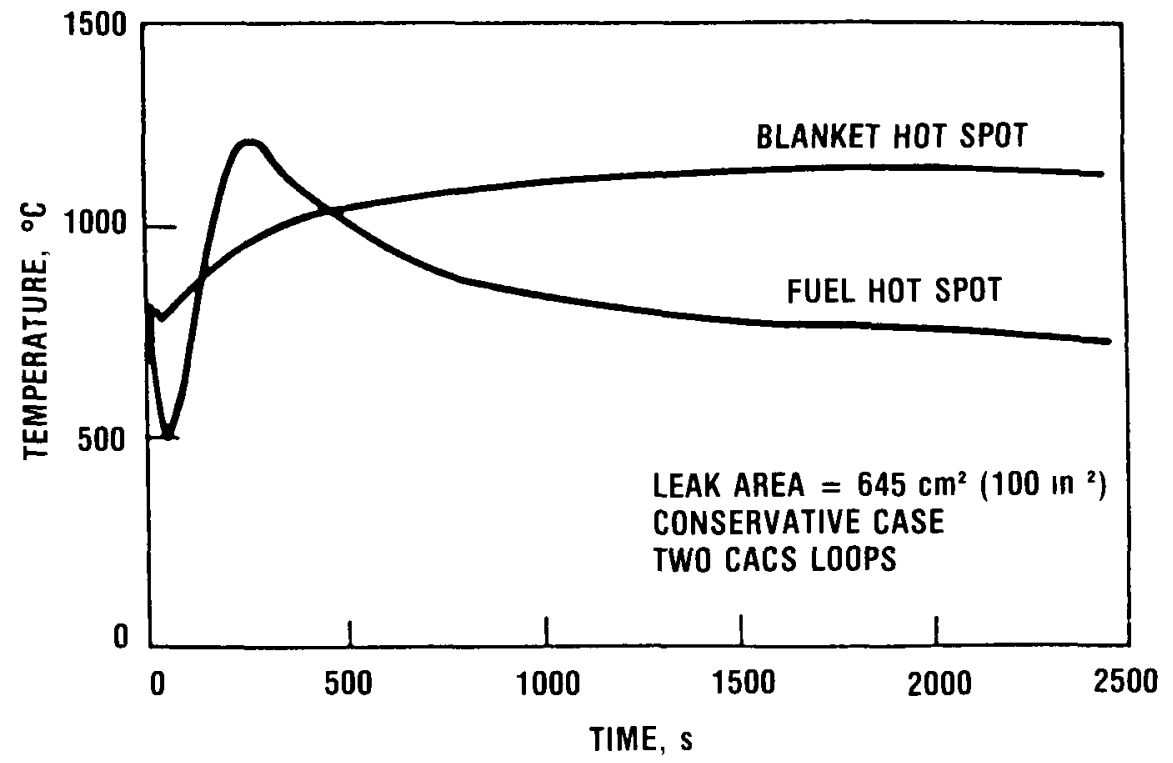

Fig 10-14 Fuel and blanket maximum hot spot claddıng temperatures following a DBDA 


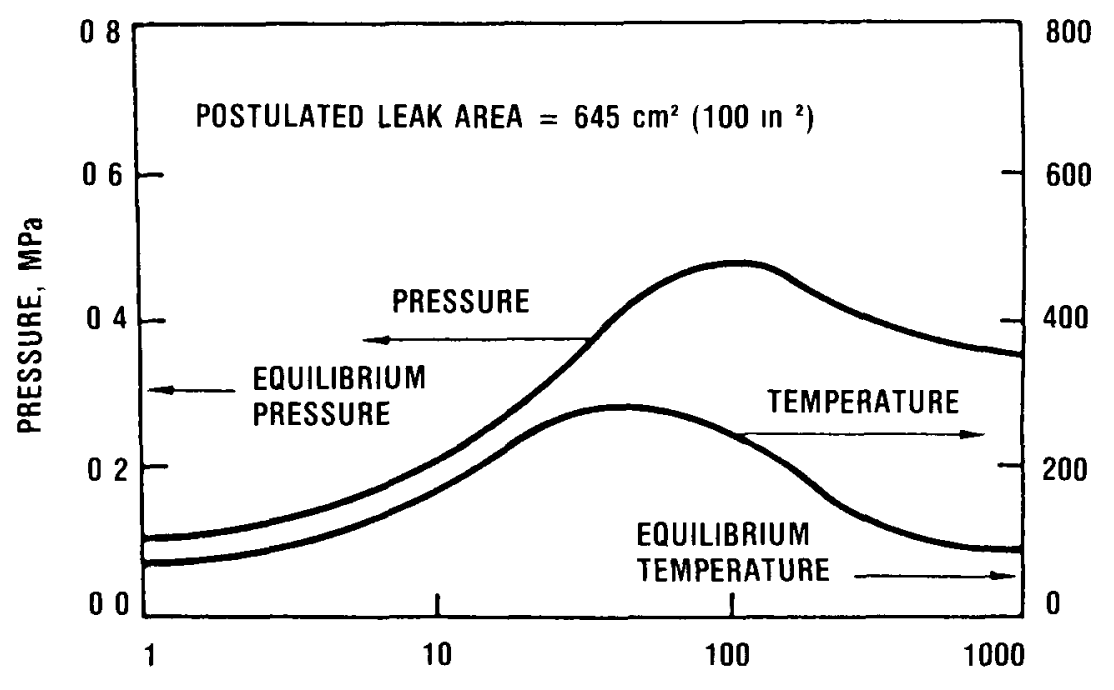

TIME, s

Fig 10-15 Containment building gas pressure and temperature following a DBDA

the energy and mass conservation equations These volumes are connected by paths that represent the components of the system, namely, the reactor core, the steam generators, the helium circulator, and a leak path to the containment Each of these components is, in turn, dynamically modeled by its governing equations

The core thermal response, particularly the maximum cladding temperatures of the fuel and the blanket rods, following a most severe DBDA is shown in Fig 10-14 The results are obtained with the conservative model and assuming operation of two out of three auxiliary cooling loops It is shown that the peak of the conservatively calculated hot spot cladding temperature of the maximumpowered typical fuel rod is $\sim 100^{\circ} \mathrm{C}$ lower than the tentatıve claddıng damage limit of $1300^{\circ} \mathrm{C}$ and $170^{\circ} \mathrm{C}$ lower than the cladding melting point of $1370^{\circ} \mathrm{C}$

The GCFR blanket rods are, in general, at much lower temperatures than the fuel rods durıng normal full-power operation However, blanket coolıng becomes more important at low-flow conditions after reactor trip due to decay heat and flow redistributions between core and blanket regions The maximum blanket cladding temperature, shown in Fig 10-14, is lower than the fuel cladding value The blanket rod diameter is much larger and therefore responds more slowly than the fuel rods, as also seen in Fig 10-14

To provide greater insight into the safety margins supplied in the design, the result of the conservative model is compared with that of the best-estimate model in Fig 10-16 The difference between the maximum fuel cladding temperatures obtained by the conservative and the best-estimate models is $280^{\circ} \mathrm{C}$, indicating that the cumulative combination of all the uncertainty margins employed in the 


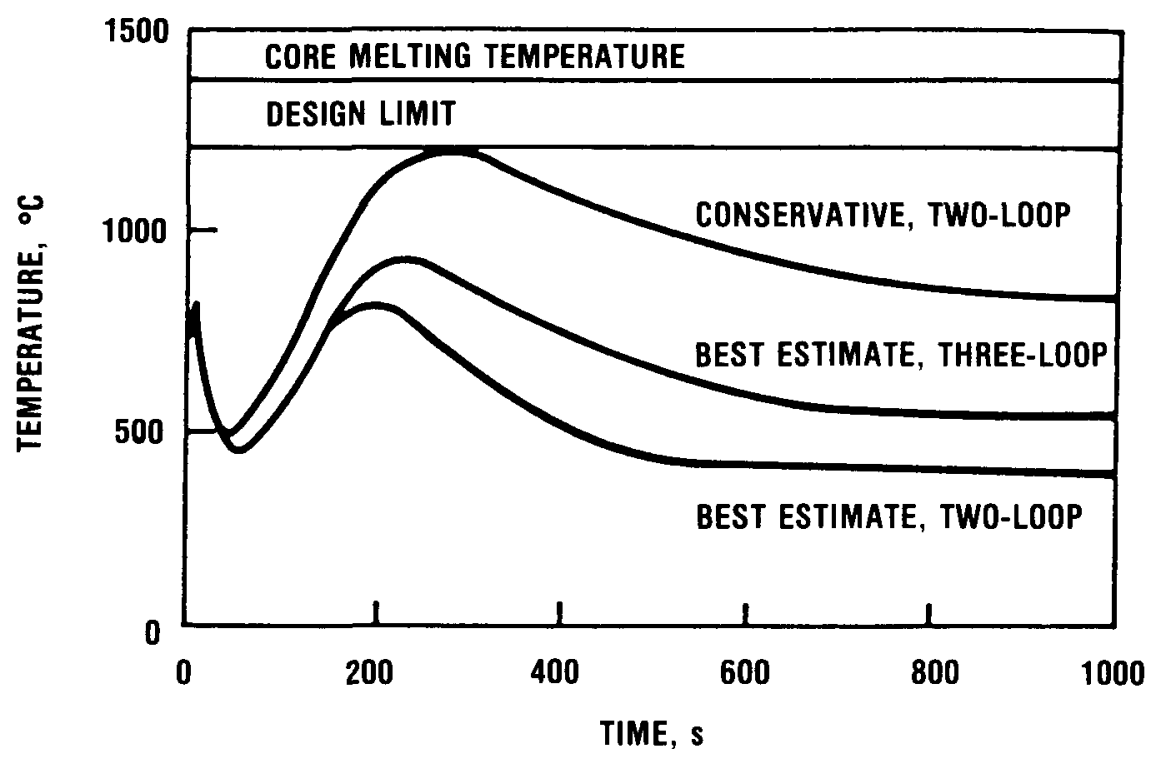

Fig. 10-16. Effect of cumulative uncertainty margins in a conservative model and number of cooling loops on the hot spot fuel cladding temperature during a DBDA.

conservative model results in a large safety margin. The best-estimate model, using all three loops, indicates further reduction of the cladding temperature by $100^{\circ} \mathrm{C}$.

\section{0-7B Residual Heat Removal by Natural Circulation (Pressurized Coolant)}

The three independent means of forced circulation RHR employed by the GCFR demonstration plant are shown schematically in Fig. 10-17. These systems, listed in the order of their intended sequence of operation, are:

1. the main loop cooling system (MLCS)

2. the shutdown cooling system (SCS)

3. the core auxiliary cooling system (CACS).

The MLCS consists of the main loop helium circulators, isolation valves, the steam generators, and the normal secondary plant components associated with operation of the steam turbines at power. During periods in which electrical power is not produced, steam bypasses the turbine and is desuperheated before flowing to the condenser.

The SCS is an independent safety class system designed to remove decay heat through the steam generators in the event of failure of the circulator motors, the feedwater system, or the condenser of the MLCS. Components include a 


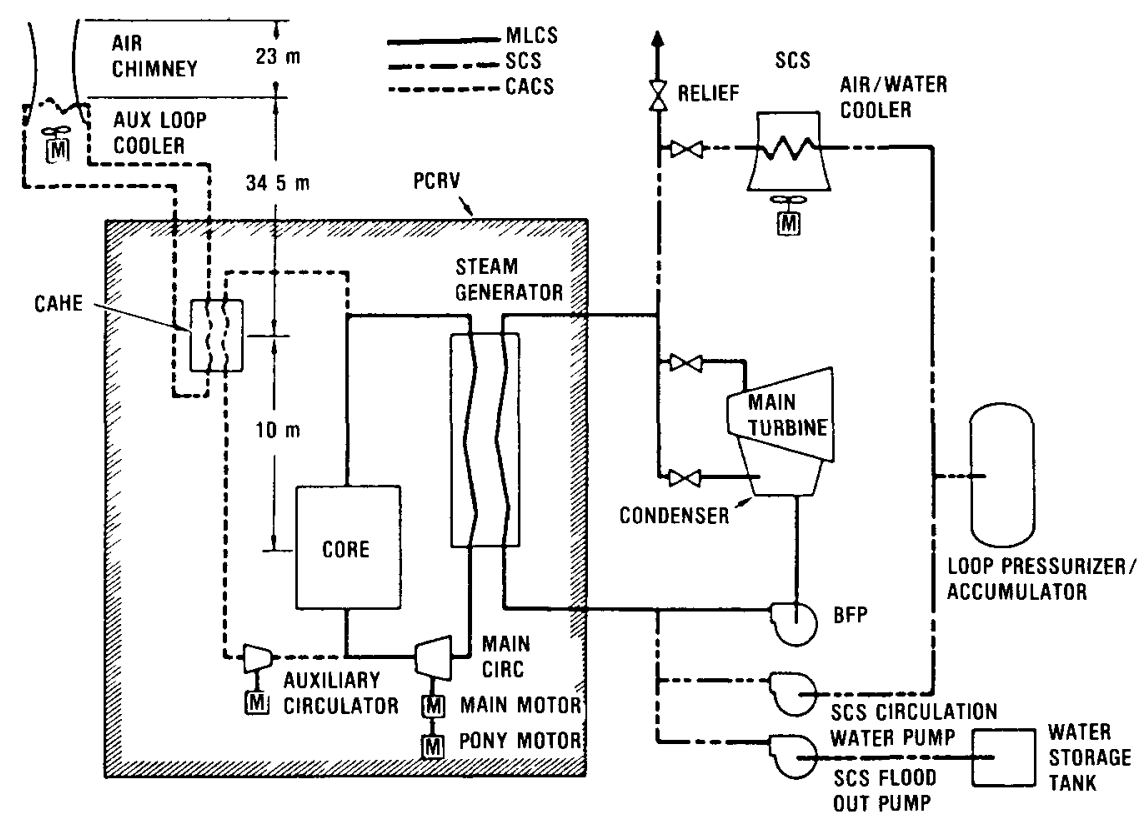

Fig 10-17 Schematic flow diagram showing GCFR RHR systems

separate safety class $1 E$ powered pony motor on the main circulator shafts, separate steam generator feed pumps and circulating water pumps, and the SCS water/air heat exchanger, as shown in Fig 10-17

The CACS is a second safety class decay heat removal system Each of three CACS loops is comprised of an electrically driven auxiliary circulator, a check valve, and a helium-to-water heat exchanger, the CAHE The water from the CAHE is circulated through a pressurized water loop with pumps and a pressurizer, and the heat is rejected to the atmosphere by air from fans in the ALC, which is a heat exchanger made of banks of finned tubes

The CACS design incorporates natural circulation capabilities on the helium, water, and air sides as a backup to normal forced-circulation capabilities Core decay heat is transported by the primary coolant helium to the pressurized water cooled CAHE, which is elevated $10 \mathrm{~m}$ above the core Heated water from the CAHE reaches the ALC located $345 \mathrm{~m}$ above the CAHE by natural circulation in the pressurized water loop The heat from the ALC is ultimately rejected to the atmosphere by natural draft of air through a 23-m chimney For a total lossof-forced circulation accident, the natural circulation capability of the CACS provides cooling for an indefinite period if the primary coolant is pressurized

Natural circulation RHR has been adopted as an engineered safety feature of the GCFR The GCFR design goal is for natural circulation to provide passive short- and long-term RHR to the ultımate atmospheric heat sink

The CAHEs and the steam generators have been located above the core This 
provides the possibility for natural circulation in either main or auxiliary coolant loops or simultaneously in both. Natural circulation in the auxiliary loops has been identified as the preferred mode of operation because of the system simplicity possible while achieving the design goal of a totally passive RHR train to the ultimate heat sink. This goal is achieved by designing gravity-actuated primary coolant isolation valves, providing elevation differences between the CAHEs and the ALCs, and by adding an air draft chimney to the ALC.

The isolation valves have been designed to integrate natural circulation into the hierarchy of RHR systems. During normal operation, the pressure head of the main helium circulator keeps the main loop isolation valves open and the auxiliary loop isolation valves closed. Upon loss of forced circulation in the main loops, the main circulators coast down. When the circulator pressure head reaches a small value (typically at $9 \%$ circulator speed when all circulators are in operation), the main loop isolation valves are closed and the auxiliary loop isolation valves are opened by gravity. If the main loop valves fail to close during auxiliary loop natural circulation, flow bypassing the core is limited to a small amount by buoyancy forces in the main loop. This self-isolation feature of main loops is a function of relative CAHE, steam generator, and upper main loop cross-duct elevations. Criteria for these elevations have been established to assure that the self-isolation feature is maintained in the design.

Design criteria have been developed to maintain flow path and ducting configurations that provide adequate natural circulation startup potential and low flow resistance and also avoid potential thermal traps. The effort to eliminate or minimize flow paths requiring the rise of cold gas or the downward flow of hot gas not only ensures startup under all conditions but also limits the uncertainty of the computational models employed in the analysis.

The natural circulation analysis was performed using two GCFR system codes, RATSAM and FASTRAN.

The RATSAM program ${ }^{39}$ numerically solves a set of ordinary differential equations and relations governing the entire flow system. The program's analytical model assumes that the primary coolant system can be broken down into a series of subvolumes, or nodes, interconnected by flow paths. The transient forms of conservation of mass and energy, as well as the equation of state, are then applied to the nodes, while the transient conservation of momentum with the buoyancy term is applied to the interconnecting flow paths. Specifically, the program calculates the transient coolant pressure, temperature, and flow throughout the primary coolant system, taking into account the dynamic behavior of the circulators and valves, the actions of the plant protection systems, and the heat transfer between coolant, core, steam generators, CAHE, and reactor internals.

The FASTRAN code models the transient performance of the GCFR and its associated cooling systems under pressurized and depressurized conditions. The FASTRAN program incorporates detailed models of the reactor core with kinetics, the steam generators, the main circulators, and the entire auxiliary cooling loop (which includes the auxiliary circulator and drive motor, the CAHE, the ALC, 
and all interconnecting piping). Point model neutron kinetics and reactivity effects of the grid plate, fuel, coolant, etc. are included. Safety, plant protection, and control system actions are all modeled. Also, FASTRAN divides the CACS (naturally circulating) water system into a number of volume nodes with both thermal and fluid inertia effects being modeled. For pressurized conditions, FASTRAN divides the primary system into two volume nodes. In computing the primary coolant flow, fluid inertia, which is modeled in RATSAM, is ignored and flow around the loop is assumed to be constant. Typically RATSAM, excluding core nodes, models the auxiliary loop using ten nodes as compared to two nodes used in FASTRAN. However, due to the low fluid inertia of the GCFR and a generally uniform temperature profile in the auxiliary loop after initial startup of natural circulation, the FASTRAN model simplifications are justified. Figure 10-18 illustrates the good agreement obtained between FASTRAN and RATSAM results for an identical natural circulation transient.

The performance of the GCFR following a complete loss of forced circulation was analyzed first for a base case. Sensitivities to the assumed base case conditions were then determined by varying individual assumptions.

The initiating event of the base case is a total loss of drive power to the main circulators. The main circulators immediately begin coasting down, followed by a reactor scram due to a high power-to-flow ratio. However, it is also assumed

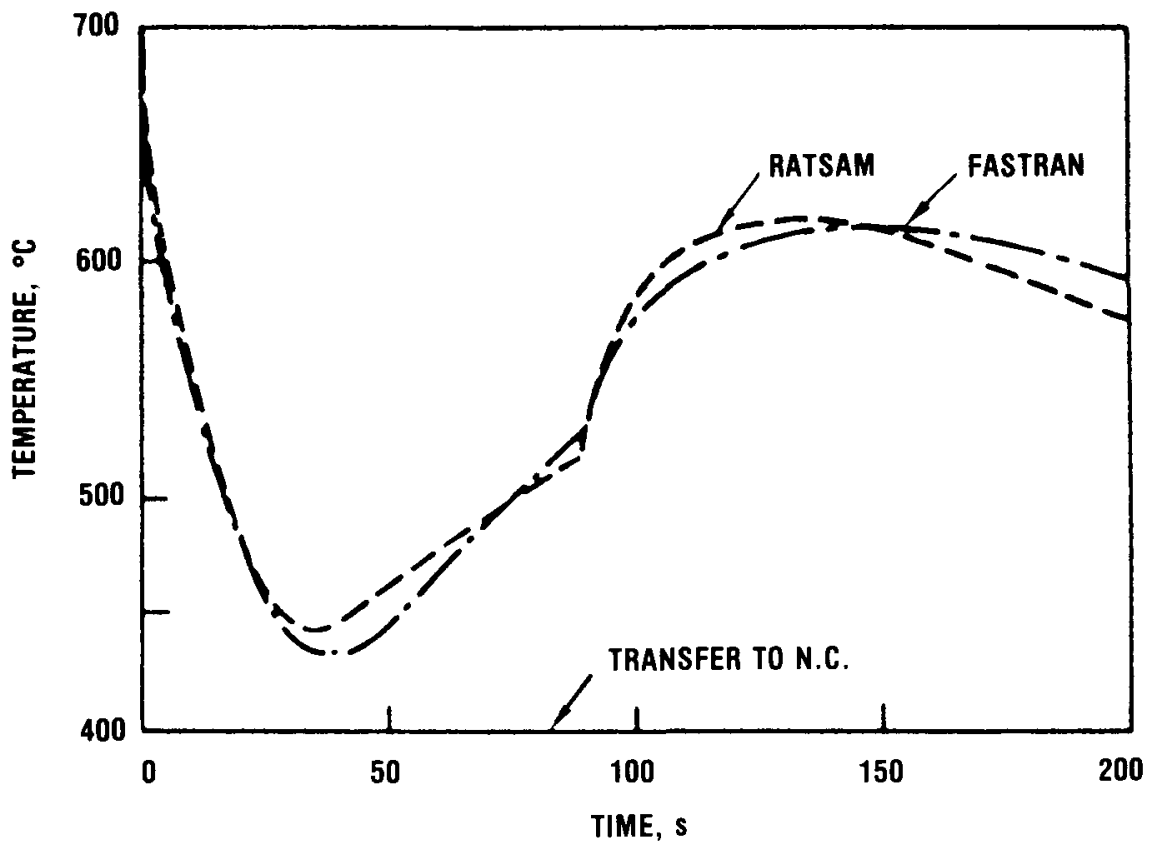

Fig. 10-18. Comparison of peak fuel cladding temperatures predicted by FASTRAN and RATSAM during auxiliary loop natural circulation. 
that the SCS pony motors are unavailable In addition, an extremely conservative assumption is made that none of the three CACS circulators start Ninety seconds after the loss-of-circulator drive power, core flow decays to $<10 \%$ The low flow then allows the main loop isolation valves to shut by gravity while the auxiliary loop isolation valves fall open The temperature profile existing in the auxiliary loop rapidly induces natural circulation between the core and the CAHEs This helium coolant flow is found to increase from nearly 0 to $35 \%$ of its normal design flow in $\sim 3 \mathrm{~s}$ Simultaneously, the increased heat load to the CAHE increases the natural circulation in the CACS water loop and in the natural draft chimney These natural circulation flows are found to maintain hot spot fuel claddıng temperatures below $620^{\circ} \mathrm{C}$ (The maxımum hot spot claddıng temperature at the design point is $700^{\circ} \mathrm{C}$, the faulted temperature damage limit for the cladding $151300^{\circ} \mathrm{C}$ ) The maximum temperature reached in the CACS pressurized water loop is $185^{\circ} \mathrm{C}$ (The saturation temperature of the water loop is $302^{\circ} \mathrm{C}$ )

It is assumed in the above case that all gravity-actuated isolation valves are successfully repositioned after $90 \mathrm{~s}$ of main circulator coastdown The sensitivity to this assumption was evaluated by considering a number of variations from the base case

1 While later transfer times that make full use of circulator coastdown can have a marked effect in limiting cladding temperature rise, natural circulation alone is capable of preventing damage very shortly after scram without utilizing full circulator coastdown

2 Cladding temperature is relatively insensitive to the number of auxiliary loops avallable

3 The effect of a common mode fatlure of the loop isolation valves to operate correctly was analyzed by considering two limiting cases all three auxiliary loop isolation valves open early before completion of main circulator coastdown, and the main loop isolation valves fall to shut after completion of main circulator coastdown The peak fuel cladding temperatures for multiple auxiliary and main loop valve farlures may be shown to be acceptable, within $\sim 100^{\circ} \mathrm{C}$ of the temperature for the base case

\section{0-7C Comparison of Natural Circulation Properties of Coolant Gases}

It has been shown that natural circulation cooling of upflow GCFR cores with pressurized helium is satisfactory for RHR, and that a depressurized GCFR may be cooled by forced circulation with the shutdown cooling system or with the core auxiliary cooling system Natural circulation of depressurized helium in the primary loop is not sufficient, although natural circulation in the secondary water loop and the tertiary air loop is adequate The possibility of injecting another gaseous coolant to replace atmospheric helium has been considered in order to accomplish RHR in the primary loop with natural circulation at atmospheric or 
low (equilibrium) pressure. Carbon dioxide is the primary candidate in view of its widespread utilization in Magnox reactors in Europe and of its good natural circulation properties. ${ }^{40}$ We shall derive simplified equations for natural circulation cooling ${ }^{41}$ and compare $\mathrm{CO}_{2}$ and helium in the case of GCFRs.

For an elevation difference, $\Delta L$, between core midplane and heat sink, the pressure drop induced by a coolant temperature rise, $\Delta T$, is:

$$
\Delta p=g \Delta L \beta \rho_{a v} \Delta T,
$$

where $\beta$ is the coolant expansion coefficient and $\rho_{a v}$ is its average density. The system pressure drop in a channel of hydraulic diameter $d$ and length $L$ may be expressed as a function of the flow velocity, $u$ :

$$
\Delta p=\frac{f Z L}{2 d} \rho_{a v} u^{2},
$$

where $Z$ is the ratio of total system pressure drop to core friction pressure drop, and $f$ is the friction factor.

Equations (10.20) and (10.21) could be combined to yield an expression for the dimensionless elevation difference:

$$
\frac{\Delta L}{L}=\frac{f Z u^{2}}{2 g \beta d \Delta T}=\frac{f Z v^{2}}{2 g \beta d^{3} \Delta T} \operatorname{Re}^{2},
$$

with the flow Reynolds number

$$
\operatorname{Re}=\frac{u d}{v} .
$$

The Grashof number may be written ( $\Delta t$ being the film temperature drop):

$$
\mathrm{Gr}=g \beta \Delta t \frac{d^{3}}{\nu^{2}}
$$

The importance of natural convection (induced by the temperature difference $\Delta t$ ) compared to forced convection during natural circulation is indicated by the ratio:

$$
\frac{\mathrm{Gr}}{\mathrm{Re}^{2}}=\frac{g d \beta \Delta t}{u^{2}} \text {. }
$$

For instance, natural convection effects in a GCFR have been found to be negligible when $\mathrm{Gr} / \mathrm{Re}^{2}<3 \times 10^{-3}$.

Combining Eqs. (10.22) and (10.25), we find simply:

$$
\frac{\mathrm{Gr}}{\mathrm{Re}^{2}}=\frac{f Z}{2} \frac{\Delta t}{\Delta T}\left(\frac{\Delta L}{L}\right)^{-1},
$$

i.e., $\mathrm{Gr} / \mathrm{Re}^{2}$ will be small, or natural convection relatively unimportant, for large values of the relative elevation difference, $\Delta L / L$, which induces forced convection flow. 
Substituting $\Delta t / \Delta T=\left(\frac{1}{4 \text { St }} \frac{d}{L}\right)$ (see Ref. 41) into Eq. (10.26) yields:

$$
\frac{\Delta L}{L}=Z\left(\frac{f}{8 \mathrm{St}}\right) \frac{d}{L}\left(\frac{\mathrm{Gr}}{\mathrm{Re}^{2}}\right)^{-1},
$$

where St is the flow Stanton number. Except for liquid metals, one finds the approximate correlation for turbulent flow on smooth surfaces as

$$
\frac{f}{8 \mathrm{St}} \cong(\operatorname{Pr})^{2 / 3}
$$

and therefore Eq. (10.27) gives a simple expression for the ratio of elevation difference to hydraulic diameter:

$$
\frac{\Delta L}{d} \cong Z(\operatorname{Pr})^{2 / 3}\left(\frac{\mathrm{Gr}}{\operatorname{Re}^{2}}\right)^{-1}
$$

About $5 \%$ of the nominal reactor power must be removed right after shutdown. Assuming the same coolant temperature rise, the Reynolds number will be $5 \%$ of its design value. For most reactors, the flow will still be turbulent and therefore the friction factor can be approximated for smooth surfaces by:

$$
f(\mathrm{Re})=0.184(\mathrm{Re})^{-02} \text {. }
$$

Equation (10.22) may now be written, using Eq. (10.30) and also Eq. (10.23) for $\mathrm{Re}$, as:

$$
\frac{\Delta L}{L} \cong \frac{Z}{10 \beta \Delta T}\left(\frac{\nu}{d}\right)^{02} \frac{u^{18}}{g d}=\frac{Z}{10 g d^{12} \Delta T}\left(\frac{Q}{A \Delta T}\right)^{18} \frac{v^{02}}{\beta\left(\rho_{a v} C_{p}\right)^{18}},
$$

since the thermal power can be written

$$
Q=\rho_{a v} u A C_{p} \Delta T
$$

where $C_{p}$ is the coolant specific heat (at constant pressure).

The last term indicating dependence on coolant properties may also be written with the Prandtl number, $\operatorname{Pr}=\mu C_{p} / K$, or $v=K \operatorname{Pr} / \rho_{a v} C_{p}$ :

$$
\frac{\nu^{02}}{\beta\left(\rho_{a v} C_{p}\right)^{18}}=\frac{(K \mathrm{Pr})^{02}}{\beta\left(\rho_{a v} C_{p}\right)^{2}}
$$

For given temperature, $T_{a v}$, and pressure, $p$, conditions, we find the following dependence on gas properties:

$$
\frac{\Delta L}{L} \sim(K \operatorname{Pr})^{02}\left(1-\frac{1}{\gamma}\right)^{2} \frac{T_{a v}{ }^{3}}{p^{2}},
$$

since $\beta \sim T^{-1}$ and $\rho_{a v} C_{p} \sim(1-1 / \gamma)^{-1} p T_{a v}^{-1}$, where $\gamma=C_{p} / C_{v}$.

As an example, the elevation difference, $\Delta L$, required with $\mathrm{CO}_{2}$ is found to be only $11 \%$ of the elevation required with helium for the same core geometry, 
coolant temperature rise, and thermal power. Similarly, for a given elevation, the $\mathrm{CO}_{2}$ pressure need only be about one-third of the pressure required with helium.

In the laminar regime, which would occur for low afterheat power, the correlations for friction factor and Nusselt numbers are, respectively, for onephase flow of nonmetallic fluids in rod bundles with $p / d=1.4$ (Ref. 26):

$$
f=120 / \operatorname{Re} \text { and } \mathrm{Nu} \cong 10 .
$$

Hence, we find the following relation for the Stanton number:

$$
\mathrm{St}=\frac{\mathrm{Nu}}{\operatorname{Re} \operatorname{Pr}}=\frac{10}{\operatorname{Re} \operatorname{Pr}}=\frac{f}{12 \operatorname{Pr}} \text {. }
$$

Equations (10.22) and (10.29) read, respectively,

$$
\frac{\Delta L}{L}=\frac{60 Z v^{2} \operatorname{Re}}{g \beta d^{3} \Delta T}
$$

and

$$
\frac{\Delta L}{d}=1.5 Z \operatorname{Pr}\left(\frac{\mathrm{Gr}}{\mathrm{Re}^{2}}\right)^{-1}
$$

With the Reynolds number from Eqs. (10.23) and (10.32), Eq. (10.37) reads:

$$
\frac{\Delta L}{L}=\frac{60 Z v Q}{g \beta \Delta T^{2} d^{2} A \rho_{a v} C_{p}} .
$$

Therefore, the dependence on coolant properties is given by the expression

$$
\frac{\Delta L}{L} \sim \frac{v}{\beta \rho_{a v} C_{p}},
$$

which yields the following relationship for gases:

$$
\frac{\Delta L}{L} \sim \frac{\nu T_{a v}}{\rho_{a v} C_{p}} \sim(K \operatorname{Pr})\left(1-\frac{1}{\gamma}\right)^{2} \frac{T_{a v}{ }^{3}}{p^{2}},
$$

to be compared with Eq. (10.34) for turbulent flow.

We thus find that the elevation difference with $\mathrm{CO}_{2}$ is only $\sim 1 / 30$ of the value required with helium, or else, for a given elevation, the pressure required with $\mathrm{CO}_{2}$ is only $\sim 18 \%$ of the pressure with helium (for laminar flows).

Under some conditions, the flow of helium could be laminar while the flow of $\mathrm{CO}_{2}$ is turbulent because of the higher Reynolds number. In such a case, the ratio of pressures for $\mathrm{CO}_{2}$ and helium would be somewhere between 18 and $33 \%$ (Ref. 40). It has also been found that $\sim 2 \%$ residual heat could be removed with 2 atm (absolute) $\mathrm{CO}_{2}$ natural circulation and a 10 -m elevation difference; less than $0.01 \%$ afterheat would be removed with 2 atm of helium under similar conditions. 
Thus injection of $\mathrm{CO}_{2}$ into a shutdown depressurized GCFR core may be adequate for RHR by natural circulation, although transition from helium to $\mathrm{CO}_{2}$ cooling should be further studied

\section{NOMENCLATURE}

\section{Symbol}

$A \quad=$ cross-sectional area

$\mathrm{B}_{1}=\alpha h / k_{c}, B_{10}$ number, characterizing the fin efficiency of a roughness rib (d1mensionless)

$b \quad=$ width of the roughness $\mathrm{rib}$

$C_{p} \quad=$ gas specific heat at constant pressure

$D_{h} \quad=4 A / P$, hydraulic diameter of the coolant channel

$d \quad=$ diameter of the rod in a rod bundle

$f \quad=2\left(\tau / \rho_{B}\right) u_{B}^{2}$, friction factor evaluated at the gas bulk temperature, $T_{B}$ (dimen sionless)

$G\left(h^{+}, \operatorname{Pr}\right)=G\left(h^{+}\right)$for gases, function defined by Eq (10 9)

$\mathrm{Gr}=$ Grashof number, $g \beta \Delta t d^{3} / \nu^{2}$

$h_{R} \quad=$ height of the roughness $\mathrm{rib}$

$h^{+} \quad=h u^{*} / v_{B}=h / D_{h}\left[\operatorname{Re}_{B}\left(f_{B} / 8\right)^{1 / 2}\right]$, dimensionless height of roughness ribs, roughness cavity Reynolds number

$K=$ coefficient in Eq (10 3)

$k \quad=$ gas thermal conductivity

$k_{c} \quad=$ thermal conductivity of the wall of the rod

$L \quad=$ length of the coolant channel

$M \quad=$ mass flow rate

$N \quad=$ pumping power

$\mathrm{Nu} \quad=$ Nusselt number, $\alpha D_{h} / k$

$\operatorname{Pr} \quad=$ Prandtl number, $\mu c_{p} / k$

$p=$ axial pitch of the repeated roughness ribs, pitch of rods, coolant pressure

$\Delta p \quad=$ pressure difference

$Q \quad=$ heat generated

$q \quad=$ heat flux

$r \quad=$ radius

$\operatorname{Re} \quad=$ Reynolds number, $u_{B} \rho_{B} D_{h} / \mu_{B}$, evaluated at the gas bulk temperature (dmensionless)

$R\left(h^{+}\right) \quad=$ constant in the turbulent velocity distribution of Nikuradse, equal to the gas velocity of the tip of the roughness ribs divided the friction velocity ( $d_{1}$ mensionless)

$R_{0 \mathrm{I}} \quad=$ value of $R\left(h^{+}\right)$in the region of fully rough flow, where $R\left(h^{+}\right)$is independent of $h^{+}$and reduced to $T_{W} / T_{B}=1$ and $h_{R / y}=001$ (dimensionless)

St $\quad=$ Stanton number (dimensionless)

$T \quad=$ temperature of the gas at the considered point, $K$

$t^{+} \quad=\left(T_{W}-T\right) \rho_{B} C_{p B} u^{*} / q$, dimensionless gas temperature

$u \quad=$ velocity of the gas

$u^{+} \quad=u / u^{*}$, dimensionless gas velocity 
$=\sqrt{\tau / \rho}$ friction velocity

$=$ radial distance from the wall

$=$ length of the velocity profile

$=v u^{*} / v_{B}$, dimensionless radial distance from the wall

Greek

$\alpha=$ convective heat transfer coefficient between wall surface and bulk gas

$\eta \quad=$ efficiency of the circulator

$\mu \quad=$ gas dynamic viscosity

$\nu \quad=$ gas kinematic viscosity

$\rho \quad=$ gas density

$\tau=$ shear stress at the wall

\section{Subscripts}

$B \quad=$ gas properties evaluated at the gas bulk temperature, $T_{B}$

$R \quad=$ rough

$S \quad=$ smooth

$W \quad=$ gas properties evaluated at the wall temperature, $T_{W}$

$\bar{W} \quad=$ gas properties evaluated at the wall temperature, $T_{\bar{W}}$, average between the temperature of the surfaces surrounding the coolant channel

$x \quad=$ at the section $x$

$1,2=$ the inner and outer regions, respectively, of an annulus or inlet and outlet

$0=$ at the plane of zero shear

Superscript

$=$ average value

\section{REFERENCES}

1 A Weinberg, "The Maturity and Future of Nuclear Energy," Am Scl, 64, 16 (Jan -Feb 1976)

2 W Pardue, "An Evaluation of Alternatıve Energy Strategies," Ann Nucl Energy, 2, 11/12, 819 (1975)

3 W Pardue et al , "A Comparıson of Advanced Reactor Potentıals," Proc ANS/ASME Joint Int Conf Advanced Nuclear Energy Systems, Pittsburgh, Pennsylvania, March 14-17, 1976, CONF-760303, p 159, American Society of Mechanıcal Engıneers (1976)

4 R Cerbone and M Nagel, “Reactor Strategy Studıes," GA-A13984, GA Technologies (June 1976)

5 R D Vaughan, “Necessary Characteristics of Breeder Reactors," Nuclear Energy Maturty, Proc Paris Conf, Progress in Nuclear Energy Series, Plenary Sessions, p 327, Pergamon Press (1976)

6 R D Vaughan and J Chermanne, "The Need for Hıgh-Performance Breeder Reactors,' Proc IAEA Int Conf Nuclear Power and Its Fuel Cycle, Salzburg, Austria, May 2-13, 1977, paper CN-36/478, Vol 1, p 543, International Atomic Energy Agency (1977)

7 C Zaleskı and J Chermanne, "The Urgent Need for the Breeder," Power Eng, 79, 11, 60 (Nov 1975) 
8 M M El Wakıl, Nuclear Energy Conversion, 2nd ed, pp 359-362, American Nuclear Society, La Grange Park (1971)

9 C P Gratton et al , "Some Design and Safety Aspects of Gas Breeder Reactors," Proc 4th Int Conf Peaceful Uses of Atomic Energy, Geneva, Switzerland, September 6-16, 1971, Vol 5, p 433, United Nations, New York (1972)

10 G P Verkhivker, "A Comparison of Coolants for Nuclear Power Stations with GasCooled Fast Neutron Reactors," Therm Eng , 22, 12, 68 (Dec 1976)

11 A Krasin, "Dissociatıng Gases as Heat Transfer Media and Workıng Fluids in Power Installations," AEC-Tr-7295, U S Atomic Energy Commission (1975)

12 A Krasin et al , "Prıncipal Performance Problems and Prospects of the 1200-1500 MW Gas-Cooled Fast Reactors with Dissociatıng Coolant," Proc IAEA Int Conf Nuclear Power and Its Fuel Cycle, Salzburg, Austria, May 2-13, 1977, paper CN36/332, Vol 1, p 569, International Atomic Energy Agency (1977)

13 J Yellowlees et al , "The High-Temperature Gas-Cooled Breeder Reactor (HTBR)," Trans Am Nucl Soc, 20, 704 (1975)

14 J Yellowlees et al , "The Progress of the GBR Association in the Design and Development of the Gas-Cooled Fast Breeder Reactor, Proc ANS Topl Mtg Gas-Cooled Reactors HTGRs and GCFBRs, Gatlınburg, Tennessee, May 7-10, 1974, CONF740501, p 306, National Technical Information Service (1974)

15 J Chermanne, "Gas-Cooled Breeder Reactor Making Progress in Europe," Power Eng , 81, 4, 74 (Apr 1977)

16 G Melese-d'Hospital, "Influence of the Chorce of Coolant Gas on Reactor Thermal Performance," Nucl Appl, 2, 205 (June 1966)

17 J Chermanne, R H Simon, and J J Scoville, "GCFR Development Status and Introduction," OECD NEA report, Vol III, OECD Nuclear Energy Agency (July 1980)

18 J Megy et al , "Phenix Construction and Operating Expenence," Proc ANS/ASME Joint Int Conf Advanced Nulcear Energy Systems, Pittsburgh, Pennsylvania, March 14-17, 1976, CONF-760303, p 3, American Society of Mechanical Engineers (1976)

19 "PFR A Special Feature on the Britısh Prototype Fast Reactor," Nucl Eng Int, 16, 183, 629 (Aug 1971)

20 "The LMFBR Program in France," 76-14, Energy Research and Development Admin1stration (Mar 1976)

21 R H Simon, C J Hamilton, and R S Hunter, "Fuel Cycles and Advanced Core Designs for the GCFR,' Proc BNES Conf Gas-Cooled Reactors Today, Bristol, United Kingdom, September 20-24, 1982, Vol 1, p 293, Britısh Nuclear Energy Society (1982)

22 G Melese-d'Hospital, “Merit Index for Gas-Cooled Reactor Heat Transfer,' Nucl Scl Eng , 50, 83 (1973)

23 M Peehs, J R Lindgren, and P Moser, "Gas-Cooled Fast Breeder Core Element Fabrication Technology," Nucl Eng Des, 40, 101 (1977)

24 M Dalle Donne, "Comparison of the Performances of 1000 MWe GCFR's with Two and Three-Dimensional Roughnesses on the Fuel Rods," Proc Sth GCFR Specialsst Mtg , Wurenlıngen, Switzerland, May 14-16, 1979, OECD-NEA Coordınatıng Group on Gas-Cooled Fast Reactor Development (1979)

25 C B Baxı and M Dalle Donne, "Fluid Flow and Heat Transfer in the Gas-Cooled Fast Breeder Reactor,' Chapter 5, Part 3 in Heat Transfer and Fluid Flow in Nuclear Reactor Systems, Henr1 Fenech, Ed, Pergamon Press, New York (1981) 
26 M Hudına, "Roughenıng Characterıstıcs and Choices for the Gas Cooled Fast Breeder Reactor," Nucl Eng Des , 40, 133 (1977)

27 W I Thompson, "CALIOP, A Multichannel Design Code for Gas-Cooled Fast Reactors Code Description and User's Guide," GA-A15949, GA Technologies (Oct 1980)

28 C B Baxı, C J Burhop, and F O Bennett, "COBRA*GCFR, A Computer Code for Thermal-Hydraulıc Analysis of GCFR Fuel Assembly," Trans Am Nucl Soc, 29, 743 (1978)

$29 \mathrm{C}$ L Wheeler et al, "COBRA-IV-1 An Interım Version of COBRA for ThermalHydraulic Analysis of Rod Bundle Nuclear Fuel Elements and Cores,' BNWL-1962, Pacific Northwest Laboratories (1976)

30 M Dalle Donne et al , "BR-2 Bundle Mockup Heat Transfer Experıments,' Nucl Eng Des, 40, 143 (1977)

31 E M Sparrow and A L Loeffler, "Longitudınal Lamınar Flow Between Cylınders Arranged in Regular Array," AIChE J , 5, 325 (1959)

32 B S Petukov and L I Roizen, "Heat Exchange and Friction Resistance in Pipes and Channels of Various Geometrical Shapes," Heat Mass Transfer, 1, Nouka 1 Tekhnıka, Minsk (1965)

33 W H McAdams, Heat Transmission, 3rd ed, McGraw-Hill Book Co, New York (1954)

34 M Dalle Donne et al , "EIR/KfK Joint Heat Transfer Experıments on a Single Rod, Roughened with Trapezoidal Ribs and Cooled by Varıous Gases," Joint EIR-KfK report, KfK-2674, EUR-5755e, EIR-349 (Oct 1978)

35 M Dalle Donne and L Meyer, "Turbulent Convective Heat Transfer from Rough Surfaces with Two-Dimensional Rectangular Ribs," Int J Heat Mass Transfer, 20, 583 (1977)

36 H S Chung et al, "GCFR Residual Heat Removal Following Depressurization Accidents," in Decay Heat Removal and Natural Convection in Fast Breeder Reactors, A Agrawal and J Guppy, Eds , Hemisphere Publishing Corp, New York (1981)

37 D R Buttemer and H S Chung, "Depressurizatıon Accident Studies for GCFRs," Proc Int Mtg Fast Reactor Safety and Related Physıcs, Chicago, Illınois, October 1976, CONF-761001, Vol 3, p 195, U S Department of Commerce (1977)

38 W A Medwid et al, "Design, Analysis and Verification of Natural Circulation in the GCFR,' in Decay Heat Removal and Natural Convection in Fast Breeder Reactors, A Agrawal and J Guppy, Eds, Hemisphere Publishing Corp, New York (1981)

39 R K Deremer and T Shih, "RATSAM Computer Program to Analyze the Transient Behavior of the HTGR Prımary Coolant System Durıng Accıdents," GA-A13705, GA Technologies (May 1977)

40 G Melese-d'Hospital and C B Bax1, "Comparison of $\mathrm{CO}_{2}$ and He for Natural Convection Cooling of GCFR's," in Decay Heat Removal and Natural Convection in Fast Breeder Reactors, A Agrawal and J Guppy, Eds, Hemısphere Publıshıng Corp , New York (1981)

41 G Melese-d'Hospital, "Review of Gas-Cooled Reactors' Thermal Hydraulics,' in Nuclear Reactor Thermal Hydraulics, NUREG/CP0014, Vol 3,p 2147, U S Nuclear Regulatory Commission (Oct 1, 1980) 


\section{1}

\section{GAS COOLING OF FUSION REACTORS*}

\section{1-1 Introduction}

Fusion is the nuclear reaction between the nuclel of light atoms, such as hydrogen, whereby two light nucleı will fuse to form a heavier nucleus and release energy Fusion powers the stars and a number of possible reactions are known to exist As a form of nuclear power, fusion shares with fission the nuclear characteristics of high energy release per reaction, large fuel supply, high capital cost, and the requirement of dealing with radiations Because of the potential to tap the unlimited fuel resource of deuterium in the sea and the potential for achieving a very low inventory of radioactive materials, fusion is often considered the ultımate form of nuclear power ${ }^{\text {I }}$ This chapter reviews the thermal-hydraulic aspects of helium cooling applied to fusion power reactor systems

\section{1-1A Fusion Energy Concepts}

The basic fusion reactions shown below were known even before the discovery of fission

$$
\begin{aligned}
{ }_{1}^{2} \mathrm{D}+{ }_{1}^{2} \mathrm{D} & \rightarrow{ }_{2}^{3} \mathrm{He}+{ }_{0}^{1} n+327 \mathrm{MeV}, \\
& \rightarrow{ }_{1}^{3} \mathrm{~T}+{ }_{1}^{1} p+402 \mathrm{MeV}, \\
{ }_{1}^{2} \mathrm{D}+{ }_{1}^{3} \mathrm{~T} & \rightarrow{ }_{2}^{4} \mathrm{He}+{ }_{0}^{1} n+176 \mathrm{MeV},
\end{aligned}
$$

and

$$
{ }_{1}^{2} \mathrm{D}+{ }_{2}^{3} \mathrm{He} \rightarrow{ }_{2}^{4} \mathrm{He}+{ }_{\mathrm{l}}^{\mathrm{l}} p+183 \mathrm{MeV}
$$

To get the nuclet to fuse, they must overcome the strong mutual Coulomb barriers between them This may be accomplished by heatıng them to very high temperatures $(\sim 10$ million $\mathrm{K}$ or even higher) Since matter is ionized at those temperatures, basic studies of high-temperature plasmas are involved

The cross sections for the three fusion reactions as a function of the particle energy or temperature (since $1 \mathrm{keV}$ corresponds to $\sim 10^{7} \mathrm{~K}$ ) are shown in Fig

*K R Schultz, G R Hopkins, and C P C Wong contributed to this chapter 


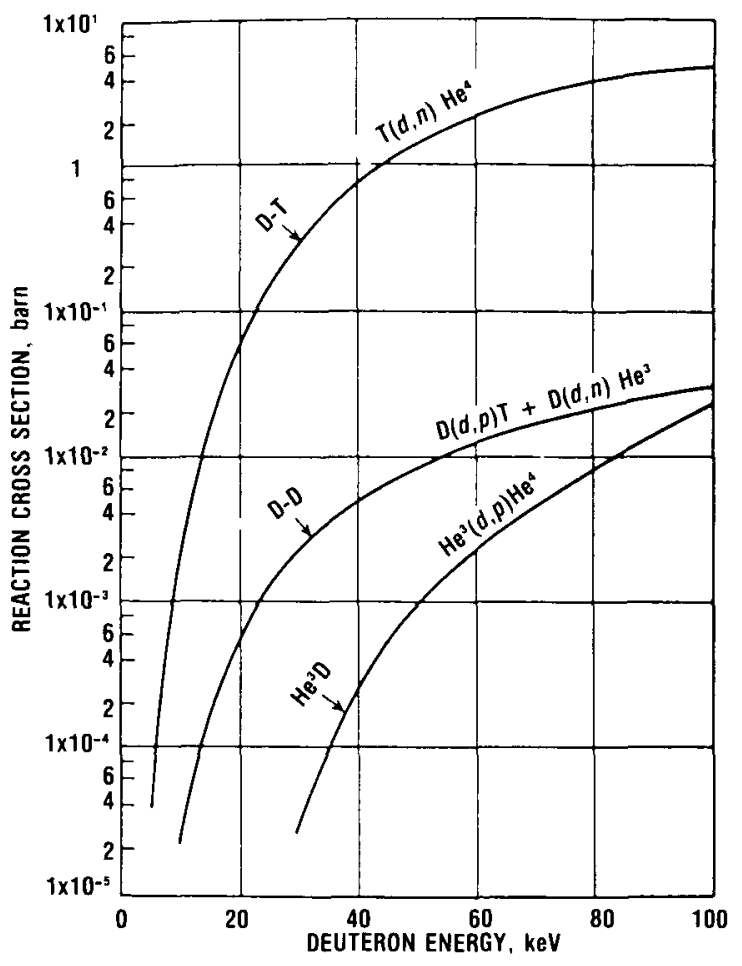

Fig. 11-1. Nuclear fusion reaction cross section as a function of relative particle energy.

11-1. This figure clearly shows that the cross section for the deuterium-tritium (D-T) reaction at temperatures of the order of 100 million $\mathrm{K}$ is $\sim 100$ times higher than the cross section for the two deuterium-deuterium (D-D) reactions. Furthermore, its energy production is higher. The reaction involving tritium and deuterium is thus most likely to be developed first. While deuterium is readily available at reasonable cost (heavy water costs from 50 to $100 \$ / \mathrm{kg}$ ), tritium must be produced artificially. In a fusion reactor, the reaction chamber needs to be surrounded by lithium components where neutrons coming from the fusion reaction will react with lithium to generate tritium. Natural lithium is $7.4 \%{ }^{6} \mathrm{Li}$ and $95.6 \%{ }^{7} \mathrm{Li}$ :

$$
n+{ }_{3}^{6} \mathrm{Li} \rightarrow{ }_{1}^{3} \mathrm{~T}+{ }_{2}^{4} \mathrm{He}+4.8 \mathrm{MeV}
$$

and

$$
n+{ }_{3}^{7} \mathrm{Li} \rightarrow{ }_{1}^{3} \mathrm{~T}+{ }_{2}^{4} \mathrm{He}+{ }_{0}^{1} n-2.8 \mathrm{MeV} .
$$

A fusion reactor will consist of a central vacuum chamber containing the reacting D-T plasma. The first wall, which receives a high energy flux (20 to $100 \mathrm{~W} / \mathrm{cm}^{2}$ ) and must be cooled, will be surrounded by a blanket where the 14-MeV fusion neutron will be absorbed in lithium to breed tritium. The blanket, which must 
also be cooled, will be surrounded by radiation shields to protect the external reactor systems.

The plasma could be confined by using magnetic fields or by inertial confinement. It is necessary to maintain a very hot gas within the vacuum chamber, without allowing any appreciable amount of gas to reach the chamber walls to avoid cooling the plasma. Since enough reactions must occur to produce fusion, the so-called "Lawson criterion" 2 must be satisfied, i.e., the product of the ion number density, $n$, and the confinement time, $\tau$, must be such that $n \tau \geqslant 10^{14}$ $\mathrm{s} / \mathrm{cm}^{3}$ at an ion temperature of at least $10 \mathrm{keV}$. This may be accomplished by achieving a very high density for a short time (inertial fusion) or a lesser density for longer time (magnetic fusion).

\section{Magnetic Confinement}

Several magnetic confinement schemes have been proposed to constrain hot plasma under conditions that could lead to fusion reactions. ${ }^{3}$ The effect of a uniform magnetic field is to prevent the plasma as a whole from expanding as each charged particle moves in a circular or helical path around the lines of force. Since the plasma is composed of all charged particles, the magnetic field exerts a pressure, $\sim H^{2} / 8 \pi$, that is balanced against the plasma pressure, $\sim n K T$, due to thermal motion of the particles. As an example, a magnetic field of $15 \mathrm{~T}(150 \mathrm{kG})$ exerts a pressure of $750 \mathrm{~atm}$, which can theoretically hold a plasma of density $6 \times 10^{16} \mathrm{~cm}^{-3}$ at a kinetic energy of $10 \mathrm{keV}$. Not only must the plasma be kept away from the containment walls, but it must always be first heated to some minimum operating temperature (to start the fusion reaction) and maintained against various instabilities and losses. These problems have led to the design of a number of different configurations for achieving magnetic confinement. The mirror machine consists of a magnetic bottle, built by shaping the coils around a straight tube in such a way that the particles are reflected back from the mirror ends by stronger magnetic fields at each end as shown in Fig. 11-2. Because the ends of the magnetic bottle are not closed, the mirror suffers from a fairly short confinement time. A new concept called the "tandem mirror" promises to improve this by effectively squeezing the ends still more tightly.

The leading magnetic fusion confinement concept at the present time is the tokamak concept, first developed in the Soviet Union, where the plasma is maintained inside a vacuum chamber by a constant toroidal magnetic field and is heated by joule heating due to a current produced by another set of coils. This current creates a poloidal field, which also helps stabilize the plasma (see Fig. 11-3).

\section{Inertial Confinement}

Inertial confinement includes the laser pellet reactor concept ${ }^{3,4}$ and other concepts that use electron beams and ion beams to rapidly heat and compress small pellets of D-T fuel to temperatures and densities necessary for fusion to 


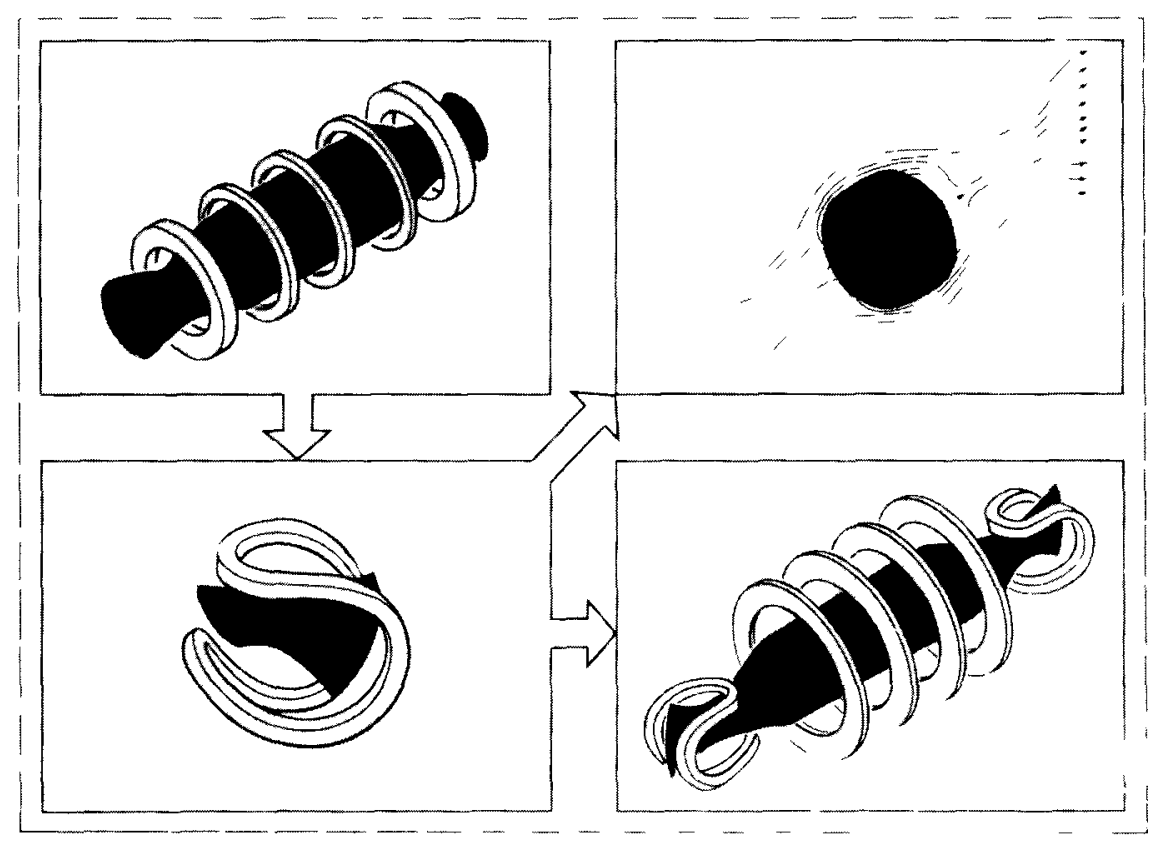

Fig. 11-2. Evolution of mirror fusion ideas.

occur. Plasma heating energy in the form of laser light is delivered to a D-T fuel pellet in a nanosecond $\left(10^{-9} \mathrm{~s}\right)$ within a cavity surrounded by a blanket. A pellet compression ratio of $10^{4}$ leads to an implosion heating process resulting in ignition of the central region. The compression is produced by reaction from rapidly accelerated outer layers, resulting from their rapid vaporization by the laser. A thermonuclear burn front propagates outward and ignites additional fuel. In view of the low efficiency of laser light absorption and laser designs, energy multiplication factors by the fusion process of 250 or more are required as well as high cavity pulse rates ( 1 to 10 per second). Various inertial fusion concepts differ by the way energy is transported to the pellet (laser light, electron beam, light ion beam, or heavy ion beam). The energy deposition from the microexplosion of the pellet may be accommodated at the cavity inner wall using several possible design concepts. In the "wetted wall"' concept, the laser cavity is defined by a porous metal wall wetted with lithium. In the lithium waterfall concept, the laser cavity is defined by streams of falling lithium. The space between the streams allows motion to help attenuate the microexplosion stresses on the containment vessel. Very advanced energy storage systems will also be required for energy transfer times of 3 to $5 \mu$ s and repetition rates of $10^{8}$ to $10^{9}$ pulse $/ y r$. 


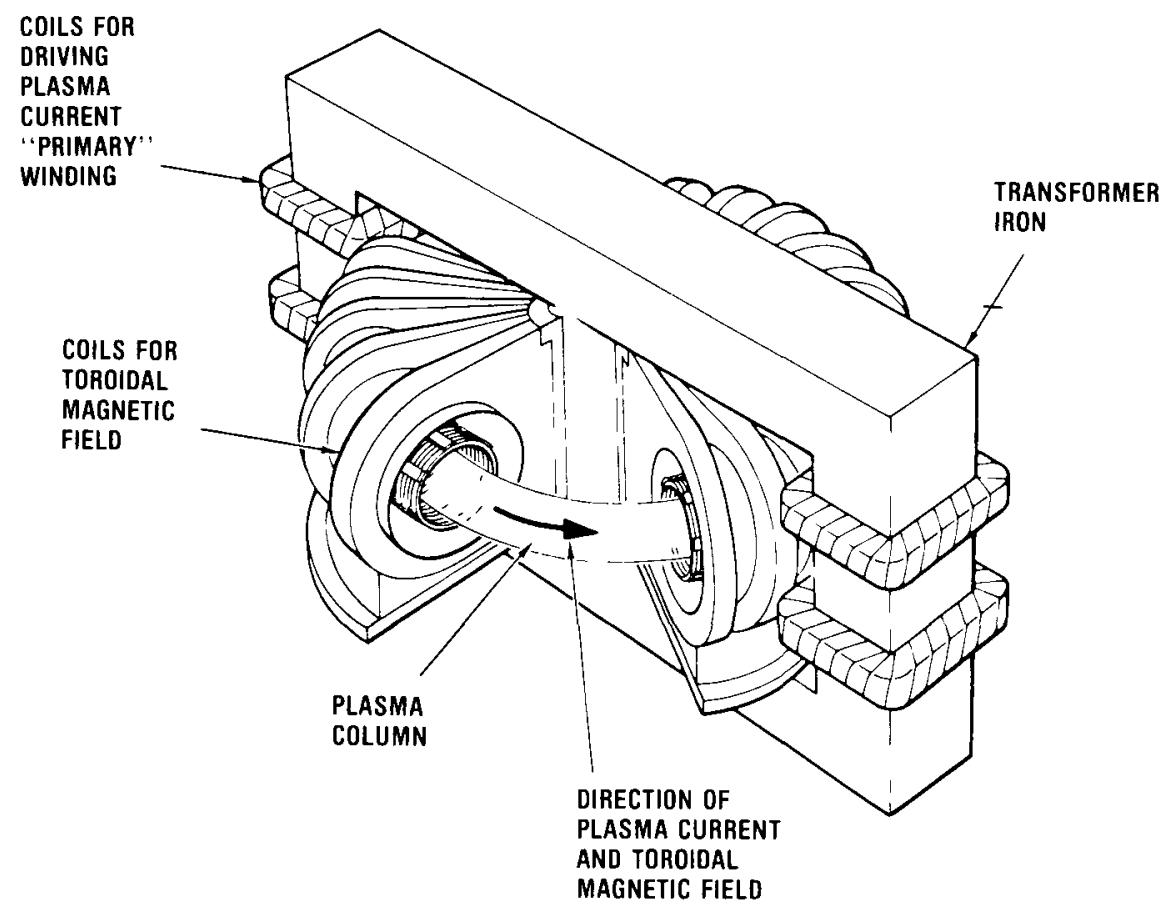

Fig. 11-3. Schematic of the tokamak device developed for the study of heating and confinement of plasmas at the Kurchatov Institute in the Soviet Union.

\section{Main Problems of Fusion Technology}

A number of outstanding technological problems remain to be solved before fusion power can be proven feasible. They have been summarized by D. Steiner ${ }^{5}$ under three major headings:

1. Power balance. Fusion reactors can be viewed as power-amplifying devices with the power amplification depending on: $Q$, the plasma amplification factor; on $\eta_{\text {heatng, }}$, the heating power input efficiency; and on $\eta_{\text {thermal }}$, the blanket thermal efficiency. For instance, in a tokamak, fuel and heat power requirements should not exceed $\sim 10 \%$ of the total power release and the system duty factor should be $\sim 80 \%$, with burn times of $40 \mathrm{~s}$ or higher. The net system efficiency is given by

$$
\eta_{\text {net }}=\frac{P_{\text {net electnc }}}{P_{\text {fusion }}}=(1+1 / Q) \eta_{\text {thermal }}-\frac{1}{Q \eta_{\text {heating }}}
$$

2. Reactor design requirements. The $\mathrm{D}-\mathrm{T}$ cycle is based on tritium breeding in the blanket. Tritium handling and recovery technology need further development, and demonstration of extremely low leakage of tritium in 
large and hot systems is required Development of large superconducting magnets and associated systems must lead to acceptable capital costs Magnets of 8 to $16 \mathrm{~T}$ ( 80 to $160 \mathrm{kG}$ ) with an energy stored in the field of $\sim 2 \times 10^{11} \mathrm{~J}$ will be required for tokamak fusion reactors $\mathrm{H}$ ighpower neutral beam injection into the plasma as additional heating (tokamaks) or to compensate for end losses (mirror) still requires further development Much progress has been made in the past few years in plasma heating of tokamaks with neutral beams and also with radiofrequency and compression heating

3 Materials considerations Erosion of the surface of the first wall by the plasma particles may limit its useful life and the resulting impurities might severely affect the plasma Various schemes have been proposed to protect the vacuum wall from erosion processes due to plasma-particle sputternng Deleterious changes in material properties, such as embrittlement and swelling, anse in fusion reactors as well as in fast breeders from neutron-induced atomic displacements and gas production The radiation effects that are most severe in the vicinity of the first wall are caused by $14-\mathrm{MeV}$ neutrons, and are difficult to simulate with sufficiently high flux without a fusion reactor Furthermore, the rate dependence of this radiation damage must be investigated for pulsed systems Induced radioactivity in blanket structural materials can create problems for decay heat removal (as in fission reactors) and rases senous questions of maintenance, handling, and disposal of first-wall and blanket modules However, the possibility exists to use materials that do not exhibit significant long-lived activation products such as aluminum, carbon, and silıcon carbide $(\mathrm{S} 1 \mathrm{C})$, thus virtually elımınatıng concerns about radioactivity and decay heat removal This concept requires further research and development on these materials

\section{1-1B Fusion Energy Recovery}

Assuming a fusion reaction has been obtained that produces more energy than is needed to initiate the reaction, there remains the problem of fusion energy recovery In the D-T fusion reaction, $80 \%$ of the reaction energy is carned by the 14-MeV fusion neutrons These neutrons escape from the plasma and deposit their energy as bulk heating in the materials that surround the plasma chamber The remaining $20 \%$ of the energy is carried by the alpha particle and the majority of this will be deposited in the plasma itself Transport of the energy from the plasma occurs by particle diffusion and photon transport processes ( $x$ rays, etc) and results in a surface heat flux to the walls of the plasma chamber In currently evolving reactor designs, the fusion energy deposition results in maximum bulk heatıng rates between 25 and $400 \mathrm{MW} / \mathrm{m}^{3}$ and average surface heat fluxes between 50 and $800 \mathrm{~kW} / \mathrm{m}^{2}$ Energy deposited in the plasma chamber wall, the blanket, 
and the shield must be recovered at temperatures high enough to allow efficient power production.

In addition to the requirement of efficient energy recovery, the first-wall/ blanket/shield region of the reactor must also use the fusion neutrons to breed tritium from lithium (in order to fuel the fusion reaction), and must provide shielding to protect the rest of the reactor system (such as magnets), the operating personnel, and the public from radiation. These elements form the plasma chamber vacuum boundary, and must be a part of the structural support system for the reactor.

The time distribution of energy production for inertial confinement fusion concepts includes an "on-time" of $<1 \mathrm{~ms}$ with a repetition rate of 1 to 10 events per second. Magnetically confined fusion concepts range from 10-ms pulsed systems through cyclic operation where the "on-time" is much longer than the "offtime," up to steady-state devices. In addition, off-normal events such as disruptions from plasma instabilities and runaway electron conditions can periodically occur. The energy content of the plasma is dissipated on a small region of the first wall in times less than a millisecond, resulting in very high heat fluxes. Thus, most components in the plasma chamber need to withstand not only relatively high steady-state heat fluxes but also the periodically pulsed high heat loads.

To accomplish these multiple design requirements is a challenging task. Each of the requirements has temperature constraints. The blanket breeding material must be hot enough to allow tritium recovery but cool enough to prevent tritium leakage and material degradation. The response of structural materials to the severe radiation environment is strongly temperature dependent and strict temperature control is needed. Because of these multiple design requirements and thermal constraints, the thermal-hydraulic design of first-wall/blanket/shield systems is a critical aspect of fusion reactor design. A variety of coolants have been proposed for fusion reactors, including gases, liquids, and liquid metals. The design concepts range from the exotic (such as boiling liquid metals) to the conventional (pressurized water). At this time, the early 1980s, an apparent consensus appears to be forming in the fusion design community that the preferred coolants for fusion power reactor applications will be pressurized water (subcooled or boiling), pressurized helium, and liquid metal (lithium or $\mathrm{Li}_{17} \mathrm{~Pb}_{83}$ ). Fairly complete and reasonably detailed designs have been performed using each of these candidates and the analysis of these designs shows that viable reactor designs could be developed based on any of them. We will examine the applications of helium cooling to fusion power reactors in this chapter.

\section{1-1C Gas Cooling of Fusion Reactors}

Gas-cooled reactor technology has been pursued since the very early days of the nuclear program. A wide variety of gases have been proposed for use in gascooled reactors including $\mathrm{CO}_{2}$, helium, dry steam, hydrogen, nitrogen, and nitrogen oxide. The technical aspects of gas cooling have been reviewed in the 
previous chapters and in Refs 6 and 7 The application of gas-cooled technology to fusion power systems is discussed in Refs 8 and 9 Because of its high heat capacity (compared to other gaseous coolants), high sonic speed, and chemical inertness, helium has generally been the preferred choice of coolant for hightemperature gas-cooled systems and will be used as a basis in the following discussion on gas-cooled fusion reactors

\section{Advantages of Helium Cooling}

The principle advantages of helium cooling for fusion reactors are summarized in Table 11-I Helium is the most inert of all proposed coolants It has very small nuclear interaction cross sections and is virtually transparent to neutrons at the densities found in reactor systems This property allows excellent neutron economy to be achieved, which is important since fusion reactor blankets must breed tritium Helium is a noble gas and is chemically inert Reactions with most materials, including liquid lithium, during both normal and accidental conditions are not of concern Because helium is a gas, no phase changes are possible, thus the heat transfer regime is stable in both normal pressurized operation and in the event of depressurization A complete loss-of-coolant accident cannot occur for a gascooled system although loss-of-coolant-pressure and loss-of-coolant-flow accidents are, of course, a possibility that must be considered This is particularly important for fusion reactor blankets, which require extensive piping

For magnetically confined fusion systems, the fact that helium is nonmagnetic and nonconductive is an advantage Even with a high level of impurities, helium will not support electromagnetic effects On the contrary, a liquid-metal coolant flowing in the magnetic field of a fusion reactor could lead to a very high pressure

\section{TABLE 11-I}

Advantages of Helium Cooling for Fusion Reactors

\begin{tabular}{|l|}
\hline Helium Characteristics \\
Chemically inert \\
Neutronically inert \\
No phase changes \\
Negligible gravity effects \\
Nonmagnetic \\
Nonconductive \\
- Developed Technology \\
Heat transfer \\
Power conversion \\
Purfication (including tritium recovery) \\
Maintenance Advantages \\
No activation \\
No isolation \\
No trace heating \\
No intermediate loop \\
Transparent \\
\hline
\end{tabular}


drop, thus requiring a high coolant inlet pressure. Because of the low density of helium coolant, gravitational effects are quite small compared to normal flow forces. As a consequence, the heat transfer in a helium system is not greatly affected by gravitational orientation. This can allow axisymmetric blanket designs, which can be quite compact and can allow full coverage of the plasma chamber surface.

Helium heat transfer and thermal-hydraulic correlations are adequately understood for both steady-state and transient conditions, and power conversion equipment (steam generators, circulators, etc.) has been developed. High thermal efficiency for energy conversion is possible because of helium's high-temperature capability at modest pressure (compared to water cooling). Helium purification systems have been successfully developed and include the capability for tritium recovery from the helium stream.

Helium cooling has several advantages from a reactor maintenance point of view that are important for fusion reactor designs. Visual observation is possible since helium is transparent. Since helium does not activate, only impurities are of concern with regard to coolant radioactivity. The helium circuits do not need to be isolated from ambient conditions during maintenance operations. Air can be allowed into the helium system ducting. Air could be used in some designs for residual heat removal during postulated accident conditions and during scheduled fuel changeout and transport operations, possibly making use of the circulators and heat exchangers designed for normal operation.

\section{Problems with Helium Cooling}

The disadvantages of helium cooling are summarized in Table 11-II. The principal disadvantage of all gas coolants is their low volumetric heat capacity. To achieve adequate heat removal with acceptable coolant pumping power requirements, pressures in the range of 40 to $80 \mathrm{~atm}$ appear to be needed. The heat transfer coefficient that may be obtained at reasonable flow velocities in a heliumcooled system is generally smaller than that found in liquid-cooled systems and hence the temperature differential is larger, leading to higher fuel and cladding

\section{TABLE 11-II}

\section{Disadvantages of Helium Cooling}

- Low Volumetric Heat Capacity $\left(16 \mathrm{~kJ} / \mathrm{m}^{3} \mathrm{~K}\right.$ at $5 \mathrm{MPa}$ and $500^{\circ} \mathrm{C}$ )

Modest pressure required ( $\sim 4$ to $8 \mathrm{MPa})$

Lower heat transfer coefficients, larger temperature differentials than with water or liquid metals

Significant pumping power requirements $(\sim 2$ to $5 \%$ of thermal power)

Natural circulation cooling only feasible when pressurized

- Low Neutron Attenuation (Radiation Streaming)

- Leak Tight Confinement Required

- Less Reactor Experience than with Water Reactors

- Possible Local Limitation of Helium Avarlability and/or Higher Cost 
temperatures. Because of the high volumetric flow rate needed, the power required to operate the helium circulator can be high. With the pressure drops encountered with a steam cycle power conversion system, the pumping power is on the order of 2 to $5 \%$ of the reactor thermal power. Most of this power is returned to the helium as it is compressed, and by using steam-driven circulators, the electrical conversion losses can be avoided.

Because of the low volumetric heat capacity of helium, natural circulation cooling is more difficult to achieve (refer to Chapter 10). Although natural circulation can provide adequate shutdown (afterheat) cooling when the coolant loop is pressurized, it usually cannot be counted on in the depressurized state shortly after shutdown. Afterheat cooling may not be required in fusion reactors with low activation materials. Cooling by thermal radiation could also be considered.

The low-density helium results in little neutron attenuation. Additional shielding must be provided to compensate for neutron streaming.

The propensity of helium to leak from small holes and to diffuse may prove to be a slight disadvantage, although all welded and brazed joints with thorough checking of components should prove adequate to control leakage. The leakage of tritium into the helium coolant stream on the other hand should prove less troublesome in separation than for the case of water as a coolant.

Despite the fact that gas-cooled reactor technology has been deployed commercially, and two HTGR plants, Peach Bottom and Fort St. Vrain, have been operated in the United States, experience is much less extensive than that enjoyed by water-cooled technology. A potential concern for helium-cooled systems in the mid-21 st century is the possibility of resource limitation. ${ }^{10}$ Helium is presently extracted from natural gas, which will be in increasingly limited supply in the future. Helium can be extracted from the atmosphere but at a higher cost. ${ }^{11}$ The helium produced in the fusion reactions of a fusion reactor would amount to $\sim 1 \%$ of the power conversion system helium inventory each year, which could only account for routine losses. The initial inventory will still have to be provided, however, but its costs should not have any significant effect on the total power cost.

\section{Application to Fusion Reactor Blankets}

In the application of gas cooling to fusion reactors, maximum benefit must be taken of the advantages of gas cooling and the disadvantages must be avoided as much as possible. Caution must be used in any performance comparison because the blanket designs of systems using different coolants will differ considerably. The pressure, temperature, and materials characteristics of the blankets must be adapted to the coolant choice and thus differences in blanket performance may be due to a number of different effects. Nevertheless, the nuclear performance of helium-cooled blankets can be superior to that of alternative coolants because helium is essentially transparent to neutrons.

The desire to minimize pumping power and pressure drop in a gas-cooled 
system leads to use of a relatively large coolant temperature rise, $\Delta T$, in the blanket in order to minimize the flow rate required. A minimum helium temperature rise of $\sim 100^{\circ} \mathrm{C}$ is needed to match helium and water temperature profiles in the steam generator. In blankets with metallic structures, an upper limit on $\Delta T$ of $\sim 300^{\circ} \mathrm{C}$ is imposed by materials temperature limits. The power density profile found in a blanket peaks strongly at the first wall and falls off quite rapidly with distance from the plasma, as shown in Fig. 11-4 for a helium-cooled fusion blanket design. ${ }^{12}$ The combination of steep power density profile and large coolant temperature rise calls for a radially outward coolant flow path. Coolant is brought into a plenum just behind the first wall and then flows radially outward through the blanket. This can lead to fuel material temperature profiles that are quite flat, as shown in Fig. 11-5. The first wall can also be cooled at the same time with the full flow of cold inlet coolant. This allows an acceptable first-wall temperature without the complication of additional flow paths.

Gas coolants have safety-related advantages because a total loss of coolant is not possible. Although loss-of-coolant pressure greatly reduces cooling capability, active cooling can be maintained by forced circulation of low-pressure

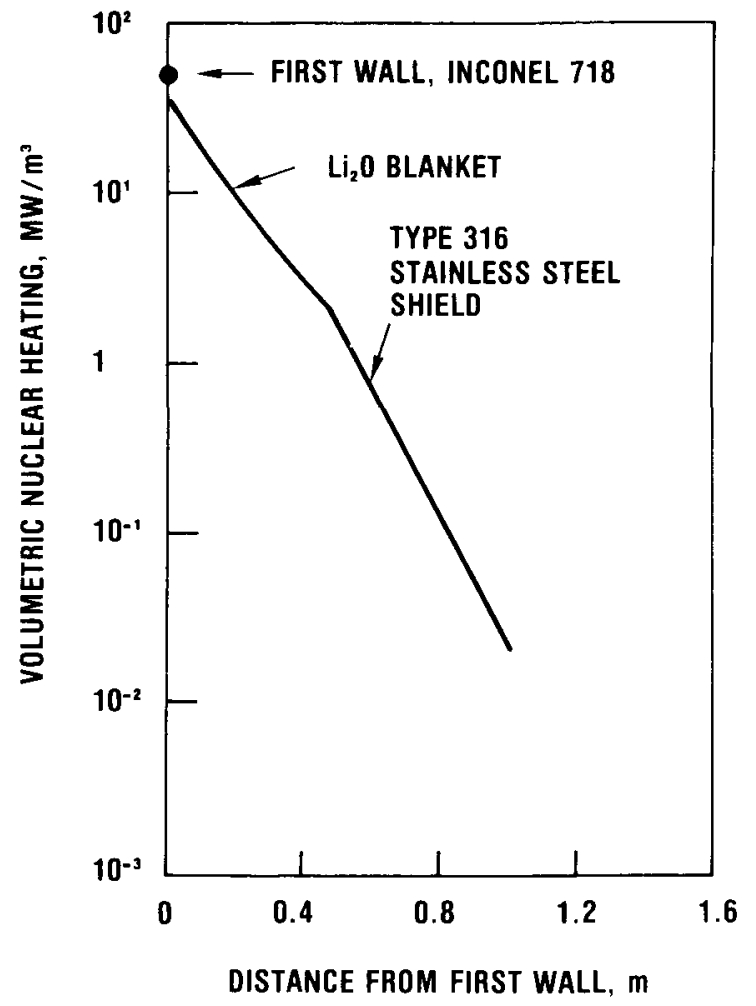

Fig. 11-4. Power density variations in a typical fusion reactor blanket (from Ref. 12). 


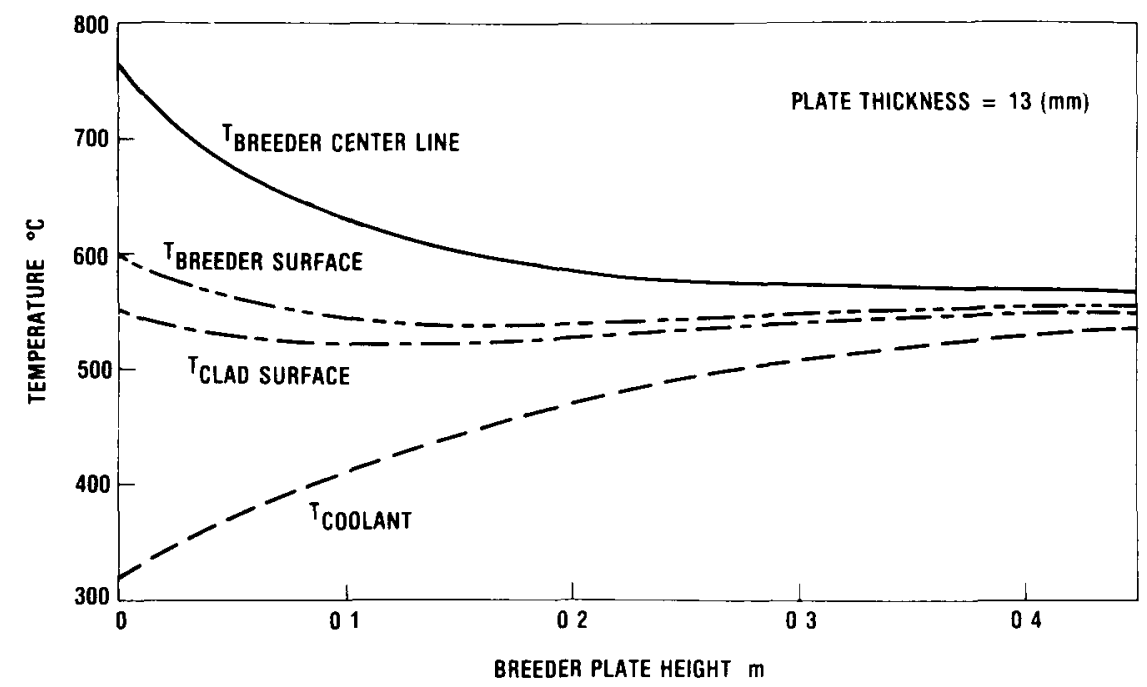

Fig 11-5 Typıcal gas-cooled blanket temperature distribution (from Ref 12)

helium or even with air, if necessary, in the event of a major coolant boundary fallure This feature may prove to be particularly important to the achievement of adequate blanket cooling system redundancy and reliability The safety advantages of a coolant that cannot change phase are expected to contribute greatly to protection against loss-of-cooling accidents This is particularly important given the awkward geometries and convoluted coolant boundary topologies generally associated with fusion reactors

An area of concern for gas-cooled fusion reactors is that of the primary coolant piping Because of the large volumetric flow rates required for gas cooling and the need to minimize pressure drop, the coolant ducting can be quite large In large gas-cooled fission reactors, the reactor and primary coolant loop ducting are contained within a prestressed concrete reactor vessel (PCRV) but the PCRV does not appear adaptable to most fusion reactor geometries As a consequence, distributed piping will be needed This raises the concerns of providing adequate space for large ducts in the fusion reactor geometry and avalability of large diameter $(Z 1-m)$ high-pressure piping Because of the low coolant density, seismic concerns appear to be manageable, despite the large duct size

\section{1-2 Design of Gas-Cooled Fusion Reactor Systems}

The energy of the fusion reactor is deposited by charged particles and electromagnetic radiation on the first wall that surrounds the plasma chamber and by the fusion neutrons in the first wall, blanket, and shield The arrangement of these components into the first-wall/blanket/shield system is shown schematically in 


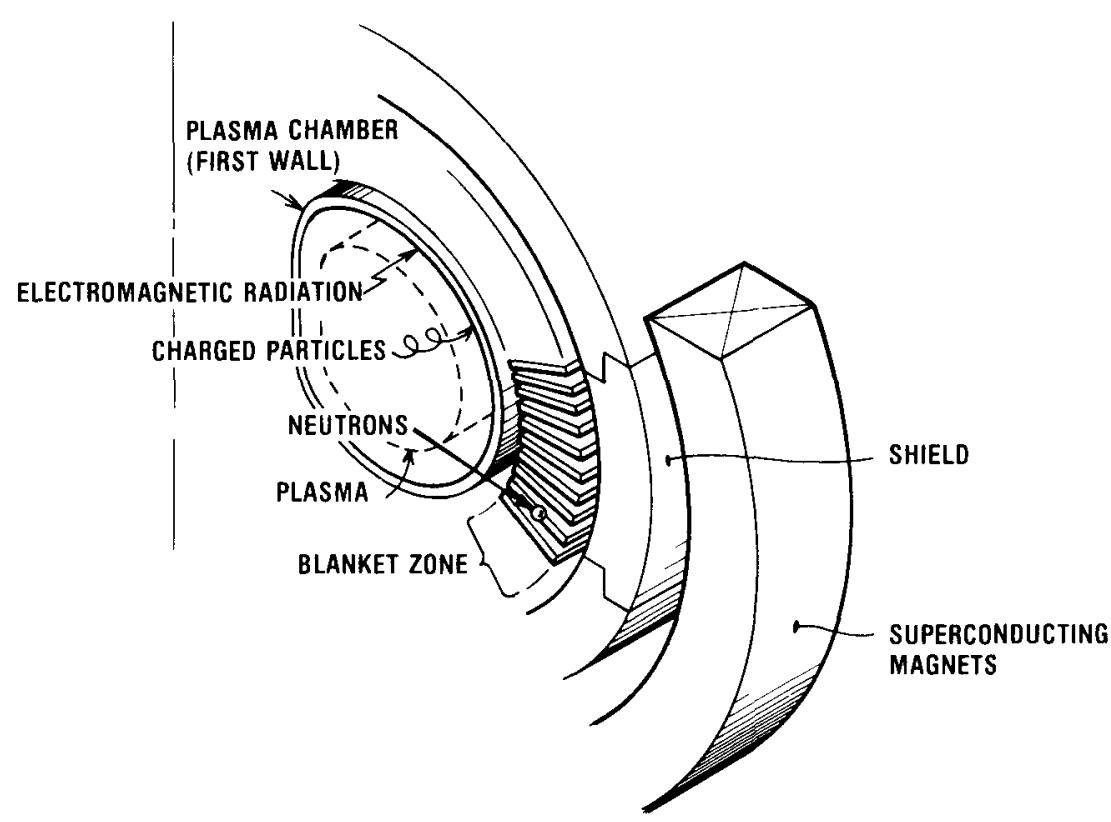

Fig 11-6 Fusion reactor first-wall/blanket/shıeld schematıc

Fig 11-6 The design of these fusion system components must be optımized according to the coolant chosen

\section{1-2A First-Wall Designs}

All of the emissions from the plasma are incident on the first wall These include low-energy electromagnetic radiation, neutrons, electrons, and the particles comprisıng the plasma including hydrogen, deutenum, tritıum, helium, and impurities The particles are either charged particles or neutral atoms Particle emissions from the first wall produced by interaction with plasma can be a major source of impurities for the plasma The design of the first wall to meet all functional requirements including adequate lifetime is one of the most difficult challenges in fusion reactor development

The energy source for the first wall is a surface heat flux from the radiation and particles, and a volumetric heat source for the neutrons About $20 \%$ of the total fusion power output appears somewhere in the first-wall region as a surface heat flux, $80 \%$ is transported via the neutrons The neutron wall load in fusion designs typically ranges from 2 to $5 \mathrm{MW} / \mathrm{m}^{2}$ A 14-MeV neutron energy flux normalized to $1 \mathrm{MW} / \mathrm{m}^{2}$ emanating from the plasma corresponds to a first-wall surface heat flux of $025 \mathrm{MW} / \mathrm{m}^{2}$ The energy deposition from the $1 \mathrm{MW} / \mathrm{m}^{2}$ neutron flux is nominally $\sim 10 \mathrm{MW} / \mathrm{m}^{3}$ and with a $10-\mathrm{mm}$ first-wall thickness this gives an equivalent heat load of $01 \mathrm{MW} / \mathrm{m}^{2}$ Thus the surface heat flux is usually 
the controlling design factor for the first wall Some systems with suppressed plasma radiation losses and localized energy deposition through divertors and limiters can reduce the first-wall surface heat load by about one order of magnitude although the volumetric source from neutrons remains

Radiation damage rates to the first wall can be high The primary 14-MeV neutron flux produces high atomic displacement damage rates in materials and, in addition, transmutation rates can be high since the neutron energy is above the threshold for many charged-particle reactions Helium generation within the firstwall material through $(n, \alpha)$ reactions is thought to be one of the most severe damage sources

The neutron slowing down and diffusion in the blanket region behind the first wall produces an additional neutron flux component, which actually accounts for $\sim 90 \%$ of the total fast flux in the first-wall region Most of the displacement damage is generated by the flux component with energies $>01 \mathrm{MeV}$ The thermal neutron flux is usually much depressed due to the high thermal neutron capture cross section of the lithium used in the blanket for tritlum breeding

Another problem is erosion of the first wall, which occurs from sputternng caused by particle impingement In the worst case $\left(10^{-2}\right.$ sputtering coefficient and 0 1-keV particle energy), erosion rates could be a millımeter every few days, which obviously is not acceptable

There are several options for reducing this erosion rate ${ }^{13}$ The flux of particles can be reduced by increasing the energy of the particles striking the wall from 01 to $10 \mathrm{keV}$, giving a factor of 100 decrease in number of particles Sputtering rates do not change as fast with energy in this range so a net gain is achievable If some means could be found to reduce the particle flux to only that required for plasma particle balance and spread them out to $100 \%$ of the plasma chamber surface, then reductions of 10000 can be projected Another option would be to reduce the particle energy below $01 \mathrm{keV}$ to a range below sputtering thresholds, this should also provide a factor of 100 reduction Utilization of a divertor to direct the particles away from the wall to an external region during either all or only part of the operating cycle would also be an effective method

\section{Steady-State Behavior}

Several design options are avalable for cooling the first wall Thermal radiation cooling can be employed with materials that operate at high temperatures As an example, the entıre first wall could be a thin liner, which would be heated on the plasma face and cooled by radiation to a suitable sink temperature on the other face Temperature limits of 1500 to $1900^{\circ} \mathrm{C}$ appear allowable for $\mathrm{SiC}$ and carbon materials and these in turn would allow neutron power flux levels of 1 to $2 \mathrm{MW} / \mathrm{m}^{2}$ on the first wall, a reasonable power density range The heat sink for this radiation-cooled first wall is usually the front face of the breeding blanket and the heat is convectively transported from there 
Convective cooling of the first wall can take on two general forms. One is a free-standing panel of a tube bank-type structure that is internally cooled. The other common approach is to incorporate the first-wall integral with the front face of the blanket. Designs for both cases have been developed.

Some advantages of the independent first wall, separate from the blanket, are a simpler design with only one function to satisfy and potentially easier replacement. It is projected that the first wall will require more frequent replacement than the blanket due to the more severe environment at the plasma interface. It thus seems desirable to avoid removal and replacement of an entire blanket module for a fault only in the first wall. On the other hand, the additional cooling liner and connections within the plasma vacuum chamber where space and coolant leakage are severely limited is a penalty that must be weighed against the other advantages.

The choice of coolant for the first wall involves the same criteria as the choice for the blanket. Helium coolant ranks high providing high-temperature materials are utilized. Candidate high-temperature materials are stainless steel, refractory metals, and carbon and $\mathrm{SiC}$ ceramic materials.

The high thermal conductivity materials such as aluminum and copper have been considered for the first wall because of the lower thermal stresses with high heat fluxes. These operate best with water cooling. A disadvantage with aluminum is that water exit temperatures are so low, $\sim 80^{\circ} \mathrm{C}$, that power conversion is not practical. This could require rejecting up to $25 \%$ of the fusion reactor power output.

The design methodology for first-wall components with surface heat flux using helium cooling is relatively straightforward. A cylindrical tube, for example, would be heated on one side only with an uneven heat source distribution over $180 \mathrm{deg}$. Temperature distributions and thermal stresses are calculated for surface and volumetric heat sources. ${ }^{14,15}$ Minimization of total stress with a suitable combination of tube wall thickness and diameter is readily done, though possible wall erosion over the first-wall operating lifetime must be taken into account.

The maximum heat flux through a tube wall may be either temperature or stress limited. In addition, radiation-induced swelling (or shrinkage), which is temperature dependent, may limit temperature gradient and therefore heat flux. Smaller tube diameters and tube wall thicknesses reduce stresses and temperatures. It is found that 5 - to $10-\mathrm{mm}$-diam tubes with wall thicknesses of a few millimeters can accommodate suitable heat fluxes with acceptable temperature and stress limits. Heat flux versus temperature for convective cooling with helium is shown in Fig. 11-7 with the temperature limits for some commonly considered first-wall materials. Note especially the very much higher heat fluxes for $\mathrm{SiC}$ and carbon.

We conclude that suitable designs can be made for steady state using presentday materials for convectively cooled first walls with the helium coolant at an acceptable pressure (20 to $80 \mathrm{~atm}$ ), a pressure drop $\leqslant 1 \mathrm{~atm}$, and pumping power $\leqslant 5 \%$ of thermal power. 


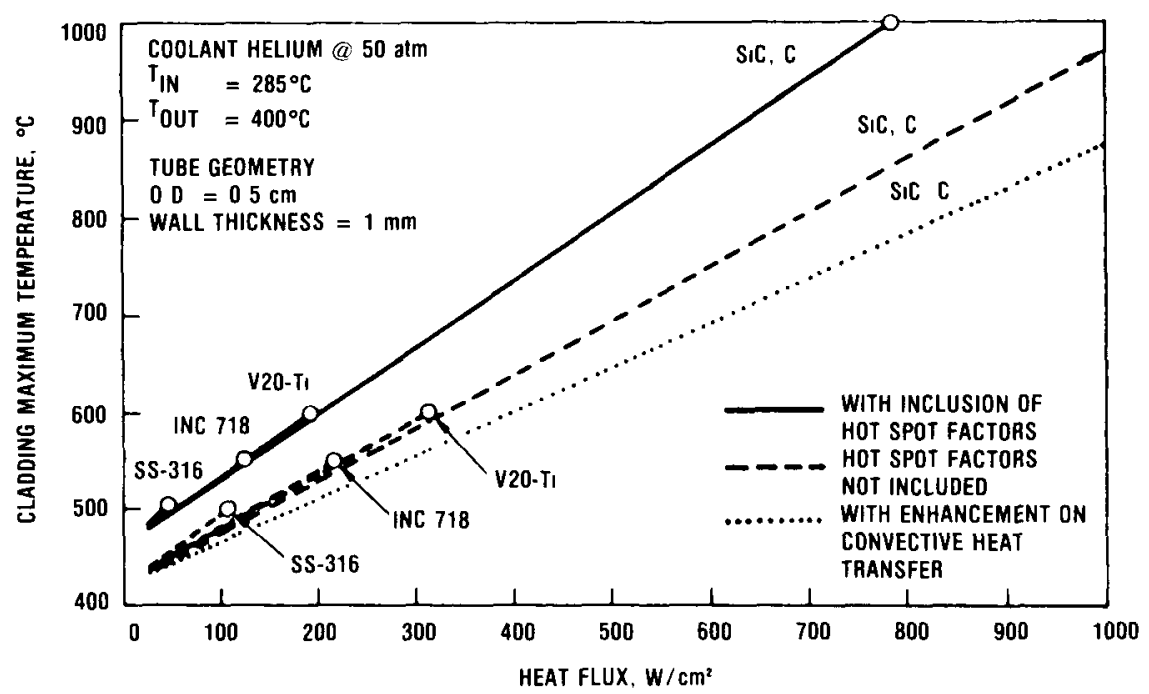

Fig. 11-7. Maximum surface temperature as a function of heat flux for different materials (from Ref. 16).

\section{Transient Behavior}

First-wall temperature responses during the plasma burn were determined in many of the blanket studies. ${ }^{17-20}$ The wall temperature depends on several factors including: heat load, coolant inlet temperature, mass flow rate, and coolant properties; and the thermal characteristics of the wall. Due to its low thermal capacitance, the first wall responds quickly to changes in heat load and surface conditions. This reponse is strongly influenced by thermal lag in the coolant.

For a helium-cooled wall, Fig. 11-8 shows typical variations-over a burn cycle-of the maximum wall temperature and the temperature drop across the wall. The temperature drop across the wall results in thermal stress, and cyclic thermal stress can be the life-limiting factor for the first wall due to cyclic fatigue or crack propagation. These results are strongly design dependent, and Table 11-III summarizes the findings from several design studies. The heat flux capabilities of first-wall tube arrays are compared for helium- and water-cooled designs with cyclic stresses for combinations of wall temperature limits and maximum fatigue life cycles; heat fluxes of 0.5 to $1 \mathrm{MW} / \mathrm{m}^{2}$ on 1 - to 2-mm-thick stainless steel tubes appear to be acceptable ${ }^{15}$ and lifetimes corresponding to $20 \mathrm{MW}-\mathrm{yr} / \mathrm{m}^{2}$ can be achieved.

In summary, the thermal behavior of the first wall during normal transient operation is critically important to wall lifetime in pulsed, magnetically confined reactors, and is determined by the strong interplay between the coolant, wall, and blanket and the plasma burn cycle. 


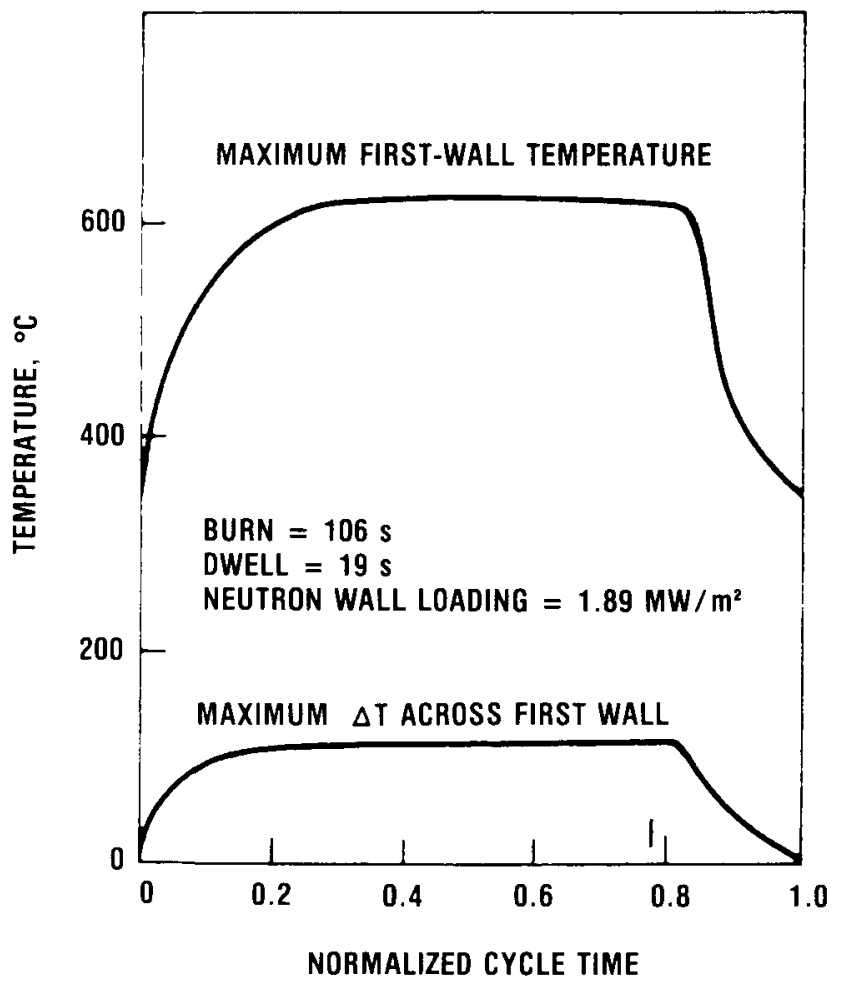

Fig. 11-8 First-wall temperature variations for helium-cooled wall with a burn time of $106 \mathrm{~s}$, a dwell tıme between burns of $19 \mathrm{~s}$, and a wall load of $1.3 \mathrm{MW} / \mathrm{m}^{2}$ (from Ref. 18)

TABLE 11-III

Transient Responses of First Walls in Pulsed Reactors

\begin{tabular}{|c|c|c|c|c|c|c|}
\hline Coolant & $\begin{array}{c}\text { Wall } \\
\text { Load } \\
\left(\mathrm{MW} / \mathrm{m}^{2}\right)\end{array}$ & $\begin{array}{l}\text { Neutron } \\
\text { Burn } \\
\text { Time } \\
\text { (s) }\end{array}$ & $\begin{array}{c}\text { Dwell } \\
\text { Time } \\
\text { (s) }\end{array}$ & Material & $\begin{array}{c}\text { Max/Min } \\
\text { Surface } \\
\text { Temperature } \\
\left({ }^{\circ} \mathrm{C}\right)\end{array}$ & $\begin{array}{c}\text { Max/Min } \\
\text { Wall } \Delta T \\
\left({ }^{\circ} \mathrm{C}\right)\end{array}$ \\
\hline Helıum $^{a}$ & 13 & 106 & 19 & Inconel 718 & $620 / 350$ & $122 / 13$ \\
\hline Helium $^{b}$ & 40 & 1140 & 60 & $\begin{array}{c}\text { Type } 316 \\
\text { stainless steel }\end{array}$ & $452 / 200$ & $71 /<1$ \\
\hline $\mathrm{H}_{2} \mathrm{O}^{\mathrm{c}}$ & 10 & 65 & 15 & $\begin{array}{c}\text { Type } 316 \\
\text { stainless steel }\end{array}$ & $402 / 321$ & $48 / 2$ \\
\hline Bolling $\mathrm{H}_{2} \mathrm{O}^{\mathrm{d}}$ & 43 & 225 & 20 & Titanium alloy & $400 / 300$ & $100 / 0$ \\
\hline
\end{tabular}

${ }^{\mathrm{a}}$ From Ref 18

${ }^{b}$ From Ref 19

cFrom Ref 20

${ }^{\mathrm{d}}$ From Ret 17 


\section{1-2B Blanket Designs}

The fusion neutrons emitted by the plasma must be slowed down and captured in order to recover their kinetic energy, breed tritium, and protect the magnets and other reactor systems. Capture of the neutrons occurs in the blanket and shield that surround the fusion plasma.

The fusion blanket is a relatively complex structure that has to fulfill three basic functions: generate tritium for the D-T fuel cycle, capture the heat generated in the blanket zone and deliver it efficiently to a power generation system, and aid in the attenuation of neutrons and gamma radiations. The shield is a much simpler structure that has the function of protecting the superconducting magnets from radiation damage and providing shielding for the reactor personnel and the general public. The maximum volumetric power generated in the shield is about two or three orders of magnitude lower than that generated in the blanket; thus, the heat-transfer design in the shield is much simpler and is not considered.

\section{General Design Considerations}

In the design of a fusion reactor blanket, the following issues must be considered and are of particular concern for helium-cooled blankets.

1. Adequate tritium breeding. For a D-T fuel cycle reactor, the breeding of tritium from lithium or a lithium compound is essential. The average tritium breeding ratio, which can be defined as the ratio of the total number of tritons generated in the blanket to the number of tritons consumed in the fusion reaction must be in the range of 1.05 to 1.10 . The required local tritium breeding ratio for a particular design will depend on the fraction of the plasma chamber surface covered by the breeding blanket and the loss of tritium in the extraction cycle in the blanket. The amount of structural materials in the blanket zone must be minimized to reduce parasitic capture of neutrons.

2. Efficient energy recovery. The nuclear heat in a blanket has to be extracted and transferred to a power conversion system. The temperature levels in the blanket are limited by the temperature limits for the structural ${ }^{21}$ materials, breeding materials, and coolant. The coolant outlet temperature must be maximized within these limits, while the pumping power required must be minimized by careful attention to the coolant pressure drop around the primary loop. Since the low volumetric heat capacity of helium results in a large volumetric flow rate, careful attention must be given to keeping the pressure drop small.

3. Good shielding property. A secondary, yet important, function of the blanket is its use as a part of the reactor neutron and gamma shield system to supplement the shield behind the blanket. Since helium is transparent to neutrons, helium-cooled blankets must be designed with minimum void fraction, and ducting must be arranged to reduce neutron streaming. Because of space restrictions, especially on the in-board side of a tokamak plasma, the design must aim at the reduction of overall blanket and shield thickness. 
4. Sound structural design. Besides designing for all normal loads during the lifetime of the blanket (for helium cooling, the coolant pressure load is probably the largest), the critical questions of material property degradation from radiation damage, the effect of magnetically induced loads, and the effect of earthquake loads have to be considered. The front of the blanket will experience a very high fluence of fast neutrons, $\sim 1$ to $5 \times 10^{26} \mathrm{n} / \mathrm{m}^{2}$ per year, and many materials will experience significant swelling due to radiation damage. Careful and ingenious designs are usually required to reduce the effect of neutron-induced swelling of metallic structural elements in order to increase blanket life. Furthermore, the fraction of structural material in the blanket has to be minimized in order to reduce parasitic neutron capture.

5. Ease of maintenance. Because of radiation damage to the fusion reactor, the blanket maintenance and replacement of blanket modules must be as simple as possible while still satisfying all the structural, vacuum boundary, and geometric constraints.

6. Materials considerations. Even though material damage data from fusion neutrons are not available, data from fission reactor experience show that radiation damage will be a major concern. Materials selection must include consideration of the blanket lifetime. This includes lifetime considerations for structural and breeding materials, and required electrical and/or thermal insulation materials. Compatibility between all blanket materials at their interfaces has to be considered in order to increase blanket life and reduce the chances of radioactivity release to the public. This is an area of major advantage for helium since it is chemically inert.

7. Safety concerns. Fusion power will produce radiations and therefore will involve radioactive materials: tritium fuel and activation products from the interaction of the fusion neutrons with the materials in the first-wall blanket and shield. The decay of these radioactive materials will produce some degree of afterheat. In optimizing safety and minimizing hazard to the workers and the general public, the bred tritium must be confined, the potential hazard from the coolant should be minimized, and the amount of induced activity from blanket materials should also be minimized. Again, helium has unique advantages here since it does not activate, does not burn, and can never be completely lost in an accident. Circulation of depressurized helium/air will guarantee cooling capability at all times.

8. Economy. All costs of the selected blanket have to be included: capital cost, operation, maintenance, decommissioning, and disposal costs. To minimize the total cost, it is important that the blanket power density be as high as possible and that the blanket use simple designs.

\section{Helium-Cooled Blanket Design Options}

Using helium as a coolant, the thermal-hydraulic problems involved in the blanket design are important and will impact the other features of the design. If these problems can be solved satisfactorily, helium offers some clear advantages 
over other candidate coolants such as liquid lithium, molten salt, and water. Helium is not subject to magnetohydrodynamic effects, which cause additional pumping power requirements, reduce the heat transfer efficiency, and may exacerbate corrosion problems. A major advantage of helium is its chemical inertness. All of the candidate breeding materials are chemically reactive with water.

However, helium has some disadvantages. It requires high volumetric flow rates. The consequences are the requirement for larger coolant tubes in order to keep the pumping power within reasonable limits. The heat transfer characteristics are poorer than those of the other candidate coolants. The design for a heliumcooled fusion reactor will look quite different from a water-cooled reactor. It will be characterized by the larger coolant manifolds. A major emphasis on the key thermal-hydraulic design problems is needed to use the clear advantages and to minimize the disadvantages of helium as a fusion blanket coolant.

Inlet/outlet temperatures selection: Generally, a lower coolant inlet temperature permits a higher neutron wall load for a given structure temperature design limit. A low helium inlet temperature also allows a larger coolant temperature increase from the blanket inlet to the outlet, which is important because a large $\Delta T$ results in a smaller coolant flow rate and smaller tubes and requires less pumping power. The lowest inlet temperature limit is given by the steam generator, which should operate under economic conditions. To have an acceptable pinch point temperature difference in the steam generator, the minimum helium temperature is limited to $\sim 250^{\circ} \mathrm{C}$.

To reach a maximum thermal conversion efficiency, the coolant outlet temperature from the blanket should be as high as possible. The outlet gas temperature is limited by the maximum allowable structural material temperatures. Unfortunately, these limits are too low to take advantage of the full potential of helium as a blanket coolant. By arranging the coolant flow path to go from the highest to the lowest heat-loaded parts of the blanket, the temperature drop between structure and coolant becomes small in the gas outlet region. Therefore, the coolant outlet temperature can be as high as $\sim 550^{\circ} \mathrm{C}$, the maximum structure temperature design limit for most structural materials being considered for fusion blankets. The resulting maximum gas temperature rise from the blanket inlet to the outlet is $\sim 300^{\circ} \mathrm{C}$. For a typical $3400-\mathrm{MW}(\mathrm{t})$ fusion reactor design, these conditions require a helium flow rate of $\sim 2400 \mathrm{~kg} / \mathrm{s}$. Development of higher temperature materials, such as ceramics, would allow for higher temperatures and more efficiency with helium cooling.

Pressure level selection: The impact of the coolant pressure level on the blanket performance is very complex and also depends on the chosen design concept. The pressure level primarily affects these blanket characteristics: pumping power, space requirements for manifolding, wall thicknesses, neutronics impact of the structure, and helium leakage.

The pumping power for helium is almost inversely proportional to the coolant pressure squared. Therefore, from this point of view, a pressure level as high as 
possible is desired. The space requirements for manifolding and thus the overall blanket thickness can also be reduced by a higher coolant pressure.

The wall thickness of the tubes, the pressure vessel, and the first wall will increase with an increasing coolant pressure level. The first-wall thickness allowed by thermal stress will be a strong limiting factor for the maximum allowable coolant pressure. The required larger first-wall thickness for higher pressures causes larger thermal stresses. If the wall thickness exceeds a certain value, the thermal stresses rise more than the stresses caused by the pressure load decline for a given pressure level. For a typical tokamak design, the coolant pressure is limited to $\sim 8 \mathrm{MPa}$ or less to keep the stresses in the first wall within the design limit. Coolant pressures of $\sim 3$ to $5 \mathrm{MPa}$ have been used in typical helium-cooled fusion reactor design studies. With these pressures, the pressure drop through a fusion blanket and its associated manifolds and piping can be kept to below $100 \mathrm{kPa}$. The primary coolant ducting and steam generator will add $\sim 40$ and $30 \mathrm{kPa}$, respectively, for a total of $\$ 170 \mathrm{kPa}$. This pressure drop will require a pumping power of $\sim 2.5 \%$ of the reactor thermal power.

Coolant flow path: It is important to put the cold (inlet) coolant near the first wall where the heat load is highest. Similarly, because the $\Delta T$ across the blanket is large with helium in order to minimize the required flow rate, pressure drop, and pumping power, the hot outlet coolant must be kept toward the back of the blanket where the heat load is low. These considerations dictate the use of radial outward coolant flow for helium-cooled designs.

In the design of a fusion reactor blanket, two basic approaches can be taken when helium is used as the coolant. They are the high-pressure module and lowpressure approaches, as illustrated in Figs. 9a and 9b.

Figure $9 \mathrm{a}$ illustrates a high-pressure module design, with the high-pressure boundary at the outer wall, withstanding a helium pressure of $\sim 50 \mathrm{~atm}$. It is a relatively simple design but it has the disadvantage of requiring a relatively thick,
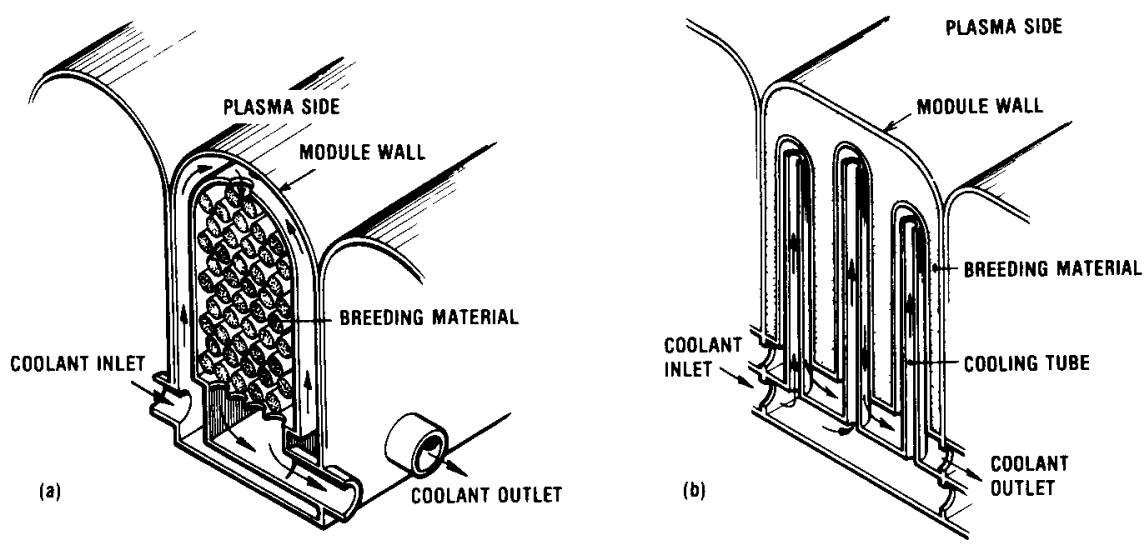

Fig. 11-9. Fusion blanket (a) high- and (b) low-pressure module schematics. 
highly stressed, metallic wall. The second zone is the breeding material zone; it can consist of solid breeders (for example $\mathrm{Li}_{2} \mathrm{O}$ ) in the form of plates, rods, or balls or of liquid breeders (lithium or $\mathrm{LiPb}$ ) contained in tubes-depending on the selection of tritium extraction and on the detailed hydraulics design. Blanket designs that use this approach are described in Refs. 12, 18, and 21. A typical helium-cooled blanket design using plate-type breeder geometry is shown in Fig. 11-10. The coolant helium goes to the front of the blanket module along the module sides; turns around at the top; and then goes through the clad breeder plates and leaves at the back of the module. This blanket is discussed further in Sec. 11-3A. Figure 9b illustrates a low-pressure module blanket design where the high-pressure helium at $\sim 5 \mathrm{MPa}$ is contained in small reentrant pressure tubes. The advantage of this design is its requirement of a minimum metallic structure, which reduces parasitic absorption and would reduce the concern of waste disposal. The disadvantage of this design is its complicated plenum connections. The breeding material zone of the low-pressure module can be sintered solid breeders, but it can also be stationary liquid metals like lithium or LiPb eutectic.

At present, the most commonly proposed structural material is stainless steel. The most commonly considered solid breeding materials are $\mathrm{Li}_{2} \mathrm{O}$ and $\mathrm{LiAlO}_{2}$. The latter would require a neutron multiplier like beryllium to increase the blanket neutron population. Liquid lithium is a prime candidate for a liquid breeder but introduces concerns because of vigorous chemical reactions with air or water. The $\mathrm{Li}_{17} \mathrm{~Pb}_{83}$ eutectic appears attractive as a liquid breeding material because of its adequate tritium breeding and its low reactivity with water, being more similar to lead than to lithium metal.

\section{1-2C Safety Issues}

In the design of fusion reactors, as in the design of fission reactors, the safety of the public and the plant personnel is of paramount importance. Fusion is a nuclear reaction and results in the production of nuclear radiation and the potential for production of radioactive materials. Unlike fission, where the reaction products are inevitably radioactive, the primary D-T fusion reaction itself produces no radioactive products. The fusion neutrons, however, will activate structural reactor materials, producing radioactive materials. These materials are hazardous because of their radioactivity, and also, as a result of their decay, produce afterheat that could act as a mechanism for release of the radioactivity by melting or vaporization of the reactor materials-if no cooling were available. Because the choice of materials can greatly influence the amount of radioactivity produced, there are two complementary approaches that can be taken for fusion reactor safety. The first is to reduce the quantity of radioactivity by the choice of the reactor materials; the second is to provide engineered safety systems to protect against accidents that might release the radioactive materials. The use of helium cooling can contribute beneficially to both of these approaches. 


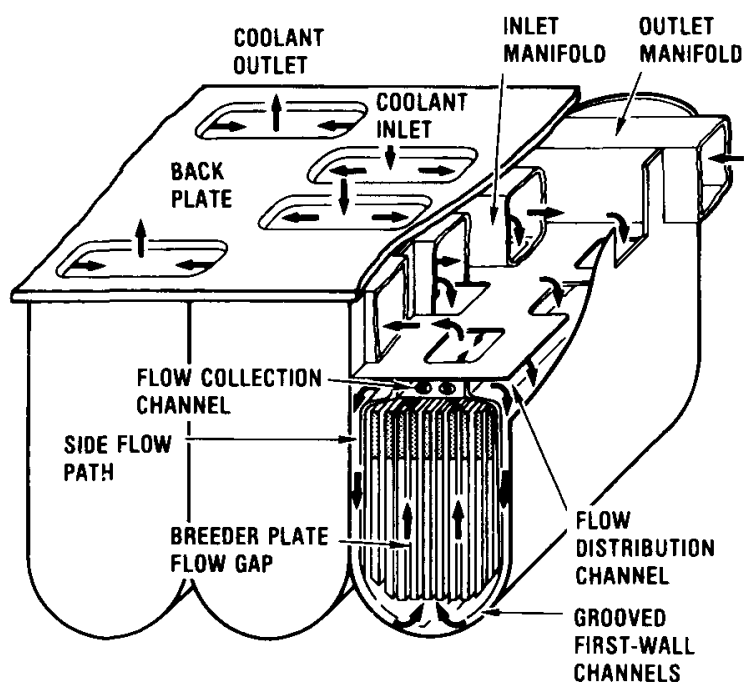

(a)

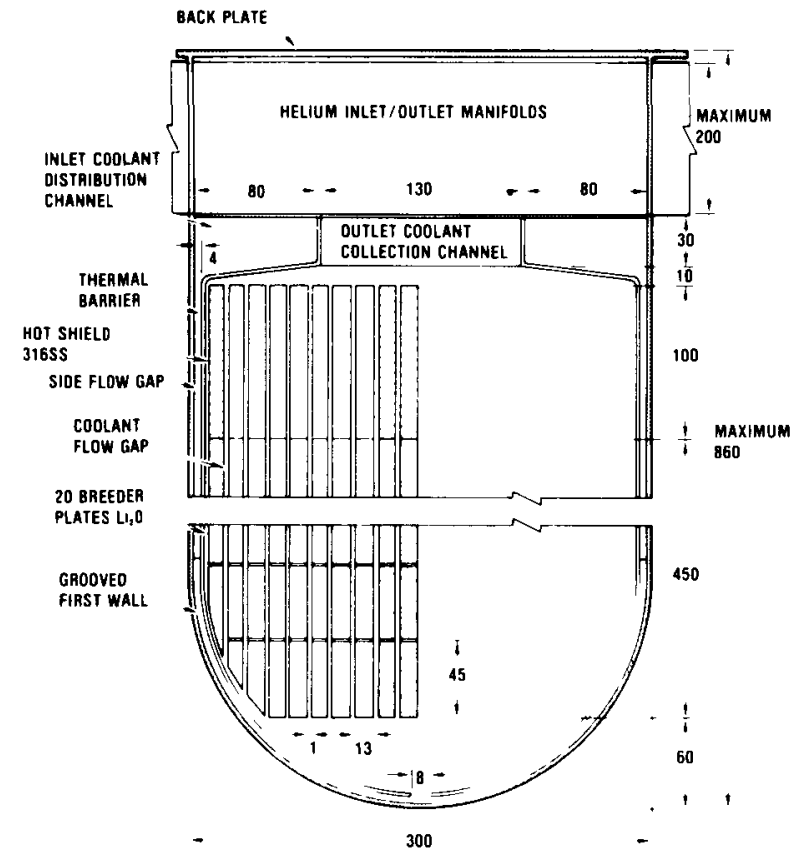

ALL DIMENSIONS IN MILLIMETEAS

(b)

Fig. 11-10. A fusion reactor (a) blanket module and (b) blanket module cross section. 


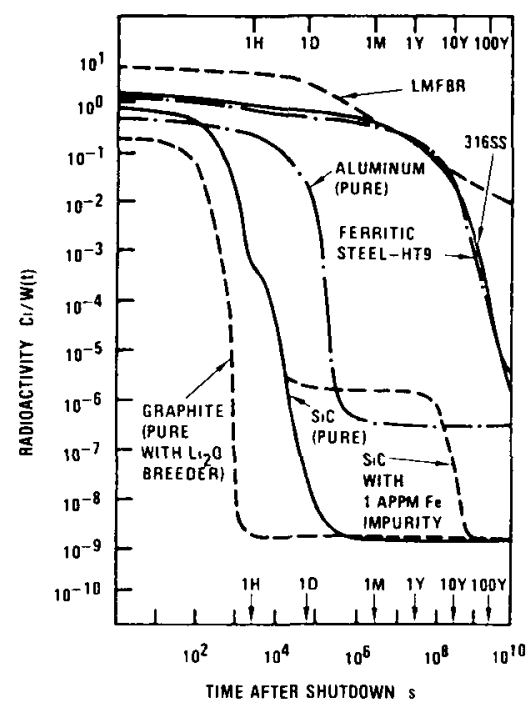

(a)

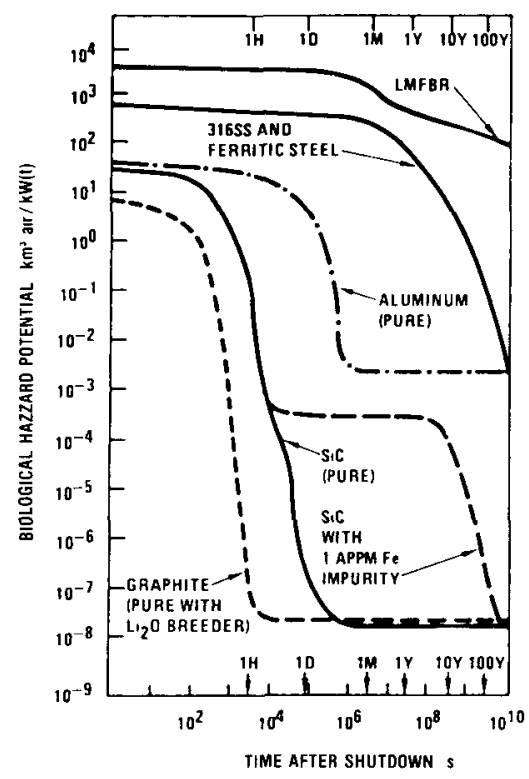

(b)

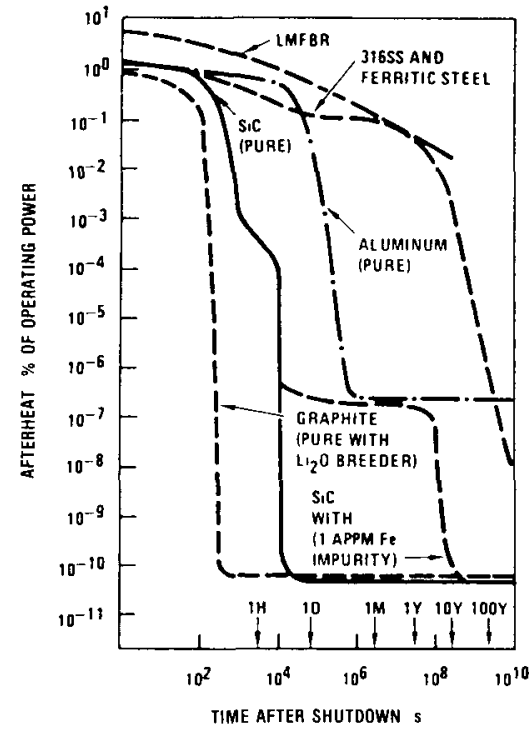

(c)

Fig. 11-11. (a) Radioactivity, (b) biological hazard potential, and (c) afterheat for liquid-metal fast bieeder reactors (LMFBRs) and fusion reactors with various structural materials (from Ref. 22). 


\section{Reduction of Radioactivity}

The radioactivity generated through neutron captures depends on the choice of construction materials used. ${ }^{22}$ With Type 316 stainless steel, for example, the activation is within a factor of 10 of the fission products activation from a fission reactor for times up to $\sim 50 \mathrm{yr}$ after shutdown. With low-activation materials such as carbon and $\mathrm{SiC}$, primary radioactivities are reduced by a factor of $10^{9}$. In fact, impurities with a practical limit of a few parts per million limit the reduction to $\sim 10^{6}$. The amount of radioactivity is directly reflected in problems of decay heat removal, biological hazards from potential releases of radioactive materials to the environment, long-term waste disposal, and personnel access limitations to the fusion reactor for maintenance.

Figure 11-11 shows the radioactivity, biological hazard potential, and afterheat as a function of time after shutdown for a $3000-\mathrm{MW}$ fusion reactor. ${ }^{22}$ Three general categories of materials can be identified: conventional materials like stainless steel give values about a factor of 10 less than those of a fission reactor; reduced activation materials like vanadium offer a further reduction of about a factor of 5 at shutdown and then decay to innocuous levels in a few decades, which would greatly reduce waste management concerns; and low-activation materials like aluminum, magnesium, and silicon alloys and the ceramics (graphite and $\mathrm{SiC}$ ) offer further reduction at shutdown, and decay to innocuous levels within a few hours to a few days after shutdown. This rapid decay could make significant improvement in the safety characteristics of the reactor and, if low impurity levels can be achieved, could allow contact maintenance over the entire reactor within a few weeks after shutdown.

The decay heat effects are illustrated ${ }^{22}$ in Table 11-IV for several candidate materials under adiabatic conditions. The first row shows that neither carbon nor $\mathrm{SiC}$ will melt and that cooling following shutdown is not necessary. The metals, on the other hand, will melt in times ranging from minutes to hours. The second row shows the time at which cooling may be terminated with no further concern for melting. Note especially that stainless steel requires cooling for $30 \mathrm{yr}$ to prevent melting. Thus there is a great incentive to consider low-activation materials for fusion reactor application.

Helium coolant can contribute to these approaches to reduce radioactivity. Helium itself does not activate and is chemically compatible with the reduced activation materials. It is ideally suited for the high-temperature ceramics and with strict impurity control is well suited for use with vanadium, which is very sensitive to oxidization. Because of the low temperature limits of aluminum alloys and the high temperatures needed to use helium effectively, helium is not well-suited to aluminum alloys.

\section{Engineered Safety Systems}

The second, complementary approach to fusion reactor safety is the conventional one of providing engineered safety systems to prevent accidents from oc- 
TABLE 11-IV

Post-Shutdown First-Wall Heating Characteristics

(1.5 MW/ $/ \mathrm{m}^{2}$ wall loading; $2 \mathrm{yr}$ of operation)

\begin{tabular}{|c|c|c|c|c|c|}
\hline & \multicolumn{5}{|c|}{ First-Wall Material } \\
\hline & Graphite & $\mathrm{SIC}$ & Alumınum Alloy & $\begin{array}{c}\text { Type } 316 \\
\text { Stainless Steel }\end{array}$ & Titanium Alloy \\
\hline Adıabatıc meltdown tıme & $\infty$ & $\infty$ & $17 \mathrm{~min}$ & $2 \mathrm{~h}$ & $3 \mathrm{~h}$ \\
\hline Post-shutdown cooling cutoff time & 0 & 0 & 7 days & $30 \mathrm{yr}$ & $1 \mathrm{yr}$ \\
\hline Afterheat at shutdown $\left(\mathrm{MW} / \mathrm{m}^{3}\right)$ & $\mathrm{N}_{11}$ & 09 & 11 & 06 & 04 \\
\hline Melting point $(\mathrm{K})$ & $\begin{array}{c}3370 \\
\text { (sublimes) }\end{array}$ & $\begin{array}{c}2900 \\
\text { (decomposition) }\end{array}$ & 890 & 1700 & 1920 \\
\hline Operatıng temperature $(\mathrm{K})$ & 1500 & 1300 & 423 & 673 & 673 \\
\hline Specific heat, $C_{p}(\mathrm{~J} / \mathrm{kg} \mathrm{K})$ & 1900 & 1286 & 963 & 460 & 565 \\
\hline Density $\left(\mathrm{kg} / \mathrm{m}^{3}\right)$ & $2 \times 10^{3}$ & $32 \times 10^{3}$ & $27 \times 10^{3}$ & $78 \times 10^{3}$ & $44 \times 10^{3}$ \\
\hline
\end{tabular}


curring and to mitigate their consequences. This approach includes use of multiple barriers between the hazard and the environment, use of redundant cooling systems, etc. Helium has both advantages and disadvantages in this area.

A disadvantage of helium is its low density, especially under depressurized conditions. The pumping power required to circulate the coolant of density $\rho$ with a mass flow rate $\dot{m}$ can be written approximately:

$$
P_{p} \sim \frac{\dot{m}^{3}}{\rho^{2}},
$$

so large auxiliary pumps are needed for pumping low-density helium. Natural circulation uses the density difference, $\Delta \rho$, between heat source and heat sink, separated by a height $h$, to provide a driving force for continued circulation:

$$
\Delta p=g \Delta \rho(T) h .
$$

Because of helium's low density, an adequate pressure difference, $\Delta p$. cannot be achieved with reasonable heights in the depressurized state.

An important safety advantage of helium is the fact that it cannot change state or be completely lost. Fusion reactors will inevitably have a complex geometry with the blanket surrounding the plasma chamber and will have distributed piping from the reactor to the power conversion system. There will thus be the possibility for a pressure boundary failure. In the event of a pipe break or firstwall rupture, the helium coolant may become depressurized. But a complete loss of coolant is not possible. Auxiliary circulators can be provided that can circulate an adequate amount of helium or even air to remove afterheat in either the pressurized or depressurized mode. Coolant will continue to be circulated through the system, across pipe breaks if necessary, assuring adequate afterheat removal. Because of the awkward geometries associated with fusion reactor blanket coolant paths, this safety advantage is expected to be important.

\section{Summary of Safety Aspects}

The safety analysis of fusion systems is in a preliminary state, as is consistent with the present state of fusion reactor design. It is clear, however, that the hazardous inventories and afterheat levels are at least an order of magnitude lower than those associated with fission systems. If alternative materials are used to reduce the level and duration of radioactivity, still further advantage may be gained. By using conventional engineered safety systems, a very safe reactor may be designed. Indeed, the environmental and safety advantages of fusion have been raised as a primary reason for its development. ${ }^{1}$ Use of a helium coolant will be beneficial to both radioactivity reduction and design of engineered safety systems.

\section{1-3 Applications of Fusion Energy}

Fusion is an energy source with virtually limitless resources-the deuterium in the oceans. Because the energy released from the fusion reaction is primarily 
TABLE 11-V

Design Data for Fusion Reactor Studies

\begin{tabular}{|c|c|c|c|c|c|c|}
\hline & DEMO & STARFIRE- $\mathrm{H}_{2} \mathrm{O}$ & STARFIRE-Helium & FRM & $\begin{array}{c}\text { MRFRM } \\
\text { Aluminum Alloy }\end{array}$ & MRR \\
\hline Year published & 1978 & 1980 & 1981 & 1981 & 1981 & 1982 \\
\hline References & 18 & 21 & 12 & 23 & 24 & 25 \\
\hline Net electrical power $[\mathrm{MW}(\mathrm{e})]$ & 307 & 1200 & 1200 & 157 & 393 & 90 \\
\hline Reactor configuration & Torus & Torus & Torus & Cylınder & Cylınder & Cylinder \\
\hline $\begin{array}{l}\text { First-wall radius or } \\
\text { plasma } 1 / 2 \text { width (m) }\end{array}$ & 127 & 194 & 194 & 065 & 2 & 125 \\
\hline Plasma shape/configuration & Doublet & D-shape & D-shape & Compact torus & Compact torus & Compact torus \\
\hline Structural material & Inconel 718 & $\mathrm{PCA}^{\mathrm{a}}$ & Inconel 718 & Inconel 718 & $\begin{array}{l}\text { Alumınum alloy } \\
+\mathrm{SIC}_{1}\end{array}$ & $\mathrm{~S}_{1 \mathrm{C}}$ \\
\hline Breedıng materıal & $\mathrm{L}_{1} \mathrm{~Pb}_{2}$ & $\alpha-\mathrm{L}_{1} \mathrm{~A}_{10}$ & $\mathrm{~L}_{2} \mathrm{O}$ & $\mathrm{L}_{2} \mathrm{O}$ & $\mathrm{L}_{2} \mathrm{O}$ & $\mathrm{L}_{2} \mathrm{O}$ \\
\hline Peak neutron wall loading $\left(\mathrm{MW} / \mathrm{m}^{2}\right)$ & 16 & 36 & 40 & 61 & 63 & 40 \\
\hline Tritium breedıng ratıo & 104 & 12 & 12 & 116 & 103 & 109 \\
\hline Blanket energy multuplication & 107 & 19 & 111 & 111 & 105 & 119 \\
\hline $\begin{array}{l}\text { Coolant } \\
\text { inlet temperature }\left({ }^{\circ} \mathrm{C}\right) \\
\text { outlet temperature }\left({ }^{\circ} \mathrm{C}\right) \\
\text { coolant pressure }(\mathrm{MPa})\end{array}$ & $\begin{array}{l}\text { Helium } \\
275 \\
585 \\
5\end{array}$ & $\begin{array}{c}\text { Pressurized } \mathrm{H}_{2} \mathrm{O} \\
280 \\
320 \\
152\end{array}$ & $\begin{array}{l}\text { Helium } \\
250 \\
550 \\
5\end{array}$ & $\begin{array}{l}\text { Helium } \\
357 \\
585 \\
56\end{array}$ & $\begin{array}{l}\text { Helium } \\
316 \\
686 \\
28\end{array}$ & $\begin{array}{l}\text { Helium } \\
417 \\
750 \\
28\end{array}$ \\
\hline Structural material, $T_{\max }\left({ }^{\circ} \mathrm{C}\right)$ & 600 & $<423$ & 550 & 600 & 687 & 829 \\
\hline Power conversion system & Helıum/steam & PWR type & Helıum/steam & Helıum/steam & Heltum/steam & $\begin{array}{l}\text { Closed-cycle } \\
\text { gas turbme }\end{array}$ \\
\hline Thermal cycle efficiency & $39 \%$ & $36 \%$ & $39 \%$ & $39 \%$ & $35 \%$ & $37 \%$ \\
\hline
\end{tabular}

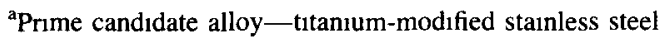


in the form of highly energetic neutrons, the potential exists for applications that make use of these neutrons for additional fission reactions or for capture and recovery of the kinetic energy that they carry. Electricity may be generated from fusion-produced heat with conventional thermal plants. In addition, the neutrons may be used to breed fissile fuel for fission reactors and also to obtain very high temperature process heat. These applications are described in this section.

\section{1-3A Electricity Production}

Table II-V summarizes the parameters of some electricity-producing fusion reactors. All of them are cooled by helium except the STARFIRE- $\mathrm{H}_{2} \mathrm{O}$ design, which is cooled by pressurized $\mathrm{H}_{2} \mathrm{O}$.

The Doublet demonstration power reactor (DPR), which is illustrated in Fig. $11-12$, is a power reactor designed to demonstrate all the technologies required for a prototype commercial reactor. It has a Doublet plasma, the shape of which is maintained by a set of field-shaping coils close to the plasma chamber. The tritium breeding material is $\mathrm{Li}_{7} \mathrm{~Pb}_{2}$. The reactor blanket modules are pressurized

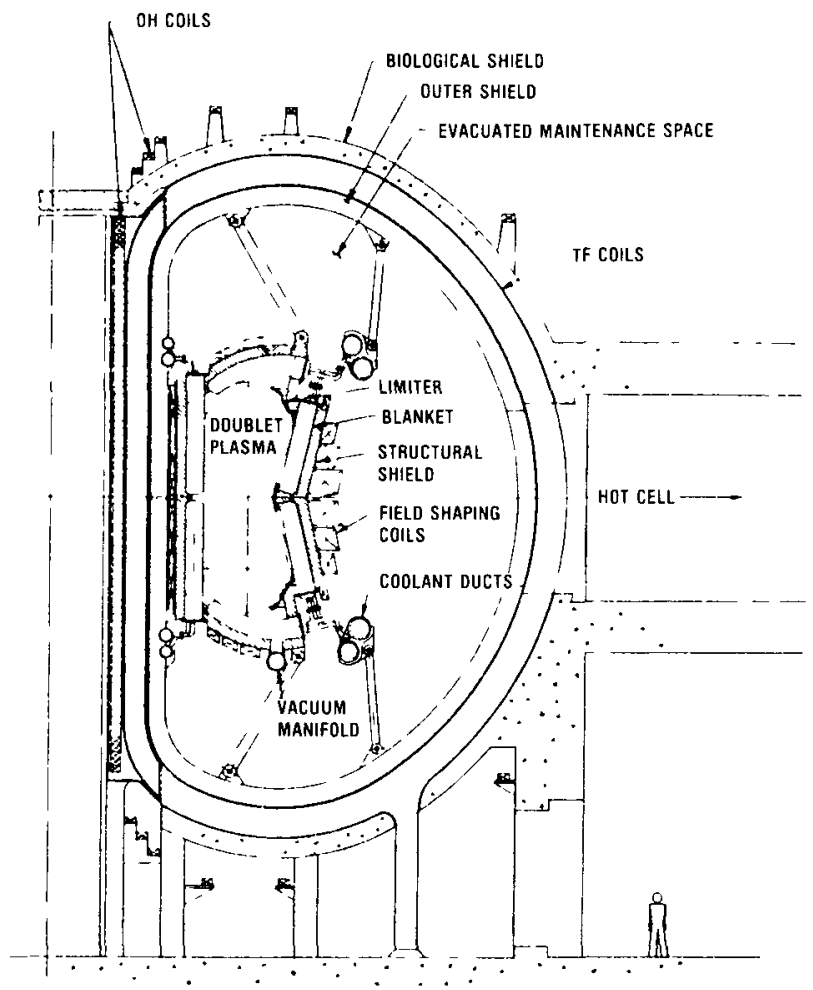

Fig. 11-12. General arrangement of the Doublet DPR. 


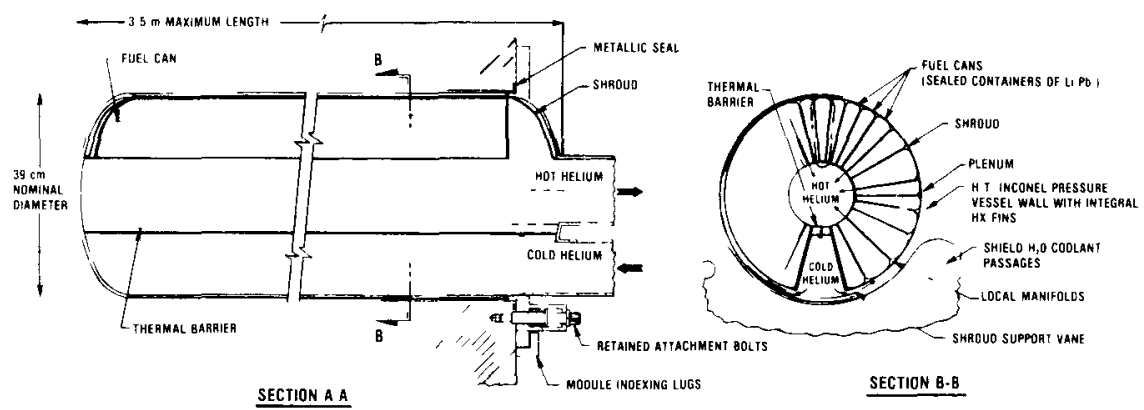

Fig. 11-13. Blanket module for the Doublet DPR.

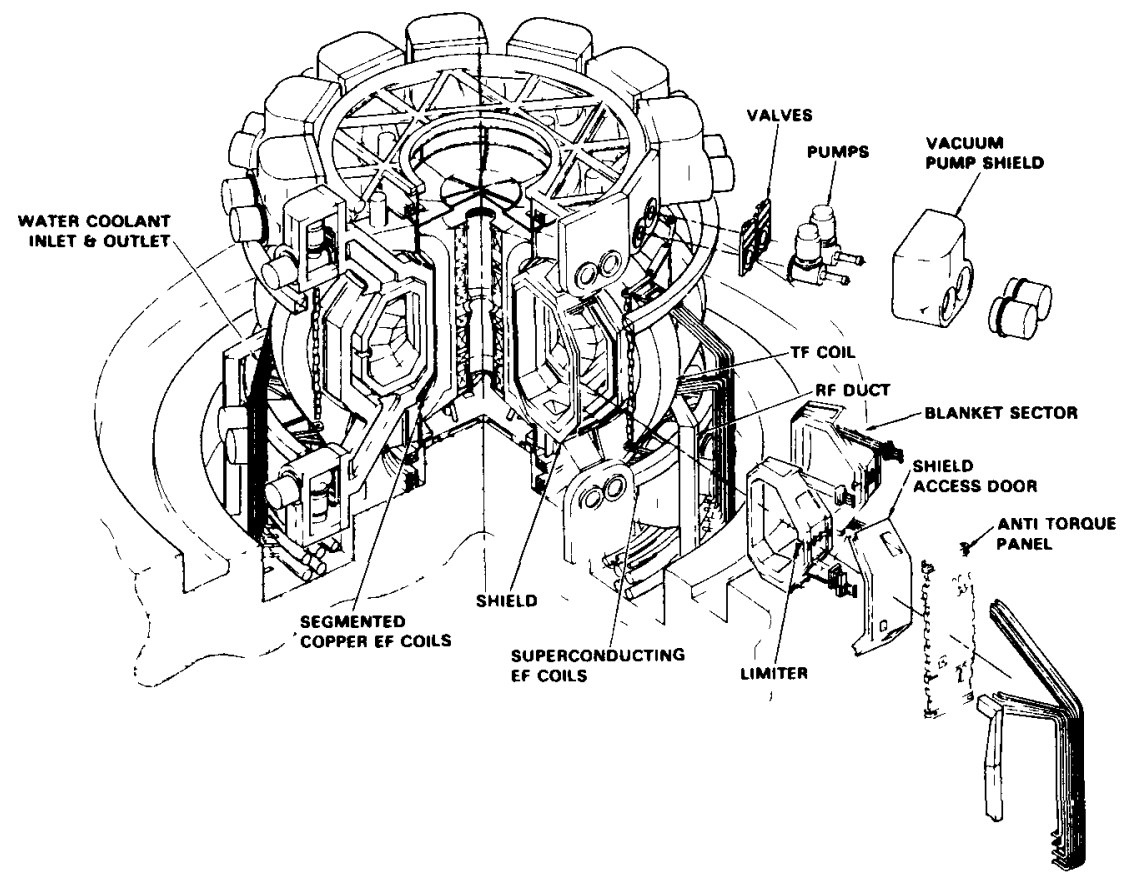

Fig. 11-14. STARFIRE reactor design.

cylinders forming the first wall of the reactor (Fig. 11-13). The cylindrical internals are removable wedge-shaped $\mathrm{Li}_{7} \mathrm{~Pb}_{2}$ plates forming the tritium breeding and heat gathering zone of the blanket.

The STARFIRE- $\mathrm{H}_{2} \mathrm{O}$ reactor, which is illustrated in Fig. 11-14, is the most detailed and up-to-date tokamak commercial fusion reactor design. It has a steadystate D-shaped plasma and employs total remote maintenance with modular design. The blanket is cooled with pressurized water. It has a conventional water/steam power cycle with no intermediate coolant loop and no thermal energy storage. It 
has a modular design with once-through pressurized cooling tubes. The STARFIRE-He blanket, which is a helium-cooled design based on the STARFIRE- $\mathrm{H}_{2} \mathrm{O}$ reactor (see Figs. 11-10a and 11-10b), is described later in more detail to show the thermal-hydraulics design of both the first wall and the blanket.

The field-reversed mirror (FRM), the moving ring field-reversed mirror (MRFRM), and the moving ring reactor (MRR) designs were sponsored by the Electric Power Research Institute with the aim of designing small reactors with an electrical power output of $\sim 100 \mathrm{MW}(\mathrm{e})$.

The FRM is a single-cell reactor ${ }^{23}$ that requires neutral beam injection to maintain the steady-state plasma ring density, energy, and current. The blanket/ shield design makes use of the metallic shield rings to form the high-pressure helium plenum. It is a pressurized module design with coolant helium flowing between $\mathrm{Li}_{2} \mathrm{O}$ plates clad with Inconel-718.

The MRFRM (Ref. 24) and MRR (Ref. 25) reactors have a low-activation blanket design with hands-on maintenance behind the blanket as the goal. The cylindrical geometry of the reactors was fully utilized for reactor maintenance. The MRFRM blanket uses water-cooled aluminum-alloy-6063 T6 as the structural material, and $\mathrm{SiC}$-clad $\mathrm{Li}_{2} \mathrm{O}$ tubes (with helium cooling) as the tritium breeding zone design. This is also a high-pressure module design. The MRR blanket is an all-ceramic blanket design, that uses small concentric $\mathrm{SiC}$ helium tubes at high pressure $(28 \mathrm{~atm})$ and large $\mathrm{SiC}$ modules containing $\mathrm{Li}_{2} \mathrm{O}$ at low pressure. The hot helium is coupled directly to a closed-cycle gas turbine because of the potential advantages (see Chapter 8).

In addition to these U.S. designs, a number of attractive fusion reactor conceptual designs with helium cooling have been developed in the international fusion engineering community. These include: FINTOR in Italy, JXFR in Japan, and MKIIA in the United Kingdom. ${ }^{26-28}$

\section{STARFIRE-He Design}

The blanket module used in this design ${ }^{12}$ is a pressurized canister with the integrated semicircular first wall facing the plasma, the solid breeder material canned in rectangular tubes forming breeder plates, and the coolant manifold integrated into the rear of the module (Fig. 11-10a). The cold inlet coolant is directed immediately through the inlet distribution channels and the side flow paths to the first wall. This guarantees efficient cooling with the lowest possible firstwall temperatures and allows the highest neutron wall load. The coolant then reaches the front of the breeding zone, flowing between the breeder plates, to the collection channel and the outlet manifolds. The structure temperatures can be kept nearly constant within the whole module and the coolant outlet temperature is close to the maximum allowable structure temperature. Figure 11-10b shows a cross section of the blanket module with its main dimensions.

The important parameters influencing the blanket design are the helium inlet and outlet temperatures and the coolant pressure level. Generally, a lower coolant 
inlet temperature permits a higher neutron wall load for a given structure temperature design limit and also allows a larger coolant temperature increase from the blanket inlet to the outlet, a smaller coolant flow rate, and less pumping power. The minimum helium temperature is limited to $250^{\circ} \mathrm{C}$ and this value was selected to be the coolant inlet temperature to the blanket. The outlet gas temperature is limited by the maximum allowable structural material temperatures and was selected to be $550^{\circ} \mathrm{C}$.

The impact of the coolant pressure level on the blanket performance is complex and depends on the chosen design concept. The pressure level influences mainly the pumping power, space requirements for manifolding, wall thickness, neutronics, and helium leakage. For the design study, a moderately high coolant pressure of $5 \mathrm{MPa}$ was chosen. The coolant flow rate for the whole reactor with a total thermal power in the blanket of $3700 \mathrm{MW}$ and a coolant temperature rise of $300^{\circ} \mathrm{C}$ is $2372 \mathrm{~kg} / \mathrm{s}$. Of the total energy, $20 \%$ is deposited at the first wall and $\sim 70 \%$ in the $\mathrm{Li}_{2} \mathrm{O}$ breeder zone.

To design a first wall that is capable of keeping the temperatures within the limit required with a minimum pressure drop and a reasonable flow channel dimension, a grooved wall was chosen. The convective heat transfer can be enhanced by increasing the transfer surface (see Table 11-VI).

The thermal-hydraulic concerns for the breeder plates are the determination of the plate thickness and the cooling of the plates. From the neutronics point of view, a plate thickness as large as possible is desired in order to have a high breeder material fraction. But the plate thickness is restricted by the following temperature limits: breeder centerline, $910^{\circ} \mathrm{C}$; breeder surface, $600^{\circ} \mathrm{C}$; and cladding

TABLE 11-VI

Grooved First-Wall Design Parameters for STARFIRE-Helium

\begin{tabular}{|lc|}
\hline Wall material & Inconel 718 \\
Neutron wall load & $4 \mathrm{MW} / \mathrm{m}^{2}$ \\
Surface heat load & $1 \mathrm{MW} / \mathrm{m}^{2}$ \\
Volumetric heat generation & $48 \mathrm{MW} / \mathrm{m}^{3}$ \\
Groove width & $1 \mathrm{~mm}$ \\
Fin thickness & $1 \mathrm{~mm}$ \\
Groove height & $35 \mathrm{~mm}$ \\
Wall thickness & $2 \mathrm{~mm}$ \\
Equivalent wall thickness & $375 \mathrm{~mm}$ \\
Outside wall maximum temperature & $550^{\circ} \mathrm{C}$ \\
Inside wall maximum temperature & $440^{\circ} \mathrm{C}$ \\
Average wall temperature & $495^{\circ} \mathrm{C}$ \\
Helium coolant maximum temperature & $320^{\circ} \mathrm{C}$ \\
Reynolds number & 12900 \\
Heat transfer coefficient & $5995 \mathrm{~W} / \mathrm{m}^{2} \cdot \mathrm{K}$ \\
Fin efficiency & $357 \%$ \\
Coolant velocity & $62 \mathrm{~m} / \mathrm{s}$ \\
Coolant friction pressure drop & $37 \times 10^{4} \mathrm{~Pa}$ \\
Coolant pressure drop ratio $\Delta P / P$ & $074 \%$ \\
Coolant pressure & $50 \mathrm{MPa}$ \\
\hline
\end{tabular}


TABLE 11-VII

Breeder Plate Design Parameters for STARFIRE-Helium

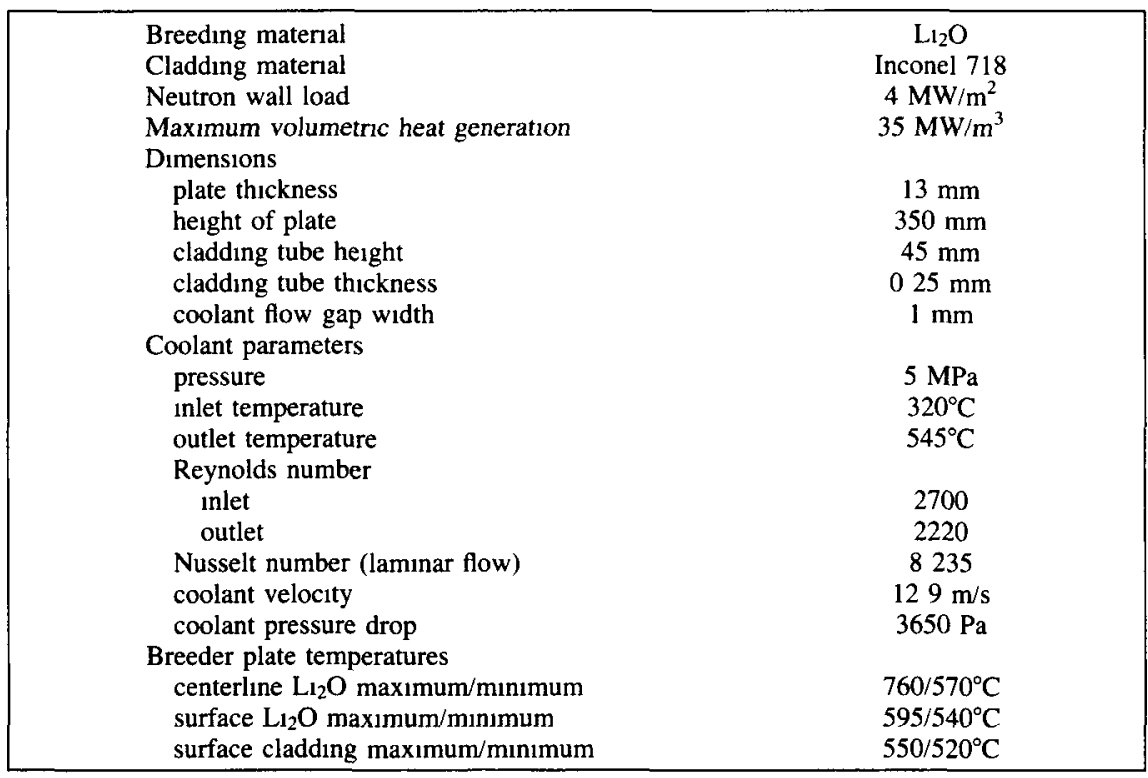

surface, $550^{\circ} \mathrm{C}$. The maximum volumetric heat generation occurs at the edge of the plate near the first wall and is $35 \mathrm{MW} / \mathrm{m}^{3}$. The coolant temperature at this location is $320^{\circ} \mathrm{C}$. The coolant flows through the gaps between the plates from the front to the rear of the module. To reach a small void fraction, a small gap width is also necessary. The minimum gap width was limited to $1 \mathrm{~mm}$. Because it is not possible to reach fully turbulent flow conditions $\left(\operatorname{Re}>10^{4}\right)$ and because it is desirable to avoid the transition flow regions, a minimum number of 18 plates is required to be in the laminar flow regime. A plate thickness of $13 \mathrm{~mm}$ was chosen in order to keep all temperatures within the design limits. The resulting number of plates to complete the breeder zone width is 20 . The breeder plate design parameters are summarized in Table 11-VII.

Thermal barriers to minimize heat transfer from the hot outlet to the inlet coolant streams are of great concern for the overall performance of the proposed blanket design with its compact geometry. Thermal barriers using stagnant helium as an insulation between two shrouds were used. They reduce the heat flow between the coolant channels by a factor of 5 and the maximum recuperation effect is less than a $5^{\circ} \mathrm{C}$ increase for the inlet coolant flow.

The total pressure drop in the blanket and the integrated coolant manifolds adds up to $93.1 \mathrm{kPa}$. The total primary coolant pressure drop is given by the sum of the losses in the blanket, the sector lines, the ring ducts, the steam generator piping, and the steam generators themselves. The total pressure drop in the primary 
helium loop is $160 \mathrm{kPa}$ and the $\Delta p / p$ ratio is $3.2 \%$. The ideal pumping power required for the whole loop is estimated to be $2.5 \%$ of the total reactor thermal power.

A helium-cooled, solid breeder blanket design that fits into the STARFIRE tokamak fusion reactor has been developed that is capable of bearing a $4 \mathrm{MW} / \mathrm{m}^{2}$ neutron wall load with a pumping power for the whole primary loop of $2.5 \%$ of the total thermal power. This good performance has been reached primarily because high coolant velocities are restricted to locations where they really are needed, due to either heat transfer requirements or space limitations. This compact design requires a low structure fraction and has a small overall blanket thickness of only $86 \mathrm{~cm}$. In spite of the relatively wide coolant temperature range, it is possible by means of an appropriate flow routing to keep the structure temperature differences small and to hold the breeder material temperatures within the recommended range for adequate tritium release.

\section{1-3B Process Heat/Synfuels}

While the main direction of the world fusion development program has been toward central station electricity generation, modest programs have been pursued to explore the application of fusion power to various synthetic fuel production processes. An initial survey was performed of candidate fusion chemical applications. ${ }^{29}$ Production of hydrogen was identified as a particularly attractive application and a number of hydrogen production processes were identified for coupling to the fusion heat source.

A potential hydrogen production application for commercial fusion reactors is to generate high-temperature process heat in the blanket region. The basic motivation for this application is the utilization of the penetration capability of the fusion neutrons, which in the D-T fuel cycle carry $\sim 80 \%$ of the fusion energy, in order to separate physically the high-temperature zone and the reactor structure. The high-energy neutrons can penetrate the low- or moderate-temperature firstwall structural material and deposit their energy in a thermally insulated, nonstructural, very high temperature zone. Thermochemical water splitting ${ }^{30,31}$ and high-temperature electrolysis ${ }^{32}$ appear to be processes in which the very high temperature capabilities of fusion could be usefully applied.

In designing a high-temperature synfuel fusion reactor, the main potential problem areas to be investigated are: the temperature-energy distribution of the heat delivered to the synfuel process, the tritium breeding and handling concerns, concerns about materials compatibility at high temperatures, the requirements for efficient heat removal, and the need to avoid radioactivity contamination of the hydrogen product. A high-temperature modification of the sulfur-iodine cycle (for thermochemical water-splitting), which was adapted to the fusion heat source, ${ }^{31}$ was found to have a good "heat line" match. Thirty-five percent of the process heat was delivered to the chemical cycle at $1773 \mathrm{~K}$ and the remaining $65 \%$ at $873 \mathrm{~K}$. The very high peak temperature allows over $95 \%$ decomposition of the 
$\mathrm{H}_{2} \mathrm{SO}_{4}$ into $\mathrm{H}_{2} \mathrm{O}, \mathrm{SO}_{2}$, and $\mathrm{O}_{2}$ without requiring a catalyst. Use of a rapid quench to $T<1250 \mathrm{~K}$ retains over $90 \%$ of the $\mathrm{SO}_{2} / \mathrm{O}_{2}$ product in the separated form. The very high temperature also allows larger temperature differentials to be used in the synfuel process with considerable equipment and components savings possible due to reduced heat transfer surface requirements and reduced need for energy recuperation between process steps.

The materials problems associated with fusion synfuel production are difficult because of the very high temperature and corrosive process fluid, which is a mixture of $\mathrm{SO}_{3}, \mathrm{SO}_{2}, \mathrm{O}_{2}$, and steam. High-temperature-zone design concepts employing a nonbreeding refractory ceramic material such as $\mathrm{SiC}$ were found to be necessary. The heat recovered from energy deposited in the tritium breeding zones is limited to considerably lower temperatures $(\sim 873 \mathrm{~K})$ by the nature of breeding materials available and the need to control tritium mobility, leading to a blanket concept with multiple thermal zones and multiple coolant flows. The design concept focused on indirect heat transfer with a high-temperature helium coolant and external heat exchangers, thus allowing product radioactivity to be controlled or eliminated. Two helium streams are needed for removing the heat from the medium-temperature $(\sim 873 \mathrm{~K})$ tritium breeding zones and from the hightemperature $(\sim 1773 \mathrm{~K})$ process heat zone. Helium is unique in this application; it is chemically inert, transparent to neutrons, and does not become activated. Thus very high temperatures can be achieved and product radioactivity can be controlled.

Adequate tritium breeding, a maximum fraction of nuclear heating in the high-temperature zone, and maximum blanket energy multiplication are among the most important goals and requirements for the nuclear design of a synfuel blanket. A three-zone blanket concept, where the helium-cooled high-temperature zone is placed between two tritium breeding zones was found to achieve the best performance toward the design goals. When $\mathrm{Li}_{7} \mathrm{~Pb}_{2}$ is employed as the breeding material, and when the zone thicknesses are optimized so that a tritium breeding ratio of 1.1 is obtained, the fraction of nuclear heating in the $\mathrm{SiC}$ high-temperature zone was found to be 0.40 , providing an excellent "heat line" match for the sulfur-iodine cycle.

The high-temperature sulfur-iodine thermochemical water-splitting cycle is an extension of the moderate-temperature water-splitting cycle that is currently being developed for HTGR nuclear fission and solar heat source applications. Thus it appears that the application of fusion energy to production of hydrogen for synfuels could be accomplished by extending process technologies that are already being developed for other applications.

\section{1-3C Fusion-Fission Hybrid Reactors}

A fusion-fission hybrid reactor is simply a fusion reactor with a blanket of fertile and/or fissile material around it to intercept and utilize the neutrons released in the fusion reaction process. The neutrons may be used to cause fission, thus 
enhancing the energy and neutron production of the fusion reaction or may be captured in fertile materials to produce fissile fuel. In most potential applications, a combination of energy and fuel production is obtained.

\section{The Hybrid Reactor Concept}

The fusion-fission hybrid concept was first proposed ${ }^{33}$ in 1954. An excellent summary of earlier work may be found in Ref. 34 while a recent review is given in Ref. 35.

The fusion-fission hybrid concept is of interest primarily as a potential copious source of fissile fuel. An abundant external source of fissile material would allow continued use of existing thermal reactor technology beyond the depletion of lowcost uranium reserves. Both the energy and the fuel produced in a hybrid blanket are valuable products that could help fusion become economically attractive and may allow the performance requirements imposed on the fusion driver to be relaxed somewhat. Easier fusion performance requirements and enhanced economics could allow earlier application of fusion power than would be possible via electrical power production by pure fusion alone. Recognizing the continuum of modes between fuel production and energy production, the definition "fuel-producing hybrid" is used for reactors whose main product is fuel, "energy-producing hybrid" if the main product is energy, and "fuel and energy hybrid" if both products are important.

The energy-producing hybrid would produce and consume fissile fuel in situ, producing energy as its only external product. A hybrid reactor design study done at Princeton Plasma Physics Laboratory explored this concept. ${ }^{36}$ The energyproducing hybrid provides a challenging design environment, high power density, high fissile fuel burnup, high afterheat level, and a significant radioactive inventory with concomitant safety concerns. It appears that the bred fuel would be better used in an external fission burner reactor where additional fertile conversion can improve fuel utilization.

In the fuel- and energy-producing hybrid, fissile fuel is the primary product although significant amounts of energy may be produced by fast fission of the fertile material. The best overall blanket performance in terms of fuel and energy produced can be obtained from this sort of fast-fission hybrid blanket. ${ }^{37}$ Fastfission uranium and thorium blankets have been designed for tokamak and mirror fusion drivers.

The fuel-producing hybrid attempts to minimize the energy production in the blanket by suppressing fission. ${ }^{38}$ Neutron multiplication through $(n, 2 n)$ reactions are used to improve breeding performance. The intent in suppressing fission is to simplify safety and blanket design considerations by operating at low power density with low afterheat. In a fission-suppressed blanket (a tandem mirror hybrid reactor), ${ }^{39}$ fuel production rates comparable to fast-fission blankets can be obtained ( $\sim 0.6$ to 0.8 atoms per fusion neutron). The lower energy production of the fission-suppressed blanket allows the fuel production per unit thermal power to 
be quite high and thus the modest energy production is counterbalanced by the larger number of fission burner reactors that a hybrid reactor of fixed thermal power can support Although the fission-suppressed hybrid has a higher capital cost than the alternate fast-fission hybrid, the total system electricity cost is the same This means that the safety advantages, less stringent design requirements, and reduced technology development needs of the fission-suppressed hybrid blanket may be obtained without economic penalty The fuel-producing fission-suppressed hybrid reactor appears to lead toward the optimum symbiosis of fusion and fission reactors

The average performance characteristics of typical hybrid blankets are shown on Table 11-VIII The blankets can produce significant amounts of fissile fuel If this fuel is assumed to be burned in a thermal spectrum fission reactor, a large number of burner reactors could be supported by each hybrid reactor The lower breeding performance of the thonum blanket is offset by the higher value of the bred ${ }^{233} \mathrm{U}$ as a fuel for thermal burner reactors ${ }^{41}$ Use of more efficient thermal converter reactors, such as the HTGR, can further enhance the hybrid reactor support ratio, as shown

\section{Gas-Cooled Hybrid Designs}

In the application of gas cooling to hybrid reactors, maximum benefit must be taken of the advantages of gas cooling ${ }^{42}$ The fact that helium is virtually transparent to neutrons will allow better nuclear performance than with other coolants Companing helium and bolling water for use with a uranium-fueled hybrid blanket for the commercial tokamak hybrid reactor, ${ }^{43}$ it was found that the helium-cooled desıgn produced $30 \%$ more bred plutonium and 5\% more blanket

\section{TABLE 11-VIII}

Typıcal Fuel Production Hybrid Blanket Performance Characterıstıcs

\begin{tabular}{|lccc|}
\hline & $\begin{array}{c}\text { Fast-Fission } \\
\text { Uranium } \\
\text { Blanket } \\
\text { (Ref 40) }\end{array}$ & $\begin{array}{c}\text { Fast-Fission } \\
\text { Thorium } \\
\text { Blanket } \\
\text { (Ref 39) }\end{array}$ & $\begin{array}{c}\text { Fission-Suppressed } \\
\text { Thorium } \\
\text { Blanket } \\
\text { (Ref 39) }\end{array}$ \\
\hline $\begin{array}{l}\text { Fuel production } \\
\text { (atom/fusion neutron) }\end{array}$ & 15 & 075 & 040 \\
Energy multiplication (M) & 104 & 30 & 13 \\
$\begin{array}{l}\text { Fuel production } \\
\text { (kg/MW fusion-yr) }\end{array}$ & 65 & 32 & 17 \\
$\begin{array}{c}\text { Fuel production } \\
\text { [kg/MW(t)-yr] }\end{array}$ & 076 & 125 & 116 \\
$\begin{array}{l}\text { Support ratio } \\
\text { (Pel-burner/Pel-hybrid)-LTTGR }\end{array}$ & 40 & 96 & 89 \\
\hline
\end{tabular}

${ }^{a}$ Thermal power $=$ fusion neutron power $\times$ blanket energy multiplication + fusion alpha power

${ }^{\mathrm{b}}$ Assumed fuel consumption $[\mathrm{kg} / \mathrm{GW}(\mathrm{e}) \mathrm{yr}] \mathrm{LWR}-\mathrm{Pu}, 533 \mathrm{~kg}, \mathrm{LWR}-{ }^{233} \mathrm{U}, 360 \mathrm{~kg}, \mathrm{HTGR}-{ }^{233} \mathrm{U}$, $168 \mathrm{~kg}$ 


\section{TABLE 11-IX}

Gas-Cooled Hybrid Blanket Safety Characteristics*

\begin{tabular}{|lccc|}
\hline Safety Characteristics & $\begin{array}{c}\text { Uranium } \\
\text { Fast-Fission }\end{array}$ & $\begin{array}{c}\text { Thorium } \\
\text { Fission-Suppressed }\end{array}$ & $\begin{array}{c}\text { Thorium } \\
\text { Fission-Suppressed } \\
\text { Fertile Dilute }\end{array}$ \\
\hline $\begin{array}{c}\text { Time to melt } \\
\text { fuel } \\
\text { first wall }\end{array}$ & $15 \mathrm{~min}$ & $115 \mathrm{~h}$ & $\begin{array}{c}\text { not applicable } \\
8 \text { to } 10 \mathrm{~h}\end{array}$ \\
$\begin{array}{c}\text { Bological hazard } \\
\text { potential } \\
\left(\mathrm{km}^{3} \text { of air) }\right.\end{array}$ & $50 \mathrm{~mm}$ & $2 \mathrm{~h}$ & $10^{9}$ \\
$\begin{array}{c}\text { Probabilistic relative } \\
\text { risk (rem/yr) }\end{array}$ & $10^{11}$ & $10^{10}$ & not avallable \\
\hline
\end{tabular}

*From Ref 46

${ }^{a}$ Accident dose $\times$ probability of accident, summed over all accidents

power. A similar helium/water comparison for a thorium-fueled blanket for the demonstration tokamak hybrid reactor showed that the helium-cooled design could produce $19 \%$ more bred ${ }^{233} \mathrm{U}$ and $37 \%$ higher blanket power at the beginning of life, although a thicker blanket was required.

An important consideration for hybrid blankets is afterheat removal. Like a fission reactor, the hybrid blanket will have fission product decay heat and will need to be cooled actively after shutdown to maintain acceptable fuel temperatures. The time required for the fuel to reach its melting point if none of the decay heat is removed ("adiabatic melt time") has been used as a measure of the sensitivity of various hybrid designs to loss-of-cooling accidents. ${ }^{39}$ This measure is very conservative because it ignores coolant flow coast-down, natural convection, radiation, and conduction within the blanket, each of which will help limit fuel temperature rise. Adiabatic melt times ranging from a few minutes to tens of hours have been reported for various hybrid blankets ${ }^{39}$ (see Table 11-IX). It is possible that afterheat concerns can be eliminated by use of fission-suppressed blanket designs. Although preliminary safety analysis of hybrid reactors has begun, ${ }^{44-46}$ the state of hybrid reactor design has not yet progressed to the point at which detailed accident initiation and progression analysis can use probabilistic risk assessment techniques to calculate subsystem reliability targets. Nevertheless, the safety advantages of a coolant that cannot change phase are expected to contribute to protection against loss-of-cooling accidents.

\section{1-4 Conclusions}

From this review of gas-cooled fusion reactor concepts, some general conclusions and observations may be made. Helium gas is attractive as the coolant for fusion systems and technically viable designs have been developed. Helium is chemically inert, nonmagnetic, and nonconductive, which greatly reduces ma- 
terials compatibility concerns. It is neutronically virtually transparent to neutrons, giving excellent breeding performance. Helium undergoes no phase changes in the temperature range of interest, experiences negligible gravity effects, and even in the case of primary coolant boundary failure, will not be completely lost. These features facilitate blanket design and offer safety advantages by ruling out the possibility of a loss-of-coolant accident. But designs must also take into account the disadvantages of helium: a low heat capacity, a low heat transfer coefficient, a high pumping power, and transparency to neutrons, which, though it improves breeding, leads to additional shielding requirements.

Viable design concepts using helium cooling have been developed for all potential fusion applications. These applications include electricity production, generation of high-temperature process heat for synthetic chemical fuel processes, and breeding of fissile materials. In several of these concepts, the use of helium is essential to their success in meeting the design objectives. An example of this is high-temperature process heat production where the very high temperatures preclude use of a coolant not chemically inert. In other applications, such as electricity production, helium is one of several potentially viable coolant candidates.

As a result of the various design studies summarized in this chapter, it is clear that the choice of coolant will strongly affect the entire design. For helium cooling, the design concept and configuration must be arranged in such a way as to take advantage of the many favorable characteristics of helium and to minimize the impact of the disadvantages associated with its use. When this design optimization is done, it is clear that helium can be a very attractive choice as a coolant for fusion reactors, making full use of the technology developed for fission systems.

\section{REFERENCES}

1. J. P. Holdren, "Fusion Energy in Context: Its Fitness for the Long Term,"' Science, 200, 4338, 168 (Apr. 14, 1978).

2. D. J. Lawson, "Some Criteria for a Power Producing Thermonuclear Reactor," Proc. Phys. Soc. London, B70, 6 (1957).

3. C. C. Baker, G. A. Carlson, and R. A. Krakowski, "Trends and Developments in Magnetic Confinement Fusion Reactor Concepts," Nucl. Technol./Fusion, 1, 1, 5 (Jan. 1981).

4. M. J. Monsler, J. Hovingh, D. L. Cook, T. G. Frank, and F. A. Moses, “'An Overview of Inertial Fusion Reactor Design," Nucl. Technol./Fusion, 1, 3, 302 (July 1981).

5. D. Steiner, "The Technological Requirements for Power by Fusion," Nucl. Sci. Eng., 58, 107 (1975).

6. G. B. Melese-d'Hospital and P. Fortescue, "On the Choice of Gas Coolant for Nuclear Reactors," GA-7344, GA Technologies (Aug. 1966).

7. G. B. Melese-d'Hospital and M. Simnad, "Status of Helium-Cooled Nuclear Power Systems," GA-A14067, GA Technologies (Sep. 1976). 
8 G B Melese-d'Hospital and G R Hopkıns, "Gas Coolıng for Fusion Reactor Blankets,"' Proc IECEC Energy 70 Conf, Las Vegas, Nevada, September 21-25, 1970, Vol 1, p 1-65, American Nuclear Society (1972)

9 P H Sager, "Thermal Power Conversion Systems for Fusion Power Plants," GAA13405, GA Technologies (May 29, 1975)

10 E G Hammel, "A Proposed Federal Helium Conservation Policy as Related to the Helıum Demands of Energy-Related New Technologies," Trans Am Nucl Soc , 22, 56 (Nov 1975)

11 E Cook, "The Helium Question," Science, 206, 1141 (Dec 7, 1979)

12 M Huggenberger and K R Schultz, "Helıum-Cooled Solıd Breeder Blanket Desıgn for a Tokamak Fusion Reactor," Proc 9th Symp Engineering Problems of Fusion Research, Chicago, Illıno1s, October 26-29, 1981, Vol II, p 1992, IEEE 81CH17152, Institute of Electrical and Electronics Engineers (1982)

13 G R Hopkıns, "First-Wall Engineerıng and Technology in Fusıon," Proc 4th Topl Mtg Technology of Controlled Nuclear Fuston, King of Prussia, Pennsylvania, October 14-17, 1980, CONF-801011, Vol II, p 583, National Technical Information Service (July 1981)

14 J A Fillo, "First Wall Thermal Hydraulic Models for Fusion Blankets," Nucl Eng Des , 68, 3, 243 (Apr 1, 1982)

15 M A Hoffman, "Heat Flux Capabilitıes of First Wall Tube Arrays for an Experımental Fusion Reactor,' Nucl Eng Des , 64, 2, 283 (1981)

16 G R Hopkıns et al , "Actively Cooled Limiter for Doublet III," GA-A16181, GA Technologies (Nov 1980)

17 D K Sze et al , "A BWTR (Bolling Water Tokamak Reactor) Blanket Study," Proc 3rd ANS Topl Mtg Technology of Controlled Nuclear Fusion, Santa Fe, New Mexico, May 9-11, 1978, CONF-780508, Vol 1, p 239, National Technical Information Service (1978)

18 D W Kearney et al , "Doublet Demonstration Fusion Power Reactor Study," GAA14742, GA Technologies (July 1978)

19 A Y Lee, "Thermal and Hydraulıc Analysıs of a Cylındrıcal Blanket Module Desıgn for a Tokamak Reactor,' WFPS-TME-78 103, Westınghouse Electric Corp (Oct 1978)

20 D L Smith and I Charak, "Thermal Responses of Tokamak Reactor First Walls During Cyclic Plasma Burns," Proc 7th IEEE Symp Engineering Problems of Fusion Research, Knoxville, Tennessee, October 25-28, 1977, Vol II, p 1465, Instıtute of Electrical and Electronics Engineers (1978)

21 "'STARFIRE-A Commercial Tokamak Fusion Power Plant Study," ANL/FPP-801, Argonne National Lab (Sep 1980)

22 G R Hopkins et al , "Low Actıvation Materials Safety Studies," GA-A16005, GA Technologies (Dec 1980)

23 "Field-Reversed Mirror Pilot Reactor,"' EPRI AP-1544, Electric Power Research Institute (Sep 1980)

24 “The Moving-Ring Field-Reversed Mirror Reactor Annual Report, 1979-1980,' Electric Power Research Institute (to be publıshed)

25 "A Low Activation Blanket for the Moving Ring Field-Reversed Mirror Reactor," GA-A16543, GA Technologies (Oct 1981)

26 FINTOR Group, "Conceptual Design Studies of Experimental and Demonstration Fusion Reactor," presented at IAEA Technical Committee Meetıng and Workshop of 
Fusıon Reactor Design, Madison, Wisconsın, October 1972

27 K Sako et al , “JXFR An Experımental Power Reactor," presented at IAEA Technical Committee Meetıng and Workshop of Fusıon Reactor Desıgn, Madison, Wisconsin, October 1972

28 R Hancox, "Progress in Nuclear Fusion Development,"' Nucl Energy, 20, 3, 221 (June 1981)

29 L H Rovner et al , “Study of Chemical Production Utılızıng Fusion Neutrons," GAA15371, GA Technologies (1979)

30 R W Werner et al , "Synfuels from Fusıon-Producıng Hydrogen with the Tandem Mirror Reactor and Thermochemical Cycles," UCID-18909, Lawrence Livermore Natıonal Lab (Jan 1981)

31 E T Cheng et al , "Thermochemical Hydrogen Production Using Fusion Energy," GA-A15831, GA Technologies (Oct 1980)

32 O W Lazareth et al, "HYFIRE A Tokamak-High-Temperature Electrolysis System,' Proc 4th Topl Mtg Technology of Controlled Nuclear Fusion, King of Prussia, Pennsylvania, October 14-17, 1980, CONF-801011, Vol III, p 1639, National Technical Information Service (July 1981)

33 D H Imhoff, W H Karker, F E Bjorkland, H A Brammer, and A E Stoddard, "A Driven Thermonuclear Power Breeder," CR-6, Calıfornia Research Corp (June 1954)

34 B R Leonard, "A Review of Fusion-Fission (Hybrid) Concepts," Nucl Technol, 20, 161 (Dec 1973)

35 R P Rose, "The Case for the Fusion Hybrid," J Fusion Energy, 1, 2, 185 (1981)

36 F H Tenney et al , "A Systems Study of Tokamak Fusion-Fission Reactors," PPPL1450, Princeton Plasma Physics Lab (Nov 1978)

37 J D Lee, "Nuclear Design of Fast Hybrid Blankets," Proc 2nd Fusion-Fission Energy Systems Review Mtg , Washington, DC, November 2-3, 1977

38 L M Lidsky, "Fission-Fusion Symbiosis General Considerations and a Specific Example," Proc Nuclear Fusion Reactors Conf , Culham, England, September 1719, 1969, p 41, Britısh Nuclear Energy Society (1970)

39 R W Morr, et al , "Tandem Mirror Hybrid Reactor Design Study Annual Report," UCRL-52875, Lawrence Livermore National Lab (Nov 1980)

40 D J Bender et al , "Reference Design for the Standard Mirror Hybrid Reactor," UCRL-52478/GA-14796, Lawrence Livermore Lab /GA Technologies (May 1978)

41 K R Schultz, "A Review of Hybrid Reactor Fuel Cycle Considerations," GAA14475, GA Technologies (July 1977)

42 K R Schultz, "Gas-Cooled Fusion-Fissıon Hybrid Reactor Systems," $J$ Fusion Energy, 1, 2, 163 (1981)

43 J L Kelly et al, "Status Report on the Prelıminary Conceptual Desıgn of a Demonstration Tokamak Hybnd Reactor (DTHR),' WFPS-TME-086, Westınghouse Electric Corp (June 1978)

44 W E Kastenberg et al, "On the Safety of Conceptual Fusion-Fission Hybrid Reactors," Nucl Eng Des, 5, 311 (1979)

45 K R Schultz et al , "Hybrid Reactor Safety Study Annual Report," GA-A15578, GA Technologies (Dec 1979)

46 K R Schultz et al , "Hybrid Reactor Safety Study Annual Report," GA-A16185, GA Technologies (Dec 1980) 


\section{APPENDIX A}

\section{Conversion Table}

(Five figure accuracy based on U.S. metric practice, reference ASTM 380-76.)

\section{Acceleration}

$$
1 \mathrm{~m} / \mathrm{s}^{2}=3.2808 \mathrm{ft} / \mathrm{s}^{2}
$$

$9.8067 \mathrm{~m} / \mathrm{s}^{2}=32.174 \mathrm{ft} / \mathrm{s}^{2}$ (standard gravitational acceleration)

\section{Density}

Energy

$$
1 \mathrm{~kg} / \mathrm{m}^{3}=0.062428 \mathrm{lb} / \mathrm{ft}^{3}
$$

$1 \mathrm{~J}=0.23885$ cal (International Table)

$1 \mathrm{~J}=9.4782 \times 10^{-4}$ Btu (International Table)

$1 \mathrm{~J}=0.73756 \mathrm{ft} \cdot \mathrm{lbf}$

$1 \mathrm{~J}=2.77778 \times 10^{-7} \mathrm{kWh}$

Flow (mass and volumetric)

$$
\begin{aligned}
1 \mathrm{~kg} / \mathrm{s} & =2.2046 \mathrm{lb} / \mathrm{s} \\
1 \mathrm{~m}^{3} / \mathrm{s} & =2118.9 \mathrm{ft}^{3} / \mathrm{min} \\
1 \mathrm{~m}^{3} / \mathrm{s} & =15850 \mathrm{gal}(\text { U.S. }) / \mathrm{min}
\end{aligned}
$$

Force

Heat

$$
\begin{aligned}
& 1 \mathrm{~N}=10^{5} \mathrm{dyn} \\
& 1 \mathrm{~N}=0.22481 \mathrm{lbf} \\
& 1 \mathrm{~N}=0.10197 \mathrm{kgf}
\end{aligned}
$$

$$
1 \mathrm{~J} / \mathrm{kg}=4.2992 \times 10^{-4} \mathrm{Btu} / \mathrm{lb} \text { (specific energy) }
$$

$1 \mathrm{~J} / \mathrm{kg} \cdot \mathrm{K}=2.3885 \times 10^{-4} \mathrm{Btu} / \mathrm{lb} \cdot{ }^{\circ} \mathrm{F}$ (specific heat capacity)

$1 \mathrm{~W} / \mathrm{m} \cdot \mathrm{K}=0.57779 \mathrm{Btu} / \mathrm{h} \cdot \mathrm{ft} \cdot{ }^{\circ} \mathrm{F}$ (thermal conductivity)

$1 \mathrm{~W} / \mathrm{m}^{2} \cdot \mathrm{K}=0.17611 \mathrm{Btu} / \mathrm{h} \cdot \mathrm{ft}^{2} \cdot{ }^{\circ} \mathrm{F}$ (thermal conductance)

Length, area, volume

$$
\begin{aligned}
1 \mathrm{~m} & =39.370 \mathrm{in} . \\
1 \mathrm{~m} & =3.2808 \mathrm{ft}^{2} \\
1 \mathrm{~m}^{2} & =10.764 \mathrm{ft}^{2} \\
1 \mathrm{~m}^{3} & =35.315 \mathrm{ft}^{3} \\
1 \mathrm{~m}^{3} & =264.17 \mathrm{gal} \text { (U.S.) } \\
1 \mathrm{~m}^{3} & =1000 \text { liter }
\end{aligned}
$$

Mass

$1 \mathrm{~kg}=2.2046$ pound (avoirdupois)

$1000 \mathrm{~kg}=1$ tonne 


\section{Power}

Pressure

$$
\begin{aligned}
1 \mathrm{~W} & =9.4782 \times 10^{-4} \mathrm{Btu} / \mathrm{s} \text { (International Table) } \\
1 \mathrm{~W} & =3.4121 \mathrm{Btu} / \mathrm{h}(\text { International Table) } \\
1 \mathrm{~W} & =1.3410 \times 10^{-3} \mathrm{hp}(550 \mathrm{ft} \cdot \mathrm{lbf} / \mathrm{s}) \\
1 \mathrm{~W} & =44.254 \mathrm{ft} \cdot \mathrm{lbf} / \mathrm{min} \\
1 \mathrm{~W} / \mathrm{m} & =3.048 \times 10^{-4} \mathrm{~kW} / \mathrm{ft} \text { (linear heat rating) } \\
1 \mathrm{~W} / \mathrm{m}^{2} & =0.31700 \mathrm{Btu} / \mathrm{h} \cdot \mathrm{ft}^{2}(\text { heat flux }) \\
1 \mathrm{~W} / \mathrm{m}^{3} & =9.6623 \times 10^{-2} \mathrm{Btu} / \mathrm{h} \cdot \mathrm{ft}^{3} \text { (power density) }
\end{aligned}
$$

$$
\begin{aligned}
& 1 \mathrm{~Pa}=1 \mathrm{~N} / \mathrm{m}^{2} \\
& 1 \mathrm{~Pa}=10^{-5} \text { bar } \\
& 1 \mathrm{~Pa}=1.4504 \times 10^{-4} \mathrm{psi} \\
& 1 \mathrm{~Pa}=9.8692 \times 10^{-6} \text { standard atmosphere } \\
& 1 \mathrm{~Pa}=7.5006 \times 10^{-3} \text { millimeter mercury }\left(0^{\circ} \mathrm{C}\right) \\
& 1 \mathrm{~Pa}=2.9613 \times 10^{-4} \text { inch mercury }\left(60^{\circ} \mathrm{F}\right) \\
& 1 \mathrm{~Pa}=4.0186 \times 10^{-3} \text { inch water }\left(60^{\circ} \mathrm{F}\right)
\end{aligned}
$$

\section{Temperature}

$$
\begin{aligned}
& { }^{{ }^{\circ} \mathrm{C}}=\mathrm{t}_{\mathrm{K}}-273.15 \\
& \mathrm{t}^{\circ} \mathrm{C}=\left(\mathrm{t}_{\circ} \mathrm{F}-32\right) / 1.8 \\
& { }^{{ }^{\circ} \mathrm{R}}=\mathrm{t}^{\circ} \mathrm{F}+459.67=1.8 \mathrm{t}_{\mathrm{K}}
\end{aligned}
$$

Velocity

$$
1 \mathrm{~m} / \mathrm{s}=3.2808 \mathrm{ft} / \mathrm{s}
$$

Viscosity

$$
\begin{aligned}
& 1 \mathrm{~m}^{2} / \mathrm{s}=10^{4} \text { stokes (kinematic viscosity) } \\
& 1 \mathrm{~m}^{2} / \mathrm{s}=10.764 \mathrm{ft}^{2} / \mathrm{s} \text { (kinematic viscosity) } \\
& 1 \mathrm{~Pa} \cdot \mathrm{s}=1000 \text { centipoise (dynamic viscosity) } \\
& 1 \mathrm{~Pa} \cdot \mathrm{s}=2419.1 \mathrm{lb} / \mathrm{ft} \cdot \mathrm{h} \text { (dynamic viscosity) }
\end{aligned}
$$

Multiplication Factor

$$
\begin{aligned}
& 10^{12} \\
& 10^{9} \\
& 10^{6} \\
& 10^{3} \\
& 10^{2} \\
& 10^{1} \\
& 10^{-1} \\
& 10^{-2} \\
& 10^{-3} \\
& 10^{-6} \\
& 10^{-9} \\
& 10^{-12}
\end{aligned}
$$

\section{Prefix}

$\begin{array}{ll}\text { tera } & \mathrm{T} \\ \text { giga } & \mathrm{G} \\ \text { mega } & \mathrm{M} \\ \text { kilo } & \mathrm{k} \\ \text { hecto } & \mathrm{h} \\ \text { deka } & \mathrm{da} \\ \text { deci } & \mathrm{d} \\ \text { centi } & \mathrm{c} \\ \text { milli } & \mathrm{m} \\ \text { micro } & \mu \\ \text { nano } & \mathrm{n} \\ \text { pico } & \mathrm{p}\end{array}$




$\begin{array}{ll}\text { Symbol } & \text { Unit } \\ \mathrm{J} & \text { joule } \\ \mathrm{kg} & \text { kilogram } \\ \mathrm{K} & \text { kelvin } \\ \mathrm{m} & \text { meter } \\ \mathrm{N} & \text { Newton } \\ \mathrm{Pa} & \text { Pascal } \\ \mathrm{S} & \text { second } \\ \mathrm{W} & \text { watt }\end{array}$




\section{APPENDIX B}

\section{Thermodynamic and Transport Properties of Helium}

The following equations and correlations* are valid in the temperature range of 273 to $1500 \mathrm{~K}$ and pressure range of $10^{5}$ to $10^{7} \mathrm{~Pa}$. Where relevant, an estimate is given on the error bounds for the particular quantity in question. The uncertainty values represent the estimated error bounds except for the viscosity and thermal conductivity, for which the standard deviations are given. Values in parentheses are estimated for the extended temperature range of 90 to $3000 \mathrm{~K}$. Where only one value is given, it may be used for the complete temperature range.

Gas Constant:

Uncertainty

$$
\begin{aligned}
\mathrm{R} & =2077.22 \mathrm{~J} / \mathrm{kg} \cdot \mathrm{K} \\
& =386.0 \mathrm{ft} \cdot \mathrm{lbf} / \mathrm{lbm} \cdot \mathrm{R}
\end{aligned}
$$$$
<0.05 \%
$$

Equation of state:

$$
P V=R T+P B(T),
$$

where

$$
\begin{aligned}
& B(T)=C_{1}+\frac{C_{2}}{1-C_{3} T}+\frac{C_{4}}{1+C_{5} T} \\
& C_{1}=9.489433 \times 10^{-4}\left(\mathrm{~m}^{3} / \mathrm{kg}\right)=1.520021 \times 10^{-2} \mathrm{ft}^{3} / \mathrm{lb} \\
& C_{2}=9.528079 \times 10^{-4}\left(\mathrm{~m}^{3} / \mathrm{kg}\right)=1.526212 \times 10^{-2} \mathrm{ft}^{3} / \mathrm{lb} \\
& C_{3}=3.420680 \times 10^{-2}\left(\mathrm{~K}^{-1}\right)=1.900378 \times 10^{-2} \mathrm{R}^{-1} \\
& C_{4}=2.739470 \times 10^{-3}\left(\mathrm{~m}^{3} / \mathrm{kg}\right)=4.388095 \times 10^{-2} \mathrm{ft}^{3} / \mathrm{lb} \\
& C_{5}=9.409120 \times 10^{-4}\left(\mathrm{~K}^{-1}\right)=5.227289 \times 10^{-4} \mathrm{R}^{-1} .
\end{aligned}
$$

Compressibility:

$$
Z=1+\frac{P}{R T} B(T)
$$

*J. Goodman et al., "The Thermodynamic and Transport Properties of Helium," GA-A13400, GA Technologies (Oct. 1975). 
Density:

\section{Uncertainty}

$$
\rho=\frac{P}{R T+P B(T)} .
$$

Specific heat:

$$
\begin{aligned}
& C_{p}=5193 . \mathrm{J} / \mathrm{kg} \cdot \mathrm{K}=1.2404 \mathrm{Btu} / \mathrm{lbm} \cdot \mathrm{R}, \\
& C_{v}=3116 . \mathrm{J} / \mathrm{kg} \cdot \mathrm{K}=0.7443 \mathrm{Btu} / \mathrm{lbm} \cdot \mathrm{R},
\end{aligned}
$$$$
<0.5 \%(<4 \%)
$$$$
<0.5 \%(<4 \%)
$$

and

$$
\gamma=C_{p} / C_{v}=1.666
$$

Enthalpy:

$$
H-H_{o}=C_{p} T+\left[B(T)-T \frac{d}{d T} B(T)\right] P .
$$

Entropy:

$$
S-S_{o}=C_{p} \ln \left(T / T_{o}\right)-R \ln \left(P / P_{o}\right)-P \frac{d}{d T} B(T) .
$$

Sonic velocity:

$$
c=Z \sqrt{\gamma R T}
$$

Viscosity:

$$
\begin{aligned}
\mu & =3.953 \times 10^{-7} T^{0687} \mathrm{~N} \cdot \mathrm{s} / \mathrm{m}^{2} \\
& =6.388 \times 10^{-4} T^{0687} \mathrm{lbm} / \mathrm{ft} \cdot \mathrm{h} .
\end{aligned}
$$

Thermal conductivity:

$$
\begin{aligned}
k & =2.774 \times 10^{-3} T^{0701} \mathrm{~W} / \mathrm{m} \cdot \mathrm{K} \\
& =1.062 \times 10^{-3} T^{0701} \mathrm{Btu} / \mathrm{h} \cdot \mathrm{ft} \cdot \mathrm{R} .
\end{aligned}
$$$$
\sigma_{k}=2.4 \%
$$

Prandtl number:

$$
\begin{aligned}
\operatorname{Pr} & =\frac{\mu C_{p}}{k} \\
& =0.740 T^{-0014} ; T \text { in } \mathrm{K} \\
& =0.746 T^{-0014} ; T \text { in }^{\circ} \mathrm{R} .
\end{aligned}
$$




\section{INDEX}

Advanced gas-cooled reactor (AGR), 1 , 15

commercial, 19

WAGR, 15

AGR (see Advanced gas-cooled reactor)

Air cooling, 23

ALC (see Auxiliary loop cooler)

Ammonia, bottoming cycle, 284

Auxiliary loop cooler, GCFR, 346, 350

AVR (see Pebble bed reactor)

Beryllium oxide, 23

Binary cycle, bottoming cycle, 283

Biot number, 336

Blanket

fusion, $362,366,370,378$

GCFR, 325, 327, 344

Breeding ratio

fusion, tritium, 378

GCFR, 319, 323

Carbon dioxide, 2, 4, 144

GCFR coolant, 353, 356

CCGT (see Closed-cycle gas turbine reactor)

Chopped cosine distribution, 77

Closed-cycle gas turbine reactor

CCGT, 252

HTGR, 178, 250

MGCR, 23

MLI, 22

pebble bed, 62

Coal

gasification, 302

liquefaction, 302

Coated particle, $3,28,35,38,40,42$, $45,48,54,105$

BISO, 186, 188, 210, 211

design parameters, 211

TRISO, 188, 210, 211
Cogeneration

HTGR-GT, 278

HTGR-SC/C, 62, 299, 303

Conductance

cladding, 97

fuel cladding gap, 97, 98

fuel temperature, 99

Conductivity integral, 103

Confinement

inertial, 363

magnetic, 363

Control rods burnable poison, 193, 210, 215

design parameters, 193

GCFR, 327

HTGR, 209

materials, 193

Coolant mixing, 134

Creep, graphite, 186

Crossflow, 224

Design-basis depressurization accident (DBDA), 242

GCFR, 345

Deuterium, 362

District heating, 280

DRAGON high-temperature reactor, 33

Dry-cooling, 260, 279

EBOR (see Experimental beryllium oxide reactor)

EGCR (see Experimental gas-cooled reactor)

Experimental beryllium oxide reactor, 22

Experimental gas-cooled reactor, 25

Film temperature rise, 81

Fission per initial metal atom (FIMA), 189 
First wall

design, 373

fusion reactor, 362,366

Flow resistance, HTGR, 223

Fort St Vrain

construction, startup, operation, and

$R \& D, 57$

HTGR, 52

plant description, 52

Friction factor

correlation, 113

Darcy, 107

Fanning, 107

GCFR, 332

HTGR, 224

lamınar, 109

\section{Gas}

coolant choice, 142

coolant comparison, fast breeders, 320 , 321,353

coolıng, 1

natural circulation, 349

Gas-cooled fast reactor (GCFR), 4, 319

blanket, 327

codes

CALIOP, 329

COBRA, 330, 339

FASTRAN, 346, 351

RATSAM, 351

fuel, 325,340

system description, 322

GCFR (see Gas-cooled fast reactor)

Graphite

Irradiation effects, 182

moderation, $1,3,7,15,24,32$

properties, 38,182

Grashof number, 354

\section{Heat exchangers}

Dragon reactor, 35

Fort St Vrain, 52

HTGR gas turbıne, 271

Peach Bottom, 41

process heat HTGR, 308, 311

\section{Helium}

coolant, 4, 144, 145, 320, 367

EBOR, 23

effects of impurities, 193

EGCR, 25

fusion reactors, 367

GCFR, 319, 320

helium-cooled reactor, 367

HTGR, 32

UHTREX, 27, 28

High-temperature gas-cooled reactor (HTGR)

flow resistance, 223

fuel cycle, 177

fuel element, 205

fuel rods, 189, 210

HTGR-GT, 62, 250

HTGR-PH, 299

direct cycle, 308

indirect cycle, 307

process heat, 300

HTGR SC/C, 62, 300, 303, 305

low-enriched uranium cycle, 181

modular, 62, 64

Hot channel, 76

Hot spot factor, 126

GCFR, 130, 337

HTGR (see High-temperature gas-cooled reactor)

Hybrid reactor

fusion-fission, 395

gas-cooled, 397, 398

Hydraulıc diameter, 87

Hydrogen

cooling, 24, 143

fusion, 394

production, 282, 315, 317

Intermediate heat exchanger (IHX)

HTGR-GT, 255

process heat, 309

Intercooler, 255

Lamınar instabılity, 230

LIFE code, 104 
Liquid-metal fast breeder reactor, 319

Lithum, 362

Mach number, 109

Magnox

characteristics, 7

experience, 12

reactor, 1

Mirror machıne, 363

Mobile reactors, 22

Modular HTGR reactor, 62, 64

Natural circulation, 144

comparison of gases, 353

GCFR, 349

Nitrogen coolant, 22

Nusselt number, 85

correlation, 86

GCFR, 333

pebble bed, 146

Orificing, 80, 118, 138

GCFR, 327, 344, 345

HTGR, 222

PCPV (see Prestressed concrete pressure vessel)

PCRV (see Prestressed concrete reactor vessel)

Peach Bottom HTGR, 38

Peaking factor age, 181,246

fuel temperature dependence, 219,238

heat flux dependence, 232, 233

power, $211,232,238$

region radial, 216

Pebble Bed Reactor (PBR)

AVR, 43

modular, 139

process heat, 317

thermal hydraulics of, 145

THTR, 48

Plasma, 361

Prandtl number, 86
Precooler, 263, 275

Pressure drop, 106

fusion reactors, 378,387

GCFR, 340

HTGR, 223

parasitic (also see Spacer), 224

pebble bed, 145

Pressurized water reactor (PWR), 320

Prestressed concrete pressure vessel (PCPV), 308

Prestressed concrete reactor vessel (PCRV)

AGR, 19

experience, 69

Fort St Vrain, 52

GCFR, 322, 324

HTGR, 32, 48, 50, 202

Magnox, 1, 11

Process heat reactor

direct cycle, 308

fusion, 394, 395

HTGR, 302

HTGR-GT, 282

indirect cycle, 307, 308

Japanese VHTR, 62

Process steam, 282

Process steam/cogeneration, 302

Propulsion reactors, 23

Pumping power, 120, 142, 387

PWR (see Pressurized water reactor)

Ratchetıng, 173

Recuperator, 262, 272

Reformer, steam-methane, 311

Residual heat removal (RHR), 345

Reynolds number, 86

RHR (see Residual heat removal)

Rod bundle

coolant mixing, 134

heat transfer, 87

Roughening

AGR, 18, 19, 140

correlations, 333

GCFR, 323, 326, 328, 333, 334, 340

surface, 94, 323

Roughness

correlation, 114 
definition, 114

optımum, 141

surface, $94,140,323$

Safety analyses

fusion issues, 382

GCFR, 345

HTGR, 242

Sensible energy transport system (SETS), 306,315

Sodıum coolıng, 320, 321

Spacer

GCFR, 336

pressure drop, 117

Stainless steel cladding, 15

Stanton number, 81,86 rough surface, 336

STARFIRE fusion reactor design

$\mathrm{H}_{2} \mathrm{O}, 390$

Helium, 391

Steam generators (see Heat exchangers)

Surface roughness (see Roughening)

Synfuel, 302, 312

Thermal stress, 167

fuel pin, 170

thin tube, 170

Thermochemical water splitting

fission, 312, 315

fusion, 394

Thermodynamic cycles, 255

Brayton, 255

Rankıne, 255, 292
Thorium fuel cycle, 32, 38, 54, 179

THTR, 48

Time-dependent thermal analysis, 244

Tokamak, 363

Transients (HTGR)

categones, 196, 197

thermal analysis, 238

Trituum

breeding, 362, 378

deutenum-tritium cycle, 362

hazards of, 379

Turbomachıne, 265

Ultra high temperature reactor experiment (UHTREX), 27

Uranium

carbide, 188

metal, 7

natural, 7

oxide, 15

${ }^{233} \mathrm{U}, 32,54,179$

Very high temperature reactor (VHTR), 308

Japan, 62

Vibration, flow induced, 152

acoustic, 159

excitation, 165

source, 163

cross flow, 155

parallel flow, 158 


\section{ACKNOWLEDGMENTS}

Figure 1-1 is from Nucleonics, Vol 14, No 3 Copynght (C) 1956 by the McGraw-Hill Publishing

Company Reprnted by permıssion of the McGraw-Hıll Publıshing Company, New York

Figures 1-2, 1-5, 1-6, and 1-8 are reprnted courtesy of the United Kingdom Atomic Energy Authonty, London

Figures 1-3, 1-4, and 1-7 are repnnted courtesy of the Commissariat à l'Energie Atomique

Figure 1-9 is from Journal of the British Nuclear Society, Vol 22, No 2 Copynght (C) 1983 by the British Nuclear Energy Society Reprinted by permission of Thomas Telford Ltd, London

Figure 2-8 is from Proceedings of the IAEA International Symposium on Gas-Cooled Reactors with Emphasis on Advanced Systems, Vol I Copyright $(1976$ by the International Atomic Energy Agency Reprinted by permission of the International Atomic Energy Agency, Vienna

Figure 2-14 is from Proceedings of the American Power Conference, Vol 44 Copyright (\$) 1982 by the American Power Conference Reprinted by permission of the Illinots Institute of Technology, Chicago

Figures 2-17 and 2-18 are from Proceedings of the American Power Conference, Vol 45 Copynght (C) 1983 by the Amencan Power Conference Reprinted by permission of the Illinois Institute of Technology, Chicago

Figure 2-19 is from Journal of the Brittsh Nuclear Energy Soctety, Vol 22, No 3 Copyright $\mathbb{C} 1983$ by the Britısh Nuclear Energy Society Reprinted by permission of Thomas Telford Ltd, London

Figures 3-9 and 3-10 are adapted from International Developments in Heat Transfer, Part III Copynght (C) 1961 by the American Society of Mechanical Engineers Reprinted by permission of the Amencan Society of Mechanical Engineers, New York

Figures 3-12 and 3-13 are adapted from Convectwe Heat and Mass Transfer, by W M Kays Copynght (C) 1966 by McGraw-Hıll, Inc Reprinted by permission of the McGraw-Hill Book Company, New York

Figures 10-13 through 10-18 are from Decay Heat Removal and Natural Convection in Fast Breeder Reactors, edited by Ashok K Agrawal and James G Guppy Copynght (C) 1981 by Hemisphere Publishung Corporation Reprnted by permission of the Hemisphere Publishing Corporation, New York 
Engineering Department at the University of Illinois, Urbana-Champaign, where G. Melese was a visiting professor during the final steps of the book's publication. Finally we wish to thank the ANS for its continual encouragement and support of this book. Professor Donald Eggen was primarily responsible for obtaining approval for this project. The competent editorial review of the manuscript by Lorretta Palagi of the ANS publications staff is gratefully acknowledged.

As a final note, it should be mentioned that references cited as originating from GA Technologies Inc. were meant to avoid possible confusion should anyone wish to obtain one of these reports. This organization has at various times been named: General Atomic Division/General Dynamics Corp., Gulf General Atomic, and General Atomic, Inc. References originating from these companies are available from GA Technologies.

Gilbert Melese 